
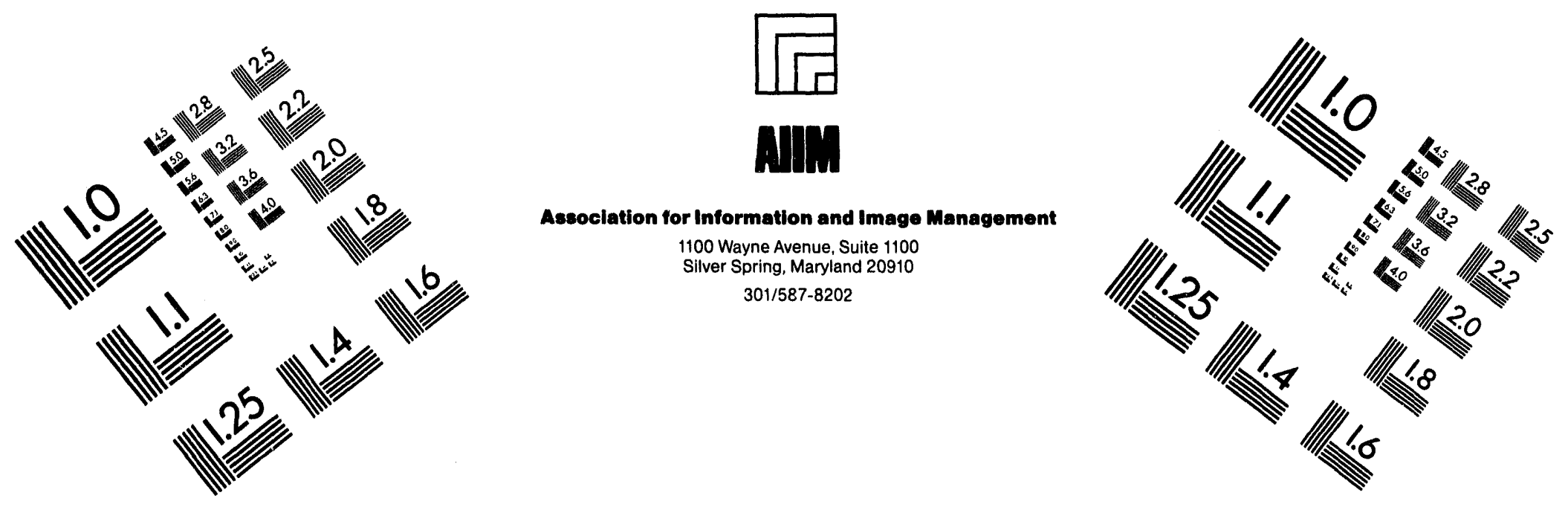

\title{
Centimeter
}

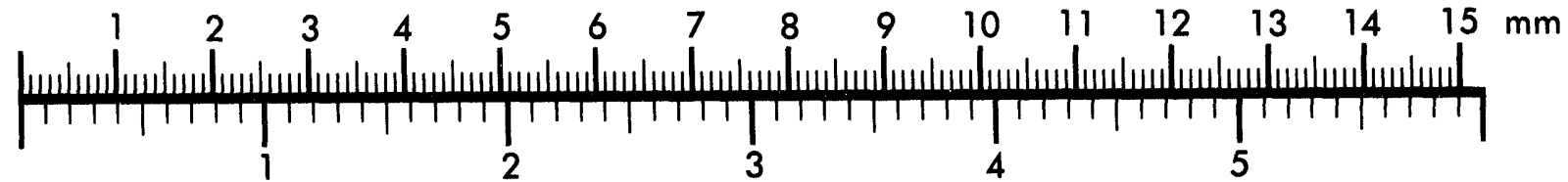
Inches
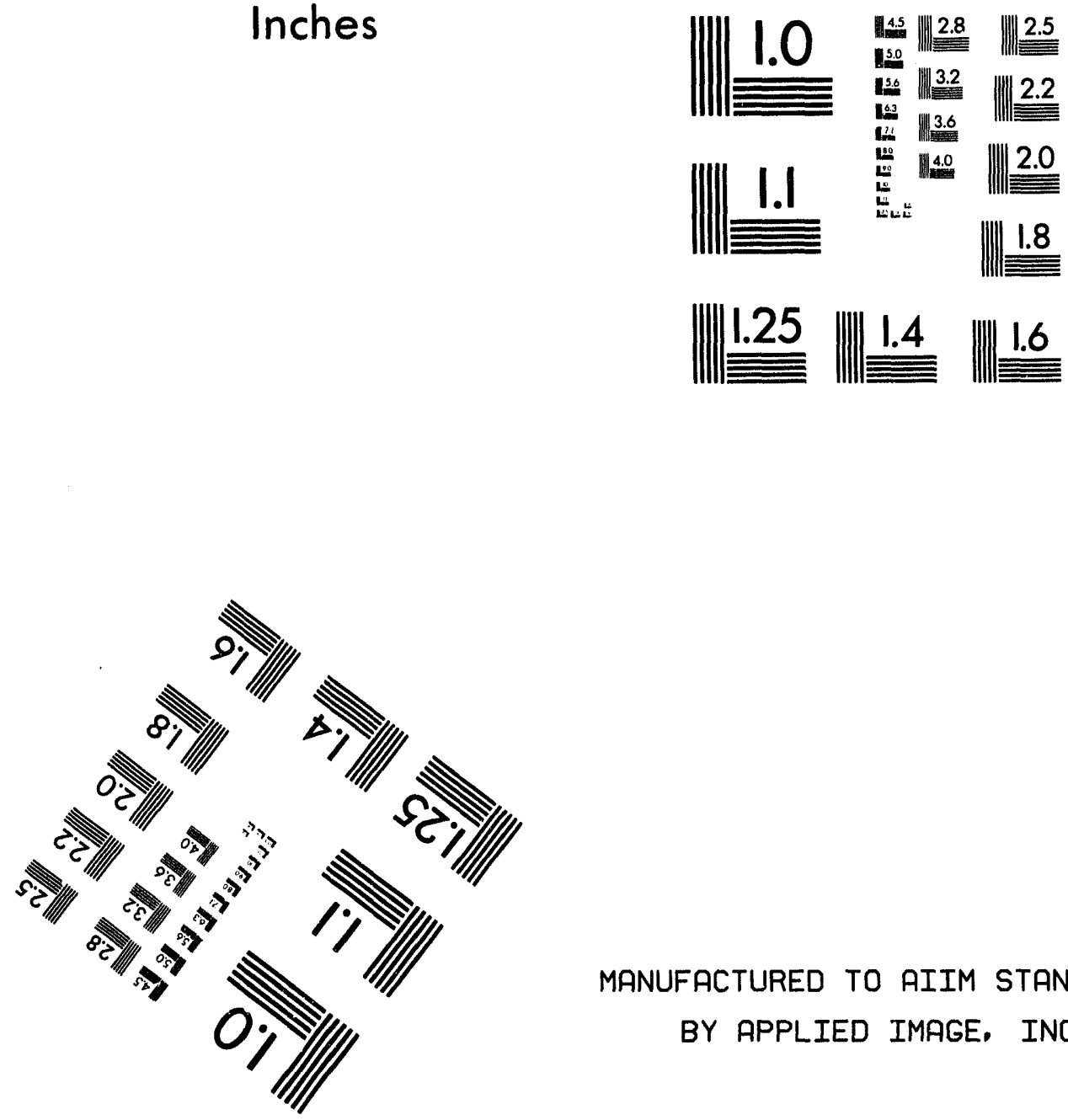

MANUFACTURED TO AIIM STANDARDS BY APPLIED IMAGE, INC.

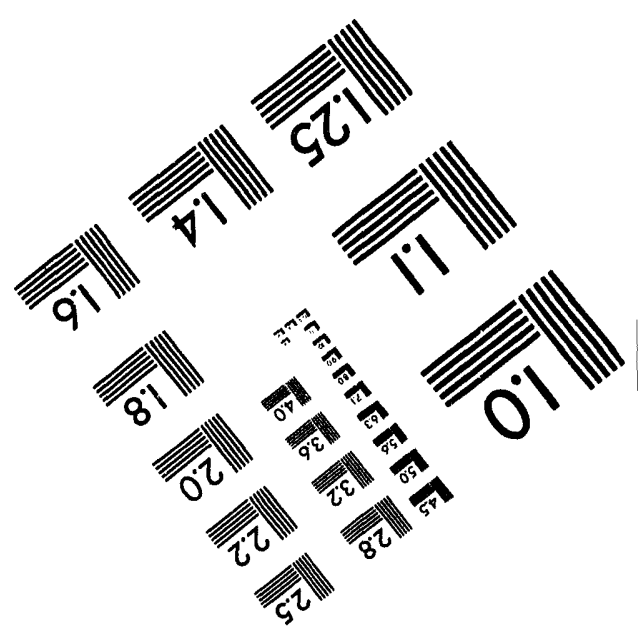



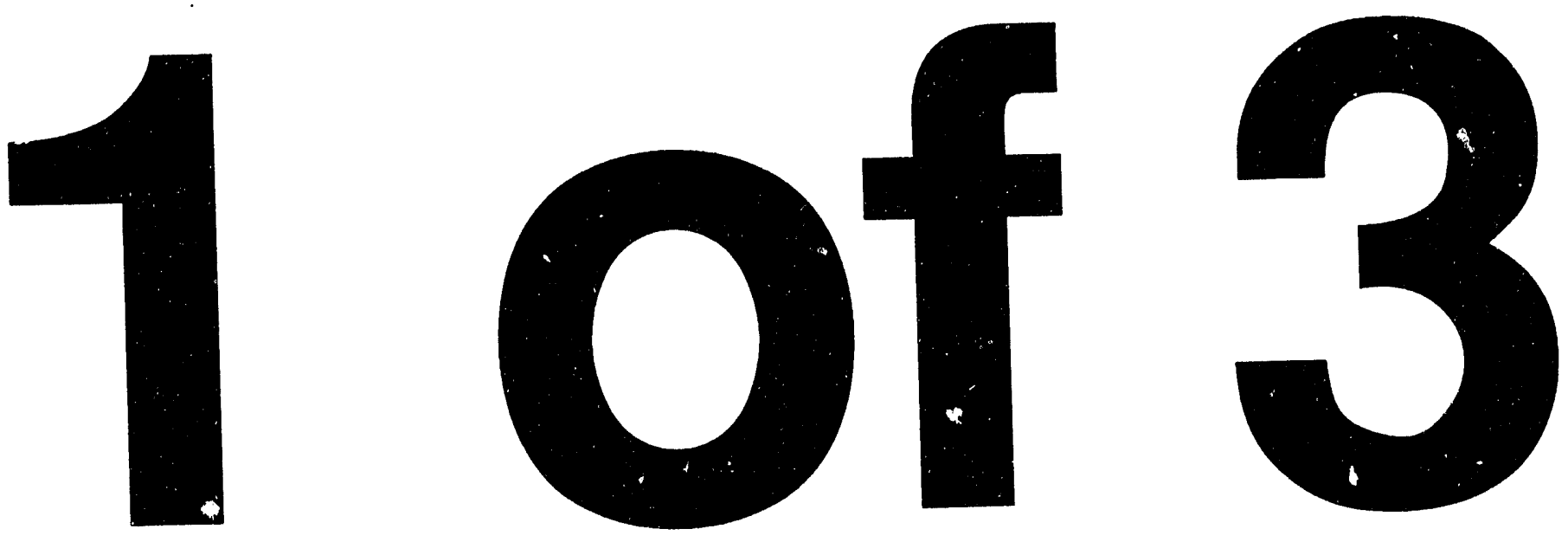
NUREG/CR-6201

EGG-2736

\section{Compression and Immersion Tests and Leaching of Radionuclides, Stable Metals, and Chelating Agents From Cement-Solidified Decontamination Waste Collected From Nuclear Power Stations}

Prepared by

D. W. Akers, N. C. Kraft, J. W. Mandler

Idaho Engineering Laboratory

EG\&G Idaho, Inc.

Idaho Falls, ID 83415

\section{Prepared for}

Division of Regulatory Applications

Office of Nuclear Regulatory Research

U.S. Nuclear Regulatory Commission

Washington, DC 20555-0001

NRC FIN A6359 


\section{DISCLAIMER}

NUREG/CR-6201 is not a substitute for NRC regulations and compliance is not required. The approaches and/or methods described in this NUREG/CR are provided for information only. Publication of this report does not necessarily constitute NRC approval or agreement with the information contained herein. 


\begin{abstract}
A study was performed for the Nuclear Regulatory Commission (NRC) to evaluate structural stability and leachability of radionuclides, stable metals, and chelating agents from cement-solidified decontamination ion-exchange resin wastes collected from seven commercial boiling water reactors and one pressurized water reactor. The decontamination methods used at the reactors were the Can-Decon, AP/Citrox, Dow NS-1, and LOMI processes. Samples of untreated resin waste and solidified waste forms were subjected to immersion and compressive strength testing. Some waste-form samples were leach-tested using simulated groundwaters and simulated seawater for comparison with the deionized water tests that are normally performed to assess waste-form leachability. This report presents the results of these tests and assesses the effects of the various decontamination methods, waste form formulations, leachant chemical compositions, and $\mathrm{pH}$ of the leachant on the structural stability and leachability of the waste forms. Results indicate that releases from intact and degraded waste forms are similar and that the behavior of some radionuclides such as ${ }^{55} \mathrm{Fe},{ }^{60} \mathrm{Co}$, and ${ }^{99} \mathrm{Tc}$ were similar. In addition, the leachability indexes are greater than 6.0, which meets the requirement in the NRC's "Technical Position on Waste Form," Revision 1.
\end{abstract}

FIN No. A6359-Characteristics of Low-Level Radioactive Waste: Decontamination Waste 


\section{CONTENTS}

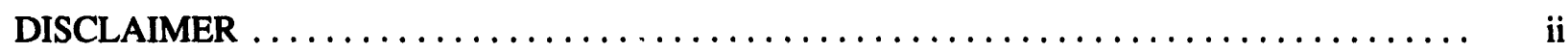

ABSTRACT $\ldots \ldots \ldots \ldots \ldots \ldots \ldots \ldots \ldots \ldots \ldots \ldots \ldots \ldots \ldots \ldots \ldots \ldots \ldots \ldots \ldots \ldots$

LIST OF FIGURES $\ldots \ldots \ldots \ldots \ldots \ldots \ldots \ldots \ldots \ldots \ldots \ldots \ldots \ldots \ldots \ldots \ldots \ldots \ldots$

LIST OF TABLES $\ldots \ldots \ldots \ldots \ldots \ldots \ldots \ldots \ldots \ldots \ldots \ldots \ldots \ldots \ldots \ldots \ldots \ldots \ldots \ldots \ldots \ldots \ldots$

EXECUTIVE SUMMARY $\ldots \ldots \ldots \ldots \ldots \ldots \ldots \ldots \ldots \ldots \ldots \ldots \ldots \ldots \ldots \ldots \ldots \ldots \ldots \ldots$

ACKNOWLEDGMENTS $\ldots \ldots \ldots \ldots \ldots \ldots \ldots \ldots \ldots \ldots \ldots \ldots \ldots \ldots \ldots \ldots \ldots \ldots \ldots \ldots \ldots \ldots$

ACRONYMS $\ldots \ldots \ldots \ldots \ldots \ldots \ldots \ldots \ldots \ldots \ldots \ldots \ldots \ldots \ldots \ldots \ldots \ldots \ldots \ldots \ldots \ldots$

INTRODUCTION $\ldots \ldots \ldots \ldots \ldots \ldots \ldots \ldots \ldots \ldots \ldots \ldots \ldots \ldots \ldots \ldots \ldots \ldots \ldots$

DECONTAMINATION PROCESSES $\ldots \ldots \ldots \ldots \ldots \ldots \ldots \ldots \ldots \ldots \ldots \ldots \ldots \ldots$

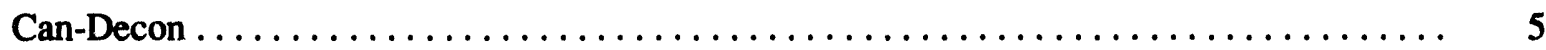

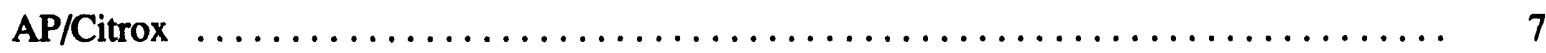

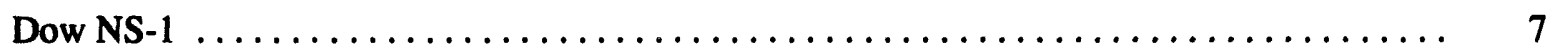

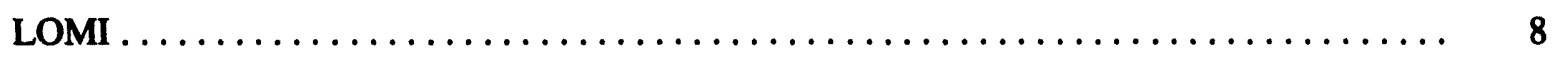

DECONTAMINATION ION-EXCHANGE RESIN WASTE SOLIDIFICATION PROCESS $\ldots \ldots \quad 9$

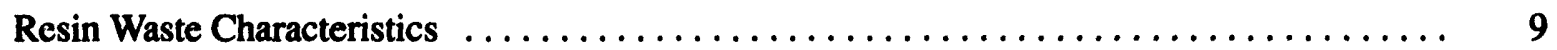

Cement Solidification Chemistry $\ldots \ldots \ldots \ldots \ldots \ldots \ldots \ldots \ldots \ldots \ldots \ldots \ldots \ldots$

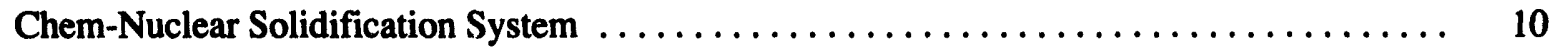

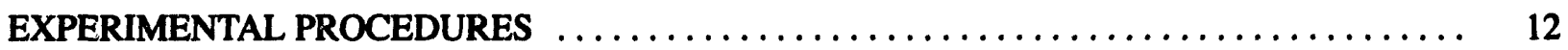

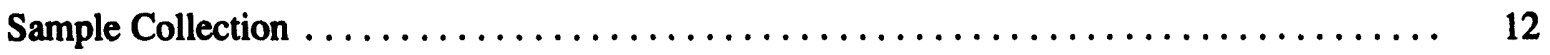

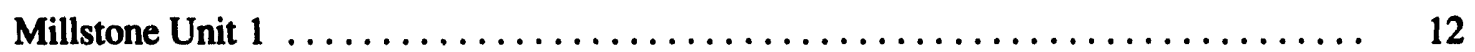

Peach Bottom Atomic Power Station Unit $2 \ldots \ldots \ldots \ldots \ldots \ldots \ldots \ldots \ldots \ldots \ldots \ldots \ldots$

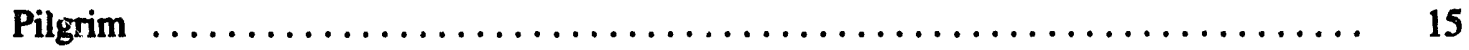

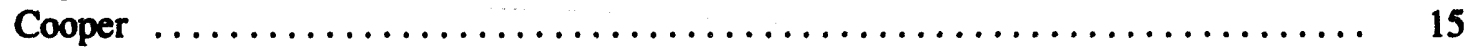

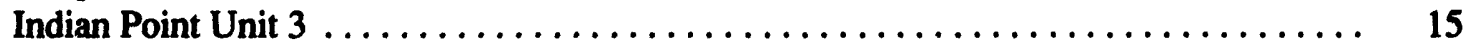

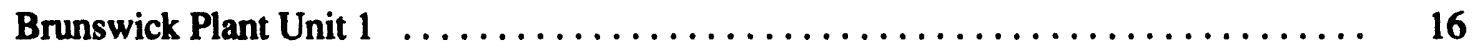

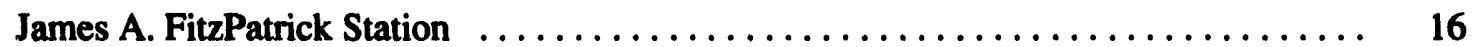

Peach Bottom Atomic Power Station Unit $3 \ldots \ldots \ldots \ldots \ldots \ldots \ldots \ldots \ldots \ldots$

Compressive Strength Test Method $\ldots \ldots \ldots \ldots \ldots \ldots \ldots \ldots \ldots \ldots \ldots \ldots \ldots \ldots \ldots$

Leach Test Method $\ldots \ldots \ldots \ldots \ldots \ldots \ldots \ldots \ldots \ldots \ldots \ldots \ldots \ldots \ldots \ldots \ldots \ldots \ldots \ldots$ 


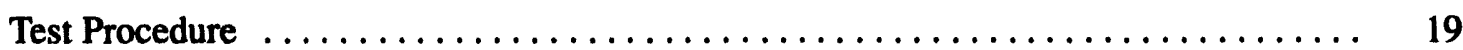

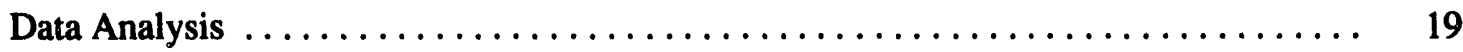

Analytical Methods $\ldots \ldots \ldots \ldots \ldots \ldots \ldots \ldots \ldots \ldots \ldots \ldots \ldots \ldots \ldots \ldots \ldots \ldots \ldots \ldots \ldots, 22$

EXPERIMENTAL RESULTS AND DISCUSSION $\ldots \ldots \ldots \ldots \ldots \ldots \ldots \ldots \ldots \ldots \ldots \ldots$

Waste Form Struct Iral Stability $\ldots \ldots \ldots \ldots \ldots \ldots \ldots \ldots \ldots \ldots \ldots \ldots \ldots \ldots \ldots \ldots \ldots$

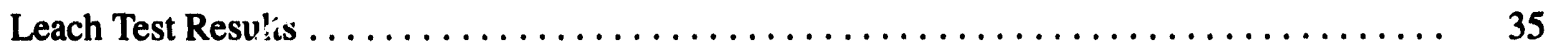

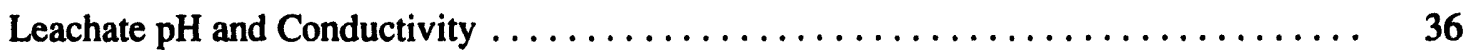

Waste Form Inventories of Radionuclides, Stable Metals and Chelating Agents ..... 38

Releases of Radionuclides, Chelating Agents, and Stable Metals ............ 40

The Effects of Leachants with Different pHs and Compositions on the Release of Chelating

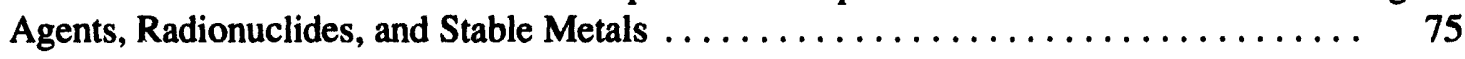

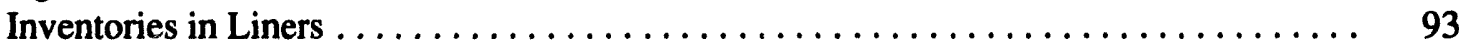

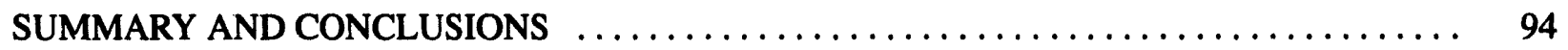

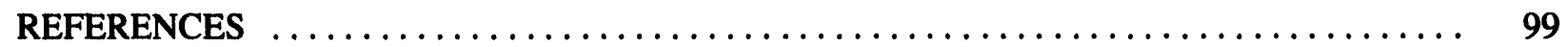

Appendix A - Recent Leaching Studies and the Effect of Waste Form Constituents on

Solidification of Nuclear Power Plant Wastes $\ldots \ldots \ldots \ldots \ldots \ldots \ldots \ldots \ldots \ldots \ldots \ldots \ldots$

Appendix B - Cement Chemistry $\ldots \ldots \ldots \ldots \ldots \ldots \ldots \ldots \ldots \ldots \ldots \ldots \ldots \ldots \ldots \ldots \ldots \ldots \ldots \ldots$

Appendix C - ANSI/ANS 16.1 Leach-Test Procedure and ASTM C39 Compressive Strength

Appendix D - General Analytical Methods $\ldots \ldots \ldots \ldots \ldots \ldots \ldots \ldots \ldots \ldots \ldots \ldots \ldots \ldots \ldots$

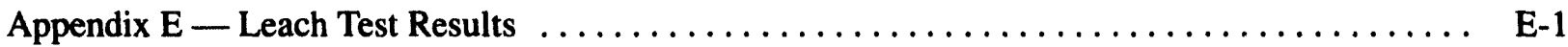

Appendix F - Average Release Rates and Effective Diffusivities $\ldots \ldots \ldots \ldots \ldots \ldots \ldots \ldots$ F-1

Appendix G - Radionuclide, Chelating Agent, and Stable Metal Inventory in Liners Solidified

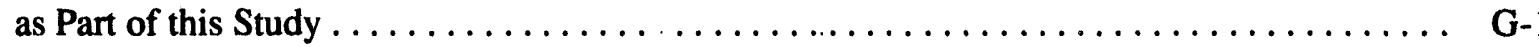




\section{LIST OF FIGURES}

1. Boiling water reactor primary coolant recircuiation system $\ldots \ldots \ldots \ldots \ldots \ldots \ldots \ldots \ldots$

2. Chem Nuclear Services Inc. skid-mounted solidification system $\ldots \ldots \ldots \ldots \ldots \ldots \ldots \ldots$

3. Brunswick-1 cation resin waste form sample $\ldots \ldots \ldots \ldots \ldots \ldots \ldots \ldots \ldots \ldots \ldots$

4. Brunswick-1 mixed-bed resin waste form sample $\ldots \ldots \ldots \ldots \ldots \ldots \ldots \ldots \ldots$

5. FitzPatrick mixed-bed resin waste form sample $\ldots \ldots \ldots \ldots \ldots \ldots \ldots \ldots \ldots \ldots \ldots$

6. Peach Bottom-3 waste form sample $\ldots \ldots \ldots \ldots \ldots \ldots \ldots \ldots \ldots \ldots \ldots \ldots \ldots \ldots$

7. Brunswick-1 cation resin waste-form specimen leaching in synthetic seawater during the

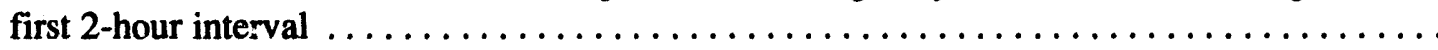

8. Brunswick-1 cation resin waste-form specimen after leaching in synthetic seawater for

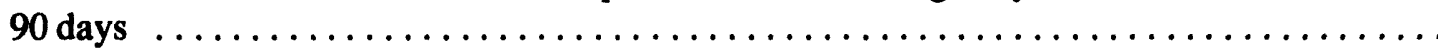

9. Brunswick-1 mixed-bed resin waste-form specimen leaching in synthetic seawater during

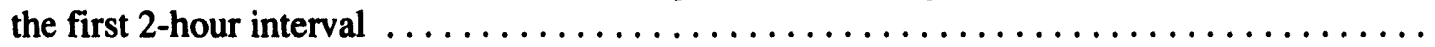

10. Brunswick-1 mixed-bed resin waste-form specimen after leaching in synthetic seawater

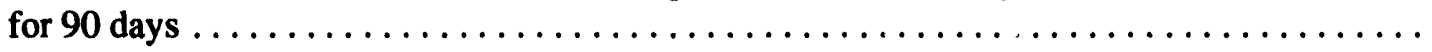

11. Brunswick-1 mixed-bed resin waste-form specimen during first hour of leaching in synthetic Barnwell groundwater

12. Brunswick-1 cation resin waste-form specimen after leaching in deionized water for 239 days

13. FitzPatrick waste-form specimen after leaching in deionized water for 90 days

14. FitzPatrick waste-form specimen after leaching in synthetic water for 90 days

15. FitzPatrick waste-form specimen, which was baked during initial curing, after leaching in deionized water for 90 days

16. FitzPatrick waste-form specimen, which was baked during initial curing, after leaching for 90 days in synthetic Barnwell groundwater with $\mathrm{pH} 4.2$

17. Leachant $\mathrm{pH}$ for Brunswick-1 cation resin waste-form specimens $\ldots \ldots \ldots \ldots \ldots \ldots \ldots$

18. Average fractional release rates of chelating agents $\left(\mathrm{cm}^{-2} \cdot \mathrm{s}^{-1}\right) \ldots \ldots \ldots \ldots \ldots \ldots \ldots$

19. Cumulative fractional reiease of chelating agents $\ldots \ldots \ldots \ldots \ldots \ldots \ldots \ldots \ldots \ldots$

20. Effective diffusivity for chelating agents $\left(\mathrm{cm}^{2} \cdot \mathrm{s}^{-1}\right) \ldots \ldots \ldots \ldots \ldots \ldots \ldots \ldots \ldots \ldots \ldots \ldots \ldots$

21. Leachability indexes for chelating agents $\ldots \ldots \ldots \ldots \ldots \ldots \ldots \ldots \ldots \ldots \ldots \ldots$ 
22. Cesium-137 average fractional release rates $\left(\mathrm{cm}^{-2} \cdot \mathrm{s}^{-1}\right) \ldots \ldots \ldots \ldots \ldots \ldots \ldots \ldots \ldots \ldots$

23. Cesium-137 cumulative fractional release $\ldots \ldots \ldots \ldots \ldots \ldots \ldots \ldots \ldots \ldots \ldots$

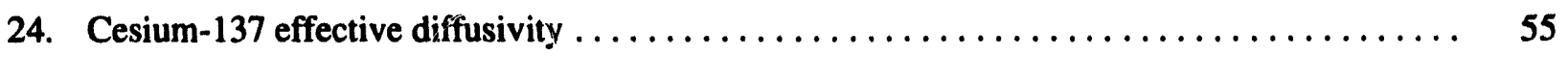

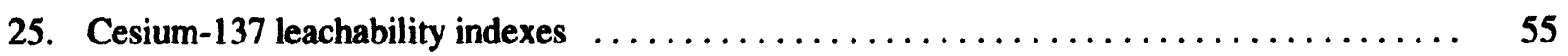

26. Cobalt-60 average fractional release rates $\left(\mathrm{cm}^{-2} \cdot \mathrm{s}^{-1}\right) \ldots \ldots \ldots \ldots \ldots \ldots \ldots \ldots \ldots$

27. Iron-55 average fractional release rates $\left(\mathrm{cm}^{-2} \cdot \mathrm{s}^{-1}\right) \ldots \ldots \ldots \ldots \ldots \ldots \ldots \ldots$

28. Nickel-63 average fractional release rates $\left(\mathrm{cm}^{-2} \cdot \mathrm{s}^{-1}\right) \ldots \ldots \ldots \ldots \ldots \ldots \ldots \ldots \ldots$

29. Average fractional release rate cutves for ${ }^{60} \mathrm{Co}\left(\mathrm{cm}^{-2} \cdot \mathrm{s}^{-1}\right) \ldots \ldots \ldots \ldots \ldots \ldots \ldots \ldots$

30. Cobalt- 60 cumulative fractional release $\ldots \ldots \ldots \ldots \ldots \ldots \ldots \ldots \ldots \ldots \ldots \ldots \ldots \ldots \ldots \ldots \ldots$

31. Iron-55 cumulative fractional release $\ldots \ldots \ldots \ldots \ldots \ldots \ldots \ldots \ldots \ldots \ldots \ldots \ldots \ldots$

32. Nickel-63 cumulative fractional release $\ldots \ldots \ldots \ldots \ldots \ldots \ldots \ldots \ldots \ldots \ldots \ldots \ldots .67$

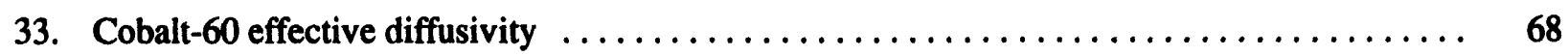

34. Iron-55 effective diffusivity $\ldots \ldots \ldots \ldots \ldots \ldots \ldots \ldots \ldots \ldots \ldots \ldots \ldots \ldots \ldots \ldots \ldots \ldots$

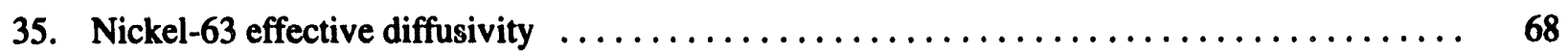

36. Cobalt-60 leachability indexes $\ldots \ldots \ldots \ldots \ldots \ldots \ldots \ldots \ldots \ldots \ldots \ldots \ldots \ldots \ldots \ldots \ldots$

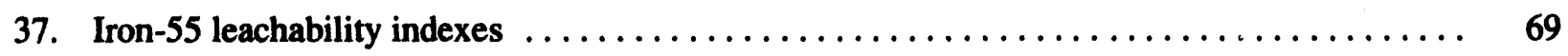

38. Nickel-63 leachability indexes $\ldots \ldots \ldots \ldots \ldots \ldots \ldots \ldots \ldots \ldots \ldots \ldots \ldots \ldots \ldots \ldots$

39. Stable nickel average fractional release rates $\left(\mathrm{cm}^{-2} \cdot \mathrm{s}^{-1}\right) \ldots \ldots \ldots \ldots \ldots \ldots \ldots \ldots$

40. Stable iron average fractional release rates $\left(\mathrm{cm}^{-2} \cdot \mathrm{s}^{-1}\right) \ldots \ldots \ldots \ldots \ldots \ldots \ldots \ldots \ldots \ldots$

41. Stable nickel cumulative fractional release $\ldots \ldots \ldots \ldots \ldots \ldots \ldots \ldots \ldots \ldots \ldots \ldots, 74$

42. Stable iron cumulative fractional release $\ldots \ldots \ldots \ldots \ldots \ldots \ldots \ldots \ldots \ldots \ldots \ldots \ldots$

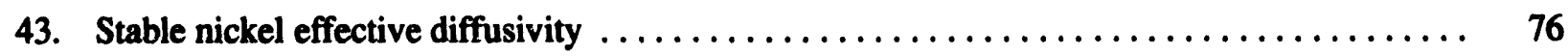

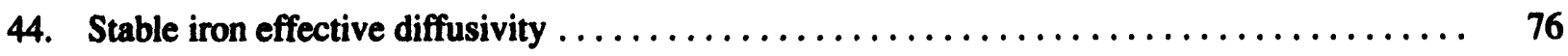

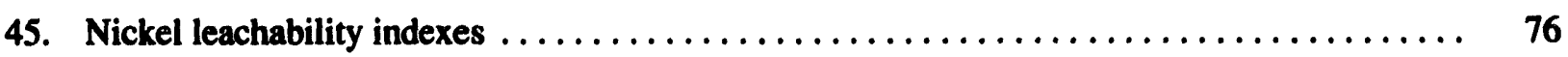

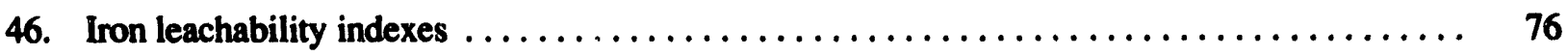

47. Fractional release rate of oxalic acid from five Brunswick-1 mixed-bed resin waste-form

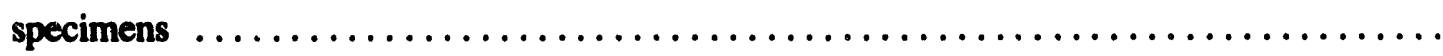


48. Fractional release rate of citric acid from five Brunswick-1 mixed-bed resin waste-form

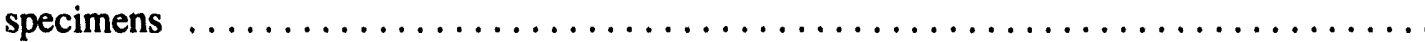

49. Fractional release rates of picolinic acid from seven FitzPatrick ion-exchange resin

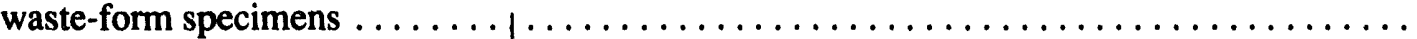

50. Cumulative fractional release of oxalic acid from five Brunswick-1 mixed-bed resin

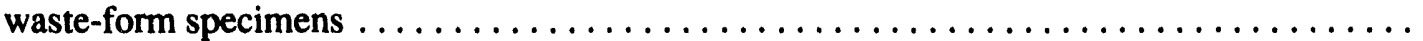

51. Cumulative fractional release of citric acid from five Brunswick-1 mixed-bed resin

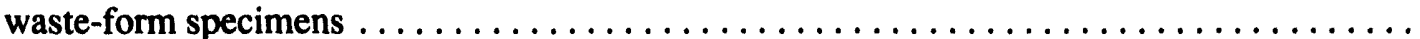

52. Cumulative fractional release of picolinic acid from seven FitzPatrick ion-exchange resin

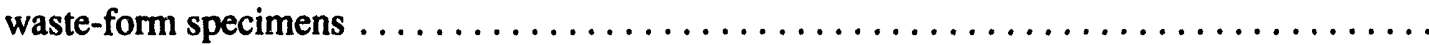

53. Cumulative fractional release of ${ }^{137} \mathrm{Cs}$ from five Brunswick-1 cation resin waste-form

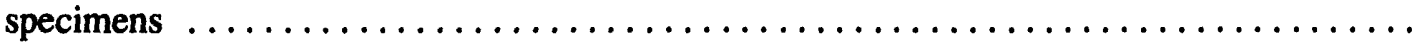

54. Cumulative fractional release of ${ }^{137} \mathrm{Cs}$ from five Brunswick-1 mixed-bed resin waste-form specimens

55. Cumulative fractional release of ${ }^{137} \mathrm{Cs}$ from seven FitzPatrick ion-exchange resin

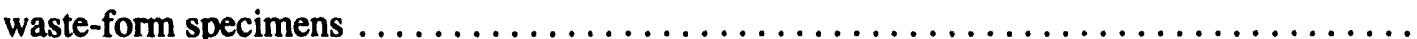

56. Fractional release rate of ${ }^{60} \mathrm{Co}$ from five Brunswick- 1 cation resin waste-form specimens ... 83

57. Fractional release rate of ${ }^{60} \mathrm{Co}$ from five Brunswick-1 mixed-bed resin waste-form specimens

58. Fractional release rate of ${ }^{60} \mathrm{Co}$ from seven FitzPatrick ion-exchange resin waste-form specimens

59. Fractional release rate of ${ }^{55} \mathrm{Fe}$ from five Brunswick-1 cation resin waste-form specimens ....

60. Fractional release rate of ${ }^{55} \mathrm{Fe}$ from five Brunswick-1 mixed-bed resin waste-form specimens

61. Fractional release rate of ${ }^{55} \mathbf{F e}$ from seven FitzPatrick ion-exchange resin waste-form

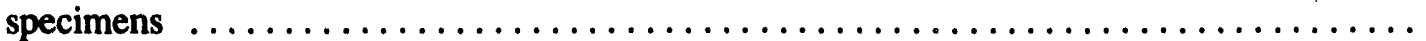

62. Fractional release rate of ${ }^{63} \mathrm{Ni}$ from five Brunswick-1 cation resin waste-form specimens ....

63. Fractional release rate of ${ }^{63} \mathrm{Ni}$ from five Brunswick-1 mixed-bed resin waste-form specimens

64. Fractional release rate of ${ }^{\mathbf{6}} \mathbf{N i}$ from seven FitzPatrick ion-exchange resin waste-form

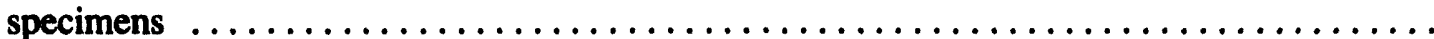

65. Cumulative fractional release of ${ }^{60} \mathrm{Co}$ from five Brunswick-1 cation resin waste-form

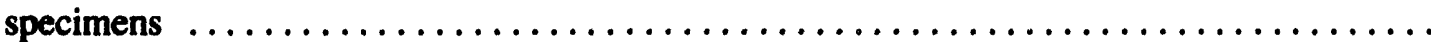

66. Cumulative fractional release of ${ }^{60} \mathrm{Co}$ from five Brunswick-1 mixed-bed resin waste-form specimens.

67. Cumulative fractional release of ${ }^{60} \mathrm{Co}$ from seven FitzPatrick ion-exchange resin waste-form specimens 
68. Cumulative fractional release of ${ }^{55} \mathrm{Fe}$ from five Brunswick-1 cation resin waste-form specimens

69. Cumulative fractional release of ${ }^{55} \mathrm{Fe}$ from five Brunswick-1 mixed-bed resin waste-form specimens

70. Cumulative fractional release of ${ }^{55} \mathrm{Fe}$ from seven FitzPatrick ion-exchange resin waste-form specimens

71. Cumulative fractional release of ${ }^{63} \mathrm{Ni}$ from five Brunswick-1 cation resin waste-form specimens

72. Cumulative fractional release of ${ }^{63} \mathrm{Ni}$ from five Brunswick-1 mixed-bed resin waste-form specimens

73. Cumulative fractional release of ${ }^{63} \mathrm{Ni}$ from seven FitzPatrick ion-exchange resin wasteform specimens 


\section{LIST OF TABLES}

1. Reactors decontaminated and decontamination processes $\ldots \ldots \ldots \ldots \ldots \ldots \ldots \ldots \ldots$

2. Densities and water content of resins $\ldots \ldots \ldots \ldots \ldots \ldots \ldots \ldots \ldots \ldots \ldots \ldots \ldots \ldots \ldots$

3. Physical parameters of solidified decontamination ion-exchange resin waste samples ..... 13

4. Compressive strengths of intact waste-form samples $\ldots \ldots \ldots \ldots \ldots \ldots \ldots \ldots \ldots \ldots$

5. Compressive strengths of Peach Bottom waste-form samples $\ldots \ldots \ldots \ldots \ldots \ldots \ldots \ldots \ldots$

6. Structural stability of the Cooper and Brunswick-1 samples $\ldots \ldots \ldots \ldots \ldots \ldots \ldots \ldots \ldots$

7. Structural stability of the FitzPatrick waste forms $\ldots \ldots \ldots \ldots \ldots \ldots \ldots \ldots \ldots \ldots$

8. Composition of simulated leachants $(\mathrm{g} / \mathrm{L}) \ldots \ldots \ldots \ldots \ldots \ldots \ldots \ldots \ldots \ldots \ldots \ldots \ldots$

9. Primary radionuclides present in decontamination ion-exchange resin wastes $\ldots \ldots \ldots . \ldots 39$

10. Transuranic radionuclides present in decontamination ion-exchange resin wastes $\ldots \ldots \ldots 41$

11. Stable metals present in decontamination resin wastes $\ldots \ldots \ldots \ldots \ldots \ldots \ldots \ldots \ldots, 42$

12. Chelating agents present in decontamination resin wastes $\ldots \ldots \ldots \ldots \ldots \ldots \ldots \ldots \ldots$

13. Cumulative fractional releases, chelating agent release rates, effective diffusivities, and

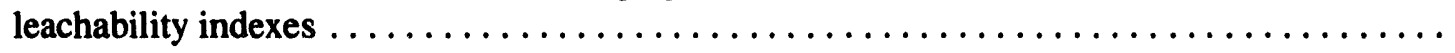

14. Cesium-137 release rates, cumulative fractional releases, effective diffusivities, and

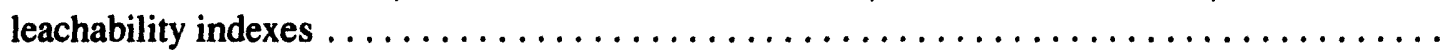

15. Cobalt-60 release rates, cumulative fractional releases, effective diffusivities, and

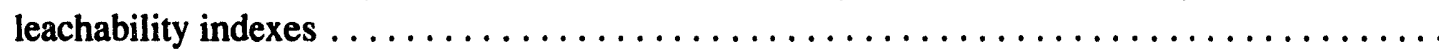

16. Iron-55 release rates, cumulative fractional releases, effective diffusivities, and

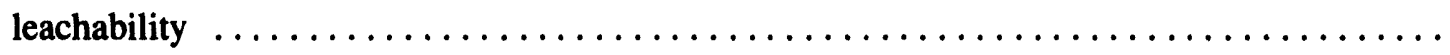

17. Nickel-63 release rates, cumulative fractional releases, effective diffusivities, and

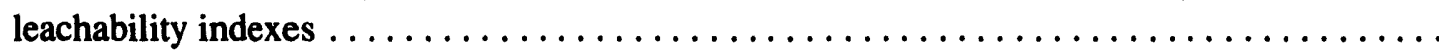

18. Weighted-average fractional release rates $\ldots \ldots \ldots \ldots \ldots \ldots \ldots \ldots \ldots \ldots \ldots \ldots \ldots$

19. Weighted-average absolute release rates $\ldots \ldots \ldots \ldots \ldots \ldots \ldots \ldots \ldots \ldots \ldots \ldots \ldots \ldots \ldots \ldots$

20. Stable iron release rates, cumulative fractional releases, effective diffusivities, and

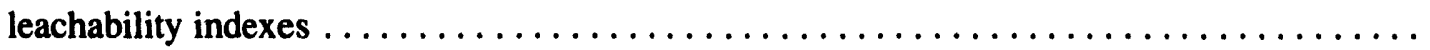

21. Stable nickel release rates, cumulative fractional releases, effective diffusivities, and

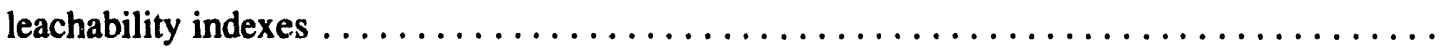




\section{EXECUTIVE SUMMARY}

A study was performed for the U.S. Nuclear Regulatory Commission (NRC) to assess the stability (physical stability and leachability) of cement-solidified waste forms and to determine realistic release rates. Waste forms were collected from seven commercial boiling water reactors (BWRs) and one commercial pressurized water reactor (PWR). The objective of this report is to integrate the results of the individual reactor studies and to provide a comprehensive assessment of the structural stability and leachability characteristics of cement-solidified decontamination ionexchange resin waste forms.

Test procedures to demonstrate waste form structural stability and to quantify leachability for the low-level wastes from light water reactors have been specified by the NRC in the Low-Level Waste Management Branch's "Technical Position on Waste Form," published in 1983, and in the "Technical Position on Waste Form," Revision 1, published in January 1991. Both documents specify that small-scale waste-form specimens must be prepared and tested to certify the stability of the full-scale waste form.

The purpose of this research study is to evaluate the stability of actual low-level radioactive ion-exchange wastes solidified in cement using the tests from the "Technical Position on Waste Form," Revision 1, for compression testing and leachability, and to determine the release rates of radionuclides, chelating agents, and transition metals from solidified ion-exchange resin wastes that have been immersed in deionized water and simulated groundwaters.

The primary coolant recirculation systems were decontaminated at seven BWRs using four different decontamination processes: Millstone-1 (Can-Decon), Peach Bottom Unit 2 (Can-Decon), Pilgrim (NS-1), Cooper (AP/Citrox), James A. FitzPatrick (LOMI/NP/LOMI), Brunswick Unit 1 (Citrox/AP/Citrox), and Peach Bottom Unit 3 (LOMI/NP/LOMI). The LOMI process was used to decontaminate a steam generator channel head at a PWR, Indian Point Unit 3. This report describes these decontamination processes.
During the course of this study, resin wastes and solidified resin waste-form specimens were collected from the PWR and the BWRs. The characteristics of the resins that were solidified, the cement chemistry, and the solidification methods used at the plants sampled are described in this report, followed by summary descriptions of the leach test procedure, data analysis methods, and analytical methods. These sections are followed by a discussion of the results of the compression and leach tests performed on the solidified decontamination resin waste specimens. The leaching section is divided up into three parts: an assessment of the effects of $\mathrm{pH}$ and conductivity on releases from the waste forms, a comparison of the leachability characteristics of the waste forms from the various decontamination processes, and an assessment of the effects of differing leachants (i.e., deionized water, simulated seawater and groundwaters) on the releases of chelating agents, radionuclides, and stable metals from the waste forms.

According to 10 CFR 61.56 (b)1, "a structurally stable waste form will generally maintain its physical dimensions and its form under the expected disposal conditions such as weight of overburden and construction equipment." The initial criterion for structural stability as identified in the NRC's "Technical Position on Waste Form" is that the cement-solidified waste-form specimen must exhibit a compressive strength of $50 \mathrm{psi}\left(3.4 \times 10^{2} \mathrm{kPa}\right)$. This was later raised to $60 \mathrm{psi}\left(4.1 \times 10^{2} \mathrm{kPa}\right)$ to reflect an increase in burial depth to $55 \mathrm{ft}$ at the Hanford site. Appendix A of Revision 1 of the "Technical Position on Waste Form" recommends a mean compressive strength of $500 \mathrm{psi}\left(3.4 \times 10^{3} \mathrm{kPa}\right)$ for wasteform specimens cured for a minimum of 28 days. It has been determined in previous studies that solidified ion-exchange resins should be able to meet this criterion.

Key conclusions of the compression tests performed to assess physical stability are that the waste forms, which survived the immersion testing, meet the requirements for integrity identified in applicable revisions of the "Technical 
Position on Waste Form." Post-immersion compression-testing results in "cate that the compressive strengths of the Peach Bottom-3 waste forms, which used the newest LOMI formulation, were all well above the regulatory requirement $\left(500 \mathrm{psi}\right.$ or $3.4 \times 10^{3} \mathrm{kPa}$ ) and ranged from 960 to 1,370 psi for all leachants. In contrast, all AP/ Citrox waste forms that were tested decomposed during immersion testing, and no post immersion compressive strength measurements were performed.

Primary results of the physical stability tests are the following:

- $\quad$ All AP/Citrox waste forms that were tested decomposed within several hours of the beginning of the leach test and that the probable mechanisms for waste form degradation noted in the body of this report significantly affect the capability of these waste forms to meet the regulatory requirement defined in the "Technical Position on Waste Form" for compression testing.

- The FitzPatrick LOMI waste forms also decomposed during leach testing; however, the FitzPatrick samples are a special case due to the formation of a gel in the bulk liners during the $\mathrm{pH}$ adjustment phase. Studies have indicated that the gel formation was due to the high concentration $(\sim 8 \mathrm{wt} \%)$ of picolinic acid in the waste form and that this would not be expected to occur again due to changes in the LOMI formulation.

Other results from the compression tests are the following: (a) Decontamination ion-exchange waste-form specimens have compressive strengths, typically 1,000 to $2,000 \mathrm{psi}$, (b) compression tests performed on unleached specimens prior to immersion testing do not appear to be indicative of the ability of the waste form to survive the immersion and the subsequent compression test, and (c) immersion significantly affects the ability of the waste form to survive compression testing.

In the evaluation of the leach test results, the key conclusion is that all waste forms, including those that decomposed during leach testing, met the leachability index requirement of 6.0 specified in the NRC's "Technical Position on Waste Form," Revision 1. In addition, all stable metals and all chelating agents with the exception of the chelating agent EDTA in the Dow NS-1 waste form (5.7) all have leachability indexes greater than 6.0

The $\mathrm{pH}$ effects on leachability and the characteristics of radionuclide and stable metal releases from the waste forms were also assessed. The $\mathrm{pH}$ data indicate that the $\mathrm{pH}$ of the leachate is affected within a few hours and probably within a few minutes by the chemistry of the waste form. These data suggest that $\mathrm{pH}$ effects are limited to the period before the leachate is affected by the cement chemistry and that the primary factors affecting radionuclide release are probably sol' ivility and the ion strength of the leachart. It should be noted that radionuclide release rates from the Peach Bottom-3 LOMI waste form, where a new formulation was used, are typically less than those for other LOMI waste forms, indicating the success of the improved formulation.

Some station waste forms (i.e., Brunswick-1 and FitzPatrick) were tested to assess the effects of $\mathrm{pH}$. The results of this study suggest that the $\mathrm{pH}$ of the leachant (with the exception of seawater) is controlled by the $\mathrm{pH}$ of the cement-solidified waste form and that $\mathrm{pH}$ effects are probably limited to the period ( $<1 \mathrm{hr}$ ) before the $\mathrm{pH}$ of the leachant is significantly affected by the $\mathrm{pH}$ of the waste form. However, further study would be required to fully evaluate these effects.

In order to determine the inventories of radionuclides, stable metals, and chelating agents that could be leached from the waste forms being leach-tested, waste stream samples were obtained from all waste streams used to prepare the wasteform samples. The concentrations of the primary radionuclides, transuranic radionuclides, stable metals, and chelating agents present in the resin wastes were measured. The primary decontamination radionuclides whose leachability characteristics are discussed are ${ }^{55} \mathrm{Fe},{ }^{60} \mathrm{Co},{ }^{63} \mathrm{Ni}$, and ${ }^{14} \mathrm{C}$. Manganese- 54 is not discussed in detail because it was not measurable in most leachate 
samples. In addition to neutron activationproduced radionuclides, assessments have been performed for the fission products ${ }^{137} \mathrm{Cs},{ }^{99} \mathrm{Tc}$, and ${ }^{129} \mathrm{I}$ for the Peach Bottom-3 samples.

The measured concentrations of the transuranic radionuclides in the resin wastes were typically low with the exception of ${ }^{241} \mathrm{Pu}$, which has the highest concentrations of the transuranic radionuclides, ranging from $10^{-3}$ to $10^{-1} \mu \mathrm{Ci} / \mathrm{cm}^{3}$, whereas most other transuranic radionuclides had concentrations ranging from $10^{-8}$ to $10^{-4}$ $\mu \mathrm{Ci} / \mathrm{cm}^{3}$. The higher concentrations of ${ }^{241} \mathrm{Pu}$ are primarily due to the higher specific activity associated with this radionuclide. The leachability characteristics of the transuranic radionuclides were not discussed in detail because these radionuclides were not often measurable in the leachates, and the concentrations in the waste forms are dependent on the quantities present in the system that was decontaminated and the decontamination process used.

The stable metal constituents of the resin wastes included iron whose concentration was typically the highest and ranged from $5 \times 10^{2}$ to $10^{4} \mu \mathrm{g} / \mathrm{cm}^{3}$ resin waste. The concentration of nickel in the Cooper cation and Millstone resins was approximately $10^{3} \mu \mathrm{g} / \mathrm{cm}^{3}$ resin. Typical concentrations for other elements ranged from $10^{1}$ to $10^{2} \mu \mathrm{g} / \mathrm{cm}^{3}$ resin.

Typical concentrations of chelating agents ranged from about $10^{2} \mu \mathrm{g} / \mathrm{cm}^{3}$ of resin for oxalic and citric acid for the Cooper AP/Citrox process to about $5 \times 10^{4} \mu \mathrm{g} / \mathrm{cm}^{3}$ resin for picolinic acid in the Peach Bottom-3 LOMI resin wastes. Other decontamination processes (Can-Decon and DOW NS-1) had chelate concentrations between those noted for the AP/Citrox and LOMI processes. The high concentration of picolinic acid in the Peach Bottom-3 waste form may have resulted in some of the initial problems that occurred with this solidification.

Key conclusions from the leach testing are:

- $\quad$ For the LOMI waste forms, the structural stability of the waste form does not significantly affect the fractional release rates of chelating agents (e.g., picolinic acid) as indicated by comparisons between the releases from the FitzPatrick waste form that decomposed during leach testing and the Peach Bottom-3 waste form that maintained its structure.

- The inventory of the chelating agent in the waste form does not appear to have a significant effect on fractional or : ibsolute release rates, which generally appear to be controlled by chemical mechanisms other than pure diffusion. This is confirmed by the fact that the average fractional release rate of ${ }^{137} \mathrm{Cs}\left(\sim 5 \times 10^{-9} \mathrm{~cm}^{-2} \cdot \mathrm{s}^{-1}\right)$, which is ionic and probably released purely via diffusion, is one to two orders of magnitude higher than those of the chelating agents for most waste forms $\left(\sim 3 \times 10^{-10} \mathrm{~cm}^{-2} \cdot \mathrm{s}^{-1}\right.$ for the AP/Citrox and Can-Decon waste forms). In contrast, picolinic acid is released at about the same rate as ${ }^{137} \mathrm{Cs}$, and purely diffusional release is suggested for this chelating agent.

- Leachability indexes for the waste forms follow this general order from the lowest to highest: ${ }^{129} \mathrm{I}<{ }^{137} \mathrm{Cs}<{ }^{90} \mathrm{Sr}<{ }^{63} \mathrm{Ni}<{ }^{99} \mathrm{Tc}<$ ${ }^{60} \mathrm{Co}<{ }^{55} \mathrm{Fe}<{ }^{14} \mathrm{C}$ (i.e., leachability is highest for ${ }^{129} \mathrm{I}$ and lowest for ${ }^{14} \mathrm{C}$ ). As expected, the cations $\left({ }^{137} \mathrm{Cs}\right.$ and $\left.{ }^{90} \mathrm{Sr}\right)$ and anions $\left({ }^{129} \mathrm{I}\right)$ had the lowest leachability indexes (8-9), and ${ }^{14} \mathrm{C}$ had the highest (13.5).

- Comparisons of chelating agent release rate data with laboratory studies indicates that simulated cement-solidified decontamination ion-exchange waste forms produced in the laboratory may not accurately reproduce the waste compositions found in actual commercial nuclear power plant wastes and that, indeed, the commercial reactor wastes may contain constituents that enhance the release of chelating agents and radionuclides from the wastes.

- Cesium-137 leaches as quickly or more quickly than the chelating agents and radionuclides from most waste forms and is 
probably an indicator of a purely diffusioncontrolled release with no significant solubility effects, due to the relatively high solubility of ${ }^{137} \mathrm{Cs}$. These data suggest that some chelating agents are being retained in the waste form to a greater extent than the ionic radionuclides, probably due to the lower solubilities of the chelating agents.

- Differences in the average fractional release rates of the transition metal radionuclides between the FitzPatrick and Peach Bottom-3 LOMI waste forms and the Indian Point-3 LOMI waste form suggest that differences in the waste stream of a BWR (FitzPatrick and Peach Bottom-3) and that of a PWR (Indian Point-3) can have a significant impact on release rates of the transition metal radionuclides. Typically, lower fractional release rates $(\sim 10)$ are indicated for the PWR, although other factors such as resin type and waste loading may have had an effect.

- Transition metal radionuclide release rate data for all LOMI waste forms indicates that ${ }^{60} \mathrm{Co}$ and ${ }^{55} \mathrm{Fe}$ have the same release rates and appear to behave similarly chemically. In contrast, ${ }^{63} \mathrm{Ni}$ has statistically higher release rates by about an order of magnitude. The Irving-Williams correlation indicates that the stability of transition metal complexes fall in the order $\mathrm{Ni}^{\mathrm{II}}>\mathrm{Co}^{\mathrm{II}}>\mathrm{Fe}^{\mathrm{II}}$. These data suggest that the stability of the nickel complex with a chelating agent may result in the higher average fractional release rate of ${ }^{63} \mathrm{Ni}$ relative to the other transition metals, due to the greater solubility of the ${ }^{63} \mathrm{Ni}$ complex.

- Average absolute release rates for the transition metal radionuclides for the LOMI samples vary considerably, with the average absolute release rates ranging from $7 \times 10^{-10}$ to $5 \times 10^{-8} \mu \mathrm{Ci} / \mathrm{cm}^{2} \cdot \mathrm{s}^{1}$. Iron-55 typically has the lowest absolute release rate, and ${ }^{60} \mathrm{Co}$ and ${ }^{63} \mathrm{Ni}$ have the highest. However, if the specific activity of these radionuclides is taken into account and the release rates of these radionuclides are converted to $\mu \mathrm{g} / \mathrm{cm}^{2} \cdot \mathrm{s}^{1},{ }^{63} \mathrm{Ni}$ has a higher $\left(10^{2}\right)$ absolute mass release rate than do the other radionuclides, which may be a contributing factor to the higher concentrations of ${ }^{63} \mathrm{Ni}$ in the leachate due to the larger concentration gradient for this radionuclide between the resin, the waste form, and finally the leachant.

- If the weighted-average fractional release rates for the AP/Citrox mixed-bed waste forms (i.e., Brunswick-1 and Cooper) are compared with the results from the Brunswick-1 cation resin waste form, which does not contain a chelating agent, it is suggested that chelating agent effects may have increased the average fractional release rates of the transition metal radionuclides by the following factors: ${ }^{60} \mathrm{Co}(48),{ }^{55} \mathrm{Fe}(7.3)$, and ${ }^{63} \mathrm{Ni}(6)$. However, further tests would be required to confirm this conclusion, as other factors such as waste loading and resin type may also have affected the release rates.

- With the exception of the ${ }^{63} \mathrm{Ni}$ data, the average fractional release rates of the transition metals for the LOMI, AP/Citrox, and Can-Decon waste forms all fall into a narrow range between $5 \times 10^{-12}$ and $6 \times 10^{-11} \mathrm{~cm}^{-2} \cdot \mathrm{s}^{-1}$, which suggests relatively generic release rate behavior for these transition metal radionuclides. In the case of ${ }^{63} \mathrm{Ni}$, the release rates appear to be dependent on the decontamination process, with higher rates from the LOMI and Can-Decon waste forms and lower rates from the AP/ Citrox waste forms.

- Average effective diffusivities for ${ }^{60} \mathrm{Co}$ range from $1 \times 10^{-13} \mathrm{~cm}^{2} \cdot \mathrm{s}^{-1}$ for the Millstone-1 (Can-Decon) samples to $5 \times 10^{-11} \mathrm{~cm}^{2} \cdot \mathrm{s}^{-1}$ for the FitzPatrick LOMI samples. If the Brunswick-1 (AP/Citrox) cation resin (low) value and Pilgrim (NS-1) (high) values are excluded, for reasons discussed in the report, the typical average effective diffusivities for the waste forms are: LOMI $\left(1.8 \times 10^{-11} \mathrm{~cm}^{2} \cdot \mathrm{s}^{-1}\right)$, 
AP/Citrox $\left(4 \times 10^{-12} \mathrm{~cm}^{2} \cdot \mathrm{s}^{-1}\right)$ and CanDecon $\left(1 \times 10^{-13} \mathrm{~cm}^{2} \cdot \mathrm{s}^{-1}\right)$. These data indicate that the LOMI waste forms, either including or excluding FitzPatrick, have the highest average effective diffusivities followed by the AP/Citrox and Can-Decon waste forms.

- The low release rate of ${ }^{14} \mathrm{C}$ measured for the Peach Bottorn-3 (LOMI) samples is probably due to the formation of insoluble hydrates and carbonates, which slow the release of this radionuclide, although other factors such as resin type may have an effect. Further, others have suggested that the fractional release rate of ${ }^{60} \mathrm{Co}$ should be slower than ${ }^{14} \mathrm{C}$ unless the rate is increased due to chelating agent effects as shown in this study.

- The release rate behavior of ${ }^{99} \mathrm{Tc}$ for the Peach Bottom-3 (LOMI) samples is statistically the same as that for ${ }^{55} \mathrm{Fe}$ and ${ }^{60} \mathrm{Co}$, and suggests similar chemical and release rate behavior for ${ }^{99} \mathrm{Tc}$. This might be expected as technetium is a metal and would be expected to form organo metallic complexes.

- Iodine, an anion, would be expected to diffuse similarly to other ionic elements such as cesium, and its release would not be expected to be affected by chelating agent effects as discussed for ${ }^{137} \mathrm{Cs}$. The fractional release rates of ${ }^{129} \mathrm{I}$ and ${ }^{137} \mathrm{Cs}$ for the Peach Bottom-3 (LOMI) samples are the highest of all radionuclides present in the waste form and are statistically the same as that for picolinic acid $\left(5.8 \times 10^{-10}\right.$ $\mathrm{cm}^{-2} \cdot \mathrm{s}^{-1}$ ) from the Peach Bottom-3 waste form, and are higher than those for other chelating agents.

- Comparisons of stable metal release rates with those of ${ }^{63} \mathrm{Ni}$ and ${ }^{55} \mathrm{Fe}$ indicate that the average fractional release rates for nickel and iron are higher than those of the radionuclides by one to two orders of magnitude except for the LOMI waste form. These data indicate that these radionuclides in the AP/ Citrox and Can-Decon waste forms may be in a chemical form in the waste form that causes them to be retained to a greater extent than the elemental iron and nickel.

- A comparison of the LOMI ${ }^{63} \mathrm{Ni}$ data with the elemental nickel data indicates that ${ }^{63} \mathrm{Ni}$ has the same weighted-average fractional release rate $\left(4.8 \pm 1.0 \times 10^{-10} \mathrm{~cm}^{-2} \cdot \mathrm{s}^{-1}\right.$ excluding Indian Point-3) as elemental nickel for the LOMI waste forms. However, for the Indian Point-3 sample, the fractional release rate of ${ }^{63} \mathrm{Ni}$ is about $2 \%$ of the release of nickel. These data indicate that for Indian Point-3 (LOMI), the elemental nickel and ${ }^{63} \mathrm{Ni}$ are in different chemical forms.

- A comparison of the only measurable LOMI ${ }^{55} \mathrm{Fe}$ and iron fractional release rate data (Peach Bottom-3) indicates that the fractional release rate of ${ }^{55} \mathrm{Fe}$ is about two orders of magnitude higher than that for elemental iron. The explanation for this behavior is not known and is not consistent with the expected kinetics of this radionuclide, which suggest that it should be released as the same rate as the iron.

- Leachant effects (i.e., the use of different leachants) have been observed for ${ }^{55} \mathrm{Fe}$ and ${ }^{63} \mathrm{Ni}$ that apparently affect the release rates of these radionuclides from the waste form. Specific leachant effects may affect the fractional release rate by one to two orders of magnitude.

- Based on the Brunswick-1 (AP/Citrox) and FitzPatrick (LOMI) studies, high ionic strength leachants (e.g., simulated seawater) and some groundwaters may affect the release rates of radionuclides. It should be noted that in many cases, deionized water may not be the most aggressive leachant. The Barnwell groundwater $\mathrm{pH} 10.4$ had higher release rates and cumulative fractional releases for some transition metal radionuclides than did the deionized water. 
- Leach test results suggest that release rates obtained during the first 5 days are not indicative of trends for later times particularly when degraded waste forms are being tested and that further testing may be required to determine actual release rates from these waste forms.

The results of this study provide substantial information on the release rates of chelating agents, radionuclides, and stable metals; however, the results present a number of questions concerning the mechaniz:ns that retain the species of interest in the :-aste forms or accelerate releases. The ANSI/ANS 16.1 standard assumes that release rates are diffusion driven, which is shown in this study. However, this study also indicates that solubility and leachant ion strength may also be significant in defining absolute releases from the waste form. The results of this study show that the waste forms tested meet the "Technical Position on Waste Form" requirements for physical stability for cases in which the waste forms survived the immersion test, and for leachability for both intact and degraded waste forms. 


\section{ACKNOWLEDGMENTS}

The authors are grateful to the NRC technical monitor, Dr. Phillip R. Reed, for his long-term support of this project and to the many individuals who participated in the project. Particularly, we thank C. V. McIsaac, J. W. McConnell, Jr., and $\mathrm{N}$. Morcos, who were extensively involved in various aspects of the project. In addition, we thank all members of the staff at the Idaho National Engineering Laboratory who performed the radiochemical analysis, which was essential to the completion of this project. 


\section{ACRONYMS}

\begin{tabular}{|c|c|c|c|}
\hline ANSI/ANS & $\begin{array}{l}\text { American National Standards } \\
\text { Institute/American Nuclear } \\
\text { Society }\end{array}$ & DTPA & $\begin{array}{l}\text { diethylenetriaminepentaacetic } \\
\text { acid } \\
\text { deionized water }\end{array}$ \\
\hline $\mathbf{A P}$ & alkaline permanganate & EDTA & ethylenediaminetetraacetic acid \\
\hline ASTM & $\begin{array}{l}\text { American Society for Testing } \\
\text { and Materials }\end{array}$ & HGW & Hanford groundwater \\
\hline B-BGW & $\begin{array}{l}\text { baked, Barnwell-groundwater } \\
\text { FitzPatrick sample }\end{array}$ & LOMI & $\begin{array}{l}\text { low oxidation-state } \\
\text { transition-metal ion }\end{array}$ \\
\hline & & LWR & light water reactor \\
\hline B-DW & $\begin{array}{l}\text { baked, deionized-water } \\
\text { FitzPatrick sample }\end{array}$ & NP & nitric permanganate \\
\hline BGW & Barnwell groundwater & NRC & $\begin{array}{l}\text { U.S. Nuclear Regulatory } \\
\text { Commission }\end{array}$ \\
\hline BWRs & boiling water reactors & PCRS & $\begin{array}{l}\text { primary coolant recirculation } \\
\text { system }\end{array}$ \\
\hline CFR & Code of Federal Regulations & PWR & pressurized water reactor \\
\hline CFRs & cumulative fraction releases & RWCS & reactor water cleanup system \\
\hline Citrox & citric acid/oxalic acid & SW & simulated seawater \\
\hline
\end{tabular}




\section{Compression and Immersion Tests and Leaching of Radionuclides, Stable Metals, and Chelating Agents from Cement-Solidified Decontamination Waste Collected from Nuclear Power Stations}

\section{INTRODUCTION}

A study was performed for the U.S. Nuclear Regulatory Commission (NRC) to assess the physical stability and leachability of cementsolidified decontamination ion-exchange resin wastes collected from seven commercial boiling water reactors (BWRs) and one commercial pressurized water reactor (PWR). Detailed results of this study are presented in References 1 through 3. The objective of this report is to integrate the results of the individual reactor studies and to provide a comprehensive assessment of the structural stability and leachability characteristics of cement-solidified decontamination ion-exchange resins.

During light water reactor (LWR) operation, the corrosion of fuel rod cladding and other reactor structural surfaces introduces neutron activation products such as ${ }^{54} \mathrm{Mn},{ }^{55} \mathrm{Fe},{ }^{60} \mathrm{Co}$, and ${ }^{63} \mathrm{Ni}$ into the primary coolant recirculation system (PCRS). These neutron activation products are transported by the primary coolant throughout the primary system. Some fraction of these neutron activation products adheres to internal primary system surfaces, and, over time, the buildup of deposited activity can result in substantial radiation fields in the vicinity of these surfaces. In order to minimize occupational exposure during primary system maintenance and inspection activities, chemical decontamination methods are now commonly being employed to remove neutron activation products from primary system internal surfaces.

Two generic processes have been developed for the chemical decontamination of primary system components: concentrated processes ( 5 to $25 \mathrm{wt} \%$ chemicals in solution) and dilute processes (1 wt\% or less chemicals in solution). Examples of chemical processes that can be used in both concentrated and dilute forms are NS-1, developed by Dow Chemical Company, and AP/ Citrox. The Can-Decon, low oxidation-state transition-metal ion (LOMI), and LOMI-nitric permanganate (NP)-LOMI processes are examples of dilute reagent processes (normally less than $0.2 \%$ reagent by weight). The reagents used in both the concentrated and dilute processes include chelating or complexing agents such as ethylenediaminetetraacetic acid (EDTA), diethylenetriaminepentaacetic acid (DTPA), citric acid, oxalic acid, picolinic acid, and formic acid. Chelating agents and organic acids are used in decontamination formulas because they form strong complexes with actinides, lanthanides, heavy metals, and transition metals and assist in keeping these elements in solution. Generally, these chemical decontamination solutions, once used, are treated with ion-exchange resins to extract the soluble activity, and it is these resins that constitute the final waste from the decontamination process that must be processed by solidification or other methods.

Wastes from these chemical decontamination processes contain relatively large quantities of chelates or complexing agents in addition to inventories of neutron activation and corrosion products. A potential problem with decontamination wastes disposed in shallow land burial sites is the increased solubility of the organo-radionuclide complexes. During recent years, a number of studies have focused on the issue of chelate enhanced mobility of low-level radioactive waste. A definite association of industrially used chelating agents with increased movement of certain radionuclides through soil columns was reported in $1967 . .^{4}$ In 1977 , chelated radionuclide migration was documented at the Chalk River Nuclear Facility in Canada ${ }^{5}$ and at Oak Ridge 
National Laboratory in Tennessee. ${ }^{6}$ EDTA was subsequently identified as the main organic compound associated with ${ }^{60} \mathrm{Co}$ and trace amounts of ${ }^{238} \mathrm{Pu},{ }^{241} \mathrm{Am}$, and ${ }^{244} \mathrm{Cm}$ at the Oak Ridge site. ${ }^{7}$ Laboratory studies and analyses of actual water collected from the site indicated that the presence of organic chelants in the leachates was responsible for diminished shale and soil adsorption of ${ }^{60} \mathrm{Co}^{7}$ In 1981, EDTA was identified in radioactive waste containing ${ }^{238} \mathrm{Pu}$, this time in trench leachates from the Maxey Flats burial ground in Kentucky. ${ }^{8}$

If organo-radionuclide complexes are formed before decontamination reagents, and radionuclides have leached from waste forms in a burial trench, they may migrate rapidly away from the trench because of the reduction in the sorption of these species by the geomedia. ${ }^{9}$ The actual hazard posed to the public by disposal of chelated decontamination resin wastes will depend on a number of factors. Leachability is a function of the radionuclide, its chemical form, resin waste chemistry, solidification agent, and final solidified matrix. Burial site hydrology and groundwater chemistry also influence leaching rates, as do cyclic wet and dry conditions. The complexity of the interactions that occur among radionuclides, complexing agents, groundwater, and soil introduces uncertainties into the models used to predict the impact of the decontamination resin wastes on the performance of shallow land burial sites. Therefore, it is important to better understand the leachability of actual decontamination resin waste forms that result from commonly used decontamination processes.

The NRC is concerned with the safe disposal of these chemical decontamination wastes and has made provisions for their disposal in "Licensing Requirements for Land Disposal of Radioactive Waste" (U.S. Code of Federal Regulations, Standard 10, Part 61). Section 61.56 provides requirements for the stability of waste forms that must be met for the waste form to be acceptable for nearsurface disposal. Additional requirements for the disposal of chelated wastes are also given in burial site regulations. In Section 61.54, the wastes are classified as Class A, B, or C, based on the concentrations of radionuclides in the wastes. Class A wastes have lower concentrations and may be disposed without being stabilized; however, Class A wastes buried with Class B and C wastes must be stabilized. All Class B and C wastes must be structurally stabilized to ensure that the waste form does not degrade and promote slumping, collapse, or failure of the cap or cover of the near-surface disposal trench. In addition, the stability of the waste form limits exposure to inadvertent intruders. Class B and C low-level wastes from LWRs may bc solidified at LWR sites using cement to meet the stability requirements identified in the "Technical Position on Waste Form," Revision 1. Solidification of these wastes is intended to provide the structural stability needed to ensure that no collapse of the disposal trench occurs and that the release of radionuclides via leaching is minimized.

Test procedures to demonstrate waste-form structural stability and to quantify leachability for the low-level wastes from LWRs have been specified by the NRC in the Low-Level Waste Management Branch's "Technical Position on Waste Form," 10 published in 1983, and in the "Technical Position on Waste Form," Revision $1,{ }^{11}$ published in January 1991. Both documents specify that small-scale waste-form specimens must be prepared and tested to certify the stability of the fullscale waste form.

The NRC's "Technical Position on Waste Form," stipulated that the small-scale waste-form specimen must exhibit a compressive strength of $50 \mathrm{psi}\left(3.4 \times 10^{2} \mathrm{kPa}\right)$. This was later raised to $60 \mathrm{psi}\left(4.1 \times 10^{2} \mathrm{kPa}\right)$ to reflect an increase in burial depth to $55 \mathrm{ft}$ at the Hanford site. Appendix A of the "Technical Position on Waste Form," Revision 1, recommends a mean compressive strength of $500 \mathrm{psi}\left(3.4 \times 10^{3} \mathrm{kPa}\right)$ for wasteform specimens cured for a minimum of 28 days when tested in accordance with the American Society for Testing and Materials (ASTM) Standard C39, "Compressive Strength of Cylindrical Concrete Specimens." 12 Further, Appendix A stipulates that compressive strengths be measured after either a 7-day or 90-day immersion test and that the compressive strengths should be equal to or greater than 500 psi and not less than $75 \%$ of 
the pre-immersion test results or further testing should be performed.

The "Technical Position on Waste Form" also stipulates that the small-scale waste-form specimen should have a leachability index greater than 6.0 when leach-tested for a minimum of 90 days in accordance with the American National Standards Institute/American Nuclear Society (ANSI/ ANS) Standard 16.1, "Measurement of the Leachability of Solidified Low-Level Radioactive Wastes by a Short- Term Test Procedure."13 In January 1991, this procedure was modified by the "Technical Position on Waste Form," Revision 1 , which reduced the leach test period from 90 days to 5 days.

The results of numerous investigations reported in the literature indicate that the rate of radionuclide release from a waste form is influenced by poorly understood interactions related to the properties of the solid and the leaching system. Among the factors that are known to influence the leachability of cement-solidified waste forms are the chemical composition of the cement and waste used, the waste-to-binder ratio, the amount of water used to set the cement, and the presence of additives that are used to accelerate or retard cement hydration. Other factors such as temperature, leachant composition, $\mathrm{pH}$, volume, and residence time may also influence leachability. These factors were discussed in depth at the Workshop on Cement Stabilization of Low-Level Radioactive Waste, ${ }^{14}$ where specific process details and problem wastes were reviewed. Appendix A summarizes some of the important experimental results of leaching studies that have been performed on other wastes and decontamination ion-exchange resins. In addition, waste form constituents and other factors that might be expected to affect waste form stability and leachability are discussed.

To date, however, most leaching studies that have focused on assessing the stability and leachability of solidified decontamination resin wastes that contain chelating agents have been conducted using simulated decontamination resin wastes that were solidified in the laboratory.
None of the studies, other than those performed at this laboratory, have investigated the leaching of radionuclides in the presence of high concentrations of chelating agents and/or stable transition metals. Application of simulated waste data to the performance of actual solidified decontamination waste in near-surface disposal sites is necessarily limited because of poiential mechanistic and equilibrium influences of proprietary additives that are present in the decontamination and solidification formulas. As actual cement-solidified commercial nuclear power plant wastes are used in this study, the release rate data developed are more representative of actual waste site releases.

The purpose of this research study is to evaluate the stability of actual low-level radioactive ion-exchange wastes solidified in cement using the tests from the "Technical Position on Waste Form," Revision 1, for compression testing and leachability, and to determine the release rates of radionuclides, chelating agents, and transition metals from solidified ion-exchange resin wastes that have been immersed in deionized water. This work is identified in the NRC's Low-Level Radioactive Waste Research Program Plan, which defines a strategy for conducting research on issues of concern to the NRC in its effort to ensure stability of solidified low-level radioactive waste, leading to safe disposal.

The PCRSs were decontaminated at seven BWRs using four different decontamination processes: Millstone-1 (Can-Decon), Peach Bottom-2 (Can-Decon), Pilgrim (NS-1), Cooper (AP/Citrox), James A. FitzPatrick (LOMI/NP/ LOMI), Brunswick-1 (Citrox/AP/Citrox), and Peach Bottom-3 (LOMI/NP/LOMI). The LOMI process was used to decontaminate a steam generator channel head at a PWR, Indian Point-3. The dates of the decontaminations, the processes used, and the names of the companies that performed the decontaminations are summarized in Table 1. In addition, specific information on the decontaminations at the James A. FitzPatrick and Peach Bottom-3 nuclear plants can be found in the Third Seminar on Chemical Decontamination of BWRs. ${ }^{15,16}$ 
Introduction

Table 1. Reactors decontaminated and decontamination processes.

\begin{tabular}{|c|c|c|c|c|c|c|}
\hline $\begin{array}{c}\text { Commercial nuclear } \\
\text { reactor }\end{array}$ & $\begin{array}{c}\text { Decontaminaticn } \\
\text { date }\end{array}$ & $\begin{array}{c}\text { System } \\
\text { decontaminated }\end{array}$ & $\begin{array}{c}\text { Purpose of } \\
\text { decontamination }\end{array}$ & $\begin{array}{l}\text { Decontamination } \\
\text { process used }\end{array}$ & $\begin{array}{l}\text { Decontamination } \\
\text { contractor }\end{array}$ & $\begin{array}{c}\text { Waste } \\
\text { volume } \\
\text { generated } \\
\left(\mathrm{m}^{3}\right)\end{array}$ \\
\hline Millstone-1 (BWR) & $04 / 84$ & PCRSa & Pipe inspection & Can-Decon & $\begin{array}{l}\text { London Nuclear } \\
\text { Services Corp. }\end{array}$ & 1.27 \\
\hline $\begin{array}{l}\text { Peach Bottom-2 } \\
\text { (BWR) }\end{array}$ & 08/84 & PCRS & $\begin{array}{l}\text { Pipe } \\
\text { replacement }\end{array}$ & Can-Decon & $\begin{array}{l}\text { London Nuciear } \\
\text { Services Corp. }\end{array}$ & 1.47 \\
\hline Pilgrim (BWR) & $07 / 84$ & PCRS & Pipe inspection & Dilute NS-1 & $\begin{array}{l}\text { IT Nuclear } \\
\text { Services Corp. }\end{array}$ & 2.55 \\
\hline Cooper (BWR) & $11 / 84$ & PCRS & $\begin{array}{l}\text { Pipe } \\
\text { replacement }\end{array}$ & AP/Citrox & $\begin{array}{l}\text { Pacific Nuclear } \\
\text { Services }\end{array}$ & 4.72 \\
\hline Brunswick-1 (BWR) & $12 / 87$ & PCRS & Pipe inspection & Citrox/AP/Citrox & $\begin{array}{l}\text { Pacific Nuclear } \\
\text { Services }\end{array}$ & 6.51 \\
\hline $\begin{array}{l}\text { James A. FitzPatrick } \\
\text { (BWR) }\end{array}$ & $9 / 88$ & $\mathbf{R W C S}^{\mathbf{b}}$ & $\begin{array}{l}\text { Inspection of } \\
\text { RHR crosstie } \\
\text { piping }^{c}\end{array}$ & LOMI/NP/LOMI & $\begin{array}{l}\text { Pacific Nuclear } \\
\text { Services }\end{array}$ & 5.88 \\
\hline $\begin{array}{l}\text { Peach Bottom-3 } \\
\text { (BWR) }\end{array}$ & $12 / 87(1 / 88)$ & PCRS/RWCS & Pipe inspection & LOMINAPROMI & $\begin{array}{l}\text { Pacific Nuclear } \\
\text { Services }\end{array}$ & 7.7 \\
\hline $\begin{array}{l}\text { Indian Point-3 } \\
\text { (PWR) }\end{array}$ & $06 / 85$ & SGCHd & $\mathrm{SGCH}^{\mathrm{d}}$ cleanup & LOMI & Quadrex HPS & 3.45 \\
\hline a. Primary coolant recinc & ion system. & & & & & \\
\hline $\begin{array}{l}\text { b. Greater than } 90 \% \text { of } \\
\text { residual heat removal cro }\end{array}$ & $\begin{array}{l}\text { vaste generated came } \\
\text { and the PCRS. }\end{array}$ & $\mathrm{n}$ the decontaminat & of the reactor water & anup system with the & nce from the deconta & ations of the \\
\hline
\end{tabular}

In the following section of this report, the decontamination processes are described that were used at the eight BWRs. In addition, the resins solidified, the cement chemistry, and the solidification methods used at the plants sampled are described. Next, summary descriptions of the leach test procedure, data analysis methods, and analytical methods are presented. This is followed by a discussion of the results of the compression and leach tests on the solidified decontamination resin waste specimens. This sec- tion is divided up into three parts: an assessment of the effects of $\mathrm{pH}$ and conductivity on releases from the waste forms, a comparison of the leachability characteristics of the waste forms from the various decontamination processes, and an assessment of the effects of differing leachants (i.e., deionized water, seawater, and groundwaters) on the releases of chelating agents, radionuclides, and stable metals from the waste forms. Finally, a summary of results is presented along with recommendations for future work. 


\section{DECONTAMINATION PROCESSES}

A variety of decontamination processes were used to decontaminate the reactor systems listed in Table 1. These decontamination processes utilize differing chelating agents and other chemical constituents that may be expected to affect radionuclide or other releases from the cement-solidified waste form. This section describes the reactor systems decontaminated and the processes used to decontaminate those systems. A schematic of a BWR PCRS is shown in Figure 1. The PCRS provides the driving force for the movement of reactor coolant from the annulus area up through the reactor core region. The main components of the PCRS are the suction lines that allow water to be removed from the annulus area, the recirculation pumps, the discharge lines that carry water from the recirculation pump to the ring header, and the risers that direct the water to the jet pumps in the annulus. ${ }^{17}$ Decontamination is performed on the PCRS piping to reduce the dose to workers who are performing maintenance activities in the vicinity of the piping.

As noted in Table 1, a steam generator channel head was decontaminated at the Indian Point-3 reactor. The steam generator channel head serves to direct reactor coolant flow through the steam generator heat exchanger tubes. Personnel access to perform much of the steam generator inspection, maintenance, and repair work is through the channel head manway openings. As a consequence, decontamination of this area around the steam generator channel head serves to reduce the radiation dose to workers in the vicinity of the steam generators.

There are two general methods that have been developed to perform decontaminations of BWRs: concentrated chemical processes and dilute chemical processes. The concentrated processes use reagent concentrations of between 5 and $25 \mathrm{wt} \%$ of the coolant, and the dilute processes that are currently employed use reagent concentrations of $0.2 \mathrm{wt} \%$ or less. Based on these concentrations, the quantity of reagents required for a concentrated process decontamination ranges from about 48 to $248 \mathrm{~kg}$ of reagent per cubic meter of primary system volume to be contaminated. A similar estimate for a dilute process decontamination is less than $2 \mathrm{~kg}$ per cubic meter. During recent years, the dilute chemical processes have become the most widely used.

The decontamination processes used at the LWRs from which samples were obtained were dilute chemical, single or multi-step processes. Most of the processes were approximately 0.1 wt\% reagent and were multi-step in the respect that they required an initial oxide removal step, a chrome removal step, and a final oxide removal step. The processes were performed at either high temperature and high pressure [i.e., $393 \mathrm{~K}$ $\left(120^{\circ} \mathrm{C}\right)$ and $\left.2.4 \times 10^{2} \mathrm{kPa}(35 \mathrm{psig})\right]$ or at low temperature [i.e., 333 to $363 \mathrm{~K}\left(60\right.$ to $\left.90^{\circ} \mathrm{C}\right)$ ] and atmospheric pressure. The processes, in general, use a combination of organic acids and chelating agents to dissolve the oxide film from surfaces and suspend the resulting organo-metal complexes in solution. Corrosion inhibitors are added to reduce the attack on the base metal by the organic acids. Because of the higher chromium content of oxide films in reactor water cleanup systems, when decontaminating these systems, an oxidizing pretreatment step is added that oxidizes chromium to a readily soluble state (i.e., +3 to +6 valence).

The reagents are slurried and injected directly into the primary system water and circulated for 1 to 3 days. During the process, the decontamination solution is passed through cation exchange resins to remove the corrosion and activation products and regenerate the reagents. Following completion of decontamination, mixed-bed resins are used to remove the residual metallic ions and the decontamination reagents. The four decontamination processes evaluated in this study are described below.

\section{Can-Decon}

During recent years, the Can-Decon process has been one of the most widely used decontamination processes. It was developed by Atomic 
Decontamination Processes

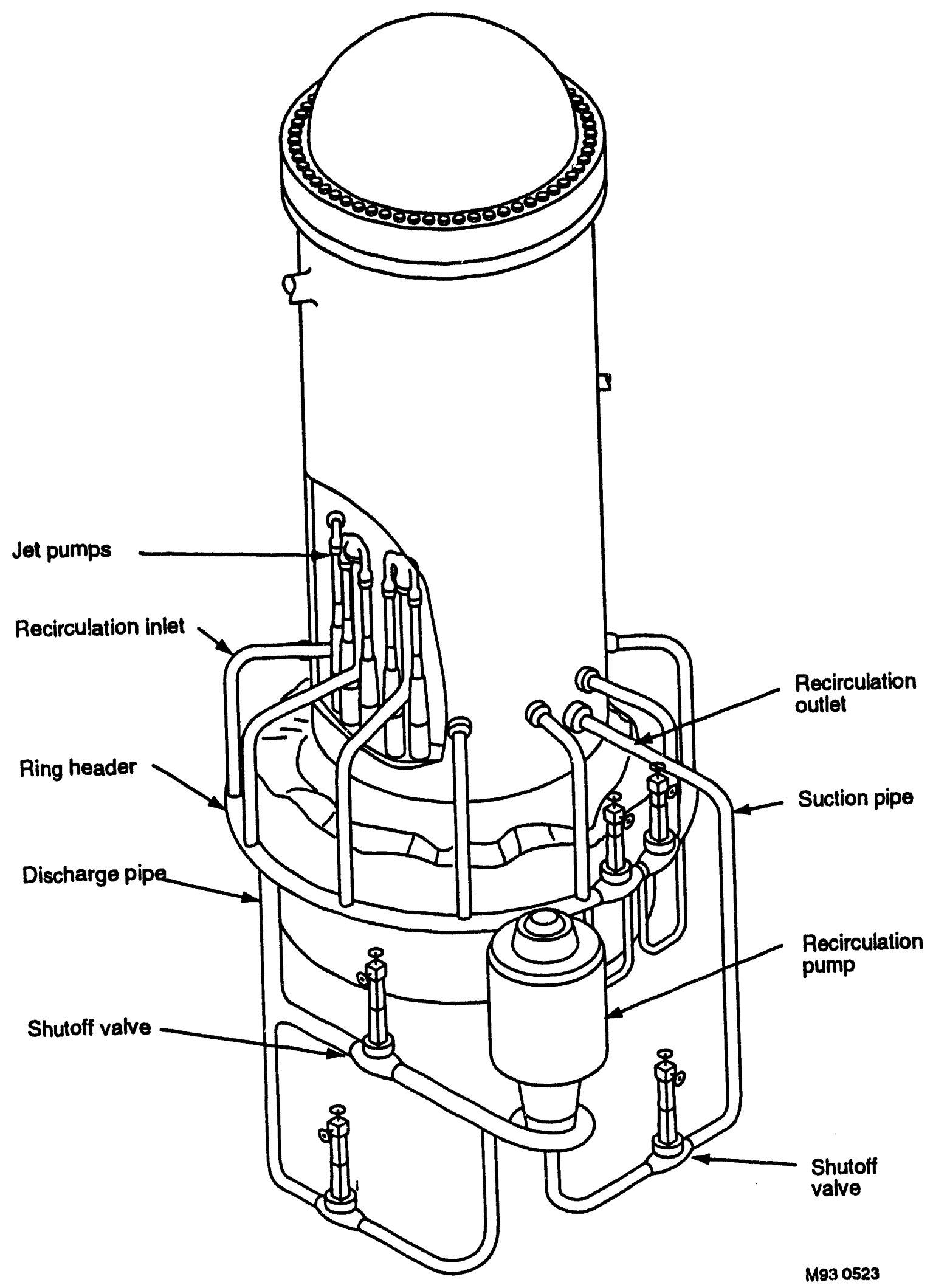

Figure 1. Boiling water reactor primary coolant recirculation system. 
Energy of Canada Limited for use in CANDU reactors and was subsequently modified for use in LWRs in the United States. It is a dilute chemical process that utilizes oxalic acid, citric acid, and EDTA. ${ }^{18}$ Prior to the start of decontamination, the primary coolant is treated by ion exchange and chemical addition to ensure neutral $\mathrm{pH}$, low conductivity, and low dissolved oxygen. Coolant temperature is maintained at about $393 \mathrm{~K}$ $\left(120^{\circ} \mathrm{C}\right)$, and system pressure is kept at about $2.4 \times 10^{2} \mathrm{kPa}(35 \mathrm{psig})$. Once these conditions are met, a concentrated slurry of the reagent is injected into the primary coolant circulating in the system to be decontaminated.

The reagents dissolve the contaminated oxide layer by a reduction process that converts $\mathrm{Fe}^{+3}$ to $\mathrm{Fe}^{+2}$. The dissolved corrosion and activation products are maintained in solution by the complexing agents. When used to decontaminate a BWR system, a single-step reducing solution is used; but when used on PWR systems, a dual-step process is utilized that alternates the reducing step with a dilute oxidizing step. ${ }^{19}$ In order to prevent cross-contamination of the two solutions, free oxygen from the oxidizing step is scavenged with hydrazine before the reducing solution is introduced. During the time the reducing solution is used, the primary coolant is cycled through cation exchange resins to maintain reagent concentrations. The oxidizing solution is, on the other hand, not regenerated; but at the end of the process, which may cover a period of from 1 to 3 days, mixed-bed ion-exchange resins are used to remove residual metallic ions and the decontamination reagents. These media-the cation and mixed-bed ion-exchange resins-are the wastes that must be processed.

\section{AP/Citrox}

Pacific Nuclear Services, Inc. developed and licensed this proprietary process for application in the United States for both PWR and BWR systems. The AP/Citrox (alkaline permanganate)/(citric acid/oxalic acid) process is a dilute, low-temperature, low-pressure process. ${ }^{18}$ For a PWR system, the AP/Citrox process is normally performed in the following steps: a heated slurry of alkaline permanganate (AP) is injected into the system being decontaminated; the primary coolant is circulated; then the coolant is drained, and the system is rinsed with reagent-free water. This step is followed by an optional dilute Citrox rinse that neutralizes any remaining AP solution. Following these initial steps, a more concentrated, heated Citrox solution is then circulated to accomplish the actual decontamination of the internal surfaces. This solution is then flushed from the system, and the system is rinsed with reagent-free water. These solutions are treated with cation and mixed-bed ion-exchange resins to remove the soluble metallic ions and residual reagents.

For a BWR, system decontamination is performed as follows: a heated dilute Citrox solution is injected into the system and circulated for about 24 hours. Oxalic and citric acids are then removed from the primary coolant by cycling it through mixed-bed ion-exchange resins. Next, a heated AP solution is circulated in the system for about 8 hours, after which time the primary coolant is again cycled through ion-exchange resins. This chromium-conditioning step is followed by a second treatment with dilute Citrox solution. This last step is normally accomplished in 10 to 20 hours. During this time, the primary coolant is cycled through cation-exchange resins to remove soluble metallic ions and regenerate the reagents. The Citrox reagents and residual corrosion products are removed by mixed-bed ion-exchange resins following completion of the decontamination operation. These mixed-bed decontamination ion-exchange resin wastes must then be processed for disposal at a low-level radioactive waste disposal site.

\section{Dow NS-1}

The Dow Chemical Company developed the NS-1 process. The Dow NS-1 process is a hightemperature, high-pressure process that may be used in either a concentrated or dilute form. ${ }^{18}$ For BWRs, it is usually a single-step process that requires about 100 hours to be completed. The NS-1 reagents are added to the primary coolant during several successive injections until the concentration is at the appropriate level. Active 
constituents of the NS-1 formulation include EDTA, oxalic acid, citric acid, and DTPA. The primary coolant is circulated until no further increases in metallic ion concentrations are observed. After the decontamination is completed, the spent decontamination solution is drained from the system and the system is flushed with reagent-free water to remove any residual reagents. A copper removal step is sometimes used at the end of the decontamination process. Solution reagents and soluble metallic ions are removed by passing the decontamination solution and flush water through a particulate filter and mixed-bed ion-exchange resins. These mixedbed resins are then processed for disposal.

\section{LOMI}

The LOMI ${ }^{18,19,20}$ or LOMI-NP-LOMI process was developed by the Central Electricity Generating Board of Britain and is now being marketed in the United States by Pacific Nuclear Services and other groups including Westinghouse Nuclear.
The basic feature of the process is the use of $\mathrm{V}^{+2}$ (as vanadous formate) to reduce the $\mathrm{Fe}^{+3}$ in oxide films to $\mathrm{Fe}^{+2}$. The process involves electron stripping rather than attack of the film by acid. It is a multi-step process that is applied differently to BWR and PWR systems. When LOMI is used to decontaminate a PWR, $\mathrm{AP}^{21}$ is injected into the system under acidic conditions for nickel-based systems or under alkaline conditions for stainless steel systems. The permanganate solution is circulated in the system and then drained and normally destroyed using oxalic acid. Degassed picolinic acid (as sodium picolinate) is then injected into the coolant, and the coolant is circulated while being maintained at a temperature of between 353 and $363 \mathrm{~K}\left(80\right.$ and $\left.90^{\circ} \mathrm{C}\right)$ under atmospheric pressure. Vanadous formate $\left[\mathrm{V}(\mathrm{HCOO})_{2}\right]$ is then injected to reduce $\mathrm{Fe}^{+3}$ to $\mathrm{Fe}^{+2}$. The picolinic acid maintains the $\mathrm{Fe}^{+2}$ and other corrosion products in solution. The resulting spent reagent solutions are drained from the system being decontaminated and are treated with mixed-bed ion-exchange resins. These resins constitute the decontamination waste product. 


\section{DECONTAMINATION ION-EXCHANGE RESIN WASTE SOLIDIFICATION PROCESS}

The decontamination ion-exchange resin waste solidification process is summarized in this section. The important elements of the solidification process are the characteristics of the resins that are being solidified, the cement chemistry, and the waste solidification technique. All three elements contribute to the formation of a stable waste form that will meet the NRC's requirements for leachability in the "Technical Position on Waste Form" or Revision 1 of the Technical Position.

\section{Resin Waste Characteristics}

The ion-exchange resins most frequently used to treat decontamination process solutions are organic bead resins of cation or mixed-bed form. Individual resin beads have diameters that are typically in the range of 0.35 to $1.15 \mathrm{~mm}$ in order to maximize effective surface area. The cationexchange resin most often encountered during the course of this study was Amberlite IRN-77, which is manufactured by Rohm and Haas Company, Philadelphia, PA. This resin has a polystyrene-divinylbenzene matrix with sulfonic $\left(\mathrm{SO}_{3}^{-}\right)$ exchange groups and is supplied in the $\mathrm{H}^{+}$form (i.e., $\mathrm{H}^{+}$is the exchangeable counter ion). The mixed-bed resins generally consist of mixtures of Amberlite IRN-77 cation and either Amberlite IRN-78 anion or Ionac A-365 anion resins. IRN-78 is a strongly basic anion-exchange resin having a polystyrene divinylbenzene matrix that has a minimum of $85 \%$ of its exchange sites in the $\mathrm{OH}^{-}$form. Ionac A-365 anion-exchange resin, which is manufactured by Sybron, is a weak-base polyacrylate-based anion-exchange resin that is supplied in the free-base and $\mathrm{OH}^{-}$forms. The latter resin is normally used, in mixed-bed form, to process LOMI decontamination solutions.

The minimum total exchange capacities of IRN-77 cation- and IRN-78 anion-exchange resins are, respectively, 1.8 and 0.78 milliequivalents per cubic centimeter of wet resin. Piciulo et al. ${ }^{22}$ calculated the approximate quantities of var- ious reagents that are individually required to exhaust $50 \%$ of the exchange capacities of the previously mentioned ion-exchange resins. Extrapolating those results to $100 \%$ loading, the total exchange capacities of the IRN-77 cationexchange resin, expressed as milligrams of reagent per gram of dewatered resin, are: EDTA, 256; oxalic acid, 80; citric acid, 168; picolinic acid, 216; and formic acid, 84. Similar results for a 1:2 weight mixture of IRN-77 cation resin and IRN-78 anion resin are: EDTA, 172; oxalic acid, 52; citric acid, 112; picolinic acid, 144; and formic acid, 56.

For a 1:2 weight mixture of IRN-77 cation and Ionac A-365 anion-exchange resins, the total exchange capacities expressed as milligrams of reagent per gram of dewatered resin for picolinic and formic acids in a LOMI-type mixture are: picolinic acid, 216; and formic acid, 84. In general, the total exchange capacity weight loadings are proportional to reagent formula weight.

Decontamination ion-exchange resin wastes are normally maintained in a wet slurry condition to allow pumping them from ion-exchange columns to waste holding tanks and ultimately to the containers in which they are solidified. Ordinarily, a pumpable slurry will contain about $70 \%$ resin and $30 \%$ water by volume. Resin saturated with water to equilibrium will contain a substantial amount of water by weight. Most of this water is sorbed within the resin beads, and when resin waste is solidified in cement, this water is unavailable for hydration of cement. Approximately 10 to $15 \mathrm{wt} \%$ of the moisture content of dewatered resin is held in the interstitial spaces between resin beads, and it is this water that is consumed during the hydration of cement. Neilson et al. ${ }^{23}$ measured the water content and densities of IRN-77 cation, IRN-78 anion, and IRN-77/RRN-78 mixed-bed resins under several different conditions, where the mixed-bed resin consisted of two parts cation to one part anion by weight. Their results are shown in Table 2. This information provides the basis for determining 
Table 2. Densities and water content of resins.

\begin{tabular}{lcccccc}
\hline & \multicolumn{2}{c}{ As-received } & \multicolumn{2}{c}{ Dewatered } & \multicolumn{2}{c}{ Slurry } \\
\cline { 2 - 6 } Resin & $\begin{array}{l}\text { Density } \\
\left(\mathrm{g} / \mathrm{cm}^{3}\right)\end{array}$ & Water $(\mathrm{wt} \%)$ & $\begin{array}{l}\text { Density } \\
\left(\mathrm{g} / \mathrm{cm}^{3}\right)\end{array}$ & Water $(\mathrm{wt} \%)$ & $\begin{array}{l}\text { Density } \\
\left(\mathrm{g} / \mathrm{cm}^{3}\right)\end{array}$ & Water $(\mathrm{wt} \%)$ \\
\hline IRN-77 & 1.26 & 53.6 & 1.17 & 65.7 & 1.08 & 75.0 \\
IRN-78 & 1.11 & 66.5 & 1.10 & 77.2 & 1.03 & 83.6 \\
Mixed bed & 1.21 & 57.9 & 1.15 & 72.0 & 1.06 & 79.6 \\
\hline
\end{tabular}

the water content of the decontamination ionexchange resin cement slurry and, consequently, the water-to-cement and waste-to-cement ratios that are crucial in producing a good waste form that is resistant to degradation and radionuclide leaching. Optimum water-to-cement ratios range from 0.3 to 0.5 . ${ }^{24}$

In addition, Table 2 lists the "as-received" resin densities and water contents for other resins used in this study. The resin densities are lower than the IRN-77 and IRN-78 densities because they were measured in dry resin rather than in resin with interstitial water present.

Dewatered resin, as defined by Neilson, was resin saturated with water to equilibrium, with all freestanding water removed from above the surface of the settled resin. A resin slurry was defined as a mixture of $70 \mathrm{vol} \%$ settled, watersaturated resin and 30 vol\% free-standing water. During a typical resin waste solidification process, resin waste is slurried into a large steel container, called a liner, that is the vessel used to perform the solidification. Prior to the addition of any solidification agents, free-standing water is pumped out of the liner until the free-standing water level is between about $2.5 \mathrm{~cm}(1 \mathrm{in}$.) and 5 $\mathrm{cm}$ ( 2 in.) above the surface of the resin beads. For an I . - 80 liner, which has a usable volume of about $2.2 \mathrm{~m}^{3}$, which is filled with $1.5 \mathrm{~m}^{3}$ of sett'ed resin, 2.5 to $5 \mathrm{~cm}$ of free-standing water corresponds to only about 2.8 to $5.5 \mathrm{vol} \%$. Since only a small amount of free-standing water is left in the liner under normal solidification conditions, the water contents of resin wastes are about the same as Neilson's dewatered resins.

\section{Cement Solidification Chemistry}

The objective of solidification is to convert radioactive ion-exchange resin waste into a stable monolithic form in order to minimize the potential for radionuclide release to the environment during interim storage, transportation, and disposal. Hydraulic cement is more widely used than any other solidification agent to stabilize decontamination resin wastes. Portland cement is the primary hydraulic cement produced and is the most common one used for radioactive waste solidification. Interstitial and free-standing water in the resin waste reacts chemically with Portland cement to form hydrated silicate and aluminate compounds that interact to form a monolithic solid. Resin beads are physically entrapped and act as aggregate. The chemical and physical properties of cement-solidified decontamination resin waste forms are affected by the characteristics of the resin waste (e.g., $\mathrm{pH}$, reagent loading), the waste-to-cement and water-to-cement ratios used during solidification, the type of Portland cement, the types of additives used to accelerate or inhibit cement hydration, and process variables such as temperature and cure time. Appendix B presents a summary of the chemistry of cement and the factors that affect the solidification process.

\section{Chem-Nuclear Solidification System}

Although several different vendors performed the decontaminations (see Table 1) from which samples were obtained for this study, all of the plants from which waste-form specimens were collected contracted with Chem-Nuclear 
Services, Inc. to solidify the resin wastes. Solidifications were performed using Portland Type I and I-P cement. The solidification system, illustrated schematically in Figure 2, is portable and skid-mounted. ${ }^{25}$ It consists of a control panel, from which the mixing is controlled, a cement and waste distribution system, and a mixing apparatus that is installed in the solidification liner. The mixing apparatus consists of a motor, shaft, and multiple mixing blades. As shown in Figure 2 , the blades are attached to the shaft at two or more levels and are oriented such that their movement creates a downward vortex in the center of the liner. The major components of the solidification system and their associated hydraulic pumps and air blowers are all mounted on skids that can be moved to appropriate locations and connected by hoses and electrical lines.

Solidifications were performed in either L6-80, L8-120, or L14-170 steel liners, which have usable capacities of $2.24,3.28$, or $4.79 \mathrm{~m}^{3}$, respectively. Waste resins were pumped by the plant to the Chem-Nuclear system, filling the liner to a predetermined volume. Excess freestanding water was pumped out of the liner, leaving between about 2.5 and $5 \mathrm{~cm}$ of water above the surface of the settled resin beads. Slaked lime or sodium hydroxide was mixed with the resin waste prior to the introduction of Portland cement. The waste was continuously mixed while the cement was conveyed into the liner, usually at a rate of about $900 \mathrm{~kg} / \mathrm{h}$. Mixing normally continued for about an hour after the total amount of cement had been added. When mixing was stopped, the liner fillhead was removed and the liner was vented to the plant ventilation system. The liners were usually equipped with thermocouples that monitored the hydration exotherm. The short-term hydration of tricalcium aluminate and tricalcium silicate produced peak temperatures of up to $343 \mathrm{~K}\left(70^{\circ} \mathrm{C}\right)$, and the observation of an exotherm peak was necessary to ensure that proper solidification occurred. Solidified wastes were usually shipped to burial sites within a few days following solidification.

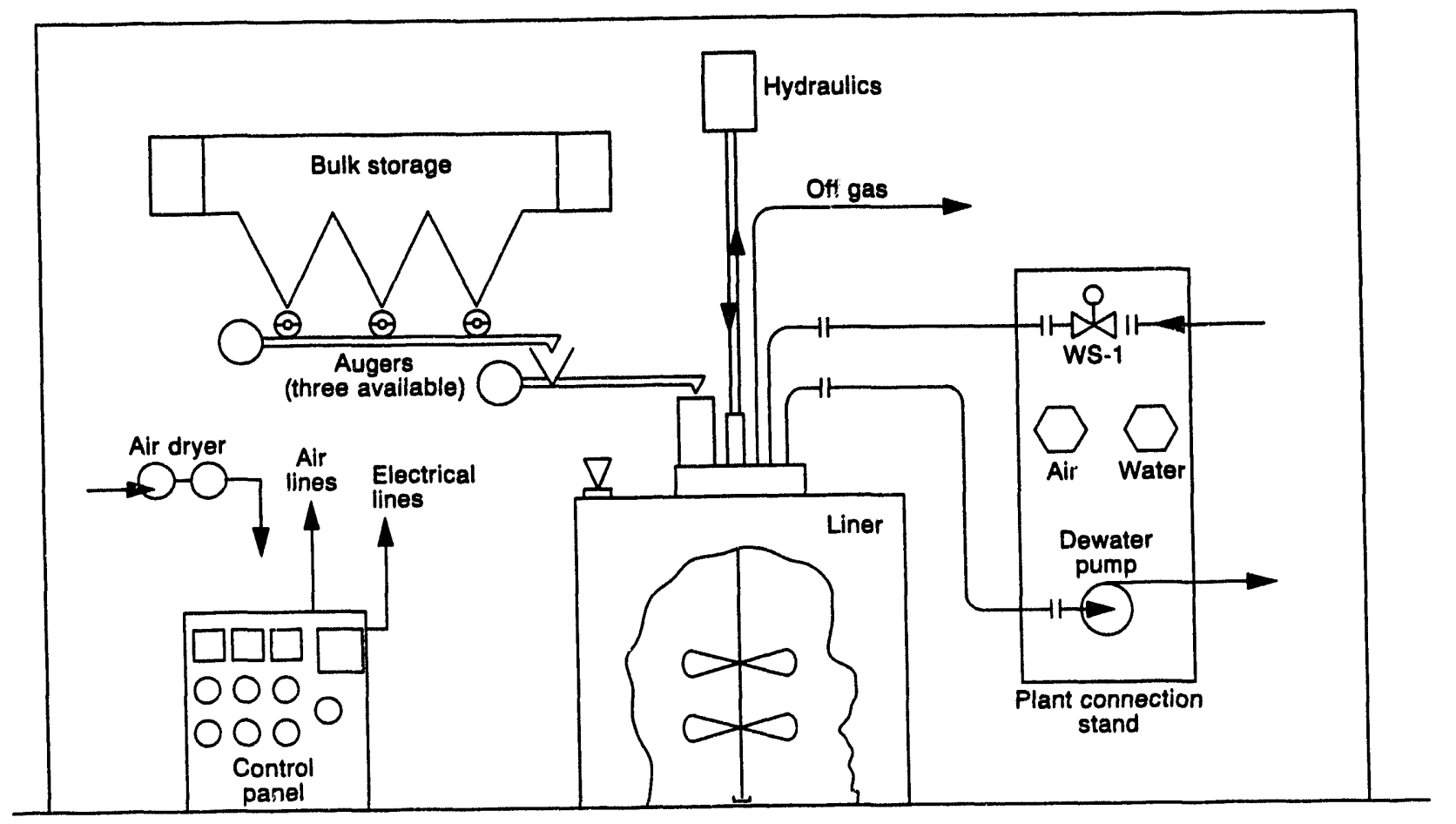

Figure 2. Chem Nuclear Services Inc. skid-mounted solidification system. 


\section{EXPERIMENTAL PROCEDURES}

Studies reported in the literature indicate that releases of radionuclides ${ }^{25-28}$ and chelating agents ${ }^{29}$ from cement-solidified waste forms closely follow predictions based on classical diffusion models. They show that for cylindrical samples, the effective diffusivities derived by using the semi-infinite plane source diffusion model do not depend on sample size. In the majority of the leaching studies summarized in Appendix A (Table A-1), the smallest samples tested were either approximately $5 \times 5 \mathrm{~cm}$ or $5 \times 10 \mathrm{~cm}$ (diameter $\times$ height). In order to allow for direct intercomparison of the results of this study with those of other studies and at the same time minimize exposure hazards and logistical requirements inherent in handling and testing radioactive samples, the majority of the waste-form samples collected during this study were approximately $5 \times 10 \mathrm{~cm}$ right-circular cylinders. The actual dimensions of the specimens collected, their volumes, surface areas, and other physical parameters are summarized in Table 3.

\section{Sample Collection}

Unsolidified resin waste and cement-solidified resin waste specimens were collected from seven BWRs and one PWR that collectively had been decontaminated using four different chemical decontamination processes. These decontaminations and subsequent sample collections took place between April 1984 and October 1989. In each case, samples of decontamination resin waste were collected from the liner that was used to perform the solidification both prior to and following the addition of Portland cement and additives. Resin waste samples were obtained by dipping a $160-\mathrm{mL}$ polyethylene wide-mouth bottle into the resin after it had been mixed a minimum of 15 minutes. The cement-solidified waste-form samples were collected during final mixing, or immediately upon completion of mixing. At the time of collection, the mixture was generally still a well-mixed thin paste, although occasionally the cement had hardened to the consistency of thick paste. In most cases, a cylindri- cal polyethylene container was lowered into the liner to collect a sample of the cement/resin paste. In the case of Brunswick, FitzPatrick, and Peach Bottom-3, another sampling tool, which was simply a plastic tube equipped with a plunger, was inserted into the resin/cement mixture five or six times to a depth of about $3 \mathrm{ft}$ below the top surface of the mixture to obtain the cement/resin paste samples. The sample containers, which were fitted with air-tight, snap-on lids, were sealed following sample collection and were stored at least 1 month prior to being shipped to the Idaho National Engineering Laboratory for all samples except some of the FitzPatrick samples and the Peach Bottom-3 samples. Three FitzPatrick samples were baked at $49^{\circ} \mathrm{C}$ for 4 hours to simulate the hydration exotherm of full-size waste forms, and all Peach Bottom-3 samples were baked at $62^{\circ} \mathrm{C}$ for about 72 hours. The baking process used for the Peach Bottom-3 samples is typically used for process control program samples and was not used on any of the other samples tested as part of this study. Precautions were taken to ensure that the samples were not subjected to temperature extremes during shipping and storage.

\section{Millstone Unit 1}

Millstone-1, which is a BWR rated at 654 MWe, began commercial operation in December 1970. The Can-Decon process was used to decontaminate the PCRS in April 1984. The PCRS decontamination generated $0.42 \mathrm{~m}^{3}$ of mixed-bed resin waste and $0.85 \mathrm{~m}^{3}$ of cation-exchange resin waste. These wastes were solidified together in an L6-80 liner, which has a usable capacity of about $2.24 \mathrm{~m}^{3}$. A $160-\mathrm{mL}$ sample of resin was dipped from the liner following 15 minutes of mixing. Two samples of cement/resin paste were obtained from the liner following the termination of mixing. Because the mixture had begun to set at the time of sampling, only two half-sized samples were collected. Both samples were allowed to cure for 684 days prior to the initiation of leach-testing. Following curing, these samples were $4.8 \times 5.1 \mathrm{~cm}$ and $4.8 \times 6.2 \mathrm{~cm}$ 
Table 3. Physical parameters of solidified decontamination ion-exchange resin waste samples.

\begin{tabular}{|c|c|c|c|c|c|c|c|c|c|c|c|}
\hline \multirow[b]{2}{*}{ S.mple ID } & \multirow[b]{2}{*}{$\begin{array}{c}\text { Collect } \\
\text { date }\end{array}$} & \multirow[b]{2}{*}{$\begin{array}{c}\begin{array}{c}\text { Cure } \\
\text { time } \\
\text { (days) }\end{array} \\
\end{array}$} & \multirow[b]{2}{*}{ Waste type } & \multicolumn{5}{|c|}{ Solidified waste form } & \multicolumn{3}{|c|}{ Resin loading } \\
\hline & & & & $\begin{array}{c}\text { Diameter } \\
\times \text { height } \\
(\mathrm{cm})\end{array}$ & $\begin{array}{c}\text { Surface } \\
\text { area } \\
\left(\mathrm{cm}^{2}\right) \\
\end{array}$ & $\begin{array}{c}\text { Mass } \\
(\mathrm{g})\end{array}$ & $\begin{array}{l}\text { Vol. } \\
\left(\mathrm{cm}^{3}\right)\end{array}$ & $\begin{array}{l}\text { Vol-to-surface- } \\
\text { area ratio } \\
(\mathrm{cm})\end{array}$ & $\begin{array}{c}\begin{array}{c}\text { Wet } \\
\text { (vol\%) }\end{array} \\
\end{array}$ & $\begin{array}{c}\text { Wet } \\
(w t \%)\end{array}$ & Dry (wt\%) \\
\hline $\begin{array}{l}\text { Millstone-1 } \\
\text { F:: }\end{array}$ & $06 / 20 / 84$ & 684 & $\begin{array}{l}\text { Rohm and Haas } \\
\text { (R\&H) IRN-77 and } \\
\text { IRN-78 }\end{array}$ & $4.8 \times 5.1$ & 107 & 114.3 & 84.9 & 0.79 & 72 & 61 & 17 \\
\hline $\begin{array}{l}\text { Ylillsione-1 } \\
\text { F201 }\end{array}$ & $06 / 20 / 84$ & 684 & $\begin{array}{l}\text { R\&H IRN-77 \& } \\
\text { IRN-78 }\end{array}$ & $4.8 \times 6.2$ & 115 & 125.9 & 93.5 & 0.81 & 72 & 61 & 17 \\
\hline $\begin{array}{l}\text { Peach } \\
\text { Bottom-2 }\end{array}$ & $08 / 09 / 84$ & 571 & $\begin{array}{l}\text { R\&H IRN-77 \& } \\
\text { IRN-78 }\end{array}$ & $4.8 \times 8.9$ & 169 & 207.7 & 158.4 & 0.94 & 72 & 63 & 18 \\
\hline Pilgrim & $08 / 17 / 84$ & 654 & NA & $4.8 \times 9.2$ & 173 & $\Upsilon 15.2$ & 164.1 & 0.95 & 71 & 62 & 17 \\
\hline $\begin{array}{l}\text { Cooper (mixed } \\
\text { bed) }\end{array}$ & $11 / 30 / 84$ & 710 & $\begin{array}{l}10 \% \text { Purolite } \\
\text { C-100-H, } 90 \% \\
\text { Purolite A-600 }\end{array}$ & $4.4 \times 9.5$ & 164 & 205.2 & 147.8 & 0.90 & 72 & 60 & 17 \\
\hline Cooper (cation) & $1 ! / 30 / 84$ & 802 & Purolite NRW-37 & $4.4 \times 10.2$ & 173 & 215.6 & 157.7 & 0.91 & 77 & 66 & 23 \\
\hline Indian Point- 3 & $6 / 24 / 85$ & 539 & $\begin{array}{l}\text { Ionac A-365, R\&H } \\
\text { IRN-77 + cation } \\
\text { resin from } \\
\text { radwaste }\end{array}$ & $4.6 \times 9.5$ & 171 & 202.5 & 158.6 & 0.93 & 70 & 63 & 18 \\
\hline $\begin{array}{l}\text { Brunswick-1 } \\
\text { cation }\end{array}$ & $12 / 18 / 87$ & $\begin{array}{l}254 \\
486^{a}\end{array}$ & $\begin{array}{l}\text { Purolite C-100-H } \\
\text { AP mixed-bed } \\
\text { Purolite NRW-37 }\end{array}$ & $5.8 \times \sim 9.5$ & $223 \mathrm{Av}$ & $322 \mathrm{Av}$ & $248 \mathrm{Av}$ & 0.77 & 74.6 & 55.4 & 19.3 \\
\hline
\end{tabular}


Table 3. (continued).

\begin{tabular}{|c|c|c|c|c|c|c|c|c|c|c|c|}
\hline \multirow[b]{2}{*}{ Sample ID } & \multirow[b]{2}{*}{$\begin{array}{c}\text { Collect } \\
\text { date }\end{array}$} & \multirow[b]{2}{*}{$\begin{array}{c}\text { Cure } \\
\text { time } \\
\text { (days) } \\
\end{array}$} & \multirow[b]{2}{*}{ Waste type } & \multicolumn{5}{|c|}{ Solidified waste form } & \multicolumn{3}{|c|}{ Resin loading } \\
\hline & & & & $\begin{array}{c}\text { Diameter } \\
\times \text { height } \\
(\mathrm{cm})\end{array}$ & $\begin{array}{c}\text { Surface } \\
\text { area } \\
\left(\mathrm{cm}^{2}\right) \\
\end{array}$ & $\begin{array}{c}\text { Mass } \\
(\mathrm{g})\end{array}$ & $\begin{array}{l}\text { Vol. } \\
\left(\mathrm{cm}^{3}\right) \\
\end{array}$ & $\begin{array}{l}\text { Vol.-to-surface- } \\
\text { area ratio } \\
(\mathrm{cm})\end{array}$ & $\begin{array}{c}\text { Wet } \\
\text { (vol\%) }\end{array}$ & $\begin{array}{c}\text { Wet } \\
\text { (wt\%) }\end{array}$ & Dry (wt\%) \\
\hline $\begin{array}{l}\text { Brunswick-1 } \\
\text { mixed bed }\end{array}$ & $12 / 18 / 87$ & $\begin{array}{l}254 \\
486^{a}\end{array}$ & $\begin{array}{l}65 \%(10 \% \text { Purolite } \\
\text { C-100-H and } 90 \% \\
\text { Purolite A-600OH } \\
\text { anion resin) and } \\
35 \% \text { Purolite } \\
\text { NRW-37 }\end{array}$ & $\sim 5.7 \times \sim 9.2$ & $196 \mathrm{Av}$ & $245 \mathrm{Av}$ & $185 \mathrm{Av}$ & 0.76 & 71.9 & 52.8 & 15 \\
\hline FitzPatrick & 9/18/88 & $\begin{array}{l}119 \\
212^{\mathrm{a}}\end{array}$ & $\begin{array}{l}80 \% \text { Ionac C-267 } \\
\text { and } 20 \% \text { Ionac } \\
\text { A-365 }\end{array}$ & $4.7 \times 9.8$ & $232 \mathrm{Av}$ & $271 \mathrm{Av}$ & $171 \mathrm{Av}$ & 0.63 & 73.8 & 52.7 & 15 \\
\hline $\begin{array}{l}\text { Peach } \\
\text { Bottom-3 }\end{array}$ & $10 / 25 / 89$ & $\begin{array}{l}950 \\
\text { and } \\
1304\end{array}$ & $\begin{array}{l}10 \% \text { lonac A-365 } \\
\text { anion and } 90 \% \\
\text { C-267 cation }\end{array}$ & $-4.5 \times 9.1$ & $128 \mathrm{Av}$. & $246 \mathrm{Av}$ & $144 \mathrm{Av}$ & 0.58 & 41.4 & 47.8 & $\begin{array}{l}\text { To be } \\
\text { determined }\end{array}$ \\
\hline
\end{tabular}


(diameter $\times$ height) rather than the nominal $5 \times 10 \mathrm{~cm}$. The surfaces of both samples were somewhat coarser than usual, and their upper surfaces were concave and irregular.

\section{Peach Bottom Atomic Power Station Unit 2}

Peach Bottom-2 began commercial operation in July 1974. It is a BWR rated at 1,065 MWe. The Can-Decon process was used to decontaminate the PCRS during August 1984. The decontamination generated $1.47 \mathrm{~m}^{3}$ of cation and mixed-bed resin waste, which were both slurried into the same L6-80 liner for solidification. A $160-\mathrm{mL}$ sample of resin was collected from the liner after about 15 minutes of mixing. Two samples of cement/resin paste were obtained immediately after mixing was terminated. Following a 571 -day curing period, the $4.8 \mathrm{~cm} \times 8.9 \mathrm{~cm}$ sample was subjected to leach-testing. The surfaces of the waste-form specimen were smooth except for the upper surface, which was rough and irregular.

\section{Pilgrim}

Pilgrim, which is a BWR rated at $670 \mathrm{MWe}$, has been in commercial operation since December 1972. The PCRS was decontaminated in August 1984 using the Dow NS-1 process. A total of $2.55 \mathrm{~m}^{3}$ of resin waste was produced during the decontamination; however, only $1.56 \mathrm{~m}^{3}$ of this waste was solidified in the liner from which samples were obtained. Samples of resin were collected at the time the resins were transferred from a temporary holding tank to the solidification liner. A portion of the resin was used to prepare a solidified waste-form specimen, and the remainder was retained for analysis. The solidified waste-form specimen that was leach-tested was prepared by Chem-Nuclear Services, Inc. using a sample of the resin waste and the same mixing parameters used for the full-scale solidification. The surface of the samples were smooth and exhibited few surface imperfections.

\section{Cooper}

Cooper, a BWR rated at $764 \mathrm{MWe}$, has been in commercial operation since July 1974 . In November 1984, its PCRS was decontaminated using the AP/Citrox process. The decontamination generated $2.61 \mathrm{~m}^{3}$ of cation-exchange resin waste and $2.12 \mathrm{~m}^{3}$ of mixed-bed resin waste. The cation and mixed-bed resins were solidified separately in L14-170 $\left(4.79 \mathrm{~m}^{3}\right)$ and $\mathrm{L} 8-120\left(3.28 \mathrm{~m}^{3}\right)$ liners, respectively. A $160-\mathrm{mL}$ sample of resin was dipped out of each liner after the contents had been mixed for about 30 minutes. One sample of cement/resin paste was removed from each liner immediately after mixing was stopped. The volumes of resins solidified were determined by measurements made inside the liners, and ChemNuclear Services, Inc. supplied information on the masses of the cement and additives used for each liner. Following curing for 710 and 802 days, respectively, the mixed-bed and cation waste-form specimens had dimensions of $4.4 \times 9.5 \mathrm{~cm}$ and $4.4 \times 10.2 \mathrm{~cm}$.

Prior to the initiation of leaching, the surface of the Cooper mixed-bed resin waste-form specimen was smooth and exhibited very little surface cracking. The only anomalous features the specimen exhibited were the numerous tiny chips that had broken off the circumference of one end of the waste form. The specimen appeared sound and well cured. In the case of the Cooper cation resin waste form, a relatively large crack traversed one side of the waste form just below its mid-plane, and several small voids pitted the surface above the mid-plane. Partially encapsulated resin beads were exposed over about one-third of the surface of the top end of the waste form. Except for the features mentioned, the surfaces of the cation resin waste form were smooth and unpitted. A photograph of this sample is shown in Reference 1.

\section{Indian Point Unit 3}

Indian Point-3 is a PWR rated at $965 \mathrm{MWe}$ and began commercial operation in August 1976. A steam generator channel head was decontaminated during June 1985 using the LOMI process. The decontamination generated $2.27 \mathrm{~m}^{3}$ of 


\section{Experimental Procedures}

mixed-bed resin waste; however, for solidification, this waste was combined with $1.19 \mathrm{~m}^{3}$ of resin waste from the plant radwaste system. A $160-\mathrm{mL}$ sample of resin waste was collected after about 30 minutes of mixing in the liner. Samples of cement/resin paste were collected about 20 minutes after final mixing was terminated. Three resin waste-form specimens were collected from the liner. Following curing for 539 days, the dimensions of the cylindrical waste form that was subjected to leach-testing were $4.6 \times 9.5 \mathrm{~cm}$. A photograph of the Indian Point-3 waste form is shown in Reference 1.

\section{Brunswick Plant Unit 1}

Brunswick-1. a BWR that is rated at $790 \mathrm{MWe}$, began commercial operation in March 1977. The Citrox/AP/Citrox process was used to decontaminate the PCRS during December 1987. Decontamination generated $2.12 \mathrm{~m}^{3}$ of Purolite C-100-H cation resin; $2.12 \mathrm{~m}^{3}$ of Citrox mixedbed resin, which was composed of $10 \%$ Purolite C-100-H and $90 \%$ Purolite A-600OH anion resin; and $1.98 \mathrm{~m}^{3}$ of AP mixed-bed Purolite NRW-37 resin waste. The three types of ion-exchange resin were solidified in two L14-170 steel liners, each having a capacity of $4.79 \mathrm{~m}^{3} .0 .85 \mathrm{~m}^{3}$ of the AP mixed-bed resin were combined with the cation resin in one liner, and $1.13 \mathrm{~m}^{3}$ of the AP mixedbed resin were added to the Citrox mixed-bed resin in a second liner. Because of the chemistry of the processes, only the Citrox mixed-bed resins contained chelates. The resins that were solidified were manufactured by the Mueller/Barnstead Division of the Paul Mueller Co., Burlington, MA. Slaked lime (calcium hydroxide) was added to the cation resin waste, and sodium hydroxide was added to the mixed-bed resin waste to raise the $\mathrm{pH}$ of the wastes prior to the addition of the Portland Type I-P cement. The "P" indicates that the formulation contains pozzolona, which is nominally flyash or blast furnace slag. The Portland Type I-P cement was a proprietary formulation provided by the vendor, Pacific Nuclear Services.

The cation resin waste-form samples obtained from Brunswick-1 were solid, right-circular cyl- inders having smooth surfaces with few surface imperfections and no cracks. In contrast, the mixed-bed resin waste forms were irregular in shape, had cracks in the surface, and rough surface texture. The condition of the mixed-bed resin waste-form specimens is the result of the fact that the resin/cement paste had begun to set up when the specimens were collected. Figures 3 and 4 show the condition of the Brunswick- 1 cation and mixed-bed resin waste forms. Additional photographs of these samples are shown in Reference 2.

\section{James A. FitzPatrick Station}

FitzPatrick, a BWR that is rated at $778 \mathrm{MWe}$, began commercial operation in July 1975 . The LOMI/NP/LOMI process was used to decontaminate the reactor water cleanup system and the smaller residual heat removal service water crosstie during September 1988. Decontamination generated $3.33 \mathrm{~m}^{3}$ of Ionac A-365 anion exchange resin and $2.55 \mathrm{~m}^{3}$ of Ionac C-267 cation-exchange resin. Ionac A-365 is a weakly

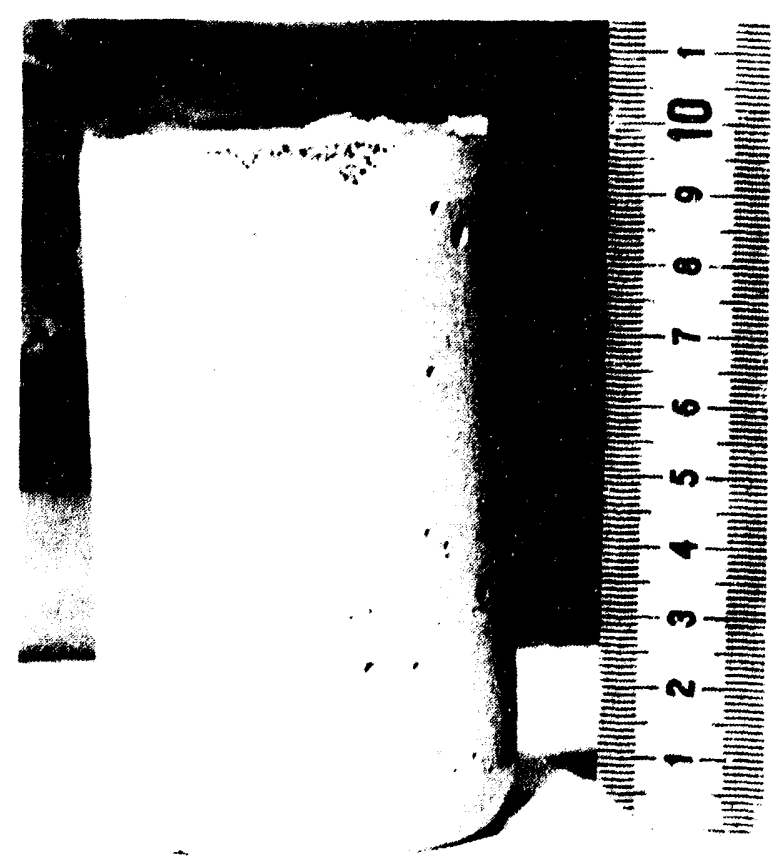

Figure 3. Brunswick-1 cation resin waste form sample. 


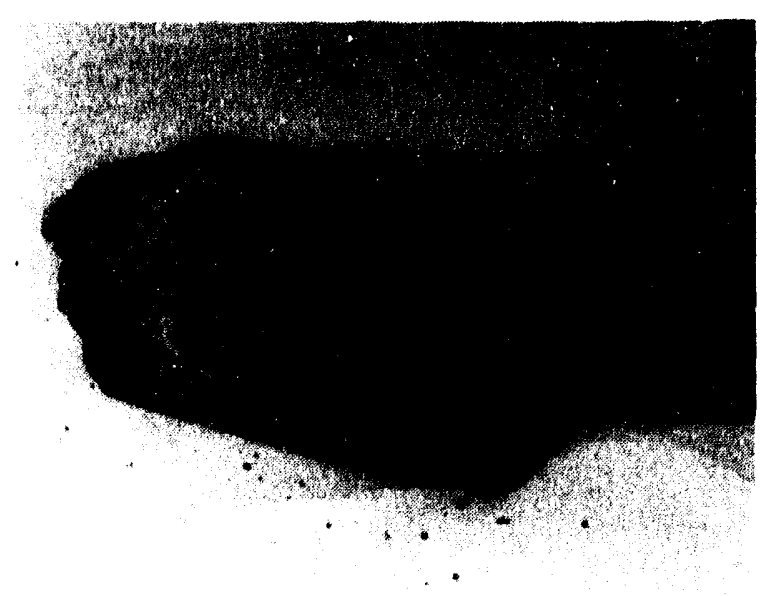

Figure 4. Brunswick-1 mixed-bed resin waste form sample.

basic polyacrylate-based anion resin with a gelbead structure. Ionac C-267 is a strong acid styrene-divinyl-benzene polymer-based cation resin that is supplied in the $\mathrm{H}^{+}$form. Both ion-exchange resins are manufactured by Sybron Chemicals, Inc., Birmingham, NJ. The $5.88 \mathrm{~m}^{3}$ of resin waste generated during decontamination was solidified in three different L14-170 steel liners. The cement was a proprietary formulation provided by the vendor, Pacific Nuclear Services.

However, when liner \#2 reached the burial site at Barnwell, SC, it was sampled because it contained approximately $8 \mathrm{wt} \%$ chelating agent (picolinic acid). It was determined that the liner had not solidified and that unsolidified ion-exchange resins were present. ${ }^{30}$

Later laboratory tests by Bishop ${ }^{30}$ indicated that a gelling of the resin slurry would occur after the addition of lime for $\mathrm{pH}$ adjustment, which made the addition of cement difficult. The laboratory study further indicated that high concentrations of picolinic acid $(8 \mathrm{wt} \%$ ) would result in the formation of the gel; consequently, an improper solidification. Solidification formulations have been changed to eliminate the problem. Peach Bottom-3 was the first test of the new formulation.

The waste-form specimens collected from the FitzPatrick station were right-circular cylinders with no evidence of cracks or other damage as determined from visual inspection upon receipt of the samples at the Idaho National Engineering Laboratory. Figure 5 shows the condition of a FitzPatrick sample. Additional photographs of the samples are shown in Reference 2.

\section{Peach Bottom Atomic Power Station Unit 3}

Resin wastes and waste-form specimens were collected at Peach Bottom-3, which is operated by the Philadelphia Electric Company, from October 17 through October 25, 1989. The solidification was performed on decontamination ionexchange resins from a LOMI/NP/LOMI decontamination performed by Pacific Nuclear Services. The Peach Bottom-3 primary coolant recirculation system (PCRS) and the reactor water cleanup system (RWCS) were decontaminated during late December 1987 and early January 1988 , and the resins were held until

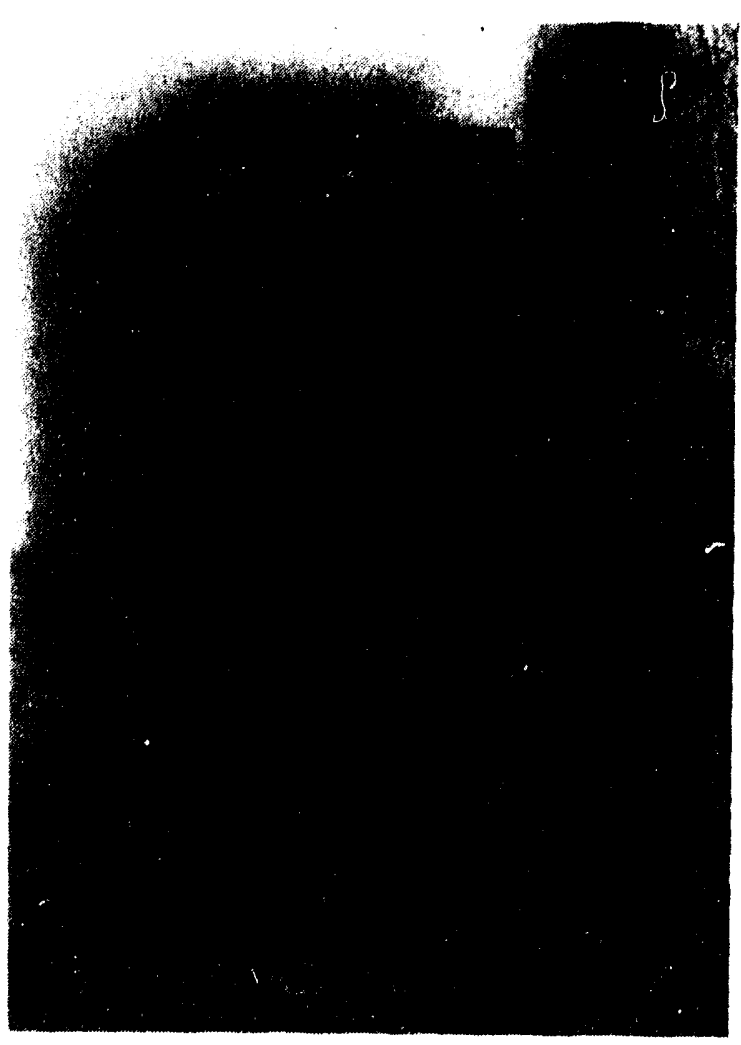

Figure 5. FitzPatrick mixed-bed resin waste form sample. 
October 1989 for solidification. The waste-form specimens obtained from Peach Bottom-3 that were leach tested were right-circular cylindrical solids having smooth surfaces with few surface imperfections and no cracks. Figure 6 shows a representative example of the Peach Bottom-3 waste forms.

\section{Compressive Strength Test Method}

The test procedure used to measure the compressive strength of waste-form specimens was ASTM C39, "Compressive Strength of Cylindrical Concrete Specimens," 12 as required by the NRC in the "Technical Position on Waste Form." The requirement is for a minimum compressive strength for waste forms of $50 \mathrm{psi}$ $\left(3.4 \times 10^{2} \mathrm{kPa}\right)$. This requirement has been modified in Appendix A of the "Technical Position on Waste Form," Revision 1, to 500 psi $\left(3.4 \times 10^{3} \mathrm{kPa}\right)$ for cement-solidified waste forms. The revised higher value is deemed necessary to ensure that cement-solidified waste forms maintain integrity and exhibit long-term stability as required by 10 CFR 61 . The procedure is described in Appendix $C$.

The vice and load gauge used to measure compressive strength are shown in Reference 3. Each specimen was placed in the vice, and the load on the specimen was gradually increased until the load gauge registered a decrease in load, which occurred when the specimen began to fail. The maximum load that each waste-form specimen withstood was recorded and was used to compute the compressive strength of the specimen based on its cross-sectional area.

\section{Leach Test Method}

The test procedure used to measure the release of radionuclides, transition metals, and chelating agents from decontamination resin wastes solidified in Portland cement was ANSI/ANS 16.1, "Measurement of the Leachability of Solidified Low-Level Radioactive Wastes by a Short-Term Test Procedure." 13 Specific requirements of
ANSI/ANS 16.1 are provided in Appendix C. The standard is recommended by the NRC in the Low-Level Waste Management Branch's "Technical Position on Waste Form"10 and in Revision $1^{11}$ to measure the release of radionuclides from solidified low-level radioactive waste. The standard is intended to provide a means of indexing the release of radionuclides from waste forms using the results of relatively short-term tests performed in a laboratory. It is not intended to be used to define the long-term leaching behavior of waste forms under conditions representing actual burial environments. The method specified by the standard for analyzing leach-test data is based on the assumption that diffusion is the predominant release mechanism. Other mechanisms such as dissolution, ion exchange, corrosion, cracking, etc., are not incorporated into the models used to describe releases. Although the adequacy of this assumption has been questioned, ${ }^{31}$ the test procedure is, however, believed suitable to establish a data base on the release of radionuclides in the presence of relatively high concentrations of chelating agents and transition metals.

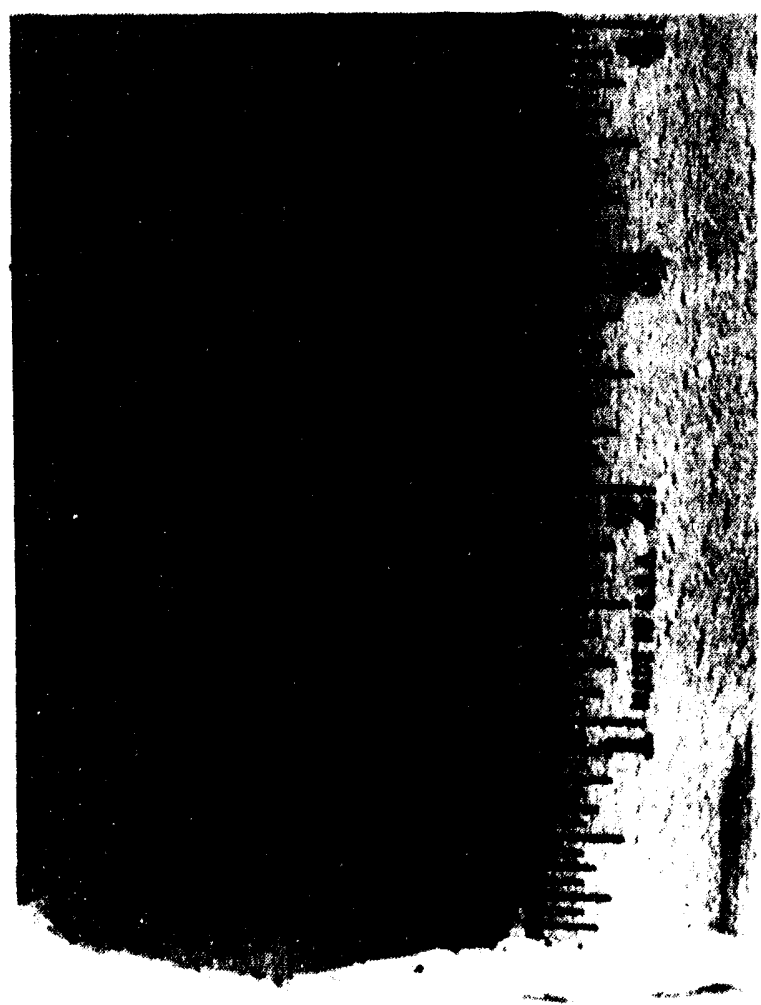

Figure 6. Peach Bottom-3 waste form sample. 


\section{Tost Procedure}

The decontamination resin waste specimens that were leach tested were right-cylindrical solids. Nominal dimensions of all samples and the cure times are listed in Table 3. The cylindrical leach-test vessels were polyethylene containers having capacities of about $3 \mathrm{~L}$. In each case, the waste-form sample was supported in the leachtest vessel by coarse mesh plastic netting that was suspended by a wire from the container lid. This mesh covered less than $2 \%$ of the sample surface as required by the ANSI/ANS 16.1 standard based on calculations performed by personnel at the Idaho National Engineering Laboratory. Deionized water having a conductivity of less than $3 \mu \mathrm{mho} / \mathrm{cm}$ at $298 \mathrm{~K}\left(25^{\circ} \mathrm{C}\right)$ was used as the leachant after being allowed to come to ambient temperature. During leaching, leachant temperature was maintained at $296 \pm 3 \mathrm{~K}\left(23 \pm 3^{\circ} \mathrm{C}\right)$. Leachant volumes ranged from $1,070 \mathrm{~mL}$ for the Millstone-1 F33 specimen to 2,030 mL for the Cooper cation-exchange resin waste-form specimen. The ANSI/ANS standard requires that the ratio of the leachant volume to specimen extemal geometric surface area must be $\geq 10$. Values of the ratio of leachant volume to specimen external geometric surface area ranged from 7.7 for the Peach Bottom-2 sample to 13.8 for the Peach Bottom-3 mixed-bed resin waste-form sample. The low value used for the Peach Bottom-2 sample was due to an error in the calculation of the surface area for that test. Leachates were changed out at the intervals specified by the ANSI/ANS 16.1 standard (see Appendix C). Minor variations in the sampling schedules are discussed in References 1 to 3 .

\section{Data Analyols}

Leaching occurs as the result of mass transport of species inside a waste form as well as outside. Mass transport processes that have been identified as occurring in solidified waste forms include diffusion, dissolution, ion exchange, corrosion, and surface effects. A considerable amount of data obtained from samples that maintained their physical integrity during leaching indicate that internal bulk diffusion is the most likely rate-de- termining mechanism during the initial phases of the leaching process. ${ }^{32-34}$ The measures used to assess leachability (i.e., absolute release rate, fractional release rate, cumulative fractional release, and leachability index) are based on the premise that internal bulk diffusion is the rate-determining process and are predicated on an intact waste form. However, because some of the Cooper, Brunswick-1, and FitzPatrick samples either partially or totally disintegrated during the ANSI/ ANS 16.1 leach period, modifications were made to the methods used to determine the surface area of the disintegrated waste forms.

The solution to the transport equation for diffusion in a homogeneous, semi-infinite medium has become the most widely used analytical expression to explain the leaching release of radionuclides and other diffusing species from solidified waste forms. This semi-infinite medium diffusion model is incorporated into ANSI/ANS 16.1. One of the boundary conditions of this solution is that some portion of the waste form must retain its initial concentration of the diffusing species. Leaching of real waste forms leads to depletion, which must be accounted for in any realistic model of leaching behavior. This limitation is addressed in ANSI/ANS 16.1 with the specification that the shape-specific solution of the mass transport equations be used for data analysis when depletion of a diffusant becomes greater than $20 \%$.

The method used to calculate the surface area of the disintegrated waste forms is based on the formation of a diffusion boundary between the layer of particulate debris on the bottom of the leaching vessel and the leachant. During the early stages of waste-form disintegration, when a large portion of the waste form was intact, the total surface area of the waste form was considered to be the sum of the exterior surface area of the partial waste form (typically 180 to $230 \mathrm{~cm}^{2}$ for the intact waste form) plus the surface area of the bottom of the leaching vessel over which the debris was spread (about $165 \mathrm{~cm}^{2}$ ). As the waste forms continued to disintegrate, the surface area of the partial waste form decreased, but the surface area of the diffusion boundary on the bottom of the leaching vessel remained essentially constant ranging from 163 to $172 \mathrm{~cm}^{2}$ depending on the 
shape of the walls of the leaching vessel. Consequently, the specimen surface areas ranged from about $220 \mathrm{~cm}^{2}$ (with no degradation) to about 370 $\mathrm{cm}^{2}$ (after waste-form degradation began) to about $165 \mathrm{~cm}^{2}$ (after complete decomposition has occurred). This approach allowed the determination of the relative leachability of waste-form specimens leached in different leachants.

For each waste-form specimen that was leachtested, the initial inventory of each species in the waste form was determined by multiplying the measured concentration of the species in the untreated wet resin waste, expressed as $\mu \mathrm{Ci} / \mathrm{g}$ or $\mu \mathrm{g} / \mathrm{g}$, times the mass of water-saturated resin estimated to be in the waste-form specimen. The quantity of resin estimated to be in the waste form is based on the weight fraction of water and resin present in the resin/cement mixture in the solidification liner from which the specimen was obtained. This method is considered relatively accurate as the waste-form samples were obtained from the interior of liners that had been well mixed before sample collection. In addition, for Peach Bottom-3, actual waste-form samples were analyzed for comparison with the resin data. Differences between the measured radionuclide concentrations for the resin sample that were corrected for the mass of the waste form (i.e., multiplied by the waste resin to other constituents ratio of 0.5 ) and the concentrations measured for the waste-form samples had maximum ranges between 2 and 10 for most radionuclides. These data indicate that the radionuclide and stable metal concentrations in the resin and the waste form are not uniform and consequently, that the inventories are not known within a factor of between about two and 10. Further, acceptable results for the cemented waste-form samples were not obtained for some radionuclides (i.e., ${ }^{99} \mathrm{Tc}$ and ${ }^{14} \mathrm{C}$ ) possibly due to interfaces from the constituents of the concrete.

The second leachability calculation performed was for the average absolute and fractional release rates of radionuclides, metals, and chelating agents from each waste-form specimen. The average absolute release rate is defined as the quantity released per unit surface area per second $\left(\mu \mathrm{Ci} / \mathrm{cm}^{2}\right.$. $s^{1}$ or $\left.\mu \mathrm{g} / \mathrm{cm}^{2} \cdot \mathrm{s}^{1}\right)$, and the fractional release rate is defined as the fraction of the initial inventory released per unit surface area per second $\left(\mathrm{cm}^{-2} \cdot \mathrm{s}^{-1}\right)$. The surface area used in this calculation is normally predicated on the external surface area of an intact waste form; however, in the cases of the Cooper, Brunswick-1 and FitzPatrick samples, the methods previously discussed above were used to compensate for the fact that the samples disintegrated during leaching.

The ANSI/ANS 16.1 standard provides for the calculation of a leachability index, which is one of the measures used in the NRC's Technical Position on Waste Form," Revision 1, to determine the acceptability of a waste form for disposal at a waste site. The leachability index, $L$, is based on the effective diffusivity of the species being leached from the waste form. When depletion of the diffusant is less than $20 \%$, the effective diffusivity $\left(D_{n}\right)$ is defined as

$$
D_{n}=\pi\left[\left(a_{n} / A_{0}\right) / \Delta_{n}\right]^{2} \times(V / S)^{2} \times T
$$

where

$$
\begin{aligned}
& D_{n}= \begin{array}{l}
\text { the effective diffusivity of a spe- } \\
\text { cies during leaching interval } n \\
\left(\mathrm{~cm}^{2} / \mathrm{s}\right)
\end{array} \\
& a_{n}=\quad \begin{array}{l}
\text { the quantity of the species } \\
\text { leached during leaching interval } \\
n(\mu \mathrm{Ci} \text { or } \mu \mathrm{g})
\end{array}
\end{aligned}
$$
$a_{n}=$ the quantity of the species leached during leaching interval $\mathrm{n}(\mu \mathrm{Ci}$ or $\mu \mathrm{g})$

$A_{0}=$ the total amount of the species originally present in the wasteform specimen ( $\mu \mathrm{Ci}$ or $\mu \mathrm{g})$
$\Delta_{n}=$ the duration of leaching interval $\mathrm{n}(\mathrm{s})$

$\mathrm{V}=$ the volume of the waste-form specimen $\left(\mathrm{cm}^{3}\right)$

$\mathrm{S}=$ the external geometric surface area of the waste-form specimen $\left(\mathrm{cm}^{2}\right)$ 
$T=$ the leaching time representing the "mean time" of the $n^{\text {th }}$ leaching interval(s).

As shown in Equation (1), effective diffusivity is proportional to the square of the ratio of specimen volume to surface area.

Surface areas of specimens that disintegrated were calculated using the method previously described. The waste-form volumes used in Equation (1) for specimens that disintegrated were the volumes of the waste-forms prior to the initiation of leaching. The specimen volumes were kept constant for the purpose of calculating effective diffusivities because the total activity in the waste form, $A_{0}$, which is calculated as the product of specimen volume and diffusant concentration, remains constant independent of the physical state of the waste form.

The leachability index is based on the effective diffusivity of the species of interest, and is also dependent on the estimated surface area of the debris. The leachability index, $\mathrm{L}$, is defined as

$L=\frac{1}{k} \sum_{n=1}^{k}[\log (b / D)]_{n}$

where

$\mathrm{b}=$ defined constant $\left(1.0 \mathrm{~cm}^{2} / \mathrm{s}\right)$

$\mathrm{D}=$ effective diffusivity of the species $\left(\mathrm{cm}^{2} / \mathrm{s}\right)$

$\mathrm{k}=$ number of leaching intervals.

As shown in Equation (2), the leachability index of a particular diffusing species is the average of the summation of the incremental leachability indexes for the all leach intervals.

As a sample disintegrates, the surface area of the sample in contact with the leachant increases by about a factor of two (as a maximum), during the disintegration process when there is debris on the bottom of the container and suspended in the netting. However, when disintegration is complete, the surface area exposed to the leachant is the surface area of the bottom of the container, which is similar to the surface area of the waste form (e.g., 160-230 $\mathrm{cm}^{2}$ ). For a given species concentration in the leachate, the fractional and absolute release rates and the effective diffusivity would become slightly smaller (about a factor of four during the disintegration process) as compared to their values for the intact waste form. However, after disintegration is complete, the surface area of the intact and disintegrated waste form would be the same based on the uncertainties associated with the actual exposed surface area, waste-form inventories, and other uncertainties associated with the leach test. Based on the assumptions made, the disintegration of the waste-form specimen would have only a minimal effect on the calculated leachability index and other metrics. Further, the assumed surface of the disintegrated samples would provide a conservative estimate of the actual leachability because of the potentially much larger surface area of the granular debris. This approach is consistent with the definition of specimen surface area as defined in ANSI/ANS 16.1, and because the same method was used for all specimens that crumbled, it allows the leachability for each specie in the waste-form specimens to be compared. It is also consistent with the leachability of the waste forms as discussed in the results section.

The cumulative fractional release of radionuclides, metals, and chelating agents from the waste-form specimens is calculated as

$C F R=\frac{\sum_{i=1}^{n}\left[\left(C_{L}\right)_{n} V_{n}\right]_{j}}{C_{R} M_{R}}$

where

$$
\begin{aligned}
&\left(C_{L}\right)_{n}= \text { the concentration of the species } \\
& \text { in the leachate collected follow- } \\
& \text { ing leaching interval } n(\mu \mathrm{Ci} / \mathrm{mL} \\
&\text { or } \mu \mathrm{g} / \mathrm{mL})
\end{aligned}
$$




$$
\begin{aligned}
& V_{n}=\quad \begin{array}{l}
\text { the volume of leachate collected } \\
\text { following leaching interval } n \\
(\mathrm{~mL})
\end{array} \\
& \mathrm{C}_{\mathbf{R}}=\begin{array}{l}
\text { the concentration of the species } \\
\text { in the resin waste }(\mu \mathrm{Ci} / \mathrm{g} \text { or } \mu \mathrm{g} / \mathrm{g})
\end{array} \\
& \mathrm{M}_{\mathrm{R}}=\quad \begin{array}{l}
\text { the mass of resin waste estimated } \\
\text { to be in the waste form }(\mathrm{g}) .
\end{array}
\end{aligned}
$$

\section{Analytical Methods}

The data analysis methods of ANSI/ANS 16.1 require a knowledge of the initial inventories of diffusing species in the waste-form sample being tested and a knowledge of their concentrations in the leachates generated during leach-testing. In order to provide a basis for estimating the initial inventories of species of interest, samples of unsolidified resin waste corresponding to the resin wastes solidified were analyzed using several different analytical techniques. Leachate solutions were analyzed using the same techniques to determine the quantities of diffusing species that had leached from the waste-form specimens. Because of the differences in their physical characteristics and because the concentrations of radionuclides and chelating agents in the leachates were expected to be as much as several orders of magnitude lower in the leachates compared to the resins, the methods required to prepare the resin and leachate samples for analysis were generally quite different. Appendix D describes the general analysis methods for the resins and leachate samples. 


\section{EXPERIMENTAL RESULTS AND DISCUSSION}

Primary objectives of this program are to assess the structural stability of the decontamination ion-exchange waste forms, and the effects of chelating agents on the leachability of radionuclides and stable metals. Further, the effects of differing leachant chemical composition on releases from the waste form have been evaluated. The stability of the waste forms are addressed in the following section. Waste-form structural stability is of particular importance in this study as the waste forms from Cooper, FitzPatrick, and Brunswick disintegrated during the leaching process and provide information on the characteristics of degraded waste forms that did not meet the compressive strength requirements identified in the NRC's "Technical Position on Waste Form," Revision 1 for post-immersion compression testing.

The assessment of the leachability of the decontamination ion-exchange resin waste forms, which follows the section on waste-form structural stability, is divided into four subsections: $\mathrm{pH}$ and conductivity, waste-form inventories, chelating agent effects, and leachant effects on releases from the waste form. The $\mathrm{pH}$ and conductivity section assesses the possible effects of leachant $\mathrm{pH}$ and conductivity on the leaching characteristics of the samples, whereas the remaining sections address the effects of waste stream constituents, and the effects of groundwaters and other leachants on the release rates, effective diffusivities, and cumulative fractional releases from the waste forms.

\section{Waste Form Structural Stability}

According to 10 CFR 61.56 (b)1, "a structurally stable waste form will generally maintain its physical dimensions and its form under the experted disposal conditions such as weight of overburden and construction equipment." The initial criterion for structural stability as identified in the NRC's "Technical Position on Waste Form," 10 is that the cement-solidified waste-form specimen must exhibit a compressive strength of $50 \mathrm{psi}\left(3.4 \times 10^{2} \mathrm{kPa}\right)$. This was later raised to
$60 \mathrm{psi}\left(4.1 \times 10^{2} \mathrm{kPa}\right)$ to reflect an increase in burial depth to $55 \mathrm{ft}$ at the Hanford site. ${ }^{35}$ Appendix A of Revision 1 of the "Technical Position on Waste Form" 11 recommends a mean compressive strength of $500 \mathrm{psi}\left(3.4 \times 10^{3} \mathrm{kPa}\right)$ for wasteform specimens cured for a minimum of 28 days. It has been determined in previous studies ${ }^{36}$ that solidified ion-exchange resins should be able to meet this criterion.

In addition, to the initial compression tests, Appendix A of Revision 1 of the "Technical Position on Waste Form" requires that a compressive strength test be performed after the waste form has been cured and immersed in water for varying periods of time depending on the waste type. In the case of decontamination ion-exchange resins with chelating agents, the waste-form specimen must be cured for at least 180 days, and the immersion period is a minimum of 7 days, followed by a drying period of 7 days. After the drying period, the waste-form compressive strength must exceed $500 \mathrm{psi}\left(3.4 \times 10^{3} \mathrm{kPa}\right)$ or $75 \%$ of the pre-immersion compressive strength to meet the regulatory requirement. The reason for the special requirements for ion-exchange resins is that several studies have shown that cure time and immersion resistance are related and that longer cure times improve the compressive strength of the waste form. ${ }^{36,37}$ In addition, in the case of pozzolonic cements (i.e., those used for solidifications at Brunswick, FitzPatrick, and Peach Bottom-3), the heat of hydration is slower and, consequently, ultimate strength may not be obtained for up to a year. ${ }^{38,39}$

In this study, compressive strength measurements were performed on specimens both before and after immersion testing. In some cases, the compressive strengths of the waste forms were marginal before the compression testing was performed; however, specimens with both marginal and acceptable compressive strengths prior to the immersion test disintegrated during the test. The results of the structural stability tests can be divided up into the results of the compression testing that was performed on the specimens before immersion testing, the results for 
specimens that maintained their structural stability through the immersion test, and the Cooper, Brunswick, and FitzPatrick samples that disintegrated during immersion testing.

The measured compressive strengths of all samples on which compression testing was performed are shown in Tables 4 and 5 and are expressed as $\mathrm{kPa}$ and psi. Uncertainties associated with the compression test measurements are approximately $2 \%$. In addition, the tables present water-to-cement ratios, total cure times, specimen cross-sectional areas, and maximum loads achieved. The compressive strength of each waste-form specimen was calculated by dividing the maximum load the specimen withstood by the cross-sectional area of the specimen.

Table 4. Compressive strengths of intact waste-form samples.

\begin{tabular}{|c|c|c|c|c|c|c|c|c|c|}
\hline \multirow[b]{2}{*}{ Waste form } & \multirow{2}{*}{$\begin{array}{c}\text { Decontamination } \\
\text { process }\end{array}$} & \multirow{2}{*}{$\begin{array}{l}\text { Water-to- } \\
\text { cement } \\
\text { ratio }^{\mathrm{a}}\end{array}$} & \multirow{2}{*}{$\begin{array}{l}\text { Cure time } \\
\text { of } \\
\text { unleached } \\
\text { specimens } \\
\text { (days) }\end{array}$} & \multicolumn{2}{|c|}{$\begin{array}{c}\text { Cross-sectional } \\
\text { area }\end{array}$} & \multicolumn{2}{|c|}{ Maximum load } & \multicolumn{2}{|c|}{ Compressive strength } \\
\hline & & & & $\left(\mathrm{cm}^{2}\right)$ & (in. $\left.{ }^{2}\right)$ & $(\mathbf{k g})$ & (lb) & $(\mathrm{kPa})$ & (psig) \\
\hline \multicolumn{10}{|l|}{ Brunswick-1 } \\
\hline Cation & Citrox & 0.27 & 486 & 26.2 & 4.1 & 720 & 1,590 & $2.70 \times 10^{3}$ & 390 \\
\hline Mixed-bed & & 0.30 & 486 & 25.4 & 3.9 & 900 & 1,990 & $3.48 \times 10^{3}$ & 500 \\
\hline \multicolumn{10}{|l|}{ FitzPatrick } \\
\hline Baked & LOMI & 0.30 & 212 & 17.5 & 2.7 & 2,290 & 5,050 & $1.28 \times 10^{3}$ & 1,860 \\
\hline Unbaked & & 0.30 & 212 & 17.4 & 2.7 & 2,330 & 5,140 & $1.31 \times 10^{4}$ & 1,910 \\
\hline \multicolumn{10}{|l|}{ Pilgrim } \\
\hline Unleached $^{\mathbf{b}}$ & DOW NS-1 & 0.37 & 1,705 & 17.2 & 2.7 & 1,120 & 2,470 & $6.37 \times 10^{3}$ & 920 \\
\hline Immersion-tested & & 0.37 & $-b$ & 17.5 & 2.7 & 2,520 & 5,560 & $1.41 \times 10^{4}$ & 2,040 \\
\hline \multicolumn{10}{|l|}{ Indian Point-3c } \\
\hline Unleached & LOMI & 0.38 & 1,394 & 17.3 & 2.7 & 1,080 & 2,370 & $6.09 \times 10^{3}$ & 880 \\
\hline Immersion-tested & & 0.38 & $-^{c}$ & 18.0 & 2.8 & 300 & 650 & $1.61 \times 10^{3}$ & 230 \\
\hline \multicolumn{10}{|c|}{$\begin{array}{l}\text { b. The leached waste-form specimen was cured } 1.8 \text { years prior to the initiation of leaching and then leached in deionized water for a total of about } 2.1 \text { years. The } \\
\text { sample had been removed from the leachate for about } 90 \text { days when the compression test was performed. The unleached specimen was cured for } 3.8 \text { years before leach } \\
\text { testing. It should be noted that the curing and leach-sesting period for these waste forms exceed the requirement of the Technical Position on Waste Form, but the } \\
\text { compressive strength requirements are met. }\end{array}$} \\
\hline $\begin{array}{l}\text { c. The waste-form sp } \\
\text { from the leachant for } \\
\text { should be noted that } \\
\text { tion on Waste Form, }\end{array}$ & $\begin{array}{l}\text { nen was cured } 1.5 \text { yea } \\
\text { out } 90 \text { days when the } \\
\text { each-tested waste form } \\
\text { plicable at the time the }\end{array}$ & efore leaching & $\begin{array}{l}\text { then leached } \mathrm{i} \\
\text { erformed. TI } \\
\text { ommended co } \\
\text { are performed. }\end{array}$ & $\begin{array}{l}\text { Jeionized } \\
\text { unleached } \\
\text { pressive st }\end{array}$ & $\begin{array}{l}\text { if for a t } \\
\text { cimen }\end{array}$ & $\begin{array}{l}1 \text { of } 2.1 \text { y } \\
\text { cured fo } \\
\text { nent of } 50\end{array}$ & $\begin{array}{l}\text { s. The le } \\
.7 \text { years b } \\
\text { i }(3.4 \times \\
\end{array}$ & $\begin{array}{l}\text { ned sample had b } \\
\text { ore leach lesting } \\
{ }^{2} \mathrm{kPa} \text { ) of the "Te } \\
\end{array}$ & $\begin{array}{l}n \text { removed } \\
\text { curred. It } \\
\text { nical Posi- }\end{array}$ \\
\hline
\end{tabular}


Table 5. Compressive strengths of Peach Bottom waste-form samples. ${ }^{a}$

\begin{tabular}{|c|c|c|c|}
\hline Sample & $\begin{array}{c}\text { Area } \\
\left.\text { (in. } .^{2} / \mathrm{cm}^{2}\right)\end{array}$ & $\begin{array}{l}\text { Yield load } \\
\text { (lb/kg) }\end{array}$ & $\begin{array}{l}\text { Yield strength } \\
\text { (psi/kPa) }\end{array}$ \\
\hline 1. Unleached ${ }^{b}$ & $2.7 / 17.4$ & $3,370 / 1,530$ & $1,240 / 8,570$ \\
\hline 2. Unleached & $2.7 / 17.4$ & $2,620 / 1,190$ & $970 / 6,710$ \\
\hline 3. Unleached & $2.7 / 17.4$ & $3,250 / 1,480$ & $1,210 / 8,340$ \\
\hline Average $\pm \sigma$ & & $\begin{array}{l}3,000 \pm 400 / \\
(1,360 \pm 180)\end{array}$ & $\begin{array}{l}1,140 \pm 150 / \\
(7,870 \pm 1,010)\end{array}$ \\
\hline 1. Deionized water ${ }^{b}$ & $2.7 / 17.4$ & $3,240 / 1,470$ & $1,190 / 8,210$ \\
\hline 2. Deionized water ${ }^{b}$ & $2.5 / 16.1$ & $3,390 / 1,540$ & $1,330 / 9,200$ \\
\hline Average $\pm \sigma$ & & $\begin{array}{l}3,320 \pm 110 / \\
(1,500 \pm 50)\end{array}$ & $\begin{array}{l}1,260 \pm 100 / \\
(8,710 \pm 700)\end{array}$ \\
\hline 1. Seawater & $2.7 / 17.4$ & $2,720 / 1,230$ & $990 / 6,840$ \\
\hline 2. Seawater & $2.7 / 17.4$ & $3,810 / 1,730$ & $1,370 / 9,630$ \\
\hline Average $\pm \sigma$ & & $\begin{array}{l}3,270 \pm 770 / \\
(1,480 \pm 350)\end{array}$ & $\begin{array}{c}1,190 \pm 280 / \\
(8,240 \pm 1,970\end{array}$ \\
\hline Control $\mathrm{c}$ & & $\begin{array}{l}2,760 \pm 30 / \\
(1,250 \pm 10)\end{array}$ & $\begin{array}{l}1,010 \pm 10 / \\
(6,980 \pm 70)\end{array}$ \\
\hline Deionized water ${ }^{c, d}$ & & $\begin{array}{l}2,590 \pm 30 / \\
(1,180 \pm 10)\end{array}$ & $\begin{array}{l}955.7 \pm 9.6 / \\
(6,600 \pm 70\end{array}$ \\
\hline Deionized water ${ }^{c, d}$ & & $\begin{array}{l}2,750 \pm 30 / \\
(1,250 \pm 10)\end{array}$ & $\begin{array}{l}1,010 \pm 10 / \\
(6,980 \pm 70)\end{array}$ \\
\hline Simulated Barnwell ${ }^{c, d}$ & & $\begin{array}{l}2,750 \pm 30 / \\
(1,250 \pm 10)\end{array}$ & $\begin{array}{l}1,020 \pm 10 / \\
(7,060 \pm 70)\end{array}$ \\
\hline Simulated Barnwellc,d & & $\begin{array}{l}2,660 \pm 30 / \\
(1,210 \pm 10)\end{array}$ & $\begin{array}{l}970 \pm 10 / \\
(6,720 \pm 70)\end{array}$ \\
\hline
\end{tabular}

a. The total cure time varied but was approximately $\mathbf{9 0 0}$ days from when samples were taken. The water-to-cement ratio is approximately 0.33 based on the interstitial water content of the samples, and the cross-sectional area for all samples is nominally $16 \mathrm{~cm}^{2}$.

b. The PCP compression tests were performed on conical samples. The compression surface area was based on the smaller of the two ends as discussed in Reference 3 . Nominally, the smaller surface area was $17 \mathrm{~cm}^{2}$. These samples were immersion tested for 90 days.

c. Additional measurements were performed to compare compression tests for deionized and simulated Barnwell groundwater samples. This compression test study was performed after the samples had been immersed in the listed leachants for a period of 7 days. The data indicate no significant differences between the effect of the deionized water and simulated Bamwell water on the compression strength.

d. Compression testing performed after 7 days immersion and 7 days drying. All other samples were immersed for 90 days prior to compression testing. 
The water-to-cement ratios shown in Table 4 and noted in Table 5 were calculated as the ratio of the weight of free interstitial water to the weight of cement and slaked lime or sodium hydroxide used during the solidification of the full-scale waste form from which the waste-form specimen was collected. The water-to-cement ratios were calculated using the method developed by Neilson, ${ }^{23}$ which divides the water content of the resins between the water content of the "as-received" and dewatered ion-exchange resins to determine the amount of available interstitial water. It should be noted that the water-to-cement ratio has been identified as the critical parameter affecting the strength and chemical resistance of a hardened cement mix $^{40}$ and in determining the permeability of a waste form. Studies (Reference 40) indicate that permeability of the waste form increases significantly at water-to-cement ratios greater than 0.5. In this study, all waste forms had water-to-cement ratios between 0.27 and 0.4 ; consequently, the increased permeability due to high water-to-cement ratios would not be expected to influence the results of this study as permeability is similar in this range of water-tocement ratios. ${ }^{40}$

As shown in Tables 4 and 5, the compressive strengths for the unleached decontamination ionexchange samples varied. The compressive strengths of the FitzPatrick samples were the highest at compressive strengths of $1,8 j 0$ to 1,900 psi and were factors of four to five greater than many of the other unleached samples. As noted in the tables, all of the unleached samples would meet the "Technical Position on Waste Form," Revision 1 requirement of 500 psi with the exception of the Brunswick-1 cation resin waste-form specimen. This specimen would meet the original requirement ${ }^{10}$ (i.e., $\left.50 \mathrm{psi}\right)$ that was in place when the sample was prepared; however, both this sample and the Brunswick-1 mixed-bed sample are near the lower limits of acceptable compressive strengths.

Cure time has also been identified as a key factor in ensuring adequate compressive strength ${ }^{41}$ of cement-solidified waste-forms, but it would not be expected to be a factor associated with the poor compressive strengths associated with the Brunswick specimens as they had been cured for 486 days prior to compression testing (Table 3). Other factors that are considered to be primary contributors to poor waste form structural stability are the cement-to-waste ratio, the type of waste being solidified, ${ }^{42}$ and hydration temperatures. ${ }^{41}$ The resin loadings for all specimens tested in this study are on the order of 50 to 60 $w t \%$, which is typical of the loadings used in waste-form studies. ${ }^{42}$ These data suggest that either the type of waste being solidified or possibly high hydration temperatures may have affected the structural stability of the waste forms.

In the case of FitzPatrick, samples were "baked" at $49^{\circ} \mathrm{C}$ for 4 hours after the samples were collected to simulate a high hydration temperature (Reference 2). The result of this experiment was a compressive strength of $1,860 \mathrm{psi}$, which is slightly lower than the unbaked specimen (1,910 psi). Although the compressive strength test system has an associated uncertainty of about $2 \%$, small variations in the waste form might be expected to cause the observed difference. Consequently, these data suggest that the simulated exotherm used on the FitzPatrick specimens had little effect on the initial compressive strength of the waste-form specimen. However, as discussed below, the FitzPatrick specimens that had the best compressive strength characteristics disintegrated during leach testing.

In addition to the initial compression tests performed on unleached samples, samples were compression tested after immersion testing. Only the samples from Pilgrim, Indian Point-3, and Peach Bottom-3 withstood the immersion tests. The immersion tests were performed for differing periods of time. The Pilgrim and Indian Point-3 samples were immersion tested for periods of 2.1 years prior to compression testing, whereas Peach Bottom specimens were immersed for periods of 7 days and 90 days prior to compression testing. The Peach Bottom samples were also immersion tested in different leachants (i.e., deionized water, simulated seawater, and simulated Barnwell groundwater). ${ }^{3}$ 
The Pilgrim and Indian Point-3 specimens were leached in deionized water, which is indicated to be an aggressive leachant in Appendix A of Revision 1 of the "Technical Position on Waste Form."11,35 These tests produced conflicting results in that the compressive strength of the Pilgrim sample increased after the immersion test, whereas the compressive strength of the Indian Point-3 sample decreased to below the 500 psi regulatory limit. No explanation for this difference in behavior has been identified.

An assessment of the Peach Bottom-3 compression testing results shown in Table 5 indicates that the compressive strengths ranged from 970 to 1,370 psi for all leachants, with both deionized water and simulated seawater immersion-tested specimens having compressive strengths near 1,350 psi. This is lower than the compressive strengths of laboratory specimens of solidified decontamination ion-exchange resin. ${ }^{22}$ Compression test data from our study indicated nominal compressive strengths for Citrox waste forms of approximately $3,000 \mathrm{psi}$ and 1,800 psi for LOMI waste forms.

The different leachants in which the specimens were immersion tested also have no apparent affect on compressive strength. Further, there were no apparent differences in the compressive strengths of the Peach Bottom specimens that were immersion tested for 7 and 90 days.

The waste forms that disintegrated during leaching were the Brunswick-1 cation resin (APCitrox waste), the FitzPatrick mixed-bed resin (LOMI/NP/LOMI waste), and the Cooper cation and mixed-bed resin (AP/Citrox waste). The structural stability of the waste-form specimens from Brunswick-1 varied significantly, and many of the samples deteriorated within several hours after the beginning of the leach test. The specimens were leached in deionized water, simulated seawater, and several simulated groundwaters as discussed in Reference 3. Table 6 summarizes the degradation of each Cooper and Brunswick waste-form specimen during leaching. Examina- tion of Table 6 indicates that the only waste-form specimens that maintained their gross physical shape during leaching were those specimens leached in simulated seawater. However, even the specimens leached in simulated seawater probably lost compressive strength very early in the leaching program as indicated by the fact that the cation resin waste-form sample split into two parts after 10 hours of leaching.

As shown in Figure 7, stalagmites grew from cracks on the upper surface of the Brunswick-1 cation resin waste form leached in simulated seawater, and after 24 hours, these growths were about $5 \mathrm{~cm}$ long. The photograph shows the stalagmites and the radial cracks that appeared on the surface of one end of the specimen during the first 2-hour leaching interval. A coating grew on both waste form samples. Examination of the results in Table 6 suggests that because all other specimens disintegrated, the composition and high ionic strength of the simulated seawater leachant may have prevented the samples from decomposing. The primary difference between the specimens leached in simulated seawater and the specimens that decomposed is the composition of the simulated seawater leachant, which contained relatively high concentrations of monovalent ions (e.g., potassium and sodium) and divalent ions (magnesium). The presence of high concentrations of these ions in the leachant could have two possible effects. First, formation of an osmotic condition could occur in which fewer water molecules would tend to move to the resin bead (high concentration of ions) from the leachant (similar concentration) and thereby cause the resin bead to minimize the increase in size that was caused by other factors. The second factor would be the competition for active sites on the resin bead between the smaller monovalent and divalent ions in the leachant and the calcium and aluminum from the cement. The behavior of the specimens that were leached in simulated seawater tends to support these observations. The fact that one specimen split in half and then retained its physical shape tends to suggest that competing mechanisms were at work. 


\section{Experimental Results and Discussion}

Table 6. Structural stability of the Cooper and Brunswick-1 samples.

\begin{tabular}{|c|c|c|c|c|}
\hline Waste form & $<1$ hour & 8 hours & $>8$ hours & 90 days \\
\hline \multicolumn{5}{|l|}{ Cooper mixed-bed } \\
\hline Deionized water & Decomposed & Rubble & Rubble & Rubble \\
\hline \multicolumn{5}{|l|}{ Cooper cation } \\
\hline Deionized water & Cracking & Decomposed & Rubble & Rubble \\
\hline \multicolumn{5}{|l|}{ Brunswick cation resin } \\
\hline Deionized water & - & Cracking & Decomposed $^{\mathrm{a}}$ & Rubble \\
\hline Seawater (pH 6.4) & - & Cracking & Two pieces ${ }^{a, b}$ & Maintained shape \\
\hline Hanford (pH 8.9) & - & Cracking ${ }^{c}$ & Decomposed $^{\mathrm{a}}$ & Rubble \\
\hline Barnwell (pH 4.2) & - & Cracking ${ }^{c}$ & Decomposed $^{\mathrm{a}}$ & Rubble \\
\hline Barnwell (pH 10.4) & - & Cracking ${ }^{c}$ & Decomposed $^{\mathrm{a}}$ & Rubble \\
\hline \multicolumn{5}{|c|}{ Brunswick mixed-bed resin } \\
\hline Deionized water & Decomposed $^{d}$ & - & Rubble & Rubble \\
\hline Seawater (pH 6.4) & - & - & - & Maintained shape \\
\hline Hanford ( $\mathrm{pH} \mathrm{8.9)}$ & Decomposed $\mathrm{d}^{\mathrm{d}}$ & - & Rubble ${ }^{a}$ & Rubble \\
\hline Barnwell (pH 4.2) & Decomposed $^{d}$ & - & Rubble $^{a}$ & Rubble \\
\hline Barnwell (pH 10.4) & Decomposed $^{d}$ & - & Rubble $^{\mathrm{a}}$ & Rubble \\
\hline
\end{tabular}

a. Within 1 week, all identified samples had decomposed to granular rubble.

b. The cation resin waste form split into two pieces after 10 hours with no further decomposition through the entire 90 days.

c. In addition to cracks covering the surface of the waste form, between 3 and $15 \%$ of each sample had sloughed off and dropped to the bottom of the leaching vessel.

d. Effervescence and crumbling began within minutes of placing the waste form in the leachant, and 20 to $30 \%$ of the original volume of the sample sloughed and dropped to the bottom of the container within 8 hours. 


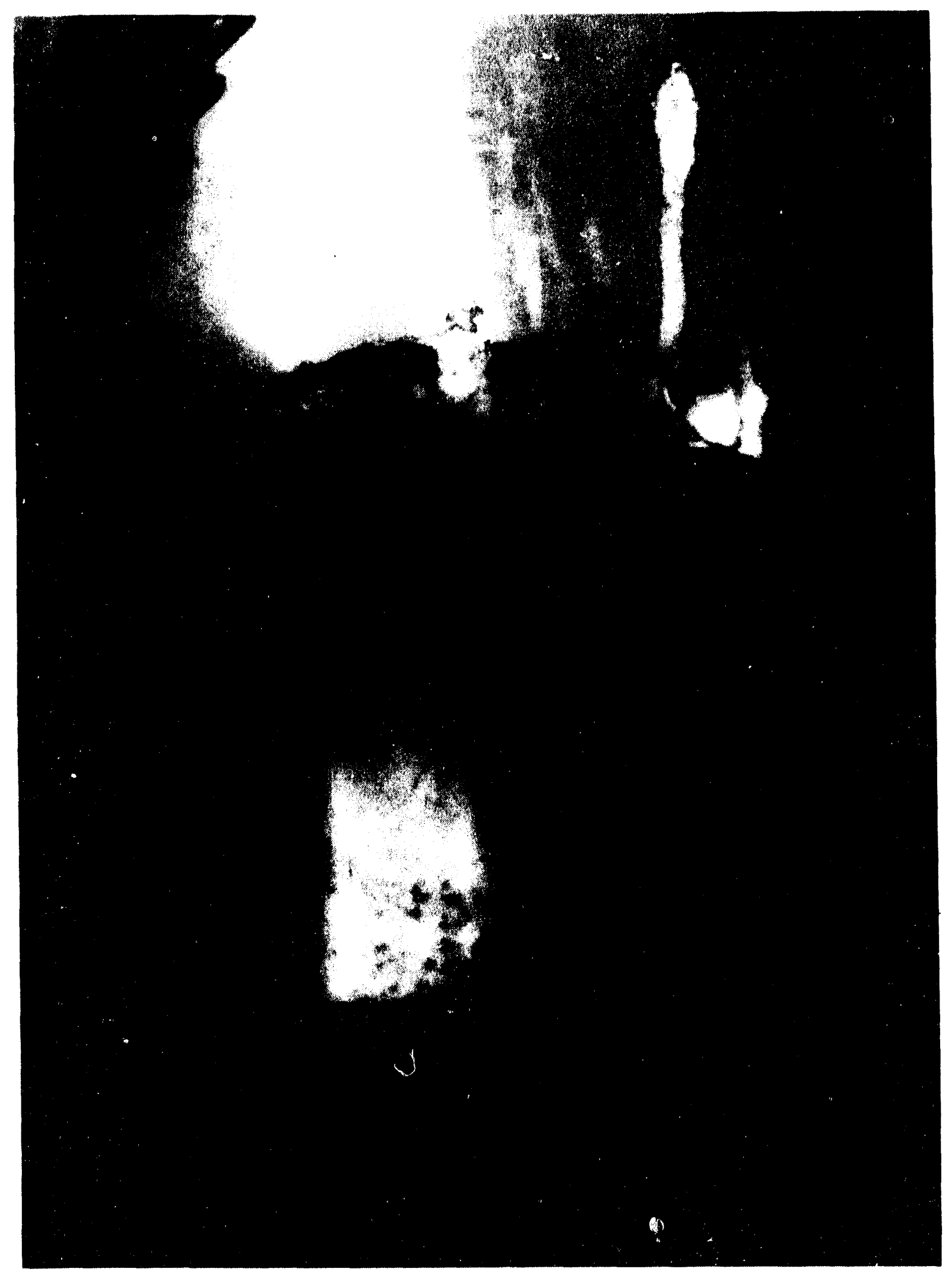

Figure 7. Brunswick-1 cation resin waste-form specimen leaching in synthetic seawater during the first 2-hour interval. 


\section{Experimental Results and Discussion}

In addition to the proposed mechanisms addressed above, an additional phenomenon was observed that could be affecting the behavior of the specimens. During the early part of the leaching test, it was observed that both specimens leached in simulated seawater became coated with white mineral deposits. Although the material that coated the specimens leached in simulated seawater was not analyzed, it is expected that the precipitate was composed of insoluble or relatively insoluble hydroxides $\left(\mathrm{Mg}(\mathrm{OH})_{2}\right)$ and carbonates $\left(\mathrm{CaCO}_{3}\right)$. Formation of these nonreactive compounds on the surface of the specimen could tend to passivate the surface of the specimen, thus preventing water movement and ion exchange and reducing the effects discussed above that would tend to cause swelling of the resin beads and, consequently, the decomposition of the waste-form specimen.

Figure 8 is a photograph of the Brunswick-1 cation resin waste-form specimen after 90 days of leaching. The striations on the surface of the waste-form specimen are the result of the specimen support netting pressing against the surface of the specimen and, therefore, preventing material from being deposited on the surface at those locations. The waste-form specimen is coated with a light grey material. The probable composition is the same as that discussed above (i.e., relatively insoluble hydroxides or carbonates).

The Brunswick-1 mixed-bed resin waste-form specimen leached in simulated seawater also cracked during the first 24 hours of leaching as shown in Figure 9. A stalactite grew from a crack on the lower surface of the sample. The photograph shows the stalactite and the relatively heavy coating of material that covered the surface of the specimen. Figure 10 is a photograph of the same specimen after the completion of 90 days of leaching in simulated seawater. Comparing Figures 8 and 10 , it is evident that the material coating the surface of the mixed-bed resin waste-form specimen was substantially thicker than that covering the surface of the cation resin waste-form specimen.
Figure 11 shows a Brunswick 1 mixed-bed resin waste-form specimen beginning to crumble during the first hour of leaching in simulated Barnwell ground water. Large grains can be seen, which had sloughed off one end of the specimen. This rapid deterioration was typical of the behavior of the majority of the Brunswick-1 waste-form specimens, the exceptions being the two specimens leached in simulated seawater. Figure 12 shows a Brunswick 1 cation resin waste-form specimen after leaching in deionized water for 239 days. The condition of the specimen shown in Figure 12 is representative of the extent of deterioration observed for all but the two specimens leached in simulated seawater.

The structural stability of the waste-form specimens from FitzPatrick varied significantly as many of the specimens deteriorated within several hours after being placed in the different leachants. However, as discussed previously, the

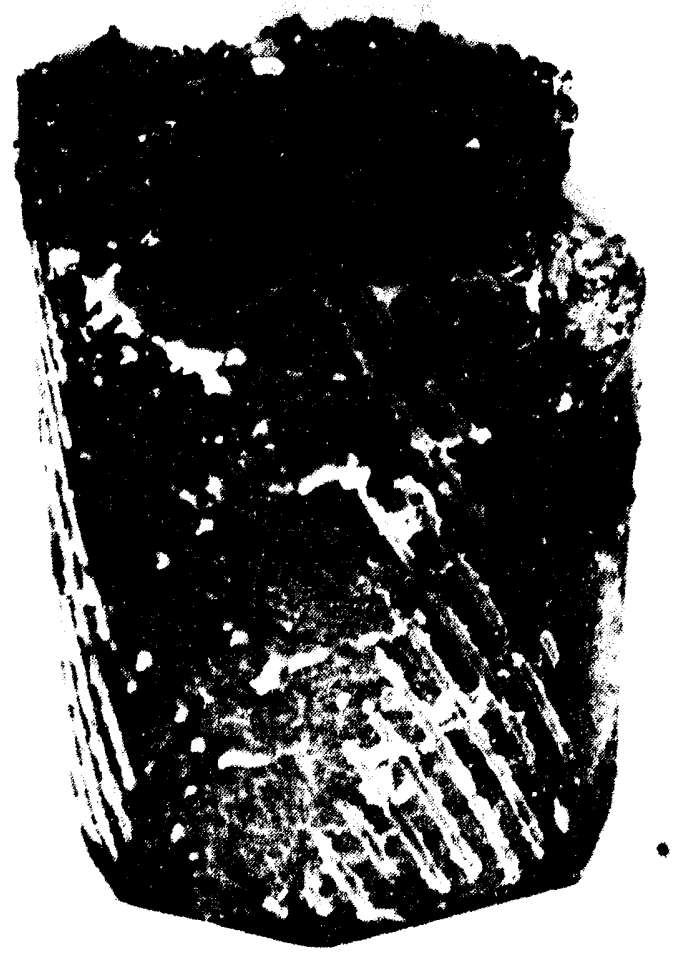

Figure 8. Brunswick-1 cation resin wasteform specimen after leaching in synthetic seawater for 90 days. 


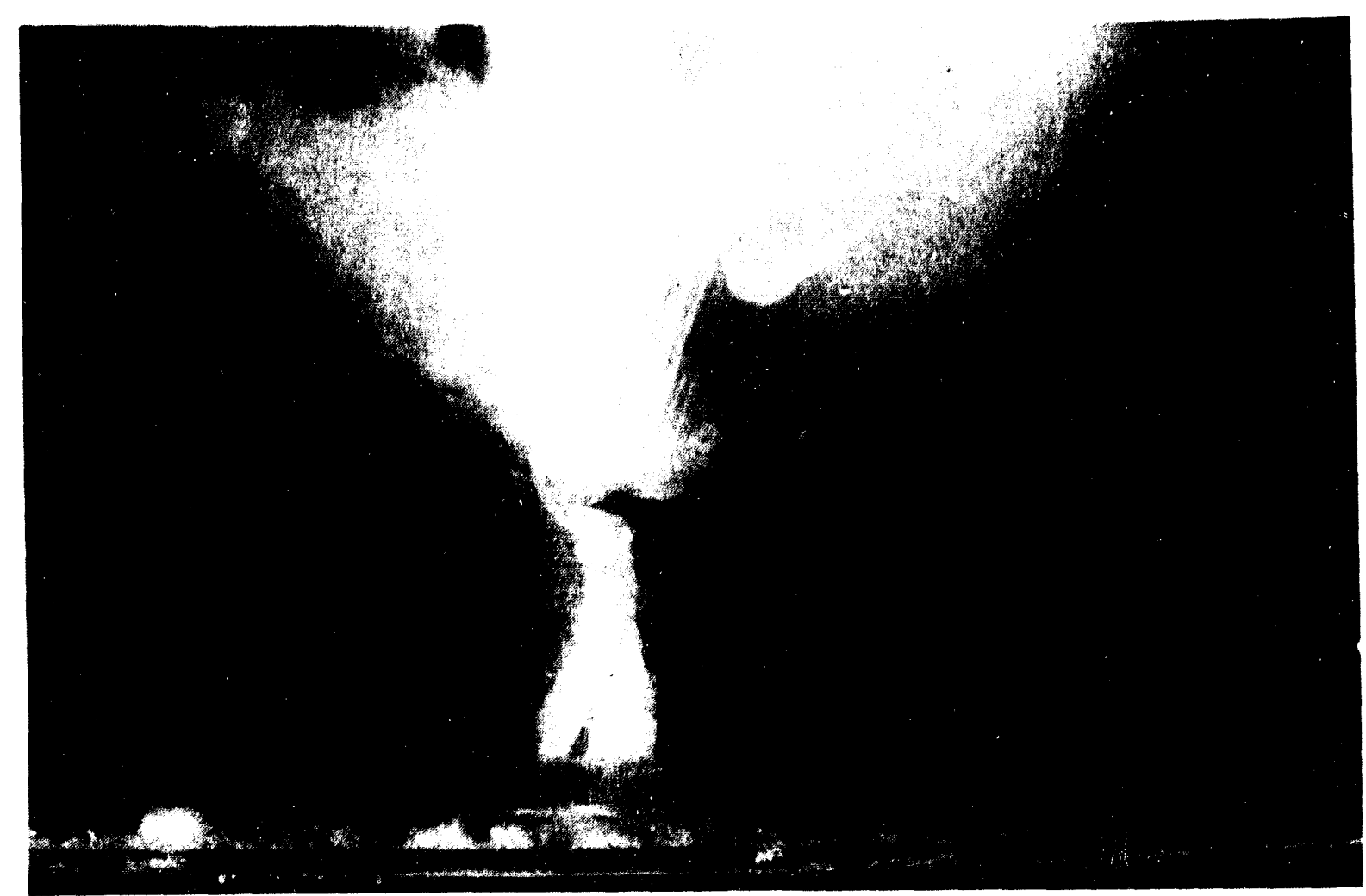

Figure 9. Brunswick-1 mixed-bed resin waste-form specimen leaching in synthetic seawater during the first 2-hour interval.

FitzPatrick waste form is a special case due to the formation of the picolinic acid gel, which prevented solidification of the lime. Table 7 summarizes the degradation of each waste-form sample that occurred during leaching. Examination of Table 7 indicates that all the specimens maintained their gross physical shape during the leaching period except those that were baked during curing. However, the samples leached in these leachants probably all lost compressive strength during the initial part of the leach test due to apparent cracking of the waste forms.

The results in Table 7 suggest that although the degradation of all samples was severe, baking early in the curing period may have resulted in additional degradation of the samples during leaching. A photograph of an unbaked wasteform specimen that was leached in deionized water for 90 days is shown in Figure 13. As shown in the photograph, the specimen seriously deteriorated during the test. Figure 14 is a photograph of an unbaked waste-form specimen after leaching in simulated seawater for 90 days. The specimen remained intact and, as was the case with the Brunswick-1 waste-form specimen that was leached in simulated seawater, the surface of the specimen was covered with the probable deposits discussed above. The degradation of the two waste-form specimens that were baked during initial curing were much more pronounced than for those cured at ambient temperature. The surfaces of the baked specimens buckled soon after they were immersed in their respective leachants. The specimens that were leached in deionized water and simulated Barnwell groundwater with $\mathrm{pH} 4.2$ crumbled into loose rubble by the end of 90 days. Photographs of the two baked waste-form specimens showing their conditions after 90 days of leaching are presented in Figures 15 and 16 , respectively.

The disintegration of the Cooper mixed-bed and cation resin waste forms (AP/Citrox waste form) (Reference 1) occurred early in the leach 


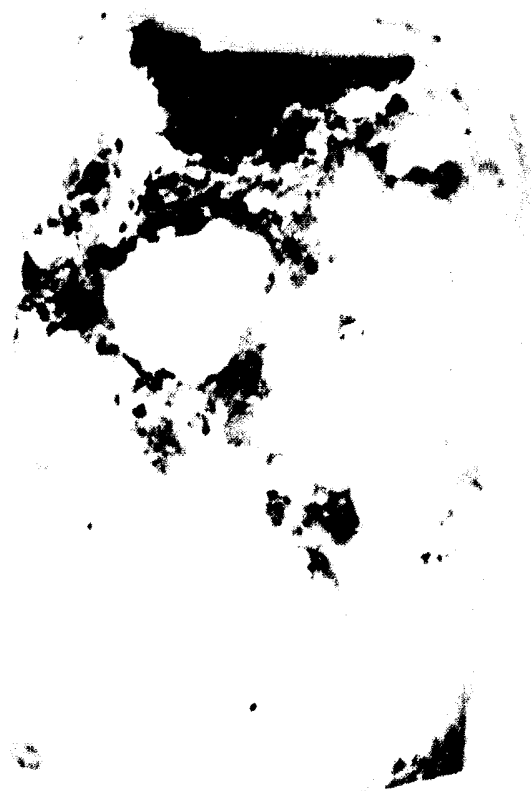

Figure 10. Brunswick-1 mixed-bed resin waste-form specimen after leaching in synthetic seawater for 90 days.

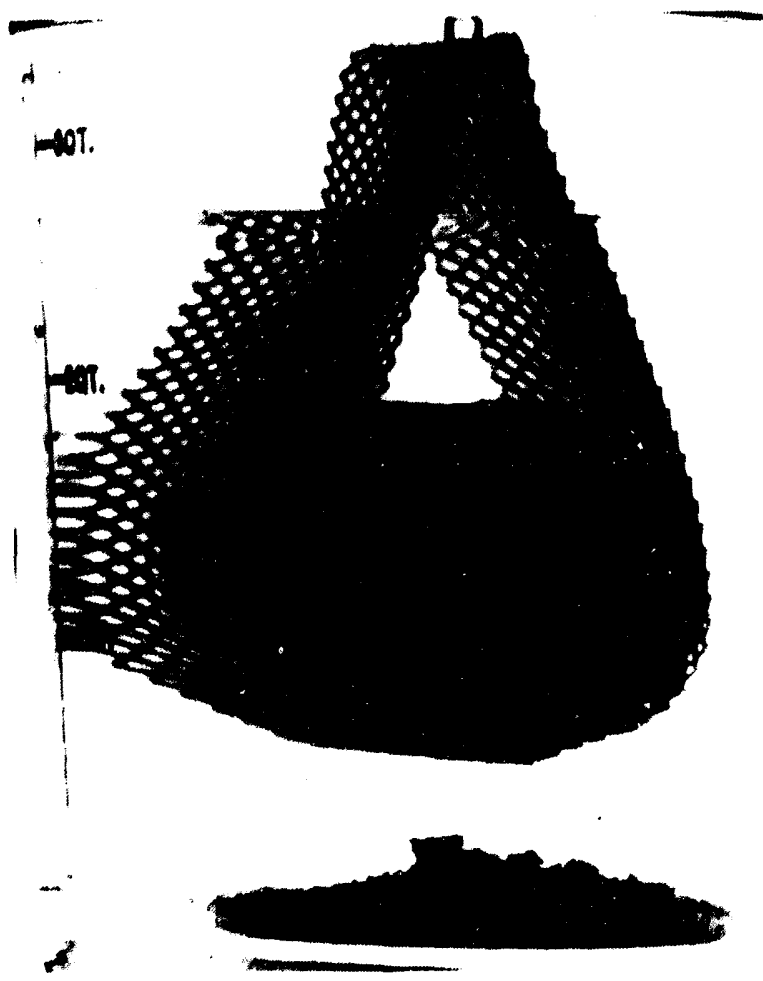

Figure 11. Brunswick-1 mixed-bed resin waste-form specimen during first hour of leaching in synthetic Barnwell groundwater.

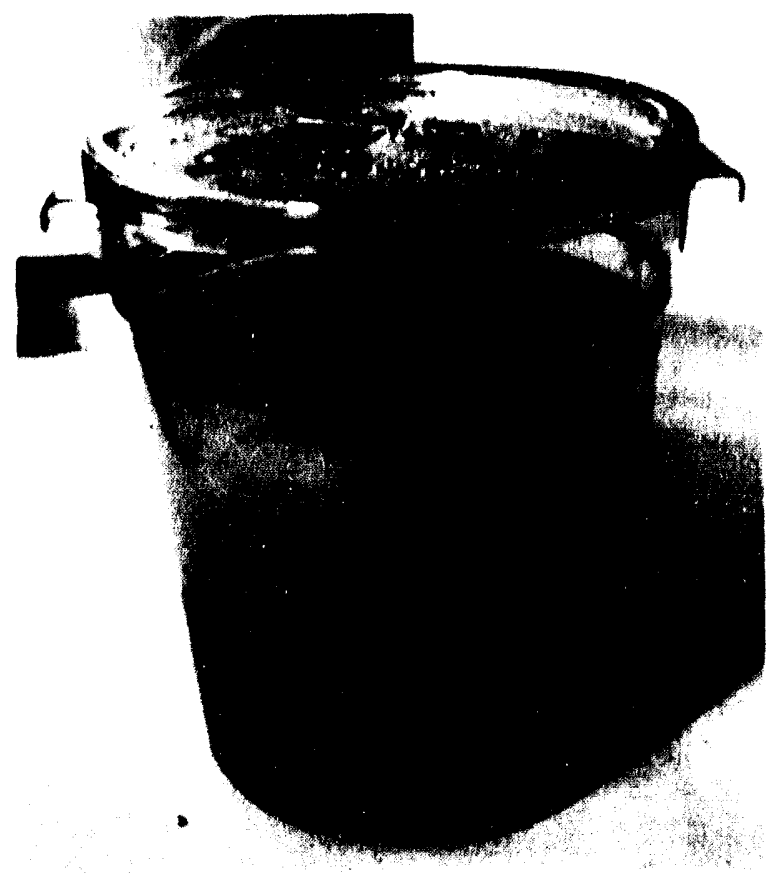

Figure 12. Brunswick-1 cation resin wasteform specimen after leaching in deionized water for 239 days.

testing. For the mixed-bed resin, initial signs of decomposition occurred during the prerinse and was followed by complete disintegration within 1 hour of the first leach cycle. The Cooper cation resin waste form suffered a similar fate, but its decomposition occurred over a longer time. In this case, cracks in the specimen began to form within 20 minutes, and the entire specimen had disintegrated within 8 hours.

The rapid decomposition of cement-solidified ion-exchange resins has been addressed by a number of laboratory studies using simulated wastes and has been attributed to a number of mechanisms. Soo ${ }^{29}$ and others ${ }^{43-46}$ have addressed the decomposition of cement-solidified decontamination ion-exchange resin waste forms. Morcos and Weiss ${ }^{45}$ postulated that resin contraction/swelling during immersion qualitatively explains how resin cement waste forms crack during water immersion. They postulated that during the resin/cement mixing and early curing periods, a cation resin (IRN-77) undergoes ion-exchange processes in which cations are sorbed on the resins and $\mathrm{H}^{+}$ions are released. The resin beads decrease in size and become encapsulated within 
Table 7. Structural stability of the FitzPatrick waste forms.

\begin{tabular}{|c|c|c|c|c|}
\hline Waste form & $<2$ hours & 8 hours & $>8$ hours & 90 days \\
\hline Deionized water & Cracking ${ }^{a}$ & - & Major cracks ${ }^{b}$ & $\operatorname{lntact} \mathfrak{c}^{\mathrm{c}}$ \\
\hline Seawater (pH 6.4) & Cracking $^{\mathrm{a}}$ & - & Major cracks ${ }^{b, d}$ & Intact $c$ \\
\hline Hanford (pH 8.9) & Cracking ${ }^{a}$ & - & Major cracks ${ }^{b}$ & Decomposed ${ }^{\circ}$ \\
\hline Barnwell (pH 4.2) & Cracking $^{\mathrm{a}}$ & - & Major cracks ${ }^{b}$ & $\operatorname{lntact}{ }^{c}$ \\
\hline Barnwell (pH 10.4) & Cracking $^{a}$ & 一 & Major cracks ${ }^{b}$ & Intact ${ }^{c}$ \\
\hline \multicolumn{5}{|l|}{ Baked during curing } \\
\hline Deionized water & Severe cracks $f$ & - & decompositiong & Rubble \\
\hline Bamwell (pH 4.2) & Severe cracks $\mathbf{f}$ & - & decompositions & Rubble \\
\hline
\end{tabular}

a. Relatively large cracks appeared on sample within 2 hours, and within 7 hours, numerous cracks covered the surface of sample.

b. Expansion of the cracks continued to where some of the cracks had grown to about $6 \mathrm{~mm}(0.25 \mathrm{in}$.) in depth. After 48 hours, major cracks traversed the body of sample, and some debris had slumped to the bottom of the net.

c. Remained primarily intac: with only small amounts of material falling off the waste form. Less than $30 \mathrm{~g}$ fell off any sample.

d. After 24 hours of leaching, one major crack had formed in the body of the specimen leached in simulated seawater, and stalagmites grew from the upper surface of the specimen. After $\mathbf{4 8}$ hours, several small additional cracks occurred, but only a negligible quantity of material flaked off the sample.

e. Approximately one-third of the sample had decomposed by the end of the 90-day leach period.

f. For the samples that had been baked for 4 hours during curing, severe cracking occurred within 2 hours, and for the sample leached in pH 4.2, general disintegration had begun, and after 7 hours, the sample had slumped into the net holding the sample.

g. After 2 days, large cracks traversed the surface of the specimen leached in the $\mathrm{pH} 4.2$ leachant, and 15 to $20 \mathrm{~g}$ had sloughed off the sample. Both samples had crumbled to loose rubble at the end of the 90-day period. 


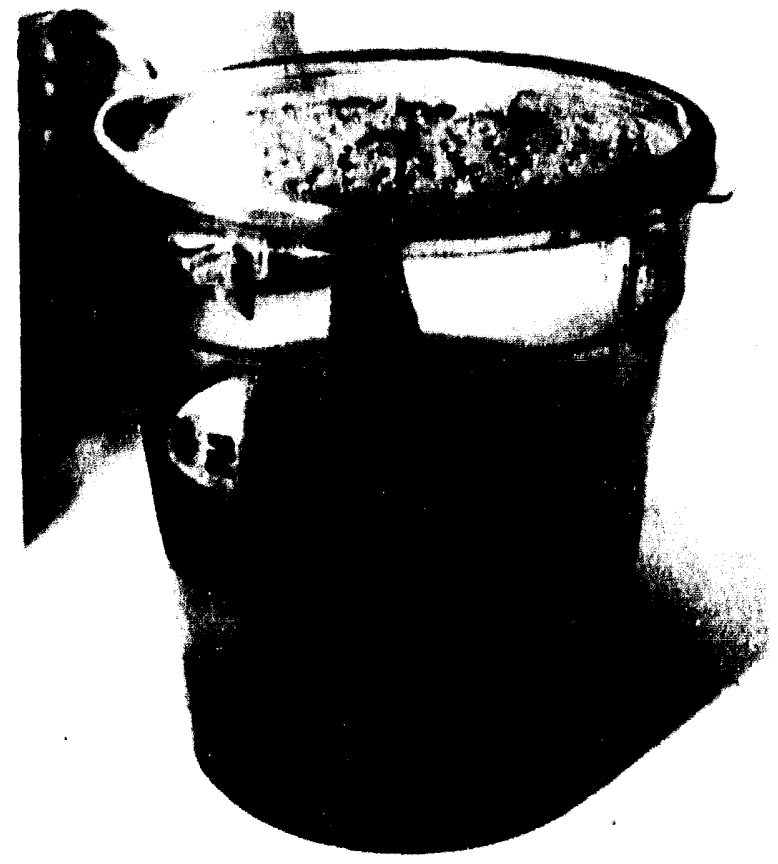

Figure 13. FitzPatrick waste-form specimen after leaching in deionized water for 90 days.

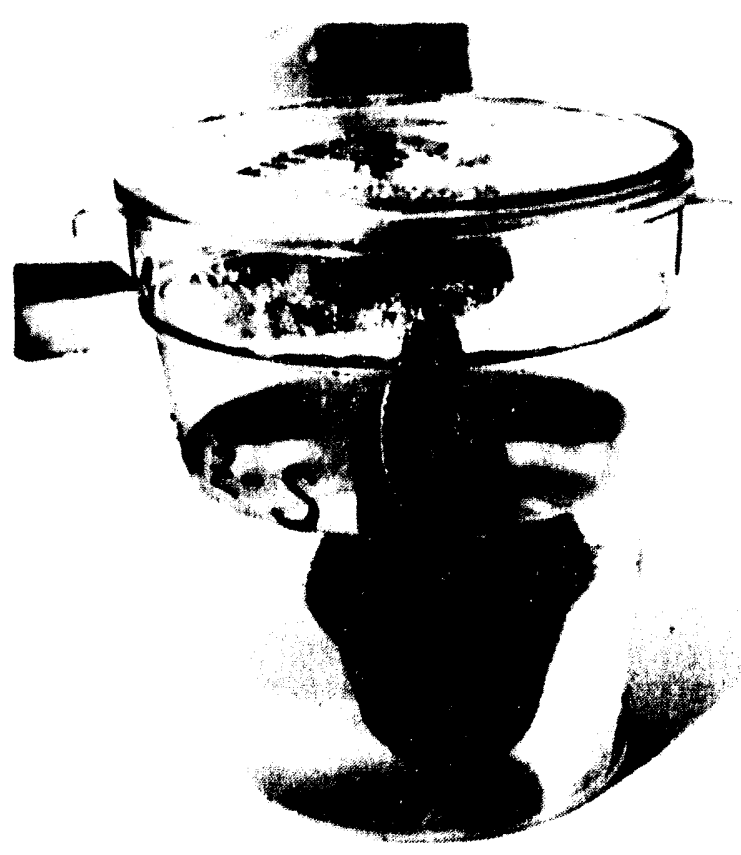

Figure 14. FitzPatrick waste-form specimen after leaching in synthetic water for 90 days.

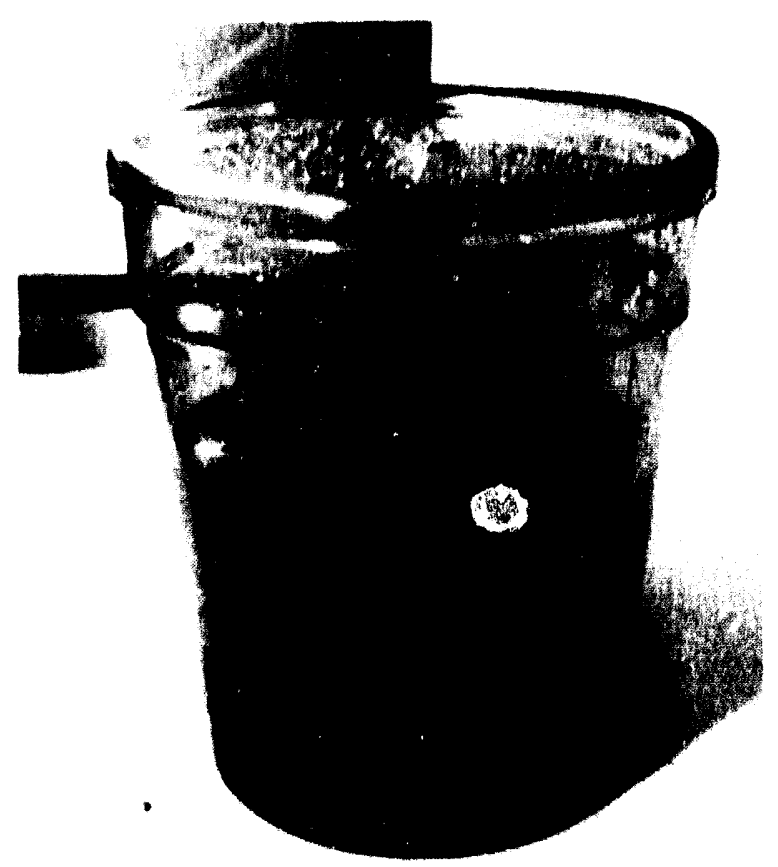

Figure 15. FitzPatrick waste-form specimen, which was baked during initial curing, after leaching in deionized water for 90 days.

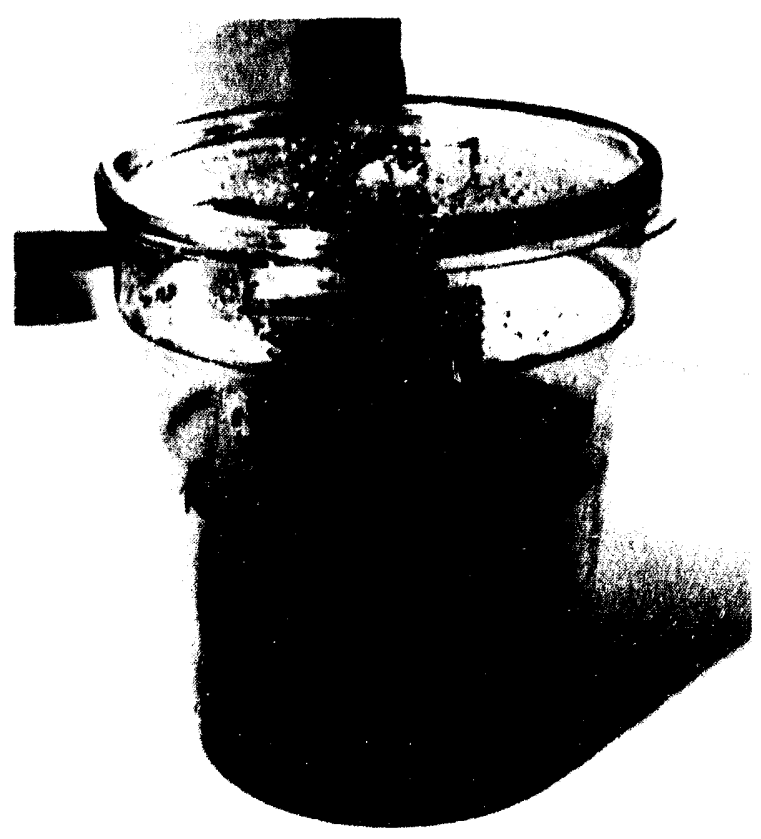

Figure 16. FitzPatrick waste-form specimen, which was baked during initial curing, after leaching for 90 days in synthetic Barnwell groundwater with $\mathrm{pH} 4.2$ 
the cement matrix. After curing, immersion of the composite in pure water allows more dilute solutions to wet the resin beads, which begin to swell and consequently cause a breakdown of the waste form. This analysis, however, does not provide consideration for the presence of other cations in the cement pore water and the leachant. Although our study was performed with resins other than the IRN.77 resin, it is expected that the same phenomena are applicable.

A study performed by Wheaton ${ }^{43}$ indicated that the degree of resin swelling is dependent on the ion-exchange capacity, ionic form, solvent, and composition of solution. For the IRN-77 cation resin, he determined that the resin volume change would be in the following order: $\mathrm{Li}^{+}>$ $\mathrm{Na}^{+}>\mathrm{K}^{+}>\mathrm{Cs}^{+}>\mathrm{Ag}^{+}$, and that with polyvalent ions, the volume increase would be less due to crosslinking and the order would be $\mathrm{Na}^{+}>\mathrm{Ca}^{+2}>$ $\mathrm{Al}^{+3}$. This theory may be more appropriate as there appear to be leachant-specific effects that either increase or reduce degradation of the waste form (i.e., the Brunswick-1 waste forms leached in simulated seawater did not completely disintegrate).

In contrast to the resin bead swelling theory, several other theories have been proposed to explain the degradation of cement-solidified waste forms containing ion-exchange resins. Constable ${ }^{47}$ suggested that the pressure from the interior of the waste form is due to the formation of crystals of calcium salts which build up during the curing process and continue to expand and generate pressure on the interior of the waste form. Scanning electron microscopy techniques have been used to observe the crystal formation in waste forms.

In contrast to these proposed mechanisms, staff at Chem Nuclear Systems, Inc. believe that an enhanced exotherm for the LOMI waste forms during the initial stages of the solidification process may result in an improper solidification and poor waste-form characteristics. ${ }^{48,49}$ They believe that calcium from lime added to adjust the $\mathrm{pH}$ and picolinic acid from the chemical decontamination solution may cause the exothermic hydration process to begin during the $\mathrm{pH}$ adjustment phase rather than the cement curing phase and therefore may result in improper solidification. Also, in the case of FitzPatrick, a picolinic acid gel was formed during the $\mathrm{pH}$ adjustment phase, which resulted in a poor solidification as discussed by Bishop..$^{30}$ To control this process, Chem Nuclear Systems, Inc. has proposed that the temperature of the liner be monitored during the $\mathrm{pH}$ adjustment phase and that it be allowed to cool before cement, which would further increase the temperature during mixing, is added. This theory would not be expected to respond to leachant effects as all waste forms would be expected to behave similarly. Consequently, it is expected that the actual degradation process may be a complex combination of the noted mechanisms, although resin bead swelling may be most likely as it would be expected to produce a gross effect due to the large amount of resin present.

In summary, key points of our studies are the following: (a) compression tests on unleached specimens do not appear to be indicative of the ability of the waste form to survive the immersion and the post-immersion compression test requirements, (b) immersion significantly affects the ability of the waste form to survive compression testing, and (c) disintegration of the waste form may occur quickly and may be the result of several apparently robust mechanisms.

\section{Leach Test Results}

Appendix A of the "Technical Position on Waste Form," Revision 111 includes two changes to the requirements of Reference 10 in the area of leach testing. First, the leach test period has been reduced from 90 days to 5 days. Second, leach testing may be conducted with one of two leachants, either deionized water or simulated seawater, whichever is most aggressive (i.e., whichever has the higher initial release rate). The change to 5 days was incorporated in Revision 1 because it was assumed that mechanisms other than diffusion that might affect leachability (i.e., erosion, corrosion, or dissolution) would be identified by visual inspection during immersion testing and that the primary diffusion-controlled release will have occurred during the initial 
5 days of leach testing. ${ }^{35}$ The objective of the leach test is to determine whether the leachability indexes calculated from the leach test results meet the requirement of 6.0 in the "Technical Position on Waste Form," Revision 1.

In this study, specimens were leached for periuds of 5 days (Peach Bottom-3), 90 days, and for longer periods (239 days) for some specimens to assess possible long-term leaching effects. Results from the 90-day leach tests are discussed in this report. Results from longer or shorter tests are identified and compared with the 90-day test results where appropriate. The leach testing section have been divided into four subsections: $\mathrm{pH}$ and conductivity, waste-form inventories, chelating agent effects on the releases of radionuclides and stable metals leached in deionized water, and the effects of different leachants on releases from the waste form. The $\mathrm{pH}$ and conductivity section assesses the possible effects of leachant $\mathrm{pH}$ and conductivity on the leaching characteristics of the samples, whereas the remaining sections address the effects of waste stream constituents and leachant composition on releases.

\section{Leachate pH and Conductivity}

To assess the potential effects of leachant $\mathrm{pH}$ and conductivity on the leachability of the wasteform specimens, $\mathrm{pH}$ and conductivity measurements were performed on the Brunswick-1 cation, Brunswick-1 mixed-bed, FitzPatrick, and Peach Bottom-3 leachates at the end of each leaching period. Table 8 lists the composition and $\mathrm{pH}$ of the synthetic leachants used in the Brunswick- 1 and FitzPatrick studies. In the Peach Bottom-3 study, this leach te $\mathrm{s} s$ were performed using deionized water as the sole leachant. Figure 17 shows the leachate $\mathrm{pH}$ for the five Brunswick-1 cation resin waste form specimens. The final $\mathrm{pH}$ of leachates other than simulated seawater were comparable throughout the leach tests. At the end of the initial 2-hour leaching ir erval, the $\mathrm{pH}$ of the leachates other than simuiated seawater ranged from 11.4 to 11.7. During the first 3 days of leaching, when leachates were changed out after elapsed times of $2,7,24,48$, and 72 hours, the final $\mathrm{pH}$ of the four leachates other than simu- lated seawater gradually increased, reaching maxima that ranged between 12.1 and 12.5. Results of the $\mathrm{pH}$ measurements indicate that the alkalinity of the cement establishes the $\mathrm{pH}$ of the leachate, with the exception of the simulated seawater leachate, and that it establishes the $\mathrm{pH}$ within a few minutes after immersion based on $\mathrm{pH}$ measurements performed on the washoff samples. Vejmelka ${ }^{50}$ indicates that the cement chemistry will control the leachate $\mathrm{pH}$ unless another constituent (i.e, magnesium) is present in the leachate in significant concentration. He indicates that the solubility of the magnesium hydroxide formed in the leachate will set the $\mathrm{pH}$.

The lower final $\mathrm{pH}$ of the simulated seawater leachates ( 9.0 to 9.8 ) measured in our study for Brunswick-1 and FitzPatrick is probably due to the buffering action of magnesium ( $14 \mathrm{~g} / \mathrm{L}$ of magnesium chloride solution) in the simulated seawater leachants. In another study by Lemire, ${ }^{51}$ higher concentrations of magnesium chloride $(449 \mathrm{~g} / \mathrm{L})$ resulted in the $\mathrm{pH}$ of the leachate being buffered to a pH of 7.1. This lower $\mathrm{pH}$ is consistent with the higher concentrations of magnesium chloride present in the leachate. The Lemire study confirms the dependence of seawater and some groundwater $\mathrm{pHs}$ on the concentrations of specific constituents in the groundwater.

The conductivity measurement results follow similar trends to the $\mathrm{pH}$ for the three types of waste forms on which conductivity measurements were performed. Nominal values ranged from 3 to $5 \mathrm{mmho} / \mathrm{cm}$ for the Brunswick-1 waste forms, approximately $7 \mathrm{mmho} / \mathrm{cm}$ for the FitzPatrick waste forms, and approximately $0.5 \mathrm{mmho} /$ $\mathrm{cm}$ for the Peach Bottom-3 samples. Where measurable, the conductivity of the simulated seawater leachate was the same as that of the other leachates.

It should be noted that although the results for the Brunswick-1 cation resin waste form specimen are representative of the Brunswick-1 mixed-bed resin and FitzPatrick mixed-bed resin waste forms that are evaluated in this study, the effects of $\mathrm{pH}$ on releases of radionuclides and stable metals are not clear as the pH (with the 
Table 8. Composition of simulated leachants $(\mathrm{g} / \mathrm{L})$.

\begin{tabular}{lccc}
\hline \multicolumn{1}{c}{ Compound } & $\begin{array}{c}\text { Simulated } \\
\text { seawater }\end{array}$ & $\begin{array}{c}\text { Barnwell } \\
\text { groundwater }^{\mathrm{b}}\end{array}$ & $\begin{array}{c}\text { Hanford } \\
\text { groundwater }^{\mathrm{c}}\end{array}$ \\
\hline $\mathrm{CaCO}_{3}$ & - & - & 2.624 \\
$\mathrm{Fe}\left(\mathrm{NO}_{3}\right)_{3} \cdot 9 \mathrm{H}_{2} \mathrm{O}$ & - & 0.00069 & - \\
$\mathrm{HNO}_{3}$ & - & - & 0.002 \\
$\mathrm{H}_{2} \mathrm{SO}_{4}$ & - & - & 1.647 \\
$\mathrm{KBr}$ & 0.096 & - & - \\
$\mathrm{KCl}$ & 0.666 & - & 0.269 \\
$\mathrm{KHCO}_{3}$ & - & 0.022 & - \\
$\mathrm{MgCl}_{2} \cdot 6 \mathrm{H}_{2} \mathrm{O}$ & 14.103 & - & 0.813 \\
$\mathrm{MgCO}_{3}$ & - & 0.088 & 0.086 \\
$\mathrm{NaCl}^{2}$ & 23.538 & - & - \\
$\mathrm{Na}_{2} 2 \mathrm{SiO}_{3} \cdot 9 \mathrm{H}_{2} \mathrm{O}$ & - & 0.048 & 2.967 \\
$\mathrm{Na}_{2} \mathrm{SO}_{4}$ & 4.087 & 0.012 & - \\
$\mathrm{pH}$ & 7.0 & $-\mathrm{d}$ & 8.9
\end{tabular}

a. The formula used to prepare simulated seawater was formula III in Appendix D of the ANSI/ANS 16.1 leach-test procedure. The $\mathrm{pH}$ of the leachants are: simulated seawater $(\mathrm{pH} \sim 7.0)$, Hanford groundwater (pH 8.9), Barnwell groundwater 1 ( $\mathrm{pH} \mathrm{4.2),} \mathrm{Barnwell} \mathrm{groundwater} 2$ (pH 10.4). Two pH values were used for the Barnwell groundwater studies because measurements indicated the presence of both.

b. The formula used to prepare simulated Bamwell groundwater was that given in Table 9 of a study by R. Buschbom et al., Characterization of Cement and Bitumen Waste Forms Containing Simulated Low Level Waste Incinerator Ash, NUREG/CR-3798, August 1984.

c. The formula for Hanford groundwater was given by L. Criscenti and R. Serne, Geochemical Analysis of Leachates from Cement/Low Level Radioactive Waste/Soil Systems, PNL-6544, September 1988. 


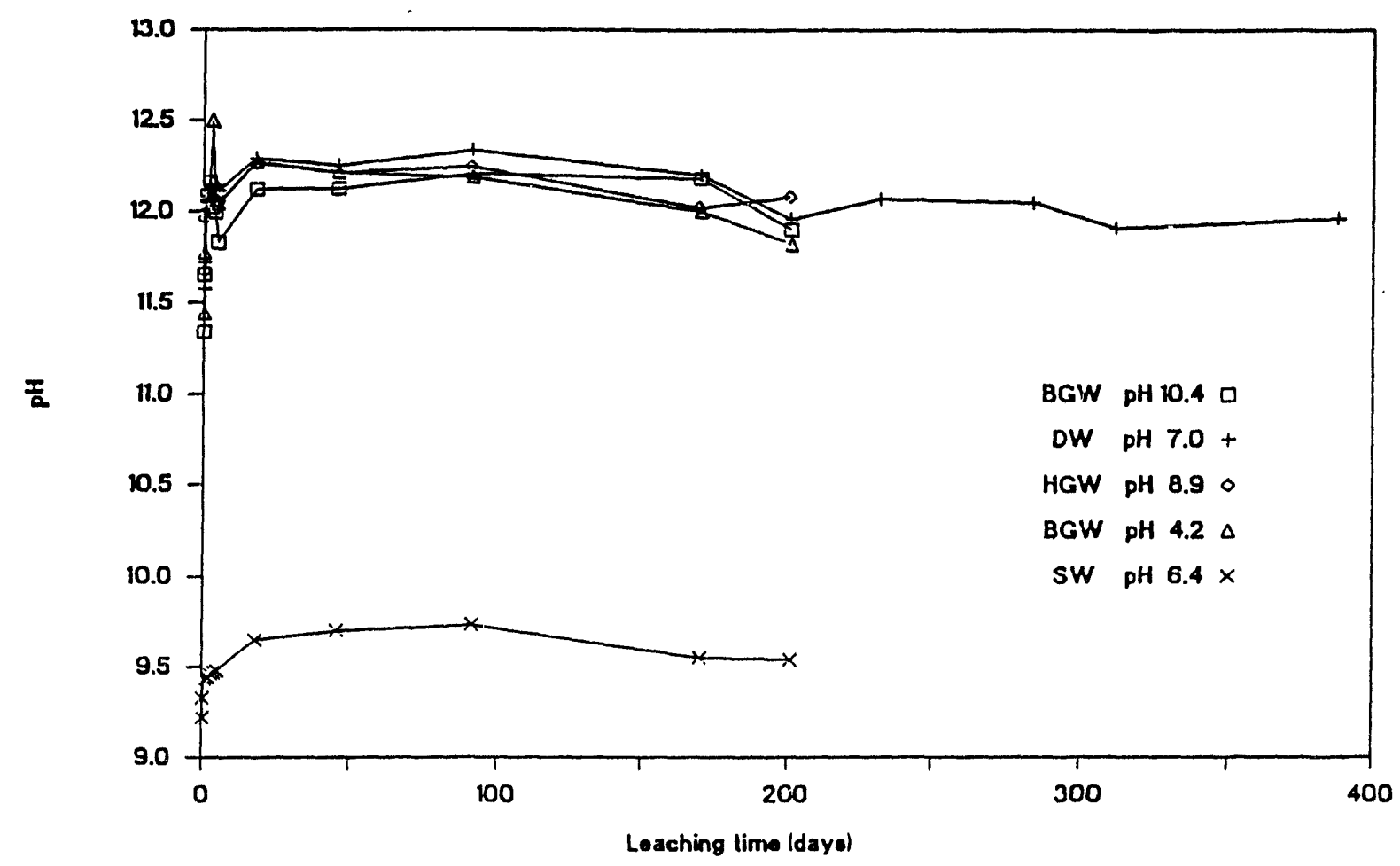

Figure 17. Leachant $\mathrm{pH}$ for Brunswick-1 cation resin waste-form specimens.

exception of simulated seawater) is controlled by the $\mathrm{pH}$ of the waste form. It has been suggested, ${ }^{51}$ as will be discussed later in the section on leachant effects and releases of radionuclides and stable metals, that the ion strength of seawater may be a more important parameter than $\mathrm{pH}$ and may have a greater effect on radionuclide solubilities in the leachate.

\section{Waste Form Inventories of Radionu- clides, Stable Metals and Chelating Agents}

Appendix A of "The Technical Position on Waste Form," Revision 1, states that although some nuclear reactor waste streams are relatively well characterized and free of secondary ingredients, others, such as ion-exchange resins, may contain chemicals that can retard or accelerate the hydration of cement or otherwise adversely affect cement waste-form performance. Appendix A of this report lists chemicals commonly found in nuclear power plants that may affect waste-form solidification as taken from the NRC regulatory documents listed in Appendix A. Further, the effects of chemical constituents are discussed in the Proceedings of the Cement Workshop. ${ }^{14}$ Primary constituents of the decontamination ion-exchange resin waste stream that have been identified as having potentially adverse effects on waste-form solidification are chelating agents such as picolinic acid and EDTA.

In order to determine the inventories of radionuclides, stable metals, and chelating agents present in the waste-form samples, waste-stream samples were obtained from the waste streams used to prepare the waste-form samples. Tables 9 , 10,11 , and 12 , respectively, list the concentrations of the primary radionuclides, transuranic radionuclides, stable metals, and chelating agents present in the decontamination ion-exchange resin wastes that were solidified. In addition to neutron-activation-produced radionuclides, Table 9 contains measured concentrations for the fission products, ${ }^{137} \mathrm{Cs},{ }^{99} \mathrm{Tc}$, and ${ }^{129} \mathrm{I}$, which have been included in the test program because either they have potentially significant dose impacts $\left({ }^{99} \mathrm{Tc}\right.$, and $\left.{ }^{129} \mathrm{I}\right)$ or they may be used for comparison purposes $\left({ }^{137} \mathrm{Cs}\right)$. The ${ }^{99} \mathrm{Tc}$ and ${ }^{129} \mathrm{I}$ measurements were made only for the Peach Bottom-3 
Table 9. Primary radionuclides present in decontamination ion-exchange resin wastes. ${ }^{a}$

\begin{tabular}{|c|c|c|c|c|c|c|c|}
\hline \multirow[b]{2}{*}{$\begin{array}{l}\text { Plant/ } \\
\text { process }\end{array}$} & \multirow[b]{2}{*}{$\begin{array}{l}\text { Collection/ } \\
\text { decay date }\end{array}$} & \multicolumn{6}{|c|}{$\begin{array}{c}\text { Concentration in wet resin } \\
\left(\mu \mathrm{Ci} / \mathrm{cm}^{3}\right)\end{array}$} \\
\hline & & ${ }^{54} \mathrm{Mn}$ & ${ }^{55} \mathrm{Fe}$ & ${ }^{60} \mathrm{Co}$ & ${ }^{63} \mathrm{Ni}$ & ${ }^{14} \mathrm{C}$ & ${ }^{137} \mathrm{Cs}^{\mathrm{a}}$ \\
\hline Indian Point-3/LOMI & $6 / 24 / 85$ & $4.8 \mathrm{E}-1$ & 1.7 & 3.9 & 4.8 & $4.8 \mathrm{E}-5$ & $1.3 \mathrm{E}-1$ \\
\hline Cooper-MBR ${ }^{b} / A P-C i t r o x$ & $11 / 30 / 84$ & $1.4 \mathrm{E}-1$ & 4.0E-1 & $7.3 \mathrm{E}-1$ & $3.6 \mathrm{E}-1$ & $<1 \mathrm{E}-5$ & $2.1 \mathrm{E}-4$ \\
\hline CooperCR $/ A P-C i t r o x$ & $11 / 30 / 84$ & 1.0 & 5.7 & 6.7 & $1.0 \mathrm{E}+1$ & $<1 \mathrm{E}-5$ & $<2 \mathrm{E}-4$ \\
\hline Millstone/Can-Decon & $6 / 20 / 84$ & 2.4 & $2.0 \mathrm{E}+1$ & 7.8 & $8.7 \mathrm{E}-1$ & $3.6 \mathrm{E}-5$ & $2.1 \mathrm{E}-3$ \\
\hline Pilgrim/NS-1 & $8 / 17 / 84$ & $3.8 \mathrm{E}-1$ & 2.7 & 5.2 & $2.8 \mathrm{E}-1$ & $5 E-5$ & $3 E-2$ \\
\hline $\begin{array}{l}\text { Peach Bottom-2/ } \\
\text { Can-Decon }\end{array}$ & $8 / 09 / 84$ & $1.7 \mathrm{E}-1$ & $-c$ & $1.18 \mathrm{E}+1$ & $-c$ & $-c$ & $2.8 \mathrm{E}-3$ \\
\hline Brunswick CR/AP-Citrox & $12 / 18 / 87$ & $5.3 \mathrm{E}-1$ & 2.8 & 2.6 & $5.2 \mathrm{E}-1$ & $-d$ & $1.4 \mathrm{E}-2$ \\
\hline $\begin{array}{l}\text { Brunswick MBR/ } \\
\text { AP-Citrox }\end{array}$ & $12 / 18 / 87$ & $2.2 \mathrm{E}-2$ & $1.5 \mathrm{E}-1$ & $1.3 \mathrm{E}-1$ & 4.2E-2 & $-d$ & 3.7E-4 \\
\hline Peach Bottom-3/LOMI & $10 / 25 / 89$ & $4.3 \mathrm{E}-1$ & $3.0 \mathrm{E}-1^{\mathrm{e}}$ & $2.4^{\mathrm{e}}$ & $5.3 \mathrm{E}-2^{\mathrm{e}}$ & 8.7 & $3.6 \mathrm{E}-3$ \\
\hline FitzPatrick/LOMI & $10 / 18 / 88$ & 1.2 & $6.8 \mathrm{E}-2$ & 4.9 & $1.7 \mathrm{E}-1$ & -c & 2.0E-2 \\
\hline \multicolumn{8}{|c|}{$\begin{array}{l}\text { a. Fission products presented for comparison purposes. Technetium-99 results were obtained only for Cooper mixed-bed resin: } \\
1.1(-4) \mu \mathrm{Ci} / \mathrm{cm}^{3} \text {, Cooper cation resin } \mathrm{CR}: 3(-5) \mu \mathrm{Ci} / \mathrm{cm}^{3} \text { and Pilgrim: } 2.2(-5) \mu \mathrm{Ci} / \mathrm{cm}^{3} \text {. lodine- } 129 \text { was measurable only at Peach } \\
\text { Bottom-3 with a concentration of } 4.8 \mathrm{E}-5 \mu \mathrm{Ci} / \mathrm{cm}^{3} \text {. Others where the }{ }^{129} \mathrm{I} \text { measurements were made (i.e., all plants except Bruns- } \\
\text { wick and FitzPatrick), detection limit values of } 10^{-5} \text { to } 10^{-6} \mu \mathrm{Ci} / \mathrm{cm}^{3} \text { resin were measured. }\end{array}$} \\
\hline \multicolumn{8}{|c|}{ b. $M B R$ is mixed-bed and $C R$ is cation resin. } \\
\hline \multicolumn{8}{|c|}{ c. Analysis result was below detection limit. } \\
\hline d. Analysis not performed. & & & & & & & \\
\hline e. Concentration based on co & ete waste-form & easuremer & & & & & \\
\hline
\end{tabular}


samples. Table 10 lists the concentrations of the transuranic radionuclides present in the resin wastes.

The primary decontamination radionuclides listed in Table 9 whose leachability characteristics are discussed are ${ }^{55} \mathrm{Fe},{ }^{60} \mathrm{Co},{ }^{63} \mathrm{Ni}$, and ${ }^{14} \mathrm{C}$. Manganese-54 is not discussed in detail because it was not measurable in most leachate samples due to its relatively short half-life. Comparison of all radionuclide inventory results should be done carefully because although the results have been decay corrected to the sample collection date, the resins were held for varying periods of time after the decontamination and prior to solidification (see Table 1). This is a minor effect for those radionuclides with long half-lives (i.e., ${ }^{55} \mathrm{Fe}$, ${ }^{63} \mathrm{Ni},{ }^{99} \mathrm{Tc},{ }^{129} \mathrm{I}$, and ${ }^{14} \mathrm{C}$ ) but may affect the results for ${ }^{54} \mathrm{Mn}$ and ${ }^{60} \mathrm{Co}$.

Examination of Table 9 indicates a range of concentrations for ${ }^{55} \mathrm{Fe},{ }^{60} \mathrm{Co}$, and ${ }^{63} \mathrm{Ni}$ between $10^{-1}$ to $10^{1} \mu \mathrm{Ci} / \mathrm{cm}^{3}$ resin, whereas for ${ }^{14} \mathrm{C}$ and ${ }^{99} \mathrm{Tc}$, the results are typically on the order of $10^{-5}$ to $10^{-4} \mu \mathrm{Ci} / \mathrm{cm}^{3}$ resin. Cesium- 137 concentrations range from $10^{-4}$ to $10^{-1} \mu \mathrm{Ci} / \mathrm{cm}^{3}$ resin. These data indicate that the primary radionuclide concentrations present in the decontamination ion-exchange resins are the radionuclides produced by neutron activation that are removed from the PCRS surfaces as part of the decontamination process. The quantities of fission products in the system are lower and have a wide range as they are typically a measure of the degree of fuel failure in the reactor system, which allows more or less quantities of fission products to be released from the fuel and deposited on surfaces in the PCRS. These fission produced radionuclides are subsequently removed from reactor system surfaces via the decontamination process and are subsequently deposited on decontamination ion-exchange resins following the decontamination process.

Table 10 lists the measured concentrations of the transuranic radionuclides in the waste resins. Plutonium-241 has the highest concentrations, ranging from $10^{-3}$ to $10^{-1} \mu \mathrm{Ci} / \mathrm{cm}^{3}$, whereas most other transuranic radionuclides have concentrations ranging from $10^{-8}$ to $10^{-4} \mu \mathrm{Ci} / \mathrm{cm}^{3}$. The higher concentrations of ${ }^{241} \mathrm{Pu}$ on the waste resins is primarily due to the higher specific activity associated with this radionuclide.

Table 11 lists the stable metal constituents of the resin waste. Among the stable metals whose concentrations were measured in the resin wastes, the iron concentration was typically the highest and ranged from $5 \times 10^{2}$ to $10^{4} \mu \mathrm{g} / \mathrm{cm}^{3}$ resin waste. The concentrations of nickel in the Cooper cation and Millstone resins were approximately $10^{3} \mu \mathrm{g} / \mathrm{cm}^{3}$ resin. Typical concentrations measured for other stable metals ranged from $10^{1}$ to $10^{2} \mu \mathrm{g} / \mathrm{cm}^{3}$ resin. These concentrations are similar to those found in another study ${ }^{52}$ and provide a basis for comparison of the radionuclide content in the waste form with the leachate for both simulated and actual waste forms.

The concentrations of the chelating agents measured in the resin wastes are listed in Table 12. Typical concentrations of chelating agents ranged from about $10^{2} \mu \mathrm{g} / \mathrm{cm}^{3}$ of oxalic and citric acids for the Cooper AP-Citrox process resin wastes to about $5 \times 10^{4} \mu \mathrm{g} / \mathrm{cm}^{3}$ of picolinic acid in the Peach Bottom-3 resin wastes. The high concentration of picolinic acid in the Peach Bottom-3 waste forms may have resulted in some of the problems that occurred with this solidification. ${ }^{3}$ Laboratory studies, ${ }^{23}$ however, typically use higher concentrations of chelating agents for their studies and do not have apparent solidification problems.

\section{Releases of Radionuclides, Chelating Agents, and Stable Metals}

Piciulo, ${ }^{23}$ Soo, ${ }^{29}$ and others ${ }^{50}$ have addressed the release of chelating agents, radionuclides, and/or stable metals in laboratory studies. However, these studies used simulated wastes that did not contain all of the constituents found in commercial nuclear power plant waste streams, and as discussed in Reference 35 and Appendix A, other waste stream constituents found at commercial nuclear reactors may affect the leachability characteristics of the waste form. 
Table 10. Transuranic radionuclides present in decontamination ion-exchange resin wastes. ${ }^{\mathrm{a}}$

\begin{tabular}{|c|c|c|c|c|c|c|c|}
\hline \multirow[b]{2}{*}{ Plant/process } & \multirow{2}{*}{$\begin{array}{l}\text { Collection/ } \\
\text { decay date }\end{array}$} & \multicolumn{6}{|c|}{$\begin{array}{l}\text { Concentration in wet resin } \\
\left(\mu \mathrm{Ci} / \mathrm{cm}^{3}\right)\end{array}$} \\
\hline & & ${ }^{238} \mathrm{Pu}$ & $239 / 240 \mathrm{Pu}$ & ${ }^{241} \mathrm{Pu}$ & ${ }^{241} \mathrm{Am}$ & ${ }^{242} \mathrm{Cm}$ & ${ }^{242} \mathrm{Cm}$ \\
\hline Indian Point-3/LOMI & $6 / 24 / 85$ & $1.2 \mathrm{E}-5$ & $1.3 \mathrm{E}-5$ & $4.9 \mathrm{E}-2$ & $9.4 \mathrm{E}-6$ & $1.9 \mathrm{E}-4$ & $1.1 \mathrm{E}-5$ \\
\hline Cooper-MBR /AP-Citrox & $11 / 30 / 84$ & $3.1 \mathrm{E}-5$ & $1.3 \mathrm{E}-5$ & $4.9 \mathrm{E}-2$ & $9.4 \mathrm{E}-6$ & $1.9 \mathrm{E}-4$ & $1.1 \mathrm{E}-5$ \\
\hline CooperCR /AP-Citrox & $11 / 30 / 84$ & $7.7 \mathrm{E}-5$ & $3 \mathrm{E}-5$ & $1.0 \mathrm{E}-2$ & $1.0 \mathrm{E}-4$ & $6.8 \mathrm{E}-5$ & $8.1 \mathrm{E}-5$ \\
\hline Millstone/Can-Decon & $6 / 20 / 84$ & $4.9 \mathrm{E}-3$ & $2.6 \mathrm{E}-3$ & $3.5 \mathrm{E}-1$ & $4.0 \mathrm{E}-3$ & $4.1 \mathrm{E}-4$ & $3.4 \mathrm{E}-3$ \\
\hline Pilgrim/NS-1 & $8 / 17 / 84$ & $2.2 \mathrm{E}-4$ & $3.1 \mathrm{E}-4$ & $3.5 \mathrm{E}-2$ & $5.3 \mathrm{E}-6$ & $1.7 \mathrm{E}-5$ & $1.4 \mathrm{E}-5$ \\
\hline $\begin{array}{l}\text { Peach Bottom-2/ } \\
\text { Can-Decon }\end{array}$ & $8 / 09 / 84$ & $-c$ & $-c$ & $5.1 \mathrm{E}-3$ & $-\mathrm{c}$ & $-c$ & $-c$ \\
\hline $\begin{array}{l}\text { Brunswick } \mathrm{CR}^{\mathrm{b}} / \\
\text { AP-Citrox }\end{array}$ & $12 / 18 / 87$ & $2.6 \mathrm{E}-7$ & $2.0 \mathrm{E}-7$ & $2.1 \mathrm{E}-3$ & $-c$ & $1.2 \mathrm{E}-8$ & $2.6 \mathrm{E}-8$ \\
\hline $\begin{array}{l}\text { Brunswick MBR }{ }^{\mathrm{b}} \\
\text { AP-Citrox }\end{array}$ & $12 / 18 / 87$ & $7.9 \mathrm{E}-8$ & $6.9 \mathrm{E}-8$ & $2.1 E-3$ & $-c$ & $3 \mathrm{E}-8$ & $5 E-9$ \\
\hline Peach Bottom-3/LOMI & $10 / 25 / 89$ & $8.4 \mathrm{E}-5^{\mathrm{d}}$ & $2.5 \mathrm{E}-5^{\mathrm{d}}$ & $1.4 \mathrm{E}-3^{\mathrm{d}}$ & $1.2 \mathrm{E}-4^{\mathrm{d}}$ & $9.2 \mathrm{E}-6$ & $1.4 \mathrm{E}-4^{\mathrm{d}}$ \\
\hline FitzPatrick/LOMI & $10 / 18 / 88$ & $2.5 \mathrm{E}-5$ & $4.5 \mathrm{E}-5$ & $6.7 \mathrm{E}-2$ & $3.7 \mathrm{E}-5$ & $4.1 \mathrm{E}-5$ & $4.3 \mathrm{E}-6$ \\
\hline \multicolumn{8}{|c|}{ a. Transuranic concentrations in the resin wastes from References 1 to 3.} \\
\hline \multicolumn{8}{|c|}{ b. $M B R$ is mixed-bed and $C R$ is cation resin. } \\
\hline c. Analysis result was belov & ction limit. & & & & & & \\
\hline
\end{tabular}

The physical factors that influence mass transfer of chelating agents, radionuclides, and stable metals into the coolant can be divided into three mechanisms: (a) convection, (b) diffusion through pores within the waste form, and (c) diffusion at the interface of the waste form and the surrounding coolant. ${ }^{53}$ Convection refers to bulk movement through the waste form and is expected to be insignificant for intact waste forms. However, in this study, where a number of the waste forms decomposed during leaching, it may be significant, but as will be discussed, there does not appear to be a significant difference in the releases from degraded and intact waste forms. Mechanism 2, pore diffusion, is induced by concentration gradients within a waste matrix and results in the diffusion of radionuclides and other constituents to the surface of the waste form. In this mechanism, the waste form has been described as a porous solid with water-filled pores. ${ }^{54,55}$ The third mechanism is diffusion at the interface between the surface of the waste 
Table 11. Stable metals present in decontamination resin wastes.

\begin{tabular}{|c|c|c|c|c|}
\hline \multirow[b]{2}{*}{ Plant } & \multirow[b]{2}{*}{ Chromium } & \multicolumn{3}{|c|}{$\begin{array}{c}\text { Concentration in wet resin } \\
\left(\mu \mathrm{g} / \mathrm{cm}^{3}\right)^{\mathrm{a}}\end{array}$} \\
\hline & & Iron & Cobalt & Nickel \\
\hline Indian Point-3 & $9.0 \mathrm{E}+1$ & $6.6 \mathrm{E}+2$ & $<1.2 \mathrm{E}+1$ & $7.1 \mathrm{E}+2$ \\
\hline Cooper (MBR) ${ }^{c}$ & -b & $5.2 \mathrm{E}+2$ & $<1.5 \mathrm{E}+1$ & $7.4 \mathrm{E}+1$ \\
\hline Cooper $(\mathrm{CR})^{\mathrm{c}}$ & $3.0 \mathrm{E}+2$ & $1.1 \mathrm{E}+4$ & $6.0 \mathrm{E}+1$ & $1.2 \mathrm{E}+3$ \\
\hline Millstone-1 & $3.5 \mathrm{E}+2$ & $5.8 \mathrm{E}+3$ & $1.6 \mathrm{E}+1$ & $2.1 \mathrm{E}+3$ \\
\hline Pilgrim & $-b$ & $1.1 \mathrm{E}+3$ & 9.6 & $1.4 \mathrm{E}+2$ \\
\hline Peach Bottom-2 & -b & $-b$ & $-b$ & $-b$ \\
\hline Brunswick-1 CRc & $4.5 \mathrm{E}+2$ & $6.4 E+3$ & $2.1 \mathrm{E}+2$ & $7.3 \mathrm{E}+2$ \\
\hline Brunswick-1 MBR ${ }^{c}$ & $1.6 \mathrm{E}+3$ & $6.9 E+2$ & $3.0 \mathrm{E}+2$ & $6.4 \mathrm{E}+1$ \\
\hline Peach Bottom-3 & $6.5 \mathrm{E}+2$ & $3.0 \mathrm{E}+3$ & $1.4 \mathrm{E}+1$ & $7.3 \mathrm{E}+2$ \\
\hline FitzPatrick & $2.0 \mathrm{E}+2$ & $2.4 E+3$ & $2.6 \mathrm{E}+2$ & $1.2 \mathrm{E}+2$ \\
\hline \multicolumn{5}{|l|}{ a. $\mu \mathrm{g} / \mathrm{cm}^{3}$ of wet resin. } \\
\hline \multicolumn{5}{|l|}{ b. Not measured. } \\
\hline c. MBR is mixed-bed & $\mathrm{CR}$ is cation $\mathrm{r}$ & & & \\
\hline
\end{tabular}

form and the surrounding leachant, and can be defined as the formation of a concentration gradient at the surface of the waste form between the waste form and the leachant. Each of these mechanisms may contribute to releases from the intact and degraded waste forms and would be expected to be modified by the effects of other constituents in the waste form, with chelating agents possibly having the greatest effect due to their high concentration (up to $6 \mathrm{wt} \%$ ).

This section addresses the releases of chelating agents, radionuclides, and stable metals from actual solidified decontamination ion-exchange waste forms for the various decontamination processes shown in Table 1. The leaching tests performed on the waste forms in this study (with the exception of the Brunswick-1 and FitzPatrick waste forms, where multiple leachants were used) were performed using deionized water as a representative, aggressive leachant. ${ }^{35}$ Leachants tested in the multiple leachant tests include those listed in Table 8 and deionized water.

An assessment of the leachability characteristics of decontamination ion-exchange resin waste forms was performed through comparisons of release rates, cumulative fractional releases, effective diffusivities, and leachability indexes for the species of interest to assess the effects of the different chelating agents on releases from the waste forms. Appendix E contains detailed tables showing the leach test results. Various forms of data presentation are used including cumulative 
Table 12. Chelating agents present in decontamination resin wastes.

\begin{tabular}{|c|c|c|c|c|c|}
\hline \multirow[b]{2}{*}{ Plant } & \multirow{2}{*}{$\begin{array}{c}\text { Decontamination } \\
\text { process }\end{array}$} & \multicolumn{4}{|c|}{$\begin{array}{c}\text { Concentration in wet resin } \\
\left(\mu \mathrm{g} / \mathrm{cm}^{3}\right)\end{array}$} \\
\hline & & Oxalic & Citric & EDTA & Picolinic \\
\hline Indian Point-3 & LOMI & - & 一 & - & 4.1E+3a \\
\hline Cooper (MBR) & AP/Citrox & $1.62 E+4)$ & $9.6 \mathrm{E}+1$ & 一 & - \\
\hline Cooper (CR) & AP/Citrox & $2.7 \mathrm{E}+2$ & $9.6 \mathrm{E}+1$ & 一 & - \\
\hline Millstone-1 & Can-Decon & $7.4 \mathrm{E}+3$ & $6.3 \mathrm{E}+3$ & $6.1 \mathrm{E}+3$ & - \\
\hline Pilgrimb & NS-1 & $2.9 \mathrm{E}+2$ & $3.0 \mathrm{E}+3$ & $3.7 \mathrm{E}+3$ & - \\
\hline Peach Bottom-2 & Can-Decon & $5.9 \mathrm{E}+3$ & $5.1 \mathrm{E}+3$ & $4.9 E+3^{c}$ & - \\
\hline Brunswick CR & AP/Citrox & 一 & 一 & - & - \\
\hline Brunswick MBR & AP/Citrox & $2.0 \mathrm{E}+4$ & 4.1E+4 & 一 & - \\
\hline Peach Bottom-3 & LOMI/NP/LOMI & - & - & - & $5.5 \mathrm{E}+4$ \\
\hline FitzPatrick & LOMI/NP/LOMI & - & 一 & - & $1.0 \mathrm{E}+4$ \\
\hline $\begin{array}{l}\text { a. Contains } 4.0(+3 \\
\text { b. Contains } 3.6(+2\end{array}$ & $\begin{array}{l}\mathrm{cm}^{3} \text { of formic acid. } \\
\mathrm{cm}^{3} \text { of DTPA. }\end{array}$ & & & & \\
\hline
\end{tabular}

fractional release $/ \mathrm{cm}^{2}$ surface area/yr, $\mathrm{Ci} / \mathrm{yr}$, $\mathrm{Ci} / \mathrm{m}^{3} / \mathrm{yr}$, cumulative fractional release/yr, and cumulative fractional release $/ \mathrm{m}^{3} / \mathrm{yr}$. These data should be used carefully as they are plant- and waste-form specific and may not be easily intercompared as they are dependent on the inventories in the waste form, and the dimensions and surface area of the waste form.

Appendix F contains summary tables (F-1 through F-12) showing the average absolute and fractional release rates, the cumulative fractional release, the average effective diffusivities, and the leachability indexes for the 12 waste forms leached ir deionized water. Tables F-13 through F-25 contain the same data for the Brunswick-1 and FitzPatrick samples leached in different leachants. In the following sections, average release rates, cumulative fractional releases, effective diffusivities, and leachability indexes for the species of interest are compared for all waste forms that were leached. Decontamination radionuclides discussed include ${ }^{55} \mathrm{Fe},{ }^{60} \mathrm{Co},{ }^{63} \mathrm{Ni}$, and ${ }^{14} \mathrm{C}$. The results for ${ }^{99} \mathrm{Tc}$ and ${ }^{129} \mathrm{I}$, both fission products, have been added because of their long half-lives and the importance of possible releases of these radionuclides to the environment. Cesium-137 has been included in the evaluation because several studies ${ }^{50,56}$ indicate that ${ }^{137} \mathrm{Cs}$ is extremely mobile and should provide a basis for comparison with the releases of the decontamination radionuclides evaluated as part of this study. In addition, results of the transuranic radionuclides (primarily ${ }^{241} \mathrm{Pu}$ ), and ${ }^{90} \mathrm{Sr}$ are discussed.

The average absolute release rates, the average fractional release rates, and the average effective 
diffusivities are for nonlinear rate phenomena, and consequently include high-rate data from early in the leaching process and low-rate data from later in the process. Averages are not typically calculated for phenomena of this type; however, these averages and their associated internal uncertainties have been calculated as they are the common method used for comparisons with other leach test studies. Therefore, uncertainties associated with the average rates are expected to be large (typically from 50 to $100 \%$ at one standard deviation). Uncertainties listed for the average absolute release rates, the average fractional release rates, and the average effective diffusivities are the internal uncertainties associated with differences in the rate or diffusivity results and do not contain uncertainties associated with counting statistics, waste-form inventories, or other uncertainties associated with the leaching process. These uncertainties have been excluded because they are either small relative to the quoted uncertainty or are not quantifiable based on the tests performed. Exceptions (e.g., ${ }^{90} \mathrm{Sr}$ ) are discussed in the following sections. A one-standard-deviation uncertainty is quoted in the tables. Leaching data are shown graphically as plots of average release rates and cumulative fractional release versus the square root of elapsed leaching time. This presentation was chosen to facilitate evaluation of the data since the plots will be linear if diffusion is the controlling release mechanism and will have slopes that are proportional to the corresponding effective diffusivities.

The decontamination produced stable metals discussed in this section are chromium, iron, cobalt, and nickel. Primary radionuclides evaluated are iron and nickel as they were measurable in most samples and can be compared with the release data for ${ }^{55} \mathrm{Fe}$ and ${ }^{63} \mathrm{Ni}$. Characteristics of the chelating agent releases are also compared with the stable metal results.

Tables F-1 through F-12 in Appendix F show the average fractional release rate and cumulative fractional release data for all samples that were leached in deionized water. In the following sections, results are discussed in the following order: fractional and absolute release rates, cumulative fractional releases, effective diffusivities, and leachability indexes. The chelating agents are discussed first followed by the radionuclides and stable metals. The chelating agents are evaluated first because the releases of these organic compounds provide the basis for assessing the releases of the radionuclides and stable metals as the chelating agent may act as a carrier for the other species; thus, release rates of these compounds provide the basis for assessing the releases of other species.

Cholating Agents. Table 12 lists the concentrations of chelating agents in the wet resins. The primary chelating agents present in the waste forms are oxalic and citric acids, which are constituents of the AP/Citrox and Can-Decon processes, EDTA found in the Can-Decon and Dow NS-1 wastes, and the picolinic acid used in the LOMI process. The concentrations of the chelating agents typically range from $\sim 0.1$ to $5 \mathrm{wt} \%$, with the oxalic, citric, and picolinic acids having the highest concentrations in the resin wastes.

Table 13 summarizes the Appendix $F$ release rates, cumulative fractional releases, effective diffusivities, and leachability indexes for the chelating agents present in the waste forms tested. It should be noted that in the case of the Cooper samples, the fractional release rates were listed in Reference 1 in terms of $\mathrm{s}^{-1}$ because these samples decomposed during leach testing. Consequently, for comparison purposes, a nominal waste-form surface area of $2 \times 10^{2} \mathrm{~cm}^{2}$ was assumed for the surface area of the degraded waste form exposed to the leachant. A similar convention was used for the Brunswick-1 samples that decomposed during leach testing (see Reference 2).

Inspection of Table 13 indicates that the average fractional release rates for the chelating agents typically range from $10^{-11}$ to $10^{-8}$ $\mathrm{cm}^{-2} \cdot \mathrm{s}^{-1}$, whereas the average absolute release rates range from $10^{-4}$ to $10^{-3} \mu \mathrm{g} / \mathrm{cm}^{2} \cdot \mathrm{s}^{1}$, with the exception of the citric acid from the Millstone-1 F-201 and Millstone-1 F-33 sample $\left(\sim 6 \times 10^{-5}\right.$ $\left.\mu \mathrm{g} / \mathrm{cm}^{2} \cdot \mathrm{s}^{1}\right)$. In contrast to the narrower ranges associated with the average fractional and absolute release rates, the effective diffusivities range 
from $10^{-11}$ to $10^{-6} \mathrm{~cm}^{2} \cdot \mathrm{s}^{-1}$, and the leachability indexes range from 5.7 to 11.5. The narrow range of average absolute release rates suggests that the absolute release rate may be limited by diffusion or a chemical mechanism to a relatively narrow range.

Also shown in Table 13 are the cumulative fractional releases (CFRs) of the chelating agents, which range from $6.3 \times 10^{-3}$ to 1.0 . It should be noted, however, that the average CFR of picolinic acid from the Peach Bottom-3 samples is artificially low because the Peach Bottom-3 samples were leached for only 5 days in contrast to the 90 days that the other samples were leached. An extrapolation of the Peach Bottom-3 fractional release rate data to 90 days would increase the CFR of picolinic acid from $2 \times 10^{-2}$ to $1.3 \times 10^{-1}$. The effect of the duration of the leach test on the CFR for the Peach Bottom-3 samples is discussed for each of the species evaluated in the following sections.

Figures 18 and 19 show the average fractional release rates $\left(\mathrm{cm}^{-2} \cdot \mathrm{s}^{-1}\right)$ and the CFRs for all the chelating agents measured in this study. The " $D$ " in the figures indicates which samples decomposed during leach testing. Samples that decomposed completely and early in the leach tests were the Brunswick-1 and Cooper samples, whereas the FitzPatrick samples had basically decomposed by the end of the leach test.

Inspection of Table 13 and Figure 18 indicates that FitzPatrick and Indian Point-3 have statistically the same average fractional release rates of picolinic acid and formic acid, whereas the average fractional release rate of picolinic acid from the Peach Bottom-3 samples is about $20 \%$ of that from the FitzPatrick sample. However, the similarity of these data may be deceptive because the FitzPatrick sample is a special case due to the gel formation during the solidification process. The difference in the average fractional release rates from the LOMI waste forms is informative as the FitzPatrick waste form disintegrated shortly after being placed in the leach solution and yet the average fractional release rate of picolinic acid from this waste form specimen is the same as the
Indian Point-3 sample, which maintained structural stability throughout the leach test. These data suggest that the structural stability of the waste form does not significantly affect the fractional release rate of picolinic acid from the waste form. However, as noted, the fractional release rate of picolinic acid was about $20 \%$ of that from the degraded FitzPatrick waste form; however, this difference in release rate may be due to other factors besides the decomposition of the FitzPatrick waste form (e.g., the gel formation associated with the waste form). As discussed below, the average absolute release rates for the Peach Bottom-3 and FitzPatrick samples were statistically the same, which suggests that chemical mechanisms may have limited the release rates of picolinic acid from the waste forms rather than differences in the structural stability of the waste forms. The weighted-average fractional release rate of picolinic acid for all LOMI waste forms is $2.8 \pm 1.6 \times 10^{-9} \mathrm{~cm}^{-2} \cdot \mathrm{s}^{-1}$, which is a relatively small uncertainty because all the LOMI processes that were used differ significantly for the waste forms discussed.

In contrast to the average fractional release rate data listed in Table 13, the average absolute release rate data indicate similar release rates for FitzPatrick and Peach Bottom-3 and suggest that the decomposition of the FitzPatrick waste form did not affect the absolute release rate, which is the same as that for the intact waste forms. Also, the similarity of the average absolute release rates of picolinic acid for all LOMI samples indicates that inventory of picolinic acid in the waste form does not appear to affect the absolute release rates; therefore, the fractional release rates differ because of different inventories in the waste forms. The weighted average absolute release rate of picolinic acid for all waste forms is $6.0 \pm$ $5.0 \times 10^{-3} \mu \mathrm{g} / \mathrm{cm}^{2} \cdot \mathrm{s}^{1}$.

Figure 19 shows the CFR from the waste forms tested and indicates that 50 to $60 \%$ of the picolinic acid was released from the LOMI waste forms with the exception of the Peach Bottom-3 waste form, which had an average CFR of $2.0 \%$ (13\% if extrapolated to 90 days) for all samples tested, and that about $80 \%$ of the formic acid was 


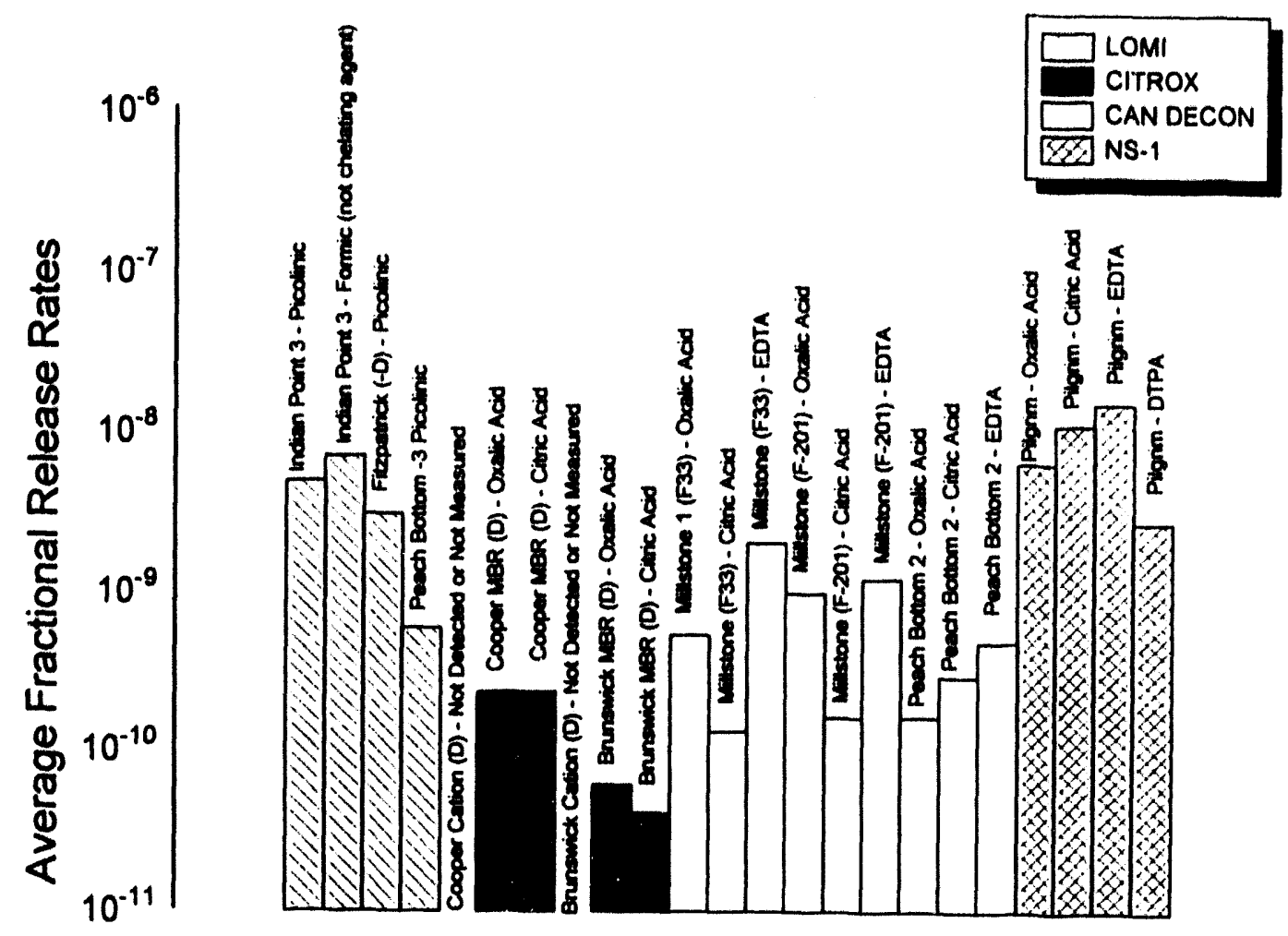

Flgure 18. Average fractional relebse rates of chelating agents $\left(\mathrm{cm}^{-2} \cdot \mathrm{s}^{-1}\right)$.

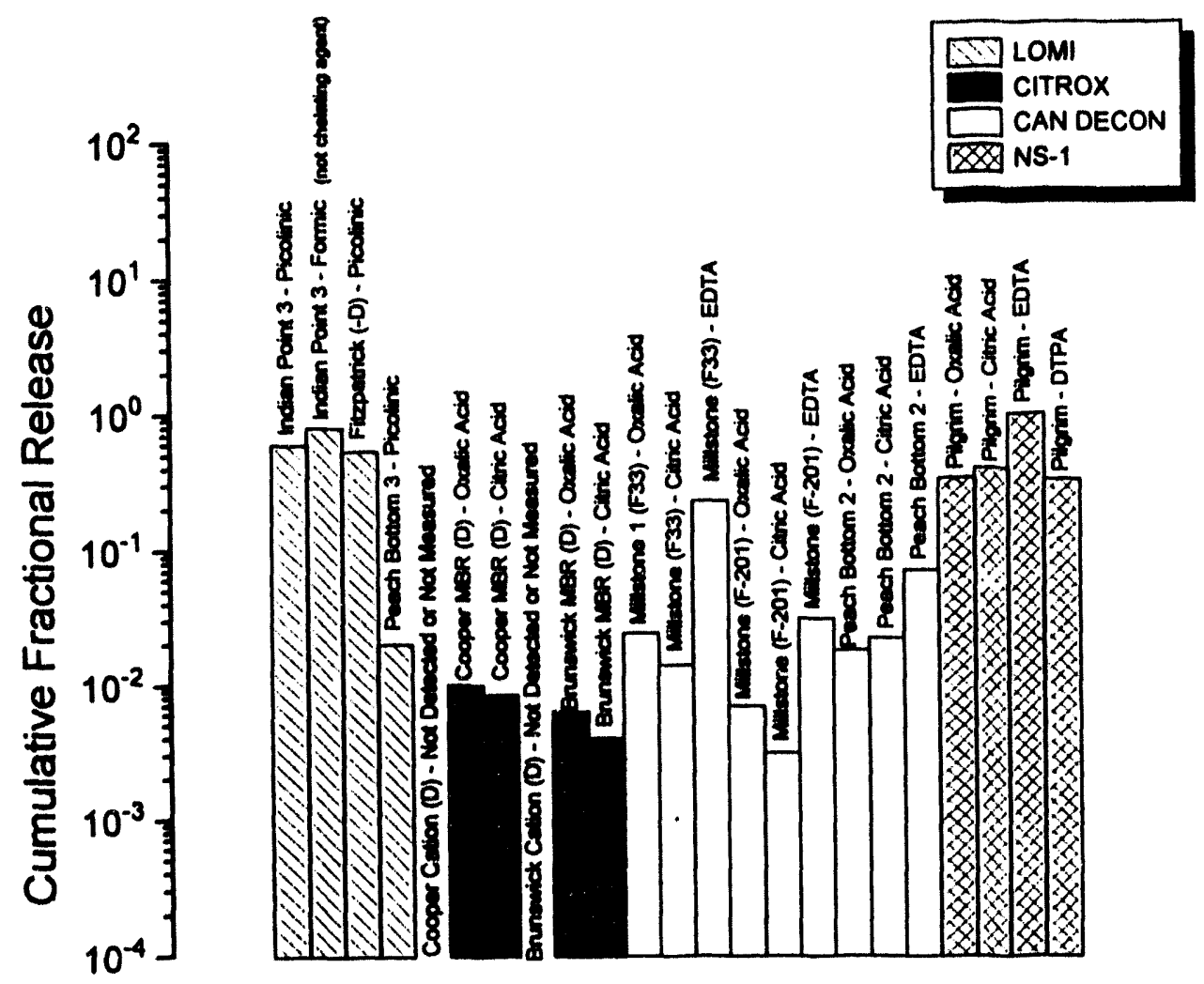

Figure 19. Cumulative fractional release of chelating agents. 
released from the Indian Point-3 waste form. These data contrast with the laboratory studies performed by Piciulo 22 in which the CFR of picolinic acid from the LOMI waste forms was 0.12 to 0.20 . In addition, the CFR for formic acid in Piciulo's study was $\sim 0.3$. These data indicate that the laboratory cement-solidified decontamination ion-exchange waste forms may not accurately reproduce the waste compositions found in actual commercial nuclear power plant wastes and that, indeed, the commercial reactor wastes may contain constituents that enhance the release of picolinic acid from some waste forms (up to a factor of three). The fact that the CFR for'Peach Bottom-3 is considerably lower than that observed for other waste forms suggests that changes in the formulation of the waste form may have improved the leaching properties of the waste form. ${ }^{3}$

In contrast to the relatively high average fractional release rates for most LOMI waste forms, the AP/Citrox waste forms (i.e., Cooper and Brunswick-1) had average fractional release rates of oxalates and citrates that ranged from $4 \times 10^{-11}$ to $2.3 \times 10^{-10} \mathrm{~cm}^{-2} \cdot \mathrm{s}^{-1}$ as shown in Table 13 and Figure 18. As shown in Table 13, the average fractional release rates of oxalates and citrates from each plant were the same. These data indicate that both chelating agents are released at statistically the same rate from the AP/ Citrox waste forms. The error-weighted average fractional release rates of oxalate and citrate acids from the AP/Citrox waste forms is $5.7 \pm$ $1.9 \times 10^{-11} \mathrm{~cm}^{-2} \cdot \mathrm{s}^{-1}$.

A comparison of the average fractional release rates of citrate and oxalate from the Citrox waste forms with the inventory data in Table 11 indicates that the release rates from the waste form do not appear to depend on the concentration of the citrate in the waste form as the concentration of citrate in the Cooper mixed-bed resin waste form was $0.2 \%$ of the concentration in the Brunswick-1 mixed-bed resin waste form, and yet the fractional release rates are within a factor of six. These data suggest that releases from the waste forms are controlled by factors other than strict diffusion. The weighted-average absolute release rate of oxalate and citrate (based on the Brunswick-1 waste form) is $1.8 \pm 0.6 \times 10^{-4}$ $\mu \mathrm{g} / \mathrm{cm}^{2} \cdot \mathrm{s}^{1}$.

The CFRs for the AP/Citrox waste forms are shown in Figure 19 and indicate that the CFRs for oxalate and citrate are similar for both Cooper and Brunswick at about $7 \times 10^{-3}$, which is about $1 \%$ of the release of picolinic acid from the LOMI waste forms. Piciulo, 22 in his study, indicated that oxalate was measured at low levels in two samples and that no release of citrate ion was measured. These data indicate that oxalate and citrate are substantially retained in the waste form as the CFR of both constituents was limited to about $0.7 \%$ of the inventory in the waste form and yet both the Cooper and Brunswick-1 waste forms decomposed.

The Can-Decon waste forms from Millstone-1 and Peach Bottom-2 contain the chelating agents oxalic and citric acid and EDTA. Inspection of Table 13 and Figure 18 indicates that the fractional release rates of oxalate and citrate from the three waste forms are similar and range from 1.6 to $9.6 \times 10^{-10} \mathrm{~cm}^{-2} \cdot \mathrm{s}^{-1}$. The error-weighted average fractional release rate of the oxalate and citrate is $4.7 \pm 0.8 \times 10^{-10} \mathrm{~cm}^{-2} \cdot \mathrm{s}^{-1}$. In contrast, the average fractional release rate of EDTA is statistically higher for the Millstone-1 samples at about $1.6 \times 10^{-9} \mathrm{~cm}^{-2} \cdot \mathrm{s}^{-1}$.

The EDTA probably has a higher average fractional release rate, but the difference is probably statistically insignificant if all uncertainties are included. These data indicate that the average fractional release rates of the chelating agents from the Can-Decon waste forms are about a factor of eight higher than those measured for the AP/Citrox waste forms. This suggests that citrate and oxalate are retained to a lesser extent in the Can-Decon waste form as compared to the Citrox waste form and suggests different mechanisms for retention in the waste form as the Can-Decon waste forms remained intact during the leach test and the Citrox waste forms decomposed. Notably, as shown in Table 13, the Brunswick-1 mixed-bed resin samples that decomposed had the lowest average fractional release rates of chelating 
agents from both the AP/Citrox and Can-Decon samples.

In contrast to the oxalate and citrate results, as noted previously, the average fractional release rates of EDTA from the Millstone-1 and Peach Bottom-2 waste forms are higher (about $1 \times 10^{-9}$ $\left.\mathrm{cm}^{-2} \cdot \mathrm{s}^{-1}\right)$. This rate is statistically the same as that messured for picolinic acid for the LOMI samples $\left(2.8 \pm 1.6 \times 10^{-9} \mathrm{~cm}^{-2} \cdot \mathrm{s}^{-1}\right)$ and suggests similar behavior for this chelating agent.

In contrast to the average fractional release rates for the Can-Decon waste fornns, the average absolute release rates for oxalate, citrate, and EDTA as shown in Table 13 are all within the range from $2 \times 10^{-4}$ to $7 \times 10^{-4} \mu \mathrm{g} / \mathrm{cm}^{2} \cdot \mathrm{s}^{1}$, with the exception of the citric acid from the Millstone-1 F-201 and F-33 samples at 5 to $7 \times 10^{-5}$ $\mu \mathrm{g} / \mathrm{cm}^{2} \cdot \mathrm{s}^{1}$. These data indicate a very narrow range of absolute release rates for the Can-Decon waste forms. The weighted-average absolute re'ease rate of oxalate and citrate is $8.8 \pm$ $3.2 \times 10^{-4} \mu \mathrm{g} / \mathrm{cm}^{2} \cdot \mathrm{s}^{1}$ and suggests that the absolute release rates are very similar because they are probably near a maximum diffusion rate in concrete for citrate and oxalate.

An inspection of the CFRs for the Can-Decon waste forms, however, indicates that the releases for the Millstone-1 and Peach Bottom-2 waste forms are less than those observed for the LOMI waste forms. The average CFRs for oxalic and citric acid are $1.6 \times 10^{-2}$ and $1.3 \times 10^{-2}$, respectively, whereas the average CFR for EDTA is $1.3 \times 10^{-1}$ or about a factor of 10 higher than the oxalic acid and citric acid CFRs. Piciulo, 22 Soo, 29 and Vejmelka ${ }^{50}$ all measured CFRs for EDTA in the range of $0.01-0.02$, which is similar to those measured in this study. This suggests that the CFR of EDTA is relatively independent of variations in waste-form constituents and that the release rates developed as part of this study are probably representative for most waste forms containing the chelating agent EDTA.

Inspection of the Pilgrim (NS-1) data in Figure 18 indicates average fractional release rates for oxalic acid, citric acid, EDTA, and DTPA that are higher than those observed for other waste forms. Typically, the average fractional release rate for these chelating agents from this intact waste form ranged from $3.0 \times 10^{-9}$ to $1.7 \times 10^{-8} \mathrm{~cm}^{-2} \cdot \mathrm{s}^{-1}$ and are considerably higher than those observed for other decontamination wastes. Further, the CFRs for this waste form are much higher as shown in Figure 19. Essentially all of the EDTA was released, and 30 to $40 \%$ of the oxalate, citrate and DTPA was released. These data suggest considerably greater releases from this waste form than those observed for the other three types of waste forms. No explanation for the behavior of this waste form has been identified.

Table 13 and Figures 20 and 21 show the average effective diffusivities and the leachability indexes for the LOMI and other waste forms. With the exception of Peach Bottom-3, the average effective diffusivities of picolinic acid for the LOMI waste forms have an average of $2.5 \times 10^{-7} \mathrm{~cm}^{2} \cdot \mathrm{s}^{-1}$ and indicate that the rates are similar for the intact and decomposed waste forms. The leachability indexes range from 6.9 to 9.3. In Piciulo's laboratory study, ${ }^{23}$ his measured leachability indexes ranged from 8.6 to 9.1 , which is indicative of the lower release rates he measured from the simulated waste forms. In addition, his leachability indexes for formic acid ranged from 8.0 to 8.6 , whereas the leachability index for formate from the Indian Point- 3 waste form was 6.7.

In contrast to the LOMI waste form results, the average effective diffusivities of oxalate and citrate from the Citrox waste forms are lower, as would be expected based on the lower average fractional release rates discussed previously. Also, the average effective diffusivities for the Cooper specimens may have a greater degree of uncertainty as a calculated surface/volume ratio was chosen for the calculation of effective diffusivities for these waste forms, which decomposed during leaching (Reference 1). This results in average effective diffusivities $4.6 \times 10^{-10}$ $\mathrm{cm}^{2} \cdot \mathrm{s}^{-1}$, which are about an order or magnitude greater than those for the Brunswick specimens $\left(1.8 \times 10^{-11} \mathrm{~cm}^{2} \cdot \mathrm{s}^{-1}\right)$. Leachability indexes for 
Experimental Results and Discussion

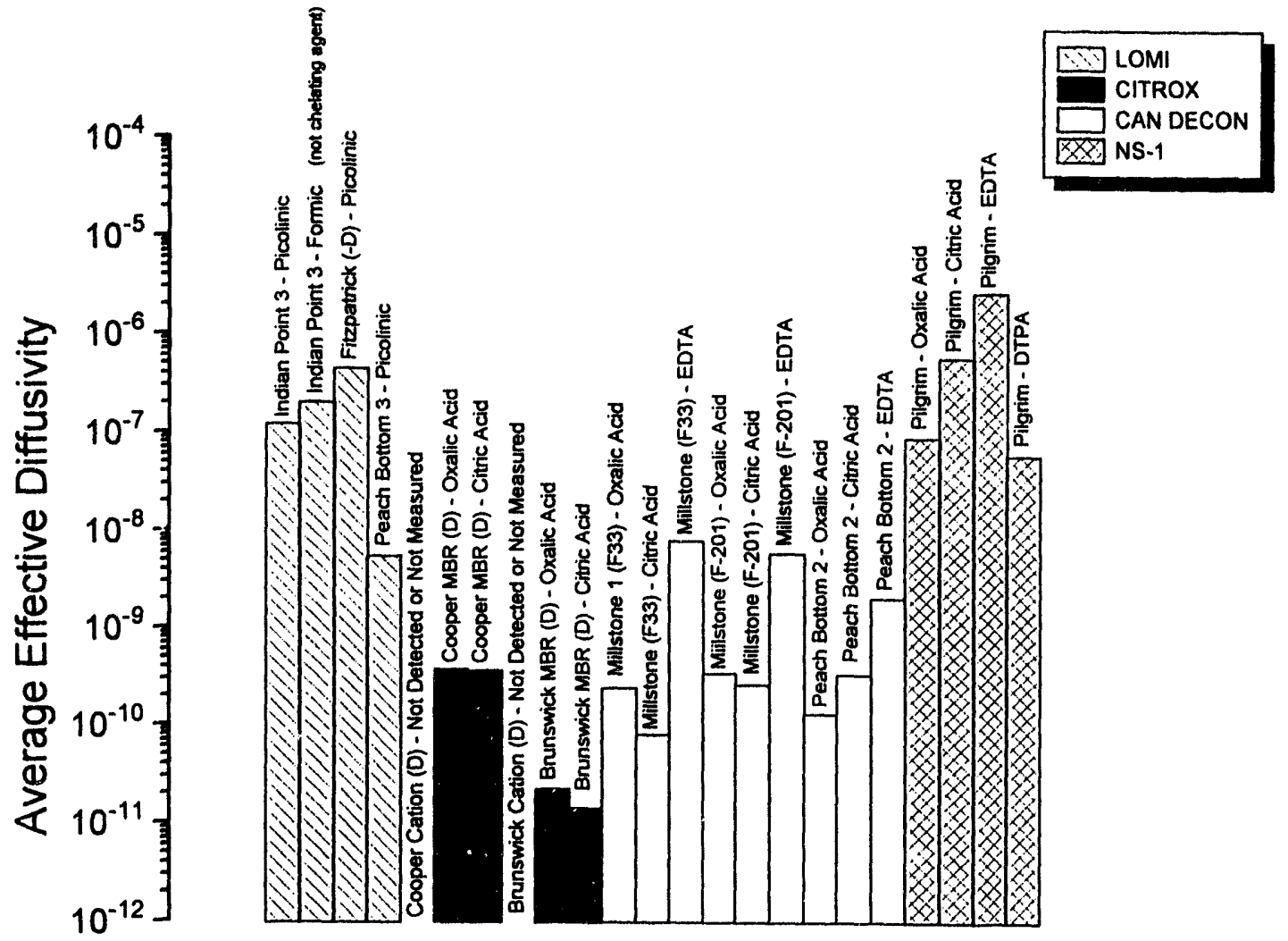

Figure 20. Effective diffusivity for chelating agents $\left(\mathrm{cm}^{2} \cdot \mathrm{s}^{-1}\right)$.

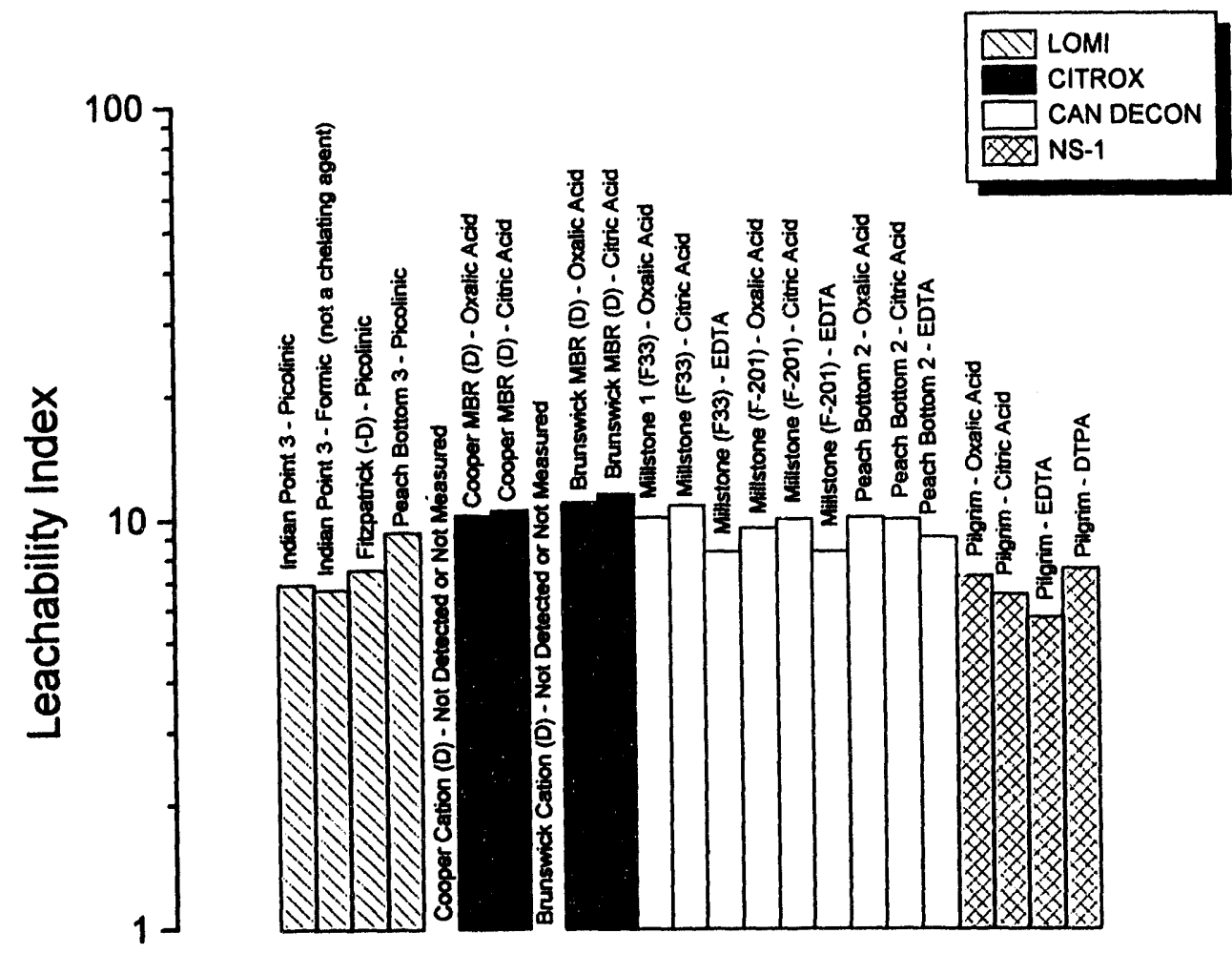

Figure 21. Leachability indexes for chelating agents. 
the Citrox samples range from 10.2 to 11.5 . Piciulo $^{23}$ measured leachability indexes for citrate and oxalate that ranged from 10.2 to 10.4.

The average of the effective diffusivities for the Can-Decon specimens are oxalate $\left(3.3 \times 10^{-10} \mathrm{~cm}^{2} \cdot \mathrm{s}^{-1}\right)$, citrate $\left(2.2 \times 10^{-10}\right.$ $\left.\mathrm{cm}^{2} \cdot \mathrm{s}^{-1}\right)$, and EDTA $\left(4.9 \times 10^{-9} \mathrm{~cm}^{2} \cdot \mathrm{s}^{-1}\right)$, as shown in Figure 20. These diffusivities follow the changes shown for the average fractional release rates. The average effective diffusivities for EDTA vary, but they are about an order of magnitude higher than the average effective diffusivity of the oxalate and citrate. As shown in Figure 21, the leachability indexes for oxalate and citrate range from 10.0 to 10.8 , whereas the EDTA leachability indexes range from 8.3 to 9.0 . Piciulo $^{23}$ had leachability indexes for EDTA from 10.1 to 10.6 , which suggests that the actual waste form tends to have higher release rates by several orders of magnitude as discussed previously.

For the Dow NS-1 sample, average fractional release rates are higher than those for the other waste forms tests and, consequently, the average effective diffusivities range from $2.6 \times 10^{-6} \mathrm{~cm}^{2} \cdot \mathrm{s}^{-1}$ for EDTA to about $5.7 \times 10^{-8} \mathrm{~cm}^{2} \cdot \mathrm{s}^{-1}$ for DTPA. The leachability indexes ranged from 5.7 to 7.5 . These leachability indexes are considerably lower than those observed in Piciulo's tests, which were not performed on NS-1 decontamination process formulations, but were performed on some of the same chelating agents. This again suggests that actual decontamination process and waste-form constituents may affect leach rates.

Radionuclldes. The releases of radionuclides from the cement-solidified waste forms is dependent not only on the physical and chemical characteristics of the waste form but on the chemistry of the radionuclide. Of the radionuclides measured in this study, the chemistry of the cationic ${ }^{137} \mathrm{Cs}$ and anionic ${ }^{129} \mathrm{I}$ are the simplest because they typically form salts as a solid and are ionic in solution. ${ }^{57}$ In contrast, ${ }^{55} \mathrm{Fe}, \mathrm{Co}^{60}$, and ${ }^{63} \mathrm{Ni}$ are transition metals and form coordination complexes (i.e., complex hybrid bonds between metals and anions, cations, or mole- cules) with chelating agents that keep these metals in solution and, consequently, potentially increase their mobility and possibly their release rates from the waste form. Other radionuclides discussed in this study, ${ }^{14} \mathrm{C},{ }^{99} \mathrm{Tc},{ }^{129} \mathrm{I}$ and ${ }^{241} \mathrm{Pu}$, have varying chemical characteristics that are discussed.

Cesilum-137. Table 14 summarizes the CFRs, average release rates, average effective diffusivities, and leachability indexes for ${ }^{137} \mathrm{Cs}$ for the samples leach tested in deionized water. Typically, CFRs are high (0.2 to 1.0$)$ with the exception of the Brunswick-1 cation resin sample and the Pilgrim waste form; average release rates and diffusivities are variable; and the leachability indexes are among the lowest measured for any radionuclide. These effects are most likely due to the low concentrations of this fission product in most waste forms and the simple anionic characteristics of the radionuclide in solution. The average fractional release rates and CFR of ${ }^{137} \mathrm{Cs}$ are shown in Figures 22 and 23, respectively. The release behavior of this radionuclide is being discussed first because studies ${ }^{50,58}$ indicate that the release of ${ }^{137} \mathrm{Cs}$ is representative of fast diffusional release from the waste form because of its high solubility. Further, similarities in the release rates of ${ }^{137} \mathrm{Cs}$ and EDTA have been identified.

As shown in Table 14, the average fractional release rates of ${ }^{137} \mathrm{Cs}$ from the LOMI waste forms from Indian Point-3 and FitzPatrick are 5.6 and $5 \times 10^{-9} \mathrm{~cm}^{-2} \cdot \mathrm{s}^{-1}$ and, as shown in Table 14 , they are statistically the same, which suggests that the integrity of the waste form does not affect the release of this radionuclide. The fact that the fractional release rates of ${ }^{137} \mathrm{Cs}$ are the same for both Indian Point-3 and FitzPatrick might not be expected because the waste stream composition would be expected to be different for the waste forms as Indian Point-3 is a PWR that had the steam generator channel head decontaminated, and FitzPatrick is a BWR that had the PCRS decontaminated.

The error-weighted average fractional release rate of ${ }^{137} \mathrm{Cs}$ from the LOMI waste forms is $\mathbf{5 . 1}$ $\pm 2.1 \times 10^{-9} \mathrm{~cm}^{-2} \cdot \mathrm{s}^{-1}$, which is statistically 
Table 14. Cesium-137 release rates, cumulative fractional releases, effective diffusivities, and leachability indexes.

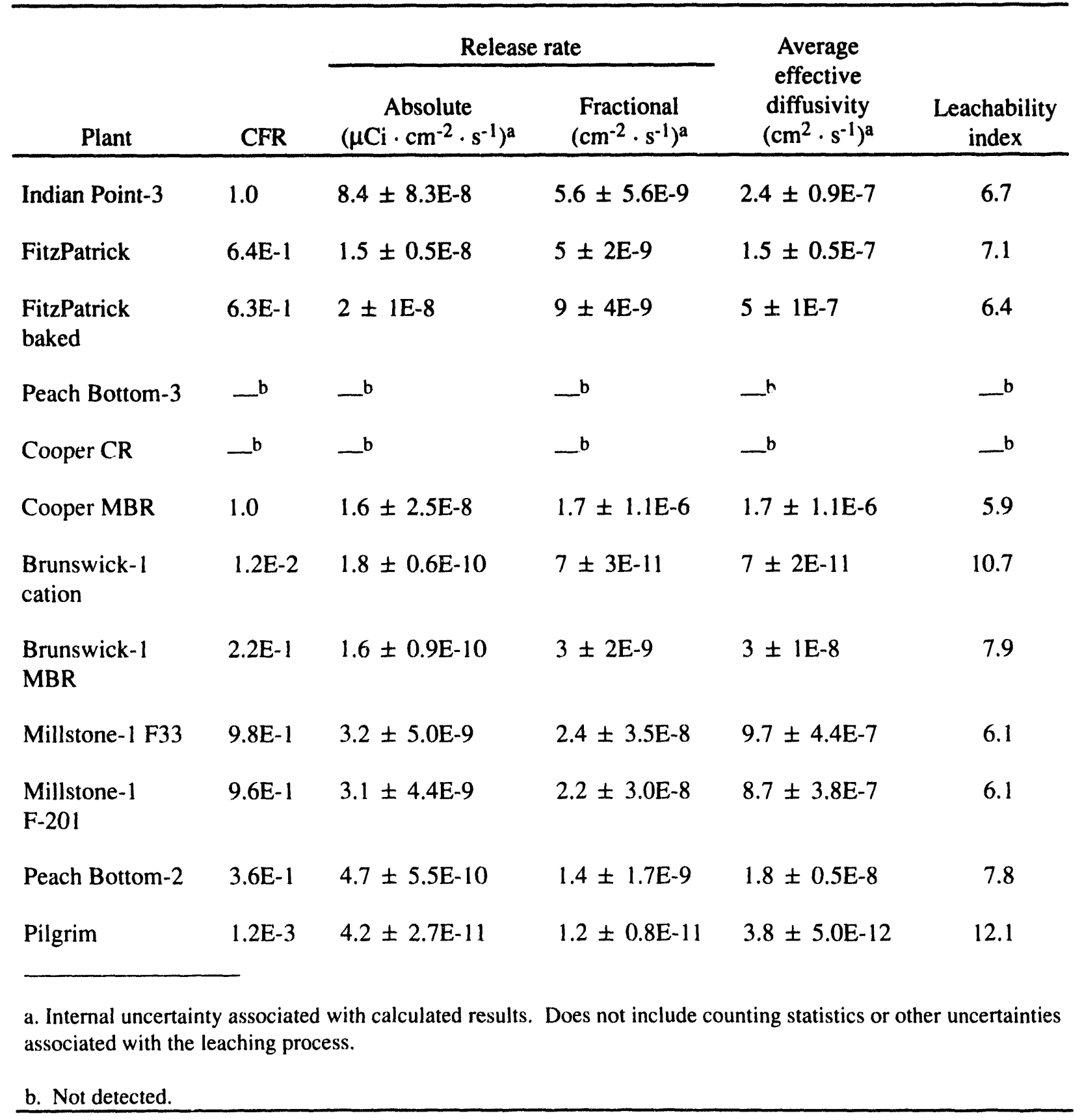

the same as that of picolinic acid $\left(\sim 1.5 \times 10^{-9}\right.$ $\left.\mathrm{cm}^{-2} \cdot \mathrm{s}^{-1}\right)$ and formic acid $\left(6.2 \times 10^{-9} \mathrm{~cm}^{-2} \cdot \mathrm{s}^{-1}\right)$ as shown in Table 13. These data suggest that the ${ }^{137} \mathrm{Cs}$ is released at the same fractional release rates as the chelating agents, and the release is probably primarily controlled by diffusion and the high solubility of ${ }^{137} \mathrm{Cs}$. De Angelis'56 experiments indicate that ${ }^{137} \mathrm{Cs}$ is strictly diffu- sion controlled. Consequently, the diffusion rate out of the LOMI waste form can be defined as approximately $5 \times 10^{-9} \mathrm{~cm}^{-2} \cdot \mathrm{s}^{-1}$.

As shown in Table 14, average absolute release rates of ${ }^{137} \mathrm{Cs}$ from the Indian Point- 3 and FitzPatrick waste forms were $8.4 \times 10^{-8} \mu \mathrm{Ci} / \mathrm{cm}^{2} \cdot \mathrm{s}^{1}$ 


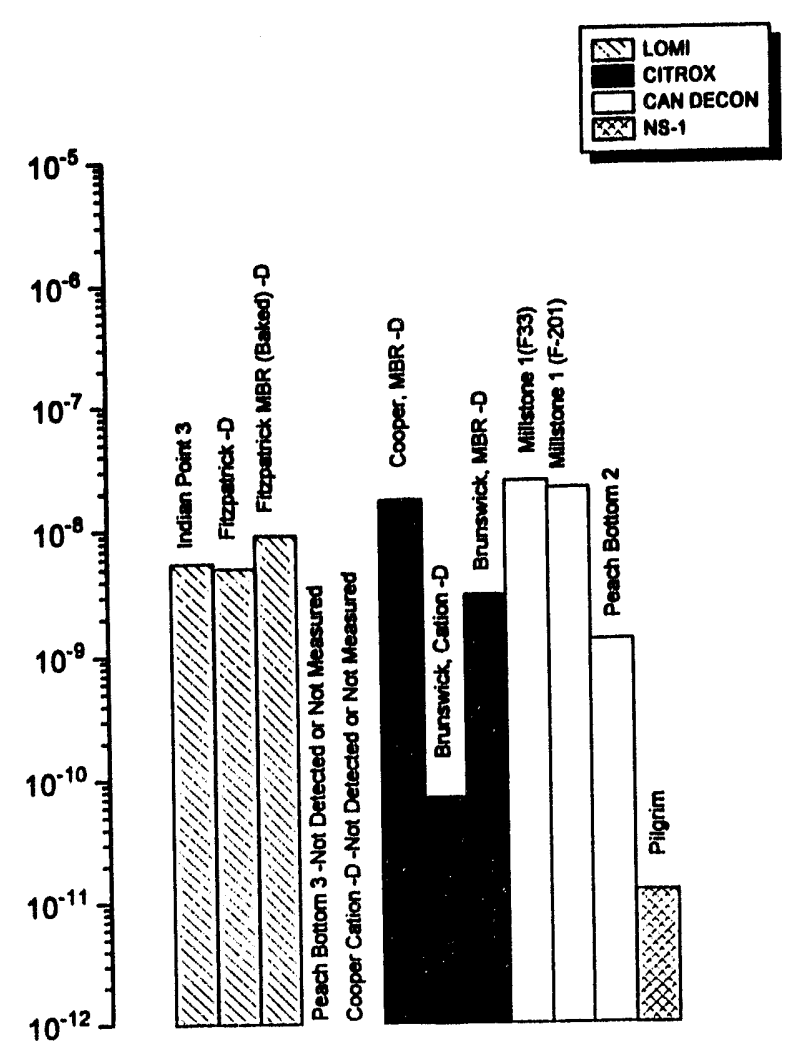

Figure 22. Cesium-137 average fractional release rates $\left(\mathrm{cm}^{-2} \cdot \mathrm{s}^{-1}\right)$.

and $1.5 \times 10^{-8} \mu \mathrm{Ci} / \mathrm{cm}^{2} \cdot \mathrm{s}^{1}$, respectively. The weighted-average fractional release rate is $1.9 \pm$ $0.6 \times 10^{-8} \mu \mathrm{Ci} / \mathrm{cm}^{2} \cdot \mathrm{s}^{1}$ because of the large uncertainty associated with the Indian Point-3 absolute release rate. These data indicate that, statistically, the average absolute release rate from the intact waste form is greater than or the same as that from the one that degraded during leach testing. These data further support the conclusion that waste-form structural stability does not significantly affect leach rates.

As shown in Figure 23, the CFRs indicate that essentially all ${ }^{137} \mathrm{Cs}$ was leached out of the Indian Point -3 waste form, whereas only $64 \%$ was leached out of the FitzPatrick waste form, although the FitzPatrick waste form was the one that decomposed during leach testing and contained a gelatinous material. These CFRs are higher than those observed in several laboratory studies $^{50,56,59,60,61}$ where typical CFRs for simulated LOMI waste forms were on the order of 0.3

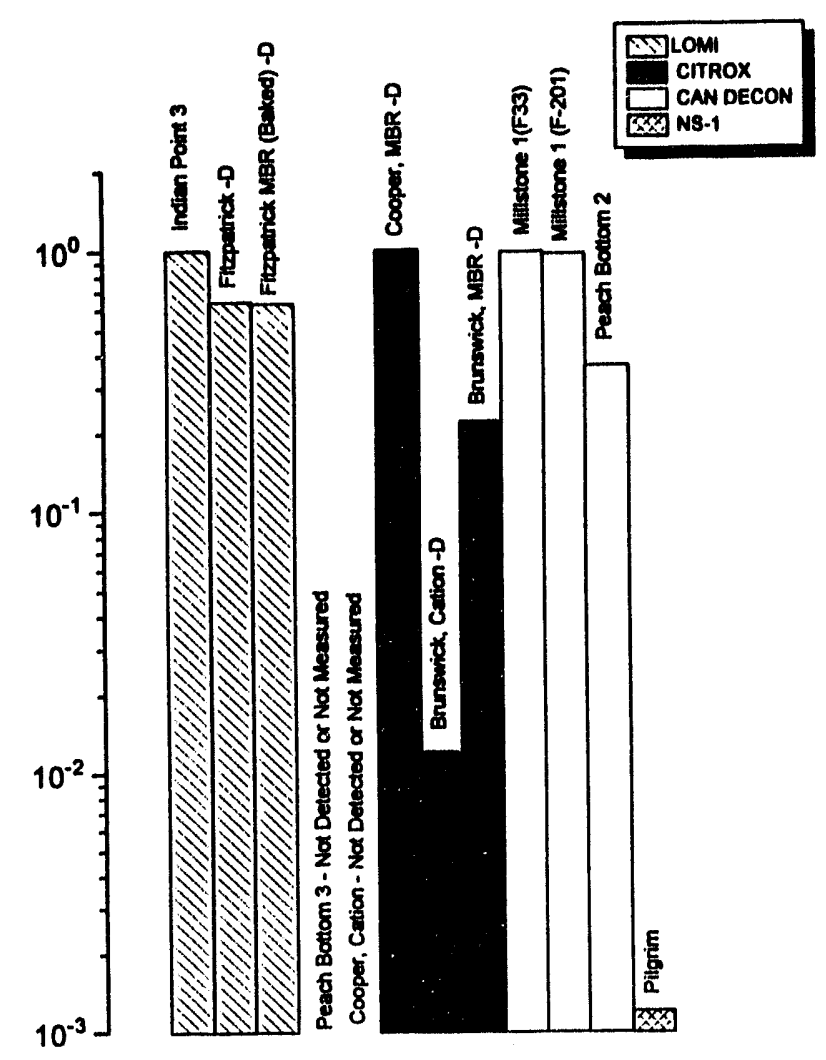

Figure 23. Cesium-137 cumulative fractional release.

to 0.4 . These data suggest that the CFRs from actual waste forms are greater than the laboratory-prepared specimens by a factor of two to three. Matsuzuru $^{61}$ has suggested that the presence of pozzolonics (e.g, blast furnace slag) may reduce releases of ${ }^{137} \mathrm{Cs}$, although ion-exchange resins were not used in his study. Our study indicates that pozzolonics may reduce release rates and CFRs from actual cement-solidified waste forms because the Indian Point-3 waste form contained no pozzolonic material and yet both the average fractional release rate and the CFR of ${ }^{137} \mathrm{Cs}$ from this waste form is higher than that for the waste form that contained pozzolona (i.e, FitzPatrick).

As shown in Figure 22, the average fractional release rates of ${ }^{137} \mathrm{Cs}$ from the $\mathrm{AP} / \mathrm{Citrox}$ waste forms range over three orders of magnitude, with the Cooper mixed-bed resin waste form having the highest average fractional release rate $\left(1.6 \times 10^{-6} \mathrm{~cm}^{-2} \cdot \mathrm{s}^{-1}\right)$ of the AP/Citrox samples. The weighted-average fractional release rate of 
${ }^{137} \mathrm{Cs}$ from the AP/Citrox waste forms is $6.1 \pm$ $2.8 \times 10^{-9} \mathrm{~cm}^{-2} \cdot \mathrm{s}^{-1}$. The Brunswick-1 cation resin waste-form data have not been included in this average because that waste form does not contain chelating agents and is addressed separately for most radionuclides. If included, the weighted average is $1.6 \pm 0.5 \times 10^{-10} \mathrm{~cm}^{-2} \cdot \mathrm{s}^{-1}$. A comparison with the weighted-average fractional release rates of citrate and oxalate $\left(5.7 \times 10^{-11} \mathrm{~cm}^{-2} \cdot \mathrm{s}^{-1}\right)$ with that for ${ }^{137} \mathrm{Cs}$ indicates that the ${ }^{137} \mathrm{Cs}$ leaches out of the AP/Citrox waste form faster than do the chelating agents, oxalate and citrate, by a factor of $\sim 100$; however, the release rate of ${ }^{137} \mathrm{Cs}$ from the Brunswick-1 cation resin waste form is similar to that of the chelating agents. These data suggest that the chelating agents, oxalate and citrate, are held up in the waste form and are not released purely via diffusion, but that solubility may be limiting the release rate. It is further interesting to note that the weighted-average fractional release rate of ${ }^{137} \mathrm{Cs}$ from the AP/Citrox waste forms is the same as that for the LOMI waste forms.

The weighted-average absolute release rate of ${ }^{137} \mathrm{Cs}$ from the AP/Citrox waste forms is $2.2 \pm$ $1.2 \times 10^{-10} \mu \mathrm{Ci} / \mathrm{cm}^{2} \cdot \mathrm{s}^{1}$ and is about $10^{2}$ less than that of ${ }^{137} \mathrm{Cs}$ for the LOMI waste forms. These data further indicate that there is a maximum diffusion rate, as noted previously, and that most species, including ${ }^{137} \mathrm{Cs}$, may be affected by chemical interactions in the waste forms as evidenced by the substantially slower rate from the AP/Citrox waste forms.

The CFRs for ${ }^{137}$ Cs shown in Figure 23 and Table 14 indicate that all of the ${ }^{137} \mathrm{Cs}$ was leached from the Cooper mixed-bed resin waste form and that about $22 \%$ leached from the Brunswick mixed-bed resin waste form. These are higher CFRs than those of the chelating agents, oxalic and citric acid $(\sim 0.4 \%)$ for the AP/Citrox waste forms, which again indicates that this radionuclide leaches more quickly than the chelating agents. These data suggest that the chelating agents are being retained in the waste form to a greater extent than the ${ }^{137} \mathrm{Cs}$, probably due to lower solubilities than the extremely soluble ${ }^{137} \mathrm{Cs}$.
The average fractional release rates of ${ }^{137} \mathrm{Cs}$ from the Can-Decon waste forms are shown in Figure 22, and the rates range from $1 \times 10^{-9}$ to $2 \times 10^{-8} \mathrm{~cm}^{-2} \cdot \mathrm{s}^{-1}$. The weighted-average fractional release rate of ${ }^{137} \mathrm{Cs}$ is $3.5 \pm 2.7 \times 10^{-9}$ $\mathrm{cm}^{-2} \cdot \mathrm{s}^{-1}$, which is statistically higher than the weighted-average fractional release rate of ${ }^{137} \mathrm{Cs}$ from the AP/Citrox waste forms but lower than those from the LOMI waste forms. These differences suggest chemical effects that reduce the mobility of the ${ }^{137} \mathrm{Cs}$ to rates lower than would be expected from pure diffusion. Again, the average fractional release rates of ${ }^{137} \mathrm{Cs}$ from the CanDecon waste forms are higher than those for the chelating agents (by about a factor of 100) and again suggests that the chelating agents are being retained in the Can-Decon waste form due to chemical interactions with the waste-form material or as suggested by Vejmelka ${ }^{50}$ possible breakdown of the chelating agent. The weighted-average absolute release rate of ${ }^{137} \mathrm{Cs}$ from the Can-Decon waste forms is $9.8 \pm$ $7.7 \times 10^{-10} \mu \mathrm{Ci} / \mathrm{cm}^{2} \cdot \mathrm{s}^{1}$, which is statistically the same as that of ${ }^{137} \mathrm{Cs}$ from the LOMI and AP/ Citrox waste forms.

Examination of Figure 23 and Table 14 indicates that almost all ( $>95 \%$ of the cesium) was released from the Millstone waste forms and about $6.5 \%$ from the Peach Bottom-2 waste form. This is reflected in the differences in the average fractional release rates.

Examination of the Pilgrim NS-1 results shown in Figures 22 and 23 indicates that the average fractional release rate of ${ }^{137} \mathrm{Cs}$ from this waste form is approximately $1.2 \times 10^{-11} \mathrm{~cm}^{-2} \cdot \mathrm{s}^{-1}$ and that the CFR is about 0.012 . This tends to be inconsistent with the ${ }^{137} \mathrm{Cs}$ data for other waste forms and the high release rates and releases of chelating agents from the Pilgrim waste form. Why the release of ${ }^{137} \mathrm{Cs}$ from this waste form is low is not known; no problems with the analysis were indicated in Reference 1.

The average effective diffusivities and leachability indexes for ${ }^{137} \mathrm{Cs}$ are shown in Figures 24 and 25 , respectively. Typically, the average effective diffusivities follow a pattern similar to the 


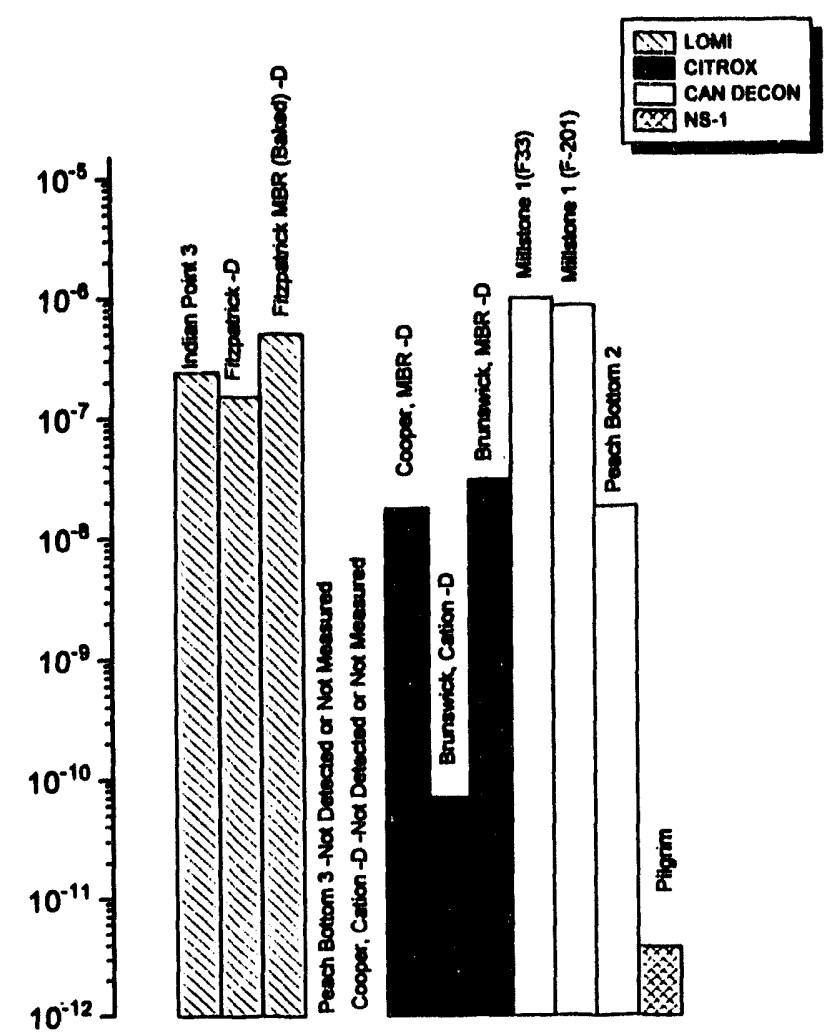

Figure 24. Cesium-137 effective diffusivity.

average fractional release rates, and the same discussion may be applied to both. The leachability indexes shown in Figure 25 indicate that the leachability indexes for ${ }^{137} \mathrm{Cs}$ for the LOMI, Citrox, and Can-Decon waste forms range from 5.8 to 7.9 with the exception of the Brunswick-1 cation resin (10.7). The reason for the high retention in this waste form is not known. However, the CFR from this waste form is only $1.2 \%$ of the ${ }^{137} \mathrm{Cs}$ inventory and is indicative of anomalous behavior. It also should be noted that this is the only waste form of those tested that does not contain a chelating agent, although no correlation between this fact and the low release rates is apparent. The leachability index for ${ }^{137} \mathrm{Cs}$ from the Dow NS-1 (Pilgrim) specimen is also anomalously high as were the average fractional release rates (see above).

Principal observations from the ${ }^{137} \mathrm{Cs}$ analysis are that the weighted-average fractional release rates of ${ }^{137} \mathrm{Cs}$ from the LOMI, AP/Citrox, and Can-Decon waste forms are statistically the same

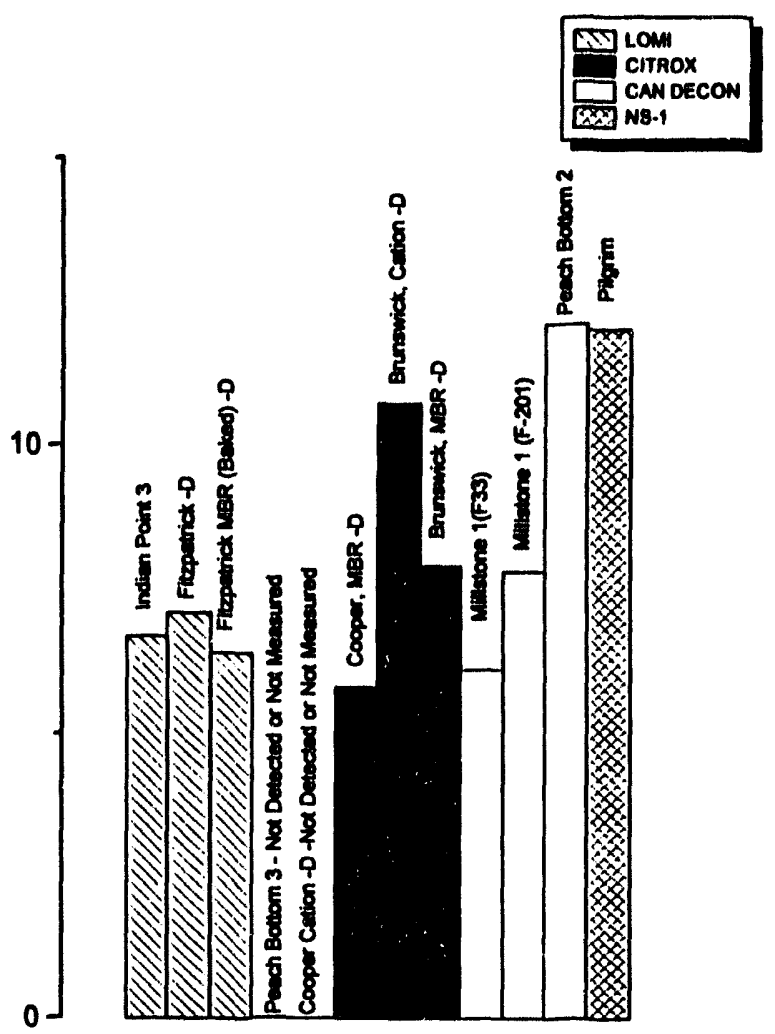

Figure 25. Cesium-137 leachability indexes.

$\left(4.6 \pm 1.4 \times 10^{-9} \mathrm{~cm}^{-2} \cdot \mathrm{s}^{-1}\right)$, although the absolute rates are different. Further, the weightedaverage fractional release rates of ${ }^{137} \mathrm{Cs}$ from the waste forms are the same as picolinic acid from the LOMI waste form, which suggests a maximum diffusional release rate of about $5 \times 10^{-9}$ $\mathrm{cm}^{-2} \cdot \mathrm{s}^{-1}$ for these waste forms. In contrast, the weighted-average fractional release rates of ${ }^{137} \mathrm{Cs}$ are about 100 times higher than the chelating agents, oxalate and citrate, from the AP/Citrox and Can-Decon waste forms, which suggests that these chelating agents are being retained to a greater extent in the anion resin or that they have lower solubilities than ${ }^{137} \mathrm{Cs}$.

Transition Metal Radionuclides. Tables 15 to 17 summarize the CFRs, average release rates, average effective diffusivities, and leachability indexes for the transition metal radionuclides ${ }^{60} \mathrm{Co},{ }^{55} \mathrm{Fe}$, and ${ }^{63} \mathrm{Ni}$. Typical CFRs for the transition metals $\left(10^{-2}\right.$ to $\left.10^{-4}\right)$ are generally lower than the chelates or ${ }^{137} \mathrm{Cs}$. In addition, the average absolute releases for the transition metal 
Table 15. Cobalt-60 release rates, cumulative fractional releases, effective diffusivities, and leachability indexes.

\begin{tabular}{|c|c|c|c|c|c|}
\hline \multirow[b]{2}{*}{ Plant } & \multirow[b]{2}{*}{ CFR } & \multicolumn{2}{|c|}{ Release rate } & \multirow{2}{*}{$\begin{array}{c}\text { Average } \\
\text { effective } \\
\text { diffusivity } \\
\left(\mathrm{cm}^{2} \cdot \mathrm{s}^{-1}\right)^{\mathrm{a}}\end{array}$} & \multirow[b]{2}{*}{$\begin{array}{c}\text { Leachability } \\
\text { index }^{\text {b }}\end{array}$} \\
\hline & & $\begin{array}{c}\text { Absolute } \\
\left(\mu \mathrm{Ci} \cdot \mathrm{cm}^{-2} \cdot \mathrm{s}^{-1}\right)^{\mathrm{a}}\end{array}$ & $\begin{array}{l}\text { Fractional } \\
\left(\mathrm{cm}^{-2} \cdot \mathrm{s}^{-1}\right)^{\mathrm{a}}\end{array}$ & & \\
\hline Indian Point-3 & $1.3 \mathrm{E}-3$ & $2.2 \pm 1.8 \mathrm{E}-9$ & $5.1 \pm 4.1 \mathrm{E}-12$ & $2.0 \pm 1.0 \mathrm{E}-13$ & 12.8 \\
\hline FitzPatrick & $1.7 \mathrm{E}-2$ & $5 \pm 1 \mathrm{E}-8$ & $7 \pm 2 E-11$ & $5 \pm 1 \mathrm{E}-11$ & 10.5 \\
\hline FitzPatrick baked & $2.2 \mathrm{E}-2$ & $1.0 \pm 0.4 \mathrm{E}-7$ & $1.4 \pm 0.6 \mathrm{E}-10$ & $8 \pm 2 E-11$ & 10.3 \\
\hline Peach Bottom-3 & $1.7 \mathrm{E}-3$ & $2.3 \pm 2.1 \mathrm{E}-8$ & $6.2 \pm 5.6 \mathrm{E}-11$ & $4.4 \pm 1.2 \mathrm{E}-12$ & 11.4 \\
\hline Cooper CR & $3.5 \mathrm{E}-4$ & $-^{c}$ & $8.1 \pm 23 \mathrm{E}-12$ & $3.6 \pm 10.7 \mathrm{E}-12$ & 14.2 \\
\hline Cooper MBR & $7.8 \mathrm{E}-4$ & $-^{c}$ & $3.0 \pm 7.7 \mathrm{E}-9$ & $4.9 \pm 12.6 \mathrm{E}-12$ & 12.8 \\
\hline Brunswick-1 CR & $8.5 \mathrm{E}-5$ & $1.9 \pm 0.5 \mathrm{E}-10$ & $4 \pm 1 E-13$ & $1.0 \pm 0.5 \mathrm{E}-14$ & 15.3 \\
\hline $\begin{array}{l}\text { Brunswick-1 } \\
\text { MBR }\end{array}$ & $1.3 \mathrm{E}-3$ & $4 \pm 2 \mathrm{E}-10$ & $2 \pm 1 \mathrm{E}-11$ & $2 \pm 2 \mathrm{E}-12$ & 13.2 \\
\hline Millstone-1 F33 & $4.4 \mathrm{E}-4$ & $3.3 \pm 3.9 \mathrm{E}-9$ & $6.9 \pm 8.2 \mathrm{E}-12$ & $6.1 \pm 5.8 \mathrm{E}-14$ & 13.6 \\
\hline Millstone-1 F201 & $1.4 \mathrm{E}-3$ & $3.1 \pm 3.6 \mathrm{E}-9$ & $5.9 \pm 6.8 \mathrm{E}-12$ & $1.1 \pm 1.8 \mathrm{E}-13$ & 13.2 \\
\hline Peach Bottom-2 & $1.3 \mathrm{E}-3$ & $5.1 \pm 4.8 \mathrm{E}-9$ & $3.8 \pm 3.5 \mathrm{E}-12$ & $1.6 \pm 0.5 \mathrm{E}-13$ & 12.8 \\
\hline Pilgrim & $5.1 \mathrm{E}-2$ & $3.4 \pm 4.0 \mathrm{E}-7$ & $5.6 \pm 6.6 \mathrm{E}-10$ & $9.8 \pm 7.2 \mathrm{E}-10$ & 9.2 \\
\hline
\end{tabular}

a. Internal uncertainty associated with calculated results. Does not include counting statistics or other uncertainties associated with the leaching process.

b. Average values were calculated excluding zeros.

c. Not detected or not measured.

radionuclides, which typically range from about $10^{-10}$ to $10^{-8} \mu \mathrm{Ci} / \mathrm{cm}^{2} \cdot \mathrm{s}^{1}$, and the average fractional release rates, which range from about $10^{-12}$ to $10^{-10} \mathrm{~cm}^{-2} \cdot \mathrm{s}^{-1}$, are lower than those of ${ }^{137} \mathrm{Cs}$ by one to two orders of magnitude. Average effective diffusivities typically have a larger range (from $10^{-14}$ to $10^{-11} \mathrm{~cm}^{2} \cdot \mathrm{s}^{-1}$ ), and leachability indexes range over seven orders of magnitude $(9.2$ to 16$)$. These data indicate that, generally, the transition metal radionuclides are retained in the waste form to a greater extent than are ${ }^{137} \mathrm{Cs}$ and the chelating agents, although the release rates may be enhanced due to chelant effects. It has been suggested that without chelating agent effects, the transition metal radionuclides should be among the least mobile of the radionuclides found in commercial nuclear power plant waste streams. ${ }^{62,63}$ 
Table 16. Iron-55 release rates, cumulative fractional releases, effective diffusivities, and leachability

\begin{tabular}{|c|c|c|c|c|c|}
\hline & & Releas & e rate & Average & \\
\hline Plant & CFR & $\begin{array}{c}\text { Absolute } \\
\left(\mu \mathrm{Ci} \cdot \mathrm{cm}^{-2} \cdot \mathrm{s}^{-1}\right)^{\mathrm{a}}\end{array}$ & $\begin{array}{l}\text { Fractional } \\
\left(\mathrm{cm}^{-2} \cdot \mathrm{s}^{-1}\right)^{\mathrm{a}}\end{array}$ & $\begin{array}{l}\text { diffusivity } \\
\left(\mathrm{cm}^{2} \cdot \mathrm{s}^{-1}\right)^{\mathrm{a}} \\
\end{array}$ & $\begin{array}{c}\text { Leachability } \\
\text { index }^{\mathrm{b}}\end{array}$ \\
\hline Indian Point-3 & $1.6 \mathrm{E}-4$ & $1.4 \pm 2.8 \mathrm{E}-9$ & $7 \pm 15 \mathrm{E}-12$ & $5.0 \pm 10 \mathrm{E}-14$ & 14.6 \\
\hline FitzPatrick MBR & $6.1 \mathrm{E}-3$ & $7 \pm 5 \mathrm{E}-10$ & $7 \pm 5 \mathrm{E}-11$ & $3 \pm 2 \mathrm{E}-11$ & 11.6 \\
\hline FitzPatrick baked & $-^{c}$ & $-c$ & $\sim^{c}$ & $-\mathbf{c}$ & $-^{c}$ \\
\hline Peach Bottom-3 & $1.4 \mathrm{E}-3$ & $7.7 \pm 7.1 \mathrm{E}-10$ & $5.1 \pm 4.7 \mathrm{E}-11$ & $6.1 \pm 7.8 \mathrm{E}-12$ & 12.2 \\
\hline Cooper CR & $5.9 \mathrm{E}-2$ & $-c$ & $4.1 \pm 12.1 E-9^{d}$ & $1.2 \pm 3.5 \mathrm{E}-7$ & 10.3 \\
\hline Cooper MBR & $3.6 \mathrm{E}-3$ & $-^{c}$ & $8 \pm 12 E-11$ & $1 \pm 1.7 \mathrm{E}-10$ & 10.3 \\
\hline Brunswick-1 CR & $2.6 \mathrm{E}-4$ & $1 \pm 1 \mathrm{E}-9$ & $3 \pm 3 \mathrm{E}-12$ & $1 \pm 1 \mathrm{E}-13$ & 16 \\
\hline Brunswick-1 MBR & $1.1 \mathrm{E}-2$ & $1.3 \pm 0.5 \mathrm{E}-9$ & $6 \pm 3 E-11$ & $9 \pm 5 E-11$ & 11 \\
\hline Millstone-1 F33 & $-^{c}$ & $-^{c}$ & - $^{\mathbf{c}}$ & -c $^{c}$ & $-^{c}$ \\
\hline Millstone-1 F201 & $6.9 \mathrm{E}-5$ & $4.9 \pm 5.8 \mathrm{E}-9$ & $3.1 \pm 4.3 \mathrm{E}-12$ & $9.2 \pm 7.7 \mathrm{E}-15$ & 14.9 \\
\hline Peach Bottom-2 & -c & $-^{c}$ & $\sim^{c}$ & - $^{c}$ & -c $^{c}$ \\
\hline Pilgrim & $6.4 \mathrm{E}-6$ & $2.6 \pm 3.2 \mathrm{E}-10$ & $8 \pm 10 \mathrm{E}-13$ & $3.8 \pm 4.4 \mathrm{E}-16$ & 16.1 \\
\hline $\begin{array}{l}\text { a. Internal uncertain } \\
\text { associated with the }\end{array}$ & $\begin{array}{l}\text { ociated } \\
\text { ng proc }\end{array}$ & calculated resul & oes not include & ng statistics o & ertainties \\
\hline b. Average values we & calculated & excluding zeros. & & & \\
\hline c. Not detected or no & neasured. & & & & \\
\hline d. Anomalously hig & sult bas & single leach result. & & & \\
\hline
\end{tabular}

The average fractional release rates for the transition metal radionuclides ${ }^{60} \mathrm{Co},{ }^{55} \mathrm{Fe},{ }^{63} \mathrm{Ni}$, are shown in Figures 26 to 28. The transition metal radionuclides are being evaluated as a group to assess differences in the behavior of these radionuclides, which would be expected to behave similarly based on their chemistry and their ability to form coordination complexes with chelating agents.
Inspection of the average fractional release rates of ${ }^{60} \mathrm{Co},{ }^{55} \mathrm{Fe}$, and ${ }^{63} \mathrm{Ni}$ for the LOMI waste forms, as shown in Figures 26 through 28 and Tables 15 through 17, indicates that the average fractional release range over three orders of magnitude for the three radionuclides. However, some similarities are indicated. Initially, from Tables 15 through 17 , it is apparent that the average fractional release rates of all three radionuclides from 
Table 17. Nickel-63 release rates, cumulative fractional releases, effective diffusivities, and leachability indexes.

\begin{tabular}{|c|c|c|c|c|c|}
\hline \multirow[b]{2}{*}{ Plant } & \multirow[b]{2}{*}{ CFR } & \multicolumn{2}{|c|}{ Release rate } & \multirow{2}{*}{$\begin{array}{c}\text { Average } \\
\text { effective } \\
\text { diffusivity } \\
\left(\mathrm{cm}^{2} \cdot \mathrm{s}^{-1}\right)^{\mathrm{a}} \\
\end{array}$} & \multirow[b]{2}{*}{$\begin{array}{c}\text { Leachability } \\
\text { index }\end{array}$} \\
\hline & & $\begin{array}{c}\text { Absolute } \\
\left(\mu \mathrm{Ci} \cdot \mathrm{cm}^{-2} \cdot \mathrm{s}^{-1}\right)^{\mathrm{a}} \\
\end{array}$ & $\begin{array}{l}\text { Fractional } \\
\left(\mathrm{cm}^{-2} \cdot \mathrm{s}^{-1}\right)^{\mathrm{a}} \\
\end{array}$ & & \\
\hline Indian Point-3 & $3.1 \mathrm{E}-4$ & $3.3 \pm 5.4 \mathrm{E}-9$ & $6 \pm 10 \mathrm{E}-12$ & $5.3 \pm 3.9 \mathrm{E}-14$ & 13.5 \\
\hline FitzPatrick MBR & $9.2 \mathrm{E}-2$ & $1.3 \pm 0.4 \mathrm{E}-8$ & $6 \pm 1 \mathrm{E}-10$ & $4 \pm 1 E-9$ & 8.9 \\
\hline FitzPatrick baked & $1.1 \mathrm{E}-1$ & $3 \pm 1 \mathrm{E}-8$ & $1.1 \pm 0.6 \mathrm{E}-9$ & $7 \pm 4 \mathrm{E}-9$ & 8.9 \\
\hline Peach Bottom-3 & $5.9 \mathrm{E}-3$ & $1.5 \pm 1.3 \mathrm{E}-9$ & $2.2 \pm 2.1 \mathrm{E}-10$ & $5.5 \pm 2.2 \mathrm{E}-11$ & 10.4 \\
\hline Cooper CR & $1.2 \mathrm{E}-3$ & $-c$ & $8 \pm 24 E-11$ & $5 \pm 14 \mathrm{E}-11$ & 14.1 \\
\hline Cooper MBR & $6.1 \mathrm{E}-5$ & -c $^{c}$ & $1.6 \pm 2.8 \mathrm{E}-12$ & $3.7 \pm 9.1 \mathrm{E}-14$ & 13.9 \\
\hline Brunswick-1 CR & $3.5 \mathrm{E}-4$ & $9 \pm 5 \mathrm{E}-11$ & $9 \pm 5 \mathrm{E}-13$ & $5 \pm 4 \mathrm{E}-14$ & 14.5 \\
\hline $\begin{array}{l}\text { Brunswick-1 } \\
\text { MBR }\end{array}$ & $3.9 \mathrm{E}-3$ & $8 \pm 5 E-11$ & $1.4 \pm 0.8 \mathrm{E}-11$ & $2.6 \pm 0.7 \mathrm{E}-12$ & 12.3 \\
\hline Millstone-1 F33 & - $^{c}$ & $-^{c}$ & -c & -c & -c $^{\mathbf{c}}$ \\
\hline Millstone-1 F201 & $5.8 \mathrm{E}-3$ & $4.6 \pm 4.2 \mathrm{E}-9$ & $7.9 \pm 7.1 \mathrm{E}-11$ & $1.4 \pm 1.1 \mathrm{E}-11$ & 11.1 \\
\hline Peach Bottom-2 & -c & -c $^{c}$ & —c & -c & $-^{c}$ \\
\hline Pilgrim & $3.3 \mathrm{E}-1$ & $2.1 \pm 2.3 \mathrm{E}-7$ & $6.3 \pm 7.0 \mathrm{E}-9$ & $1.2 \pm 1.1 \mathrm{E}-7$ & 7.1 \\
\hline \multicolumn{6}{|c|}{$\begin{array}{l}\text { a. Internal uncertainty associated with calculated results. Does not include counting statistics or other uncertainties } \\
\text { associated with the leaching process. }\end{array}$} \\
\hline \multicolumn{6}{|c|}{ b. Average values were calculated excluding zeros. } \\
\hline c. Not detected or & measure & & & & \\
\hline
\end{tabular}

the Indian Point- 3 waste form are statistically the same at about $6 \times 10^{-12} \mathrm{~cm}^{-2} \cdot \mathrm{s}^{-1}$. These data suggest that all three transition metal radionuclides have similar release rate behavior from LOMI waste forms.

However, for FitzPatrick and Peach Bottom-3, the average fractional release rates of both ${ }^{60} \mathrm{Co}$ and ${ }^{55} \mathrm{Fe}$ are statistically the same at about
$6.3 \times 10^{-11} \mathrm{~cm}^{-2} \cdot \mathrm{s}^{-1}$ and are about an order of magnitude higher than those from the Indian Point-3 waste form. In contrast to these data, the fractional release rates of ${ }^{63} \mathrm{Ni}$ from the FitzPatrick and Peach Bottom-3 waste forms are within a factor of three of each other and are about two orders of magnitude higher than the fractional release rate of ${ }^{63} \mathrm{Ni}$ from the Indian Point-3 waste 


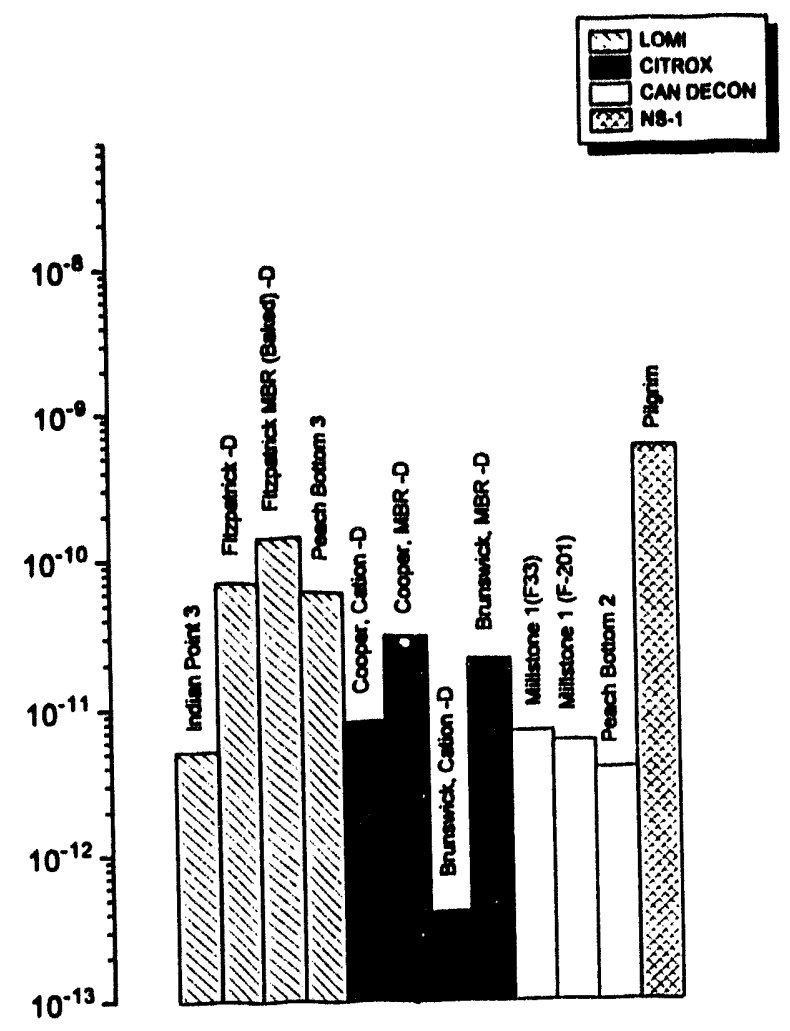

Figure 26. Cobalt-60 average fractional release rates $\left(\mathrm{cm}^{-2} \cdot \mathrm{s}^{-1}\right)$.

form. These data indicate waste-form specific effects on release rates from the LOMI waste forms.

The probable explanation for the differences between the FitzPatrick and Peach Bottom-3 data and the Indian Point-3 data are that the Indian Point -3 waste stream is considerably different from the Peach Bottom-3 and FitzPatrick waste streams because the Indian Point- 3 decontamination ion-exchange resins came from the decontamination of a PWR steam generator channel head decontamination, as noted previously. In addition, different ion-exchange resins, waste loadings, and cements may have had an effect. The PWR primary coolant chemistry is considerably different than that of BWRs and contains boron and other constituents not found in a BWR PCRS. In addition to these differences, the Indian Point- 3 waste form contained an additional chelating agent (formic acid) and contained no

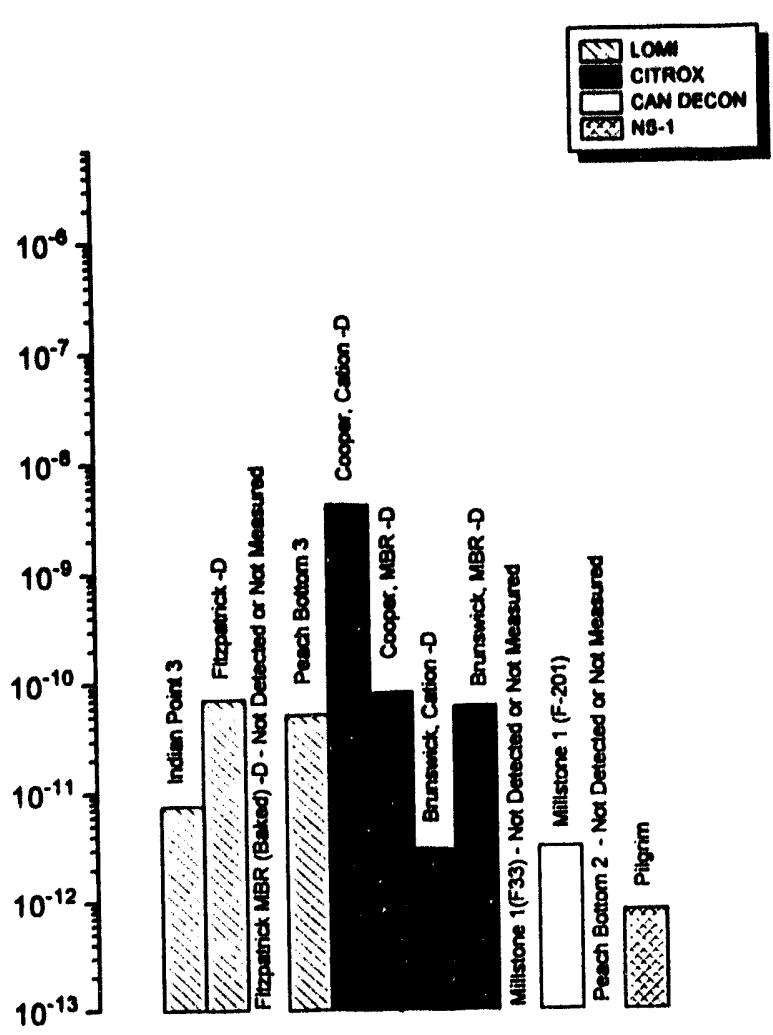

Figure 27. Iron-55 average fractional release rates $\left(\mathrm{cm}^{-2} \cdot \mathrm{s}^{-1}\right)$.

pozzolonic material (i.e., blast furnace slag). Hence, although the ${ }^{137} \mathrm{Cs}$ average fractional release rates for Indian Point-3 and FitzPatrick are the same, the Indian Point-3 release rate data are perhaps representative of PWR waste forms, whereas the Peach Bottom-3 and FitzPatrick release rate data, which are statistically the same for most species, are probably representative of BWR waste-form phenomena. These results suggest that release rate phenomena may be dependent on whether a PWR or BWR system has decontaminated. Consequently, as Indian Point-3 was the only PWR from which waste form samples were tested, the results for the FitzPatrick and Peach Bottom-3 waste forms will be used for comparison purposes with the other BWR wasteform data.

The fact that the fractional release rates of the transition metals from FitzPatrick and Peach Bottom -3 are statistically the same or are within a 


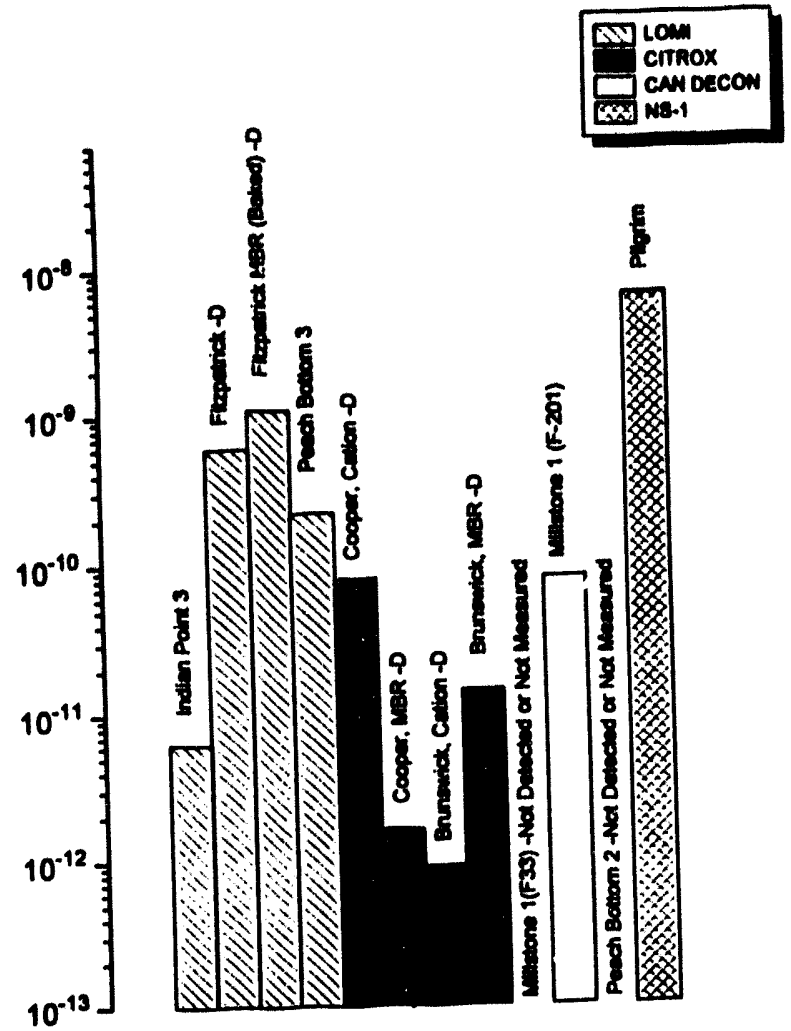

Figure 28. Nickel-63 average fractional release rates $\left(\mathrm{cm}^{-2} \cdot \mathrm{s}^{-1}\right)$.

narrow range is of particular importance as the FitzPatrick waste form decomposed during leaching and the Peach Bottom-3 waste form remained intact. The weighted-average fractional release rates for the transition metal radionuclides from the BWR LOMI waste form samples as shown in Table 18 are: ${ }^{60} \mathrm{Co}\left(6.7 \pm 2.1 \times 10^{-11}\right.$ $\left.\mathrm{cm}^{-2} \cdot \mathrm{s}^{-1}\right),{ }^{55} \mathrm{Fe}\left(6.0 \pm 3.4 \times 10^{-11} \mathrm{~cm}^{-2} \cdot \mathrm{s}^{-1}\right)$, and ${ }^{63} \mathrm{Ni}\left(4.8 \pm 1.0 \times 10^{-10} \mathrm{~cm}^{-2} \cdot \mathrm{s}^{-1}\right)$. The small standard deviation associated with the weighted averages of the FitzPatrick and Peach Bottom-3 data indicates that, in general, wasteform stability does not affect releases from the waste form. Further, the results suggest that ${ }^{60} \mathrm{Co}$ and ${ }^{55} \mathrm{Fe}$ appear to behave similarly in the LOMI waste forms in contrast to ${ }^{63} \mathrm{Ni}$, which has statistically higher release rates. It should be noted that the fractional release rates from the baked FitzPatrick waste-form sample were not included in the weighted average. Inspection of the baked sample data in Tables 15 through 17, however, indicates fractional release rates of ${ }^{60} \mathrm{Co}$ that were lower than those from the unbaked sample and average fractional release rates of ${ }^{63} \mathrm{Ni}$ that were higher than those from the unbaked sample. No reason for these differences is apparent.

The fact that the fractional release rates of the transition metals from FitzPatrick and Peach Bottom-3 are statistically the same or are within a narrow range is of particular importance as the FitzPatrick waste form decomposed during leaching and the Peach Bottom-3 waste form remained intact. The weighted-average fractional release rates for the transition metal radionuclides from the BWR LOMI waste form samples as shown in Table 18 are: ${ }^{60} \mathrm{Co}\left(6.7 \pm 2.1 \times 10^{-11}\right.$ $\left.\mathrm{cm}^{-2} \cdot \mathrm{s}^{-1}\right),{ }^{55} \mathrm{Fe}\left(6.0 \pm 3.4 \times 10^{-11} \mathrm{~cm}^{-2} \cdot \mathrm{s}^{-1}\right)$, and ${ }^{63} \mathrm{Ni}\left(4.8 \pm 1.0 \times 10^{-10} \mathrm{~cm}^{-2} \cdot \mathrm{s}^{-1}\right)$. The small standard deviation associated with the weighted averages of the FitzPatrick and Peach Bottom-3 data indicates that, in general, wasteform stability does not affect releases from the waste form. Further, the results suggest that ${ }^{60} \mathrm{Co}$ and ${ }^{55} \mathrm{Fe}$ appear to behave similarly in the LOMI waste forms in contrast to ${ }^{63} \mathrm{Ni}$, which has statistically higher release rates. It should be noted that the fractional release rates from the baked FitzPatrick waste-form sample were not included in the weighted average. Inspection of the baked sample data in Tables 15 through 17, however, indicates fractional release rates of ${ }^{60} \mathrm{Co}$ that were lower than those from the unbaked sample and average fractional release rates of ${ }^{63} \mathrm{Ni}$ that were higher than those from the unbaked sample. No reason for these differences is apparent.

In contrast to the weighted-average fractional release rate data for the transition metal radionuclides, the weighted-average fractional release rate of picolinic acid is approximately $3 \times 10^{-9}$ $\mathrm{cm}^{-2} \cdot \mathrm{s}^{-1}$, which indicates that picolinic acid is released at rates from $10^{1}$ to $10^{2}$ faster than the transition-metal radionuclides. A possible mechanism for the slower release rates and the apparent retention of ${ }^{60} \mathrm{Co},{ }^{55} \mathrm{Fe}$, and ${ }^{63} \mathrm{Ni}$ in the cement matrix relative to the chelating agent was reported by Komarneni. ${ }^{64}$ Komarneni investigated the reactions of divalent metal cations such as $\mathrm{Mn}^{+2}, \mathrm{Zn}^{+2}, \mathrm{Co}^{+2}$, and $\mathrm{Ni}^{+2}$ with calcium silicates such as tobomorite, xonotlite, and 
Tablo 18. Weighted-average fractional release rates.

Average fractional release rates

$\left(\mathrm{cm}^{-2} \cdot \mathrm{s}^{-1}\right)$

\begin{tabular}{|c|c|c|c|c|}
\hline $\begin{array}{c}\text { Radionuclide/ } \\
\text { chelating agent }\end{array}$ & LOMI & AP/Citrox & Can-Decon & Dow NS-1 \\
\hline Picolinic acida & $2.8 \pm 1.6 \mathrm{E}-9$ & -c $^{c}$ & $-c$ & -c \\
\hline AP/Citrox ${ }^{b}$ & $-c$ & $5.7 \pm 1.9 \mathrm{E}-11$ & $4.7 \pm 0.8 E-10$ & $8.5 \pm 9.0 \mathrm{E}-9 \mathrm{~d}$ \\
\hline EDTA & $-c$ & $-c$ & $1 \pm 1.2 \mathrm{E}-9$ & $1.7 \pm 1.2 \mathrm{E}-8^{\mathrm{d}}$ \\
\hline${ }^{137} \mathrm{Cs}$ & $5.1 \pm 2.1 \mathrm{E}-9$ & $6.1 \pm 2.8 \mathrm{E}-9 e$ & $3.5 \pm 2.7 \mathrm{E}-9$ & $1.2 \pm 0.8 \mathrm{E}-11^{\mathrm{d}}$ \\
\hline${ }^{60} \mathrm{Co}$ & $6.7 \pm 2.1 \mathrm{E}-11$ & $1.9 \pm 1.2 \mathrm{E}-11$ & $5.0 \pm 3.1 \mathrm{E}-12$ & $5.6 \pm 6.6 \mathrm{E}-10^{d}$ \\
\hline${ }^{55} \mathrm{Fe}$ & $6.0 \pm 3.4 \mathrm{E}-11$ & $2.2 \pm 1.1 \mathrm{E}-11$ & $3.1 \pm 4.3 \mathrm{E}-12^{\mathrm{d}}$ & $8.2 \pm 10 \mathrm{E}-13^{d}$ \\
\hline${ }^{63} \mathrm{Ni}$ & $4.8 \pm 1.0 \mathrm{E}-10$ & $5.4 \pm 3.6 \mathrm{E}-12^{e}$ & $7.9 \pm 7.1 \mathrm{E}-11$ & $6.3 \pm 7.0 \mathrm{E}-9 \mathrm{~d}$ \\
\hline Iron & $5.9 \pm 1.5 \mathrm{E}-13^{\mathrm{d}}$ & $1.3 \pm 1.9 \mathrm{E}-10$ & $-c$ & $-^{c}$ \\
\hline Nickel & $3.7 \pm 1.3 \mathrm{E}-10$ & $5 \pm 16 E-9 d$ & $1.6 \pm 1.9 \mathrm{E}-10^{d}$ & $4.9 \pm 4.0 \mathrm{E}-9$ \\
\hline \multicolumn{5}{|c|}{ a. Chelating agent picolinic acid. } \\
\hline \multicolumn{5}{|c|}{ b. Chelating agents, oxalate and citrate. } \\
\hline \multicolumn{5}{|c|}{ c. Not measured in sample or not detected. } \\
\hline \multicolumn{5}{|c|}{ d. Average fractional release rate for a single waste-form sample. } \\
\hline \multicolumn{5}{|c|}{$\begin{array}{l}\text { e. Wide range between results. Brunswick-1 mixed-bed resin waste form result for }{ }^{63} \mathrm{Ni} \text { is } 1.4 \pm 0.8 \mathrm{E}-11 \\
\mathrm{~cm}^{-2} \cdot \mathrm{s}^{-1} \text {. Cooper mixed-bed resin waste form result is } 1.7 \pm 1.1 \mathrm{E}-6 \mathrm{~cm}^{-2} \cdot \mathrm{s}^{-1} \text { for }{ }^{137} \mathrm{Cs} \text {. }\end{array}$} \\
\hline
\end{tabular}

wollastonite. A relevant finding of the study was that almost all of the $\mathrm{Ca}^{+2}$ in tobomorites and xonotlite was irreversibly replaced by $\mathrm{Co}^{+2}$ or $\mathrm{Ni}^{+2}$. This study was not performed on solidified decontamination ion-exchange resins and did not investigate the effects of chelating agents. The fact that the decomposition of the FitzPatrick waste-form specimens did not result in significant releases of transition metal radionuclides might be the result of irreversible reactions with the calcium in the cement. Fuhrman and others ${ }^{62,65}$ have further suggested that the transition metal radionuclides may be retained in the waste form due to the low solubility of the chemical forms of these radionuclides in the presence of the high $\mathrm{pH}$ of the cement complex, which forces the transition metals into insoluble forms.

These data are consistent with the laboratory study by Krishnamoorthy, ${ }^{63}$ who indicates that the average fractional release rate of ${ }^{60} \mathrm{Co}$ should be among the lowest of any radionuclide for waste forms without chelating agents present. However, our results indicate that ${ }^{60} \mathrm{Co}$ is released at an average fractional release rate about 20 times faster than other radionuclides 
such as ${ }^{14} \mathrm{C}$ (from Peach Bottom-3 results). This enhanced release rate may be due to chelating agent effects that are increasing the mobility of ${ }^{60} \mathrm{Co}$ and the other transition metal radionuclides. These mechanisms do not explain the difference between the ${ }^{60} \mathrm{Co}$ and ${ }^{55} \mathrm{Fe}$ average fractional release rates and the ${ }^{63} \mathrm{Ni}$ release rates; however, this difference in the average fractional release rates may be due to the relative stability of complexes formed by the transition metals. The Irving-Williams correlation ${ }^{57,66}$ indicates that the stability of transition metal complexes fall in the order $\mathrm{Ni}^{\mathrm{II}}>\mathrm{Co}^{\mathrm{Il}}>\mathrm{Fe}^{\mathrm{II}}$. These data suggest that the stability of the nickel complex with a chelating agent may result in the higher average fractional release rate of ${ }^{63} \mathrm{Ni}$ relative to the other transition metals. As noted above, the amount of calcium present in the waste form and the formation of insoluble complexes in the cement matrix may be producing the observed reiease rates for the transition metals and that the higher average fractional release rate of ${ }^{63} \mathrm{Ni}$ is probably due to the greater stability of the ${ }^{63} \mathrm{Ni}$-picolinate complex.

Average absolute release rates for the transition metal radionuclides vary considerably, with the average absolute release rates ranging from $7 \times 10^{-10}$ to $5 \times 10^{-8} \mu \mathrm{Ci} / \mathrm{cm}^{2} \cdot \mathrm{s}^{1}$. Iron-55 typically has the lowest average absolute release rates, and ${ }^{60} \mathrm{Co}$ and ${ }^{63} \mathrm{Ni}$ have the highest. The weighted-average absolute release rates for the FitzPatrick and Peach Bottom-3 LOMI wasteform samples as shown in Table 19 are: ${ }^{60} \mathrm{Co}(4.1$ $\left.\pm 0.9 \times 10^{-8} \mu \mathrm{Ci} / \mathrm{cm}^{2} \cdot \mathrm{s}^{1}\right),{ }^{55} \mathrm{Fe}(7.3 \pm$ $\left.4.1 \times 10^{-10} \mu \mathrm{Ci} / \mathrm{cm}^{2} \cdot \mathrm{s}^{1}\right)$, and ${ }^{63} \mathrm{Ni}(4.3 \pm$ $\left.1.4 \times 10^{-9} \mu \mathrm{Ci} / \mathrm{cm}^{2} \cdot \mathrm{s}^{1}\right)$. These data indicate that ${ }^{60} \mathrm{Co}$ has the highest absolute rate, followed by ${ }^{63} \mathrm{Ni}$ and ${ }^{55} \mathrm{Fe}$.

Table 19. Weighted-average absolute release rates.

Average absolute release rates $\left(\mu \mathrm{Ci} / \mathrm{cm}^{2} \cdot \mathrm{s}^{1}\right)$

\begin{tabular}{|c|c|c|c|c|}
\hline $\begin{array}{l}\text { Radionuclide/ } \\
\text { chelating agent }\end{array}$ & LOMI & AP/Citrox & Can-Decon & Dow NS-1 \\
\hline Picolinic acid ${ }^{\mathrm{a}}$ & $6.0 \pm 5.0 \mathrm{E}-3$ & $\sim^{c}$ & $-^{c}$ & $-c$ \\
\hline AP/Citrox ${ }^{b}$ & $\sim^{c}$ & $1.8 \pm 0.6 \mathrm{E}-4$ & $8.8 \pm 3.2 \mathrm{E}-4$ & $2 \pm 3 E-3^{d}$ \\
\hline EDTA & - $^{c}$ & $-^{c}$ & $5 \pm 6 \mathrm{E}-4$ & $7.1 \pm 9.7 \mathrm{E}-3^{\mathrm{d}}$ \\
\hline${ }^{137} \mathrm{Cs}$ & $1.9 \pm 0.6 \mathrm{E}-8$ & $2.2 \pm 1.2 \mathrm{E}-10$ & $9.8 \pm 7.7 \mathrm{E}-10$ & $4.2 \pm 2.7 \mathrm{E}-11^{\mathrm{d}}$ \\
\hline${ }^{60} \mathrm{Co}$ & $4.1 \pm 0.9 \mathrm{E}-8$ & $4 \pm 2 \mathrm{E}-10^{\mathrm{d}}$ & $3.7 \pm 2.3 \mathrm{E}-9$ & $3.4 \pm 4.0 \mathrm{E}-7^{\mathrm{d}}$ \\
\hline${ }^{55} \mathrm{Fe}$ & $7.3 \pm 4.1 \mathrm{E}-10$ & $1.3 \pm 0.5 \mathrm{E}-9 \mathrm{~d}$ & $4.9 \pm 5.8 \mathrm{E}-9^{d}$ & $2.6 \pm 3.2 \mathrm{E}-10^{d}$ \\
\hline${ }^{63} \mathrm{Ni}$ & $4.3 \pm 1.4 \mathrm{E}-9$ & 8. $\pm 5 E-11^{d}$ & $4.6 \pm 4.2 \mathrm{E}-9$ & $1.2 \pm 1.1 \mathrm{E}-7^{\mathrm{d}}$ \\
\hline Iron & $2.6 \pm 0.7 \mathrm{E}-6^{d}$ & $1.0 \pm 0.5 \mathrm{E}-5^{\mathrm{d}}$ & -d & $-c \pm$ \\
\hline Nickel & $6.3 \pm 2.4 \mathrm{E}-5$ & -c $^{c}$ & $2.0 \pm 2.5 \mathrm{E}-5^{d}$ & $8.1 \pm 6.5 \mathrm{E}-3^{\mathrm{d}}$ \\
\hline \multicolumn{5}{|c|}{ a. Chelating agent picolinic acid. } \\
\hline \multicolumn{5}{|c|}{ b. Chelating agents, oxalate and citrate. } \\
\hline \multicolumn{5}{|c|}{ c. Not measured in sample or not detected. } \\
\hline $\mathrm{rrac}$ & for a : & rm sample. & & \\
\hline
\end{tabular}


If the specific activity of these radionuclides is taken into account and the release rates of these radionuclides are converted to $\mu \mathrm{g} / \mathrm{cm}^{2} \cdot \mathrm{s}^{1},{ }^{63} \mathrm{Ni}$ has a higher $\left(10^{2}\right)$ absolute release rate than do the other radionuclides. Average absolute release rates calculated on this basis are: ${ }^{60} \mathrm{Co}$ $\left(8.8 \times 10^{-13} \mu \mathrm{g} / \mathrm{cm}^{2} \cdot \mathrm{s}^{1}\right),{ }^{55} \mathrm{Fe}\left(3.2 \times 10^{-13}\right.$ $\left.\mu \mathrm{g} / \mathrm{cm}^{2} \cdot \mathrm{s}^{1}\right)$, and ${ }^{63} \mathrm{Ni}\left(2.5 \times 10^{-11} \mu \mathrm{g} / \mathrm{cm}^{2} \cdot \mathrm{s}^{1}\right)$. These data indicate that the absolute release rates for ${ }^{60} \mathrm{Co}$ and ${ }^{55} \mathrm{Fe}$ are similar in terms of $\mu \mathrm{g} / \mathrm{cm}^{2} \cdot \mathrm{s}^{1}$ and that the absolute release rate of ${ }^{63} \mathrm{Ni}$ is higher. The similarity of the average fractional release rates and the absolute release rates (in $\mu \mathrm{g} / \mathrm{cm}^{2} \cdot \mathrm{s}^{1}$ ) for ${ }^{60} \mathrm{Co}$ and ${ }^{55} \mathrm{Fe}$ indicates that molecular diffusion is the controlling mechanism and that comparisons in terms of $\mu \mathrm{Ci} / \mathrm{cm}^{2} \cdot \mathrm{s}^{1}$ are extremely deceptive and do not provide accurate indications of the diffusional behavior of the radionuclide being evaluated. The high average fractional release rates of ${ }^{63} \mathrm{Ni}$ may be a result of the higher atomic concentration of this radionuclide in the waste form; therefore, there is a larger concentration gradient, which may result in a lower fraction of the ${ }^{63} \mathrm{Ni}$ irreversibly reacting with the cement. The differences in the fractional and absolute release rates of the transition metal radionuclides and the chelant suggests that although diffusion is the primary release mechanism, the release rates of the transition metal radionuclides are affected by other chemical mechanisms that either retard or accelerate releases.

The average fractional release rates of ${ }^{60} \mathrm{Co}$, ${ }^{55} \mathrm{Fe}$, and ${ }^{63} \mathrm{Ni}$ for the AP/Citrox waste forms are shown in Figures 26 through 28 and listed in Tables 15 through 17. The average fractional release rates of ${ }^{60} \mathrm{Co}$ for all $\mathrm{AP} / \mathrm{Citrox}$ waste forms (excluding the Brunswick-1 cation resin waste form that does not contain chelating agents) are statistically the same, and the weighted average is $1.9 \pm 1.2 \times 10^{-11} \mathrm{~cm}^{-2} \cdot \mathrm{s}^{-1}$. For comparison purposes, the average fractional release rate of ${ }^{60} \mathrm{Co}$ from the Brunswick-1 cation resin waste form $\left(4 \pm 1 \times 10^{-13} \mathrm{~cm}^{-2} \cdot \mathrm{s}^{-1}\right)$, which does not contain chelating agents, is about two orders of magnitude lower than that from the AP/Citrox waste forms. It is suggested that the fractional release rates of ${ }^{60} \mathrm{Co}$ from the Brunswick-1 cation resin waste form specimen is probably representative of the release rates of this radionuclide without chelants present. Krishnamoorthy ${ }^{63}$ measured similar average effective diffusivities for ${ }^{60} \mathrm{Co}$ to those for the Brunswick-1 cation resin waste form in his study, which was performed without chelating agents.

Inspection of the average iractional release rate data for ${ }^{55} \mathrm{Fe}$ in Figure 27 and Table 16 for the AP/Citrox waste forms indicates that, excluding the Brunswick-1 cation resin waste form data, the ${ }^{55} \mathrm{Fe}$ fractional release rates are statistically similar with the exception of the average fractional release rate from the Cooper cation resin waste form $\left(4.1 \times 10^{-9} \mathrm{~cm}^{-2} \cdot \mathrm{s}^{-1}\right)$, which is much higher than other results. This result is biased by a single leach result (as shown in Reference 1), which is three to four orders of magnitude higher than the other fractional release rates of ${ }^{55} \mathrm{Fe}$ measured for this sample. It is suggested that this result is probably not correct; therefore, it has been excluded from the weighted-average fractional release rates. The weighted-average fractional release rate of ${ }^{55} \mathrm{Fe}$ from the AP/Citrox waste form samples is $2.2 \pm 1.1 \times 10^{-11}$ $\mathrm{cm}^{-2} \cdot \mathrm{s}^{-1}$. This release rate is statistically the same as that of the ${ }^{60} \mathrm{Co}$ from the AP/Citrox waste forms.

In contrast to the similarity of the ${ }^{55} \mathrm{Fe}$ data, the average fractional release rates of ${ }^{63} \mathrm{Ni}$ range over almost two orders of magnitude. The weightedaverage fractional release rates for ${ }^{63} \mathrm{Ni}$ is $5.4 \pm$ $3.6 \times 10^{-12} \mathrm{~cm}^{-2} \cdot \mathrm{s}^{-1}$. The ${ }^{63} \mathrm{Ni}$ weighted-average fractional release rate for the AP/Citrox waste forms is the lowest measured for ${ }^{63} \mathrm{Ni}$ and the only one in which the average fractional release rate of ${ }^{63} \mathrm{Ni}$ is lower than that for ${ }^{55} \mathrm{Fe}$. However, the weighted-average fractional release rate for ${ }^{63} \mathrm{Ni}$ is biased low by the Cooper mixed-bed resin data as the average fractional release rate of ${ }^{63} \mathrm{Ni}$ from the Brunswick-1 mixed-bed resin waste form is the statistically the same as the weightedaverage fractional release rate for ${ }^{55} \mathrm{Fe}$. These data suggest that in the case of the AP/Citrox waste forms, ${ }^{63} \mathrm{Ni}$ is released at similar or lower rates than the ${ }^{60} \mathrm{Co}$ and ${ }^{55} \mathrm{Fe}$. If a complex is formed, these data indicate that the chelants oxalate and citrate do not form a strong complex with 
${ }^{63} \mathrm{Ni}$ that would enhance the release of this radionuclide from the waste form.

If the weighted-average fractional release rates for the AP/Citrox waste forms are compared with those from the Brunswick-1 cation resin waste form (and it is assumed that other effects are insignificant), the chelating agents, oxalate arid citrate, increased the average fractional release rates of the transition metal radionuclides by the following factors: ${ }^{60} \mathrm{Co}(48),{ }^{55} \mathrm{Fe}(7.3)$, and ${ }^{63} \mathrm{Ni}(6)$. These data suggest that the chelating agents have increased the release rates for all transition metal radionuclides but that the effect is greatest for ${ }^{60} \mathrm{Co}$. No reason for the greater stability of a ${ }^{60} \mathrm{Co}$-oxalate-citrate complex or the greater solubility of the ${ }^{60} \mathrm{Co}$ is known.

Average absolute release rates for the AP/ Citrox waste forms were measured for only the Brunswick- 1 cation and mixed-bed resin waste forms. Consequentily, as the Brunswick-1 cation resin waste form does not contain chelating agents, the average absolute release rates from the Brunswick-1 mixed-bed resin waste form are used for comparison purposes with other waste forms. The average absolute release rates for each radionuclide are: ${ }^{60} \mathrm{Co}\left(4 \pm 2 \times 10^{-10}\right.$ $\left.\mu \mathrm{Ci} / \mathrm{cm}^{2} \cdot \mathrm{s}^{1}\right),{ }^{55} \mathrm{Fe}\left(1.3 \pm 0.5 \times 10^{-9}\right.$ $\left.\mu \mathrm{Ci} / \mathrm{cm}^{2} \cdot \mathrm{s}^{1}\right)$, and ${ }^{63} \mathrm{Ni}\left(8 \pm 5 \times 10^{-11}\right.$ $\left.\mu \mathrm{Ci} / \mathrm{cm}^{2} \cdot \mathrm{s}^{1}\right)$. These data indicate that the average absolute release rates vary considerably similar to the LOMI waste form absolute release rates; however, if converted to $\mu \mathrm{g} / \mathrm{cm}^{2} \cdot \mathrm{s}^{1}$, the average absolute release rates are: ${ }^{60} \mathrm{Co}\left(1.6 \times 10^{-13}\right.$ $\left.\mu \mathrm{g} / \mathrm{cm}^{2} \cdot \mathrm{s}^{1}\right),{ }^{55} \mathrm{Fe}\left(1.1 \times 10^{-12} \mu \mathrm{g} / \mathrm{cm}^{2} \cdot \mathrm{s}^{1}\right)$, and ${ }^{63} \mathrm{Ni}\left(1.3 \times 10^{-12} \mu \mathrm{g} / \mathrm{cm}^{2} \cdot \mathrm{s}^{1}\right)$. These data indicate that the absolute release rates for ${ }^{63} \mathrm{Ni}$ and ${ }^{55} \mathrm{Fe}$ are approximately the same in terms of $\mu \mathrm{g} / \mathrm{cm}^{2} \cdot \mathrm{s}^{1}$ and that the absolute release rate of ${ }^{63} \mathrm{Ni}$ is about an order of magnitude lower. A comparison of the absolute $\left(\mu \mathrm{g} / \mathrm{cm}^{2} \cdot \mathrm{s}^{1}\right)$ and fractional release rates for the three radionuclides suggest that the fractional release rate of ${ }^{60} \mathrm{Co}$ is being enhanced relative to the other radionuclides if simple diffusion was assumed as the transport mechanism. These data suggest that a smaller fraction of the ${ }^{60} \mathrm{Co}$ irreversibly reacted with the cement matrix relative to the other transition metal radionuclides or that the solubility was lower.

For the Can-Decon waste forms, the average fractional release rates for ${ }^{60} \mathrm{Co}$ and ${ }^{55} \mathrm{Fe}$ are statistically the same. The weighted-average release rate for ${ }^{60} \mathrm{Co}$ is $5.0 \pm 3.1 \times 10^{-12} \mathrm{~cm}^{-2} \cdot \mathrm{s}^{-1}$ and the average fractional release rate for ${ }^{55} \mathrm{Fe}$ (measurable only in the Millstone-1 F-201 sample) is $3.1 \pm 4.3 \times 10^{-12} \mathrm{~cm}^{-2} \cdot \mathrm{s}^{-1}$. In contrast, the average fractional release rate of ${ }^{63} \mathrm{Ni}$ (measurable only in the Millstone-1 F-201 sample) is 7.9 $\pm 7.1 \times 10^{-11} \mathrm{~cm}^{-2} \cdot \mathrm{s}^{-1}$. These data indicate that for the Can-Decon samples, ${ }^{63} \mathrm{Ni}$ is released at a rate about an order of magnitude faster than those measured for ${ }^{60} \mathrm{Co}$ and ${ }^{55} \mathrm{Fe}$. Similar to the LOMI waste forms, the fractional release rate of ${ }^{63} \mathrm{Ni}$ is apparently enhanced.

A comparison of the average fractional release rates for the transition metal radionuclides with those of the Can-Decon chelating agents indicates that all radionuclides have average fractional release rates that are one to three orders of magnitude less than those measured for the chelating agents. The EDTA had the highest average fractional release rate of $2 \times 10^{-9} \mathrm{~cm}^{-2} \cdot \mathrm{s}^{-1}$. No obvious correlation between the chelating agent and the radionuclide average fractional release rates has been identified other than the possibility of a more stable ${ }^{63} \mathrm{Ni}$ complex that resulted in the higher release rates of this radionuclide from the Can-Decon waste form.

Average absolute release rates of ${ }^{60} \mathrm{Co}$ for the Can-Decon waste forms were measured for all three Can-Decon samples, whereas absolute release rates for ${ }^{55} \mathrm{Fe}$ and ${ }^{63} \mathrm{Ni}$ were measurable for only the Millstone-1 F-201 sample. The average absolute release rates for each radionuclide are: ${ }^{60} \mathrm{Co}\left(3.7 \pm 2.3 \times 10^{-9} \mu \mathrm{Ci} / \mathrm{cm}^{2} \cdot \mathrm{s}\right),{ }^{55} \mathrm{Fe}$ $\left(4.9 \pm 5.8 \times 10^{-9} \mu \mathrm{Ci} / \mathrm{cm}^{2} \cdot \mathrm{s}^{1}\right)$, and ${ }^{63} \mathrm{Ni}$ $\left(4.6 \pm 4.2 \times 10^{-9} \mu \mathrm{Ci} / \mathrm{cm}^{2} \cdot \mathrm{s}^{1}\right)$. These data indicate that the average absolute release rates are similar in contrast to the LOMI waste form absolute release rates; however, if converted to $\mu \mathrm{g} / \mathrm{cm}^{2} \cdot \mathrm{s}^{1}$, the average absclute release rates are: ${ }^{60} \mathrm{Co}\left(1.5 \times 10^{-12} \mu \mathrm{g} / \mathrm{cm}^{2} \cdot \mathrm{s}^{1}\right),{ }^{55} \mathrm{Fe}$ $\left(4.3 \times 10^{-2} \mu \mathrm{g} / \mathrm{cm}^{2} \cdot \mathrm{s}^{1}\right)$, and ${ }^{63} \mathrm{Ni}\left(7.4 \times 10^{-11}\right.$ $\left.\mu \mathrm{g} / \mathrm{cm}^{2} \cdot \mathrm{s}^{1}\right)$. These data indicate that the absolute 
release rate for ${ }^{63} \mathrm{Ni}$ is higher than that measured for the other radionuclides in terms of $\mu \mathrm{g} / \mathrm{cm}^{2} \cdot \mathrm{s}^{1}$ and suggests that the fractional release rate is higher due to the apparent correlation between higher atomic absolute release rate and higher fractional release rate. These data suggest that as there was more ${ }^{63} \mathrm{Ni}$ present, a smaller fraction of the ${ }^{63} \mathrm{Ni}$ irreversibly reacted with the cement matrix relative to the other transition metal radionuclides.

For the Dow NS-1 sample, the average fractional release rates shown in Figures 26 through 28 vary widely (three orders of magnitude). The value for ${ }^{55} \mathrm{Fe}$ is the lowest $\left(8.2 \times 10^{-13}\right.$ $\left.\mathrm{cm}^{-2} \cdot \mathrm{s}^{-1}\right)$, and the highest is for ${ }^{63} \mathrm{Ni}\left(6.3 \times 10^{-9}\right.$ $\left.\mathrm{cm}^{-2} \cdot \mathrm{s}^{-1}\right)$. The average fractional release rate of ${ }^{63} \mathrm{Ni}$ is statistically the same as that measured for the chelating agents and indicates that ${ }^{60} \mathrm{Co}$ and ${ }^{55} \mathrm{Fe}$ are less affected by chelating agent effects than the ${ }^{63} \mathrm{Ni}$.

Examination of Table 18 indicates that, typically, the weighted-average fractional releases of ${ }^{60} \mathrm{Co}$ and ${ }^{55} \mathrm{Fe}$ are the same for most waste forms and that they range over an order of magnitude from $5 \times 10^{-12}$ to $7 \times 10^{-11} \mathrm{~cm}^{-2} \cdot \mathrm{s}^{-1}$ for the LOMI, AP/Citrox, and Can-Decon waste forms. These data suggest generic behavior for these radionuclides. In contrast, only the ${ }^{63} \mathrm{Ni}$ weighted-average fractional release rate is outside this general range, which indicates that although ${ }^{63} \mathrm{Ni}$ has statistically higher release rates, the average fractional release rates of all transition metal radionuclides fall within a relatively narrow range. The Dow NS-1 fractional releases are considerably different than those of the other waste forms and share little in the way of characteristic behavior with the other waste forms.

In contrast to the weighted-average fractional release rates, the average absolute release rates shown in Table 19 cover a range of $10^{3}$. As previously discussed, however, if these data are converted to $\mu \mathrm{g} / \mathrm{cm}^{2} \cdot \mathrm{s}^{1}$, the results indicate that high elemental absolute release rates of the transition metal radionuclides are generally consistent with the high fractional release rates. These data suggest that when there is a larger concentration gradient in the waste form (i.e., higher atomic concentrations of the radionuclide), more is released to the leachant.

A comparison of the average fractional release rate curves for ${ }^{60} \mathrm{Co}$ for all samples is shown in Figure 29. As shown in the figure, the fractional release rate curves cover a range from about $5 \times 10^{-13}$ to $5 \times 10^{-9} \mathrm{~cm}^{-2} \cdot \mathrm{s}^{-1}$. The fractional release rates from the Brunswick-1 cation resin waste form, which does not contain chelating agents, is the lowest, while the fractional release rates from the Pilgrim NS-1 waste form are the highest. This figure was included to show that the fractional release rates cover a broad range and that diffusional behavior is generally indicated with high release rates in the initial part of the release and lower rates in the diffusional part of the release. Figures that show individual radionuclide fractional release rate curves are shown in References 1 to 3.

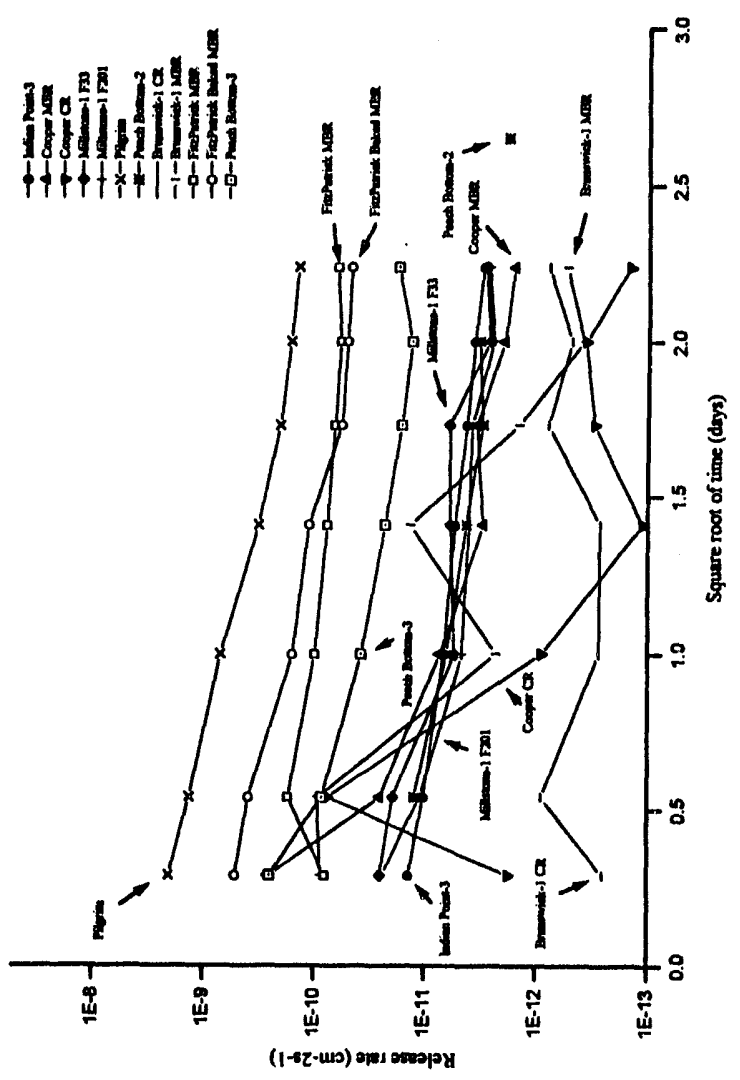

Figure 29. Average fractional release rate curves for ${ }^{60} \mathrm{Co}\left(\mathrm{cm}^{-2} \cdot \mathrm{s}^{-1}\right)$. 
Comparisons of the CFRs for the transition metal radionuclides are shown in Figures 30 through 32. An assessment of the CFRs for the LOMI waste forms indicates that the highest CFR $(11 \%)$ is for ${ }^{63} \mathrm{Ni}$ from the baked FitzPatrick waste form. Other CFRs for the LOMI waste forms ranged from $0.01 \%$ to $6 \%$, with the CFR of ${ }^{55} \mathrm{Fe}$ and ${ }^{63} \mathrm{Ni}$ from the Indian Point-3 specimen at $0.01 \%$ and $0.03 \%$. In contrast, the CFRs for the chelating agents ranged from 50 to $60 \%$ with the exception of Peach Bottom-3 ( 13\% for a 90-day leach). These data sùggest that the chelating agent concentration is not correlatable with the release of radionuclides from the waste forms as the average fractional release rate for the transition metal radionuclides from the Indian Point-3 waste form was much less than for the other plants, yet the average fractional release rate and the CFR (0.6) of the chelating agent was the highest for this type of waste form.

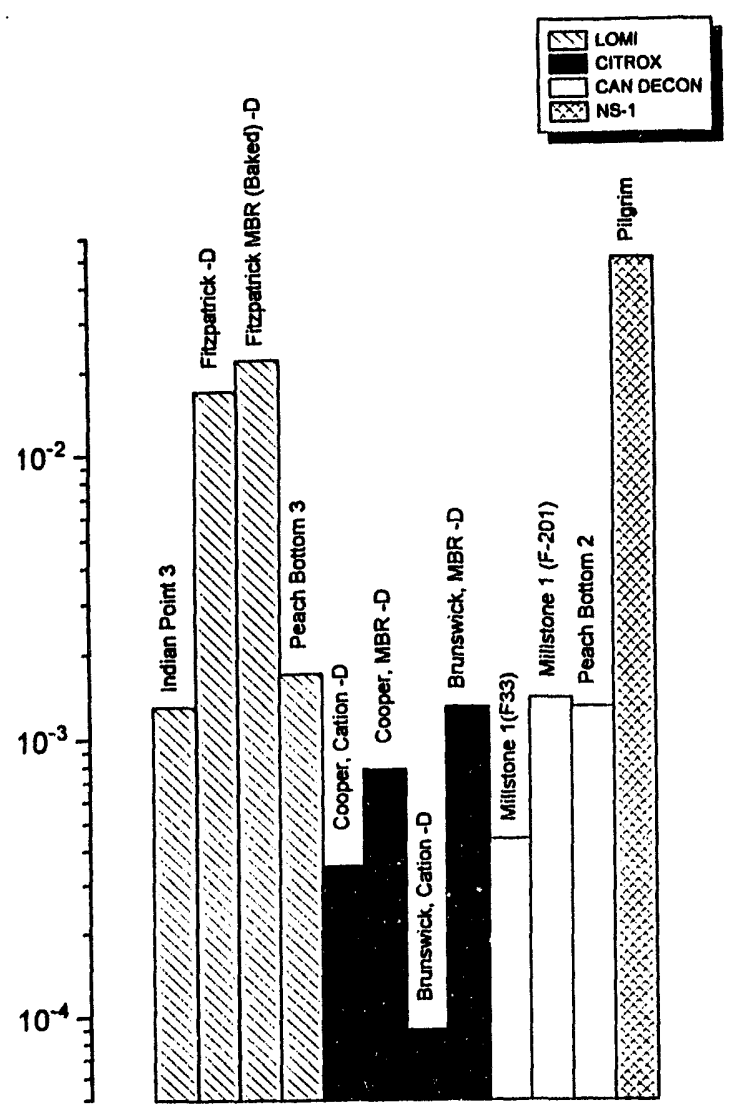

Figure 30. Cobalt-60 cumulative fractional release.
The CFRs of the transition metal radionuclides from the AP/Citrox waste forms are shown in Figures 30 through 32 . The CFRs of ${ }^{60} \mathrm{Co}$ from the Citrox waste forms, which contain chelating agents, range over an order of magnitude (from $3.5 \times 10^{-4}$ for the Cooper cation resin waste form to $1.3 \times 10^{-3}$ for the Brunswick-1 mixedbed resin waste form). The CFR of this radionuclide from the Brunswick-1 cation resin waste form that does not contain chelating agents is $8.5 \times 10^{-5}$ and is probably representative of an unchelated release from a waste form. The average CFR of ${ }^{60} \mathrm{Co}$ from the Citrox waste forms (excluding the Brunswick-1 cation resin waste form) is $8 \times 10^{-4}$. This low value as compared to the LOMI waste forms $\left(9.3 \times 10^{-3}\right.$ excluding Indian Point-3) indicates that although the Citrox waste forms decomposed during leaching, only a relatively small fraction of the ${ }^{60} \mathrm{Co}$ leached from the debris. These data further confirm the fact that

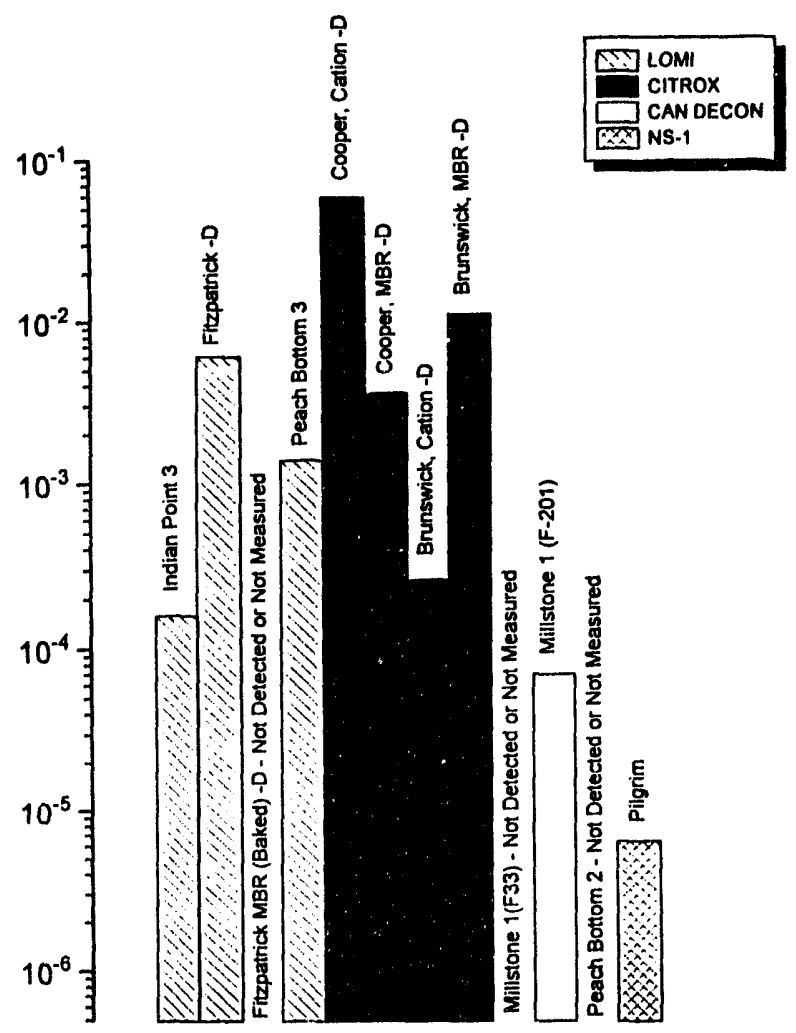

Figure 31. Iron-55 cumulative fractional release. 


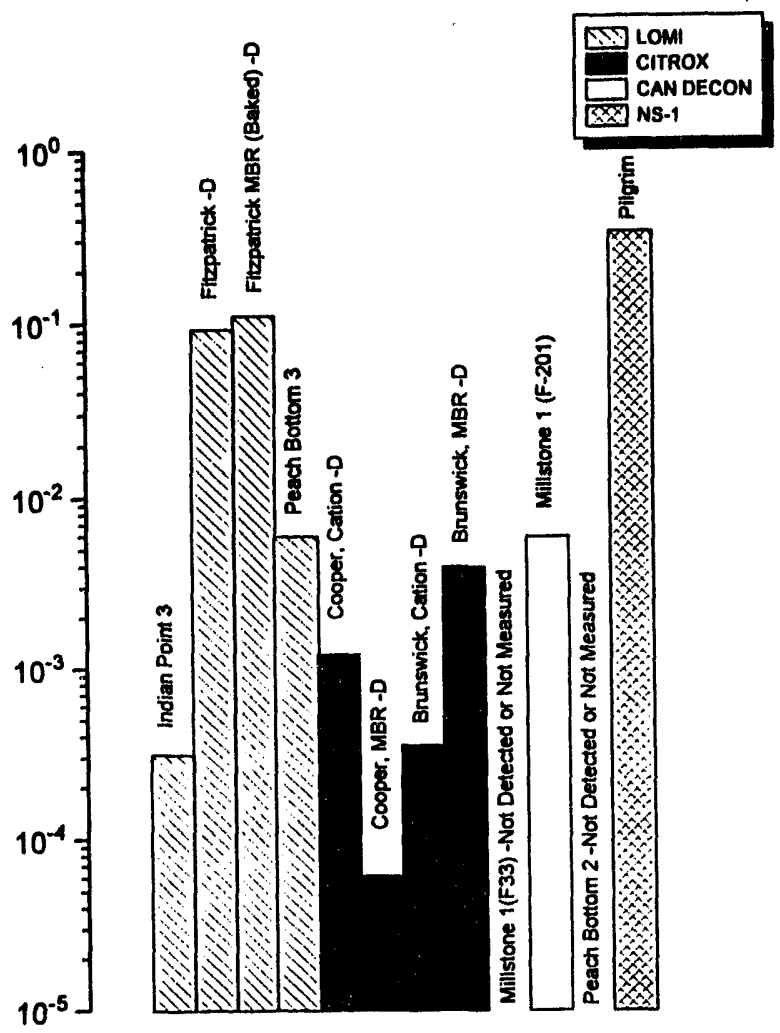

Figure 32. Nickel-63 cumulative fractional release.

waste form structural stability does not affect leachability. In contrast, the average CFR for the $\mathrm{AP} /$ Citrox waste forms for ${ }^{55} \mathrm{Fe}$ and ${ }^{63} \mathrm{Ni}$ are $7.3 \times 10^{-3}$ and $2.0 \times 10^{-3}$, respectively (excluding the Cooper cation resin waste form data). These values are similar to the averages for the LOMI waste forms, but the results are deceptive as the ${ }^{63} \mathrm{Ni}$ average CFR is based on the Brunswick-1 mixed-bed resin waste form CFR $\left(3.9 \times 10^{-3}\right)$ and the Cooper mixed-bed resin CFR $\left(6.1 \times 10^{-5}\right)$, which are a factor of 64 apart; consequently, the average is dominated by the higher CFR.

Assessment of the CFRs of the Can-Decon waste forms as shown in Figures 30 through 32 indicate that for ${ }^{60} \mathrm{Co}$, the CFRs for all waste forms range from $4 \times 10^{-4}$ through $1.4 \times 10^{-3}$ with an average of about $1 \times 10^{-3}$. The CFRs of ${ }^{63} \mathrm{Ni}$ and ${ }^{55} \mathrm{Fe}$ are based on the Millstone-1 F201 sample and are $5.8 \times 10^{-3}$ and $6.9 \times 10^{-5}$, respectively. These data that indicate that although the data are limited and there are some anomalous results, the CFRs from the Can-Decon waste forms nominally range from $1 \times 10^{-3}$ to $5 \times 10^{-3}$ and that they are in the same range as the CFRs from the AP/Citrox waste forms.

Figures 33 through 35 and Tables 15 through 17 show the average effective diffusivities for the transition metal radionuclides. These results typically follow the results of the fractional release rate calculations. The average effective diffusivities for ${ }^{60} \mathrm{Co}$ range from $1 \times 10^{-13} \mathrm{~cm}^{2} \cdot \mathrm{s}^{-1}$ for the Millstone-1 samples to $5 \times 10^{-11} \mathrm{~cm}^{2} \cdot \mathrm{s}^{-1}$ for the FitzPatrick LOMI samples. If the Brunswick-1 cation resin (low) value and Pilgrim (high) values are excluded for the previously discussed reasons, the typical average effective diffusivities for the waste forms are: LOMI $\left(1.8 \times 10^{-11} \mathrm{~cm}^{2} \cdot \mathrm{s}^{-1}\right), \mathrm{AP} /$ Citrox $\left(4 \times 10^{-12}\right.$ $\left.\mathrm{cm}^{2} \cdot \mathrm{s}^{-1}\right)$ and Can-Decon $\left(1 \times 10^{-13} \mathrm{~cm}^{2} \cdot \mathrm{s}^{-1}\right)$. These data indicate that the LOMI waste forms have the highest average effective diffusivities followed by the AP/Citrox and Can-Decon waste forms.

As shown in Tables 15 through 17, the average effective diffusivities cover ranges of $10^{2}$ to $10^{4}$ for each type of waste form; therefore, the range of leachability indexes is similarly broad. The leachability indexes shown in Figures 36 through 38 are more informative. For ${ }^{60} \mathrm{Co}$, all leachability indexes are within the requirements of the "Technical Position on Waste Form," Revision 1, and if the Brunswick-1 cation resin (low) and Pilgrim (high) values are excluded, the range is from 10.5 to 13.6 , which is well within the acceptable range and considerably higher than those for the fission product ${ }^{137} \mathrm{Cs}$. Inspection of the data for ${ }^{55} \mathrm{Fe}$ and ${ }^{63} \mathrm{Ni}$ indicates ranges of 10.3 to 16 , and 8.9 to 14 respectively. In all cases, the leachability index is above 10 with the exception of ${ }^{63} \mathrm{Ni}$ from the Pilgrim (7.1) and FitzPatrick (8.9) waste forms. These lower leachability indices are a result of the apparent mobility of ${ }^{63} \mathrm{Ni}$ as previously discussed.

Other Radionuclides. Other primary radionuclides evaluated as part of this study were ${ }^{14} \mathrm{C}$, ${ }^{99} \mathrm{Tc},{ }^{129} \mathrm{I}$, and ${ }^{241} \mathrm{Pu}$ because they have long-term 
Experimental Results and Discussion

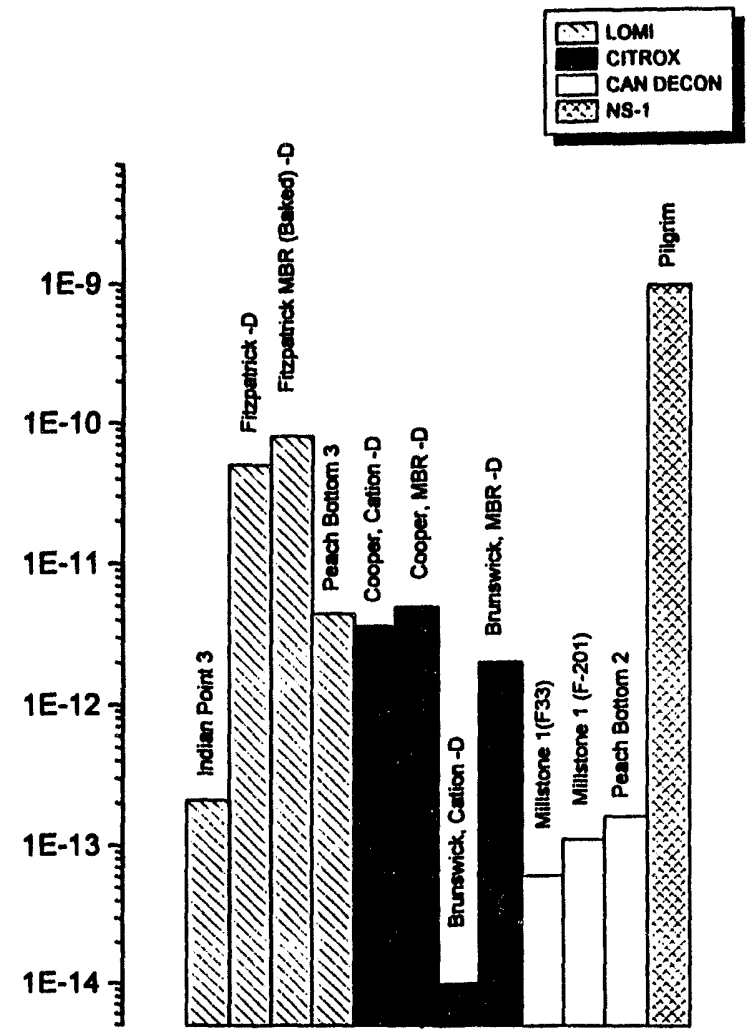

Figure 33. Cobalt-60 effective diffusivity.

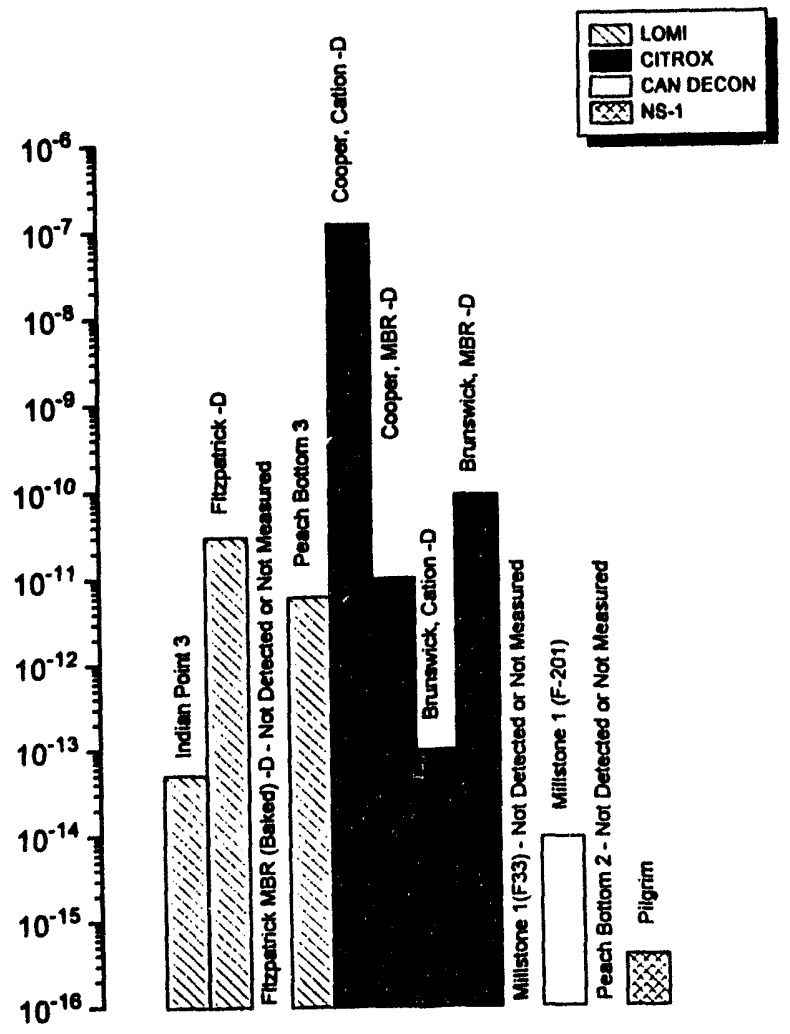

Figure 34. Iron-55 effective diffusivity.

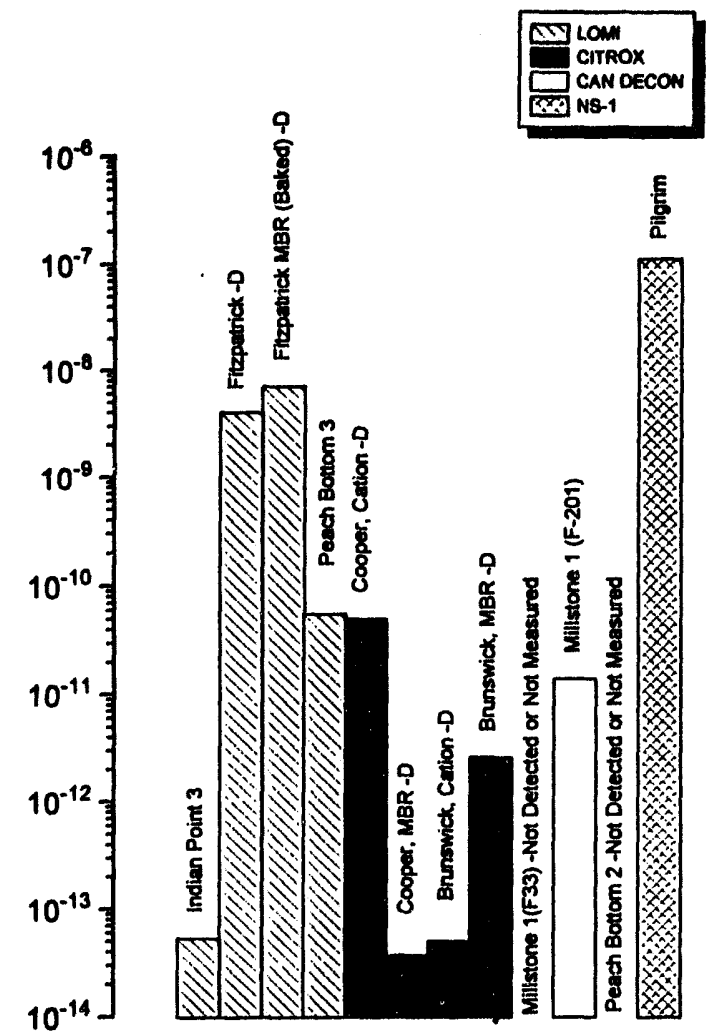

Figure 35. Nickel-63 effective diffusivity.

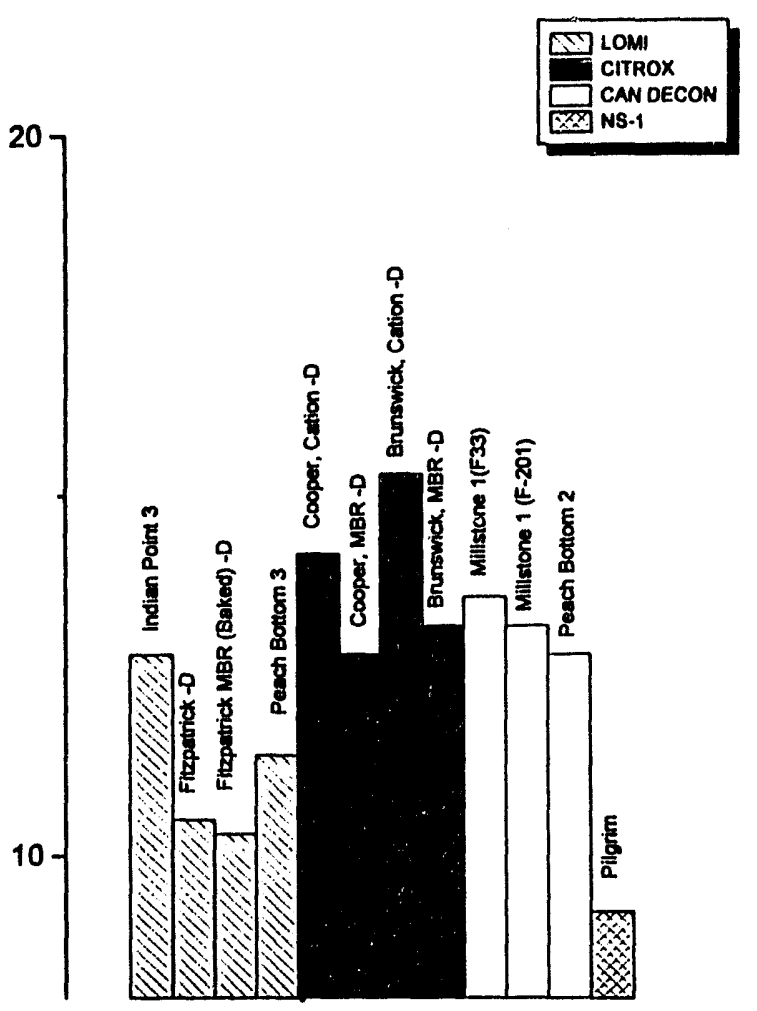

Figure 36. Cobalt- 60 leachability indexes. 


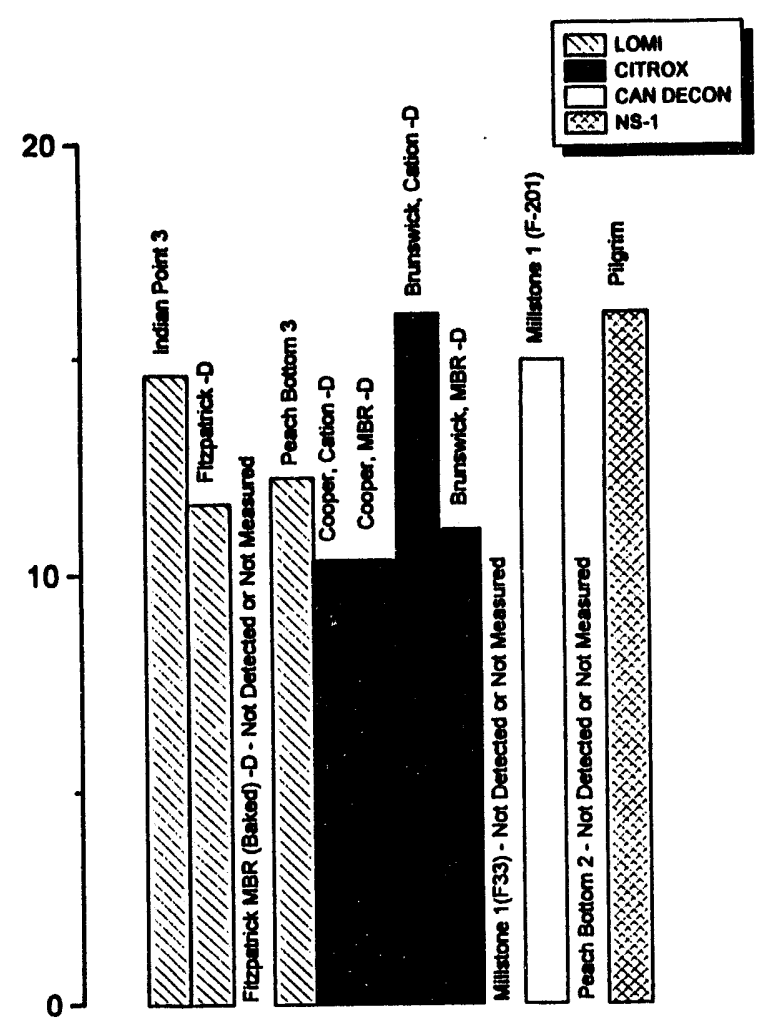

Figure 37. Iron-55 leachability indexes.

dose consequences due to their long half-lives or, in the case of ${ }^{241} \mathrm{Pu}$, because it may be indicative of the behavior of other transuranic radionuclides with long half-lives $\left({ }^{239 / 240} \mathrm{Pu},{ }^{241} \mathrm{Am},{ }^{242} \mathrm{Cm}\right.$, and ${ }^{244} \mathrm{Cm}$ ), which were not measurable in the leachate solutions. In addition to the radionuclides noted above, ${ }^{3} \mathrm{H},{ }^{57} \mathrm{Co},{ }^{89} \mathrm{Sr},{ }^{90} \mathrm{Sr},{ }^{95} \mathrm{Nb}$, and ${ }^{125} \mathrm{Sb}$ were measurable in the waste forms and some leachates; however, they were typically measured in low concentrations, as discussed in References 1 to 3 , with the exception of ${ }^{90} \mathrm{Sr}$, whose release rate behavior is discussed.

Only ${ }^{14} \mathrm{C}$ was measured for the Peach Bottom-3 samples. The average fractional release rate of ${ }^{14} \mathrm{C}$ was $5.3 \times 10^{-12} \mathrm{~cm}^{-2} \cdot \mathrm{s}^{-1}$, which is near the lowest of any of the radionuclides measured. This is consistent with the results of Krishnamoorthy, ${ }^{63}$ who attributes the low release rate of ${ }^{14} \mathrm{C}$ measured in his study to the formation of insoluble hydrates and carbonates, which slow the release of this radionuclide. Further, his measurements indicate that the fractional release rate of ${ }^{60} \mathrm{Co}$ should be slower than ${ }^{14} \mathrm{C}$ because of the

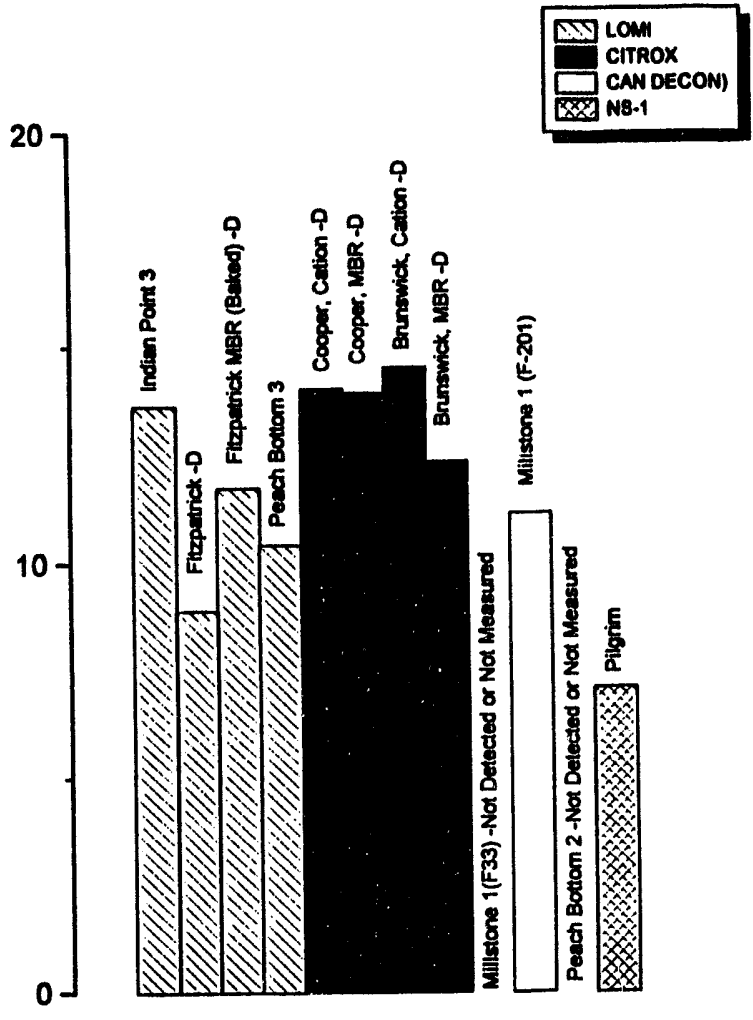

Figure 38. Nickel-63 leachability indexes.

relative insolubility of the transition metals. ${ }^{63}$ This is the case for the Brunswick-1 cation resin waste form, which does not contain a chelating agent $\left(4 \times 10^{-13} \mathrm{~cm}^{-2} \cdot \mathrm{s}^{-1}\right)$. These data further support the conclusion that the release rates of ${ }^{60} \mathrm{Co}$ are being enhanced by chelating effects for the chelated samples for which measurements were performed, or that other factors such as solubility differences affected the release rates.

In contrast to the fractional release rates, the absolute release rates of ${ }^{14} \mathrm{C}$ from the Peach Bottom-3 samples are near the highest for any radionuclide. The average absolute release rate of ${ }^{14} \mathrm{C}$ as shown in Appendix $F$ is $5.7 \times 10^{-9}$ $\mu \mathrm{Ci} / \mathrm{cm}^{2} \cdot \mathrm{s}^{1}$. The difference between the fractional and absolute release rates of ${ }^{14} \mathrm{C}$ is due to the large inventory of ${ }^{14} \mathrm{C}$ present in the Peach Bottom-3 waste form (approximately $60 \%$ of the total activity). Consequently, high absolute release rates, as noted here, can be relatively low fractional release rates due to the large inventory in the waste form. These data further confirm Krishnamoorthy's work, ${ }^{63}$ which attributes the 
low fractional release rate of ${ }^{14} \mathrm{C}$ to the formation of insoluble hydrates and carbonates, which slow the release of this radionuclide.

The ${ }^{99} \mathrm{Tc}$ fractional release rate data listed in Table F-12 indicate an average fractional release rate of ${ }^{99} \mathrm{Tc}$ of $5.2 \times 10^{-11} \mathrm{~cm}^{-2} \cdot \mathrm{s}^{-1}$ from the Peach Bottom-3 samples. This average fractional release rate is also statistically the same as that for ${ }^{55} \mathrm{Fe}$ and ${ }^{60} \mathrm{Co}$ and suggests similar chemical and release rate behavior for ${ }^{99} \mathrm{Tc}$. This might be expected as technetium is a metal and would be expected to form complexes with organic compounds such as chelating agents. ${ }^{55}$ The average absolute release rate of ${ }^{99} \mathrm{Tc}$ is $2.4 \times 10^{-10}$ $\mu \mathrm{Ci} / \mathrm{cm}^{2} \cdot \mathrm{s}^{1}$.

The average fractional release rate of ${ }^{129} \mathrm{I}$ from the Peach Bottom-3 samples is $8.4 \times 10^{-10} \mathrm{~cm}^{-2} \cdot \mathrm{s}^{-1}$. This rate is approximately a factor of two greater than the average fractional release rate of ${ }^{137} \mathrm{Cs} 4.1 \times 10^{-10}$ $\mathrm{cm}^{-2} \cdot \mathrm{s}^{-1}$. Iodine, an anion, would be expected to diffuse similarly to other ionic elements, such as cesium, and its release would not be expected to be affected by chelating agent effects as discussed previously for ${ }^{137} \mathrm{Cs}$. The fractional release rates of iodine and cesium are the highest of all radionuclides present in the waste form and are statistically the same as that for picolinic acid $\left(5.8 \times 10^{-10} \mathrm{~cm}^{-2} \cdot \mathrm{s}^{-1}\right)$ from the Peach Bottom-3 waste form, which suggests that the maximum diffusional fractional release rate from the waste form is between $5 \times 10^{-10}$ and $3 \times 10^{-9}$ $\mathrm{cm}^{-2} \cdot \mathrm{s}^{-1}$ (Table 18). Krishnamoorthy ${ }^{63}$ observed similar behavior, except that he found that cesium was released at a faster rate than the iodine. The weighted-average absolute release rate for ${ }^{129} \mathrm{I}$ from the Peach Bottom-3 samples is $5.1 \times 10^{-12}$ $\mu \mathrm{Ci} / \mathrm{cm}^{2} \cdot \mathrm{s}^{1}$ and is near the lowest for all radionuclides. This low absolute release rate is only slightly higher than that for ${ }^{90} \mathrm{Sr}$ and is an artifact of the low inventory present in the waste form.

The CFRs for ${ }^{14} \mathrm{C},{ }^{99} \mathrm{Tc}$, and ${ }^{129} \mathrm{I}$ from the Peach Bottom-3 samples are quite variable. The average CFR for ${ }^{14} \mathrm{C}\left(2.9 \times 10^{-4}\right)$ is lower than that for all other radionuclides from the Peach Bottom-3 samples. This may be due to the fact that, as discussed previously, ${ }^{14} \mathrm{C}$ may be retained better in the waste form due to the formation of insoluble hydrates and carbonates. The CFR of ${ }^{99} \mathrm{Tc}$ from the Peach Bottom-3 waste forms is $1.0 \times 10^{-2}$. This CFR is representative of those of the transition metals and suggests similar behavior for this radionuclide. This behavior may be expected because ${ }^{99} \mathrm{Tc}$ is a metal that forms complexes with organic complexing agents similar to the transition metals discussed previously. ${ }^{55}$ In contrast, the CFR of ${ }^{129}$ I from the Peach Bottom-3 waste forms is the highest at $6.0 \times 10^{-2}$. As discussed previously, this high CFR may be expected due to the ionic nature of this radionuclide.

Average effective diffusivities and leachability indexes for ${ }^{14} \mathrm{C},{ }^{99} \mathrm{Tc}$, and ${ }^{129} \mathrm{I}$ from the Peach Bottom-3 samples are listed in Table F-12. The average effective diffusivities for these three radionuclides are: ${ }^{14} \mathrm{C}\left(1.5 \times 10^{-14} \mathrm{~cm}^{2} \cdot \mathrm{s}^{-1}\right)$, ${ }^{99} \mathrm{Tc}\left(1.6 \times 10^{-11} \mathrm{~cm}^{2} \cdot \mathrm{s}^{-1}\right)$, and ${ }^{129} \mathrm{I}$ $\left(5.5 \times 10^{-9} \mathrm{~cm}^{2} \cdot \mathrm{s}^{-1}\right)$. Krishnamoorthy ${ }^{63}$ also measured effective diffusivities for cement-solidified waste forms, although his did not contain decontamination ion-exchange resins. For ${ }^{14} \mathrm{C}$, he measured an effective diffusivity of $3 \times 10^{-13}$ $\mathrm{cm}^{2} \cdot \mathrm{s}^{-1}$, which is an order of magnitude higher than the effective diffusivity of ${ }^{14} \mathrm{C}$ measured in this study. For ${ }^{131} \mathrm{I}$, Krishnamoorthy measured an effective diffusivity of $3.4 \times 10^{-7} \mathrm{~cm}^{2} \cdot \mathrm{s}^{-1}$, which is several orders of magnitude higher than the effective diffusivity of ${ }^{129}$ I measured in this study. Consequently, it can be assumed that there are differences between the behavior of the laboratory prepared specimens and the actual wasteform specimens used in this study.

The average leachability indexes of ${ }^{14} \mathrm{C},{ }^{99} \mathrm{Tc}$, and ${ }^{129} \mathrm{I}$ are $13.5,11.0$, and 8.4 , respectively. As expected, the ${ }^{14} \mathrm{C}$ would have a high leachability index, and ${ }^{129} \mathrm{I}$ would have a low one. These data again confirm the increased mobility of ${ }^{129} \mathrm{I}$.

Other radionuclides for which analyses were performed as part of this study were ${ }^{90} \mathrm{Sr},{ }^{125} \mathrm{Sb}$, and transuranics including ${ }^{239} \mathrm{Pu},{ }^{241} \mathrm{Pu},{ }^{242} \mathrm{Cm}$, ${ }^{244} \mathrm{Cm}$, and ${ }^{241} \mathrm{Am}$. However, except for ${ }^{241} \mathrm{Pu}$, the transuranics were not detectable in any of the leachate samples. Also, ${ }^{24} \mathrm{Pu}$ was only 
measurable in a few of the leachate samples. The inventory per gram of resin typically ranged from $10^{-2}$ to $10^{-1} \mathrm{mCi} / \mathrm{cm}^{3}$ of resin. The measured fractional release rates for a single period for the Brunswick-1 mixed-bed resin, and FitzPatrick mixed-bed resin were $6.3 \times 10^{-12} \mathrm{~cm}^{-2} \cdot \mathrm{s}^{-1}$ and $6.9 \times 10^{-13} \mathrm{~cm}^{-2} \cdot \mathrm{s}^{-1}$, respectively. The detection limit for the Brunswick-1 cation resin wasteform sample was $<3.4 \times 10^{-12} \mathrm{~cm}^{-2} \cdot \mathrm{s}^{-1}$. Typical detection limit values for the average fractional release rates of ${ }^{241} \mathrm{Pu}$ were $<10^{-13}$ to $<10^{-12}$ $\mathrm{cm}^{-2} \cdot \mathrm{s}^{-1}$. These fractional release rates are low and indicate that the ${ }^{241} \mathrm{Pu}$ and probably all transuranics are retained in the waste form to a greater extent than are the decontamination metals and other more mobile radionuclides. Absolute and fractional release rates, cumulative fractional releases, effective diffusivities, and leachability indexes for these radionuclides are listed in Appendix F. Less-than visues were not used for calculating release rates, effective diffusivities, and leachability indexes for the transuranics and other radionuclides in this report because, without any actual results, these data would be misleading. In contrast, release rates, effective diffusivities, and leachability indexes were calculated for the actual measurement results for ${ }^{125} \mathrm{Sb},{ }^{137} \mathrm{Cs}$, and ${ }^{90} \mathrm{Sr}$. For the Peach Bottom-3 samples, which are representative of the other waste form samples, the average fractional release rates for these radionuclides were: ${ }^{125} \mathrm{Sb}\left(5.5 \times 10^{-11}\right.$ $\left.\mathrm{cm}^{-2} \cdot \mathrm{s}^{-1}\right),{ }^{137} \mathrm{Cs}\left(4.1 \times 10^{-10} \mathrm{~cm}^{-2} \cdot \mathrm{s}^{-1}\right)$, and ${ }^{90} \mathrm{Sr}\left(3.1 \times 10^{-10} \mathrm{~cm}^{-2} \cdot \mathrm{s}^{-1}\right)$. These data indicate that the release rates of ${ }^{137} \mathrm{Cs}$ and ${ }^{90} \mathrm{Sr}$ are the same. This behavior is not expected because ${ }^{90} \mathrm{Sr}$ is not ionic and would not be expected to be released at the same rate as ${ }^{137} \mathrm{Cs}$. Examination of the Brunswick-1, Cooper, and other ${ }^{90} \mathrm{Sr}$ data indicates that release rates are high and in some cases higher than that of ${ }^{137} \mathrm{Cs}$, which suggests that this radionuclide is quite mobile. This observed behavior suggests that the release rate of ${ }^{90} \mathrm{Sr}$ may be enhanced by chelating agent effects.

Stable Metals. Of the four primary stable metals for which measurements were performed, only iron and nickel were measurable in most leachates. Results of detection-limit calculations for chromium and cobalt are listed in Tables F-1 through F-11 in Appendix F. Summaries of the CFRs, release rates, effective diffusivities, and leachability indexes for iron and nickel are shown in Tables 20 and 21 . In addition, the weighted-average fractional and absolute release rate data for both elements are shown in Tables 18 and 19.

Figures 39 and 40 show the average fractional release rates for nickel and iron, and Figures 41 and 42 show the CFRs for both metals. For the LOMI samples, the average fractional release rate of nickel is similar for all waste forms $\left(\sim 4 \times 10^{-10} \mathrm{~cm}^{-2} \cdot \mathrm{s}^{-1}\right)$, whereas the fractional release rates for iron were up to three orders of magnitude lower. In contrast, the picolinic acid fractional release rates were approximately $3 \times 10^{-9} \mathrm{~cm}^{-2} \cdot \mathrm{s}^{-1}$. This suggests that most nickel was being retained in an insoluble form with about $10 \%$ released with the chelating agent in a diffusional release. Nickel-63 has the same weighted-average fractional release rate $(4.8 \pm$ $1.0 \times 10^{-10} \mathrm{~cm}^{-2} \cdot \mathrm{s}^{-1}$ excluding Indian Point-3, a PWR) as the elemental nickel except for the Indian Point-3 sample, for which the fractional release rate of ${ }^{63} \mathrm{Ni}$ was about $2 \%$ of the release of nickel. These data suggest that for BWR waste streams, the elemental nickel and ${ }^{63} \mathrm{Ni}$ are released from the waste form by the same mechanism.

The average fractional release rate data for iron for the LOMI waste forms is primarily detection limit data, which suggests that the retention for this element is greater than that for nickel, with the nickel release rates approximately 1,000 greater than those of iron, as shown in Table 18. A comparison of the only measurable ${ }^{55} \mathrm{Fe}$ and iron fractional release rate data (Peach Bottom-3) indicates that the fractional release rate of ${ }^{55} \mathrm{Fe}$ is about two orders of magnitude higher than that for elemental iron. The explanation for this behavior is not known and is not consistent with the expected kinetics of this radionuclide, which suggests that it should be released as the same rate as the iron.

The average fractional release rate data for nickel and iron for the Citrox waste forms are detection limit values, with the exceptions of the 
Experimental Results and Discussion

Table 20. Stable iron release rates, cumulative fractional releases, effective diffusivities, and leachability indexes.

\begin{tabular}{|c|c|c|c|c|c|}
\hline \multirow[b]{2}{*}{ Plant } & \multirow[b]{2}{*}{ CFR } & \multicolumn{2}{|c|}{ Release rate } & \multirow{2}{*}{$\begin{array}{c}\text { Average } \\
\text { effective } \\
\text { diffusivity } \\
\left(\mathrm{cm}^{2} \cdot \mathrm{s}^{-1}\right)^{\mathrm{a}}\end{array}$} & \multirow[b]{2}{*}{$\begin{array}{l}\text { Leachability } \\
\text { index }^{b}\end{array}$} \\
\hline & & $\begin{array}{c}\text { Absolute } \\
\left(\mu \mathrm{Ci} \cdot \mathrm{m}^{-2} \cdot \mathrm{s}^{-1}\right)^{\mathrm{a}}\end{array}$ & $\begin{array}{l}\text { Fractional } \\
\left(\mathrm{cm}^{-2} \cdot \mathrm{s}^{-1}\right)^{\mathrm{a}}\end{array}$ & & \\
\hline Indian Point-3 & $4.4 \mathrm{E}-4$ & $<4.5 \mathrm{E}-6$ & $<6.2 \mathrm{E}-11$ & $<4.3 \mathrm{E}-12$ & $>12.1$ \\
\hline FitzPatrick MBR & $-c$ & $<1.0 \mathrm{E}-5$ & $<2.6 \mathrm{E}-11$ & $<5.4 \mathrm{E}-12$ & $>12.0$ \\
\hline FitzPatrick baked & $<2.6 \mathrm{E}-3$ & $<9.4 \mathrm{E}-6$ & $<2.8 \mathrm{E}-11$ & $<4.6 \mathrm{E}-12$ & $>12.3$ \\
\hline Peach Bottom-3 & 4.6E-5 & $2.6 \pm 0.7 \mathrm{E}-6$ & $5.9 \pm 1.5 \mathrm{E}-13$ & $3.2 \pm 0.9 \mathrm{E}-15$ & 14.4 \\
\hline Cooper CR & $1.4 \mathrm{E}-1$ & $-^{c}$ & $1.4 \pm 3.1 \mathrm{E}-8$ & $10 \pm 21 \mathrm{E}-7$ & 10.0 \\
\hline Cooper MBR & $-^{c}$ & $-^{c}$ & $<3.0 \mathrm{E}-11$ & $<7.8 \mathrm{E}-12$ & $>11.2$ \\
\hline Brunswick-1 CR & $1.8 \mathrm{E}-3$ & $1.0 \pm 0.5 \mathrm{E}-5$ & $9 \pm 4 \mathrm{E}-12$ & $2 \pm 1 \mathrm{E}-12$ & 12.7 \\
\hline $\begin{array}{l}\text { Brunswick-1 } \\
\text { MBR }\end{array}$ & $<2.1 \mathrm{E}-2$ & $<1.6 \mathrm{E}-5$ & $<1.7 \mathrm{E}-10$ & $<1.5 \mathrm{E}-10$ & $>10.5$ \\
\hline Millstone-1 F33 & $-^{c}$ & - $^{c}$ & $-^{c}$ & $-^{c}$ & $-^{c}$ \\
\hline Millstone-1 F201 & $-^{c}$ & $<2.4 \mathrm{E}-6$ & $<6.0 \mathrm{E}-12$ & $<2.4 \mathrm{E}-14$ & $>14$ \\
\hline Peach Bottom-2 & $-^{c}$ & $-c$ & $一^{c}$ & $-^{c}$ & $\sim^{c}$ \\
\hline Pilgrim & $-^{c}$ & - & $-^{c}$ & - $^{c}$ & $-^{c}$ \\
\hline
\end{tabular}

a. Internal uncertainty associated with calculated results. Does not include counting statistics or other uncertainties associated with the leaching process.

b. Average values were calculated excluding zeros.

c. Not detected or not measured.

Cooper cation resin waste form for nickel and iron $\left(5.3 \times 10^{-9} \mathrm{~cm}^{-2} \cdot \mathrm{s}^{-1}\right.$ and $1.4 \times 10^{-8}$ $\mathrm{cm}^{-2} \cdot \mathrm{s}^{-1}$, respectively). In addition, the Brunswick-1 cation resin waste form, which does not contain chelating agents, had a fractional release rate of $9 \times 10^{-12} \mathrm{~cm}^{-2} \cdot \mathrm{s}^{-1}$ for iron. The results for iron and nickel from the Cooper waste form are statistically the same and suggest similar release rates for both elements. Comparisons with
${ }^{63} \mathrm{Ni}$ and ${ }^{55} \mathrm{Fe}$ indicate that the average fractional release rates for nickel and iron are higher than those of the radionuclides by one to two orders of magnitude. These data indicate that the radionuclides may be in a chemical form in the waste form that causes them to be retained to a greater extent than the elemental iron and nickel. Kinetics suggest that this is unlikely and that the radionuclides should exchange and should be 
Table 21. Stable nickel release rates, cumulative fractional releases, effective diffusivities, and leachability indexes.

\begin{tabular}{|c|c|c|c|c|c|}
\hline \multirow[b]{2}{*}{ Plant } & \multirow[b]{2}{*}{ CFR } & \multicolumn{2}{|c|}{ Release rate } & \multirow{2}{*}{$\begin{array}{c}\text { Average } \\
\text { effective } \\
\text { diffusivity } \\
\left(\mathrm{cm}^{2} \cdot \mathrm{s}^{-1}\right)^{\mathrm{a}}\end{array}$} & \multirow[b]{2}{*}{$\begin{array}{l}\text { Leachability } \\
\text { index }^{b}\end{array}$} \\
\hline & & $\begin{array}{c}\text { Absolute } \\
\left(\mu \mathrm{Ci} \cdot \mathrm{cm}^{-2} \cdot \mathrm{s}^{-1}\right)^{\mathrm{a}} \\
\end{array}$ & $\begin{array}{l}\text { Fractional } \\
\left(\mathrm{cm}^{-2} \cdot \mathrm{s}^{-1}\right)^{\mathrm{a}}\end{array}$ & & \\
\hline Indian Point-3 & $1.4 \mathrm{E}-2$ & $2.0 \pm 2.8 \mathrm{E}-5$ & $2.6 \pm 3.5 \mathrm{E}-10$ & $1.5 \pm 0.9 \mathrm{E}-10$ & 10.1 \\
\hline FitzPatrick MBR & $5.0 \mathrm{E}-2$ & $5 \pm 2 E-6$ & $3 \pm 1 \mathrm{E}-10$ & $1.1 \pm 0.5 \mathrm{E}-9$ & 9.4 \\
\hline FitzPatrick baked & $5.8 \mathrm{E}-2$ & $7 \pm 5 \mathrm{E}-6$ & $5 \pm 3 E-10$ & $1.5 \pm 0.7 \mathrm{E}-9$ & 9.5 \\
\hline Peach Bottom-3 & $2.9 \mathrm{E}-2$ & $1.4 \pm 1.2 \mathrm{E}-5$ & $9.3 \pm 8.1 \mathrm{E}-10$ & $1.2 \pm 0.3 \mathrm{E}-9$ & 8.9 \\
\hline Cooper CR & $7.8 \mathrm{E}-2$ & $\sim_{c}^{c}$ & $5.3 \pm 15.6 \mathrm{E}-9$ & $2.0 \pm 5.9 \mathrm{E}-7$ & 9.3 \\
\hline Cooper MBR & $1.8 \mathrm{E}-2$ & $-_{c}^{c}$ & $<1.5 \mathrm{E}-9$ & $<1.0 \mathrm{E}-8$ & $>8.1$ \\
\hline Brunswick-1 CR & $<9.8 \mathrm{E}-3$ & $<1.3 \mathrm{E}-5$ & $<9.4 \mathrm{E}-11$ & $<2.8 \mathrm{E}-11$ & $>10.9$ \\
\hline $\begin{array}{l}\text { Brunswick-1 } \\
\text { MBR }\end{array}$ & $<1.6 \mathrm{E}-1$ & $<1.0 \mathrm{E}-5$ & $<1.1 \mathrm{E}-9$ & $<6.7 \mathrm{E}-9$ & $>8.5$ \\
\hline Millstone-1 F33 & - $^{c}$ & $-c$ & $-^{c}$ & $-^{c}$ & $-^{c}$ \\
\hline Millstone-1 F201 & $8.1 E-3$ & $2.0 \pm 2.5 \mathrm{E}-5$ & $1.6 \pm 1.9 \mathrm{E}-10$ & $3.2 \pm 2.4 \mathrm{E}-11$ & 10.7 \\
\hline Peach Bottom-2 & $-^{c}$ & $-c$ & $-^{c}$ & $-^{c}$ & $\sim^{c}$ \\
\hline Pilgrim & $3.5 \mathrm{E}-1$ & $8.1 \pm 6.5 \mathrm{E}-3$ & $4.9 \pm 4.0 \mathrm{E}-9$ & $2.3 \pm 1.8 \mathrm{E}-7$ & 6.9 \\
\hline
\end{tabular}

a. Internal uncertainty associated with calculated results. Does not include counting statistics or other uncertainties associated with the leaching process.

b. Average values were calculated excluding zeros.

c. Not detected or not measured.

released at the same rates as the elements. Further investigation is required to better understand this phenomena.

For the Can-Decon and NS- 1 waste forms, only nickel was measurable, and the average fractional release rate was $1.6 \times 10^{-10} \mathrm{~cm}^{-2} \cdot \mathrm{s}^{-1}$ for the Millstone-1 (F-201) Can-Decon sample and $4.9 \times 10^{-9} \mathrm{~cm}^{-2} \cdot \mathrm{s}^{-1}$ for Pilgrim. Comparisons with the ${ }^{63} \mathrm{Ni}$ data indicate that the average fractional release rates of the stable metal are similar to those measured for the radionuclide.

CFRs for nickel and iron are shown in Figures 41 and 42 and are listed in Tables 20 and 21 . Nominal CFRs for the LOMI data range from $10^{-2}$ to $5 \times 10^{-2}$ for nickel with a wide range of CFRs for iron, $1 \times 10^{-5}$ to 0.1 . For the Citrox 


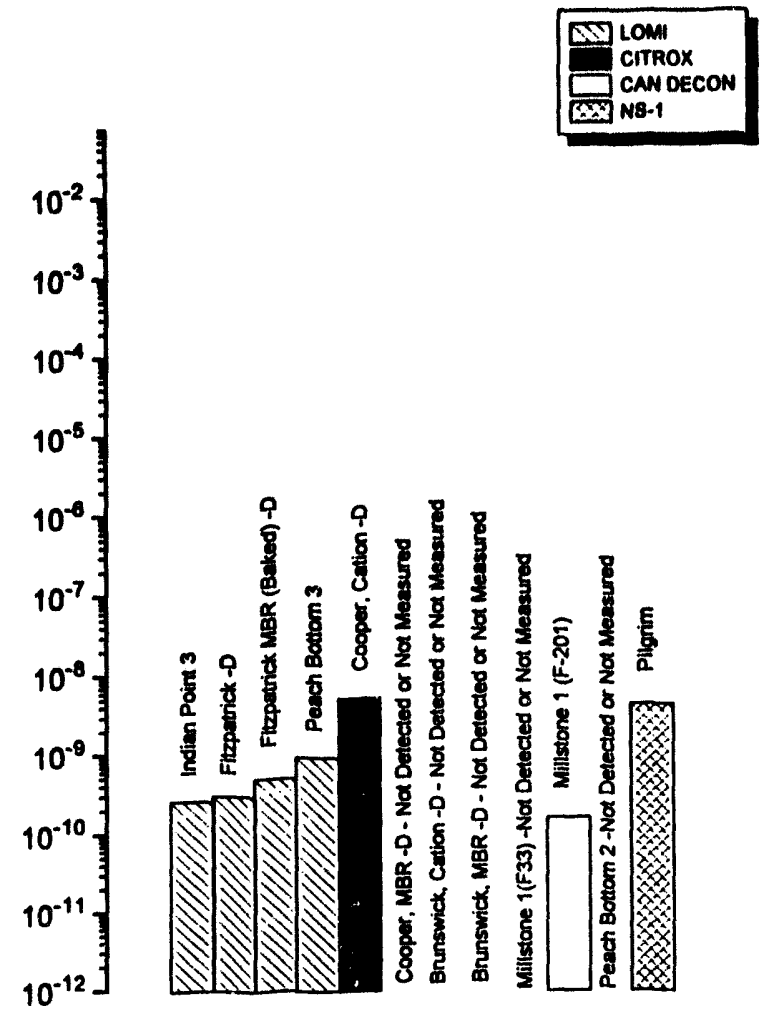

Figure 39. Stable nickel average fractional release rates $\left(\mathrm{cm}^{-2} \cdot \mathrm{s}^{-1}\right)$.

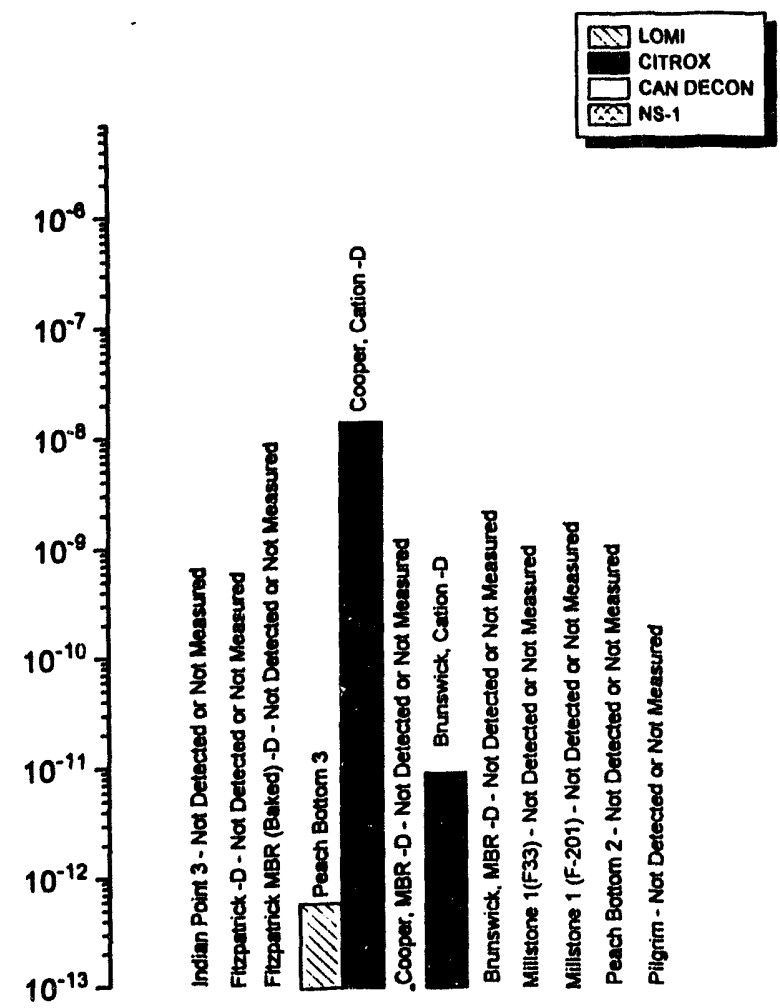

Figure 40. Stable iron average fractional release rates $\left(\mathrm{cm}^{-2} \cdot \mathrm{s}^{-1}\right)$.

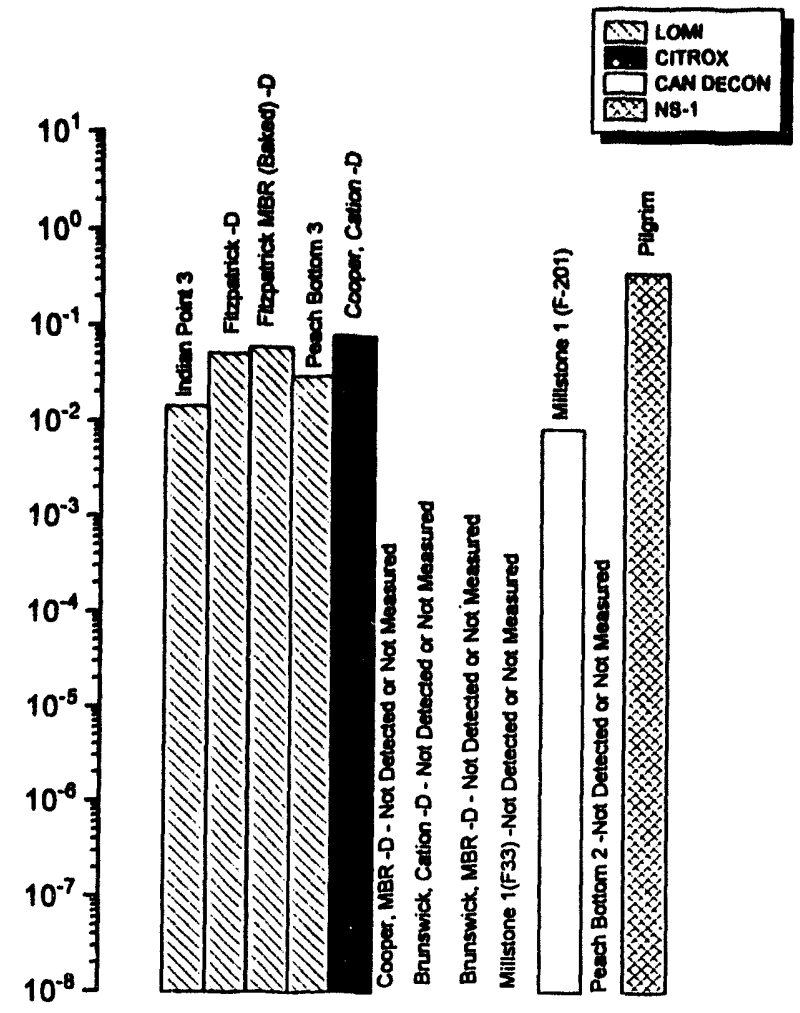

Figure 41. Stable nickel cumulative fractional release.

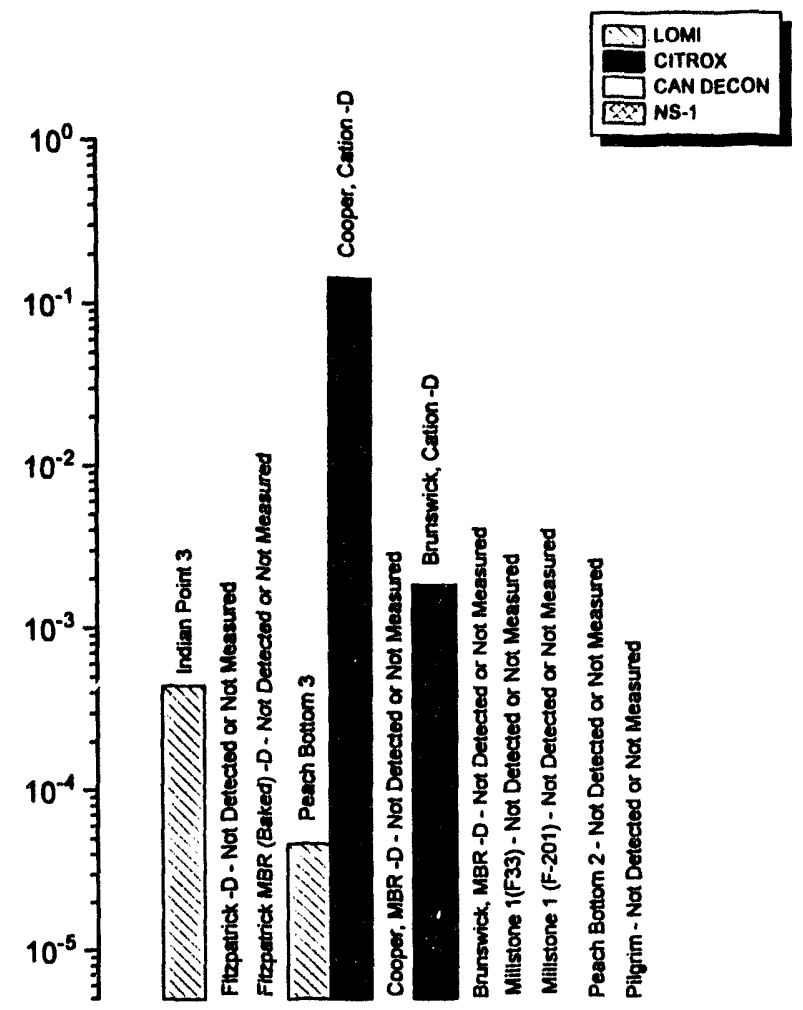

Figure 42. Stable iron cumulative fractional release. 
waste forms, the range for nickel is based on the Cooper cation resin waste form which has a CFR of $8 \times 10^{-2}$. The high CFR for iron for this sample is due to a single data point $\left(7.6 \times 10^{-2}\right)$. Other measured incremental releases are approximately $10^{-4}$. In contrast, the iron average fractional release rate from the Brunswick-1 cation resin waste form is $2 \times 10^{-3}$. For the Can-Decon and NS-1 waste forms, only nickel was measurable, and the Millstone 1 (F-201) CFR for nickel is 0.007 , whereas for Pilgrim the value is 0.35 . As discussed previously, the reason for the high release rates from the Pilgrim sample are not known. Comparison with ${ }^{63} \mathrm{Ni}$ and ${ }^{55} \mathrm{Fe}$ suggests that the average fractional release rates from the metals are similar to those of the radionuclides. For the Pilgrim NS-1 specimen, the CFR for ${ }^{63} \mathrm{Ni}$ and nickel are approximately the same.

The average effective diffusivities for stable iron and nickel are shown in Figures 43 and 44, and the leachability indexes are shown in Figures 45 and 46. For the LOMI waste forms, the average effective diffusivities for nickel are similar and suggest a rate of approximately $7 \times 10^{-10} \mathrm{~cm}^{2} \cdot \mathrm{s}^{-1}$. This is one to two orders of magnitude higher than that measured for ${ }^{63} \mathrm{Ni}$. The effective diffusivity of iron for the LOMI samples are detection limit results, except for the Peach Bottom-3 waste form at $2.3 \times 10^{-15}$ $\mathrm{cm}^{2} \cdot \mathrm{s}^{-1}$. Results for the Citrox samples are limited and, with the exception of the high values for the Cooper cation resin, as discussed previously, most are detection-limit values.

Leachability indexes for nickel and iron are similar for all waste forms from about 7 to 10 for nickel and a range of 11 to 15 for iron. Leachability indexes for the stable metals are all well above the regulatory limit and suggest that the stable metals are retained even in the degraded waste forms.

Primary observations from the stable metal analyses are that ${ }^{63} \mathrm{Ni}$ has the same weighted-average fractional release rate as the elemental nickel for the LOMI (excluding Indian Point-3) and the Can-Decon samples whereas, for the AP/
Citrox samples, the fractional release rates of the stable metals are one to two orders of magnitude higher than those for the radionuclides. In addition, the fractional release rate of ${ }^{63} \mathrm{Ni}$ from the Indian Point-3 sample was about $2 \%$ of the release of nickel. These data suggest that, in general, there are differences between the release rates of the stable metals and the radionuclides, which suggests that the radionuclides are retained in the waste form to a greater extent than are the stable metals. These results are not expected as kinetic exchange would be expected between the stable metals and the radionuclides of the same element and suggests that further work is required.

\section{The Effects of Leachants with Different pHs and Compositions on the Release of Chelating Agents, Radionuclides, and Stable Motals}

As part of this study, an evaluation was performed on Brunswick-1 and FitzPatrick samples to assess the effects of different groundwaters on the leachability of chelating agents, radionuclides, and stable metals. Studies ${ }^{7,67}$ have suggested that the effects of groundwaters on leachability are significant. In a study by De Angelis ${ }^{56}$ and others, ${ }^{68,69}$ it was shown that ion strength, leachant chemical composition, and leachant replacement frequency may affect leachability. Our study used leachants that simulated groundwaters and seawater and whose composition is shown in Table 8. This study was performed on specimens of the Brunswick-1 cation resin (no chelating agent), Brunswick-1 mixedbed resin (Citrox), and FitzPatrick mixed-bed resin (LOMI) waste form specimens. Use of these waste forms for the study is of particular value because the Brunswick-1 cation resin waste form does not contain chelating agents, whereas the Brunswick-1 mixed-bed resin waste forms contain oxalic and citric acid and the FitzPatrick waste forms contain picolinic acid. The following sections discuss the effects of the leachant on the chelating agents, radionuclides, and stable metals present in the waste forms. Leaching results are presented in Appendix E, and summary tables 


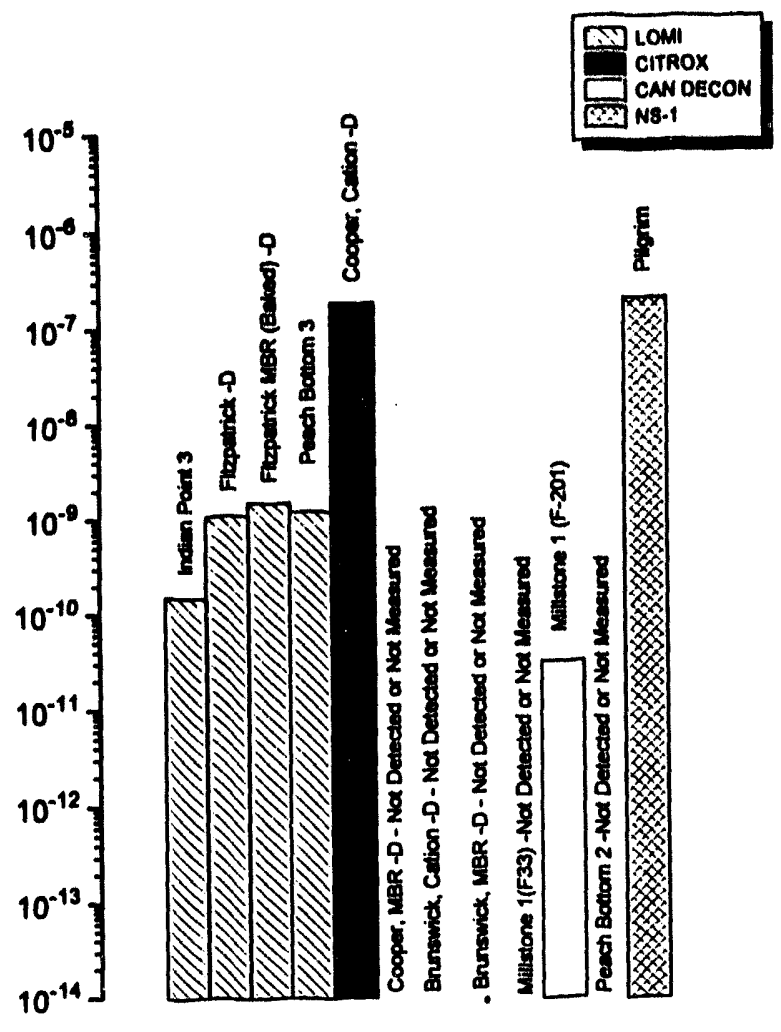

Figure 43. Stable nickel effective diffusivity.

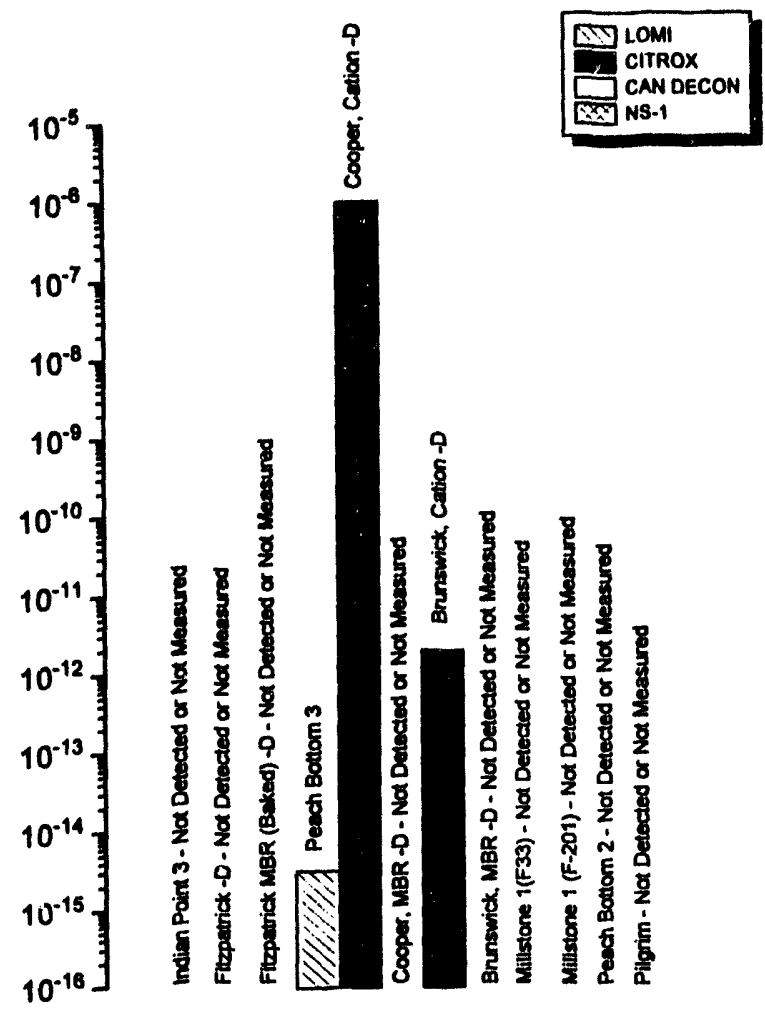

Figure 44. Stable iron effective diffusivity.

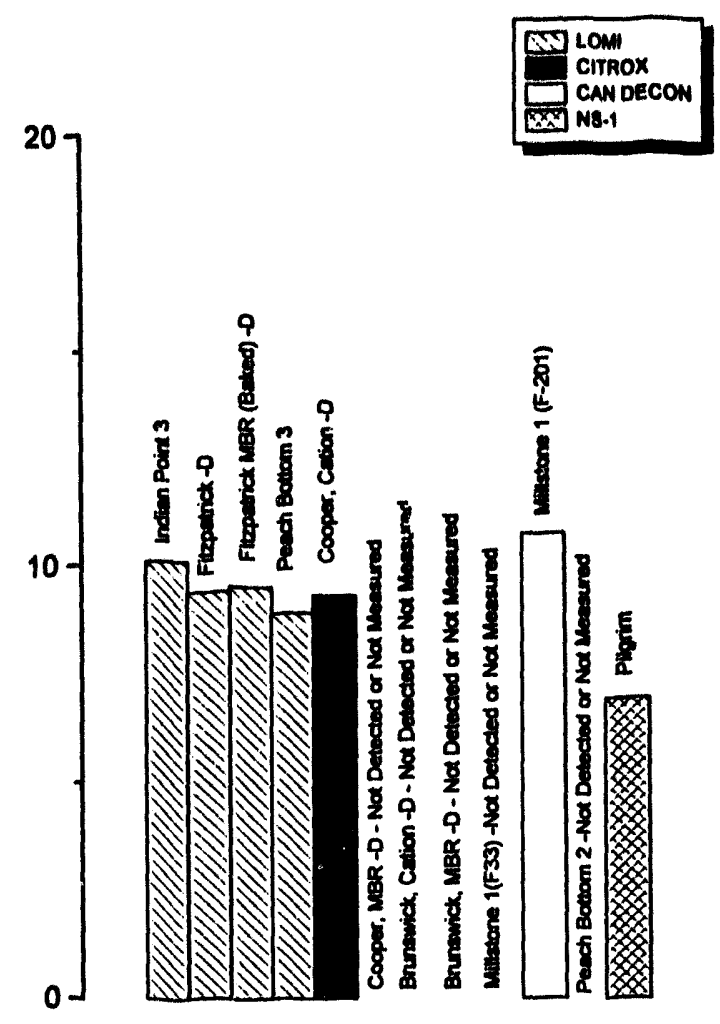

Figure 45. Nickel leachability indexes.

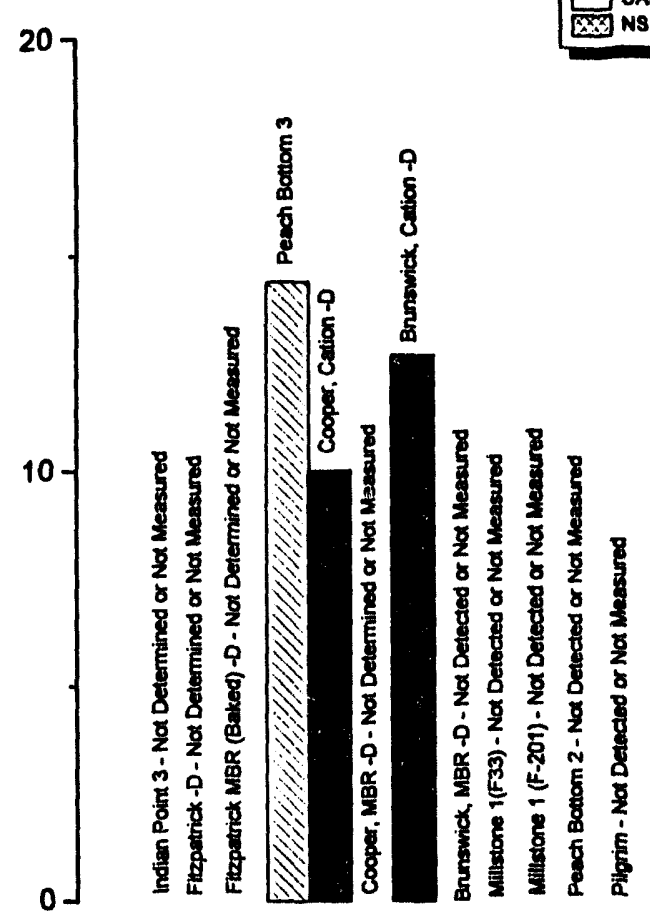

Figure 46. Iron leachability indexes. 
showing the average fractional release rates, CFRs, effective diffusivities, and leachability indexes are presented in Appendix $F$.

Chelating Agents. Chelating agents were either not present in the Brunswick-1 cation resin waste form or were present at low concentrations. In contrast, as shown in Table 11, the Brunswick-1 mixed-bed resin waste form contained about $2 \mathrm{wt} \%$ oxalic acid and $4 \mathrm{wt} \%$ citric acid, and the FitzPatrick waste-form specimens contained about 2.2 wt\% picolinic acid. Figures 47 through 49 show the fractional release rates of oxalic acid citric acid and picolinic acid from representative Brunswick-1 and FitzPatrick mixedbed resin waste forms. The waste-form leachates are identified in the figure legends as Barnwell groundwater (BGW), deionized water (DW). Hanford groundwater (HGW), and simulated seawater (SW). The samples identified as B-DW and B-BGW are the FitzPatrick samples that were baked prior to leaching. Examination of Fig- ures 47 and 48 indicates that there appears to be little or no effect of the leachant on the fractional release rates of oxalic acid and citric acid from the waste form, with the exception of the citric acid for the HGW pH 8.9 and the BGW pH 4.2, which may have increased the fractional release rate slightly, and the simulated seawater leachant, which apparently reduced the fractional release rate of citrate from the sample. The average fractional release for oxalic acid is $8.2 \times 10^{-11}$ $\mathrm{cm}^{-2} \cdot \mathrm{s}^{-1}$, and for citric acid, it is $6.8 \times 10^{-11}$ $\mathrm{cm}^{-2} \cdot \mathrm{s}^{-1}$.

Through examination of Figure 49, the fractional release rates of picolinic acid for the FitzPatrick samples indicates again that the fractional release rate does not appear to be significantly affected by the leachant, although the fractional release rates are higher than those for the Brunswick-1 samples. The average fractional release rate for all FitzPatrick specimens is about $3 \times 10^{-9} \mathrm{~cm}^{-2} \cdot \mathrm{s}^{-1}$.

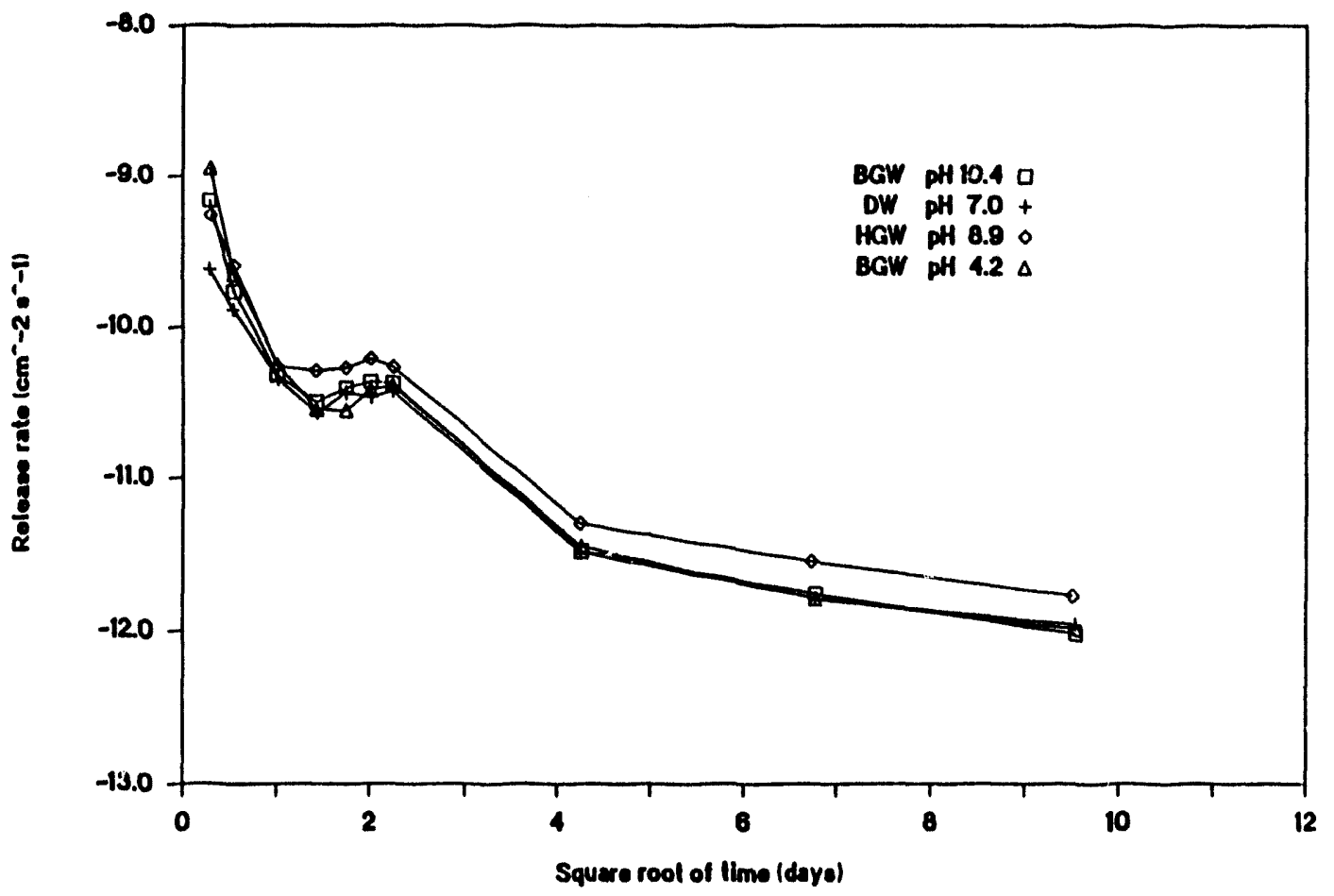

Figure 47. Fractional release rate of oxalic acid from five Brunswick-1 mixed-bed resin waste-form specimens. 

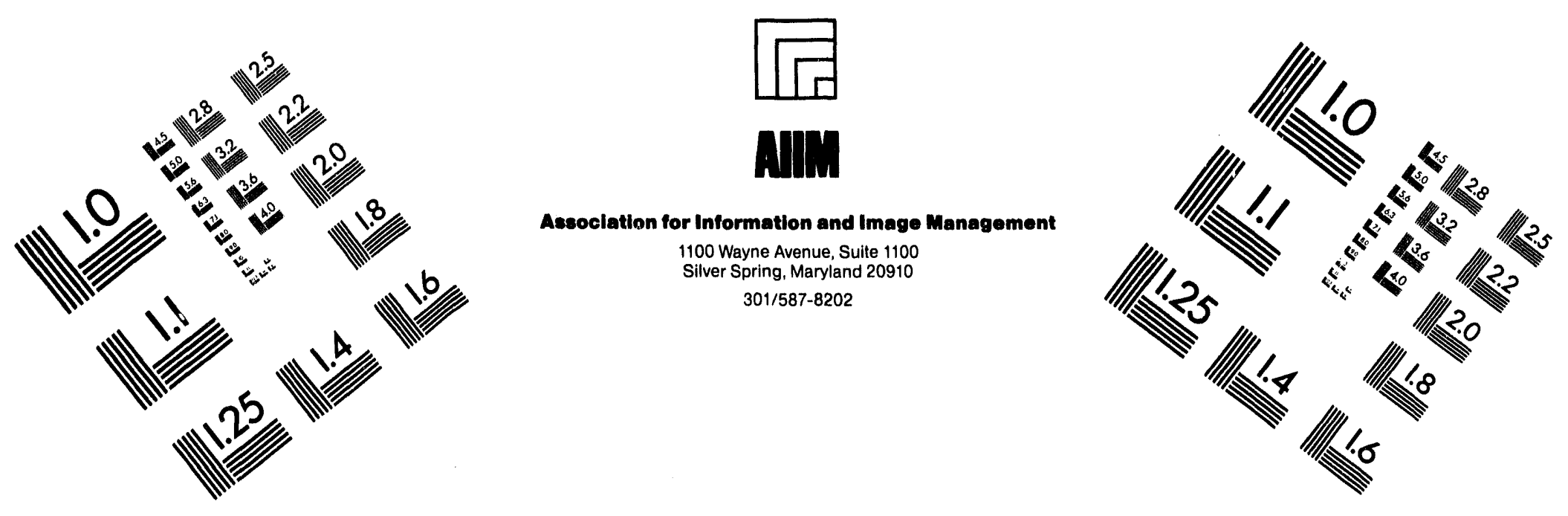

\section{Centimeter}

|m.m. Inches
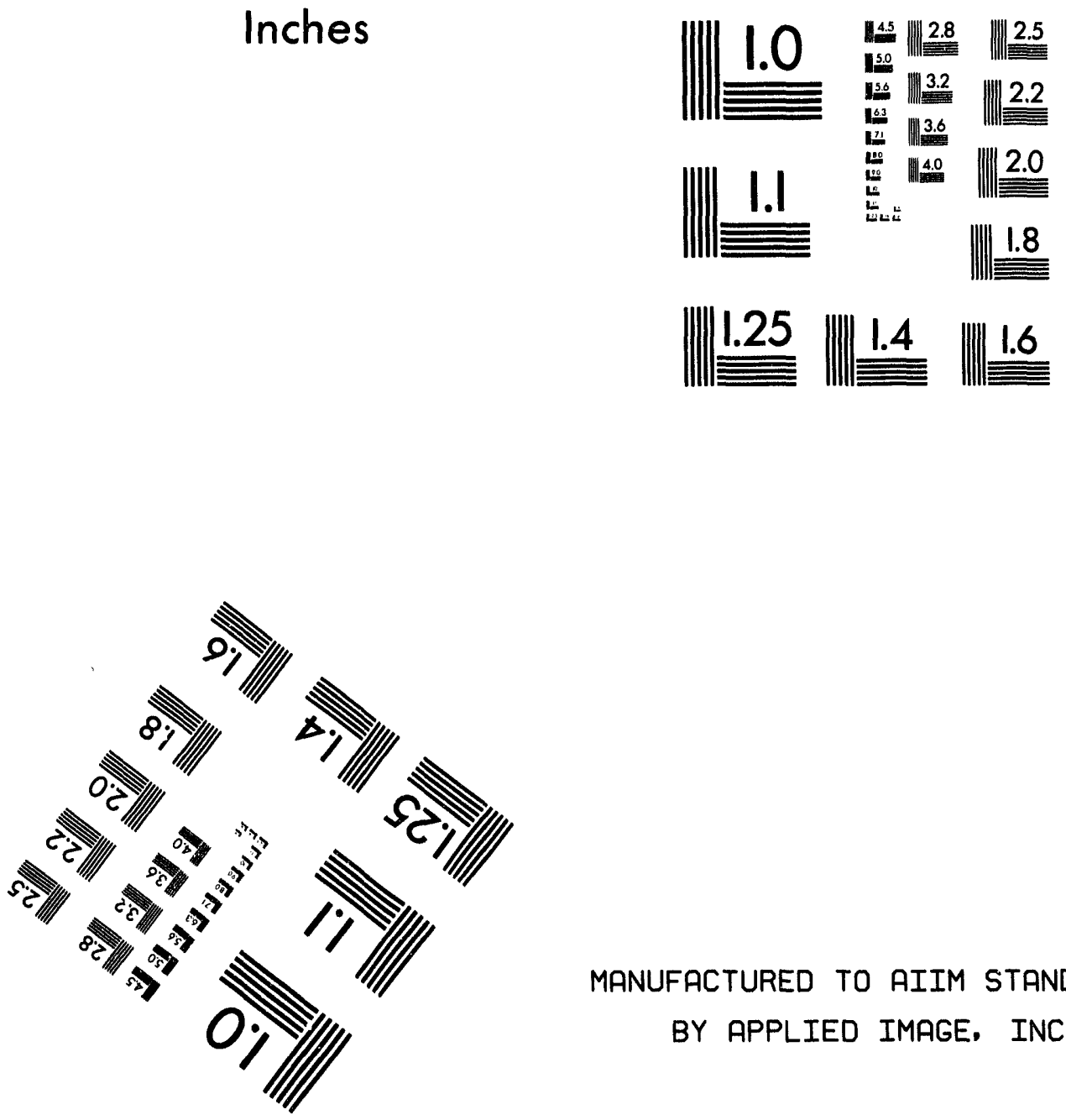

MANUFACTURED TO AIIM STANDARDS

BY APPLIED IMAGE, INC.

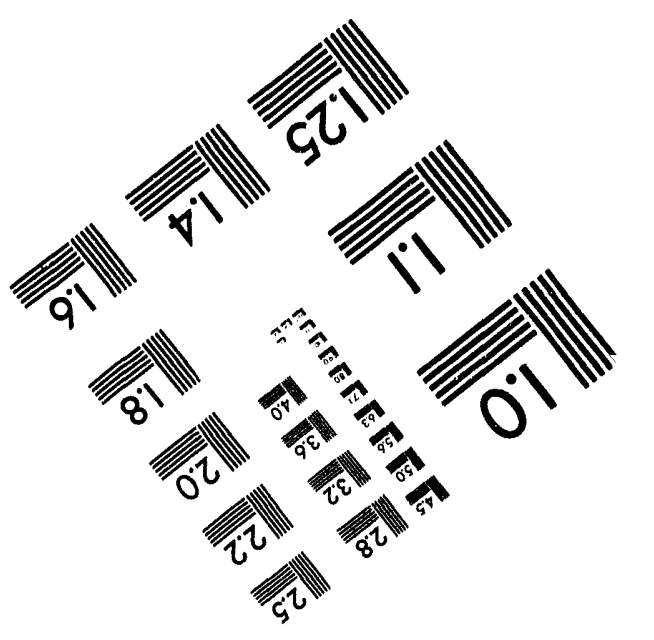



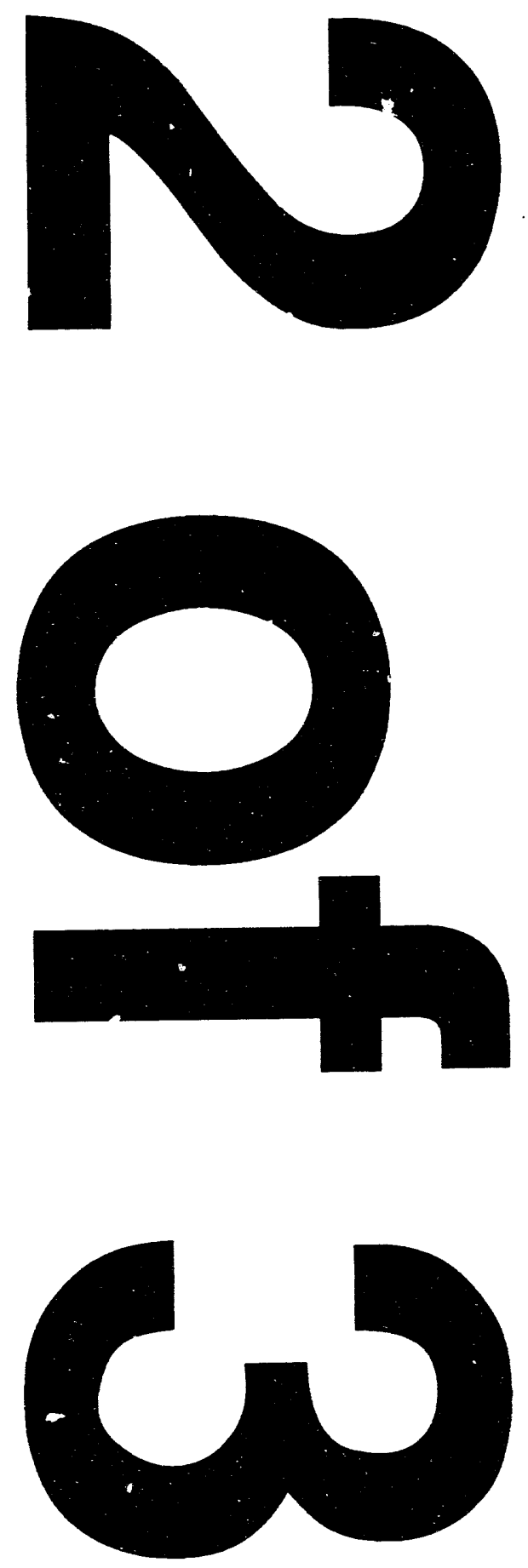
Experimental Results and Discussion

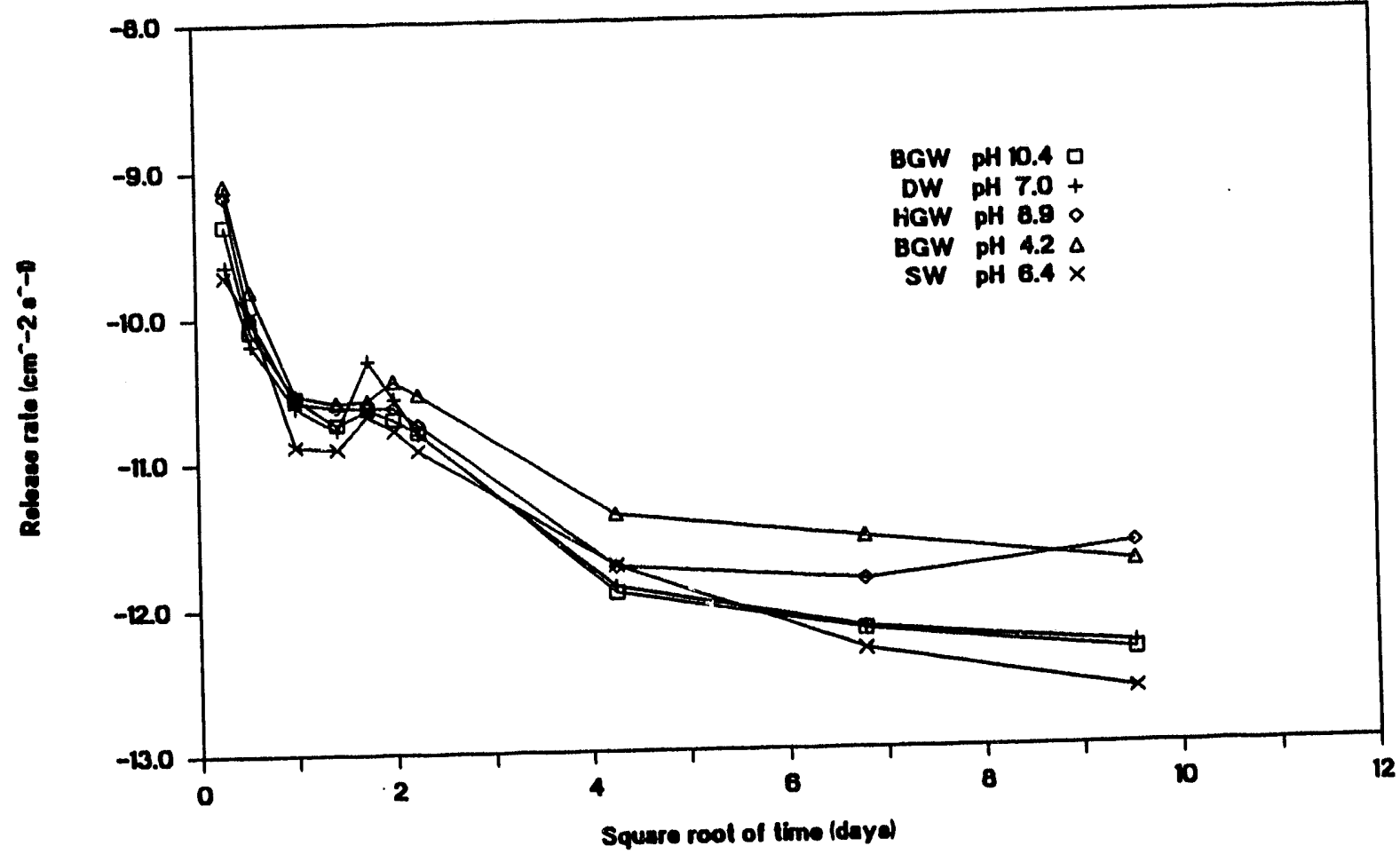

Figure 48. Fractional release rate of citric acid from five Brunswick-1 mixed-bed resin waste-form specimens.

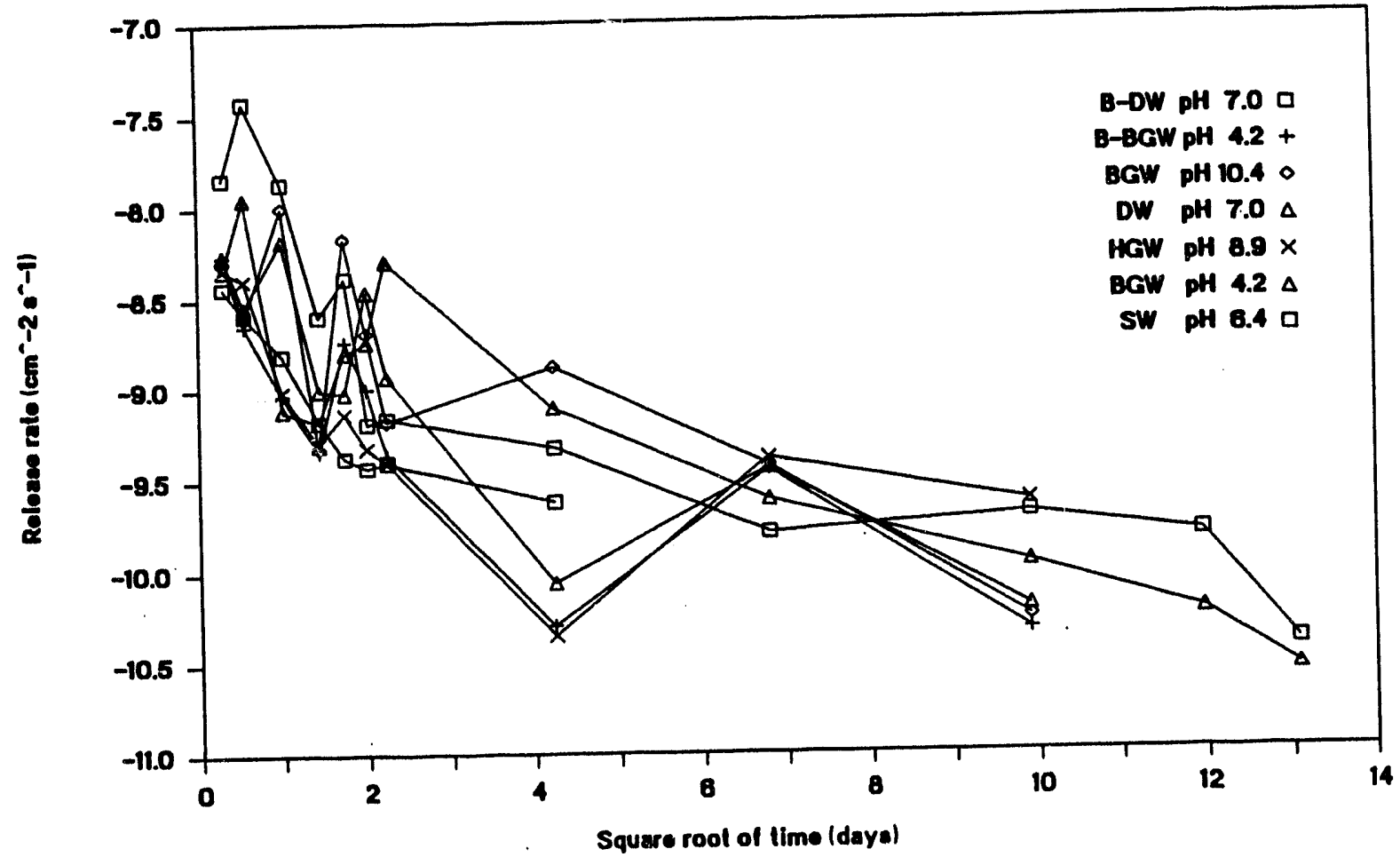

Figure 49. Fractional release rates of picolinic acid from seven FitzPatrick ion-exchange resin wasteform specimens. 
The CFRs for the chelating agents are shown in Figures 50 through 52. Examination of these figures shows that the CFRs for oxalic and citric acid are similar for all leachants (within a factor of two for oxalic and a factor of four for citric). The average CFRs for all specimens for oxalic acid and citric acid are $8.4 \times 10^{-3}$ and $5.1 \times 10^{-3}$, respectively.

Examination of Figure 52 indicates a broad range of CFRs for picolinic acid from the FitzPatrick specimens and that about $86 \%$ was released from the baked waste form leached in deionized water. This compares with 54\% leached from the unbaked specimen. In addition to the samples leached in deionized water, the CFR for the sample leached in BGW pH 10.4 was also high (75\%). These data suggest that baking and leachant composition are affecting releases from the FitzPatrick waste forms. However, comparison of the CFR data with the fractional release rate data in Figure 49 suggests that the differences in the CFRs may be related to the breakup of the waste form because the fractional release rates are quite variable, but that near the end of the leach test, the rates are all quite similar. This suggests that there is little effect of leachant composition on the release rate of the chelating agents.

The average effective diffusivities and the leachability index for each leachant and each waste form are listed in Appendix F. The leacha jility indexes for the Brunswick-1 mixed-bed resin waste form range from 10.9 to 11.6 for both oxalic and citric acids. In contrast, the leachability indexes for the FitzPatrick samples range from 6.5 to 8.3. The 6.5 value was for the baked sample leached in deionized water. These results suggest that there may be a leachant effect associated with the LOMI samples that is not apparent for the Citrox samples.

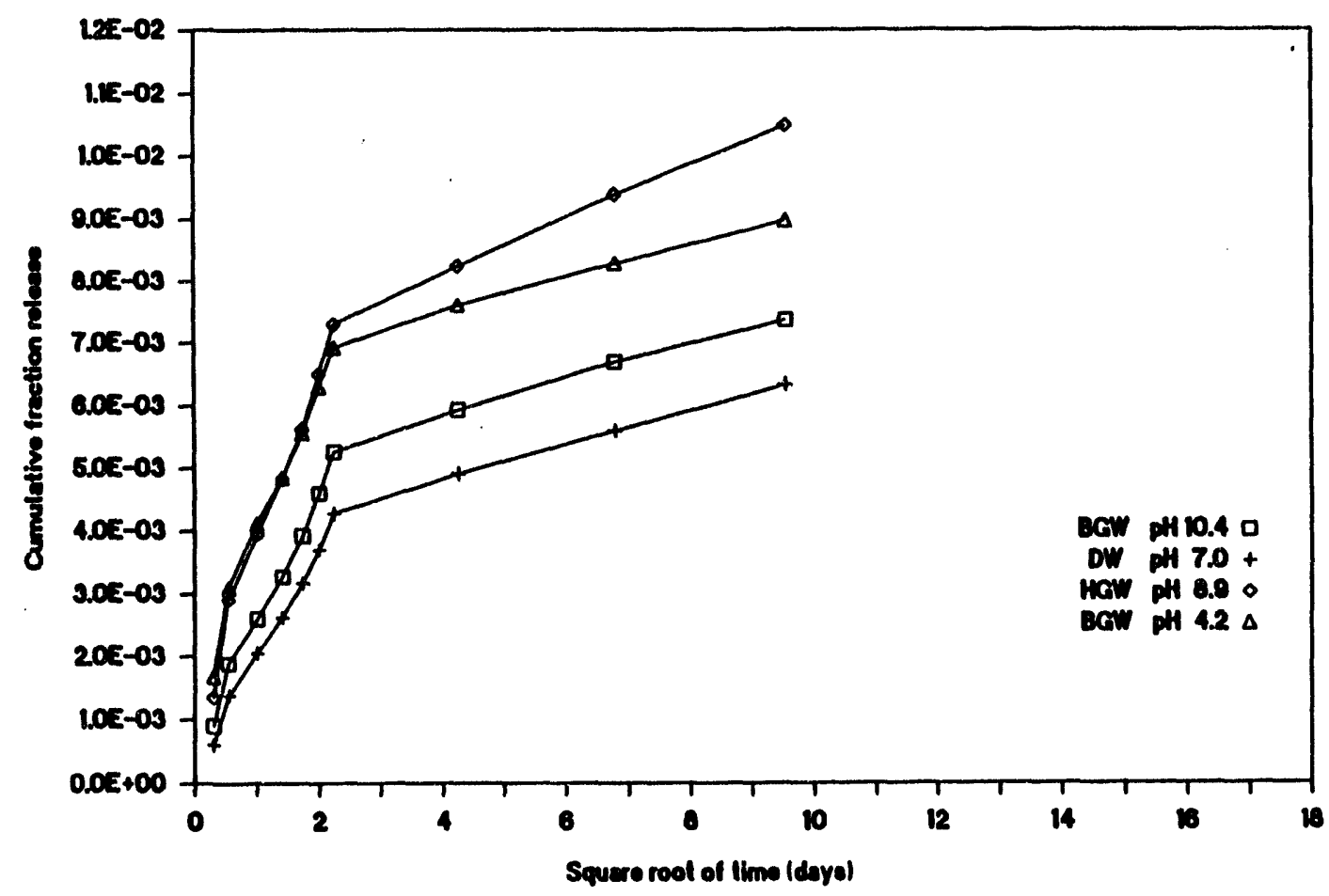

Figure 50. Cumulative fractional release of oxalic acid from five Brunswick-1 mixed-bed resin wasteform specimens. 
Experimental Results and Discussion

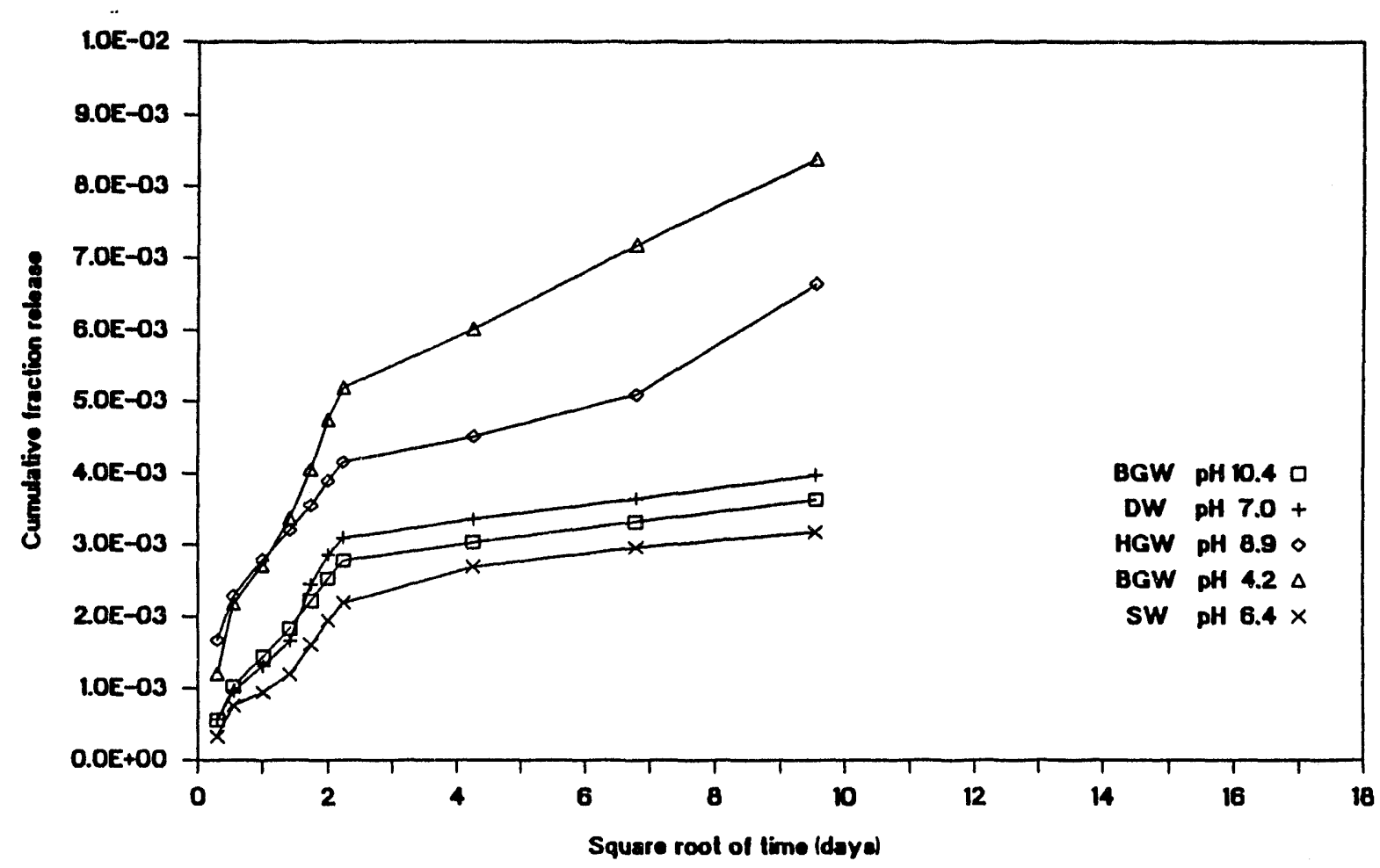

Figure 51. Cumulative fractional release of citric acid from five Brunswick-1 mixed-bed resin wasteform specimens.

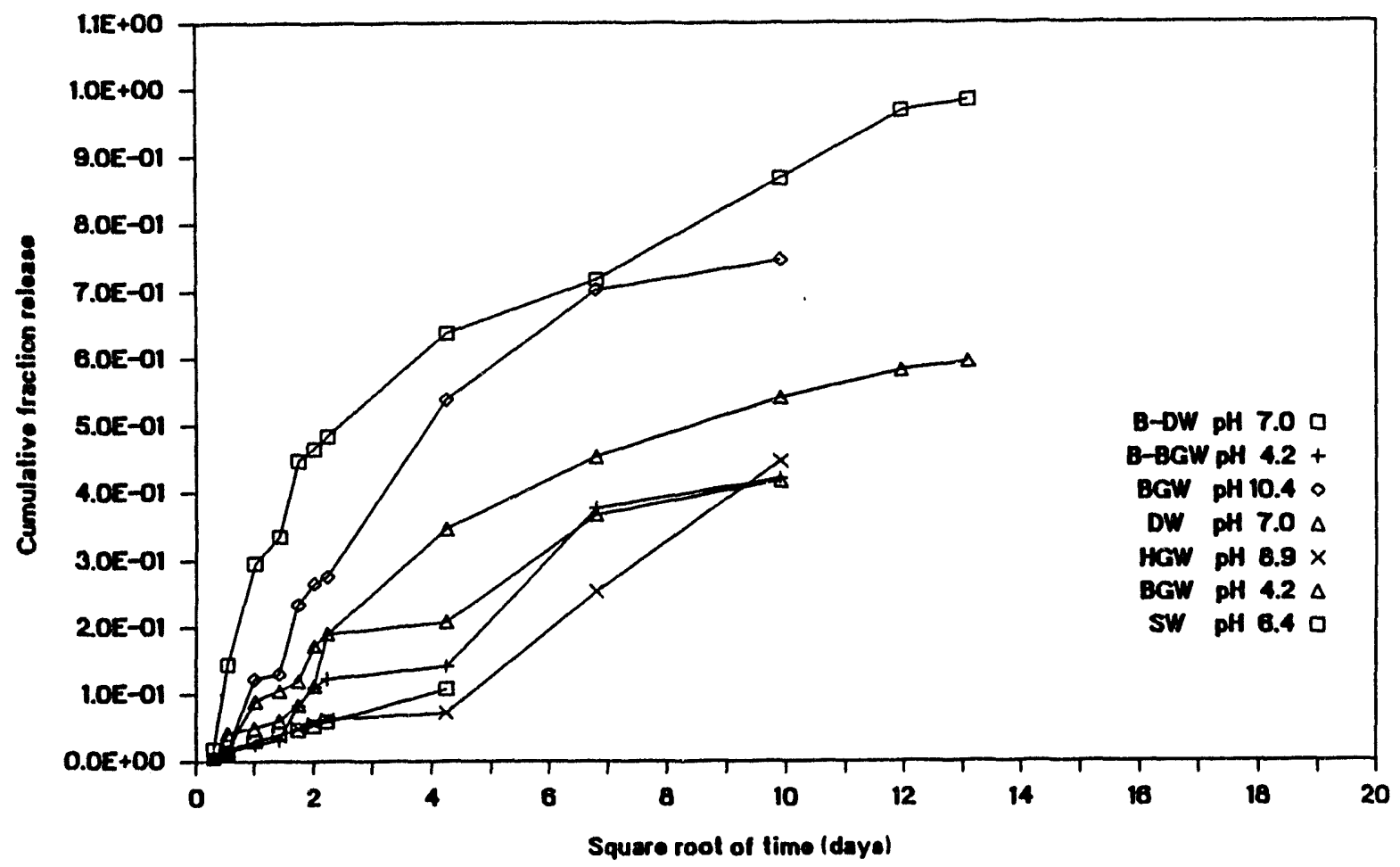

Figure 52. Cumulative fractional release of picolinic acid from seven FitzPatrick ion-exchange resin waste-form specimens. 
Radlonuclldes. Releases of radionuclides from the cement-solidified waste forms may be caused by the leachants and may also be dependent on the chemistry of the radionuclide being leached. The first radionuclide to be discussed is ${ }^{137} \mathrm{Cs}$, because it is ionic and is probably most representative of diffusional release. In contrast, ${ }^{55} \mathrm{Fe}, \mathrm{Co}^{60}$, and ${ }^{63} \mathrm{Ni}$ are transition metals that would be expected to react with the cement matrix ${ }^{63}$ but form coordination complexes with chelating agents that may potentially increase their mobility from a waste form. Leachant chemistry is expected to affect the releases of these radionuclides more than the purely ionic radionuclides as they would be more solubility limited. ${ }^{56}$

The fractional release rates of ${ }^{137} \mathrm{Cs}$ from the Brunswick-1 cation resin, the Brunswick-1 mixed-bed resin, and the FitzPatrick resin waste forms are all similar for each leachant as shown in Reference 2 . The average fractional release rates for each waste form are: Brunswick-1 cation resin $\left(1.1 \times 10^{-10} \mathrm{~cm}^{-2} \cdot \mathrm{s}^{-1}\right)$, Brunswick-1 mixed-bed resin specimens $\left(3.7 \times 10^{-9} \mathrm{~cm}^{-2} \cdot \mathrm{s}^{-1}\right)$, and FitzPatrick $\left(5.1 \times 10^{-9} \mathrm{~cm}^{-2} \cdot \mathrm{s}^{-1}\right)$. The ranges for all average fractional release rates are small and indicate that the fractional release rates of ${ }^{137} \mathrm{Cs}$ do not appear to be affected by leachant effects. Comparison of these results with the chelating agent average fractional release rates indicates that ${ }^{137} \mathrm{Cs}$ is leaching out of the waste form faster than the chelating agents by one to two orders of magnitude and suggests that the ${ }^{137} \mathrm{Cs}$ is probably representative of pure diffusional release.

Figures 53 through 55 show the CFRs of ${ }^{137} \mathrm{Cs}$ from the three types of waste forms. The Brunswick-1 cation CFRs shown in Figure 53 are similar at about 0.012; however, the CFR for the simulated seawater leachant is about $1.6 \times 10^{-2}$. It is not obvious whether this is significant, however, because the highest CFR of ${ }^{137} \mathrm{Cs}$ from the Brunswick-1 mixed-bed resin waste form (0.26) is also indicated for the simulated seawater leachant. It should be noted that the CFRs of ${ }^{137} \mathrm{Cs}$ from the Brunswick-1 mixed-bed resin waste

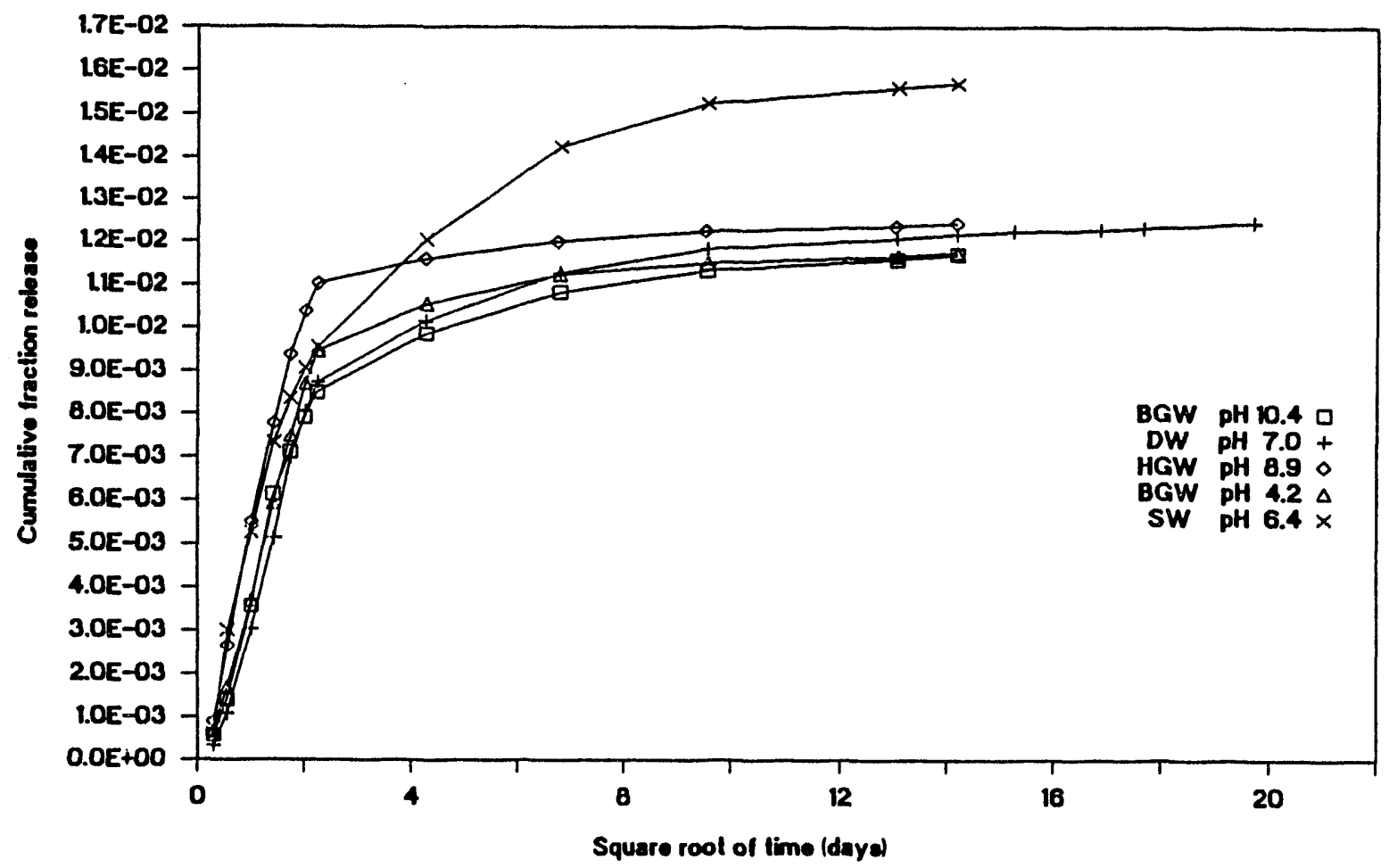

Figure 53. Cumulative fractional release of ${ }^{137} \mathrm{Cs}$ from five Brunswick-1 cation resin waste-form specimens. 
Experimental Results and Discussion

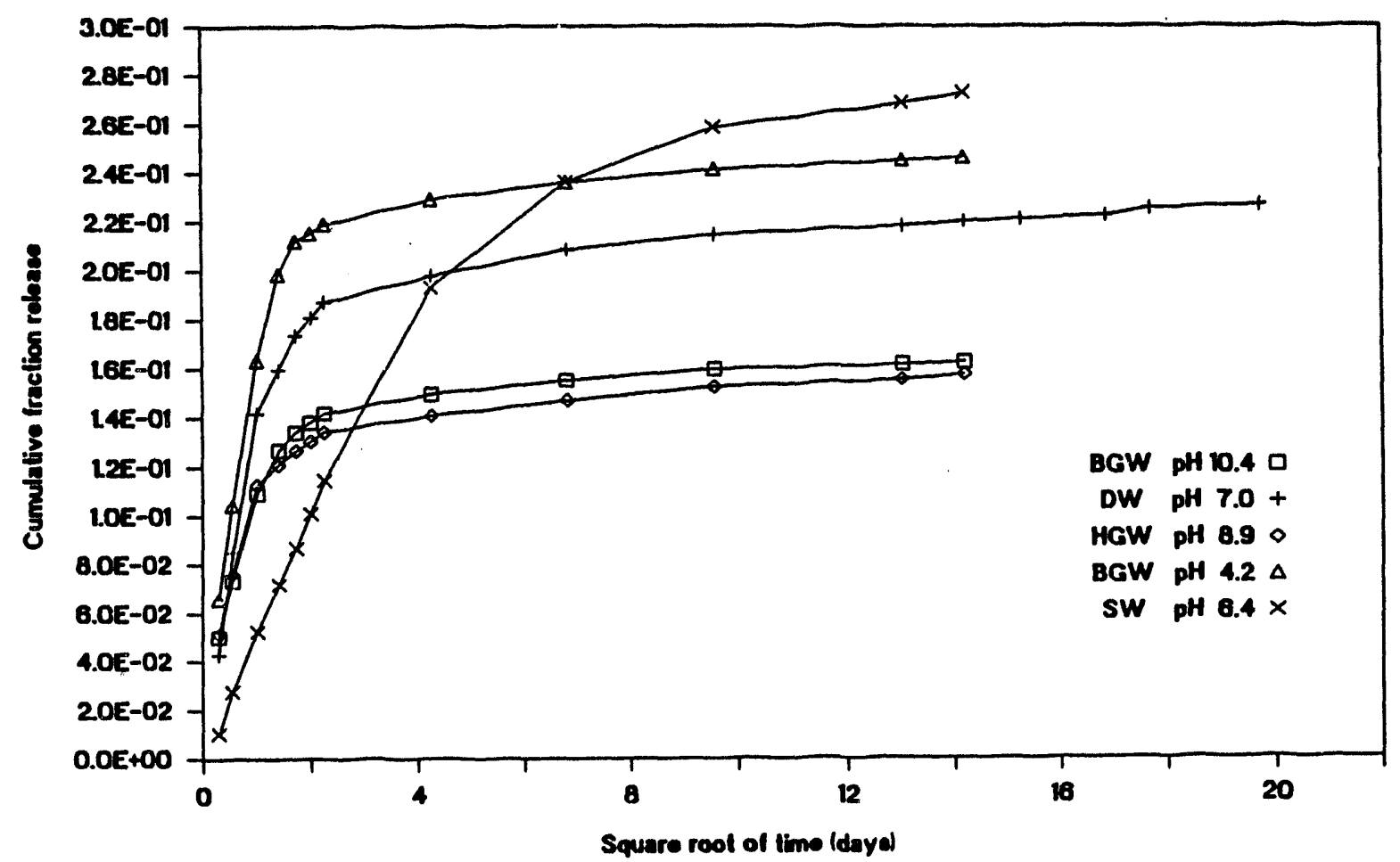

Figure 54. Cumulative fractional release of ${ }^{137} \mathrm{Cs}$ from five Brunswick-1 mixed-bed resin waste-form specimens.

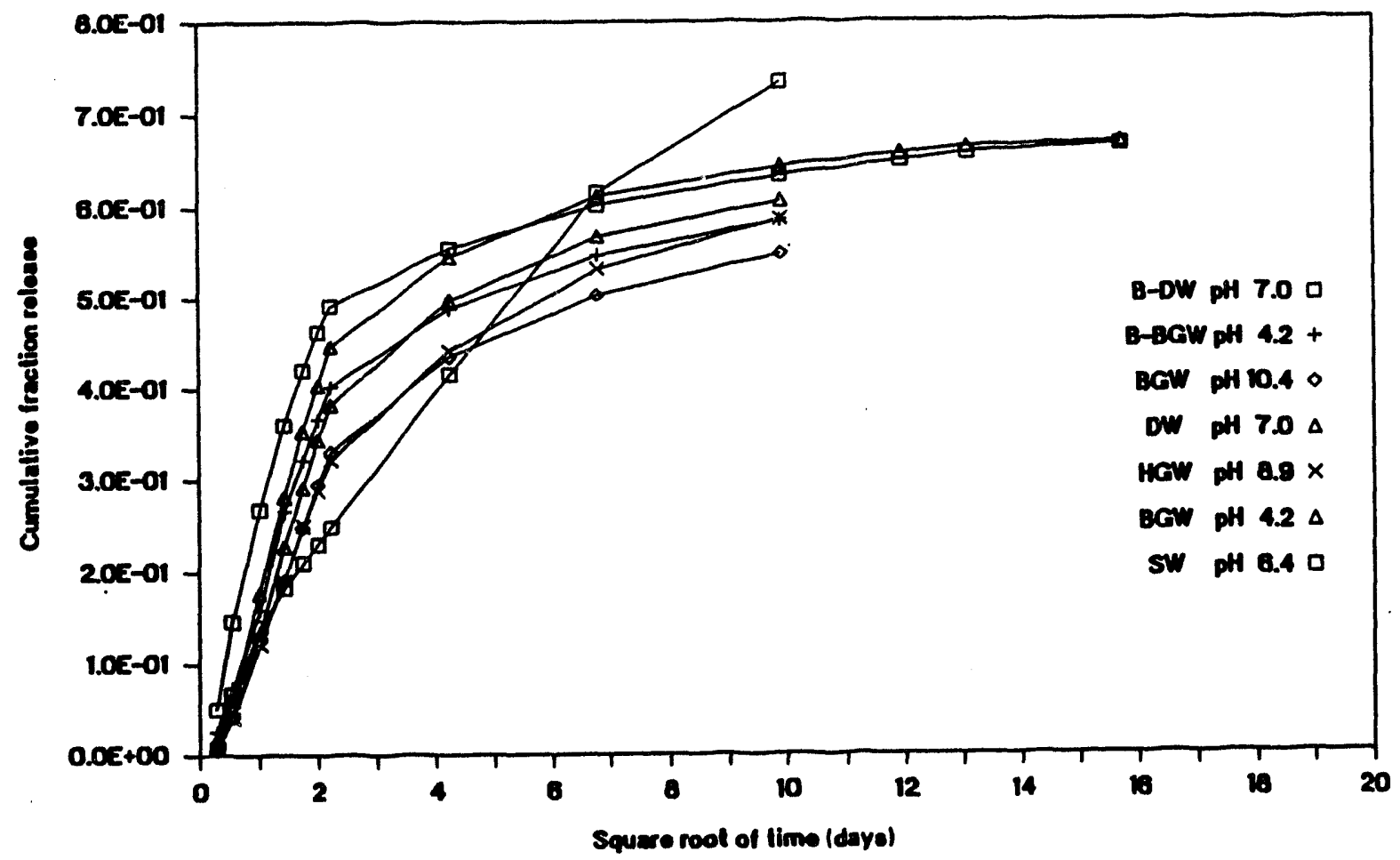

Figure 55. Cumulative fractional release of ${ }^{137} \mathrm{Cs}$ from seven FitzPatrick ion-exchange resin waste-form specimens. 
form samples are approximately two orders of magnitude greater than that from the cation resin waste forms that do not contain chelating agents and are greater than the CFRs of the chelating agents oxalic and citric acid. These data further suggest that ${ }^{137} \mathrm{Cs}$ is probably controlled completely by diffusional release due to its high solubility, whereas other radionuclides and chelating agents are affected by chemical retention mechanisms such as lower solubility.

The CFRs for ${ }^{137} \mathrm{Cs}$ for the FitzPatrick samples are shown in Figure 55 and indicate similar releases for all leachants; however, the magnitude of the release is from 40 to $60 \%$ of inventory with no obvious relationship, except that the highest CFR is for simulated seawater. Similar high CFRs were observed for the Brunswick-1 samples. These results suggest that the $\mathbf{M g}$ content ${ }^{48}$ or ionic strength of the simulated seawater may affect the release from the waste form. It has been suggested ${ }^{51}$ that the ion strength of seawater may be a more important parameter and have a greater effect on radionuclide solubilities in the leachate.
This result tends to be confirmed for ${ }^{137} \mathrm{Cs}$ by the differences in the release rates and CFRs of this radionuclide for the simulated seawater leachant as compared to the groundwater leachants and deionized water.

The average effective diffusivities and leachability indexes for ${ }^{137} \mathrm{Cs}$ and are shown in Appendix F. The leachability indexes for the Brunswick-1 cation resin samples range from 10.3 to 10.8 , whereas the leachability indexes for the Brunswick-1 mixed-bed resin waste form range from 7.2 to 8.9. For FitzPatrick, the leachability indexes are similar and range from 6.4 to 7.1 .

The fractional release rates of the transition metals ${ }^{60} \mathrm{Co},{ }^{55} \mathrm{Fe}$, and ${ }^{63} \mathrm{Ni}$ for each waste form and leachant are shown in Figures 56 through 64. Figures 56 through 58 show the fractional release rates of ${ }^{60} \mathrm{Co}$ for the three waste forms. Inspection indicates that although there are some changes in the fractional release rates during the early leaching periods, the fractional release rates

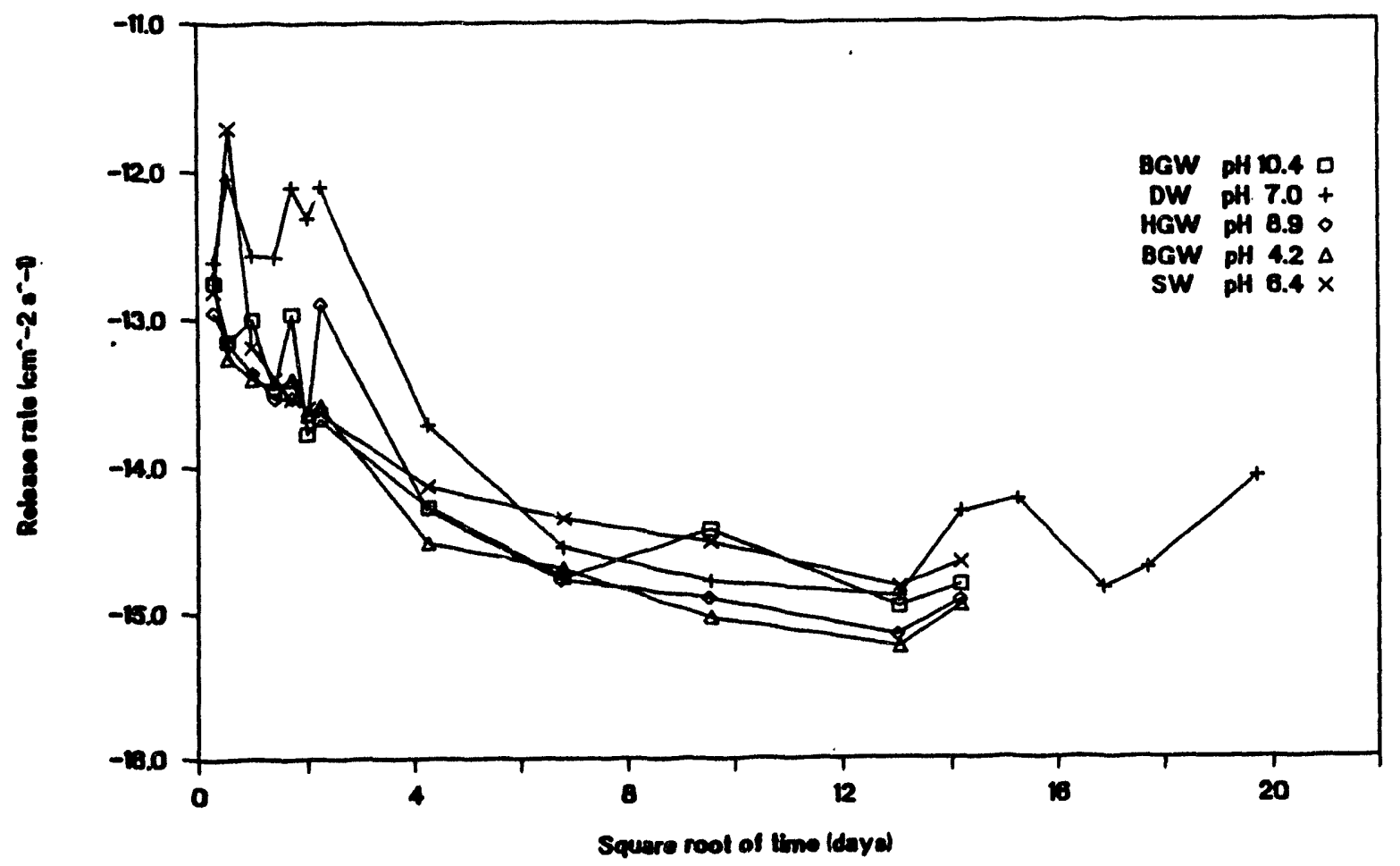

Figure 56. Fractional release rate of ${ }^{60} \mathrm{Co}$ from five Brunswick-1 cation resin waste-form specimens. 
Experimental Results and Discussion

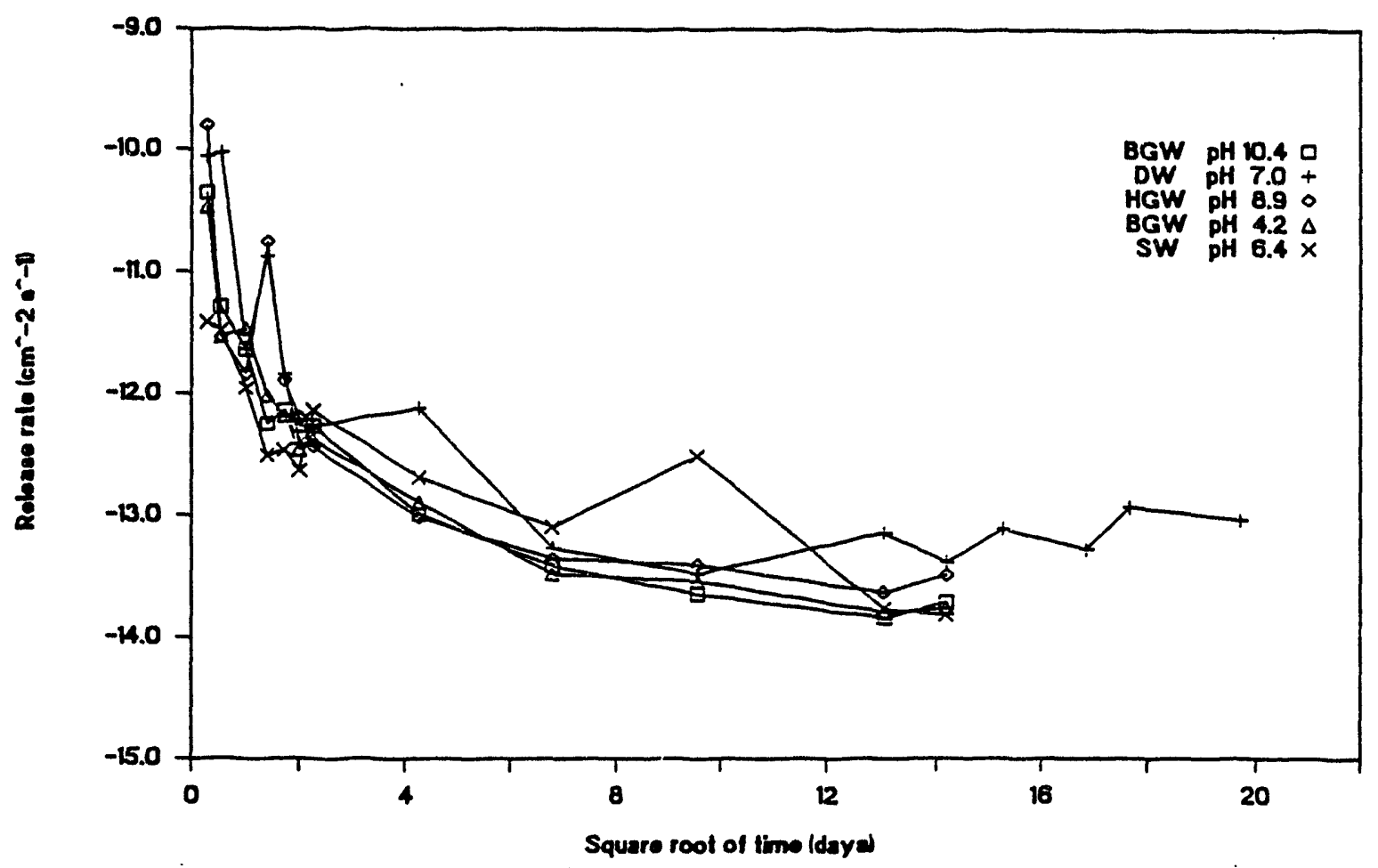

Figure 57. Fractional release rate of ${ }^{60} \mathrm{Co}$ from five Brunswick-1 mixed-bed resin waste-form specimens.

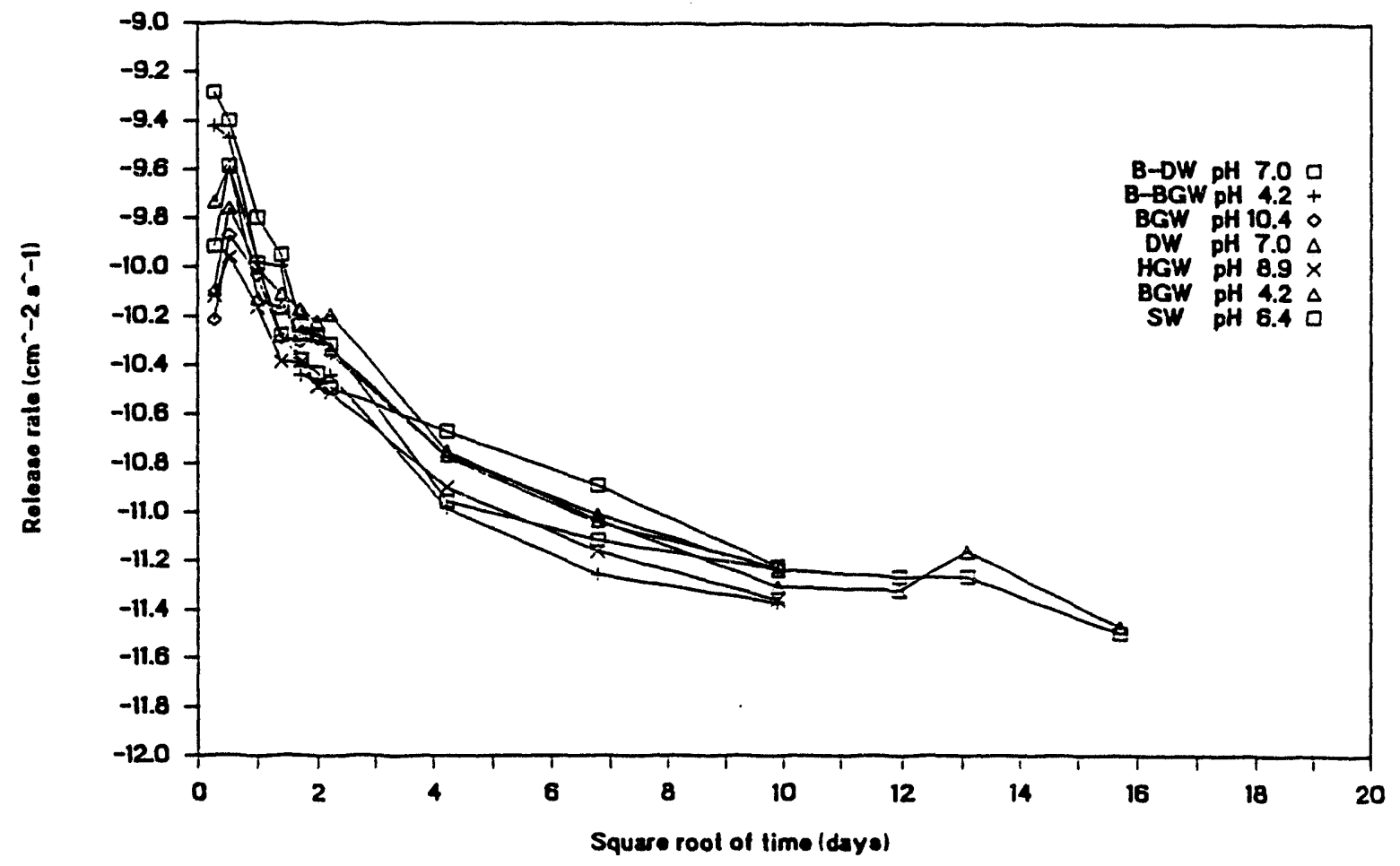

Figure 58. Fractional release rate of ${ }^{60} \mathrm{Co}$ from seven FitzPatrick ion-exchange resin waste-form specimens. 
Experimental Results and Discussion

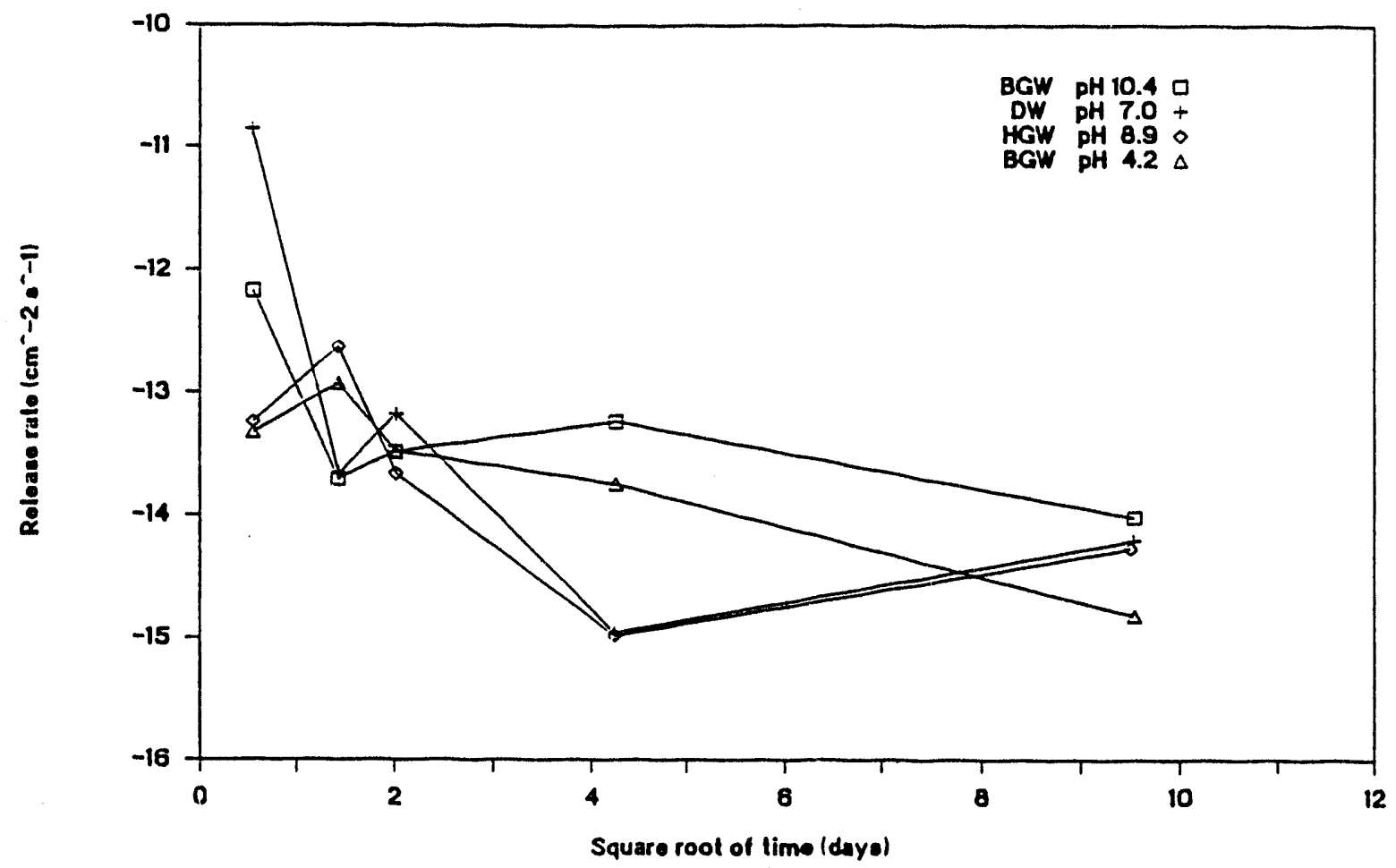

Figure 59. Fractional release rate of ${ }^{55} \mathrm{Fe}$ from five Brunswick-1 cation resin waste-form specimens.

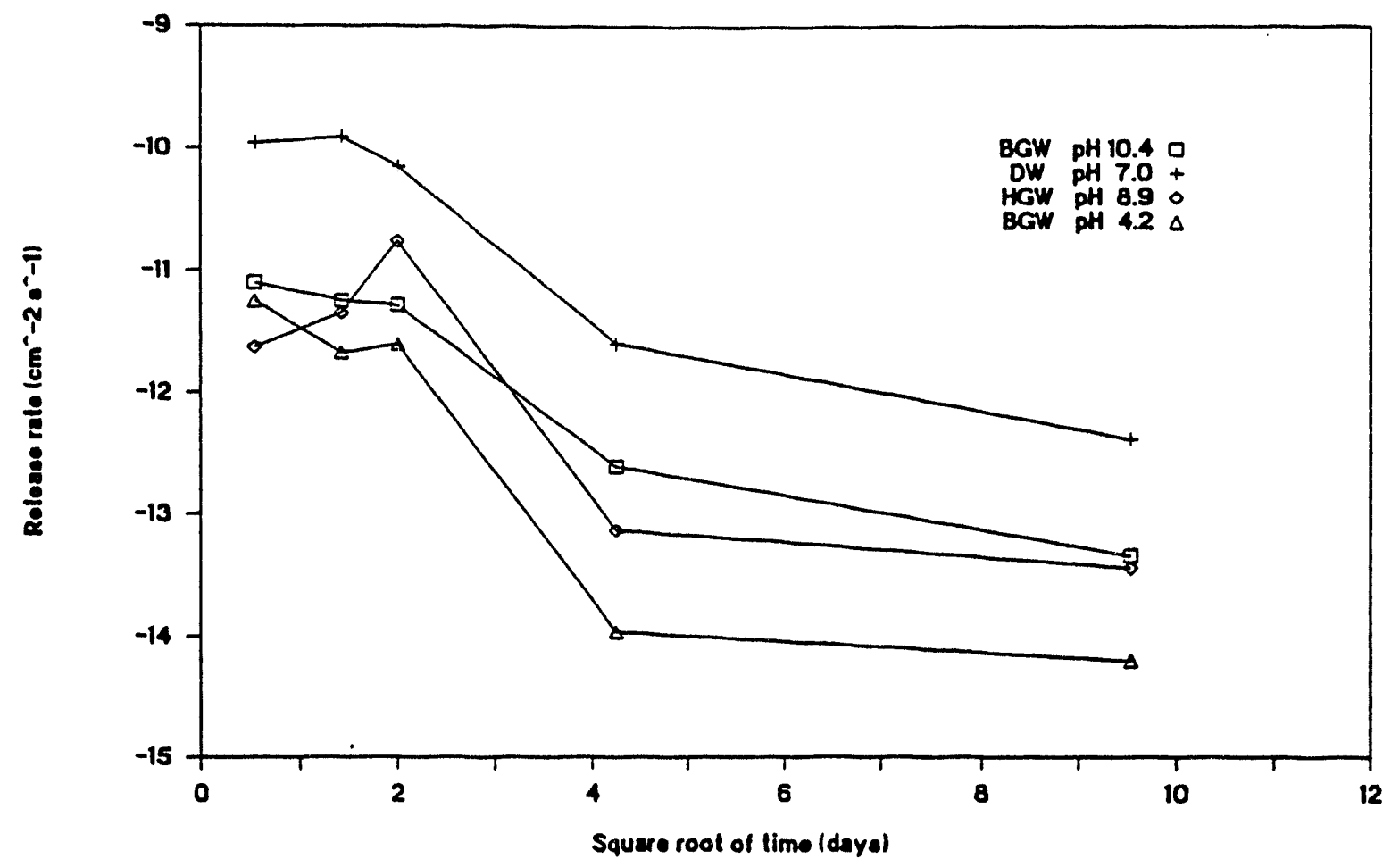

Figure 60. Fractional release rate of ${ }^{55} \mathrm{Fe}$ from five Brunswick-1 mixed-bed resin waste-form specimens. 


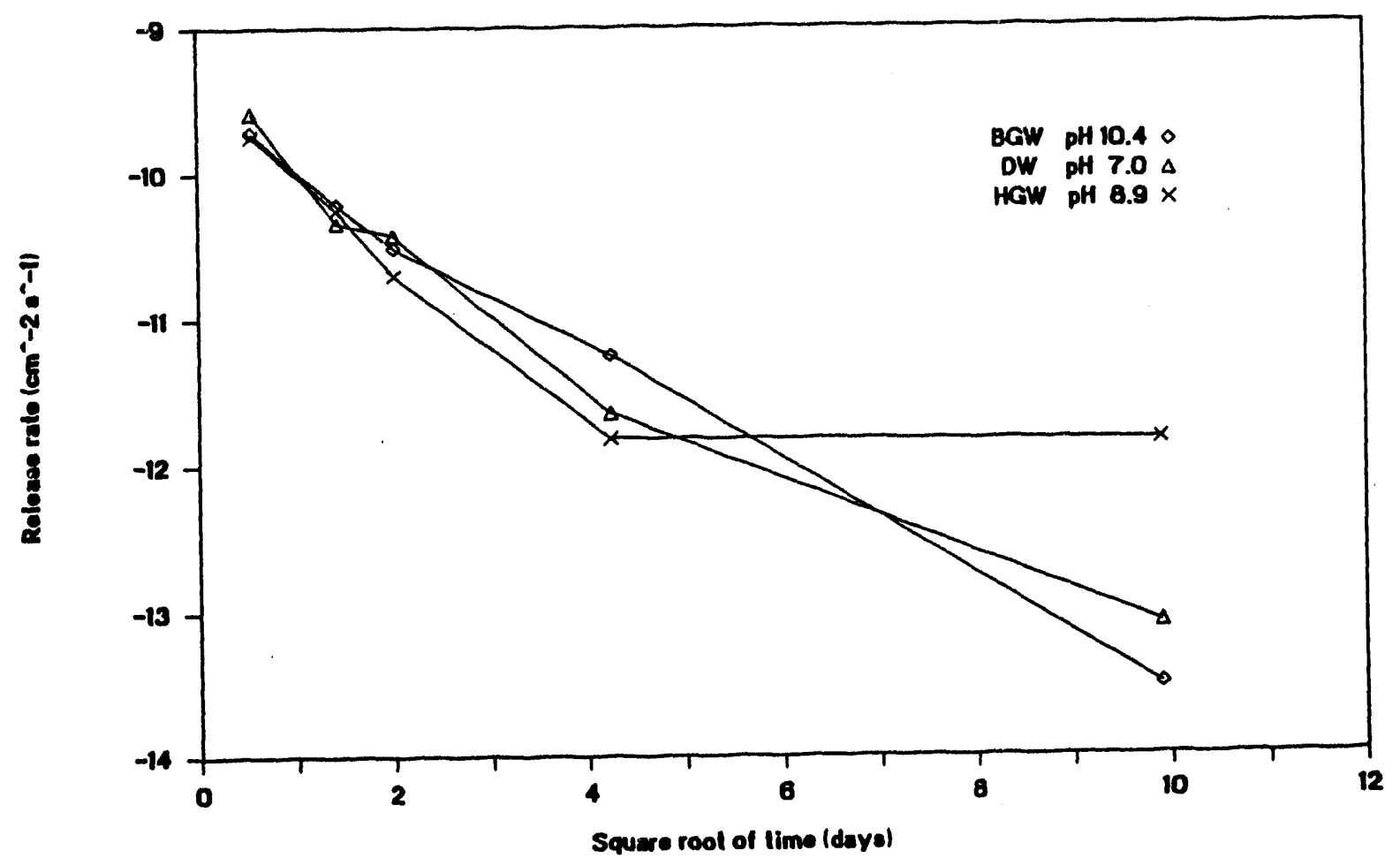

Figure 61. Fractional release rate of ${ }^{55} \mathrm{Fe}$ from seven FitzPatrick ion-exchange resin waste-form specimens.

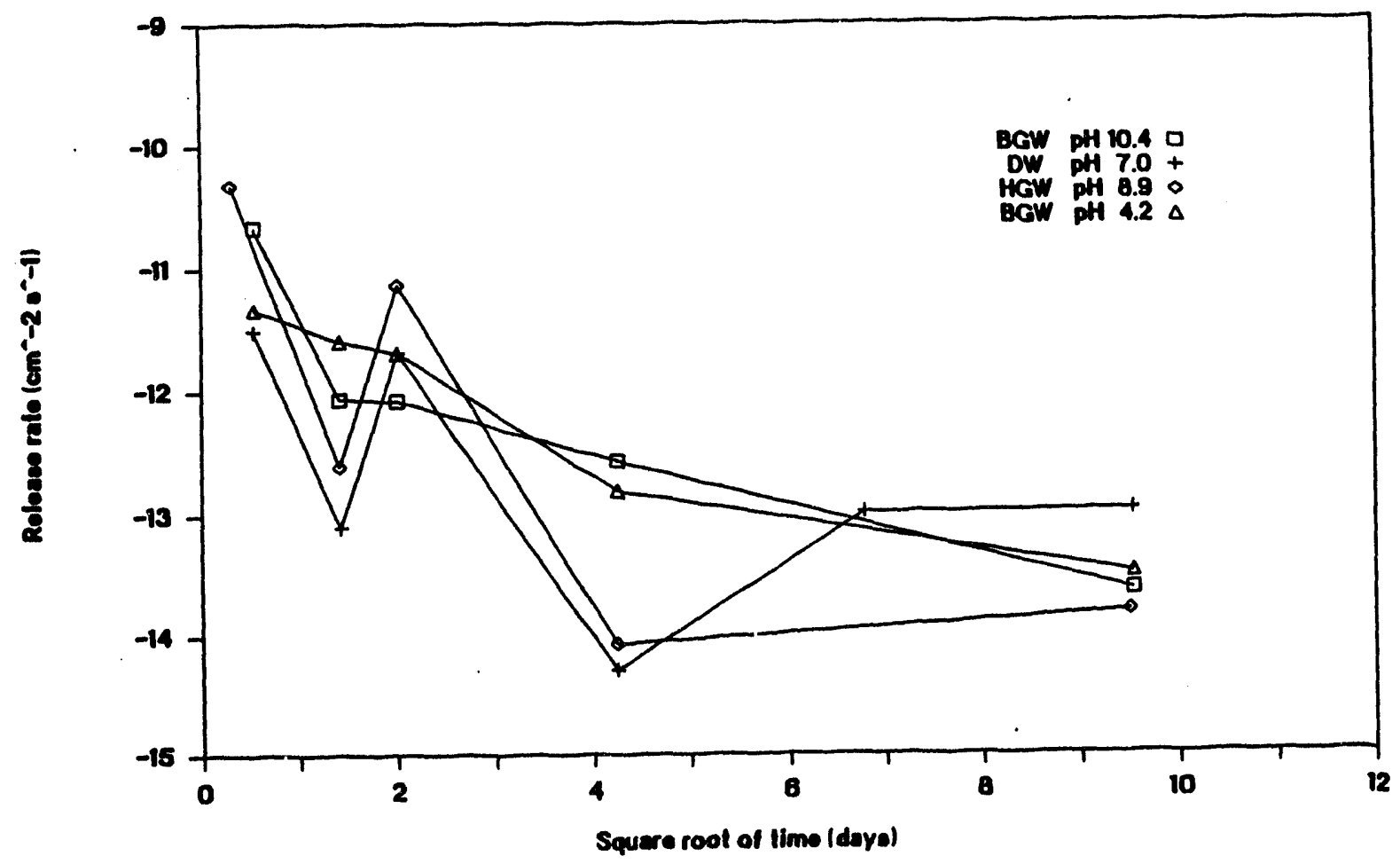

Flgure 62. Fractional release rate of ${ }^{63} \mathrm{Ni}$ from five Brunswick-1 cation resin waste-form specimens. 


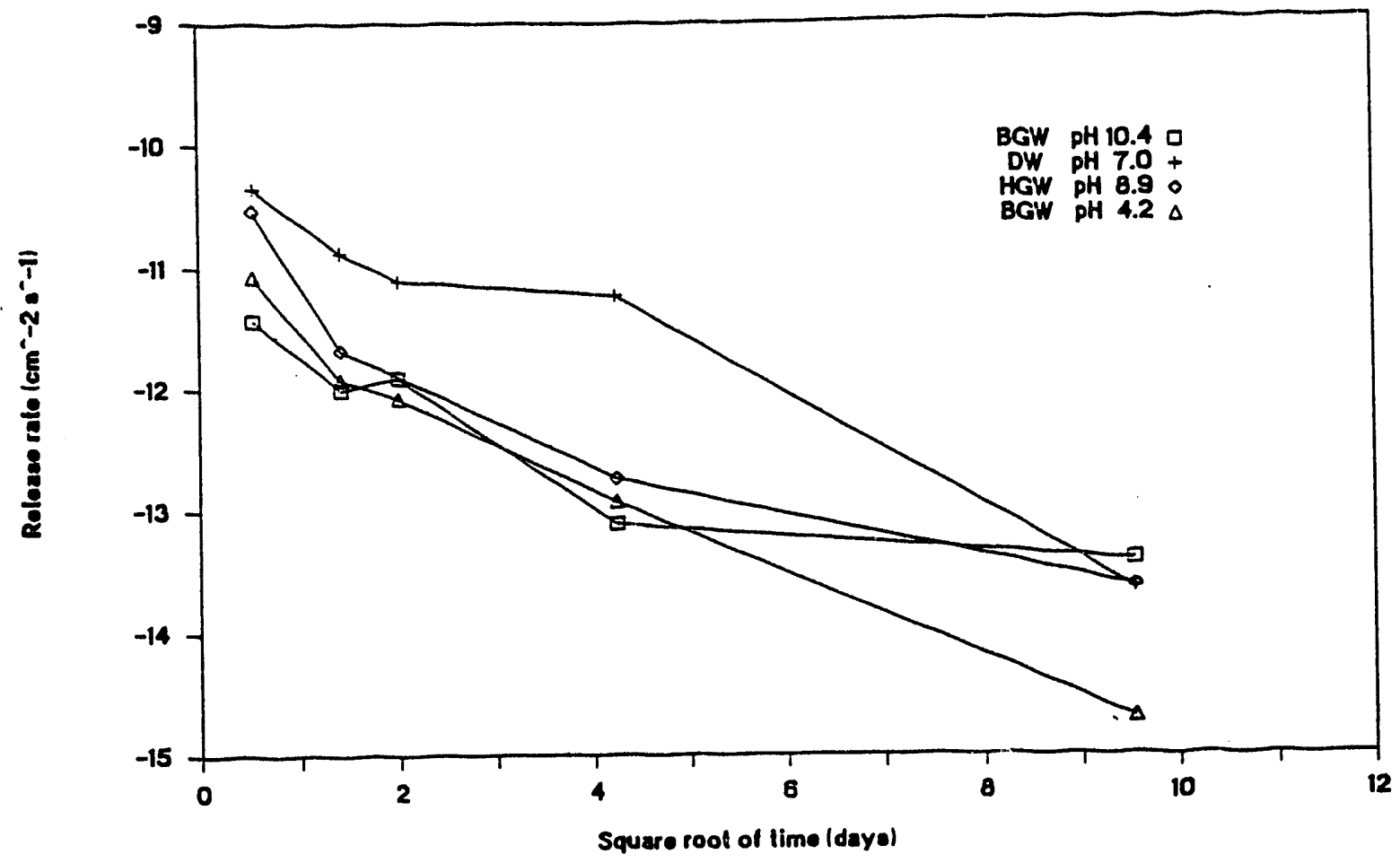

Figure 63. Fractional release rate of ${ }^{63} \mathrm{Ni}$ from five Brunswick-1 mixed-bed resin waste-form specimens.

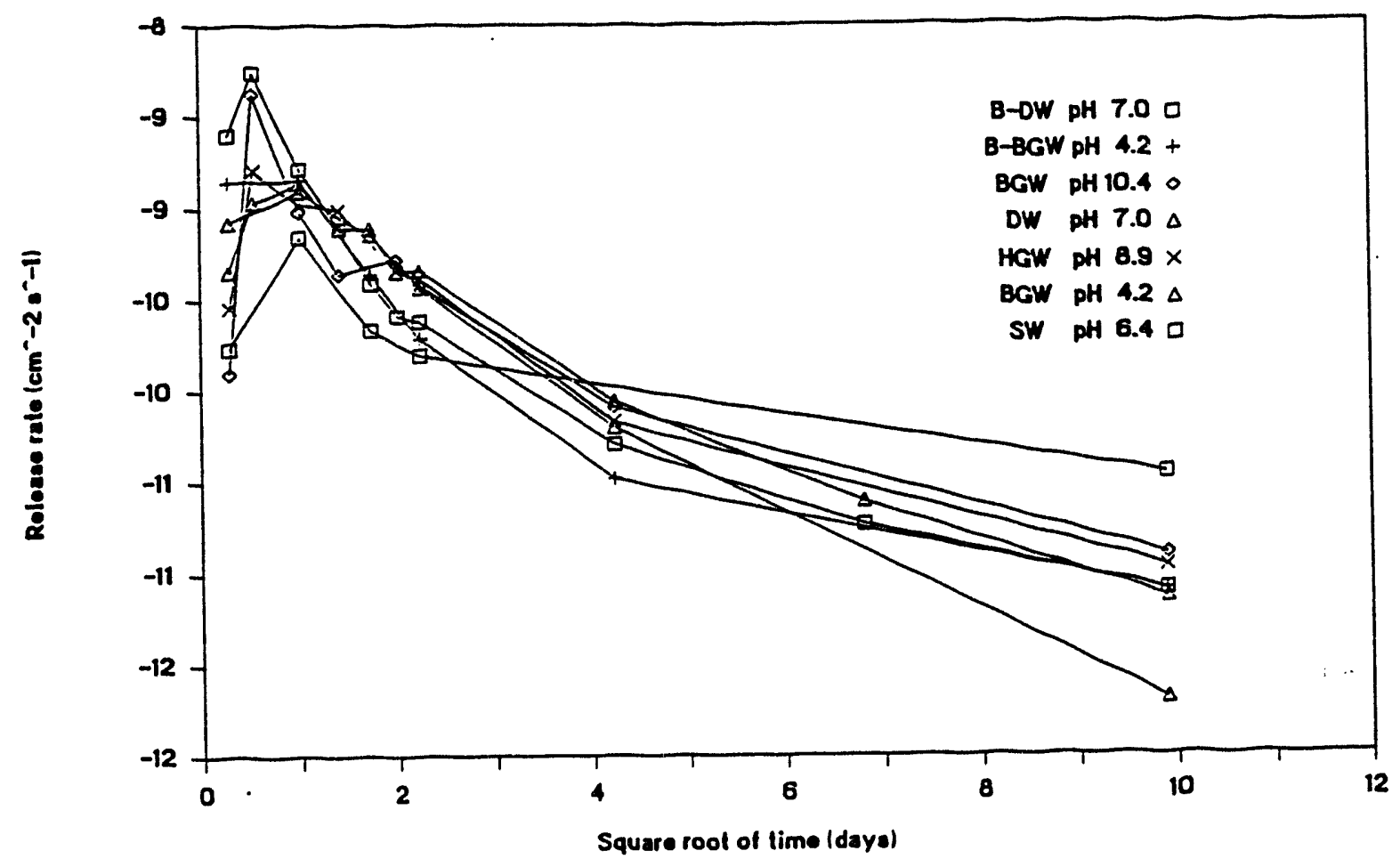

Figure 64. Fractional release rate of ${ }^{63} \mathrm{Ni}$ from seven FitzPatrick ion-exchange resin waste-form specimens. 
are similar for the different leachants after diffusional release (i.e., when the slope flattens) is established. The changes during the early periods may be due to the breakup of the waste forms and release from washoff or convection..$^{51}$ The average fractional release rates of ${ }^{60} \mathrm{Co}$ for the three waste forms are Brunswick-1 cation resin $\left(2 \times 10^{-13} \mathrm{~cm}^{-2} \cdot \mathrm{s}^{-1}\right)$, Brunswick-1 mixed-bed resin $\left(1 \times 10^{-11} \mathrm{~cm}^{-2} \cdot \mathrm{s}^{-1}\right)$, and FitzPatrick $\left(8 \times 10^{-11} \mathrm{~cm}^{-2} \cdot \mathrm{s}^{-1}\right)$. The low release rate of ${ }^{60} \mathrm{Co}$ from the Brunswick-1 cation resin waste form appear to be due to the lack of chelating agents in this waste form as compared to those with chelants. Leachant effects are not obvious as the fractional release rates are similar for all leachants.

Figures 59 through 61 show the fractional release rates for ${ }^{55} \mathrm{Fe}$. These figures suggest that for ${ }^{55} \mathrm{Fe}$, there are some initial variations in the release rates possible due to the breakup of the waste forms; however, for the Brunswick and FitzPatrick mixed-bed specimens, there appears to be leachant-specific effects. For the Brunswick-1 specimen, the average fractional release rate of ${ }^{55} \mathrm{Fe}$ for deionized water is about $10^{-12} \mathrm{~cm}^{-2} \cdot \mathrm{s}^{-1}$, whereas for the BGW $\mathrm{pH} 4.2$, the average fractional release rate is about $10^{-14} \mathrm{~cm}^{-2} \cdot \mathrm{s}^{-1}$, which suggests that in this case, deionized water is much more aggressive than the groundwater. In contrast, for the FitzPatrick specimens, the average fractional release rate of ${ }^{55} \mathrm{Fe}$ from the HGW pH 8.9 is about two orders of magnitude higher than that for $B G W$ pH 10.4. No reason for this anomalous behavior is known other than leachant-specific effects on the ${ }^{55} \mathrm{Fe}$ fractional release rates. The average fractional release rates also diverge for the three waste forms. The average fractional release rates for the Brunswick-1 cation resin waste form is $8 \times 10^{-13} \mathrm{~cm}^{-2} \cdot \mathrm{s}^{-1}$, whereas the rate for the Brunswick 1 mixed-bed resin waste form is $3 \times 10^{-12} \mathrm{~cm}^{-2} \cdot \mathrm{s}^{-1}$ and the average fractional release rate for the FitzPatrick waste form is $6 \times 10^{-11} \mathrm{~cm}^{-2} \cdot \mathrm{s}^{-1}$. These data suggest that although there appears to be no specific trend as to which leachant is most aggressive as it differs by waste form, there appears to be leachant-specific differences in the release rates, which can affect release rates of ${ }^{55} \mathrm{Fe}$ by one to two orders of magnitude.

The fractional release rates for ${ }^{63} \mathrm{Ni}$ for the three waste forms are shown in Figures 62 through 64 . The fractional release rates from the Brunswick-1 cation resin waste form are within a factor of five near the end of the leaching period. In contrast, the fractional release rates of ${ }^{63} \mathrm{Ni}$ from the Brunswick-1 mixed-bed resin waste form range over two orders of magnitude, with a low fractional release rate for the BGW $\mathrm{pH} 4.2$ leachant. The fractional release rates for the FitzPatrick waste form also range over two orders of magnitude and also suggest leachant-specific release-rate effects, with simulated seawater having the highest release rate and deionized water the lowest. These data suggest that an increase in ionic strength of the leachant may increase releases from the waste form.

Figures 65 through 73 show the CFRs for the transition metals. Figures 65 through 67 show the CFRs for ${ }^{60} \mathrm{Co}$. Apparent high CFRs for some leachants are deceptive because comparisons with the fractional release rate results indicate that the higher releases occurred during the early leach periods and that for all three waste forms, the fractional release rates were similar for all leachants after the initial release. These higher initial release rates may be due to initial washoff during degradation of the waste form, but no long-term leaching diffusion effect can be inferred from these data. Figure 65 shows that after the initial spike (deionized water) during the first 5 days, the curve is parallel to the other curves, but approximately four times as much ${ }^{63} \mathrm{Ni}$ has been released. These data suggest that release rates obtained during the first $\mathbf{5}$ days are not indicative of trends for later times, particularly when degraded waste forms are being tested.

Figures 68 through 70 show the CFRs for ${ }^{55} \mathrm{Fe}$. For the Brunswick-1 specimens, the CFR for the deionized water leachant is higher than the others by an order of magnitude. Examination of the fractional release rate data indicates that this release occurred early in the leach test; however, after this initial release, the fractional release 
Experimental Results and Discussion

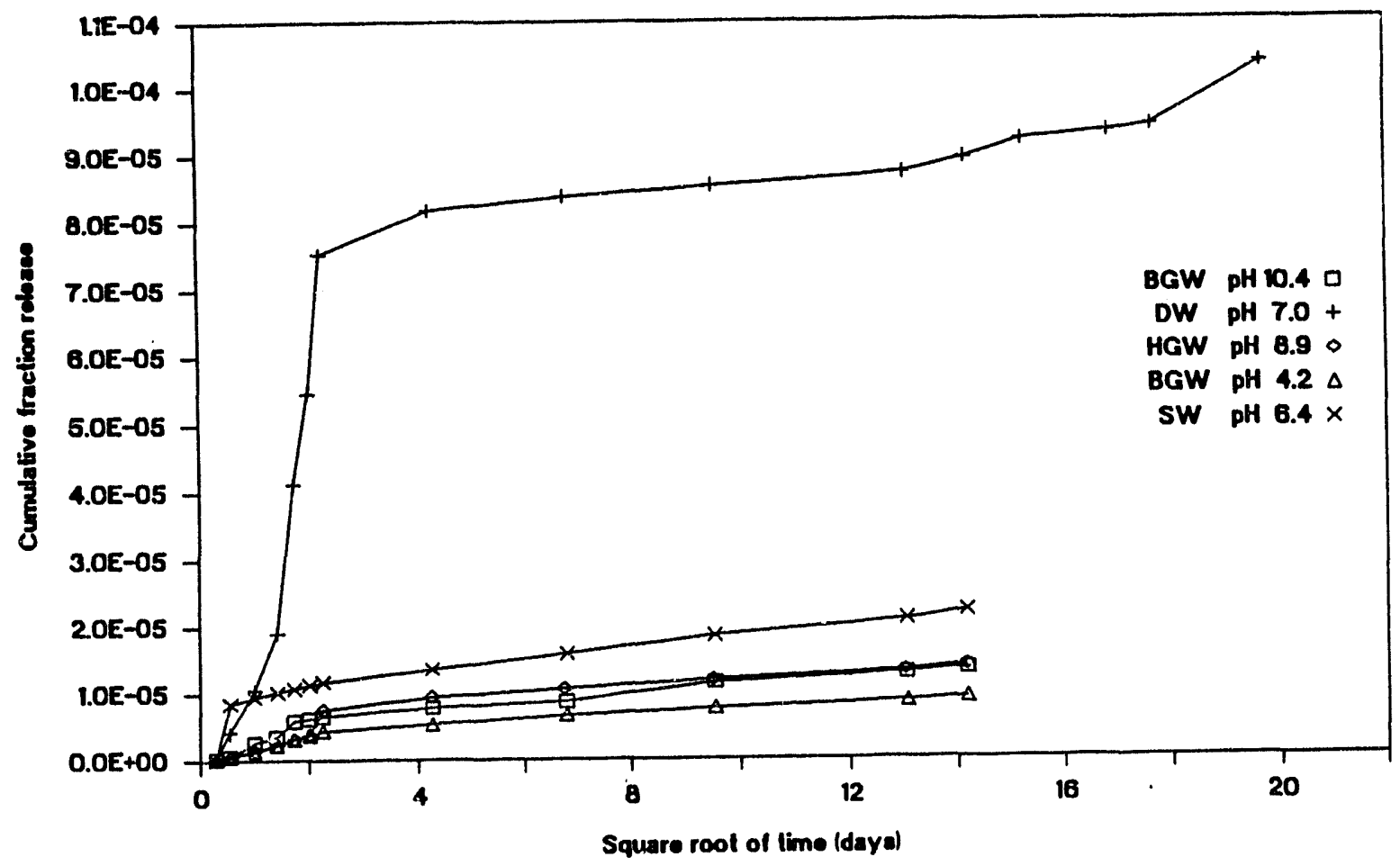

Figure 65. Cumulative fractional release of ${ }^{60} \mathrm{Co}$ from five Brunswick-1 cation resin waste-form specimens.

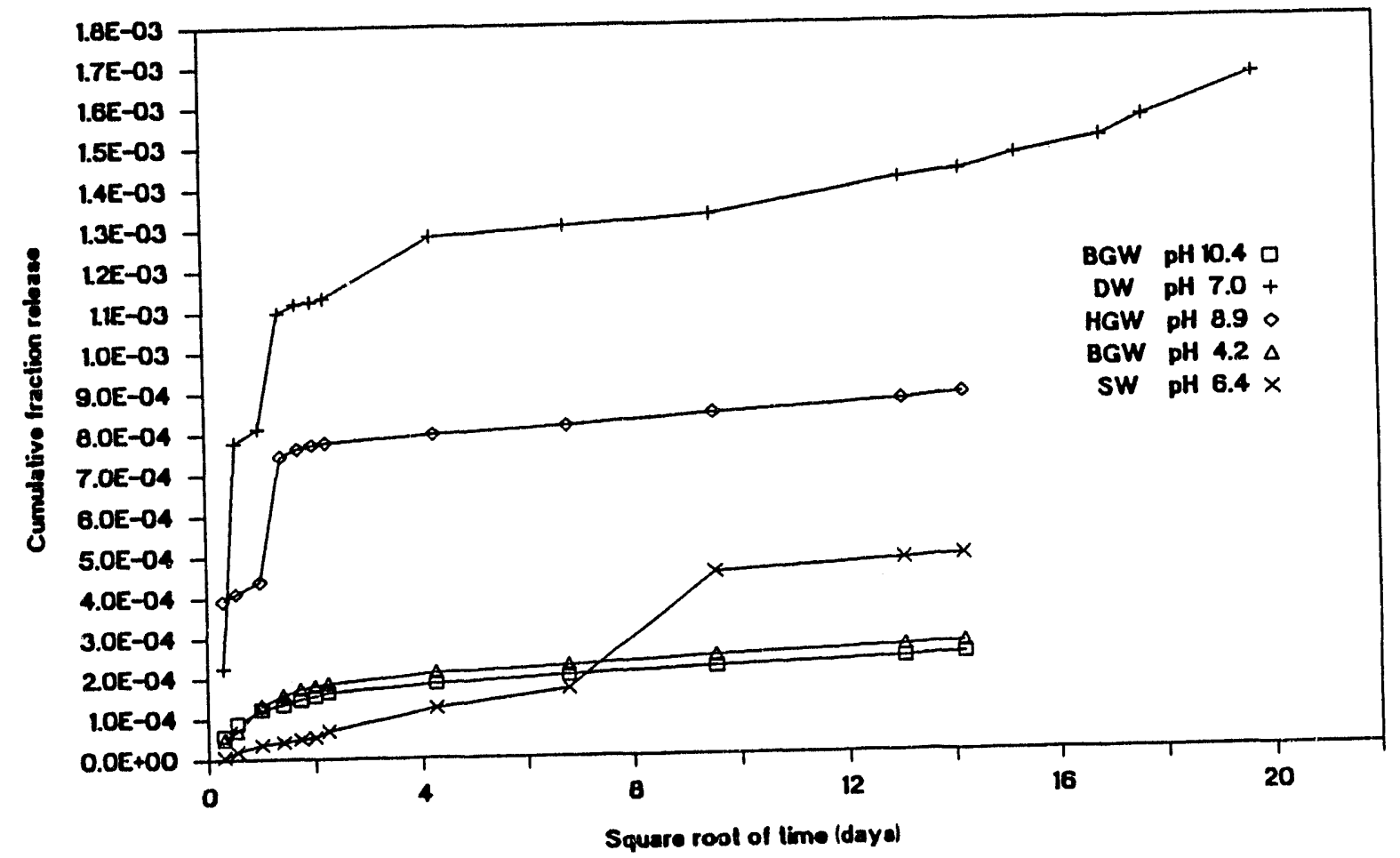

Figure 66. Cumulative fractional release of ${ }^{60} \mathrm{Co}$ from five Brunswick-1 mixed-bed resin waste-form specimens. 
Experimental Results and Discussion

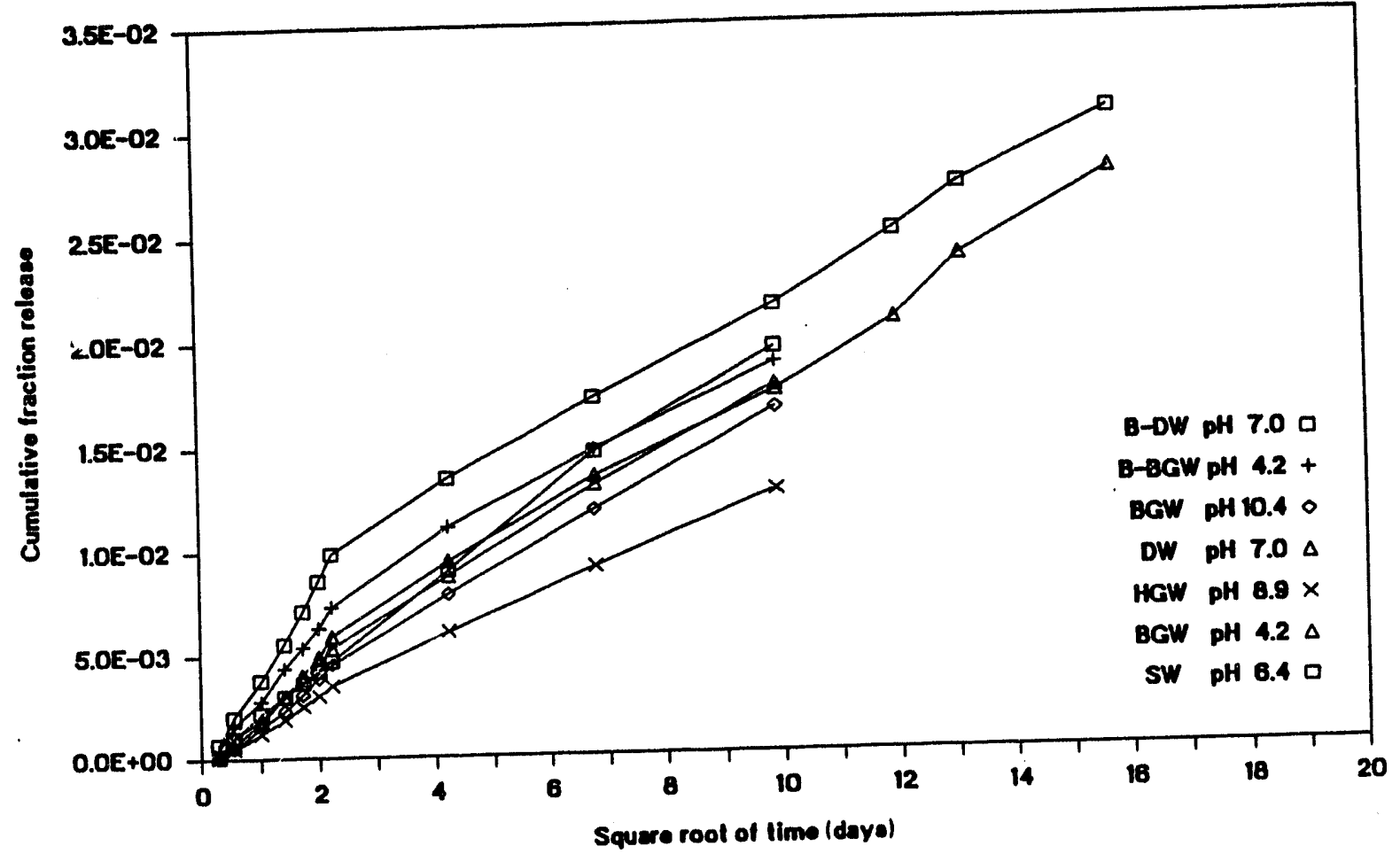

Figure 67. Cumulative fractional release of ${ }^{60} \mathrm{Co}$ from seven FitzPatrick ion-exchange resin waste-form specimens.

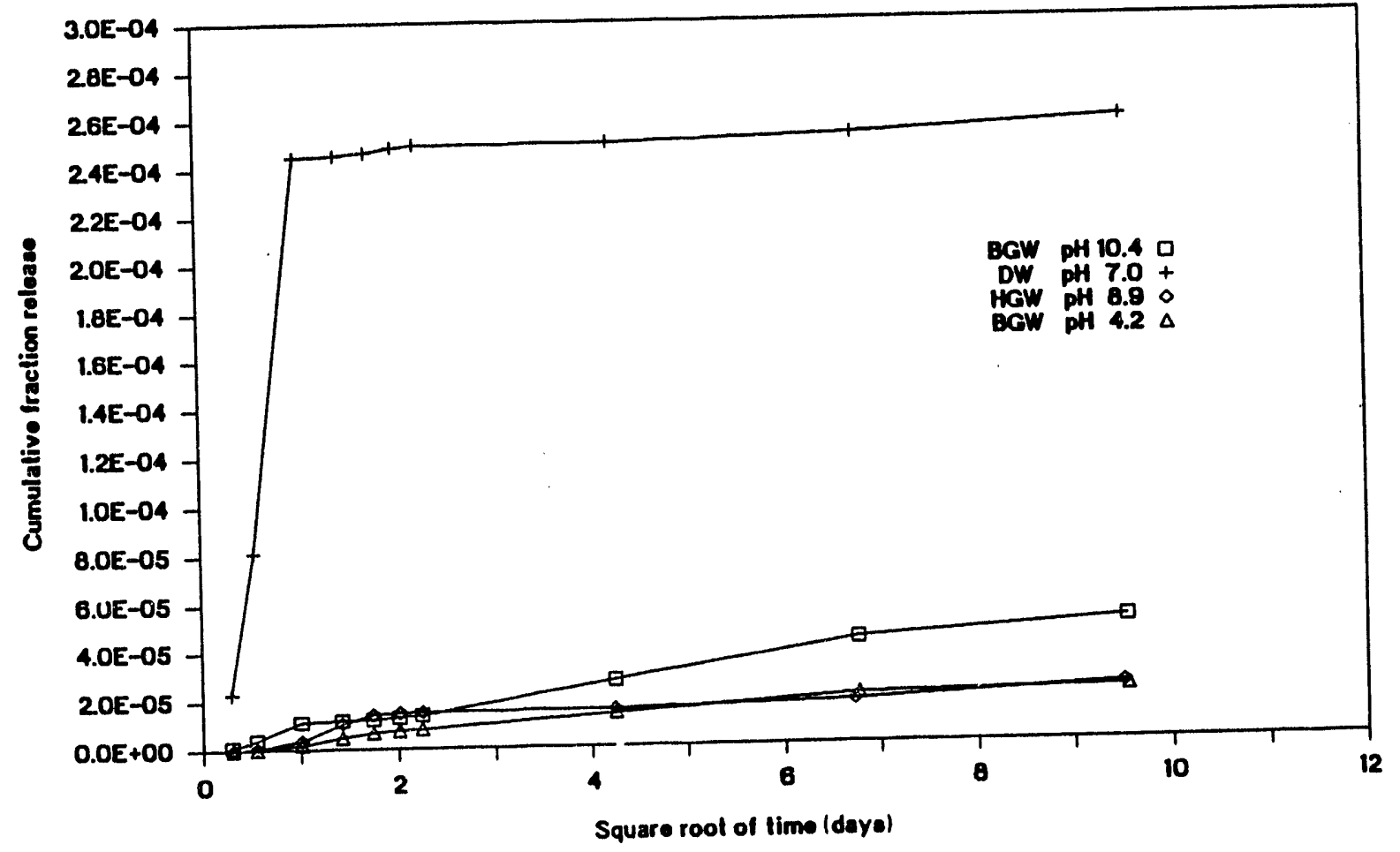

Figure 68. Cumulative fractional release of ${ }^{55} \mathrm{Fe}$ from five Brunswick-1 cation resin waste-form specimens. 


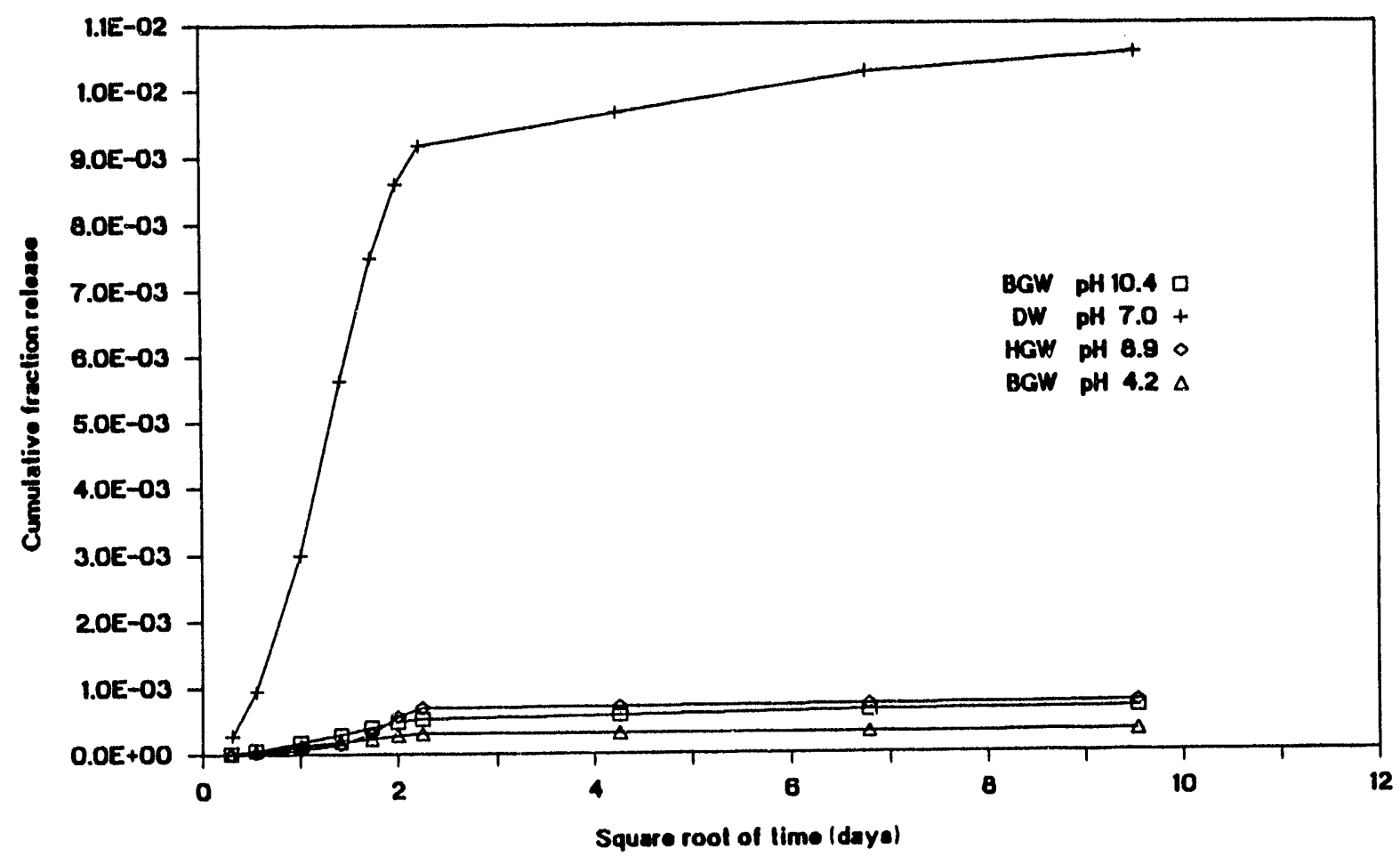

Figure 69. Cumulative fractional release of ${ }^{55} \mathrm{Fe}$ from five Brunswick-1 mixed-bed resin waste-form specimens.

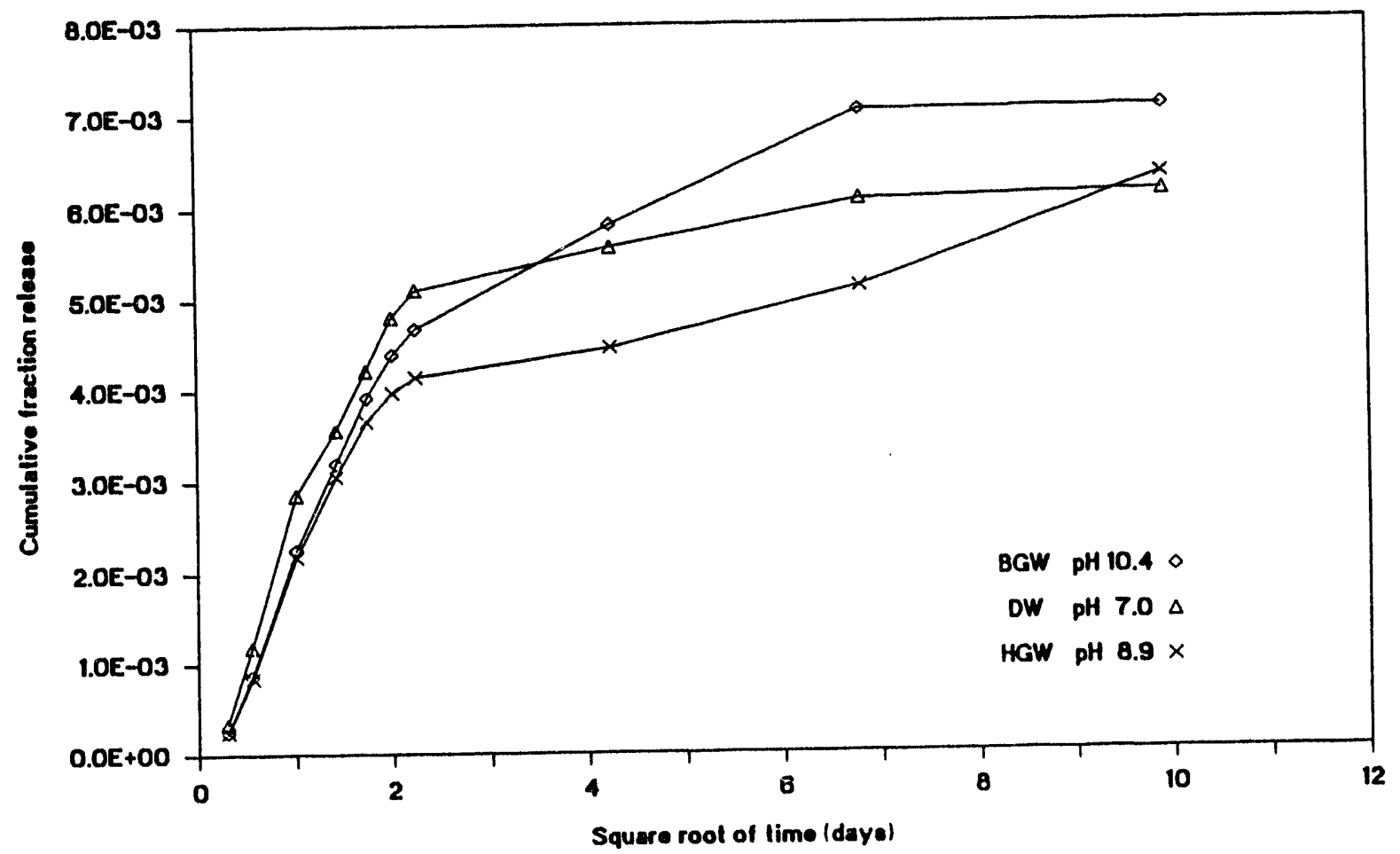

Figure 70. Cumulative fractional release of ${ }^{55} \mathrm{Fe}$ from seven FitzPatrick ion-exchange resin waste-form specimens. 
Experimental Results and Discussion

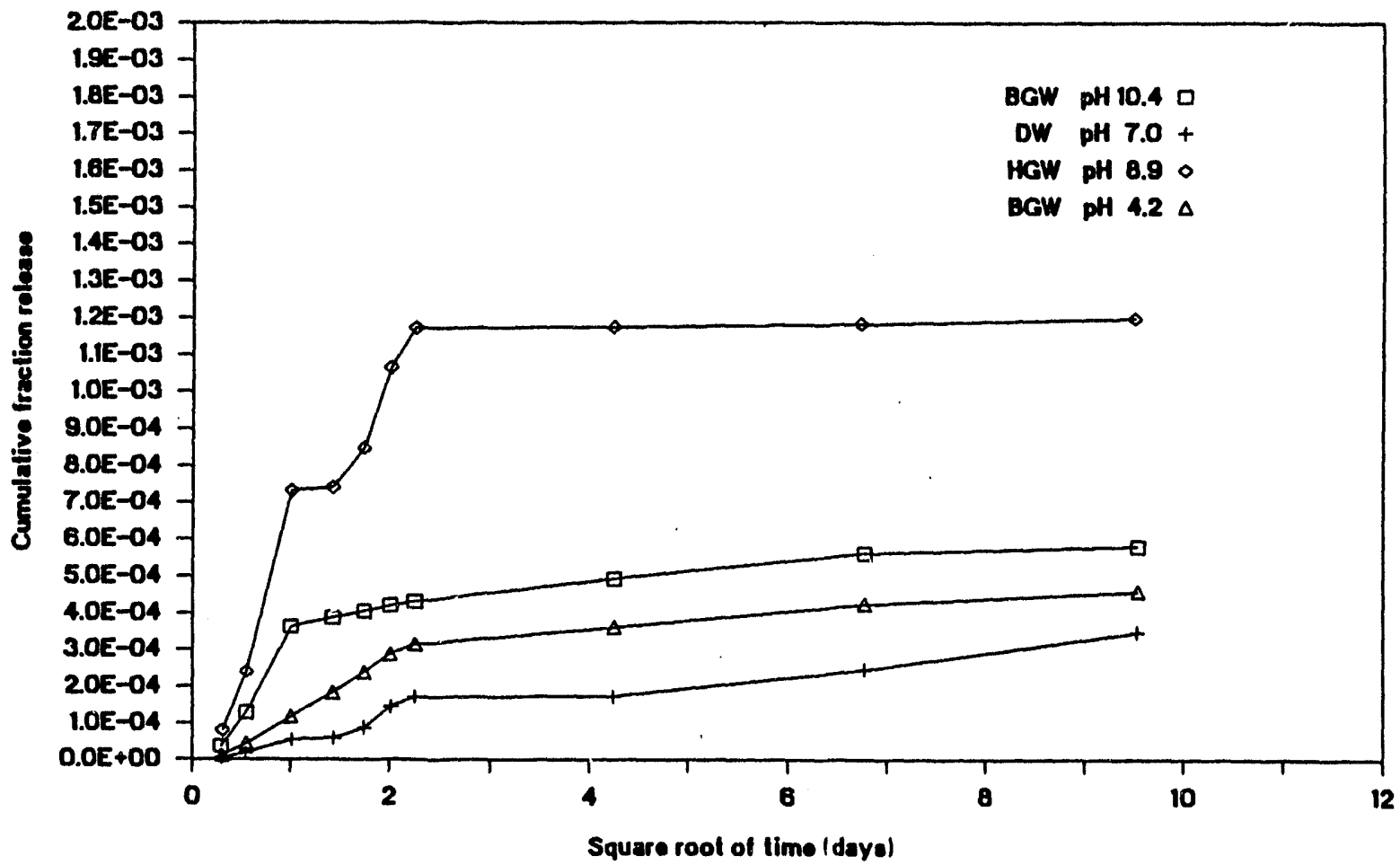

Figure 71. Cumulative fractional release of ${ }^{63} \mathrm{Ni}$ from five Brunswick-1 cation resin waste-form specimens.

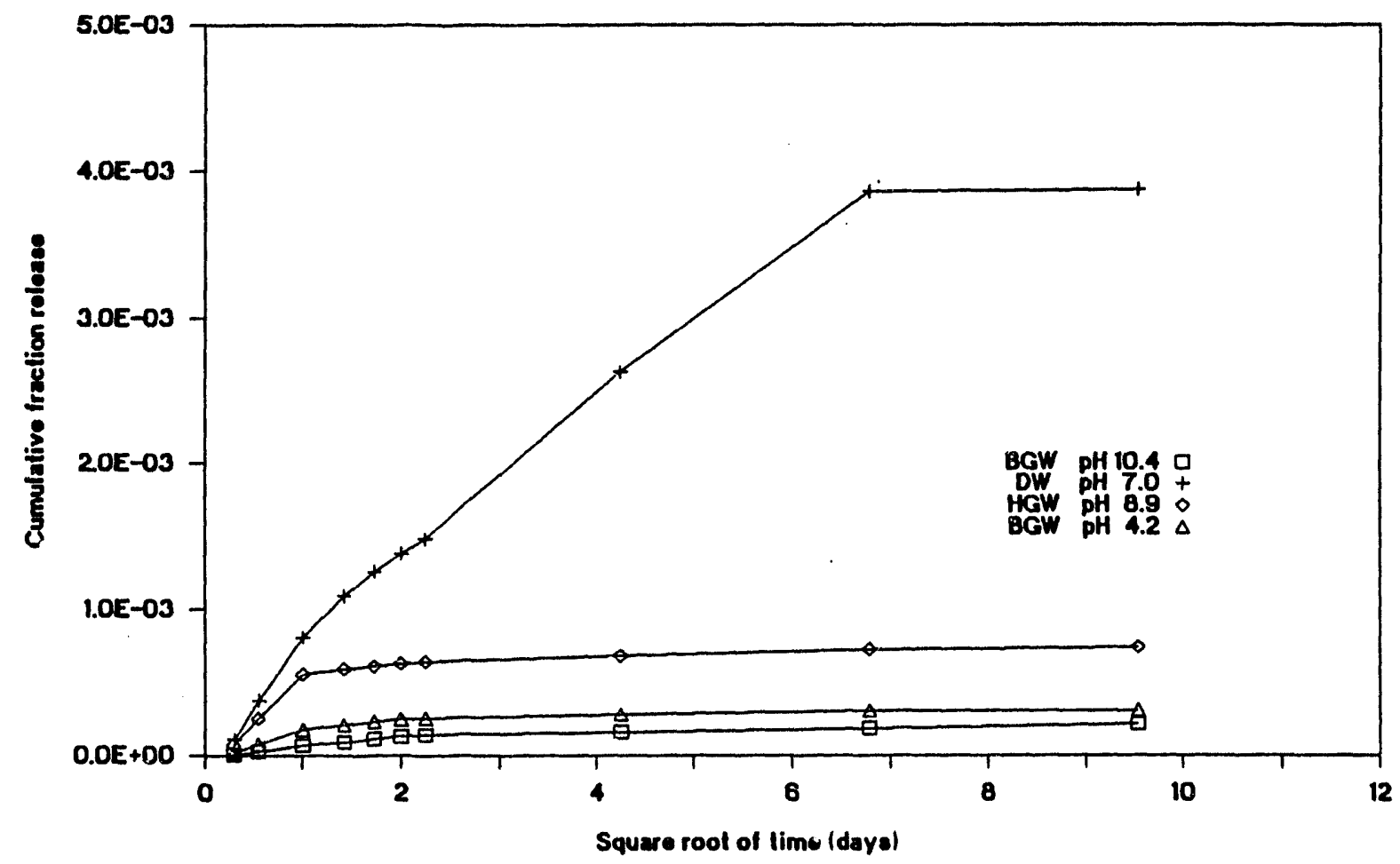

Figure 72. Cumulative fractional release of ${ }^{63} \mathrm{Ni}$ from five Brunswick-1 mixed-bed resin waste-form specimens. 


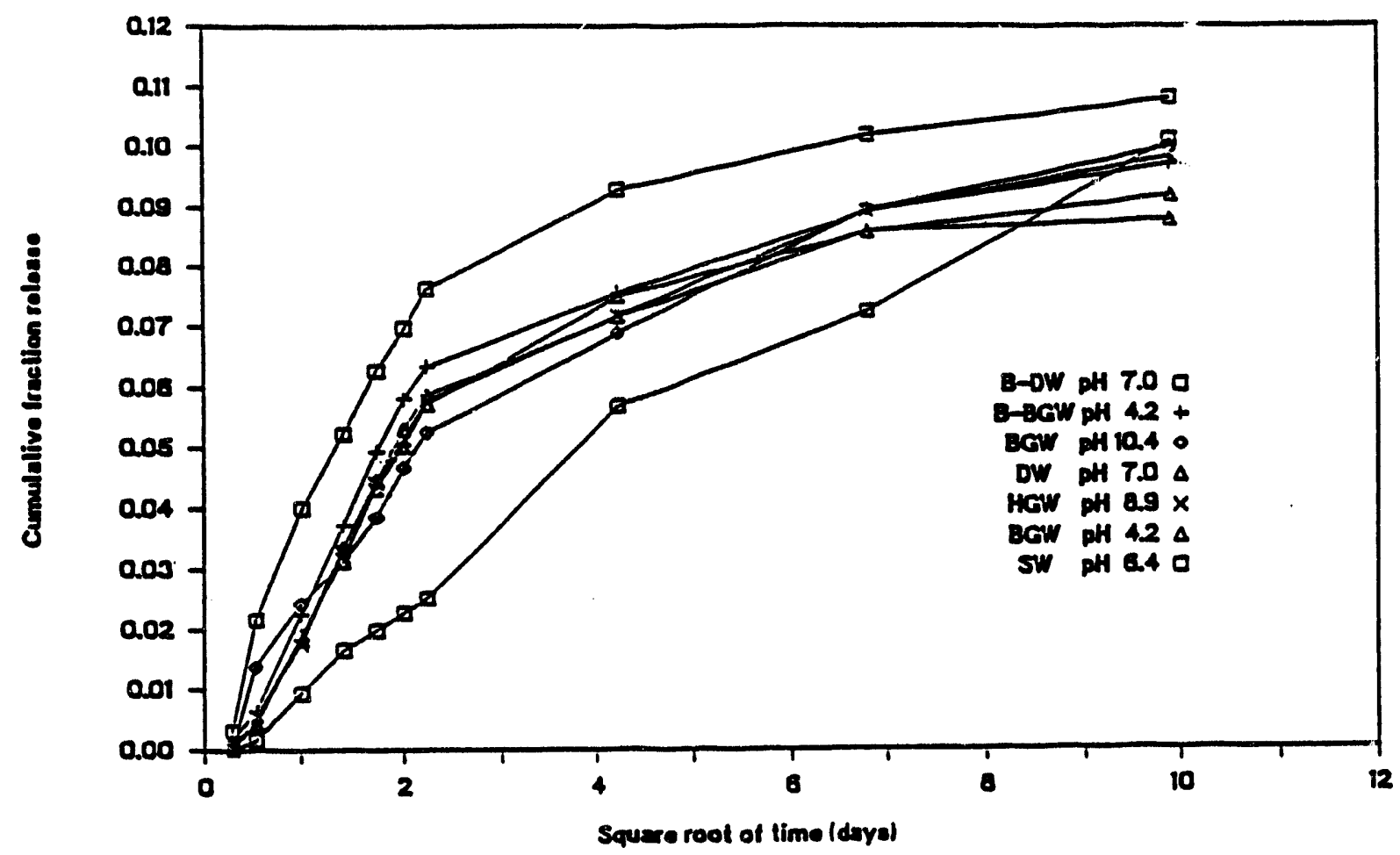

Figure 73. Cumulative fractional release of ${ }^{63} \mathrm{Ni}$ from seven FitzPatrick ion-exchange resin waste-form specimens.

rates are similar to those for the other leachants. No reason for this initially high release rates is known. Figures 71 through 73 show the CFRs for ${ }^{63} \mathrm{Ni}$, which indicate that there are apparent higher releases from the samples leached in deionized water; however, the releases for simulated seawater are near those for the deionized water.

The average effective diffusivities and leachability indexes for the samples leached in different leachants are shown in Appendix F. Average effective diffusivities anci leachability indexes have not been used to characterize leachant effects because these results typically follow the average fractional release rate results and add little to the discussion. In all cases, the leachability indexes were above the regulatory requirement.

In summary, leachant effects have been observed for ${ }^{55} \mathrm{Fe}$ and ${ }^{63} \mathrm{Ni}$ that apparently affect the release rates of these radionuclides from the waste form. Specific leachant effects may affect the fractional release rate by one to two orders of magnitude and are probably due to differences in the relative solubilities of these radionuclides and the ion strength of the leachant. Further, there was evidence that high ionic-strength leachants (i.e., simulated seawater) and some groundwaters may also enhance the release rate. It should be noted that in many cases, deionized water may not be the most aggressive leachant.

\section{Inventories in Liners}

Appendix $\mathbf{G}$ contains a summary of the radionuclide, stable metal, and chelating agent inventories in the liner that were sampled as part of this study. Typically, the primary radionuclides present are from the transition metals $\left({ }^{55} \mathrm{Fe},{ }^{60} \mathrm{Co}\right.$, and ${ }^{63} \mathrm{Ni}$ ). However, as noted previously, ${ }^{14} \mathrm{C}$, which was measured only in the Peach Bottom-3 (LOMI) sample, makes up about $58 \%$ of the inventory in the Peach Bottom-3 liner and is probably present in significant concentrations in other liners. 


\section{SUMMARY AND CONCLUSIONS}

In this report, the decontamination processes are described that were used at the seven BWRs and one PWR that were studied. In addition, the characteristics of the resins that were solidified, the cement chemistry, and the solidification methods used at the plants sampled are also described. Key conclusions of this study relate to wasteform structural integrity, the effects of leachant $\mathrm{pH}$ on the releases from waste forms, the effects of waste-form constituents such as chelating agents on releases, and the effects of leachants with different compositions on release rates.

Key conclusions of the compression tests performed to assess structural integrity are that the waste forms, which survived the immersion testing, meet the requirements for waste form integrity identified in applicable revisions of the "Technical Position on Waste Form." Post-immersion compression-testing results indicate that the compressive strengths of the Peach Bottom-3 waste forms, which used the newest LOMI formulation, were all well above the regulatory requirement $\left(500 \mathrm{psi}\right.$ or $\left.3.4 \times 10^{3} \mathrm{kPa}\right)$ and ranged from 960 to 1,370 psi for all leachants. All AP/ Citrox waste forms that were tested decomposed during immersion testing, and no post immersion compressive strength measurements were made.

In the evaluation of the leach test results, the key conclusion is that all waste forms, including those that decomposed during leach testing, met the leachability index requirement of 6.0 specified in the NRC's "Technical Position on Waste Form," Revision 1. In addition, all stable metals and all chelating agents with the exception of EDTA (5.7) for the Dow NS-1 waste form all have leachability indexes greater than 6.0

The $\mathrm{pH}$ effects on leachability and the characteristics of radionuclide and stable metal releases from the waste forms were also assessed. The $\mathrm{pH}$ data indicate that the $\mathrm{pH}$ of the leachate is affected within a few hours and probably within a few minutes by the chemistry of the waste form. These data suggest that $\mathrm{pH}$ effects are limited to the period before the leachate is affected by the cement chemistry and that the primary factors affecting radionuclide release are probably radionuclide solubility and the ion strength of the leachant. It should be noted that radionuclide release rates from the Peach Bottom-3 LOMI waste form, where a new formulation was used, are typically less than those for other LOMI waste forms, indicating the success of the improved formulation.

Key results from the compression tests are that (a) decontamination ion-exchange waste-form specimens have compressive strengths, typically 1,000 to $2,000 \mathrm{psi}$, (b) compression tests performed on unleached specimens prior to immersion testing do not appear to be indicative of the ability of the waste form to survive the immersion and the subsequent compression test, (c) immersion significantly affects the ability of the waste form to survive compression testing, (d) high ionic-strength leachants such as simulated seawater tend to minimize degradation of the shape and structure of the waste form, and (e) disintegration of the waste form may occur quickly and may be the result of several apparently robust mechanisms.

Primary mechanisms that have been postulated as being probably responsible for the decomposition of the cement-solidified decontamination ionexchange resin waste forms are the following:

- Resin contraction/swelling during immersion causes the waste form to split and decompose. It is indicated that the resin beads decrease in size and become encapsulated within the cement matrix. After curing, immersion of the composite in pure water allows more dilute solutions to wet the resin beads, which begin to swell and, consequently, cause a breakdown of the waste form. This mechanism alone probably did not result in the decomposition of most waste-form samples that were tested.

- Resin swelling is dependent on the ion-exchange capacity, ionic form, solven $\hat{\imath}$, and composition of solution. Our study confirms this theory as there appear to be leachant 
specific effects that either increase or reduce degradation of the waste form (i.e., the Brunswick-1 waste forms leached in simulated seawater did not completely disintegrate).

In contrast to the resin bead swelling theory, several other theories have been proposed to explain the degradation of cement-solidified waste forms containing ion-exchange resins. Others have suggested that the pressure from the interior of the waste form is due to the formation of crystals of calcium salts that build up during the curing process and continue to expand and generate pressure on the interior of the waste form. Scanning eluctron microscopy techniques have been used to observe the crystal formation in waste forms. These data indicate that an actual mechanism has not been adequately defined or that all mechanisms may contribute to the rapid decomposition of the waste form.

Primary results of the physical stability measurements are the following:

- All AP/Citrox waste forms that were tested decomposed within several hours of the beginning of the leach test and that the probable mechanisms noted above significantly affect the capability of these waste forms to meet the regulatory requirement defined in the "Technical Position on Waste Form" for compression testing.

- The FitzPatrick waste forms also decomposed during leach testing; however, the FitzPatrick samples are a special case due to the formation of a gel in the bulk liners during the $\mathrm{pH}$ adjustment phase. Studies have indicated that the gel formation was due to the high concentration $(\sim 8 \mathrm{wt} \%)$ of picolinic acid in the waste form and that this would not be expected to occur again due to changes in the LOMI formulation.

Some station waste forms (i.e., Brunswick-1 and FitzPatrick) were tested to assess the effects of $\mathrm{pH}$. The results of this study suggest that the $\mathrm{pH}$ of the leachant (with the exception of seawater) is controlled by the $\mathrm{pH}$ of the cementsolidified waste form and that $\mathrm{pH}$ effects are probably limited to the period $(<1 \mathrm{hr})$ before the $\mathrm{pH}$ of the leachant is significantly affected by the $\mathrm{pH}$ of the waste form. However, further study would be required to fully evaluate these effects.

In order to determine the inventories of radionuclides, stable metals, and chelating agents that could be leached from the waste forms being leach-tested, waste st:eam samples were obtained from all waste streams used to prepare the wasteform samples. The concentrations of the primary radionuclides, transuranic radionuclides, stable metals, and chelating agents present in the resin wastes were measured. The primary decontamination radionuclides whose leachability characteristics are discussed are ${ }^{55} \mathrm{Fe},{ }^{60} \mathrm{Co},{ }^{63} \mathrm{Ni}$, and ${ }^{14} \mathrm{C}$. Manganese-54 is not discussed in detail because it was not measurable in most leachate samples. In addition to neutron activation-produced radionuclides, assessments have been performed for the fission products ${ }^{137} \mathrm{Cs},{ }^{99} \mathrm{Tc}$, and ${ }^{129}$ I for the Peach Bottom-3 samples.

The measured concentrations of the transuranic radionuclides in the waste resins were typically low with the exception of ${ }^{241} \mathrm{Pu}$, which has the highest concentrations of the transuranic radionuclides, ranging from $10^{-3}$ to $10^{-1} \mu \mathrm{Ci} / \mathrm{cm}^{3}$, whereas most other transuranic radionuclides had concentrations ranging from $10^{-8}$ to $10^{-4}$ $\mu \mathrm{Ci} / \mathrm{cm}^{3}$. The higher concentrations of ${ }^{241} \mathrm{Pu}$ are primarily due to the higher specific activity associated with this radionuclide. The leachability characteristics of the transuranic radionuclides were not discussed in detail because these radionuclides were not often measurable in the leachates, and the concentrations of the waste forms are dependent on the quantities present in the system that was decontaminated and the decontamination process used.

The stable metal constituents of the resin waste included iron whose concentration was typically the highest and ranged from $5 \times 10^{2}$ to $10^{4}$ $\mu \mathrm{g} / \mathrm{cm}^{3}$ resin waste. The concentration of nickel in the Cooper cation and Millstone resins was approximately $10^{3} \mu \mathrm{g} / \mathrm{cm}^{3}$ resin. Typical 
concentrations for other elements ranged from $10^{1}$ to $10^{2} \mu \mathrm{g} / \mathrm{cm}^{3}$ resin.

Typical concentrations of chelating agents ranged from about $10^{2} \mu \mathrm{g} / \mathrm{cm}^{3}$ of resin for oxalic and citric acid for the Cooper AP/Citrox process to about $5 \times 10^{4} \mu \mathrm{g} / \mathrm{cm}^{3}$ resin for picolinic acid in the Peach Bottom-3 LOMI resin wastes. Other decontamination processes (Can-Decon and DOW NS-1) had chelate concentrations between those noted for the A.P/Citrox and LOMI processes. The high concentration of picolinic acid in the Peach Bottom-3 waste form may have resulted in some of the problems that occurred with this solidification.

Key results of the leach testing are:

- For the LOMI waste forms, the structural stability of the waste form does not significantly affect the fractional release rates of chelating agents (e.g., picolinic acid) as indicated by comparisons between the releases from the FitzPatrick waste form that decomposed during leach testing and the Peach Bottom-3 waste form that maintained its structure.

- The inventory of the chelating agent in the waste form does not appear to have a significant effect on fractional or absolute release rates, which appear to be controlled by chemical mechanisms other than pure diffusion. This is confirmed by the fact that the average fractional release rate of ${ }^{137} \mathrm{Cs}$ $\left(\sim 5 \times 10^{-9} \mathrm{~cm}^{-2} \cdot \mathrm{s}^{-1}\right)$, which is ionic and probably released purely via diffusion, is one to two orders of magnitude higher than those of the chelating agents for most waste forms $\left(\sim 3 \times 10^{-10} \mathrm{~cm}^{-2} \cdot \mathrm{s}^{-1}\right.$ for the AP/Citrox and Can-Decon waste forms). In contrast, picolinic acid is released at about the same rate as ${ }^{137} \mathrm{Cs}$, and purely diffusional release is suggested for this chelating agent.

- Leachability indexes for the waste forms follow this general order from the lowest to highest: ${ }^{129} \mathrm{I}<{ }^{137} \mathrm{Cs}<{ }^{90} \mathrm{Sr}<{ }^{63} \mathrm{Ni}<{ }^{99} \mathrm{Tc}<$ ${ }^{60} \mathrm{Co}<{ }^{55} \mathrm{Fe}<{ }^{14} \mathrm{C}$ (i.e., leachability is high- est for ${ }^{129}$ I and lowest for ${ }^{14} \mathrm{C}$ ). As expected, the cations $\left({ }^{137} \mathrm{Cs}\right.$ and $\left.{ }^{90} \mathrm{Sr}\right)$ and anions $\left({ }^{129} \mathrm{I}\right)$ had the lowest leachability indexes (8-9), and ${ }^{14} \mathrm{C}$ had the highest (13.5).

- Comparisons of chelating agent release rate data with laboratory studies indicates that simulated cement-solidified decontamination ion-exchange waste forms produced in the laboratory may not accurately reproduce the waste compositions found in actual commercial nuclear power plant wastes and that, indeed, the commercial reactor wastes may contain constituents that enhance the release of chelating agents and radionuclides from the wastes.

- Cesium-137 leaches as quickly or more quickly than the chelating agents and radionuclides from most waste forms and is probably an indicator of a purely diffusion-controlled release, with no significant solubility effects due to the relatively high solubility of ${ }^{137} \mathrm{Cs}$. These data suggest that some chelating agents are being retained in the waste form to a greater extent than the ionic radionuclides, probably due to the lower solubilities of the chelating agents.

- Differences in the average fractional release rates of the transition metal radionuclides between the FitzPatrick and Peach Bottom-3 LOMI waste forms and the Indian Point-3 LOMI waste form suggest that differences in the waste stream of a BWR (FitzPatrick and Peach Bottom-3) and that of a PWR (Indian Point-3) can have a significant impact on release rates of the transition metal radionuclides. Typically, lower fractional release rates $(\sim 10)$ are indicated for the PWR, although other factors such as resin type and waste loading may have had an effect.

- Transition metal radionuclide release rate data for all LOMI waste forms indicates that ${ }^{60} \mathrm{Co}$ and ${ }^{55} \mathrm{Fe}$ have the same release rates and appear to behave similarly chemically. In contrast, ${ }^{63} \mathrm{Ni}$ has statistically higher 
release rates by about an order of magnitude. The Irving-Williams correlation indicates that the stability of transition metal complexes fall in the order $\mathrm{Ni}^{\mathrm{Il}}>\mathrm{Co}^{\mathrm{Il}}>\mathrm{Fe}^{\mathrm{II}}$. These data suggest that the stability of the nickel complex with a chelating agent may result in the higher average fractional release rate of ${ }^{63} \mathrm{Ni}$ relative to the other transition metals, due to the greater solubility of the ${ }^{63} \mathrm{Ni}$ complex.

- Average absolute release rates for the transition metal radionuclides for the LOMI samples vary considerably, with the average absolute release rates ranging from $7 \times 10^{-10}$ to $5 \times 10^{-8} \mu \mathrm{Ci} / \mathrm{cm}^{2} \cdot \mathrm{s}^{1}$. Iron-55 typically has the lowest absolute release rate, and ${ }^{60} \mathrm{Co}$ and ${ }^{63} \mathrm{Ni}$ have the highest. However, if the specific activity of these radionuclides is taken into account and the release rates of these radionuclides are converted to $\mu \mathrm{g} / \mathrm{cm}^{2} \cdot \mathrm{s}^{1},{ }^{63} \mathrm{Ni}$ has a higher $\left(10^{2}\right)$ absolute mass release rate than do the other radionuclides and higher concentrations of this radionuclide in the waste form may be a contributing factor to the higher concentrations of ${ }^{63} \mathrm{Ni}$ in the leachate due to the larger concentration gradient between the resin, the waste form, and finally the leachant.

- If the weighted-average fractional release rates for the AP/Citrox mixed-bed waste forms (i.e., Brunswick-1 and Cooper) are compared with the results from the Brunswick-1 cation resin waste form, which does not contain a chelating agent, it is suggested that chelating agent effects may have increased the average fractional release rates of the transition metal radionuclides by the following factors: ${ }^{60} \mathrm{Co}(48),{ }^{55} \mathrm{Fe}(7.3)$, and ${ }^{63} \mathrm{Ni}(6)$. However, further tests would be required to confirm this conclusion, as other factors such as waste loading and resin type may also have affected the release rates.

- With the exception of the ${ }^{63} \mathrm{Ni}$ data, the average fractional release rates of the transition metals for the LOMI, AP/Citrox, and Can-Decon waste forms all fall into a nar- row range between $5 \times 10^{-12}$ and $6 \times 10^{-11} \mathrm{~cm}^{-2} \cdot \mathrm{s}^{-1}$, which suggests relatively generic release rate behavior for these transition metal radionuclides. In the case of ${ }^{63} \mathrm{Ni}$, the release rates appear to be dependent on the decontamination process, with higher rates from the LOMI and Can-Decon waste forms and lower rates from the AP/ Citrox waste forms.

- Average effective diffusivities for ${ }^{60} \mathrm{Co}$ range from $1 \times 10^{-13} \mathrm{~cm}^{2} \cdot \mathrm{s}^{-1}$ for the Millstone-1 (Can-Decon) samples to $5 \times 10^{-11}$ $\mathrm{cm}^{2} \cdot \mathrm{s}^{-1}$ for the FitzPatrick LOMI samples. If the Brunswick-1 (AP/Citrox) cation resin (low) value and Pilgrim (NS-1) (high) values are excluded, for reasons discussed in the report, the typical average effective diffusivities for the waste forms are: LOMI $\left(1.8 \times 10^{-11} \mathrm{~cm}^{2} \cdot \mathrm{s}^{-1}\right), \quad$ AP/Citrox $\left(4 \times 10^{-12} \mathrm{~cm}^{2} \cdot \mathrm{s}^{-1}\right)$ and Can-Decon $\left(1 \times 10^{-13} \mathrm{~cm}^{2} \cdot \mathrm{s}^{-1}\right)$. These data indicate that the LOMI waste forms, either including or excluding FitzPatrick, have the highest average effective diffusivities followed by the AP/Citrox and Can-Decon waste forms.

- The low release rate of ${ }^{14} \mathrm{C}$ measured for the Peach Bottom-3 (LOMI) samples is probably due to the formation of insoluble hydrates and carbonates, which slow the release of this radionuclide, although other factors such as resin type may have an effect. Further, others have suggested that the fractional release rate of ${ }^{60} \mathrm{Co}$ should be slower than ${ }^{14} \mathrm{C}$ unless the rate is increased due to chelating agent effects as shown in this study.

- The release rate behavior of ${ }^{99} \mathrm{Tc}$ for the Peach Bottom-3 (LOMI) samples is statistically the same as that for ${ }^{55} \mathrm{Fe}$ and ${ }^{60} \mathrm{Co}$, and suggests similar chemical and release rate behavior for ${ }^{99} \mathrm{Tc}$. This might be expected as technetium is a metal and would be expected to form organo metallic complexes.

- Iodine, an anion, would be expected to diffuse similarly to other ionic elements such 
as cesium, and its release would not be expected to be affected by chelating agent effects as discussed for ${ }^{137} \mathrm{Cs}$. The fractional release rates of ${ }^{129} \mathrm{I}$ and ${ }^{137} \mathrm{Cs}$ for the Peach Bottom-3 (LOMI) samples are the highest of all radionuclides present in the waste form and are statistically the same as that for picolinic acid $\left(5.8 \times 10^{-10}\right.$ $\mathrm{cm}^{-2} \cdot \mathrm{s}^{-1}$ ), and are higher than those for other chelating agents.

- Comparisons of stable metal release rates with those of ${ }^{63} \mathrm{Ni}$ and ${ }^{55} \mathrm{Fe}$ indicate that the average fractional release rates for nickel and iron are higher than those of the radionuclides by one to two orders of magnitude except for the LOMI waste form. These data indicate that the radionuclides may be in a chemical form in the AP/Citrox and CanDecon waste forms that causes them to be retained to a greater extent than the elemental iron and nickel.

- A comparison of the LOMI ${ }^{63} \mathrm{Ni}$ data with the elemental nickel data indicates that ${ }^{63} \mathrm{Ni}$ has the same weighted-average fractional release rate $\left(4.8 \pm 1.0 \times 10^{-10} \mathrm{~cm}^{-2} \cdot \mathrm{s}^{-1}\right.$ excluding Indian Point-3) as elemental nickel for the LOMI waste forms. However, for the Indian Point-3 sample, the fractional release rate of ${ }^{63} \mathrm{Ni}$ is about $2 \%$ of the release of nickel. These data indicate that for Indian Point-3 (LOMI), the elemental nickel and ${ }^{63} \mathrm{Ni}$ are in different chemical forms.

- A comparison of the only measurable LOMI ${ }^{55} \mathrm{Fe}$ and iron fractional release rate data (Peach Bottom-3) indicates that the fractional release rate of ${ }^{55} \mathrm{Fe}$ is about two orders of magnitude higher than that for elemental iron. The explanation for this behavior is not known and is not consistent with the expected kinetics of this radionuclide, which suggest that it should be released as the same rate as the iron.

- Leachant effects (i.e., the use of different leachants) have been observed for ${ }^{55} \mathrm{Fe}$ and
${ }^{63} \mathrm{Ni}$ that apparently affect the release rates of these radionuclides from the waste form. Specific leachant effects may affect the fractional release rate by one to two orders of magnitude.

- Based on the Brunswick-1 (AP/Citrox) and FitzPatrick (LOMI) studies, high ionic strength leachants (e.g., simulated seawater) and some groundwaters may affect the release rates of radionuclides. It should be noted that in many cases, deionized water may not be the most aggressive leachant. The Barnwell groundwater $\mathrm{pH} 10.4$ had higher release rates and CFRs for some transition metal radionuclides than did the deionized water.

- Leach test results suggest that release rates obtained during the first 5 days are not indicative of trends for later times particularly when degraded waste forms are being tested and that further testing may be required to determine actual release rates from these waste forms.

The results of this study provide substantial information on the release rates of chelating agents, radionuclides, and stable metals; however, the results present a number of questions concerning the mechanisms that retain the species of interest in the waste forms or accelerate releases. The ANSI/ANS 16.1 standard assumes that release rates are diffusion driven, which is shown in this study. However, this study also indicates that solubility and leachant ion strength may also be significant in defining releases from the waste form. Specific areas that require more study are the following: (a) the mechanisms by which the chelating agents interact with the radionuclides and stable metals, (b) the differences in the chemistry of ${ }^{63} \mathrm{Ni}$ that result in higher release rates, (c) the significant differences between the release rates of the stable metals and the transition metal radionuclides, (d) how leachant composition results in the observed wide range of release rates and releases from the waste forms, and (e) the effects of $\mathrm{pH}$ on leachability. 


\section{REFERENCES}

1. C. V. McIsaac and J. W. Mandler, The Leachability of Decontamination Ion-Exchange Resins Solidified in Cement at Operating Nuclear Power Plants, NUREG/CR-5224, March 1989.

2. C. V. McIsaac, D. W. Akers, and J. W. McConnell, Jr., Effect of pH on the Release of Radionuclides and Chelating Agents from Cement-Solidified Decontamination Ion-Exchange Resins Collected from Operating Power Stations, NUREG/CR-5601, June 1991.

3. D. W. Akers and N. C. Kraft, Releases of Radionuclides and Chelating Agents From Cement-Solidified Decontamination Ion-Exchange Resins from the Peach Bottom Atomic Power Station Unit 3, NUREG/CR-6164, 1994.

4. H. Nishita and E. Essington, "Effect of Chelating Agents on the Movement of Fission Products in Soils," Soil Science, 103, p. 168, 1967.

5. Jackson, W. Merritt, D. Champ, J. Guiens, and K. Inch, The Distribution Coefficient as a Geochemical Measure of the Mobility of (Contaminants in a Ground Water Flow System, Vienna: International Atomic Energy Agency, 1977.

6. J. Means, D. Crerar, and J. Duguid, "Application of Gel Filtration Chromatography to Evaluation of Organo-Metallic Interactions in Natural Waters," Limn. and Ocean., 22, p. 557, 1977.

7. J. Means, D. Crerar, and J. Duguid, "Migration of Radioactive Wastes: Radionuclide Mobilization by Complexing Agents," Science, 200, pp. 1447-1481, 1978.

8. J. Cleveland and T. Rees, "Characterization of Plutonium in Maxey Flats Radioactive Trench Leachates," Science, 212, p. 1506, 1981.

9. J. L. Means and C. A. Alexander, "The Environmental Biogeochemistry of Chelating Agents and Recommendations for the Disposal of Chelated Radioactive Waste," Nuclear and Chemical Waste Management, 2, p. 183, 1981.

10. "Technical Position on Waste Form," U.S. Nuclear Regulatory Commission, Low-Level Waste Management Branch, Washington, D.C., May 1983.

11. "Technical Position on Waste Form," Revision 1, U.S. Nuclear Regulatory Commission, Low-Level Waste Management Branch, Washington, D.C., January 1991.

12. "Compressive Strength of Cylindrical Concrete Specimens," ASTM C39, American Society for Testing and Materials, October 1984.

13. "Measurement of the Leachability of Solidified Low-Level Radioactive Wastes by a Short-Term Test Procedure," ANSI/ANS-16.1-1986, American Nuclear Society Standards Committee, April 1986.

14. M. Tokar et al., Proceedings of the Workshop of Cement Stabilization of Low-Level Radioactive Waste, Gaithersburg, MD, NUREG/CR-0103, June 1989.

15. M. A. Miller and J. F. Remark, "Philadelphia Electric Company Peach Bottom Atomic Power Station Unit 3 Decontamination Experience," Proceedings of the Third Seminar on Chemical Decontamination of BWRs, December 6-8, 1988, EPRI 89-wk-52. 


\section{References}

16. D. Schneidmiller, "Recent Pacific Nuclear Decontamination Experience," Proceedings of the Third Seminar on Chemical Decontamination of BWRs, December 6-8, 1988, EPRI 89-wk-52.

17. S. W. Duce and J. T. Case, Effectiveness and Safety Aspects of Selected Decontamination Processes, NUREG/CR-4445, August 1986.

18. M. S. Davis, The Impact of LWR Decontaminations on Solidification, Waste Disposal, and Associated Occupational Exposure, NUREG/CR-3444, August 1983.

19. R. Soto, Decontamination Waste Management, EPRI NP-4240, September 1985.

20. Electric Power Research Institute, Development of LOMI Chemical Decontamination Technoiogy, EPRI NP-3177, July 1983.

21. A. Valvasori, "Westinghouse Recent Decontamination Experience," Proceedings of the Fifth Workshop on Chemical Decontamination, Electric Power Research Institute, 1993.

22. P. L. Piciulo, J. W. Adams, M. S. Davis, L. W. Milian, and C. I. Anderson, Release of Organic Chelating Agents from Solidified Decontamination Wastes, NUREG/CR-4709, July 1986.

23. R. M. Neilson, Jr. and P. Colombo, Waste Form Development Program Annual Progress Report, October 1981 - September 1982, BNL-51614, September 1982.

24. International Atomic Energy Agency, Improved Cement Solidification of Low and Intermediate Level Radioactive Wastes, Technical Report No. 350, pp. 13-15, January 1993.

25. S. T. Croney, Leachability of Radionuclides from Cement Solidified Waste Forms Produced at Operating Nuclear Power Plants, NUREG/CR-4181, March 1985.

26. R. Dayal, H. Arora, and N. Morcos, Estimation of Cesium-137 Release from Waste/Cement Composites Using Data from Small-Scale Specimens, NUREG/CR-3382, July 1983.

27. H. Arora and R. Dayal, Leaching Studies of Cement-Based Low-Level Radioactive Waste Forms, NUREG/CR-4756, October 1986.

28. J. H. Westsik, Jr. (Comp.), Characterization of Cement and Bitumen Waste Forms Containing Simulated Low-Level Waste Incinerator Ash, NUREG/CR-3798, August 1984.

29. P. Soo, L. Milian, and P. Piciulo, The Leachability and Mechanical Integrity of Simulated Decontamination Resin Wastes Solidified in Cement and Vinyl Ester-Styrene, NUREG/CR-5153, May 1988.

30. J. V. Bishop, "Solidification of Ion-Exchange Resin from a LOMI Decontamination," Proceedings of the Third Seminar on Chemical Decontaminaticn of BWRs, December 6-8, 1988, EPRI.

31. D. R. Dougherty and P. Colombo, Leaching Mechanisms of Solidified Low-Level Waste, The Literature Survey, BNL-51899, June 1985.

32. J. E. Mendel et al., A State-of-the-Art Review of Materials Properties of Nuclear Waste Forms, PNL-3802, 1981.

33. H. W. Godbee and D. S. Joy, "Assessment of the Loss of Radioactive Isotopes from Waste Solids to the Environment," Part 1: Background and Theory, ORNL-TM-4333, 1974. 
34. O. U. Anders, J. F. Bartel, and S. J. Altschuler, "Determination of the Leachability of Solids," Analytical Chemistry, 50, 4, pp. 564-569, 1978.

35. B. Siskind and M. G. Cowgill, "Technical Justifications for the Tests and Criteria in the Waste Form Technical Position Appendix on Cement Stabilization," Proceedings of Waste Management '92, pp. 1753-1759, 1992.

36. P. L. Piciulo, J. W. Adams, J. H. Clinton and B. Siskind, The Effect of Cure Conditions on the Stability of Cement Waste Forms After Immersion in Water, WM-3171-4, Brookhaven National Laboratory, September 1987.

37. B. Siskind, J. W. Adams, J. H. Clinton and P. L. Piciulo, "The Effect of Cure Conditions on the Stability of Cement Waste Forms After Immersion in Water," Proceedings of Waste Management '88, pp. 613-618, 1989.

38. International Atomic Energy Agency, Improved Cement Solidification of Low and Intermediate Level Radioactive Wastes, Technical Report No. 350, p. 54, January 1993.

39. International Atomic Energy Agency, Treatment of Spent Ion Exchange Resins for Storage and Disposal, Technical Report No. 254, 1985.

40. International Atomic Energy Agency, Improved Cement Solidification of Low and Intermediate Level Radioactive Wastes, Technical Report No. 350, p. 15, January 1993.

41. R. O. Lokken, J. W. Shade, and P. F. C. Martin, "Effect of Curing Temperature on the Properties of Cementitious Waste Forms," Materials Research Society Symposium Proceedings, 176, 1990.

42. International Atomic Energy Agency, Improved Cement Solidification of Low and Intermediate Level Radioactive Wastes, Technical Report No. 350, p. 84, January 1993.

43. R. M. Wheaton and A. H. Seamster, "A Basic Reference on Ion Exchange," Encyclopedia of Chemical Technology, 2nd Edition, II, pp. 871-899, 1966.

44. P. Colombo and R. M. Neilson, Properties of Radioactive Wastes and Waste Containers, Quarterly Progress Report, January-March 1979, BNL-NUREG-51101, 1979.

45. N. Morcos and A. J. Weiss, Properties of Radioactive Wastes and Waste Containers, BNLNUREG-51316, 1981.

46. R. E. Barletta and R. E. Davis, Review of a Test Program for Qualifying the Solidification of EPICORII Resins with Cement, BNL-NUREG-51712.

47. M. Constable, C. G. Howard, and D. J. Lee, "Expansive Failure Reactions and Their Prevention in the Encapsulation of Phenol Formaldehyde Type Ion Exchange Resins in Cement Based Systems," Proceedings of Waste Management '92, pp. 1581-1586, 1993.

48. J. Jeffrey, "Waste Processing of Resins," Proceedings of the Third Seminar on Chemical Decontamination of BWRs, December 6-8, 1988, EPRI 89-wk-52.

49. International Atomic Energy Agency, Improved Cement Solidification of Low and Intermediate Level Radioactive Wastes, Technical Report No. 350, p. 60, January 1993. 
50. P. Vejmelka and R. Koster, "Leach Studies of Chelating Agents and Influence on Radionuclide Leaching from Simulated LLW/ILW Cement Waste Forms," Proceedings of Waste Management '90, 1990.

51. R. J. Lemire and F. Garisto, "The Effect of Ionic Strength, Groundwater Composition and Temperature on Calculated Radionuclide Solubilities," Radiochimica Acta, 58/59, 1992.

52. L. W. Jones, M. Bricka, and M. J. Cunnane, "Effects of Selected Waste Constituents on Solidified/Stabilized Waste Leachability," Proceedings of the Second International ASTM Symposium on Stabilization/Solidification of Hazardous, Radioactive, and Mixed Wastes, May 29, 1990.

53. J. O. Lee, K. W. Han, and L. P. Buckley, "Short-Term Leaching Behavior of Co-60, Sr-85, and Cs-137 from Cemented Ion-Exchange Resin Waste Forms," Stabilization and Solidification of .Hazardous, Radioactive, and Mixed Wastes, Vol. 2, ASTM STP 1123, 1992.

54. K. Andersson, B. J. Torstenfeldt, and B. Allard, Sorption and Diffusion Studies of Cs and I in Concrete, Report 5-412-96, Chalmers University of Technology, Goteburg Sweden, 1981.

55. J. E. Mendel et al., A State-of-the-Art Review of Material Properties of Nuclear Waste Forms, PNL-3802, Battelle Pacific Northwest Laboratory, Richland, WA, 1981.

56. G. De Angelis, A. Marchetti, and S. Balzamo, "Leach Studies: Influence of Various Parameters on the Leachability of Cesium from Cemented BWR Evaporator Concentrates," Stabilization and Solidification of Hazardous, Radioactive, and Mixed Wastes, Vol. 2, ASTM STP 1123, 1992.

57. N. N. Greenwood and A. Earnshaw, Chemistry of the Elements, Pergamon Press, New York, NY, 1986.

58. G. Rudolph and R. Koester, "Source Term Evaluation or Actinide Elements in the System Cemented Waste Form/Salt Brines - Influences of Organic Complexants," Migration 89 International Conference on Geochemistry and Migration of Actinides and FP, Monterey, California, November 6-10, 1989.

59. R. Crawford, F. Glasser, A. Rahman, M. Angus, and C. McCulloch, "Diffusion Mechanisms Affecting Leaching of Cesium-134 from Cement Based Waste Lattices," Radioactive Waste Management and the Fuel Cycle, pp. 177-196, June 1985.

60. N. Morcos, R. Dayal, L. Milian, P. Hayde, and A. Weiss, "Correlation of ${ }^{137}$ Cs Release from SmallScale to Large-Scale Cement Waste Forms," Material Research Society Symposium, 15, pp. 259-268, 1983.

61. International Atomic Energy Agency, Improved Cement Solidification of Low and Intermediate Level Radioactive Wastes, Technical Report No. 350, p. 81, January 1993.

62. T. M. Krishnamoorthy, S. N. Joshi, G. R. Doshi, and R. N. Nair, "Desorption Kinetics of Radionuclides Fixed in Cement Matrix," Nuclear Technology, 104, December 1993.

63. S. Komarneni, E. Breval, D. Roy, and R. Roy, "Reactions of Some Calcium Silicates with Metal Cations," Cement and Concrete Research, 18, p. 204, 1988.

64. M. Fuhrman, R. Pietrzak, J. H. Heiser, E. M. Franz, and P. Colombo, "The Effects of Temperature on the Leaching Behavior of Cement Waste Forms: The Cement/Sodium Sulfate System," Scientific Basis for Nuclear Waste Management, CONF-891119-20, BNL Report 43449, 1989. 
65. H. M. N. H. Irving and R. J. P. Williams, "The Stability of Transition-Metal Complexes," Journal of Chem. Society, pp. 3192-3210, 1953.

66. J. L. Means and D. A. Crerar, "Migration of Radioactive Wastes and Radionuclide Mobilization by Complexing Agents," Science, 200, pp. 1447-1481, 1978.

67. M. H. Baik and K. J. Lee, "Theoretical Study on the Migration Phenomena of a Chelated Radionuclide in a Porous Medium," Proceedings of Waste Management '93, pp. 1723-1778.

68. P. Colombo et al., Accelerated Leach Test(s) Program, Annual Report, BNL-51955, September 1985.

69. H. Nitsche, A. Muller, E. Standifer, R. Deinhammer, K. Becraft, T. Prussin, and R. Gatti, "Dependance of Actinide Solubility and Speciation on Carbonate Concentration and Ionic Strength in Groundwater," Radiochimica Acta, 58/59, pp. 27-32, 1992. 


\section{Appendix A}

Recent Leaching Studies and the Effect of Waste Form Constituents on Solidification of Nuclear Power Plant Wastes 


\section{Appendix A}

\section{Recent Leaching Studies and the Effect of Waste Form Con- stituents on Solidification of Nuclear Power Plant Wastes}

This appendix identifies recent leaching studies performed to assess the properties of decontamination ion-exchange resins and the effects of extraneous waste-form constituents on solidification. Table A-1 summarizes some of the important experimental aspects of several leaching studies that have recently been performed on specimens of solidified resins or decontamination solutions. ${ }^{1-9}$ In addition, the three studies performed at this laboratory ${ }^{10-12}$ addressed cementsolidified decontamination ion-exchange resins from commercial nuclear power plants. Common to these studies is an emphasis on more realistic leaching situations involving local groundwater, $1,4,10,11$ seawater, 10,11 and actual nuclear power plant resin wastes. ${ }^{2-4,10-12}$ In these studies, solidified ion-exchange resin specimens were subjected to leach tests following either the ISO 6961 leach-test procedure ${ }^{13}$ or the ANSI/ANS 16.1 leach-test procedure. Both of these methods are nonequilibrium tests in the respect that the solidified waste-form specimen is completely immersed over an extended period of time in a large volume of leachate that is periodically replaced with new leachant.

Four earlier studies summarized in Table 1 were conducted using actual nuclear plant resin wastes; however, these studies did not contain chelating agents. The types of resin waste were (a) BWR sodium sulfate evaporator concentrate mixed with plant mixed-bed resin, ${ }^{14}$ (b) BWR resin waste, ${ }^{15}$ (c) incinerator ash that prior to incineration consisted of $31 \mathrm{wt} \%$ cation-exchange resin, $11 \mathrm{wt} \%$ anion-exchange resin, and $58 \mathrm{wt} \%$ general trash, ${ }^{16}$ and (d) EPICOR-II prefilter mixed-bed resins. ${ }^{17}$ None of these waste resins contained chelating or complexing agents, and therefore the results cannot be used to define the leaching behavior of chelated resin wastes. In addition to the studies, others were reported in the proceedings of the Cement Workshop. ${ }^{18}$

\section{Constituents Affecting Waste Solidification}

The Hanford and Barnwell waste disposal state licenses require that wastes with activities greater than $1 \mu \mathrm{Ci} / \mathrm{cm}^{3}$ be stabilized. Stability of these wastes may be achieved by dewatering and disposal in a high-integrity liner or by solidifying the waste. For a typical LWR, the estimated fractional breakdown of solidified wastes is $45 \%$ letdown system and decon resins, $22 \%$ boric acid evaporator waste, $15 \%$ sludges, $11 \%$ concentrator wastes, and $4.5 \%$ oil. ${ }^{19}$ Solidification problems from inorganics such as sulfates and borates have generally been resolved; however, problems have occurred from the presence of unknown organics in oils, evaporator wastes, and sludges or from organic byproducts in decontamination or other ion-exchange resins.

Tables A-1 and A-2 are compiled from an NRC list of waste constituents that may cause problems with cement solidification. ${ }^{19}$ These constituents have been classified in three broad categories: inorganic, organic-aqueous, and organic-nonaqueous components. The primary effects of these chemicals are on the solidification process and result in no solidification or poor waste-form characteristics. Typically, however, waste streams are not well characterized, and it is not until the process control program samples are tested that it is determined that the waste form contains constituents that either retard or prevent solidification. In the case of chelating agents, they may form gels or other forms that interfere with solidification of the waste form. Additional information on these effects is presented in Reference 18. 


\section{REFERENCES}

70. L. Criscenti and R. Seme, Geochemical Analysis of Leachates from Cement/Low-Level Radioactive Waste/Soil Systems, PNL-6544, September 1988.

71. C. Howard, C. Joliffe, and D. Lee, Immobilization in Cement of Ion-Exchange Resins Arising from the Purification of Reagents Used for the Decontamination of Reactor Circuits, AEEW-M-2536, CPDG-(88)-P118, UKAEA Atomic Energy Establishment, Winfrith, England, September 1988.

72. C. Howard, C. Jolliffe, and D. Lee, Immobilization in Cement of Ion-Exchange Resins Arising from the Purification of Reagents Used for the Decontamination of Reactor Circuits, AEEW-M-2558, CPDG-(88)-P208, UKAEA Atomic Energy Establishment, Winfrith, England, February 1989.

73. A. Ipatti and H. Harkonen, Half-Scale Solidification Experiment of Spent Ion-Exchange Resins, YJT-89-11, Nuclear Waste Commission of Finnish Power Companies, August 1989.

74. B. Torstenfelt and G. Hedin, "Leaching of Cesium from a Cement Matrix," Proceedings of the International Symposium on the Scientific Basis for Nuclear Waste Management, Berlin, Germany, October 10-13, 1988, Conference Title 12, Vol. 127, Materials Research Society.

75. J. V. Bishop, Solidification in Cement of Ion-Exchange Resins from LOMI Decontamination, EPRI NP-6934, August 1990.

76. M. S. Davis, P. L. Piciulo, B. S. Bowerman, et al., The Impact of LWR Decontamination on Solidification, Waste Disposal, and Associated Occupational Exposure, Annual Report-Fiscal Year 1984, NUREG/CR-3444, February 1985.

77. J. O. Lee, K. W. Han, and L. P. Buckley, "Short-Term Leaching Behavior of Co-60, Sr-85, and Cs-137 from Cemented Ion-Exchange Resin Waste Forms," Second International Symposium On Stabilization/Solidification of Hazardous, Radioactive, and Mixed Wastes, Williamsburg, Virginia, May 29 through June 1, 1990.

78. P. Soo, L. Milian, and P. Piciulo, The Leachability and Mechanical Integrity of Simulated Decontamination Resin Wastes Solidified in Cement and Vinyl Ester-Styrene, NUREG/CR-5153, May 1988.

79. C. W. McIsaac and J. W. Mandler, The Leachability of Decontamination Ion-Exchange Resins Solidified in Cement at Operating Nuclear Power Plants, NUREG/CR-5224, March 1989.

80. C. V. McIsaac, D. W. Akers, and J. W. McConnell, Jr., Effect of pH on the Release of Radionuclides and Chelating Agents from Cement-Solidified Decontamination Ion-Exchange Resins Collected from Operating Power Stations, NUREG/CR-5601, June 1991.

81. D. W. Akers et al., Releases of Radionuclides and Chelating Agents From Cement-Solidified Decontamination Low-Level Radioactive Waste Collected from the Peach Bottom Atomic Power Station Unit 3, NUREG/CR-6164, 1994.

82. Long-Term Leach Testing of Solidified Radioactive Waste Forms, ISO 6961, p. 1,015, 1982.

83. R. M. Neilson, Jr., P. D. Kalb, and P. Colombo, Lysimeter Study of Commercial Reactor Waste Forms: Waste Form Acquisition, Characterization and Full-Scale Leaching, BNL 51613, September 1982. 
84. H. Arora and R. Dayal, Solidification and Leaching of Boric Acid and Resin LWR Wastes, NUREG/ CR-3909, June 1984.

85. J. H. Westsik, Jr., Characterization of Cement and Bitumen Waste Forms Containing Simulated LowLevel Waste Incinerator Ash, NUREG/CR-3798, August 1984.

86. R. M. Neilson, Jr., J. W. McConnell, Jr., and R. D. Rogers, "Performance Testing of High Specific Activity Waste Forms per 10 CFR Part 61," Waste Management '87, Tucson, AZ, March 1-5, 1987.

87. M. Tokar et al., Proceedings of the Workshop of Cement Stabilization of Low-Level Radioactive Waste, Gaithersburg, MD, NUREG/CR-0103, June 1989.

88. M. S. Davis, P. L. Piciulo, B. S. Bowerman, et al., The Impact of LWR Decontamination on Solidification, Waste Disposal, and Associated Occupational Exposure, Annual Report-Fiscal Year 1984, NUREG/CR-3444, February 1985. 
Table A-1. Summary of recent cement-solidified resin waste leach studies.

\begin{tabular}{|c|c|c|c|c|c|}
\hline Author & $\begin{array}{c}\text { Reference } \\
\text { number }\end{array}$ & Sample size & Leachant & $\begin{array}{l}\text { Solidification } \\
\text { agent(s) }\end{array}$ & Resin type \\
\hline $\begin{array}{l}\text { Criscenti, L. J. } \\
\text { Seme, R. J. } \\
\text { (1988) }\end{array}$ & 1 & $\begin{array}{l}2.5 \mathrm{~cm} \times 5.0 \mathrm{~cm} \\
\text { (diameter } \times \text { length) }\end{array}$ & $\begin{array}{l}\text { Hanford } \\
\text { groundwater }\end{array}$ & $\begin{array}{l}\text { Portland cement } \\
\text { type III }\end{array}$ & $\begin{array}{l}\text { BWR evaporator } \\
\text { concentrates and } \\
\text { ion-exchange resins }\end{array}$ \\
\hline $\begin{array}{l}\text { Howard, C. G. } \\
\text { Jolliffe, C. B. } \\
\text { Lee, D. J. } \\
(1988,1989)\end{array}$ & 2,3 & $\begin{array}{l}28 \mathrm{~mm} \times 28 \mathrm{~mm} \\
\text { (diameter } \times \text { length) }\end{array}$ & $\begin{array}{l}\text { Demineralized } \\
\text { water }\end{array}$ & $\begin{array}{l}\text { Portland cement, } \\
\text { blast furnace slag, } \\
\text { microsilica }\end{array}$ & $\begin{array}{l}\text { LOMI ion-exchange } \\
\text { resin DOWEX 50X8 } \\
{ }^{60} \mathrm{Co},{ }^{137} \mathrm{Cs}\end{array}$ \\
\hline $\begin{array}{l}\text { Ipatti, A. } \\
\text { Harkonen, H. } \\
\text { (1989) }\end{array}$ & 4 & $\begin{array}{l}\text { Small lab-scale } \\
\text { specimens }\end{array}$ & Groundwater & Cement & $\begin{array}{l}\text { Spent ion-exchange } \\
\text { resins from Loviisa } \\
\text { Power Plant }\end{array}$ \\
\hline $\begin{array}{l}\text { Torstenfelt, B. } \\
\text { Hedin, G. (1988) }\end{array}$ & 5 & Not specified & Not specified & $\begin{array}{l}\text { Sulfate resistant } \\
\text { Portland cement }\end{array}$ & $\begin{array}{l}\text { Powdered ion-exchange } \\
\text { resins with } 5 \text { wr.\% } \\
\text { zeolite C-100-H, and } \\
\text { A-600 }\end{array}$ \\
\hline $\begin{array}{l}\text { Bishop, J. V. } \\
\text { (1990) }\end{array}$ & 6 & $\begin{array}{l}2 \text { in. } \times 4 \text { in. } \\
\text { (diameter } \times \text { length) }\end{array}$ & $\begin{array}{l}\text { Compression test } \\
\text { only }\end{array}$ & $\begin{array}{l}\text { Portland cement } \\
\text { Lime and } \mathrm{NaOH}\end{array}$ & $\begin{array}{l}\text { Ion-exchange resins } \\
\text { Ionac A-365 and C-267 } \\
\text { with picolinic acid only }\end{array}$ \\
\hline $\begin{array}{l}\text { Davis, M. S. } \\
\text { Picuilo, P. L. } \\
\text { et al. (1989) }\end{array}$ & 7 & $\begin{array}{l}2 \mathrm{~m} \times 4 \mathrm{~m} \\
\text { (diameter } \times \text { length) }\end{array}$ & $\begin{array}{l}\text { Demineralized } \\
\text { water }\end{array}$ & $\begin{array}{l}\text { Portland cement } \\
\text { Type I and VES }\end{array}$ & $\begin{array}{l}\text { Ion-exchange resins } \\
\text { IRN-77, IRN-78, } \\
\text { Ionac-365 with chelates } \\
\text { only }\end{array}$ \\
\hline $\begin{array}{l}\text { Lee, J. O. } \\
\text { Han, K. Y. } \\
\text { Buckley, L. P. } \\
(1990)\end{array}$ & 8 & Not specified & $\begin{array}{l}\text { Demineralized } \\
\text { water }\end{array}$ & $\begin{array}{l}\text { Cement, polyester } \\
\text { resin and Zeoloin } \\
900-\mathrm{Na}\end{array}$ & $\begin{array}{l}\text { Ion-exchange resins, } \\
\mathrm{Li}^{+}-\mathrm{DH}^{-} \text {form, }{ }^{60} \mathrm{Co} \text {, } \\
{ }^{85} \mathrm{Sr} \text {, and }{ }^{137} \mathrm{Cs}\end{array}$ \\
\hline $\begin{array}{l}\text { Soo, P. } \\
\text { Milian, L. } \\
\text { Piciulo, P. (1988) }\end{array}$ & 9 & $\begin{array}{l}5 \mathrm{~cm} \times 10 \mathrm{~cm} \\
15 \mathrm{~cm} \times 15 \mathrm{~cm} \\
30 \mathrm{~cm} \times 30 \mathrm{~cm} \\
\text { (diameter } \times \text { length) }\end{array}$ & $\begin{array}{l}\text { Deionized water } \\
\text { Formate and } \\
\text { pico-linate } \\
\text { solutions }\end{array}$ & $\begin{array}{l}\text { Portland cement } \\
\text { Type I and VES }\end{array}$ & $\begin{array}{l}\text { Simulated decontam- } \\
\text { decontaminated resin } \\
\text { waste }\end{array}$ \\
\hline $\begin{array}{l}\text { McIsaac, C. V. } \\
\text { Mandler, J. W. } \\
\text { (1989) }\end{array}$ & 10 & $-4.5 \times 9$ & $\begin{array}{l}\text { Demineralized } \\
\text { water }\end{array}$ & Portland Type I & $\begin{array}{l}\text { Decontaminated } \\
\text { ion-exchange resin }\end{array}$ \\
\hline $\begin{array}{l}\text { Mclsaac, C. V. } \\
\text { et al. (1991) }\end{array}$ & 11 & $-6 \times 9$ & $\begin{array}{l}\text { Multiple ground } \\
\text { waters }\end{array}$ & Portland Type I-P & $\begin{array}{l}\text { Decontaminated } \\
\text { ion-exchange resin }\end{array}$ \\
\hline $\begin{array}{l}\text { Akers, D. W. } \\
\text { et al. (1994) }\end{array}$ & 12 & $-4.5 \times 9$ & Deionzed water & Portland Type I-P & $\begin{array}{l}\text { Decontaminated } \\
\text { ion-exchange resin }\end{array}$ \\
\hline $\begin{array}{l}\text { Neilson, R. M. } \\
\text { et al. (1982) }\end{array}$ & 14 & Full size waste & Deionized water & Cement & $\mathrm{Na}_{2} \mathrm{SO}_{4}$ mixed bed \\
\hline $\begin{array}{l}\text { Arora, H. } \\
\text { Dayal, R. (1984) }\end{array}$ & 15 & small & $\begin{array}{l}\text { Deionized water } \\
\text { groundwater }\end{array}$ & Cement & Mixed bed \\
\hline $\begin{array}{l}\text { Westsik, J. H. } \\
\text { (1984) }\end{array}$ & 16 & Variable size & $\begin{array}{l}\text { Deionized } \\
\text { simulated } \\
\text { groundwater }\end{array}$ & Cement & $\begin{array}{l}\text { Incinerator ash cation, } \\
\text { anion }\end{array}$ \\
\hline $\begin{array}{l}\text { Neilson, R. M. } \\
\text { et al. (1987) }\end{array}$ & 17 & small & Deionized water & Cement & Plant waste \\
\hline
\end{tabular}


Table A-2. Aqueous soluble waste constituents that may affect cement solidification. ${ }^{a}$

\begin{tabular}{|c|c|c|}
\hline \multicolumn{2}{|c|}{ Type } & Chemical \\
\hline Inorganic & Non-metallic anions & $\begin{array}{l}\text { Borates } \\
\text { Phosphates } \\
\text { Sodium hypochlorite } \\
\text { Ammonia } \\
\text { Sulfates } \\
\text { Nitrates } \\
\text { pH } \\
\text { Total solids } \\
\text { Total dissolved solids }\end{array}$ \\
\hline & Metals & $\begin{array}{l}\text { Lead } \\
\text { Zinc } \\
\text { Iron }\end{array}$ \\
\hline & Metals-oxidizing agents & $\begin{array}{l}\text { Manganese } \\
\text { Chromium }\end{array}$ \\
\hline \multirow[t]{3}{*}{$\begin{array}{l}\text { Organic-aqueous } \\
\text { formic acid-formates }\end{array}$} & Carboxylic acid chelates & $\begin{array}{l}\text { Oxalic acid oxalates } \\
\text { Citric acid-citrates } \\
\text { Picolinic } \\
\text { Acid-picolinates }\end{array}$ \\
\hline & Chelating agents & $\begin{array}{l}\text { NTA } \\
\text { EDTA } \\
\text { "Decon Solutions" }\end{array}$ \\
\hline & Surfactants & $\begin{array}{l}\text { Soap } \\
\text { Detergent }\end{array}$ \\
\hline
\end{tabular}

a. This list was generated from NRC Notice No. 90-31. 


\section{Appendix A}

Table A-3. Organic waste constituents that may affect cement solidification. ${ }^{2}$

Type

Chemical

Organic-nonaqueous

Aromatics

"Oils"

Benzene

Toluene

Xylene

Petroleum distillates

Vegetable oil additives

Hexane

Oil and grease

Paint thinners

Industrial cleaners

Chlorinated solvents

Trichloroethane

Trichloro-trifluorethane

Dicholorbenzene

Trichloroethene

Tetrachloroethene

Methylene chloride

Dry-cleaning solvents

Ketones

Acetone

Methyl ethyl ketone

Methyl isobutyl ketone

a. This list was generated from NRC Notice No. 90-31. 
Appendix B

Cement Chemistry 


\section{Appendlx B}

\section{Coment Chemistry}

Portland cement is composed chiefly of the basic oxides of calcium, silicon, aluminum, and iron. Portland cements are not simple mixtures of these oxides but rather are mixtures of combinations of the basic oxides in the forms of tricalcium silicate, dicalcium silicate, tricalcium aluminate, and tetracalcium aluminoferrite. The formulas for these compounds and their commonly used abbreviations are shown in Table B-1. All of the individual minerals present in Portland cement have different rates of hydration, strength development, and heat evolution. By varying the proportions of the constituents, the properties of the cement can be altered substantially.

The chemical and mineralogical compositions 1,2 of four types of Portland cement are shown in Table B-2. Type I is a general-purpose cement suitable for most uses and is the type normally used to solidify decontamination resin wastes. Type II is modified by changing the proportions of the principal oxides so as to increase the concentrations of dicalcium silicate $\left(\mathrm{C}_{2} \mathrm{~S}\right)$ and tetracalcium aluminoferrite $\left(\mathrm{C}_{4} \mathrm{AF}\right)$. Type II has a lower heat of hydration than Type I and improved resistance to sulfate attack. Type III has a lower $C_{2} S$ content and higher tricalcium silicate $\left(C_{3} S\right)$ content than Type I; as a result, it sets up faster than Type I cement. Compared to Type I, the relative concentrations of $\mathrm{C}_{3} \mathrm{~S}$ and $\mathrm{C}_{2} \mathrm{~S}$ are approximately reversed in Type IV cement. Type IV is used when the amount of heat generated during hydration must be kept to a minimum. In addition to the standard cement composition, pozzolonas (P) are sometimes added to concrete waste forms. Pozzolonas are either flyash or blast furnace slag. In this study, pozzolona was added to the Brunswick-1, FitzPatrick, and Peach Bottom-3 wastes. Pozzolonas improve the workability of harsh mixes and lower the total heat of hydration because the pozzolonic reaction is quite slow. ${ }^{3}$ Typically, the ultimate strength will not be reached for up to a year. This slower, cooler reaction tends to reduce the potential for degradation of the resins and constituents such as the chelating agent picolinic acid, which may reduce the strength of the waste form.

In general, the rate of hydration (i.e., the rate at which water chemically combines with cement) can be increased by increasing the tricalcium aluminate $\left(C_{3} A\right)$ and tricalcium silicate $\left(C_{3} S\right)$ concentrations in the cement formulation. The hydration of these compounds occurs over a relatively short period of time and liberates a substantial amount of heat. On the other hand, the heat liberated during the hydration of dicalcium silicate $\left(\mathrm{C}_{2} \mathrm{~S}\right)$ and tetracalcium aluminoferrite $\left(C_{4} A F\right)$ is low. The primary hydration reactions of the principal compounds are shown in Table B-3.

Irrespective of whether the original material is in the form of dicalcium or tricalcium silicates, the final product of cement hydration under normal conditions leads to the formation of the tricalcium disilicate hydrate ( $3 \mathrm{CaO} \cdot 2 \mathrm{SiO}_{2} \cdot 3 \mathrm{H}_{2} \mathrm{O}$ ), which has been given the name of tobermorite. Because the two silicates differ in their lime $(\mathrm{CaO})$ contents, the reactions that lead to the formation of tobermorite are also different. The hydration of 100 parts of $\mathrm{C}_{3} \mathrm{~S}$ with 24 parts $\mathrm{H}_{2} \mathrm{O}$, by weight, results in the formation of about 75 parts of tobermorite and 49 parts of calcium hydroxide. This reaction is very rapid and is largely responsible for early strength. The hydration of 100 parts of $\mathrm{C}_{2} \mathrm{~S}$ with 21 parts $\mathrm{H}_{2} \mathrm{O}$ yields about 100 parts of tobermorite and 21 parts by weight of calcium hydroxide. Hence, fully hydrated $\mathrm{C}_{2} \mathrm{~S}$ contains only about $18 \mathrm{wt} \%$ calcium hydroxide. The rate of hydration of $\mathrm{C}_{2} \mathrm{~S}$ is much slower than that of $C_{3} S$, and therefore it contributes to the waste-form strength over a longer period of time. As shown in Table B-3, the hydration reactions of $C_{3} A$ and $C_{4} A F$ consume substantially more water than the reactions of $\mathrm{C}_{3} \mathrm{~S}$ and $\mathrm{C}_{2} \mathrm{~S}$ and do not produce free calcium hydroxide. 
The hydration of both tricalcium and dicalcium silicate internally produces the calcium hydroxide required for proper set. However, a problem encountered in solidifying decontamination resin wastes is that during the resin/cement mixing and early curing periods, the cation ion-exchange sites rob the cement of cations (e.g., $\mathrm{Ca}+2)$ and thereby interfere with the normal hydration process. It has also been demonstrated that as a result of ion-exchange reactions, cation resin beads generally decrease in size prior to becoming encapsulated within the cement matrix. ${ }^{4}$ When, following curing, the waste form is immersed in deionized water, wetting of the resin beads causes them to swell; the swelling is often sufficient to crack the cement matrix. It has also been shown ${ }^{5}$ that volumetric changes occur when the resins are converted to ionic forms having varying degrees of hydration.

The deliberate addition of calcium hydroxide (slaked lime) to the resin waste prior to the addition of cement helps in minimizing the loss of calcium during cement hydration. The additional lime increases the $\mathrm{pH}$ of the waste and forms salts that have limited solubility. Sodium hydroxide is also sometimes used to increase waste $\mathrm{pH}$. In addition to slaked lime and sodium hydroxide, resin wastes are sometimes treated with additives that help reduce the mobility of soluble radionuclides such as ${ }^{134} \mathrm{Cs}$ and ${ }^{137} \mathrm{Cs}$. Additives that sorb cesium, such as zeolites and certain clays and silica, can reduce cesium leachability by factors of a hundred or more, depending upon the additive used. ${ }^{6}$

Pozzolonic cements (I-P) were used for the Brunswick, FitzPatrick, and Peach Bottom-3 solidifications. In the case of these cements, hydration of the cement is slower; consequently, ultimate strength may not be obtained for up to a year. 9,10 The type of pozzolona used for the solidifications discussed above was fly ash, which is produced during the combustion of powdered coal in modern power plants. Fly ash contains a glassy silica phase that reacts with lime produced by the hydration of Portland cement to produce calcium silicate hydrate gel. The low heat of hydration of cements that incorporate fly ash is an advantage in full-scale operations, where it reduces the curing temperature. ${ }^{9}$

Successful solidification of resin wastes requires the proper mixture of waste, cement, and additives. The stability of a particular resin waste form is tested, qualified, and certified through a formal process control program (PCP). Each PCP describes the methodology that is used for solidifying a specific type of waste. Part of the PCP requires that, prior to solidifying waste contained in a liner, a small sample of the waste must be solidified to verify that the waste form will meet the stability requirements of the NRC Branch's "Technical Position on Waste Form"7 and Revision $1 .^{8}$ The proportions of resin waste, cement, and additives anticipated to be used to solidify the waste are usually mixed in a beaker or other small container, and the sample is subsequently baked for about 12 hours to simulate the exotherm that the resin/cement mixture in the liner experiences. If the sample sets up properly, the solidification proceeds using the tested recipe; otherwise, the proportions are changed until a satisfactory test sample is obtained. 


\section{REFERENCES}

1. P. Colombo and R. M. Neilson, Jr., Properties of Radioactive Wastes and Waste Containers, NUREG/ CR-0619, August 1979.

2. D. L. Kantro and L. E. Copeland, "The Stoichiometry of the Hydration of Portland Cement," National Bureau of Standards Monograph, 1, 43, p. 442, 1962.

3. International Atomic Energy Agency, Improved Cement Solidification of Low and Intermediate Level Radioactive Wastes, Technical Report No. 350, pp. 5456, January 1993.

4. P. Soo, L. W. Milian, and P. L. Piciulo, The Leachability and Mechanical Integrity of Simulated Decontamination Resin Wastes Solidified in Cement and VinylEster-Styrene, NUREG/CR-5153, May 1988.

5. R. M. Wheaton and A. H. Seamster, "A Basic Reference on Ion Exchange," Encyclopedia of Chemical Technology, 2nd Edition, II, pp. 871-899, 1966.

6. D. R. Dougherty and P. Colombo, Leaching Mechanisms of Solidified Low-Level Waste, The Literature Survey, BNL-51899, June 1985.

7. "Technical Position on Waste Form," U.S. Nuclear Regulatory Commission, Low-Level Waste Management Branch, Washington, D.C., May 1983.

8. "Technical Position on Waste Form," Revision 1, U.S. Nuclear Regulatory Commission, Low-Level Waste Management Branch, Washington, D.C., January 1991.

9. International Atomic Energy Agency, Improved Cement Solidification of Low and Intermediate Level Radioactive Wastes, Technical Report No. 350, p. 54, January 1993.

10. International Atomic Energy Agency, Treatment of Spent Ion-Exchange Resins for Storage and Disposal, Technical Report No. 254, 1985. 
Appendix B

Table B-1. Principal compounds present in Portland cements.

\begin{tabular}{lll}
\multicolumn{1}{c}{ Compound } & Abbreviation & \multicolumn{1}{c}{ Formula } \\
\hline Tricalcium silicate & $\mathrm{C}_{3} \mathrm{~S}$ & $3 \mathrm{CaO} \cdot \mathrm{SiO}_{2}$ \\
Dicalcium silicate & $\mathrm{C}_{2} \mathrm{~S}$ & $2 \mathrm{CaO} \cdot \mathrm{SiO}_{2}$ \\
Tricalcium aluminate & $\mathrm{C}_{3} \mathrm{~A}$ & $3 \mathrm{CaO} \cdot \mathrm{Al}_{2} \mathrm{O}_{3}$ \\
Tetracalcium aluminoferrite & $\mathrm{C}_{4} \mathrm{AF}$ & $3 \mathrm{CaO} \cdot \mathrm{Al}_{2} \mathrm{O}_{3} \cdot \mathrm{Fe}_{2} \mathrm{O}_{3}$ \\
\hline
\end{tabular}


Table B-2. Chemical and mineralogical composition of Portland cements.

\begin{tabular}{|c|c|c|c|c|}
\hline & \multicolumn{4}{|c|}{$\begin{array}{c}\text { Composition } \\
(w t \%)\end{array}$} \\
\hline & Type I & Type II & Type III & Type IV \\
\hline \multicolumn{5}{|l|}{ Oxides $^{\mathrm{a}}$} \\
\hline $\mathrm{SiO}_{2}$ & 20.67 & 22.44 & 19.83 & 27.51 \\
\hline $\mathrm{CaO}$ & 63.03 & 63.81 & 63.41 & 63.73 \\
\hline $\mathrm{Al}_{2} \mathrm{O}_{3}$ & 6.13 & 3.88 & 5.21 & 1.95 \\
\hline $\mathrm{Fe}_{2} \mathrm{O}_{3}$ & 2.20 & 4.20 & 2.59 & 1.92 \\
\hline MgO & 2.05 & 1.36 & 1.28 & 1.64 \\
\hline $\mathrm{SO}_{3}$ & 2.37 & 1.59 & 1.82 & 1.82 \\
\hline Balance & 3.55 & 2.72 & 5.86 & 1.43 \\
\hline \multicolumn{5}{|l|}{ Compounds ${ }^{b}$} \\
\hline $\mathrm{C}_{3} \mathrm{~S}$ (tricalcium silicate) & 45 & 44 & 53 & 20 \\
\hline $\mathrm{C}_{2} \mathrm{~S}$ & 27 & 31 & 19 & 52 \\
\hline $\mathrm{C}_{3} \mathrm{~A}$ & 11 & 7 & 10 & 6 \\
\hline $\mathrm{C}_{4} \mathrm{AF}$ & 8 & 13 & 7 & 14 \\
\hline $\begin{array}{l}\text { Kantro and L. E. Copel } \\
\text { al Bureau of Standards }\end{array}$ & $\begin{array}{l}\text { The Stoich } \\
\text { aph 43, } 1\end{array}$ & $\begin{array}{l}y \text { of the } H \\
\text { p. } 442 \text {. }\end{array}$ & in of Port & nent," \\
\hline
\end{tabular}


Appendix B

Table E-3. Products of Portland cement hydration. ${ }^{\mathrm{a}}$

Tricalcium silicate:

$2\left(3 \mathrm{CaO} \cdot \mathrm{SiO}_{2}\right)+6 \mathrm{H}_{2} \mathrm{O} \rightarrow 3 \mathrm{CaO} \cdot 2 \mathrm{SiO}_{2} \cdot 3 \mathrm{H}_{2} \mathrm{O}+3 \mathrm{Ca}(\mathrm{OH})_{2}$ + heat

Dicalcium silicate:

$2\left(2 \mathrm{CaO} \cdot \mathrm{SiO}_{2}\right)+4 \mathrm{H}_{2} \mathrm{O} \rightarrow 3 \mathrm{CaO} \cdot 2 \mathrm{SiO}_{2} \cdot 3 \mathrm{H}_{2} \mathrm{O}+3 \mathrm{Ca}(\mathrm{OH})_{2}+$ heat

Tricalcium aluminate:

$\left(3 \mathrm{CaO} \cdot \mathrm{Al}_{2} \mathrm{O}^{3}\right)+6 \mathrm{H}_{2} \mathrm{O} \rightarrow 3 \mathrm{CaO} \cdot \mathrm{Al}_{2} \mathrm{O}_{3} \cdot 6 \mathrm{H}_{2} \mathrm{O}$ + heat

Tetracalcium aluninoferrite:

$\left.4 \mathrm{CaO} \cdot \mathrm{Al}_{2} \mathrm{O}_{3} \cdot \mathrm{Fe}_{2} \mathrm{O}_{3}\right)+2 \mathrm{Ca}(\mathrm{OH})_{2}+10 \mathrm{H}_{2} \mathrm{O} \rightarrow 3 \mathrm{CaO} \cdot \mathrm{Al}_{2} \mathrm{O}_{3} \cdot 6 \mathrm{H}_{2} \mathrm{O}$

$+3 \mathrm{CaO} \cdot \mathrm{Fe}_{2} \mathrm{O}_{3} \cdot 6 \mathrm{H}_{2} \mathrm{O}+$ heat

a. Wolfgang Czernin, Cement Chemistry and Physics for Civil Engineers, London; Crosby Lockwood \& Son Ltd., 1962, pp. 19-31. 


\section{Appendix C}

\section{ANSI/ANS 16.1 Leach-Test Procedure and ASTM C39 Compressive Strength Test Method}




\section{Appendix C}

\section{ANSI/ANS 16.1 Leach-Test Procedure and ASTM C39 Compressive Strength Test Method}

This appendix includes a summary of the Leach-Test Procedure as specified in ANSI/ ANS 16.1 and the Compressive Strength Test Method as specified in ASTM C39.

\section{C.1 ANSI/ANS 16.1 Leach-Test Procedure}

The test procedure prescribed in the NRC's "Technical Position on Waste Form"l and Revision $1^{2}$ to characterize leachability is American National Standard ANSI/ANS 16.1, "Measurement of the Leachability of Solidified Low-Level Radioactive Wastes by a Short-Term Test Procedure $^{3}$ as specified in the April 1986 version. The standard is intended to provide a means of indexing the release of radionuclides from waste forms using the results of relatively short-term tests performed in a laboratory. It is not intended to be used to define the long-term leaching behavior of waste forms under conditions representing actual burial environments. The method specified by the standard for analyzing leach-test data is based on the assumption that diffusion is the only significant release mechanism. Other mechanisms such as dissolution, ion exchange, corrosion, cracking, etc., are not incorporated into the models used to describe releases.

This section summarizes the ANSI/ANS requirements for sample preparation, the leach test apparatus, the leachant requirements, the leach test method including the volume of leachant, the leachate analysis, and reporting of results. Data analysis methods are discussed in the body of the report.

\section{Requirements for Specimen Preparation}

Specific requirements for specimen preparation include the requirements for sampling the concrete slurry and the methods used to prepare the sample for leach testing. In the case of sampling, suitable precautions shall be taken to ensure that the specimen is representative of the solidified waste and that the homogeneity of the test specimen is the same as that of the material in the actual solidified waste form.

To prepare the sample for leach testing, the test specimen shall be prepared in the same or similar manner as that established for the solidification process. The cement/waste mixture shall be cast in a form that has a well-defined shape, mass, and volume. Where possible, the specimen shall be a monolithic cylinder, parallelepiped, or sphere, with the cylindrical geometry being the preferred geometry. The casting shall conform to the sides of the specimen container and be performed in such a way that voids are eliminated and the sample is homogeneous. The thermal history of the test specimen is to be reported. The specimen container shall remain sealed during curing. The container shall be constructed of materials known to be chemically unreactive toward the specimen (e.g., polyethylene, polypropylene, stainless steel, ceramic, glass, etc.).

\section{Requirements for Leach-Test Vessel}

The vessel in which leaching takes place should be constructed of a material that:

1. Does not react chemically with the leachant or the specimen.

2. Does not sorb chemical species extracted from the specimen or those in the leachant itself.

3. Does not release interfering species which alter the composition of the leachant during the leaching process. 
4. Can withstand the conditions involved in leaching.

In addition, the leach-test vessel shall be constructed such that evaporation of the leachant is maintained below $2 \%$ per day.

The dimensions of the vessel shall be such that greater than $98 \%$ of the external geometric surface area of the immersed specimen is in contact with the leachant during the entire leaching interval. The specimen shall be supported in the leachant by any convenient device, made from unreactive material, that does not interfere with the leachate removal and replacement, does not impede leaching, does not damage the surface of the specimen, and does not preclude more than $2 \%$ of the specimen's external surface from exposure to the leachant.

\section{Requirements for Leachant}

The leachant shall be demineralized water with an electrical conductivity of less than $5 \mu \mathrm{mho} / \mathrm{cm}$ at $298 \mathrm{~K}\left(25^{\circ} \mathrm{C}\right)$ and a total organic carbon content of less than $3 \mathrm{ppm}$. The leachant shall be kept in, and not exceed, the limits of the temperature range 291 to $301 \mathrm{~K}\left(18\right.$ to $\left.28^{\circ} \mathrm{C}\right)$ during the test.

\section{Leach Test Method}

This section summarizes the requirements for leachant volumes, sampling requirements, and the length of the sampling period. It is required that sufficient leachant shall be used so that the ratio of the leachant volume, $V_{L}$, and the specimen external geometric surface area, $\mathrm{S}$, is maintained such that

$$
\frac{V_{L}(\mathrm{~cm})}{S\left(\mathrm{~cm}^{2}\right)}=10 \geq 0.1(\mathrm{~cm})
$$

After removal from the specimen container and prior to the initiation of the leach test, the test specimen shall be rinsed by immersion in demineralized water for 30 seconds. The rinse water volume shall be the same as the required leachant volume. The container used to store the specimen before leaching shall be rinsed with an amount of water equal to its volume. This water shall be combined with the specimen rinse water, and the combined rinse water shall be analyzed to determine the quantities of the species of interest that are present.

The leachate shall be sampled and the leachate completely replaced after cumulative leach times of 2,7 , and 24 hours from the initiation of the test. Subsequent leachate sampling and leachant replacements shall be made at 24-hour intervals for the next 4 days. Three additional leach intervals of 14,28 , and 43 days will be used to extend the entire test to 90 days as specified in the "Technical Position on Waste Form." In contrast, Revision 1 requires that only a 5 -day test be performed.

\section{Leachate Analysis}

An aliquot of the leachate shall be taken at the end of each leaching interval to determine the amounts of the species of interest present in the leachate volume. The release of the species of interest will be determined by measuring the amount present in the leachate rather than the residual in the specimen. Stirring of the leachate so as to suspend particulate solids prior to taking the leachate aliquot, or dissolution of such solids by the addition of chemicals to the leachate before sampling, may be necessary. If precipitation occurs in the leachate during the leaching interval, the amount of the extracted species of interest associated with the precipitate shall be determined and added to the amount of the dissolved species.

\section{Reporting of Results}

When reporting the results of leaching tests, the following information concerning the specimen tested and the leachant used during the test shall be reported:

1. The type of waste and the proportion of waste and binder incorporated in the wastebinder mixture prior to solidification.

2. The type and composition of the binder material, including additives. 
3. The radionuclides and the total amount of each in the leaching specimen, both as prepared and after the 30-second rinse.

4. Shape, mass, and dimensions of the leachtest specimen.

5. The history of the specimen between preparation and leaching, including time, temperature, and any other relevant information.
6. Electrical conductivity of leachant and total organic carbon.

7. Volume of leachant used during each leaching interval.

Data analysis methods used to assess the leaching data are discussed in the body of the report.

\section{REFERENCES}

1. "Technical Position on Waste Form," U.S. Nuclear Regulatory Commission, Low-Level Waste Management Branch, Washington, D.C., May 1983.

2. "Technical Position on Waste Form," Revision 1, U.S. Nuclear Regulatory Commission, Low-Level Waste Management Branch, Washington, D.C., January 1991.

3. "Measurement of the Leachability of Solidified Low-Level Radioactive Wastes by a Short-Term Test Procedure," ANSI/ANS-16.1-1986, American Nuclear Society Standards Committee, April 1986.

\section{C.2 ASTM C39 Compressive Strength Test Method}

This section summarizes the "Standard Test Method for Compressive Strength of Cylindrical Concrete Specimens," ASTM C39-86.

\section{Scope}

This test method covers determination of compressive strength of cylindrical concrete specimens such as molded cylinders and drilled cores. It is limited to concrete having a unit weight in excess of $50 \mathrm{lb} / \mathrm{ft}^{3}\left(800 \mathrm{~kg} / \mathrm{m}^{3}\right)$.

The values stated in inch-pound units are to be regarded as the standard.

\section{Summary of Method}

This test method consists of applying a compressive axial load to molded cylinders or cores at a rate which is within a prescribed range until failure occurs. The compressive strength of the specimen is calculated by dividing the maximum load attained during the test by the cross-sectional area of the specimen.

\section{Significance and Use}

Care must be exercised in the interpretation of the significance of compressive strength determinations by this test method since strength is not a fundamental or intrinsic property of concrete made from given materials. Values obtained will depend on the size and shape of the specimen, batching, mixing procedures, the methods of sampling, molding, and fabrication and the age, temperature, and moisture conditions during curing.

This test method may be used to determine compressive strength of cylindrical specimens prepared and cured in accordance with Methods C31, C42, and C192, Practice C617, and Test Method C873.

The results of this test method may be used as a basis for quality control of concrete proportioning, mixing, and placing operations; determination of compliance with specification; control for evaluating effectiveness of admixtures and similar uses. 


\section{Apparatus}

Tosting Machine. The testing machine shall be of a type having sufficient capacity and capable of providing the rates of loading prescribed in 7.5 .

Verification of calibration of the testing machines in accordance with Practices E 4 is required under the following conditions:

- After an elapsed interval since the previous verification of 18 months maximum, but preferably after an interval of 12 months,

- On original installation or relocation of the machine,

- Immediately after making repairs or adjustments which may in any way affect the operation of the weighing system or the values displayed, except for zero adjustments that compensate for the weight of tooling, or s;ecimen, or both, or

- Whenever there is reason to doubt the accuracy of the results, without regard to the time interval since the last verification.

Deslgn. The design of the machine must include the following features:

- The machine must be power operated and must apply the load continuously rather than intermittently, and without shock. If it has only one loading rate (meeting the requirements of 7.5), it must be provided with a supplemental means for loading at a rate suitable for verification. This supplemental means of loading may be power or hand operated.

- The space provided for test specimens shall be large enough to accommodate, in a readable position, an elastic calibration device which is of sufficient capacity to cover the potential loading range of the testing machine and which complies with the requirements of Practices E 74.
Note: The type of elastic calibration device most generally available and most commonly used for this purpose is the circular proving ring.

Accuracy. The accuracy of the testing machine shall be in accordance with the following provisions:

- The percentage of error for the loads within the proposed range of use of the testing machine shall not exceed $\pm 1.0 \%$ of the indicated load.

- The accuracy of the testing machine shall be verified by applying five test loads in four approximately equal increments in ascending order. The difference between any two successive test loads shall not exceed one third of the difference between the maximum and minimum test loads.

- The test load as indicated by the testing machine and the applied load computed from the readings of the verification device shall be recorded at each test point. Calculate the error, $E$, and the percentage of error, $E_{p}$, for each point from these data as follows:

$$
\begin{aligned}
& E=A-B \\
& E_{p}=\frac{100(A-B)}{B}
\end{aligned}
$$

where:
$\mathrm{A}=\mathrm{load}, \mathrm{lbf}($ or $\mathrm{N}$ ) indicated by the machine being verified, and
$\mathrm{B}=$ applied load, lbf (or $\mathrm{N}$ ) as deter- mined by the calibrating device.

- The report on the verification of a testing machine shall state within what loading range it was found to conform to specification requirements rather than reporting a blanket acceptance or rejection. In no case shall the loading range be stated as including loads below the value which is $\mathbf{1 0 0}$ times the smallest change of load that can be 
estimated on the load-indicating mechanism of the testing machine or loads within that portion of the range below $10 \%$ of the maximum range capacity.

- In no case shall the loading range be stated as including loads outside the range of loads applied during the verification test.

- The indicated load of a testing machine shall not be corrected either by calculation or by the use of a calibration diagram to obtain values within the required permissible variation.

The testing machine shall be equipped with two steel bearing blocks with hardened faces (see note below), one of which is a spherically seated block that will bear on the upper surface of the specimen, and the other a solid block on which the specimen shall rest. Bearing faces of the blocks shall have a minimum dimension at least $3 \%$ greater than the diameter of the specimen to be tested. Except for the concentric circles described below, the bearing faces shall not depart from a plane by more than 0.001 in. $(0.025$ $\mathrm{mm})$ in any 6 in. ( $152 \mathrm{~mm}$ ) of blocks 6 in. in diameter or larger, or by more than 0.001 in. in the diameter of any smaller block; and new blocks shall be manufactured within one half of this tolerance. When the diameter of the bearing face of the spherically seated block exceeds the diameter of the specimen by more than $1 / 2 \mathrm{in}$. (13 mm), concentric circles not more than $1 / 32$ in. $(0.8 \mathrm{~mm}$ ) deep and not more than 3/64 in. (1.2 $\mathrm{mm}$ ) wide shall be inscribed to facilitate proper centering.

Note: It is desirable that the bearing faces of blocks used for compression testing of concrete have a Rockwell hardness of not less than 55 HRC.

Bottom bearing blocks shall conform to the following requirements:

- The bottom bearing block is specified for the purpose of providing a readily machinable surface for maintenance of the specified surface conditions (see note below). The top and bottom surfaces shall be parallel to each other. The block may be fastened to the platen of the testing machine. Its least horizontal dimension shall be at least $3 \%$ greater than the diameter of the specimen to be tested. Concentric circles as described in 5.2 are optional on the bottom block.

- Final centering must be made with reference to the upper spherical block. When the lower bearing block is used to assist in centering the specimen, the center of the concentric rings, when provided, or the center of the block itself must be directly below the center of the spherical head. Provision shall be made on the platen of the machine to assure such a position.

- The bottom bearing block shall be at least 1 in. $(25 \mathrm{~mm})$ thick when new, and at least 0.9 in. $(22.5 \mathrm{~mm})$ thick after any resurfacing operations.

Note: If the testing machine is so designed that the platen itself can be readily maintained in the specified surface condition, a bottom block is not required.

The spherically seated bearing block shall conform to the following requirements:

- The maximum diameter of the bearing face of the suspended spherically seated block shall not exceed the values given below:

\begin{tabular}{cc}
\hline $\begin{array}{c}\text { Diameter of } \\
\text { test specimens, } \\
\text { in. (mm) }\end{array}$ & $\begin{array}{c}\text { Maximum } \\
\text { diameter of } \\
\text { bearing face, } \\
\text { in. }(\mathrm{mm})\end{array}$ \\
\hline $2(51)$ & $4(102)$ \\
$3(76)$ & $5(127)$ \\
$4(102)$ & $61(165)$ \\
$6(152)$ & $10(254)$ \\
$8(203)$ & $11(279)$ \\
\hline
\end{tabular}


Note: Square bearing faces are permissible, provided the diameter of the largest possible inscribed circle does not exceed the above diameter.

- The center of the sphere shall coincide with the surface of the bearing face within a tolerance of $\pm 5 \%$ of the radius of the sphere. The diameter of the sphere shall be at least $75 \%$ of the diameter of the specimen to be tested.

- The ball and the socket must be so designed by the manufacturer that the steel in the contact area does not permanently deform under repeated use, with loads up to 12,000 psi $(82.7 \mathrm{MPa})$ on the test specimen.

Note: The preferred contact area is in the form of a ring (described as preferred "bearing" area) as shown on Figure 1.

- The curved surfaces of the socket and of the spherical portion shall be kept clean and shall be lubricated with a petroleum-type oil such as convential motor oil, not with a pressure type grease. After contacting the specimen and application of small initial load, further tilting of the spherically seated block is not intended and is undesirable.

- If the radius of the sphere is smaller than the radius of the largest specimen to be tested, the portion of the bearing face extending beyond the sphere shall have a thickness not less than the difference between the radius of the sphere and radius of the specimen. The least dimension of the bearing face shall be at least as great as the diameter of the sphere (see Figure 1).

- The movable portion of the bearing block shall be held closely in the spherical seat, but the design shall be such that the bearing face can be rotated freely and tilted at least $4^{\circ}$ in any direction.

\section{Load Indication}

If the load of a compression machine used in concrete testing is registered on a dial, the dial shall be provided with a graduated scale that can be read to at least the nearest $0.1 \%$ of the full scale load (Note 6). The dial shall be readable within $1 \%$ of the indicated load at any given load level within the loading range. In no case shall the loading range of a dial be considered to include loads below the value that is 100 times the smallest change of load that can be read on the scale. The scale shall be provided with a graduation line equal to zero and so numbered. The dial pointer shall be of sufficient length to reach the graduation marks; the width of the end of the pointer shall not exceed the clear distance between the smallest graduations. Each dial shall be equipped with a zero adjustment that is easily accessible from the outside of the dial case, and with a suitable device that at all times until reset, will indicate to within $1 \%$ accuracy the maximum load applied to the specimen.

Note: As close as can reasonably be read is considered to be $1 / 50 \mathrm{in}$. $(0.5 \mathrm{~mm})$ along the are described by the end of the pointer. Also, one half of a scale interval is about as close as can reasonably be read when the spacing on the load indicating mechanism is between 1/25 in. ( $1 \mathrm{~mm}$ ) and $1 / 16 \mathrm{in}$. (1.6 mm). When the spacing is between $1 / 16$ in. and $1 / 8$ in. (3.2 mm), one third of a scale interval can be read with reasonable certainty. When the spacing is $1 / 8$ in. or more, one fourth of a scale interval can be read with reasonable certainty.

If the testing machine load is indicated in digital form, the numerical display must be large enough to be easily read. The numerical increment must be equal to or less than $0.10 \%$ of the full scale load of a given loading range. In no case shall the verified loading range include loads less than the minimum numerical increment multiplied by 100 . The accuracy of the indicated load must be within $1.0 \%$ for any value displayed within the verified loading range. Provision must be made for adjusting to indicate true zero at zero load. There shall be provided a maximum load indicator that at all times until reset will indicate 
within $1 \%$ system accuracy the maximum load applied to the specimen.

\section{Specimons}

Specimens shall not be tested if any individual diameter of cylinder differs from any other diameter of the same cylinder by more than $2 \%$.

Note: This may occur when single use molds are damaged or deformed during shipment, when flexible single use molds are deformed during molding or when a core drill deflects or shifts during drilling.

Neither end of compressive test specimens when tested shall depart from perpendicularity to the axis by more than $0.5^{\circ}$ (approximately equivalent to $1 / 8 \mathrm{in}$. in $12 \mathrm{in}$. ( $3 \mathrm{~mm}$ in $300 \mathrm{~mm}$ )). The ends of compression test specimens that are not plane within 0.002 in. $(0.050 \mathrm{~mm})$ shall be capped in accordance with Practice C617 or they may be sawed or ground to meet that tolerance. The diameter used for calculating the cross-sectional area of the test specimen shall be determined to the nearest 0.01 in. $(0.25 \mathrm{~mm})$ by averaging two diameters measured at right angles to each other at about midheight of the specimen.

The number of individual cylinders measured for determination of average diameter may be reduced to one for each ten specimens or three specimens per day, whichever is greater, if all cylinders are known to have been made from a single lot of reusable or single-use molds which consistently produce specimens with average diameters within a range of $0.02 \mathrm{in} .(0.51 \mathrm{~mm})$. When the average diameters do not fall within the range of $0.02 \mathrm{in}$. or when the cylinders are not made from a single lot of molds, each cylinder tested must be measured and the value used in calculation of the unit compressive strength of that specimen. When the diameters are measured at the reduced frequency, the cross-sectional areas of all cylinders tested on that day shall be computed from the average of the diameters of the three or more cylinders representing the group tested that day.

The length shall be measured to the nearest $0.05 \mathrm{D}$ when the length to diameter ratio is less than 1.8 , or more than 2.2 , or when the volume of the cylinder is determined from measured dimensions.

\section{Procedure}

Compression tests of moist-cured specimens shall be made as soon as practicable after removal from moist storage.

Test specimens shall be kept moist by any convenient method during the period between removal from moist storage and testing. They shall be tested in the moist condition.

All test specimens for a given test age shall be broken within the permissible time tolerances prescribed as follows:

\begin{tabular}{cc}
\hline Test age & $\begin{array}{c}\text { Permissible } \\
\text { tolerance }\end{array}$ \\
\hline 24 hours & \pm 0.5 hours or $2.1 \%$ \\
3 days & 2 hours or $2.8 \%$ \\
7 days & 6 hours or $3.6 \%$ \\
28 days & 20 hours or $3.0 \%$ \\
90 days & 2 days or $2.2 \%$ \\
\hline
\end{tabular}

Placing the Speclmen. Place the plain (lower) bearing block, with its hardened face up, on the table or platen of the testing machine directly under the spherically seated (upper) bearing block. Wipe clean the bearing faces of the upper and lower bearing blocks and of the test specimen and place the test specimen on the lower bearing block. Carefully align the axis of the specimen with the center of thrust of the spherically seated block. As the spherically seated block is brought to bear on the specimen, rotate its movable portion gently by hand so that uniform seating is obtained.

Rate of Loading. Apply the load continuously and without shock.

For testing machines of the screw type, the moving head shall travel at a rate of approximately $0.05 \mathrm{in} .(1.3 \mathrm{~mm}) / \mathrm{min}$ when the machine 
is running idle. For hydraulically operated machines, the load shall be applied at a rate of movement (platen to crosshead measurement) corresponding to a loading rate on the specimen within the range of 20 to $50 \mathrm{psi} / \mathrm{s}(0.14$ to 0.34 $\mathrm{MPa} / \mathrm{s})$. The designated rate of movement shall be maintained at least during the latter half of the anticipated loading phase of the testing cycle.

During the application of the first half of the anticipated loading phase a higher rate of loading shall be permitted.

Make no adjustment in the rate of movement of the platen at any time while a specimen is yielding rapidly immediately before failure.

Apply the load until the specimen fails, and record the maximum load carried by the specimen during the test. Note the type of failure and the appearance of the concrete.

\section{Calculation}

Calculate the compressive strength of the specimen by dividing the maximum load carried by the specimen during the test by the average crosssectional area determined as described in Section 6 and express the result to the nearest $10 \mathrm{psi}$ $(69 \mathrm{kPa})$.

If the specimen length to diameter ratio is less than 1.8 , correct the result obtained in 8.1 by multiplying by the appropriate correction factor shown in the following table.

$\begin{array}{lllll}\text { L/D: } & 1.75 & 1.50 & 1.25 & 1.00 \\ \text { Factor: } & 0.98 & 0.96 & 0.93 & 0.87\end{array}$

Note: These correction factors apply to lightweight concrete weighing between 100 and 120 $\mathrm{lb} / \mathrm{ft}^{3}\left(1600\right.$ and $\left.1920 \mathrm{~kg} / \mathrm{m}^{3}\right)$ and to normal weight concrete. They are applicable to concrete dry or soaked at the time of loading. Values not given in the table shall be determined by interpolation. The correction factors are applicable for nominal concrete strengths from 2000 to 6000 psi (13.8 to $41.4 \mathrm{MPa})$.

\section{Roport}

The report shall include the following:

- Identification number.

- Diameter (and length, if outside the range of 1.8 $\mathrm{D}$ to $2.2 \mathrm{D}$ ), in inches or millimetres.

- Cross-sectiona! area, in square inches or square centimetres.

- Maximum load, in pounds-force or newtons.

- Compressive strength calculated to the nearest $10 \mathrm{psi}$ or $69 \mathrm{kPa}$.

- Type of fracture, if other than the usual cone (see Figure 2).

- Defects in either specimen or caps.

- $\quad$ Age of specimen.

\section{Precision}

The precision of this test method has not yet been determined, but data are being collected, and a precision statement will be included when it is formulated. 


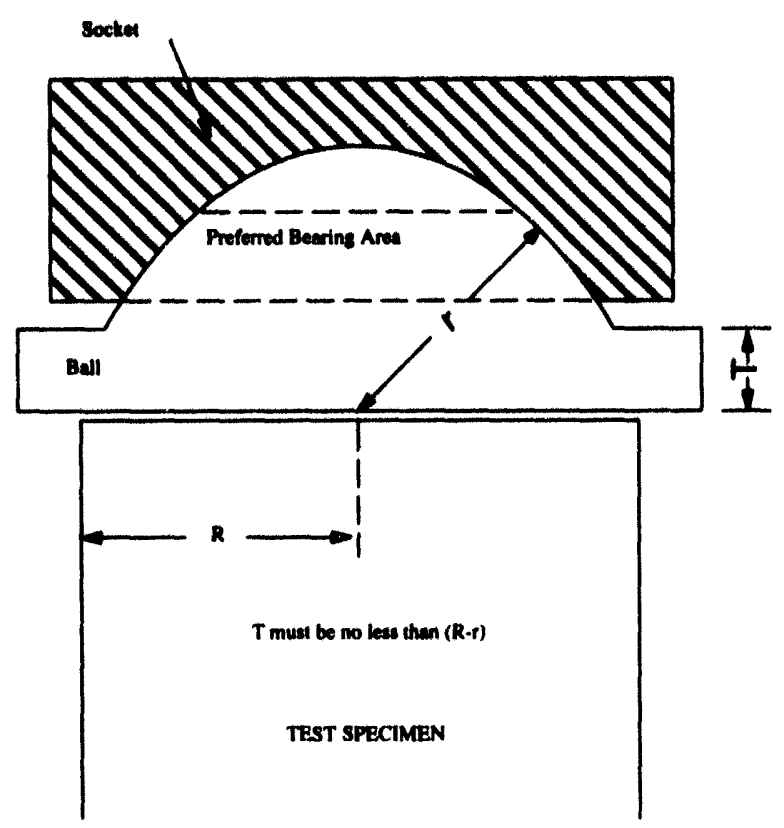

NOTE - Provinion shall be made for holding the bell in the socket and for holding the entire unit in the veating mechine.

Figure C-1. Schematic sketch of a typical spherical bearing block.
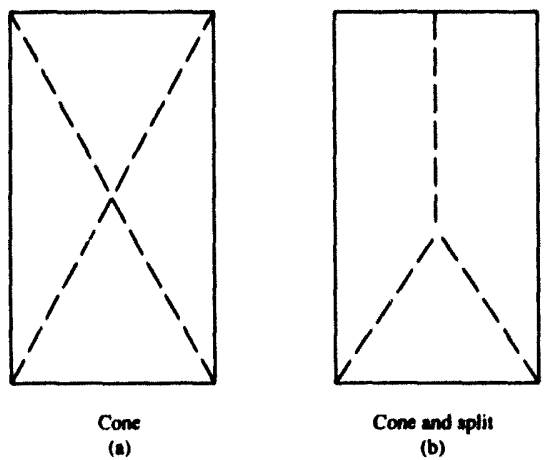

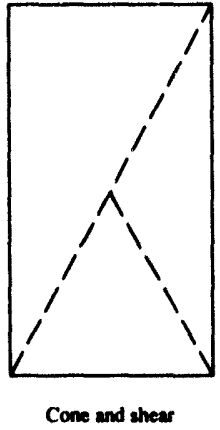

(c)

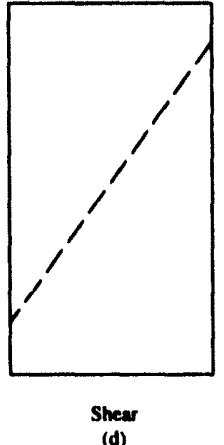

(d)

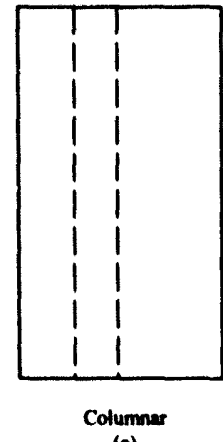

(e)

LP94 0045

Flgure C-2. Sketches of types of fracture. 


\section{Appendix D}

General Analytical Methods

D-1 


\section{Appendlx D}

\section{General Analytical Methods}

This appendix presents a general description of the analytical methods used for all samples. In some cases, variations in the methods were identified. However, the general analysis scheme is that shown below for all samples. The data analysis methods of ANSI/ANS 16.1 require a knowledge of the initial inventories of diffusing species in the waste-form sample being tested and a knowledge of their concentrations in the leachates generated during leach testing. In order to provide a basis for estimating the initial inventories of species of interest, samples of unsolidified resin waste and solidified waste-form samples were analyzed using several different analytical techniques. Because of the differences in their physical characteristics and because the concentrations of radionuclides and metals in the leachates were expected to be as much as several orders of magnitude lower in the leachates compared to the resins, the methods required to prepare the resin and leachate samples for analysis were generally different.

Prior to analysis, leachate solutions were partitioned into volumetric samples according to the general analysis scheme shown in Figure D-1. (In the case of degraded samples, samples were filtered prior to analysis to remove particulate material.) As shown in Figure D-1, the analytical methods used to determine concentrations of radionuclides, transition metals, and chelating agents in leachate samples included high-resolution gamma-ray spectrometry, liquid scintillation and gas proportional counting, inductively coupled plasma-atomic emission spectroscopy, and ion chromatography (IC). The detection of chelating agents in some leachate solutions required that the chelating agent be chemically separated from other components of the sample prior to IC analysis.

The following sections provide descriptions of the sample preparation and analysis methods used to analyze the resin waste and leachate samples obtained during the course of this study.

\section{Radionuclide Analysls}

Resin waste samples were analyzed for radionuclides specified in $10 \mathrm{CFR} 61$ (e.g., ${ }^{14} \mathrm{C},{ }^{60} \mathrm{Co}$, ${ }^{63} \mathrm{Ni},{ }^{90} \mathrm{Sr},{ }^{99} \mathrm{Tc},{ }^{129} \mathrm{I},{ }^{137} \mathrm{Cs},{ }^{238} \mathrm{Pu},{ }^{239} \mathrm{Pv}$ ' ${ }^{441} \mathrm{Am}$, and ${ }^{244} \mathrm{Cm}$ ) and other radionuclides using standard environmental analysis procedures. Concentrations of gamma-emitting radionuclides (e.g. ${ }^{60} \mathrm{Co},{ }^{137} \mathrm{Cs}$, and other measurable gamma emitters) in each resin sample were measured by diluting an aliquot of the dissolved resin with water and analyzing this volumetric sample using gamma spectrometric techniques. When resin waste-form samples were analyzed, a small sample of the solidified waste was analyzed directly at a distance of $10 \mathrm{~cm}$ from the detector, which minimizes the effect of geometry on the analysis. The HPGe spectrometers used to analyze these samples were calibrated using reference sources traceable to the National Institute of Standards and Technology.

Concentrations of beta emitters (e.g., ${ }^{14} \mathrm{C},{ }^{55} \mathrm{Fe}$, ${ }^{63} \mathrm{Ni},{ }^{90} \mathrm{Sr},{ }^{99} \mathrm{Tc},{ }^{129} \mathrm{I}$, and ${ }^{241} \mathrm{Pu}$ ) in the resin wastes were determined using radiochemical separation techniques followed by liquid scintillation or gas proportional counting. Stable iron, nickel, and strontium carriers and ${ }^{85} \mathrm{Sr}$ tracer were added to an aliquot of the dissolved resin waste, and the solution was then passed through a chloride-form anion-exchange column. Iron in the solution was left on the column while nickel and strontium passed through it. Unwanted radionuclides were washed from the column using $\mathrm{HCl}$ and $\mathrm{HF}$ acids, and the iron was then eluted using $0.5 \mathrm{M} \mathrm{HCl}$. Ammonia and iron were added to the eluent of the column, and this alkaline solution was treated with dimethylglyoxime to selectively extract nickel, and sulfate was added to another aliquot to precipitate strontium as strontium sulfate. Concentrations of ${ }^{55} \mathrm{Fe}$ and ${ }^{63} \mathrm{Ni}$ were determined by analyzing the separated activities using a liquid scintillation counter, and the concentration of 
${ }^{90} \mathrm{Sr}$ was determined using a gas proportional counter.

Concentrations of ${ }^{14} \mathrm{C},{ }^{99} \mathrm{Tc}$, and ${ }^{129} \mathrm{I}$ in leachate samples were determined by first using radiochemical techniques to selectively extract and concentrate these radionuclides. Carriers and tracers were added to volumetric samples of the leachates, and the samples were then evaporated to dryness. The samples were then dissolved in an $\mathrm{HCl}$ solution. These samples were then processed and analyzed using the same procedures used for the resin-waste samples.

The procedure used to analyze the leachates for ${ }^{238} \mathrm{Pu},{ }^{239} \mathrm{Pu},{ }^{241} \mathrm{Am}$, and ${ }^{244} \mathrm{Cm}$ was the same as that used for the resins in that a pyrosulfate fusion and the following analysis program were the same for both the waste-form samples and the leachates.

The resin and waste-form samples analyzed for concentrations of transuranic isotopes were wetashed using nitric, sulfuric, and perchloric acids. This procedure was followed by a pyrosulfate fusion to dissolve any remaining undissolved compounds. The fusion was then dissolved in $2 M$ $\mathrm{HCl}$, and the actinides were precipitated using barium sulfate. The barium sulfate precipitate was then dissolved in alkaline EDTA to precipitate the actinides as hydroxides. The hydroxide precipitate was then dissolved in acid, and then the solution was oxidized to adjust the oxidation state of plutonium. Americium and curium were precipitated as fluorides and, following filtration, this precipitate was mounted for analysis using a high-resolution alpha spectrometer. The filtrate was reduced, and plutonium was precipitated as plutonium fluoride. The plutonium fraction was also analyzed using a high-resolution alpha spectrometer.

The radionuclide analysis program for the leachate samples, as shown in Figure D-1, indicates that the concentrations of gamma-emitting radionuclides (e.g., ${ }^{54} \mathrm{Mn},{ }^{60} \mathrm{Co}$, and ${ }^{137} \mathrm{Cs}$ ) were determined using HPGe spectrometers. Concentrations of ${ }^{14} \mathrm{C},{ }^{55} \mathrm{Fe},{ }^{63} \mathrm{Ni},{ }^{99} \mathrm{Tc},{ }^{129} \mathrm{I}$, and ${ }^{90} \mathrm{Sr}$ in leachate samples were determined by first using radiochemical techniques to selectively extract and concentrate these radionuclides. Carriers and tracers were added to volumetric samples of the leachates, and the samples were then evaporated to dryness. The samples were then dissolved in an $\mathrm{HCl}$ solution. These samples were then processed and analyzed using the same procedures used for the resin-waste samples.

The procedure used to analyze the leachates for ${ }^{238} \mathrm{Pu},{ }^{239} \mathrm{Pu}$, ${ }^{241} \mathrm{Am}$, and ${ }^{244} \mathrm{Cm}$ was the same as that used for the resins in that a pyrosulfate fusion and the following analysis program were the same for both the waste-form samples and the leachates.

\section{Elemental Analysis}

Samples of dissolved resin wastes and leachate solutions were analyzed using inductively coupled plasma-atomic emission spectroscopy (ICP-AES). All samples were analyzed for concentrations of chromium, iron, and nickel. These elements were selected for analysis because they are the primary constituents of stainless steel and Inconel, the materials used to line the intemal surfaces of light water reactor primary coolant systems. In addition, the samples were analyzed for zinc, which is present in the reactor coolant system due to the presence of Admiralty brass. Leachate samples were analyzed using ICP-AES through similar calibrations, although more than one elemental analysis can be performed at a time using this technique. Potential analytical background interferences introduced by high concentrations of $\mathrm{Ca}^{+2}$ and other ions were evaluated using prepared standards. Only lot-analyzed, trace-metal analysis-grade reagents were used to prepare standards.

Several techniques were used to analyze the resin and leachate samples for chelating agents. The two primary techniques used were gas liquid chromatography (GLC) as discussed in Reference 1 and ion chromatography as discussed in References 2 and 3. The GLC technique was used for measurements of oxalic acid, citric acid, EDTA, and DTPA in both resin waste and leachate samples for Reference 1, and ion chromatography was used for the analysis of the oxalic acid, citric 
acid, and picolinic acid in References 1,2, and 3 . The techniques used are summarized below.

The GLC technique provides a means of simultaneously determining the concentrations of oxalic acid, citric acid, EDTA, and DTPA in both resin waste and leachate samples. Prior to analysis, the involatile acids are converted to their volatile methyl ester derivatives by reaction with borontrifluoride in methanol. The esterification reaction has been shown not to be affected by the presence of stable metals (e.g., $\mathrm{Fe}^{+3}, \mathrm{Cr}^{+3}$, and $\mathrm{Ni}^{+2}$ ), which are present at relatively high concentrations in decontamination resin wastes. The GLC method was used to analyze resin waste and leachate samples representing the Can-Decon, AP/ Citrox, and Dow NS-1 decontamination processes, all of which use combinations of the previously mentioned organic acids. Because the concentrations of organic acids in leachate samples were expected to be several orders of magnitude lower than their corresponding concentrations in resin waste samples, methods were developed to concentrate the organic acids in leachate samples prior to their esterification and analysis.

The preconcentration method that was initially tested was freeze-drying relatively large volumes of leachate in volumetric flasks. However, this method was eventually discarded because of the long times required to dry the samples and because of the problems associated with consolidating the dried acids following freezedrying. In order to eliminate these difficulties, anion-exchange resin columns were used to concentrate the organic acids in leachate samples. Preliminary analyses showed that a 10:0-mL leachate sample volume was normally sufficient to provide adequate analysis sensitivity. The first step in the preparation of a leachate sample involved passing a $100-\mathrm{mL}$ sample through a 6.4-mm-diameter by 76-mm-long column packed with AG MP-50, 20/50-mesh hydrogen-form ation resin. This procedure removed dissolved activity (e.g., ${ }^{60} \mathrm{Co}$ ) and also removed cations such as $\mathrm{Ca}^{+2}$ that might interfere with the GLC analysis. It also served to convert complexed organic acids to uncomplexed forms that could be trapped on the anion resin column. The eluate of the cation-exchange column was then passed through a similarly sized column packed with AG 1-X8, 100/200-mesh chloride-form anion resin. Complexed organic acids are retained on the anion-exchange resin. The anion resin was then flushed from the column into a $5-\mathrm{mL}$ reacti-vial using deionized water. The sample was placed in a freezer overnight, and then it was freeze-dried under reduced pressure.

Following freeze-drying, the anion resin was esterified directly so as to achieve a maximum concentration factor. A triangular stirring bar and $1 \mathrm{~mL}$ of boron trifluoride and $14 \%(\mathrm{w} / \mathrm{v})$ methanol were added to the reacti-vial. The vial was sealed and placed in a reacti-therm heating/stirring block where it was stirred continuously for 2 hours while heated to $348 \mathrm{~K}\left(75^{\circ} \mathrm{C}\right)$. Following esterification, the sample was allowed to cool to room temperature, and then $1 \mathrm{~mL}$ of HPLC/Spectro-grade chloroform was injected into the vial using a gas-tight syringe. The vial was then shaken vigorously to mix the solutions; then $3 \mathrm{~mL}$ of $\mathrm{KH}_{2} \mathrm{PO}_{4}$, buffer, and $100 \mu \mathrm{L}$ of a solution of ethyl benzoate and chloroform, which was used as an internal standard, were added. The sample was next shaken vigorously for 2 minutes using an electric vibrator/mixer and then centrifuged for 15 minutes at $4,000 \mathrm{rpm}$ to separate the aqueous and chloroform components. The aqueous layer was removed and discarded using a Pasteur pipette, and the chloroform layer containing the methyl esters of the organic acids was pipetted into a $1-\mathrm{mL}$ serum vial, which was sealed as soon as the transfer was completed. It was this chloroform component that was analyzed by GLC.

Waste resin samples were esterified using the same procedure employed to esterify the anion resins used to concentrate leachate organic acids. Waste resin samples were removed from the original waste resin containers after the resin had been homogenized using a mixer set at low speed. The masses of the waste resin samples that were esterified and analyzed by GLC ranged from 0.34 to $0.50 \mathrm{~g}$ (dry mass). These samples, in there original states, exhibited relatively high specific activities; however, in each case, following 
esterification, gamma-emitting radionuclides (i.e., ${ }^{54} \mathrm{Mn},{ }^{60} \mathrm{Co},{ }^{137} \mathrm{Cs}$ ) were segregated exclusively to the aqueous layer. No detectable activity was measured in the chloroform components of the esterified resin waste samples.

A Perkin Elmer model Sigma 300 gas chromatograph equipped with a flame ionization detector (FD) was used to measure the concentration of the methyl ester derivatives. The chromatograph column was contained in an oven that could be operated at temperature from $308 \mathrm{~K}\left(35^{\circ} \mathrm{C}\right)$ up to $773 \mathrm{~K}\left(500^{\circ} \mathrm{C}\right)$ and was fitted with a single-channel temperature controller that provided linear temperature programming for the oven. Separation of the esters was achieved using a 6.4-mm outside diameter, $1.83-\mathrm{m}$-long glass column packed with 5\% SP-2250 on 100/120 mesh Supeloport. Nitrogen flow through the column was kept constant at $30 \mathrm{~cm}^{3} / \mathrm{min}$., the column injector temperature was set to $558 \mathrm{~K}\left(285^{\circ} \mathrm{C}\right)$, and the FID temperature was kept constant at $583 \mathrm{~K}$ $\left(310^{\circ} \mathrm{C}\right)$. The volume of sample used for analysis was $5 \mu \mathrm{L}$. Following sample injection, the column oven temperate was maintained at $323 \mathrm{~K}$ $\left(50^{\circ} \mathrm{C}\right)$ for 4 minutes and was then raised at 10 $\mathrm{K} / \mathrm{min}\left(10^{\circ} \mathrm{C} / \mathrm{min}\right)$ to $583 \mathrm{~K}\left(310^{\circ} \mathrm{C}\right)$. The lower temperature was found to be optimum for the elution of the ester of oxalic acid, while the optimum temperatures for the elution of the esters of the other acids were above $423 \mathrm{~K}\left(150^{\circ} \mathrm{C}\right)$. For each GLC analysis, chromatogram and areas of individual peaks were recorded on a Hewlett-Packard Model 3390A integrator. The integrator recorded peak retention times and peak fit parameters. Results were recorded as the ratio of the area of the ester peak to the area of the internal standard peak. Ethyl benzoate was chosen as the internal standard because it yielded a sharp symmetrical peak that did not interfere with the peaks of any of the other esters.

To assess whet:'er of not the esterification of the chloroform anion resin produced any peaks that interfered with the internal standard peak or the peaks of the esters of the organic acids of interest, two samples of the anion resin that contained no acids were esterified following the standard procedure. To one of the two samples,
$100 \mu \mathrm{L}$ of ethyl benzoate internal standard solution was added, but no internal standard was added to the second sample. Five- $\mu \mathrm{L}$ samples of the chloroform layers of both samples were analyzed using the standard gas chromatograph operating parameters. Neither of the chromatograms of these samples exhibited any interfering peaks.

In order to determine calibration functions for the gas chromatograph, standards were prepared that contained known amounts of oxalic acid, citric acid, EDTA, and DTPA. Calibration standards were prepared by either freeze-drying aliquots of a standard solution containing known quantities of the four acids or by directly measuring the individual masses of the acids added to a mixture of the four acids. The former method was used to prepare the standards having the smaller masses, while the latter technique was used to make the larger mass standards. duplicate sets of six standards were prepared that contained the following massed of each of the four acids: $0.1 \mathrm{~g}, 0.2 \mathrm{~g}, 0.5$ $\mathrm{g}, 1.0 \mathrm{~g}, 3.0 \mathrm{~g}$, and $5.0 \mathrm{~g}$. (The exact masses of each acid were close to these values.) Following drying, the standards were esterified following the procedure previously described. Each of the 12 standards was analyzed five or more times to determine a response curve for each of the four acids. In each case, the response, expressed as the ratio of the peak area of the methylester of the acid to the peak area of the ethyl benzoate internal standard, was a linear function of acid mass. For each acid, the calibration data were fit using linear regression methods to determine the slope and intercept of the linear calibration function and the error in the estimate of measured concentrations. Correlation coefficients of these fits were equal to or better than 0.999 , indicating that the response functions closely approximated straight lines.

Picolinic acid calibration standards were also prepared following the same procedures used to prepare the standards containing oxalic acid, citric acid, EDTA, and DTPA. Four standards were prepared that contained about $1.4 \mathrm{~g}, 4.5 \mathrm{~g}, 10.9 \mathrm{~g}$, and $33.0 \mathrm{~g}$ of picolinic acid. Following freezedrying, these standards were esterified according to the usual procedure. The peak areas of the methyl ester of picolinic acid were divided by the corresponding peak areas of the ethyl benzoate 
internal standard, and the data were fit using linear regression methods to detc rmine the slope and intercept of the linear calibration function and the error in the estimate of measured concentrations. The correlation coefficient of the fit was 0.99994 .

In order to confirm that transition metal ions did not interfere with the GLC analysis of leachate samples, a standard solution containing oxalic acid, citric acid, and EDTA was analyzed with and without a metal ion component. Following an initial analysis, quantities of chromium (as chromium chloride) and iron (as ferrous chloride) were added to the standard solution such that their concentrations were each about $100 \mu \mathrm{g} / \mathrm{mL}$. Concentrations of the three acids were each about $10 \mu \mathrm{g} / \mathrm{mL}$. Samples of the spiked solution were freeze-dried, esterified, and analyzed using standard procedures. The analytical response of the GLC for oxalic acid, citric acid, and EDTA was not affected by the presence of these metal ions.

\section{Chelating Agent Analysis}

The concentrations of the waste-form specimens and leachates were analyzed for picolinic acid using ion chromatography. A Dionex ion chromatograph was used with an ion-exchange column (AS-4A) and $5 \mathrm{mM}$ sodium hydroxide as an eluent. The detector was set at $254 \mathrm{~nm}$. This method shows subparts-per-million detectability. For the Peach Bottom leachates, dilutions of the waste-form samples were required because these samples contain approximately $5.5 \mathrm{wt} \%$ picolinic acid. Representative chromatograms are shown in Reference 1 and 2. 


\section{Appendix D}

\section{REFERENCES}

1. C. V. Mclsaac and J. W. Mandler, The Leachability of Decontamination Ion-Exchange Resins Solidified in Cement at Operating Nuclear Power Plants, NUREG/CR-5224, March 1989.

2. C. V. McIsaac, D. W. Akers, and J. W. McConnell, Jr., Effect of $p H$ on the Release of Radionuclides and Chelating Agents from Cement-Solidified Decontamination Ion-Exchange Resins Collected from Operating Power Stations, NUREG/CR-5601, June 1991.

3. D. W. Akers et al., Releases of Radionuclides and Chelating Agents from Cement-Solidified Decontamination Low-Level Radioactive Waste Collected from the Peach Bottom Atomic Power Station Unit 3, NUREG/CR-6164, 1994. 


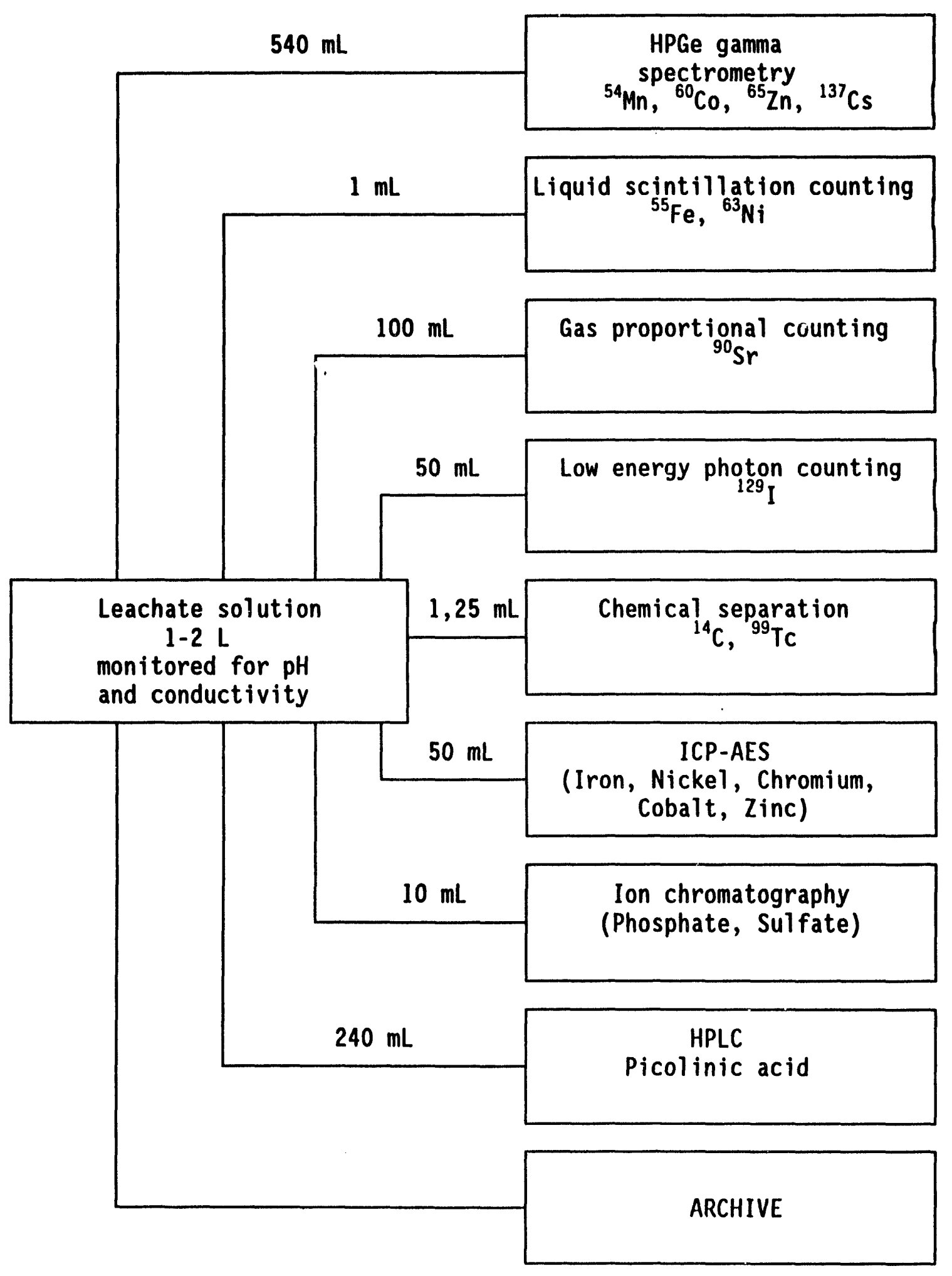

Figure D-1. Leachate analysis methods. 


\section{Appendix E}

\section{Leach Test Results}




\section{Appendix $E$ \\ Leach Test Results}

This section contains the summary leach test results for References 1 through 3. Results are presented as absolute $\left(\mu \mathrm{Ci} / \mathrm{cm}^{2}\right.$. s or $\mu \mathrm{g} / \mathrm{cm}^{2}$. s) and as fractional $\left(\mathrm{cm}^{2} \cdot \mathrm{s}^{-1}\right)$ release rates. In addition, the cumulative fraction released is shown along with the leachability index. At the request of the NRC project manager, other forms of data presentation have been included. They include cumulative fraction released $/ \mathrm{cm}^{2}$ surface area/yr, $\mathrm{Ci} / \mathrm{yr}, \mathrm{Ci} / \mathrm{m}^{3} / \mathrm{yr}$, cumulative fraction release $/ \mathrm{yr}$, and cumulative fraction release $/ \mathrm{m}^{3} / \mathrm{yr}$. Comparisons of data containing time-dependant release quantities (i.e., those containing measurements of radioactivity, in $\mathrm{Ci}$ ) should be treated carefully as these data are dependant on the decay correction date used, which differs for different waste forms.

The results in Tables E-1 through E-6 came from Reference 1. Tables E-7 through E-25 came from Reference 2, and Table E-26 came from Reference 3. 
Appendix E

\section{REFERENCES}

1. C. V. McIsaac and J. W. Mandler, The Leachability of Decontamination Ion-Exchange Resins Solidified in Cement at Operating Nuclear Power Plants, NUREG/CR-5224, March 1989.

2. C. V. McIsaac, D. W. Akers, and J. W. McConnell, Jr., Effect of pH on the Release of Radionuclides and Chelating Agents from Cement-Solidified Decontamination Ion-Exchange Resins Collected from Operating Power Stations, NUREG/CR-5601, June 1991.

3. D. W. Akers et al., Releases of Radionuclides and Chelating Agents From Cement Solidified Decontamination Low-Level Radioactive Waste Collected from the Peach Bottom Atomic Power Station Unit 3, NUREG/CR-6164, 1994. 
Table E-1. Radionuclide leach-test results for Can-Decon waste forms.

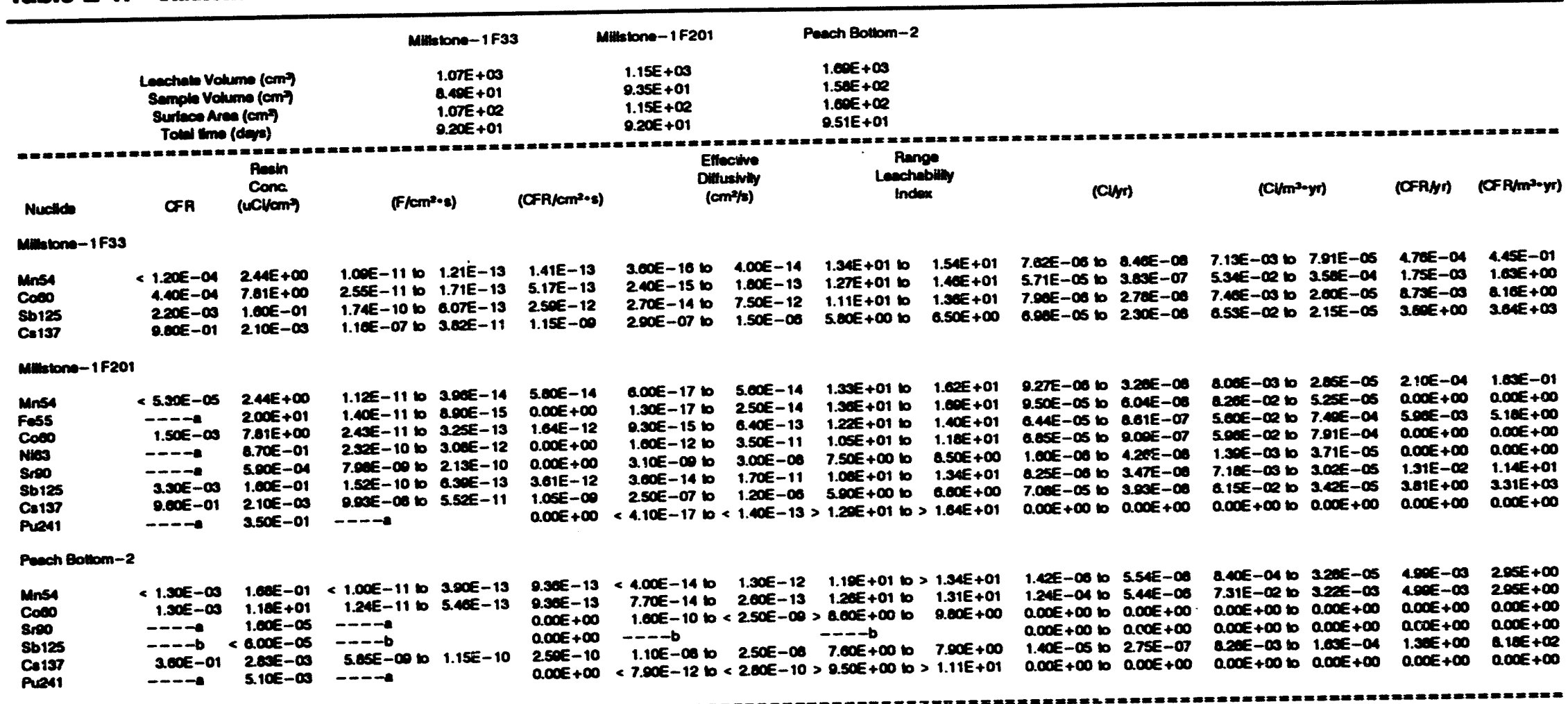

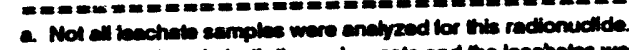

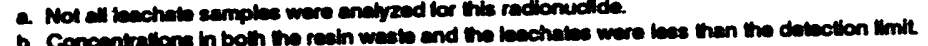


Table E-2. Radionuclide leach-test results for Citrox waste forms.

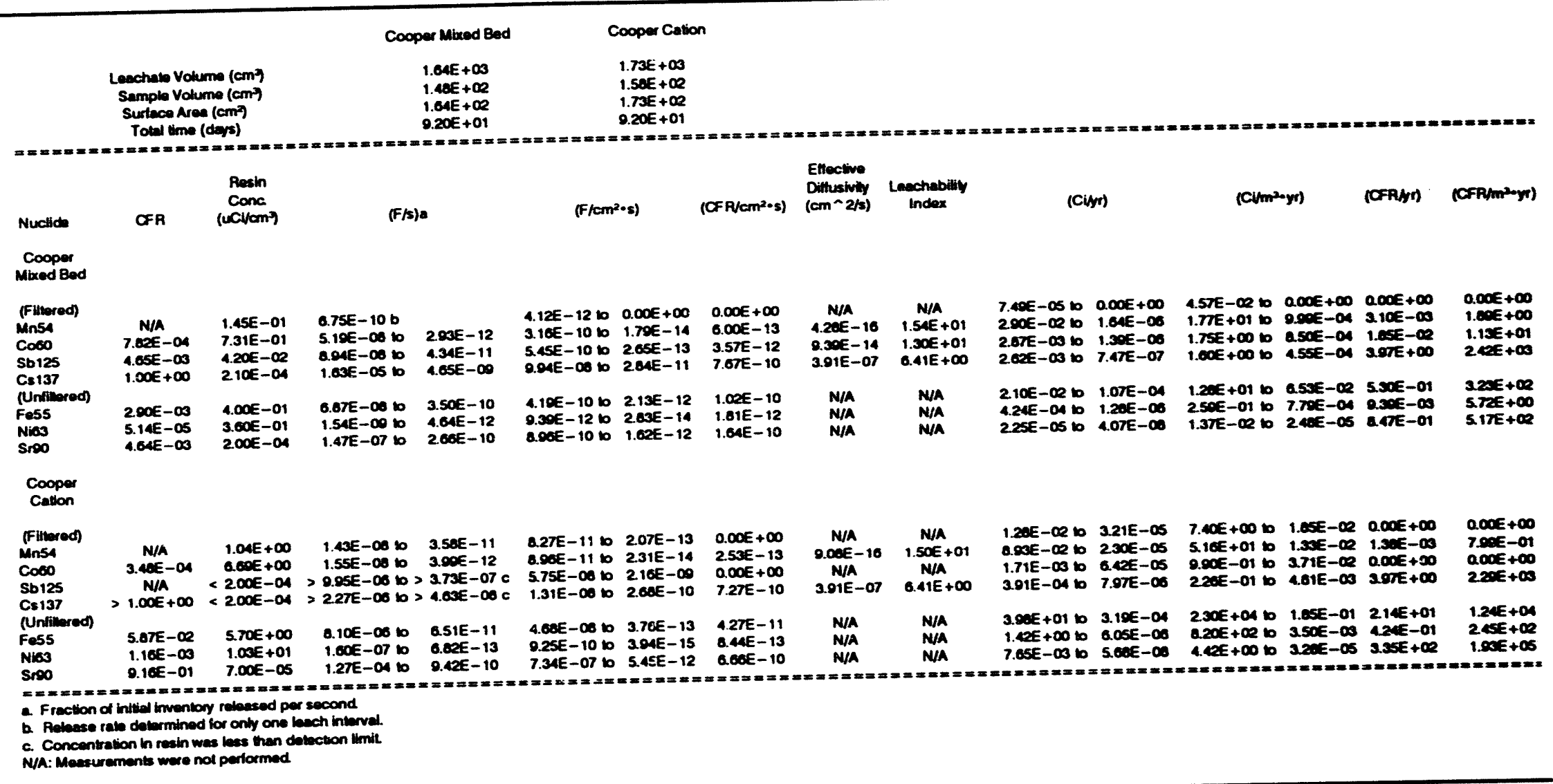


Table E-3. Radionuclide leach-test results for Pilgrim Dow NS-1 waste forms.

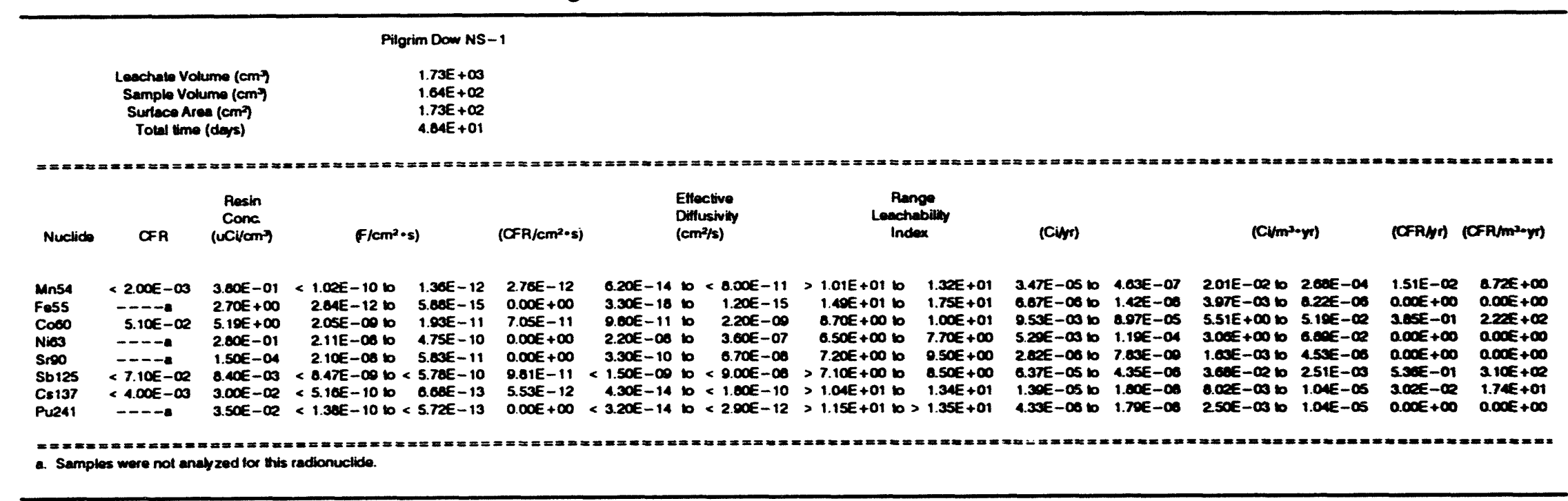


Toble E-4. Radionuclide leach-test results for Indian Point-3 LOMI waste forms.

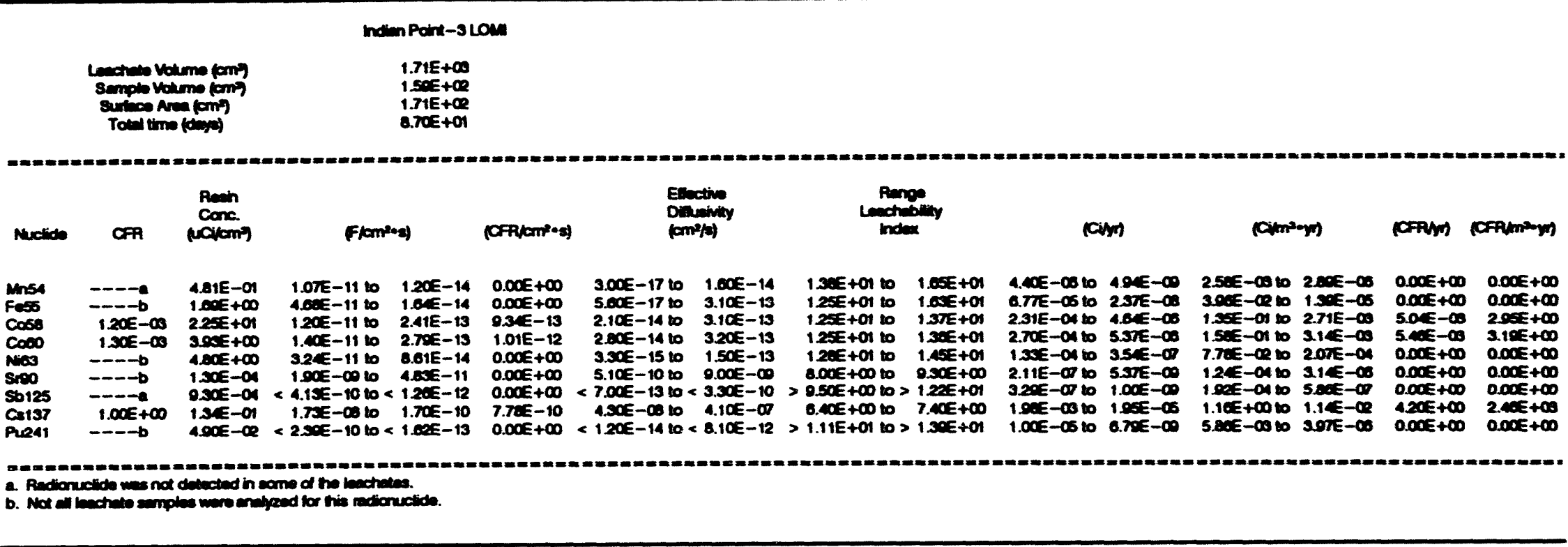


Table E-5. Stable metal leach-test results for waste forms.

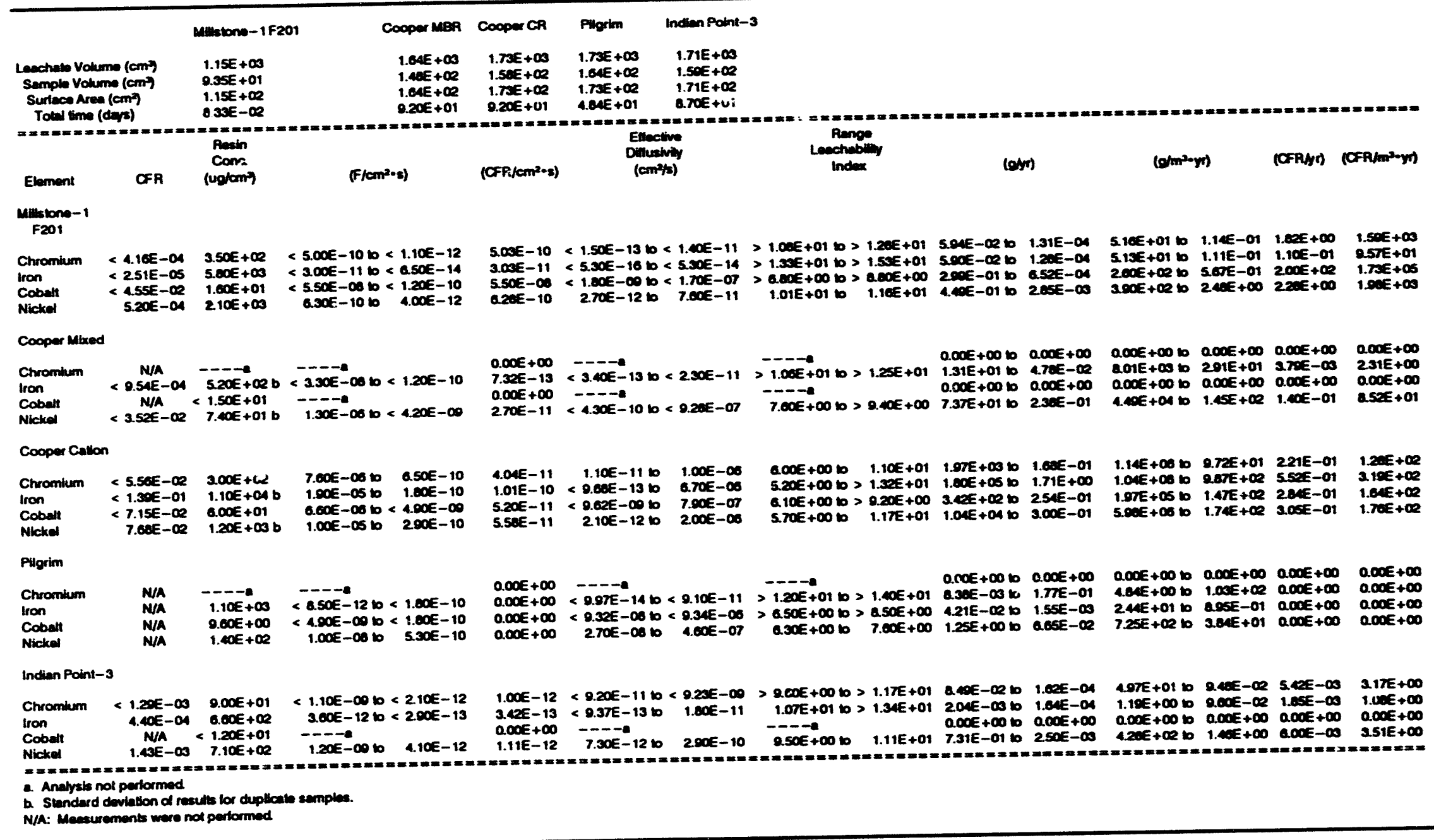


Table E-6. Acid leach-test results for waste forms.

\begin{tabular}{|c|c|c|c|c|c|c|c|c|c|c|c|c|c|c|c|}
\hline 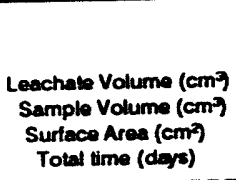 & & $\begin{array}{l}\text { Aillstone }-1 \text { F20 } \\
1.15 E+03 \\
9.35 E+01 \\
1.15 E+02 \\
9.20 E+01\end{array}$ & & $\begin{array}{l}\text { Cooper MBR C } \\
1.64 E+\infty 3 \\
1.40 E+\infty 2 \\
1.64 E+\infty 2 \\
9.20 E+01\end{array}$ & $\begin{array}{l}\text { Cooper CR } \\
1.73 E+03 \\
1.50 E+\infty 2 \\
1.73 E+02 \\
9.20 E+01\end{array}$ & $\begin{array}{l}\text { Pilgrim } \\
1.73 E+\infty 3 \\
1.64 E+\infty 2 \\
1.73 E+\infty 2 \\
4.84 E+01\end{array}$ & 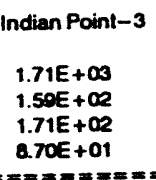 & & 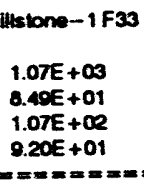 & & $\begin{array}{l}\text { ach Bottom } \\
1.00 E+\infty \\
1.50 E+\infty 2 \\
1.00 E+\infty 2 \\
0.51 E+01 \\
=x==1\end{array}$ & & & & \\
\hline Acid & CFR & $\begin{array}{l}\text { Resin } \\
\text { Conc } \\
\text { (ug/omin) }\end{array}$ & $\left(\mathrm{F} / \mathrm{cm}^{2}\right.$ & 2.5) & (CFR/ $/ \mathrm{cm}^{2 \cdot s)}$ & $\begin{array}{l}\text { Ellective } \\
\text { Diflushity } \\
\left(\mathrm{cm}^{2} / \mathrm{s}\right)\end{array}$ & & $\begin{array}{l}\text { Rang } \\
\text { Leechel } \\
\text { Inder }\end{array}$ & nge & (gyr) & & $\left(g / m^{2} \cdot y\right.$ & & (CFAGY) & $\left(C F R / m^{2} \cdot y r\right)$ \\
\hline $\begin{array}{ll}\text { MILLSTONE-1 F33 } \\
\text { Oxatic } \\
\text { Citric } \\
\text { EDTA }\end{array}$ & $\begin{array}{l}2.40 E-02 \\
1.40 E-02 \\
2.30 E-01\end{array}$ & $\begin{array}{l}7.40 E+\infty \\
6.30 E+\infty \\
6.10 E+\infty\end{array}$ & $\begin{array}{l}2.90 E-0910 \\
4.70 E-1010 \\
5.60 E-\infty 010 \\
.10\end{array}$ & $\begin{array}{l}3.80 E-12 \\
7.70 E-12 \\
1.00 E-10\end{array}$ & $\begin{array}{l}2.82 E-11 \\
1.65 E-11 \\
2.70 E-10\end{array}$ & $\begin{array}{l}2.20 E-12 \text { to } \\
5.30 E-12 \text { to } \\
1.30 E-00 \text { to }\end{array}$ & $\begin{array}{l}4.40 E-10 \\
6.60 E-10 \\
2.40 E-\infty\end{array}$ & $\begin{array}{l}9.40 E+\infty \mathrm{b} \\
9.20 E+\infty \mathrm{b} \\
7.00 E+\infty \mathrm{b}\end{array}$ & $\begin{array}{l}1.17 E+01 \\
1.13 E+01 \\
0.00 E+\infty\end{array}$ & $\begin{array}{l}0.15 E-0310 \\
8.49 E-0410 \\
9.79 E-03 \text { bo }\end{array}$ & $\begin{array}{l}8.27 E-\infty 6 \\
1.30 E-05 \\
1.75 E-04\end{array}$ & $\begin{array}{l}5.75 E+\infty 000 \\
7.93 E-01 \text { 10 } \\
9.15 E+\infty 016\end{array}$ & $\begin{array}{l}7.73 E-\infty 3 \\
1.30 E-\infty \\
1.03 E-01\end{array}$ & $\begin{array}{l}2.53 E-\infty 2 \\
5.50 E-02 \\
9.13 E-01\end{array}$ & $\begin{array}{l}.00 E+01 \\
5.19 E+01 \\
.53 E+02\end{array}$ \\
\hline $\begin{array}{l}\text { MILLSTONE-1 F2O1 } \\
\text { Oxalic } \\
\text { Citric } \\
\text { EDTA }\end{array}$ & $\begin{array}{l}---b \\
---b \\
---b\end{array}$ & $\begin{array}{l}7.40 E+\infty \\
6.30 E+\infty \\
6.10 E+\infty\end{array}$ & $\begin{array}{l}1.00 E-0910 \\
1.60 E-10 \text { 10 } \\
250 E-09 \text { 10 }\end{array}$ & $\begin{array}{l}1.00 E-10 \\
5.70 E-11 \\
6.00 E-10\end{array}$ & $\begin{array}{l}0.00 E+\infty \\
0.00 E+\infty \\
0.00 E+\infty\end{array}$ & $\begin{array}{l}2.60 E-10 \text { to } \\
1.00 E-11 \text { to } \\
2.50 E-\infty \text { to }\end{array}$ & $\begin{array}{l}4.10 E-10 \\
5.20 E-10 \\
1.30 E-\infty\end{array}$ & $\begin{array}{l}9.40 E+\infty 10 \\
9.30 E+\infty 010 \\
7.90 E+\infty 0 \mathrm{~b}\end{array}$ & $\begin{array}{l}9.60 E+\infty \\
1.10 E+01 \\
6.60 E+\infty\end{array}$ & $\begin{array}{l}2.51 E-0310 \\
3.42 E-0410 \\
5.17 E-0310\end{array}$ & $\begin{array}{l}4.02 E-04 \\
1.22 E-04 \\
1.24 E-03\end{array}$ & $\begin{array}{l}2.18 E+\infty \text { bo } \\
2.97 E-01 \mathrm{~b} \\
4.50 E+\infty \text { b }\end{array}$ & $\begin{array}{l}3.49 E-01 \\
1.00 E-01 \\
1.00 E+\infty\end{array}$ & $\begin{array}{l}0.00 E+\infty \\
0.00 E+\infty \\
0.00 E+\infty\end{array}$ & $\begin{array}{l}0.00 E+\infty \\
0.00 E+\infty \\
0.00 E+\infty\end{array}$ \\
\hline $\begin{array}{l}\text { PEACH BOTTOM-2 } \\
\text { Oxalic } \\
\text { Citric } \\
\text { EDTA }\end{array}$ & $\begin{array}{l}1.80 E-02 \\
2.20 E-02 \\
7.10 E-02\end{array}$ & $\begin{array}{l}5.91 E+\infty \\
5.00 E+\infty \\
4.00 E+\infty\end{array}$ & $\begin{array}{l}8.60 E-1010 \\
2.00 E-09 \text { to } \\
1.50 E-00 \text { to }\end{array}$ & $\begin{array}{l}1.00 E-12 \\
2.00 E-12 \\
2.20 E-12\end{array}$ & $\begin{array}{l}1.30 E-11 \\
1.58 E-11 \\
5.11 E-11\end{array}$ & $\begin{array}{l}1.80 E-1210 \\
2.10 E-1210 \\
2.40 E-1210\end{array}$ & $\begin{array}{l}3.60 E-10 \\
1.00 E-\infty \\
7.40 E-09\end{array}$ & $\begin{array}{l}9.40 E+\infty 010 \\
8.70 E+\infty 010 \\
8.10 E+\infty 010\end{array}$ & $\begin{array}{l}1.17 E+01 \\
1.17 E+01 \\
1.16 E+01\end{array}$ & $\begin{array}{l}4.29 E-03 \text { to } \\
8.58 E-03 \text { to } \\
6.21 E-03 \text { to }\end{array}$ & $\begin{array}{l}9.49 E-\infty \\
0.58 E-\infty \\
9.11 E-\infty\end{array}$ & $\begin{array}{l}2.5 A E+\infty \text { bo } \\
5.00 E+\infty b_{10} \\
3.67 E+\infty \text { bo }\end{array}$ & $\begin{array}{l}5.61 E-\infty 3 \\
5.00 E-\infty 3 \\
5.30 E-\infty\end{array}$ & $\begin{array}{l}0.91 E-\infty 2 \\
0.45 E-02 \\
2.73 E-01\end{array}$ & $\begin{array}{l}1.00 E+01 \\
5.00 E+01 \\
1.61 E+\infty 2\end{array}$ \\
\hline $\begin{array}{l}\text { COOPER (MBA) } \\
\text { Oxalic } \\
\text { Citric }\end{array}$ & $\begin{array}{l}1.00 E-02 \\
0.40 E-03\end{array}$ & $\begin{array}{l}1.62 E+\infty \\
2.50 E+\infty\end{array}$ & $\begin{array}{l}3.10 E-0710 \\
3.30 E-0710\end{array}$ & $\begin{array}{l}2.00 E-10 \\
9.00 E-11\end{array}$ & $\begin{array}{l}7.67 E-12 \\
6.44 E-12\end{array}$ & $\begin{array}{l}1.60 E-12 \text { to } \\
4.80 E-13 \text { 10 }\end{array}$ & $\begin{array}{l}1.50 E-\infty \\
1.70 E-\infty\end{array}$ & $\begin{array}{l}0.00 E+\infty 10 \\
8.80 E+\infty 065\end{array}$ & $\begin{array}{l}1.18 E+01 \\
1.23 E+01\end{array}$ & $\begin{array}{l}3.64 E-0110 \\
6.31 E-0110\end{array}$ & $\begin{array}{l}2.40 E-04 \\
1.07 E-04\end{array}$ & $\begin{array}{l}2.34 E+\infty 210 \\
3.05 E+\infty 210\end{array}$ & $\begin{array}{l}1.51 E-01 \\
1.14 E-01\end{array}$ & $\begin{array}{l}3.97 E-\infty 2 \\
3.33 E-\infty 2\end{array}$ & $\begin{array}{l}242 E+01 \\
203 E+01\end{array}$ \\
\hline $\begin{array}{l}\text { COOPER (CR) } \\
\text { Oxalic } \\
\text { Citric }\end{array}$ & $\begin{array}{l}---a \\
---b\end{array}$ & $\begin{array}{l}2.70 E+\infty \\
9.60 E+\infty 0\end{array}$ & $\begin{array}{l}---a \\
---b\end{array}$ & $\begin{array}{l}--a \\
--b\end{array}$ & $\begin{array}{l}0.00 E+\infty \\
0.00 E+\infty\end{array}$ & $---0.00-0010$ & $2.00 E-07$ & $---a$ & $---9 \mathrm{a}$ & $\begin{array}{l}0.00 E+\infty 010 \\
0.00 E+\infty 10\end{array}$ & $\begin{array}{l}0.00 E+\infty \\
0.00 E+\infty\end{array}$ & $\begin{array}{l}0.00 E+\infty 010 \\
0.00 E+\infty 10\end{array}$ & $\begin{array}{l}0.00 E+\infty \\
0.00 E+\infty\end{array}$ & $\begin{array}{l}0.00 E+\infty \\
0.00 E+\infty\end{array}$ & $\begin{array}{l}0.00 E+\infty \\
0.00 E+\infty\end{array}$ \\
\hline $\begin{array}{l}\text { PILGAIM } \\
\text { Oxalic } \\
\text { Citric } \\
\text { EDTA } \\
\text { DTPA }\end{array}$ & $\begin{array}{l}3.40 E-01 \\
4.00 E-01 \\
1.00 E+\infty \\
3.30 E-01\end{array}$ & $\begin{array}{l}2.03 E+\infty \\
3.00 E+\infty \\
3.70 E+\infty \\
3.62 E+\infty\end{array}$ & $\begin{array}{l}2.50 E-0010 \\
4.40 E-00 \text { 10 } \\
6.00 E-00 \text { 10 } \\
9.90 E-09 \text { 10 }\end{array}$ & $\begin{array}{l}1.20 E-10 \\
3.30 E-11 \\
4.70 E-11 \\
1.30 E-10\end{array}$ & $\begin{array}{l}4.70 E-10 \\
5.53 E-10 \\
1.38 E-09 \\
4.56 E-10\end{array}$ & $\begin{array}{l}2.30 E-06 \text { to } \\
3.20 E-08 \text { 10 } \\
1.90 E-0710 \\
7.60 E-09 \text { 10 }\end{array}$ & $\begin{array}{l}2.90 E-07 \\
2.40 E-06 \\
4.70 E-06 \\
1.60 E-07\end{array}$ & $\begin{array}{l}6.50 E+\infty 010 \\
5.60 E+\infty 010 \\
5.30 E+\infty 010 \\
6.80 E+\infty 010\end{array}$ & $\begin{array}{l}7.60 E+\infty \\
7.50 E+\infty \\
6.70 E+\infty \\
6.10 E+\infty\end{array}$ & $\begin{array}{l}6.50 E-02 b \\
1.10 E-01 \text { bo } \\
2.20 E-01 \text { bo } \\
3.21 E-02 \text { b }\end{array}$ & $\begin{array}{l}3.15 E-04 \\
0.87 E-05 \\
1.50 E-04 \\
4.22 E-04\end{array}$ & $\begin{array}{l}3.79 E+01 b \\
6.64 E+01 b \\
1.32 E+02 b 0 \\
1.06 E+01 \text { b }\end{array}$ & $\begin{array}{l}1.02 E-01 \\
5.13 E-\infty \\
9.01 E-\infty \\
2.44 E-01\end{array}$ & $\begin{array}{l}2.57 E+\infty \\
3.02 E+\infty \\
7.55 E+\infty \\
240 E+\infty\end{array}$ & $\begin{array}{l}1.40 E+\infty \\
1.74 E+\infty 3 \\
4.36 E+\infty 3 \\
1.41 E+03\end{array}$ \\
\hline $\begin{array}{l}\text { INDIAN POINT-3 } \\
\text { Formic } \\
\text { Picolinic }\end{array}$ & $\begin{array}{l}6.30 E-01 \\
6.00 E-01\end{array}$ & $\begin{array}{l}4.00 E+\infty \\
4.10 E+\infty\end{array}$ & $\begin{array}{l}2.10 E-\infty 610 \\
1.30 E-\infty 610\end{array}$ & $\begin{array}{l}5.20 E-10 \\
3.40 E-10\end{array}$ & $\begin{array}{l}6.46 E-10 \\
4.67 E-10\end{array}$ & $\begin{array}{l}6.40 E-08 \text { to } \\
250 E-08 \text { 10 } \\
=E======\end{array}$ & $\begin{array}{l}2.90 \mathrm{E}-07 \\
1.90 \mathrm{E}-07 \\
====== \pm==\end{array}$ & $\begin{array}{l}6.50 E+\infty 10 \\
6.70 E+\infty 10 \\
========\end{array}$ & $\begin{array}{c}7.20 E+\infty \\
7.60 E+\infty \\
======== \pm\end{array}$ & $\begin{array}{l}7.19 E-0210 \\
4.50 E-0210 \\
==\approx== \pm===\end{array}$ & $\begin{array}{l}1.78 E-03 \\
1.19 E-03 \\
=== \pm== \pm\end{array}$ & $\begin{array}{c}1.20 E+0110 \\
207 E+0110 \\
===\pi==\pi=\end{array}$ & $\begin{array}{c}1.04 E+\infty \\
6.90 E-01 \\
== \pm==m=\end{array}$ & $\begin{array}{c}3.40 E+\infty \\
2.52 E+\infty \\
==m==m==1\end{array}$ & $\begin{array}{l}2.04 E+\infty \\
1.47 E+\infty \\
==x=x=x\end{array}$ \\
\hline
\end{tabular}


Table E-7. Leach test results for Brunswick-1 cation resin waste-form specimen leached in deionized water. ${ }^{\mathrm{a}}$

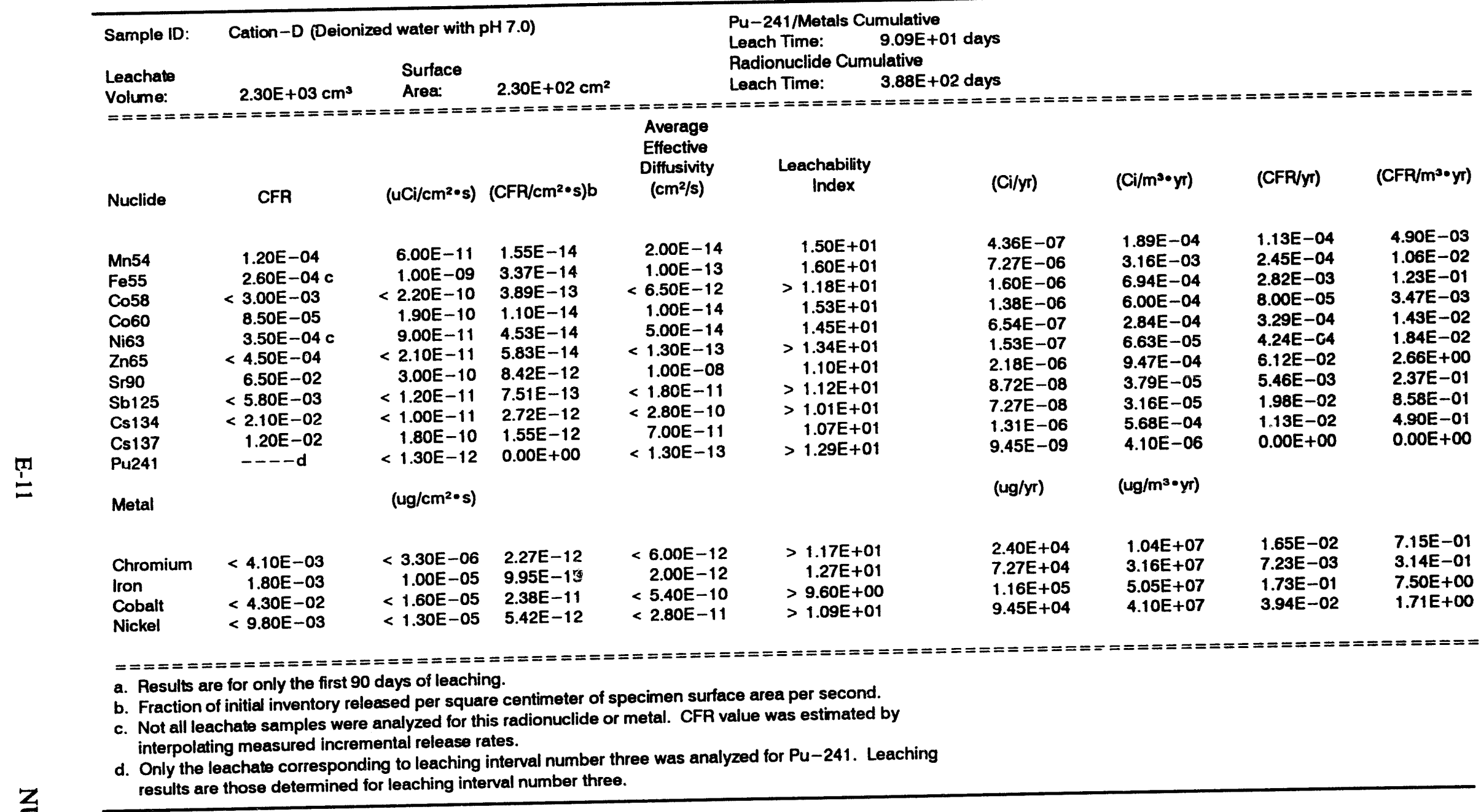


Table E-8. Leach test results for Brunswick-1 cation resin waste-form specimen leached in synthetic Barnwell groundwater with pH 10.4. ${ }^{\mathrm{a}}$

Sample ID: Cstion-B (Synthetic Barnwell ground water

Sample ID: Cstion-B (Synth

$\begin{array}{llll}\text { Leachate } & & \text { Surface } & \\ \text { Volume: } & 2.32 E+03 \mathrm{~cm}^{3} & \text { Area: } & 2.32 E+02 \mathrm{~cm}^{2}\end{array}$

\section{Pu-241/Metals Cumulative \\ Leach Time: $\quad 9.10 E+01$ days \\ Radionuclide Cumulative}

Volume: $\quad 2.32 \mathrm{E}+03 \mathrm{~cm}^{3} \quad$ Area: $2.32 E+02 \mathrm{~cm}^{2} \quad$ Leach Time: $2.01 E+02$ days

(1)

\section{Average}

Diffusivity Leachability

Nuclide

CFR

$\left(\mathrm{uCi} / \mathrm{cm}^{2} \cdot \mathrm{s}\right)\left(\mathrm{CFR} / \mathrm{cm}^{2 \cdot s}\right) \mathrm{b}$

$\left(\mathrm{cm}^{2} / \mathrm{s}\right)$

Index

(Ci/yr)

$\left(\mathrm{Ci} / \mathrm{m}^{3 \cdot y r}\right)$

(CFR/yr)

(CFR/m $\mathbf{m}^{3 \cdot y r)}$

\section{Mn54}

$\begin{aligned}< & 1.30 \mathrm{E}-05 \\ & 5.10 \mathrm{E}-0.5 \mathrm{C} \\ < & 2.20 \mathrm{E}-03\end{aligned}$

$<1.30 E-11 \quad 3.22 E-15$

$<1.80 E-16$

$>1.64 E+01$

$1.58 E+01$

9.00E-11 1.26E-14

$<2.30 E-10 \quad 5.45 E-13$

$5.00 E-16$

$<7.40 E-12$

$8.00 E-17$

$>1.19 E+01$

$1.66 E+01$

$1.10 E-05$

$2.70 E-11 \quad 2.73 E-15$

$3.00 E-13$

$1.36 \mathrm{E}+01$

$5.80 E-04 \mathrm{C}$

$<1.70 E-11 \quad 7.19 E-14$

$<9.30 \mathrm{E}-14$

$>1.36 \bar{E}+01$

$1.12 E+01$

7.00E-12 1.04E-11

4.20E-02 C

$1.40 \mathrm{E}-10$

$>1.10 E+01$

$<3.20 E-11$

O.90E+00

$<1.50 E-11 \quad 5.21 E-12$

$<5.30 E-10$

$9.90 E+00$

$\begin{array}{llrl}\text { Cs134 } & <.10 E-02 & 2.30 E-10 & 2.73 E-12 \\ \text { Cs137 } & 1.10 E-d & <1.50 E-12 & 0.00 E+00\end{array}$

2.30E-10 2.73E-12

8.00E-11

$1.05 E+01$
$>1.28 E+01$

9.53E-08

4.10E-05

2.36E-05

$6.60 E-07$

2.84E-04

4.00E-03

7.26E-04

$2.00 E-05$

$1.05 E-03$

$1.58 \mathrm{E}-03$

$1.98 \mathrm{E}-07$

$3.67 \mathrm{E}-06$
$1.25 \mathrm{E}-07$

5.13E-08 2.21E-05

5.27E-04

7.63E-02

5.36E-05

1.25E-07

4.73E-05

$1.04 E-02$

$3.82 E-02$

$2.00 E-02$

$1.69 \mathrm{E}-06 \quad 7.26 \mathrm{E}-04$

$0.00 E+\infty 0$

3.99E-03

1.72E-01

8.60E-04

4.54E-02

2.27E-02

$3.29 \mathrm{E}+00$

4.46E-01

$1.64 E+00$

$<1.70 \mathrm{E}-13$

(ug/yr)

$\left(u g / m^{3} \cdot y r\right)$

Metal

$\left(\mathrm{ug} / \mathrm{cm}^{2 \cdot \mathrm{s}}\right)$

$\begin{array}{ll}\text { Chromium } & <1.80 \mathrm{E}-02 \mathrm{c} \\ \text { Iron } & <6.50 \mathrm{E}-03 \mathrm{c} \\ \text { Cobalt } & <2.10 \mathrm{E}-01 \mathrm{c} \\ \text { Nickel } & <4.90 \mathrm{E}-02 \mathrm{c}\end{array}$

$<1.40 \mathrm{E}-05 \quad 9.86 \mathrm{E}-12$

$<1.10 E-04 \quad 3.56 E-12$

$<7.30 E-05 \quad 1.15 E-10$

$<1.10 E-10$
$<3.60 E-11$
$<1.50 E-08$
$<8.00 E-10$
$>1.05 E+01$
$>1.07 E+01$
$>8.10 E+\infty 0$
$>9.40 E+00$

$1.03 E+05$

$8.06 E+05$

$5.35 \mathrm{E}+05$

4.25E+05

$4.42 E+07$
$3.47 E+08$
$2.30 E+08$
$1.83 E+08$

7.22E-02

$3.11 E+00$

8.43E-01 3.63E +01

$\begin{array}{ll}1.97 E-01 & 8.47 E+00\end{array}$

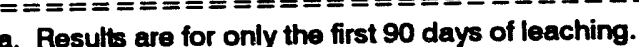

b. Fraction of initis inventory released per square centimeter of specimen r urface area per second.

c. Not all leachate samples were analyzed for this radionuclide or metal. CFR value was estimated by

c. Not all leachale samples were analing measured incremental release rates.

d. Only the leachate corresponding to leaching interval number three was analyzed for Pu-241. Leaching

results are those determined for leaching interval number three. 
Table E-9. Leach test results for Brunswick-1 cation resin waste-form specimen leached in synthetic Barnwell groundwater with pH 4.2.

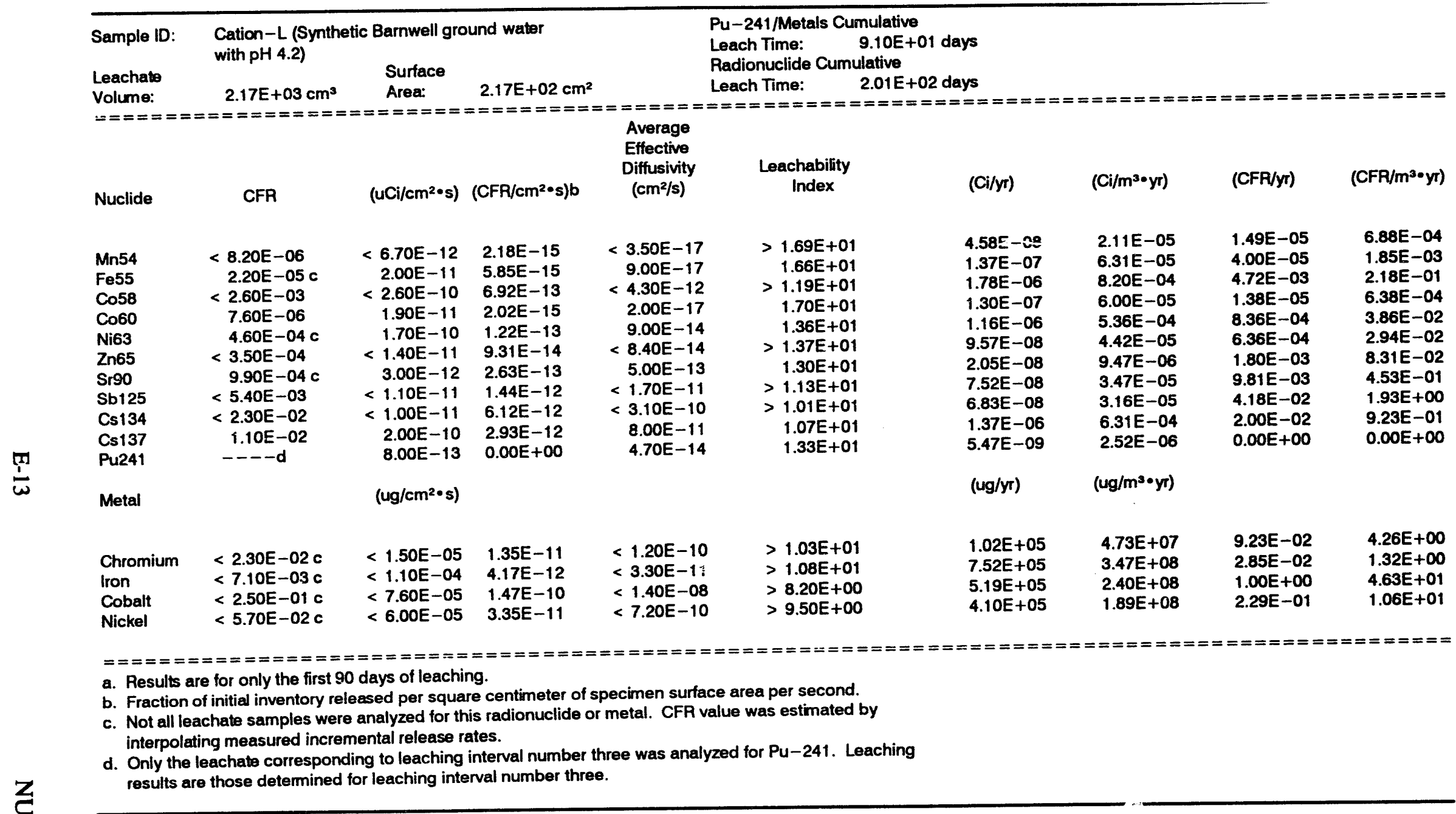


Table E-10. Leach test results for Brunswick-1 cation resin waste-form specimen leached in synthetic Hanford groundwater with pH 8.9.

Sample ID: Cation-H (Synthetic Handford ground water

Sample 1D: $\quad$ with pH 8.9)

Leachate

$20 \mathrm{E}+03 \mathrm{~cm}$

Volume:

$2.20 \mathrm{E}+03 \mathrm{~cm}^{3}$

Surface

Area:

$2.20 E+02 \mathrm{~cm}^{2}$

$======$

Nuclide

CFR

$\left(\mathrm{uCi} / \mathrm{cm}^{2} \cdot \mathrm{s}\right)\left(\mathrm{CFR} / \mathrm{cm}^{2 \cdot s}\right) \mathrm{b}$

$\left(\mathrm{cm}^{2} / \mathrm{s}\right)$

Mn54

Mn54
Fe55

Co58

Co60

Ni63

Zn65

Sr90

Sb125

Cs 134

Cs137

$<$ 1.30E-05

2.30E-05 C

$<2.20 \mathrm{E}-03$

1.20E-05

$1.20 E-03 \mathrm{C}$

$<3.30 E-04$

$1.40 E-03 c$

$<5.40 E-03$

$<1.90 E-02$

$1.20 \mathrm{E}-02$

$$
---d
$$

Metal

$\begin{array}{ll}\text { Chromium } & <2.20 \mathrm{E}-02 \mathrm{c} \\ \text { Iron } & <1.20 \mathrm{E}-02 \mathrm{c} \\ \text { Cobalt } & <2.40 \mathrm{E}-01 \mathrm{c} \\ \text { Nickel } & <5.60 \mathrm{E}-02 \mathrm{c}\end{array}$

\begin{tabular}{|c|c|}
\hline$<9.50 E-12$ & $3.42 E-15$ \\
\hline $3.00 E-11$ & $6.05 E-15$ \\
\hline$<2.30 \mathrm{E}-10$ & $5.79 E-13$ \\
\hline $2.00 E-11$ & $3.16 E-15$ \\
\hline $1.00 E-09$ & $3.16 E-13$ \\
\hline$<1.30 E-11$ & $8.68 E-14$ \\
\hline $2.00 E-12$ & $3.68 E-13$ \\
\hline$<1.20 \mathrm{E}-11$ & $1.42 E-12$ \\
\hline$<1.00 \mathrm{E}-11$ & $5.00 E-12$ \\
\hline $3.00 E-10$ & $3.16 E-12$ \\
\hline $20 E-12$ & \\
\hline
\end{tabular}

$<2.00 E-16$

$<3.00 E-16$

$<270 \mathrm{E}-12$

$1.00 E-16$

$8.00 E-13$

$<5.00 \mathrm{E}-14$

$1.00 E-12$

$<1.50 E-11$

$<2.10 E-10$

$9.00 E-11$

$1.20 E-13$

(ug/ $/ \mathrm{cm}^{2 \cdot s)}$

$<1.50 E-05 \quad 1.28 E-11$

$<1.10 E-04 \quad 6.99 E-12$

$<7.40 \mathrm{E}-05 \quad 1.40 \mathrm{E}-10$

$<5.90 E-05 \quad 3.26 \mathrm{E}-11$

$<3.00 E-11$

$<1.30 \mathrm{E}-08$

$<6.80 \mathrm{E}-10$
Pu-241/Metals Cumulative

Leach Time: $\quad 9.03 E+01$ days

Radionuclide Cumulative

Leach Time: $2.00 \mathrm{E}+02$ days

Leachability

Index

(Ci/yr)

$\left(\mathrm{Ci} / \mathrm{m}^{3} \cdot \mathrm{yr}\right)$

(CFR/yr)

(CFR/m $\left.\mathrm{m}^{3} \cdot \mathrm{yr}\right)$

$>1.67 E+01$

$1.67 E+01$

$>$ 1.21E+01

$1.69 \mathrm{E}+01$

$1.40 E+01$

$>1.38 E+01$

$1.29 \mathrm{E}+01$

$>1.13 E+01$

$>1.03 E+01$

$1.08 E+01$

$1.29 E+01$

$<1.10 E+10$

$>1.09 E+01$

$>8.20 E+00$

$>9.50 \mathrm{E}+00$
3.00E-05

9.47E-05

$7.26 \mathrm{E}-04$

6.31E-05

$3.16 \mathrm{E}-03$

4.10E-05

6.31E-06

3.79E-05

$3.79 E-05$
$3.16 E-05$

9.47E-04

3.79E-06

$\left(u g / m^{3} \cdot y r\right)$

(ug/yr)

4.73E+07

$1.04 E+05$
$7.64 E+05$

$7.64 E+05$

$5.14 E+05$

3.47E+08

$2.34 E+08$

$1.86 \mathrm{E}+08$

8.90E-02

4.85E-02

9.71E-01

2.27E-01
$1.08 E-03$

1.91E-03

1.83E-01

9.96E-04

9.96E-02

2.74E-02

1.16E-01

4.48E-01

$158 \mathrm{E}+00$

$1.58 E+\infty$

$9.96 E-01$
$0.00 E+00$

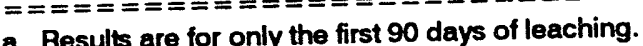

a. Results are for only the first 90 days of leaching.

b. Fraction of initial inventory released per square centimeter of specimen surface area per sectimated by

c. Not all leachate samples were analyzed for this radion

interpolating measured incremental release rates.
Only the leachate corresponding to leaching interval number three was analyzed for Pu-241. Leaching

d. Only the leachate corresponding to leaching interval number three 
Table E-11. Leach cost results for Brunswick-1 cation resin waste-form specimen leached in synthetic seawater with $\mathrm{pH} 6.4 .^{\mathrm{a}}$

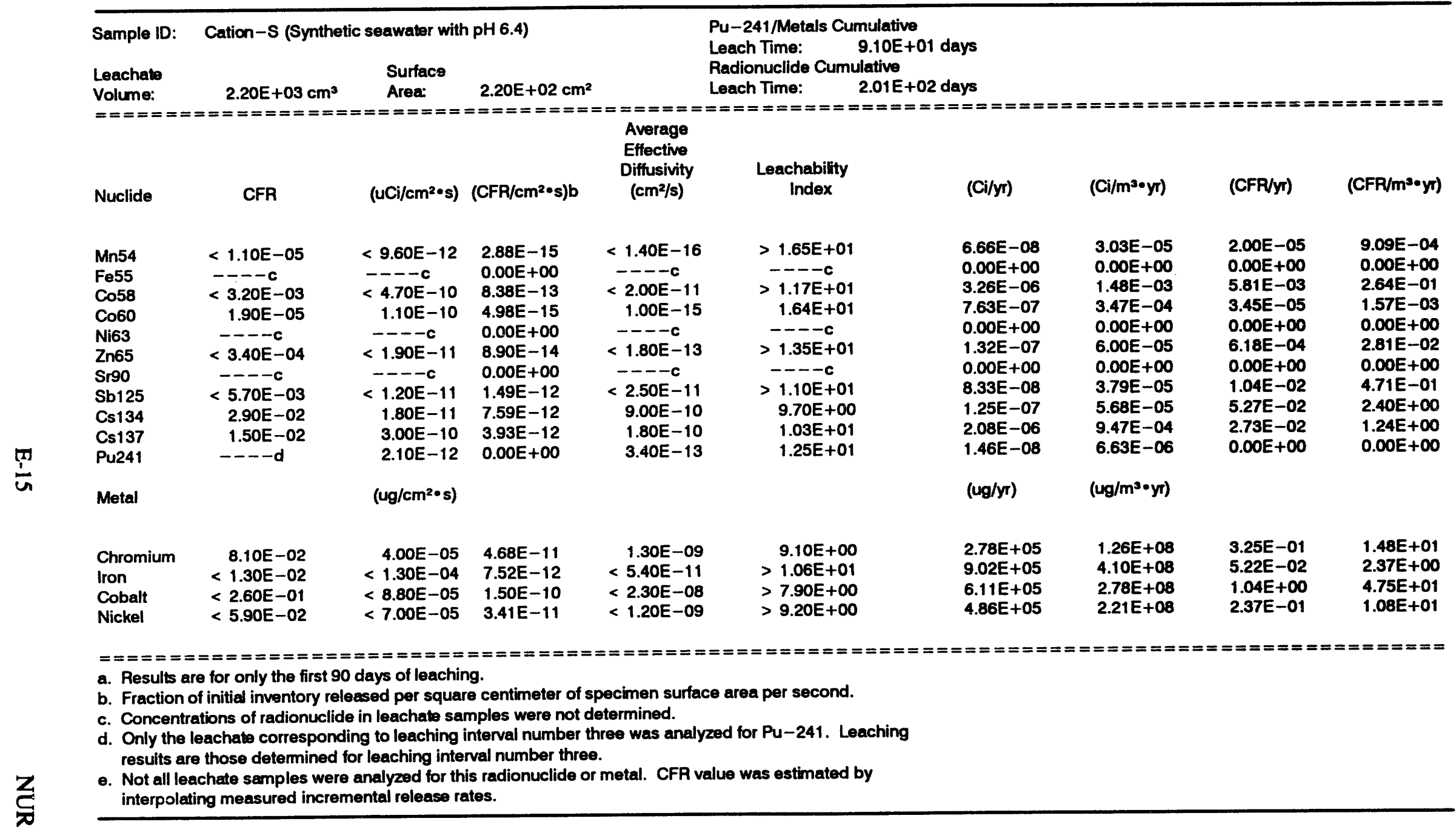




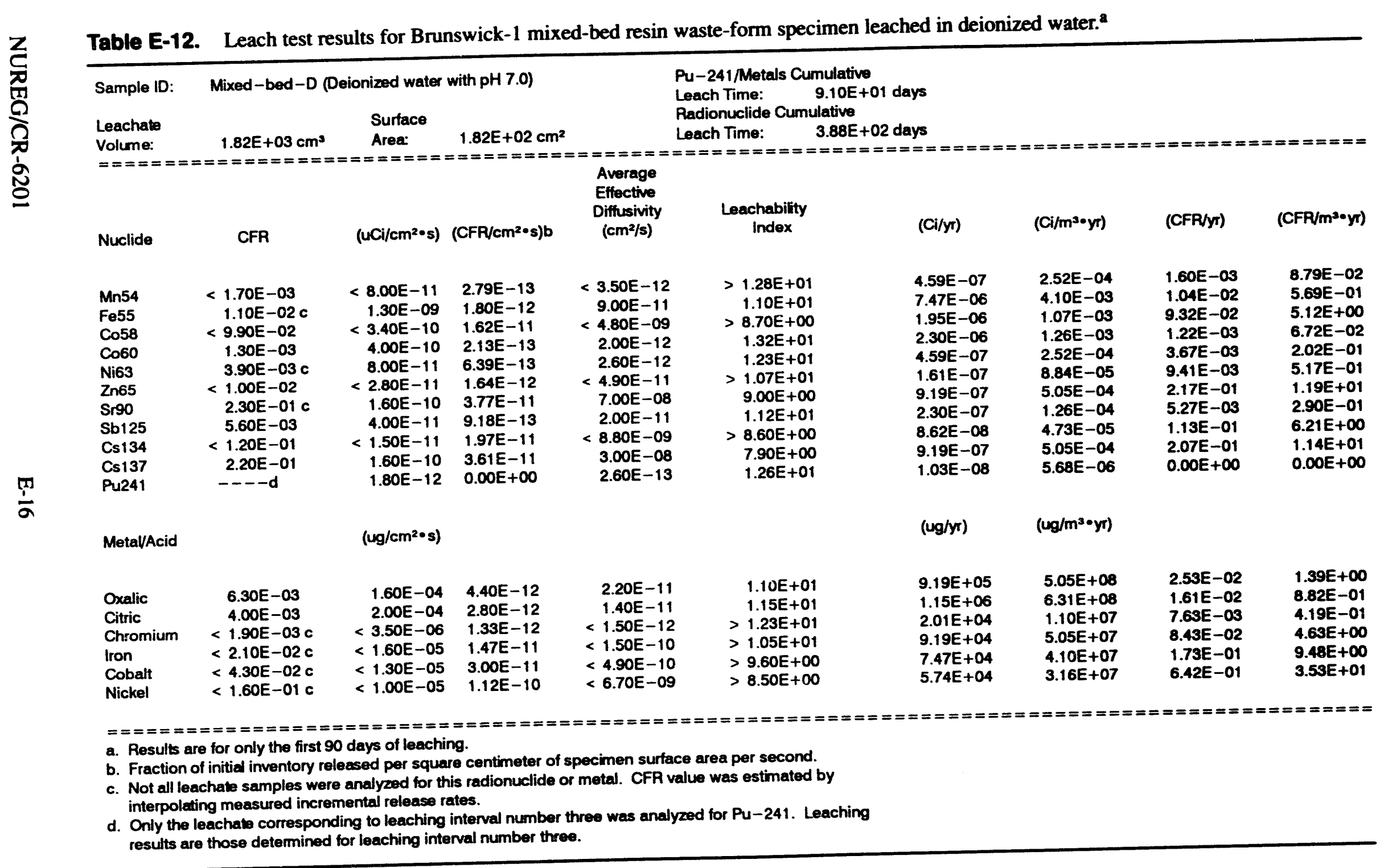


Table E-13. Leach test results for Brunswick-1 mixed-bed resin waste-form specimen leached in synthetic Barnwell groundwater with pH 10.4. ${ }^{\mathrm{a}}$

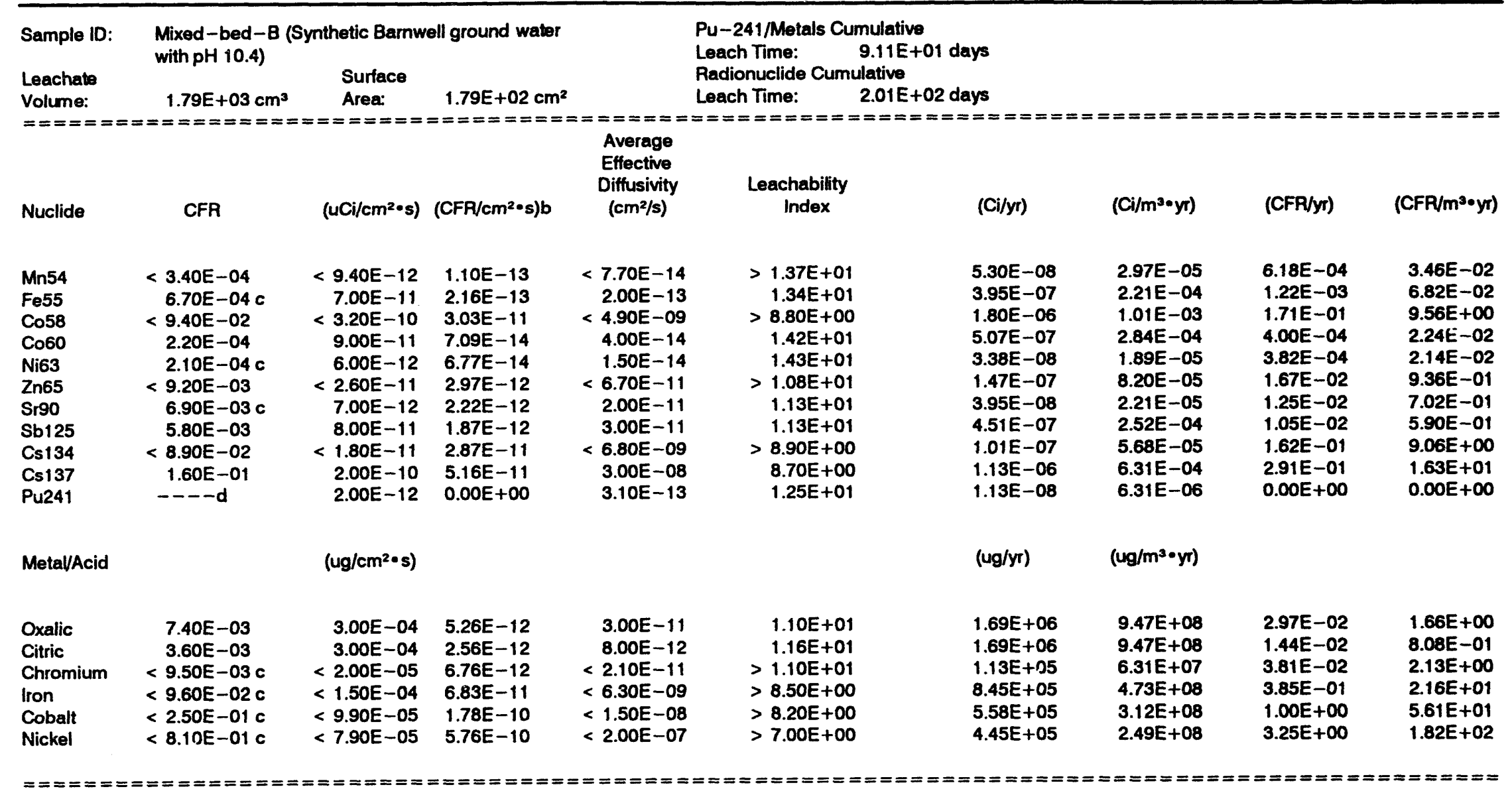

a. Results are for only the first 90 days of leaching.

b. Fraction of initial inventory released per square centimeter of specimen surface area per second.

c. Not all leachate samples were analyzed for this radionuclide or metal. CFR value was estimated by interpolating measured incremental release rates.

d. Only the leachate corresponding to leaching interval number three was analyzed for Pu-241. Leaching results are those determined for leaching interval number three. 


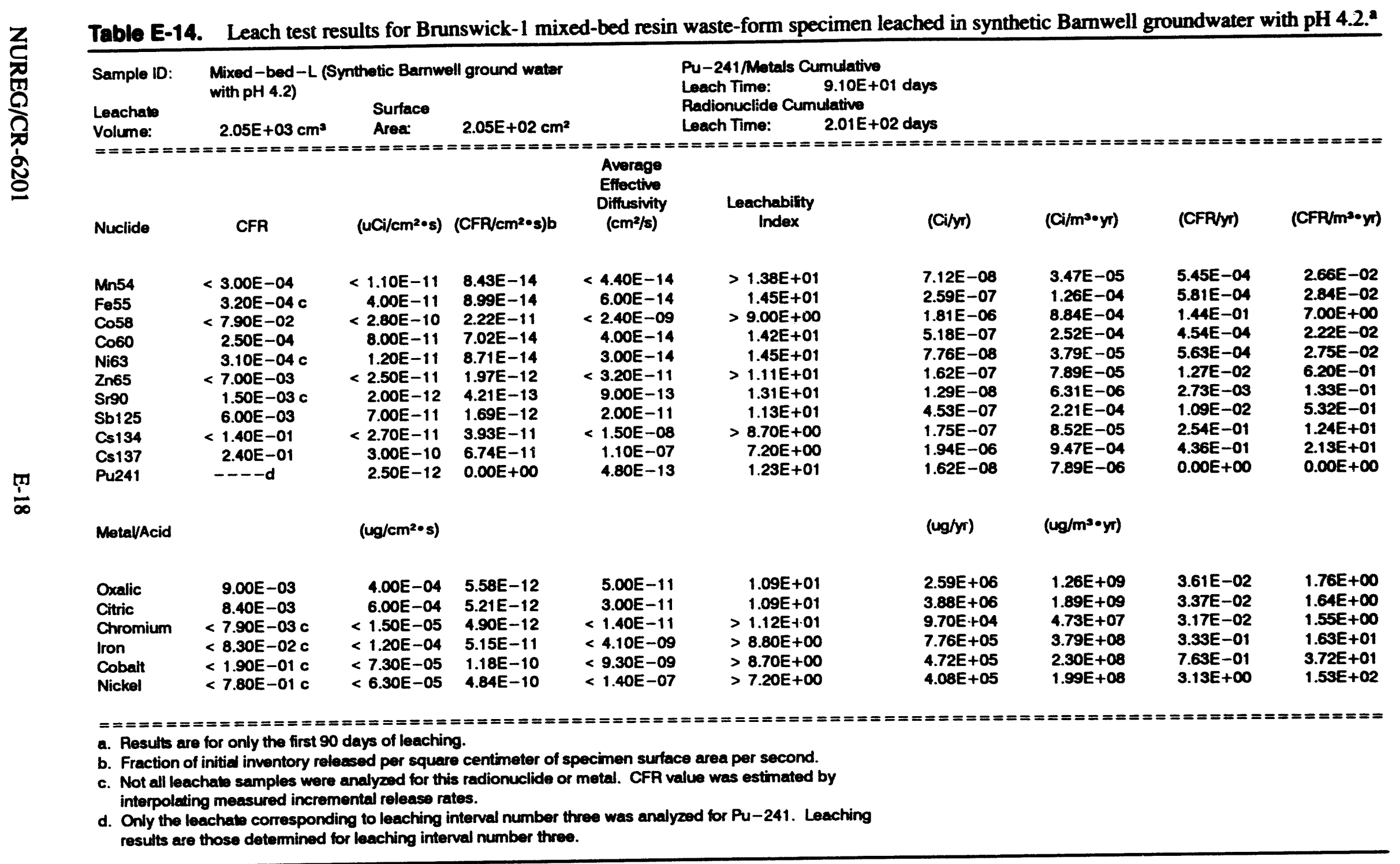


Table E-15. Leach test results for Brunswick-1 mixed-bed resin waste-form specimen leached in synthetic Hanford groundwater with pH 8.9.

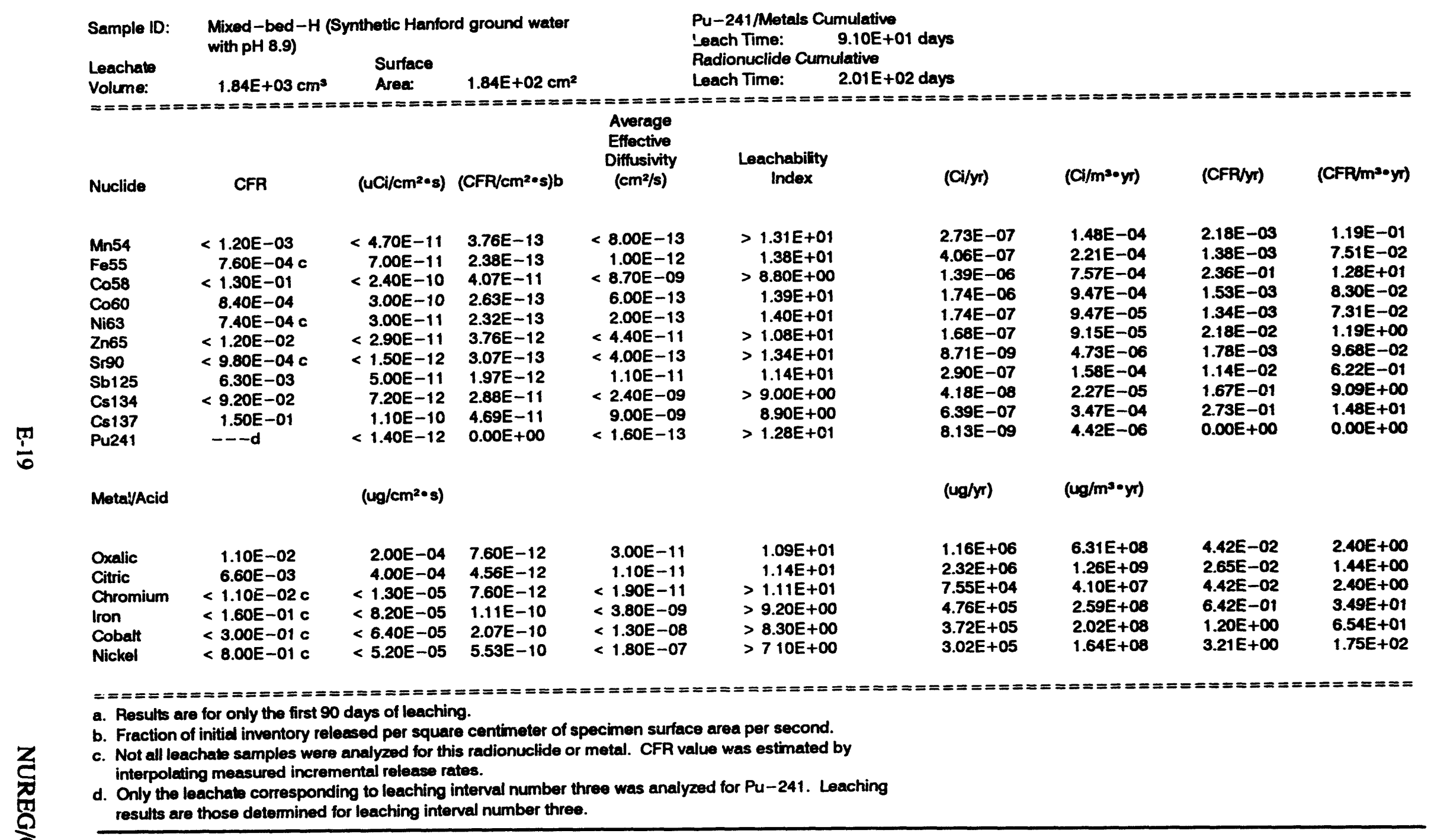


Table E-16. Leach test results for Brunswick-1 mixed-bed resin waste-form specimen leached in synthetic seawater with pH 6.4. ${ }^{2}$

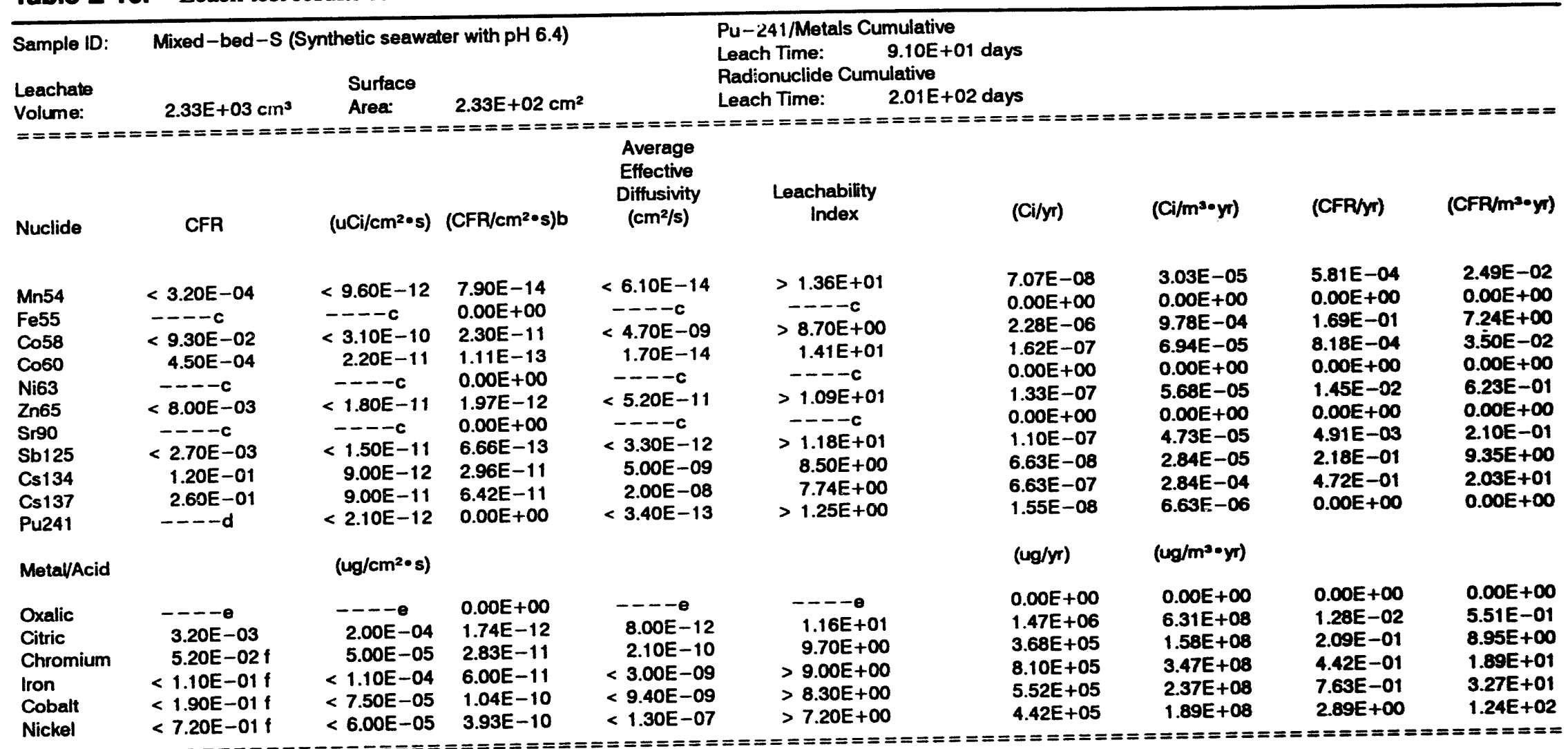

$======================$
Results are for only the first 90 days of leaching.

. Fraction of initiel inventory releesed per square centimeter of specimen surface area per second.

concentration of radionuclide in leachate samples were not determined.

d. Only the leachate corresponding to leaching interval number three was analyzed for Pu-241. Leaching

results are those determined for leaching interval number three.

Concentrations of acid in leachate samples were below detection limit.

1. Not all leechate semples were analyzed for this metal. CFR value was estimated by interpolating measured

incremental release rates. 
Table E-17. Leach test results for FitzPatrick mixed-bed resin waste-form specimen leached in deionized water. ${ }^{a}$

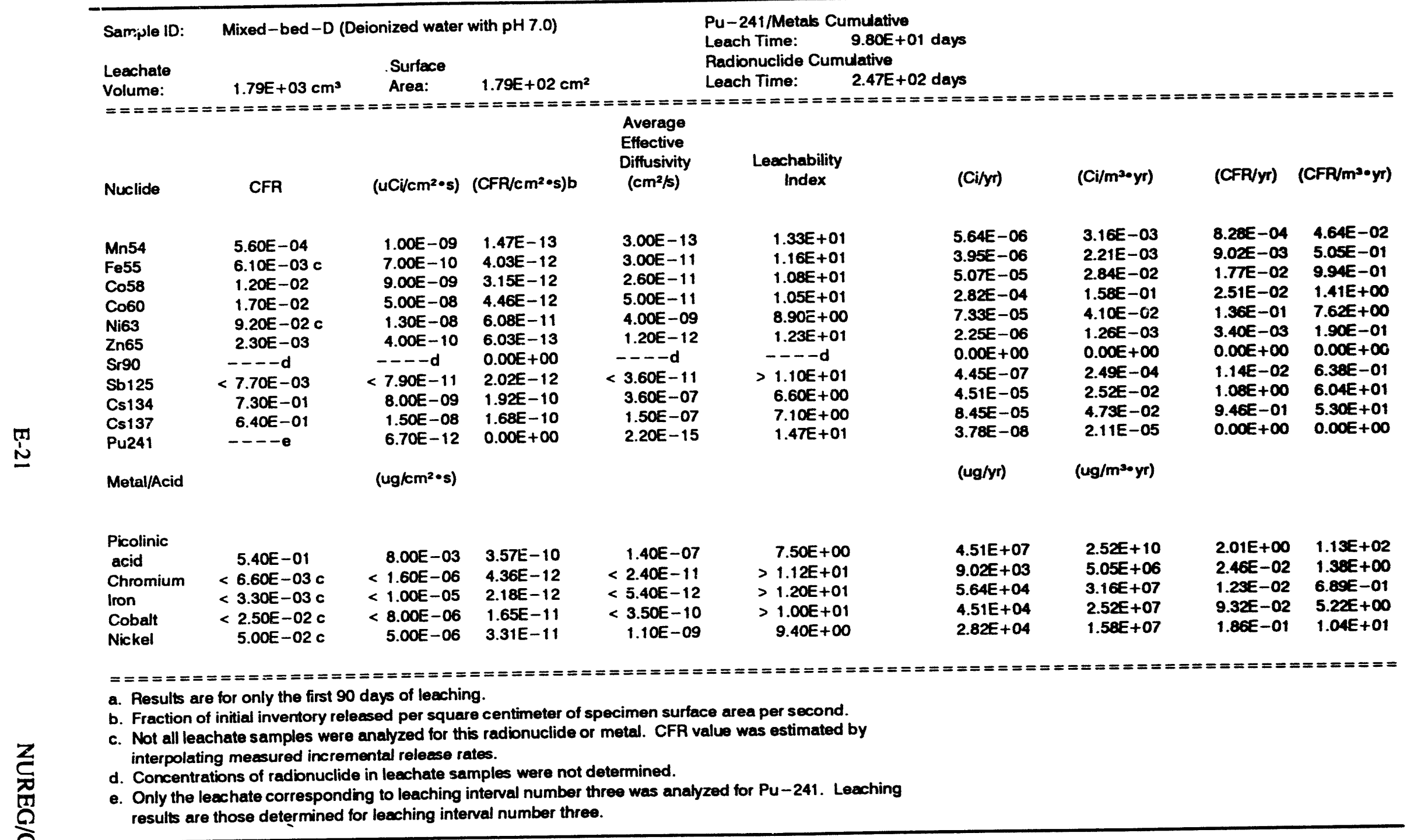


Table E-18. Leach test results for FitzPatrick mixed-bed resin waste-form specimen leached in synthetic Barnwellground water with pH 10.4. ${ }^{\mathrm{a}}$ Sample 1D: Mixed-bed-B (Synthetic Barnwell ground water with pH 10.4) $\mathrm{Pu}-241$ Metals Cumulative

$\begin{array}{ll}\text { Leachate Surface } & \text { Radionuclide Cumulative } \\ \text { Leach Time: } 9.80 E+01 \text { days }\end{array}$

Volume: $1.79 E+03 \mathrm{~cm}^{3} \quad 1.79 E+02 \mathrm{~cm}^{2}$

Leach Time:

$9.80 E+01$ days

Effective

Diffusivity Leachability

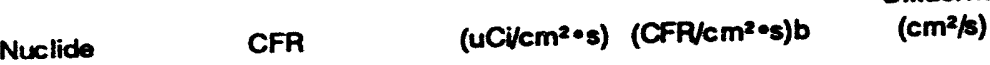

Index

$5.00 E-14$

$2.00 E-11$

1.60E-11

$3.40 E-11$

5.00E-09

$3.00 E-12$

$----d$

$<1.80 E-11$

$1.80 E-07$

$1.50 E-07$

4. $40 E-17$

$$
\begin{gathered}
1.36 E+01 \\
1.16 E+01 \\
1.10 E+01 \\
1.06 E+01 \\
9.00 E+00 \\
1.17 E+01 \\
---d \\
>1.10 E+01 \\
6.90 E+\infty \\
7.00 E+00 \\
1.64 E+01
\end{gathered}
$$

\begin{tabular}{|c|c|}
\hline 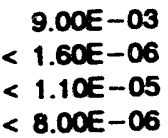 & $\begin{array}{l}4.96 E-10 \\
4.43 E-12 \\
2.18 E-12 \\
1.72 E-11\end{array}$ \\
\hline
\end{tabular}

$\left(4 \mathrm{~g} / \mathrm{cm}^{2 \cdot-s)}\right.$

Metal/Acid

$5.50 E-01 \quad 1.00 E-08 \quad 3.64 E-10$

$----6$

$\begin{array}{ll}\text { Picolinic } & \\ \text { acid } & 7.50 E-01 \\ \text { Chromium } & <6.70 \mathrm{E}-03 \mathrm{c} \\ \text { Iron } & <3.30 \mathrm{E}-03 \mathrm{c} \\ \text { Cobalt } & <2.60 \mathrm{E}-02 \mathrm{c} \\ \text { Nickel } & 5.00 \mathrm{E}-02 \mathrm{c}\end{array}$

$\begin{array}{r}1.40 E-07 \\ <2.50 E-11 \\ <6.00 E-12 \\ <3 . E 5 E-10 \\ \hline\end{array}$

$>1.12 E+01$

$>1.19 E+01$

$>1.00 E+01$

$9.50 E+00$
(Ci/yr)

$\left(\mathrm{C} / \mathrm{m}^{30} \mathrm{yr}\right)$

(CFA/yr) (CFR/mºy)

2.82E-06

$3.38 E-06$

3.95E-05

2.03E-04

$1.13 E-04$

$3.38 E-06$

$0.005+\infty 0$

4.06E-07

$3.38 E-05$

$5.64 E-05$

$5.24 E-09$

(ug/yr)

$1.58 E-03$

$1.89 E-03$

2.21E-02

$1.14 E-01$

$6.31 E-02$

$1.89 E-03$

$0.00 E+\infty 0$

2 2TE-04

$1.89 E-02$

$3.16 E-02$

$2.98 E-06$

2.05E-08 1.15E-01

$2.65 E-02 \quad 1.48 E+\infty 0$

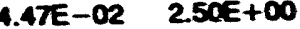

$6.34 E-02 \quad 3.55 E+\infty$

3.73E-01 2.0SE+01

$2.20 E-02 \quad 1.23 E+\infty 0$

$0.00 E+\infty 0.00 E+\infty 0$

$2.30 E-02 \quad 1.57 E+\infty 0$

$2.31 E+\infty 0 \quad 1.29 E+02$

$2.055+\infty \quad 1.15 E+\infty$

$2.05 E+\infty 00$ 1.15E+02

$0.00 E+\infty \quad 0.00 E+\infty$

$\left(u g / m^{2} \cdot y r\right)$

Pesults are for only the first 90 days of leaching.

a. Results are for only the first

b. Fraction of initial inventory relessed per square centimeler of specimen surtace area per second by

c. Not all leachate samples were analyzed for this radio

interpolating measured incremental reloase rales.

d. Concentrations of radionuclide in leachate samples wel number three wes analyzed for Pu-241. Leaching

. Only the leachale correspor for leeching interval number three. 
Table E-19. Leach test results for FitzPatrick mixed-bed resin waste-form specimen leached in synthetic Bamwell groundwater with pH 4.2.2

\begin{tabular}{|c|c|c|c|c|c|c|c|c|c|}
\hline $\begin{array}{l}\text { Sample ID: } \\
\text { Leachate } \\
\text { Volume: }\end{array}$ & $\begin{array}{l}\text { Mixed-bed-L (S } \\
\text { with } \mathrm{pH} 4.2) \\
1.80 E+03 \mathrm{~cm}^{3}\end{array}$ & $\begin{array}{l}\text { nthetic Barmive } \\
\text { Surface } \\
\text { Area: }\end{array}$ & $\begin{array}{l}\text { Il ground water } \\
1.80 E+02 \mathrm{~cm}^{2}\end{array}$ & & $\begin{array}{l}\text { Pu-241/Metals Cum } \\
\text { Leach Time: } \\
\text { Radionuclide Cumul } \\
\text { Leach Time: }\end{array}$ & $\begin{array}{l}\text { ays } \\
\text { ays }\end{array}$ & 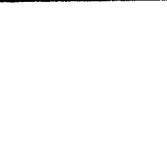 & & \\
\hline Nuclide & CFR & (uCivmem) & $\left(\mathrm{CFR} / \mathrm{cm}^{2} \cdot \mathrm{rg}\right) \mathrm{b}$ & $\begin{array}{c}====== \\
\text { Average } \\
\text { Effective } \\
\text { Diffusivity } \\
\left(\mathrm{cm}^{2} / \mathrm{s}\right)\end{array}$ & $\begin{array}{l}\text { Leachability } \\
\text { Index }\end{array}$ & (Ci/yr) & $\left(\mathrm{Ci} / \mathrm{m}^{30} \mathrm{yr}\right)$ & 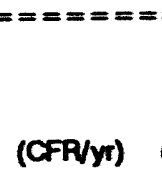 & $\left(C F P / m^{2} \cdot y\right)$ \\
\hline $\begin{array}{l}\text { Mn54 } \\
\text { Fe55 } \\
\text { Co58 } \\
\text { Co60 } \\
\text { Ni63 } \\
\text { Zn65 } \\
\text { Sr90 } \\
\text { Sb125 } \\
\text { Cs134 } \\
\text { Cs137 } \\
\text { Pu241 } \\
\text { Metal/Acid }\end{array}$ & $\begin{array}{l}7.20 E-04 \\
----c \\
1.20 E-02 \\
1.80 E-02 \\
8.70 E-02 \mathrm{~d} \\
5.20 \mathrm{E}-03 \\
----c \\
<7.50 \mathrm{E}-03 \\
6.90 \mathrm{E}-01 \\
6.10 \mathrm{E}-01 \\
----0\end{array}$ & $\begin{array}{c}2.00 E-09 \\
----c \\
1.00 E-08 \\
5.00 E-08 \\
1.30 E-08 \\
1.30 E-09 \\
----c \\
<9.00 E-11 \\
8.00 E-09 \\
1.40 E-08 \\
3.10 E-12 \\
\\
(\text { ug/cm } \\
\text {. } \cdot \mathrm{s})\end{array}$ & $\begin{array}{l}4.72 E-13 \\
0.00 E+00 \\
7.86 E-12 \\
1.18 E-11 \\
5.70 E-11 \\
3.41 E-12 \\
0.00 E+00 \\
4.92 E-12 \\
4.52 E-10 \\
4.00 E-10 \\
0.00 E+00\end{array}$ & $\begin{array}{c}8.00 E-13 \\
----c \\
2.20 E-11 \\
4.60 E-11 \\
4.00 E-09 \\
4.00 E-12 \\
----c \\
<2.30 E-11 \\
2.50 E-07 \\
1.90 E-07 \\
5.00 E-16\end{array}$ & $\begin{array}{c}1.34 E+01 \\
----c \\
1.08 E+01 \\
1.05 E+0 ! \\
9.20 E+00 \\
1.16 E+01 \\
----c \\
>1.10 E+01 \\
6.70 E+00 \\
6.80 E+\infty 0 \\
1.53 E+01\end{array}$ & $\begin{array}{l}1.14 E-05 \\
0.00 E+00 \\
5.69 E-05 \\
2.84 E-04 \\
7.39 E-05 \\
7.39 E-06 \\
0.00 E+00 \\
5.12 E-07 \\
4.55 E-05 \\
7.96 E-05 \\
1.76 E-08 \\
(\text { ug/yr) }\end{array}$ & $\begin{array}{l}6.31 E-03 \\
0.00 E+00 \\
3.16 E-02 \\
1.58 E-01 \\
4.10 E-02 \\
4.10 E-03 \\
0.00 E+00 \\
2.84 E-04 \\
2.52 E-02 \\
4.42 E-02 \\
9.78 E-06 \\
\left(u g / m^{20} y r\right)\end{array}$ & $\begin{array}{l}2.68 E-03 \\
0.00 E+00 \\
4.47 E-02 \\
6.71 E-02 \\
3.24 E-01 \\
1.94 E-02 \\
0.00 E+00 \\
2.80 E-02 \\
2.57 E+\infty 0 \\
2.27 E+\infty 0 \\
0.00 E+\infty\end{array}$ & $\begin{array}{l}1.49 E-01 \\
0.00 E+\infty 0 \\
2.48 E+\infty 0 \\
3.72 E+\infty 0 \\
1.60 E+01 \\
1.00 E+\infty 0 \\
0.00 E+\infty 0 \\
1.55 E+\infty 0 \\
1.45 E+02 \\
1.26 E+02 \\
0.00 E+\infty 0\end{array}$ \\
\hline $\begin{array}{l}\text { Picolinic } \\
\text { acid } \\
\text { Chromium } \\
\text { Iron } \\
\text { Cobalt } \\
\text { Nickel }\end{array}$ & $\begin{aligned} & 4.20 E-01 \\
< & 6.70 E-03 d \\
< & 5.10 E-03 d \\
< & 2.50 E-02 d \\
& 4.80 E-02 d\end{aligned}$ & $\begin{array}{r}7.00 E-03 \\
<\quad 1.60 E-06 \\
<2.00 E-05 \\
<\quad 7.90 E-06 \\
4.00 E-06\end{array}$ & $\begin{array}{l}2.75 E-10 \\
4.39 E-12 \\
3.34 E-12 \\
1.64 E-11 \\
3.15 E-11\end{array}$ & $\begin{array}{r}7.00 E-08 \\
<2.50 E-11 \\
<2.20 E-11 \\
<3.60 E-10 \\
7.00 E-10\end{array}$ & $\begin{aligned} & 7.50 E+\infty 0 \\
> & 1.12 E+01 \\
> & 1.16 E+01 \\
> & 1.00 E+01 \\
& 9.50 E+00\end{aligned}$ & $\begin{array}{l}3.98 E+07 \\
9.10 E+03 \\
1.14 E+05 \\
4.49 E+04 \\
2.27 E+04\end{array}$ & $\begin{array}{l}2.21 E+10 \\
5.05 E+06 \\
6.31 E+07 \\
2.49 E+07 \\
1.26 E+07\end{array}$ & $\begin{array}{l}1.57 E+00 \\
2.50 E-02 \\
1.90 E-02 \\
9.32 E-02 \\
1.79 E-01\end{array}$ & $\begin{array}{l}8.6 S E+01 \\
1.39 E+\infty 0 \\
1.05 E+\infty \\
5.17 E+\infty \\
9.93 E+\infty\end{array}$ \\
\hline
\end{tabular}

Results are for only the first 90 days of leaching.

b. Fraction of initial inventory released per square centimeter of specimen surface area per second.

c. Concentrations of radionuclide in leachate samples were not determined.

d. Not all leachate samples were analyzed for this radionuclide or metal. CFR value was estimated by

interpolating measured incremental releese rates.

6. Only the leachate corresponding to leaching interval number three was analyzed for Pu-241. Leaching results are those determined for lesching interval number three. 
Table E-20. Leach test results for FitzPatrick mixed-bed resin waste-form specimen leached in synthetic Hanford groundwater with pH 8.9.

Mixed-bed-H (Synthetic Hantord ground water Pu-241/Metals Cumulative

Sample ID: Mixed-bed-H (Synthetic Hantord ground water $\quad$ Lu-241/Metals Cumulative

with pH 8.9) Surface Radionuclide Cumulative

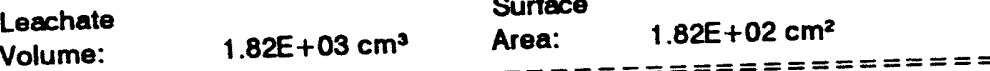

Leach Time: $\quad 9.79 E+01$ days

$==+=0=+=0=+=+=0=+$ Average

Average

\begin{tabular}{|c|c|c|c|c|c|c|c|c|c|}
\hline Nuclide & CFA & $\left(\mathrm{uCi} / \mathrm{cm}^{2 \cdot s}\right)$ & $\left(C F R / c^{2} \cdot s\right) b$ & $\begin{array}{l}\text { Diffusivity } \\
\left(\mathrm{cm}^{2} / \mathrm{s}\right)\end{array}$ & $\begin{array}{l}\text { Leachability } \\
\text { Index }\end{array}$ & (Ci/yr) & $\left(\mathrm{Ci} / \mathrm{m}^{\mathbf{3} \bullet} \mathrm{yr}\right)$ & (CFR/yr) & (CFR/mavyr) \\
\hline $\begin{array}{l}\text { Mn54 } \\
\text { Fe55 } \\
\text { Co58 } \\
\text { Co60 } \\
\text { Ni63 } \\
\text { Zn65 } \\
\text { Sr90 } \\
\text { Sb125 } \\
\text { Cs134 } \\
\text { Cs137 } \\
\text { Pu241 } \\
\text { Metal/Acid }\end{array}$ & $\begin{array}{l}1.20 E-04 \\
6.30 E-03 \mathrm{c} \\
8.80 \mathrm{E}-03 \\
1.30 \mathrm{E}-02 \\
9.80 \mathrm{E}-02 \mathrm{c} \\
1.60 \mathrm{E}-03 \\
----\mathrm{d} \\
<5.60 \mathrm{E}-03 \\
6.60 \mathrm{E}-01 \\
5.90 \mathrm{-}-01 \\
----0\end{array}$ & $\begin{array}{l}3.00 E-10 \\
5.00 E-10 \\
6.00 E-09 \\
3.00 E-08 \\
1.50 E-08 \\
2.00 E-10 \\
----d \\
<6.90 E-11 \\
6.00 E-09 \\
1.10 E-08 \\
5.4 C \equiv-13 \\
\\
(\text { ug/cm } \\
\end{array}$ & $\begin{array}{l}7.81 E-14 \\
4.10 E-12 \\
5.73 E-12 \\
8.46 E-12 \\
6.38 E-11 \\
1.04 E-12 \\
0.00 E+00 \\
3.64 E-12 \\
4.29 E-10 \\
3.84 E-10 \\
0.00 E+00\end{array}$ & $\begin{array}{l}1.00 E-14 \\
2.00 E-11 \\
1.00 E-11 \\
2.00 E-11 \\
4.00 E-09 \\
2.30 E-13 \\
----d \\
<1.80 E-11 \\
1.80 E-07 \\
1.50 E-07 \\
1.50 E-17\end{array}$ & $\begin{array}{c}1.46 E+01 \\
1.13 E+01 \\
1.11 E+01 \\
1.08 E+01 \\
8.90 E+00 \\
1.29 E+01 \\
----d \\
>1.12 E+01 \\
6.90 E+00 \\
7.00 E+00 \\
1.68 E+01\end{array}$ & $\begin{array}{l}1.72 E-06 \\
2.87 E-06 \\
3.44 E-05 \\
1.72 E-04 \\
8.60 E-05 \\
1.15 E-06 \\
0.00 E+00 \\
3.96 E-07 \\
3.44 E-05 \\
6.31 E-05 \\
3.10 E-09 \\
(4 \mathrm{~g} / \mathrm{yr})\end{array}$ & $\begin{array}{l}9.47 E-04 \\
1.58 E-03 \\
1.89 E-02 \\
9.47 E-02 \\
4.73 E-02 \\
6.31 E-04 \\
0.00 E+00 \\
2.18 E-04 \\
1.89 E-02 \\
3.47 E-02 \\
1.70 E-06 \\
\left.\text { (ug/m } / \mathrm{m}^{30} \mathrm{yT}\right)\end{array}$ & $\begin{array}{l}4.48 E-04 \\
2.35 E-02 \\
3.28 E-02 \\
4.85 E-02 \\
3.66 E-01 \\
5.97 E-03 \\
0.00 E+00 \\
2.09 E-02 \\
2.46 E+00 \\
2.20 E+00 \\
0.00 E+\infty\end{array}$ & $\begin{array}{l}2.46 E-02 \\
1.29 E+00 \\
1.81 E+\infty 0 \\
2.67 E+\infty 0 \\
2.01 E+01 \\
3.29 E-01 \\
0.00 E+\infty 0 \\
1.15 E+00 \\
1.36 E+02 \\
1.21 E+02 \\
0.00 E+00\end{array}$ \\
\hline $\begin{array}{l}\text { Picolinic } \\
\text { acid } \\
\text { Chromium } \\
\text { Iron } \\
\text { Cobalt } \\
\text { Nickel }\end{array}$ & $\begin{aligned} & 4.50 E-01 \\
< & 6.50 E-03 c \\
< & 4.30 E-03 c \\
< & 2.50 E-02 c \\
& 5.10 E-02 c\end{aligned}$ & 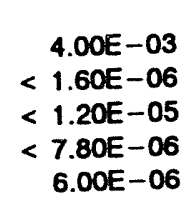 & $\begin{array}{l}2.93 E-10 \\
4.23 E-12 \\
2.80 E-12 \\
1.65 E-11 \\
3.32 E-11\end{array}$ & 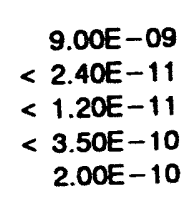 & $\begin{array}{r}8.30 E+00 \\
>1.12 E+01 \\
>1.15 E+01 \\
>1.00 E+01 \\
1.02 E+01\end{array}$ & $\begin{array}{l}2.29 E+07 \\
9.17 E+03 \\
6.88 E+04 \\
4.47 E+04 \\
3.44 E+04\end{array}$ & $\begin{array}{l}1.26 E+10 \\
5.05 E+06 \\
3.79 E+07 \\
2.46 E+07 \\
1.89 E+07\end{array}$ & $\begin{array}{l}1.68 E \div 00 \\
2.43 E-02 \\
1.60 E-02 \\
9.33 E-02 \\
1.90 E-01\end{array}$ & $\begin{array}{l}9.24 E+01 \\
1.35 E+00 \\
8.83 E-01 \\
5.13 E+00 \\
1.05 E+01\end{array}$ \\
\hline
\end{tabular}

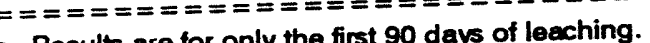

of specimen surface area per second.

b. Fraction of initial inventory released per square centimeter of specimen suraclide was estimated by

c. Not all leachate samples were analyzed for this radion

interpolating measured incremental release rates.

d. Concentrations of radionuclide in leachate samples were not deter was analyzed for Pu-241. Leaching

e. Only the leachate corresponding to leaching interval number three 
Table E-21. Leach test results for FitzPatrick mixed-bed resin waste-form specimen leached in synthetic seawater with $\mathrm{pH} 6.4 .^{\mathrm{a}}$

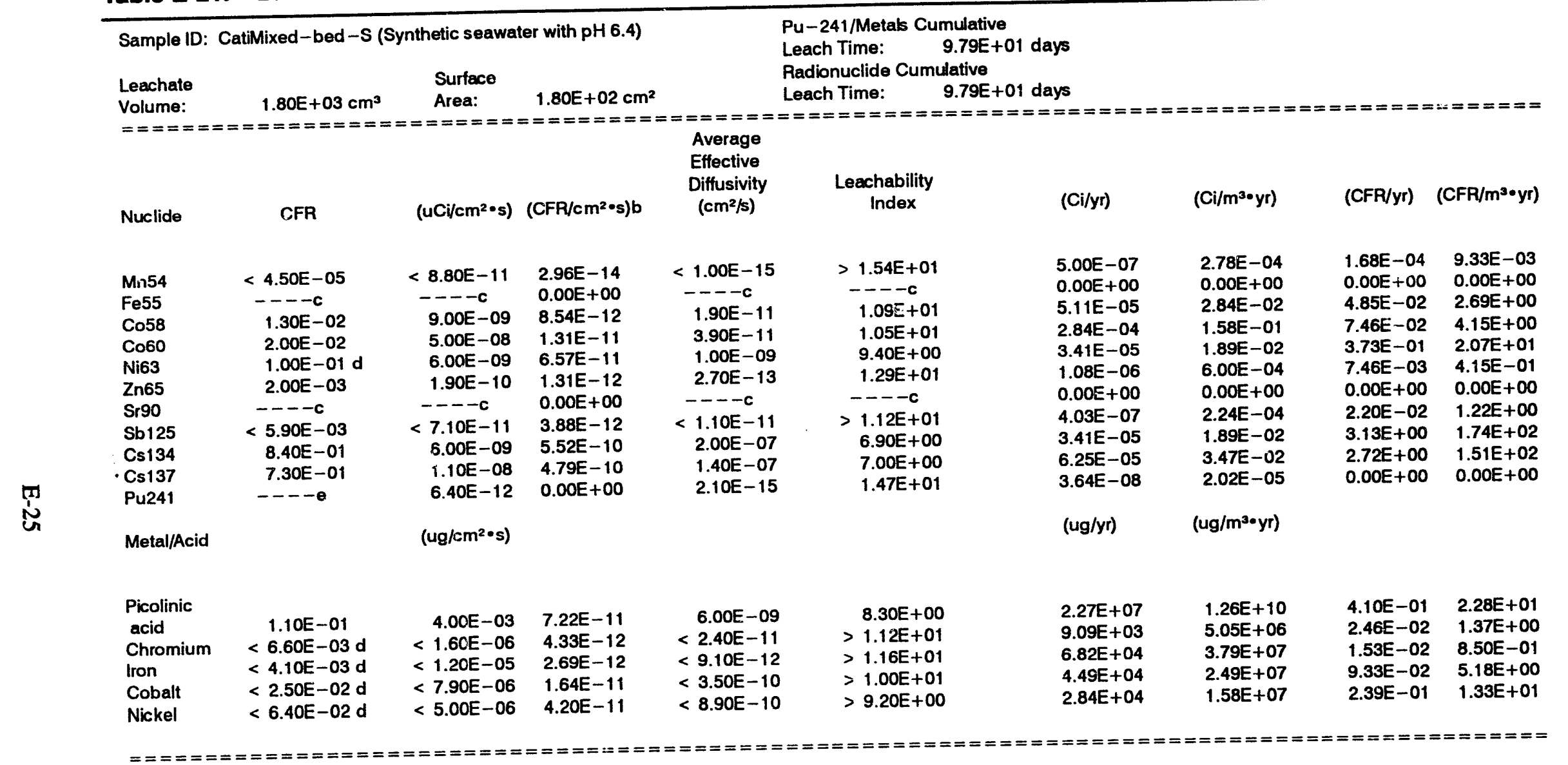

a. Results are for only the first 90 days of leaching.

b. Fraction of initial inventory released per square centimeter of specimen surface area per second.

b. Fraction of initial inventory released per square centimeter of specimetilis leachate samples were analyzed for this radionuclide or metas estimated by

interpolating measured incremental release rates.

Concentrations of radionuclide in leachate samples were not determined.

d. Concentrations of radionuclide in lo leaching interval number three was analyzed for Pu-241. Leaching

results are those determined for leaching interval number three. 
Table E-22. Leach test results for baked FitzPatrick mixed-bed resin waste-form specimen leached in deionized water. ${ }^{\mathrm{a}}$

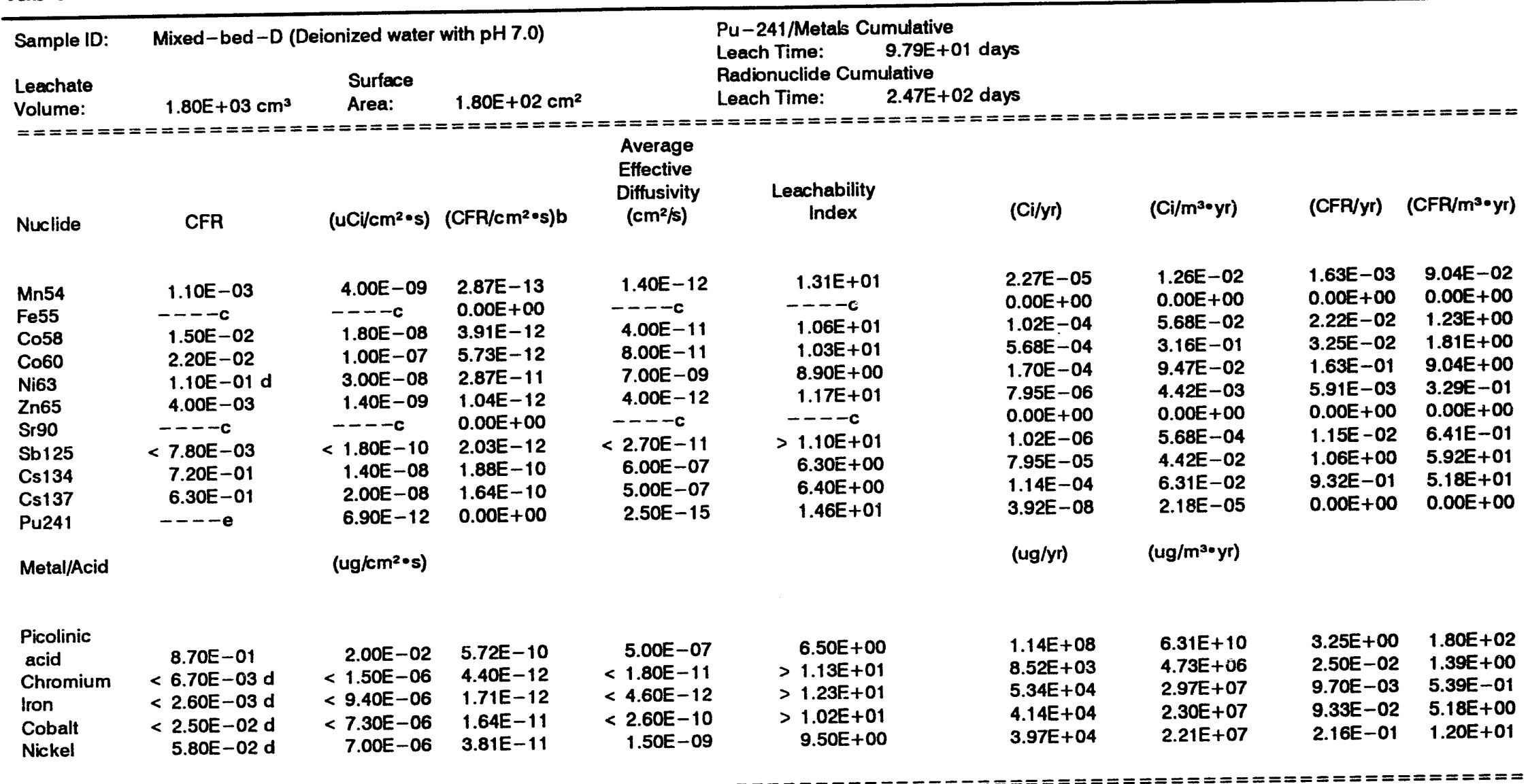

a. Results are for only the first 90 days of leaching.

a. Results are lor only the firsecen surface area per second.

b. Fraction of initial inventory released per square centimeter of specimetic this radionuclide or metal. CFR value was estimated by

c. Not all leachate samples were analyzed for this radio

Concentrations of radionuclide in leachate samples were not determined.

. Only the leachate corresponding to leaching interval number three was analyzed for Pu-241. Leaching

results are those determined for leaching interval number thiee. 
Table E-23. Leach test results for baked FitzPatrick mixed-bed resin waste-form specimen leached in synthetic Barnwell groundwater with pH 4.2. ${ }^{\mathrm{a}}$

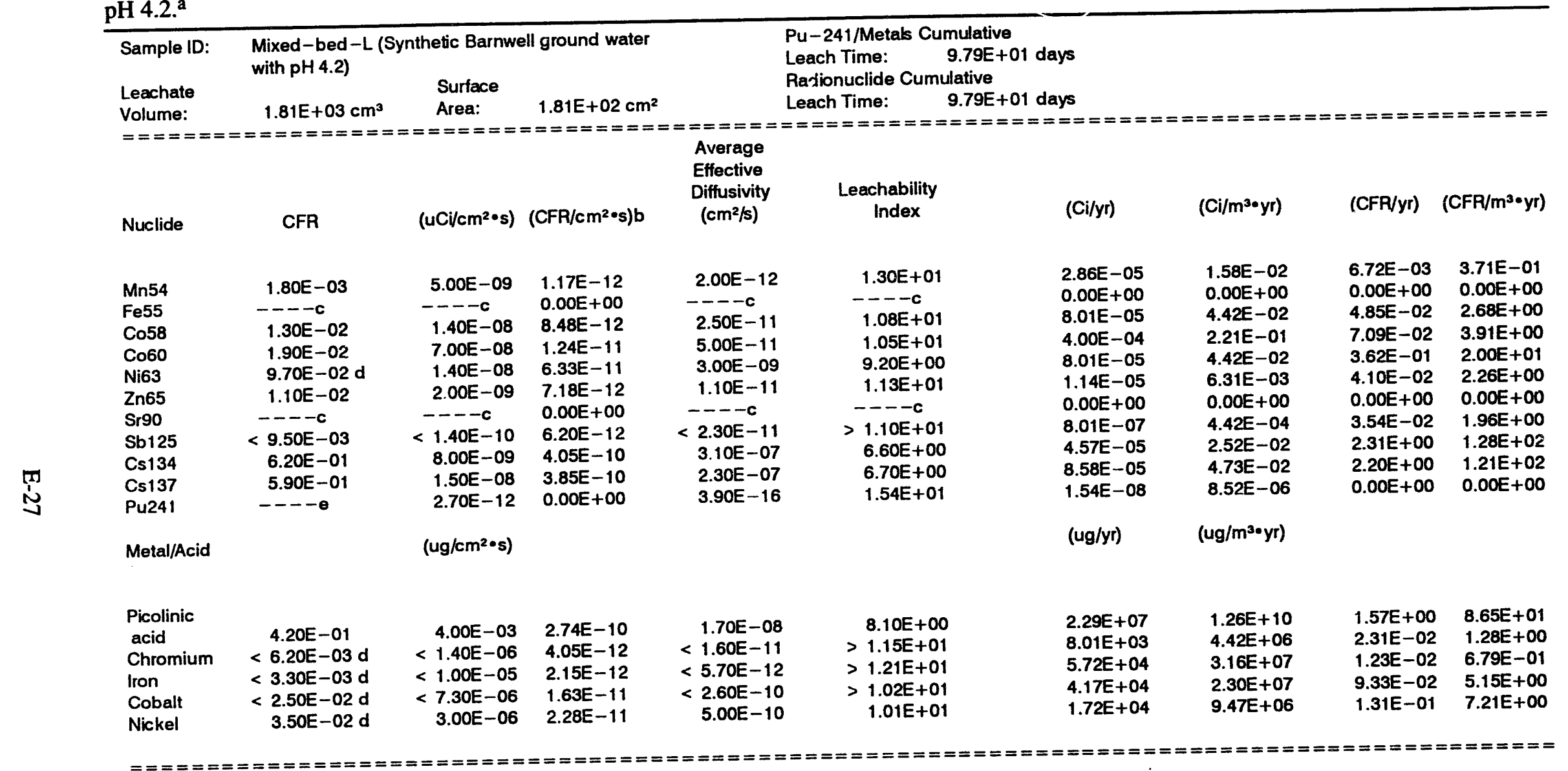

a. Results are for only the first 90 days of leaching.

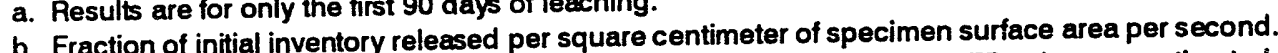

b. Fraction of initial inventory released per square centimeter of specimen surface area per seconation

c. Not all leachate samples were analyzed for this radior

d. Concentrations of radionuclide in leachate samples were not determined.

e. Only the leachate corresponding to leaching interval number three was analyzed for Pu-241. Leaching

results are thcse determined for leaching interval number three. 
Table E-24. Peach Bottom sample \#4 cumulative fraction releases, release rates, effective diffusivities, and leachability indexes.

FILE NAME: $C-14$

SAMPLE ID: PEACHBOTTOM \#4

\begin{tabular}{|c|c|c|c|c|c|c|c|c|c|}
\hline$\underset{\text { ID }}{\text { LEACH }}$ & $\begin{array}{l}\text { CUMULATIVE } \\
\text { LEACH TIME } \\
\text { (day) }\end{array}$ & $\begin{array}{l}\text { ACTVIY } \\
\text { LEACHED } \\
\text { (LCi) }\end{array}$ & $\begin{array}{l}\text { RELEASE } \\
\text { RATE } \\
\text { (UCI.cm-2.9- }\end{array}$ & $\begin{array}{l}\text { RELEASE } \\
\text { RATE } \\
(\mathrm{cm}-2 \cdot 3-1)\end{array}$ & $\begin{array}{l}\text { AELEASE } \\
\text { RATE } \\
(\text { Cl•yr-1) }\end{array}$ & $\begin{array}{l}\text { INCAEMENT } \\
\text { RELEASE }\end{array}$ & $\begin{array}{l}\text { CUMULATIVE } \\
\text { RELEASE }\end{array}$ & $\begin{array}{l}\text { EFFECTIVE } \\
\text { DIFFUSIVIT } \\
\text { (cmeas-1) }\end{array}$ & $\begin{array}{l}\text { IEACH } \\
\text { INDEX }\end{array}$ \\
\hline$=-9$ & $1 \mathrm{~m}=\mathrm{x}=\mathrm{m}$ & $\Rightarrow=0$ & c-m-n=m- & 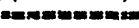 & & 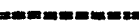 & & & \\
\hline $\begin{array}{l}\text { 1. (30s) } \\
\text { 2. (2hr) } \\
\text { 3. (7hr) } \\
\text { 4. (1d) } \\
\text { 5. (2d) } \\
\text { 6. (3d) } \\
\text { 7. (4d) } \\
\text { 8. (5d) }\end{array}$ & $\begin{array}{l}3.47 E-\infty 1 \\
8.44 E-\infty \\
2.03 E-01 \\
1.00 E+\infty \\
2.00 E+\infty \\
3.00 E+\infty \\
4.00 E+\infty \\
5.00 E+\infty\end{array}$ & $\begin{array}{l}0.01 E-\infty \\
4.40 E-\infty \\
1.04 E-\infty \\
1.80 E-\infty \\
7.38 E-\infty \\
6.05 E-\infty \\
3.56 E-\infty \\
2.26 E-\infty\end{array}$ & $\begin{array}{l}3.00 E-\infty \\
3.73 E-\infty \\
1.80 E-10 \\
5.40 E-10 \\
4.51 E-10 \\
2.05 E-\infty \\
1.08 E-\infty\end{array}$ & $\begin{array}{l}3.40 E-11 \\
3.34 E-12 \\
1.70 E-13 \\
4.92 E-13 \\
4.04 E-13 \\
2.37 E-12 \\
1.51 E-12\end{array}$ & $\begin{array}{l}-\overline{-1.02 E-04} \\
1.83 E-\infty 6 \\
0.30 E-07 \\
2.70 E-\infty \\
2.21 E-\infty \\
1.30 E-\infty \\
8.27 E-\infty\end{array}$ & $\begin{array}{l}-\overline{3.94 E-\infty} \\
0.36 E-\infty \\
1.61 E-\infty \\
6.61 E-\infty \\
5.42 E-\infty \\
3.19 E-\infty \\
2.03 E-\infty\end{array}$ & $\begin{array}{l}-\overline{-}-\overline{0}-\infty \\
4.88 E-\infty 5 \\
5.04 E-\infty 5 \\
5.70 E-\infty 5 \\
0.24 E-\infty 5 \\
9.43 E-\infty 5 \\
1.15 E-04\end{array}$ & $\begin{array}{l}--\overline{1.32 E-13} \\
9.91 E-15 \\
8.77 E-17 \\
1.81 E-15 \\
2.07 E-15 \\
1.01 E-13 \\
5.24 E-14\end{array}$ & $\begin{array}{l}-\overline{-19 E+01} \\
1.40 E+01 \\
1.01 E+01 \\
1.47 E+01 \\
1.47 E+01 \\
1.30 E+01 \\
1.33 E+01\end{array}$ \\
\hline & tandard De & $\begin{array}{l}\text { Mean: } \\
\text { Lation: }\end{array}$ & $\begin{array}{l}0.89 E-\infty \\
1.32 E-\infty 8\end{array}$ & $\begin{array}{l}0.17 E-12 \\
1.18 E-11\end{array}$ & $\begin{array}{l}3.39 E-\infty 5 \\
0.47 E-\infty\end{array}$ & & & $\begin{array}{l}4.27 E-14 \\
5.01 E-14\end{array}$ & $\begin{array}{l}1.41 E+01 \\
1.07 E+\infty\end{array}$ \\
\hline
\end{tabular}

FILE NAME: Fe-55 SAMPLE ID: PEACH BOTTOM *4

\begin{tabular}{|c|c|c|c|c|c|c|c|c|c|}
\hline$\underset{\text { ID }}{\text { LEACH }}$ & $\begin{array}{l}\text { CUMULATIVE } \\
\text { LEACH TIME } \\
\text { (days) }\end{array}$ & $\begin{array}{l}\text { ACTIMTY } \\
\text { LEACHED } \\
\text { (LCI) }\end{array}$ & $\begin{array}{l}\text { RELEASE } \\
\text { RATE } \\
\text { (UCl.cm-2.s - }\end{array}$ & $\begin{array}{l}\text { RELEASE } \\
\text { RATE } \\
\left(\mathrm{cm}-2 \cdot \mathrm{s}^{-1}\right)\end{array}$ & $\begin{array}{l}\text { RELEASE } \\
\text { RATE } \\
(\text { Ci・yr-1) }\end{array}$ & $\begin{array}{l}\text { INCREMEN } \\
\text { RELEASE }\end{array}$ & $\begin{array}{l}\text { CUMU } \\
\text { RELE }\end{array}$ & $\begin{array}{l}\text { EFFECTIVE } \\
\text { DIFFUSIVIT } \\
\left(\mathrm{cm}^{2} \cdot \mathrm{g}^{-1}\right)\end{array}$ & $\begin{array}{l}\text { LEACH } \\
\text { INDEX }\end{array}$ \\
\hline & & & & - & & & & & \\
\hline $\begin{array}{l}\text { 1. }(30 \mathrm{~s}) \\
\text { 2. (2hr) } \\
\text { 3. (7hrr) } \\
\text { 4. (1d) } \\
\text { 5. (2d) } \\
\text { 6. (3d) } \\
\text { 7. (4d) } \\
\text { 8. (5d) }\end{array}$ & $\begin{array}{l}3.47 E-04 \\
8.44 E-\infty 2 \\
2.03 E-01 \\
1.00 E+\infty \\
2.00 E+\infty \\
3.00 E+\infty \\
4.00 E+\infty \\
5.00 E+\infty\end{array}$ & $\begin{array}{l}1.74 E-\infty \\
8.02 E-\infty \\
1.88 E-\infty \\
1.09 E-\infty \\
1.94 E-\infty 5 \\
1.41 E-04 \\
7.23 E-\infty 4 \\
5.53 E-\infty 4\end{array}$ & $\begin{array}{l}7.11 E-\infty \\
6.73 E-10 \\
1.78 E-10 \\
1.44 E-12 \\
1.05 E-11 \\
5.38 E-11 \\
4.12 E-11\end{array}$ & $\begin{array}{l}-\overline{4.69 E-10} \\
4.44 E-11 \\
1.17 E-11 \\
0.50 E-14 \\
6.92 E-13 \\
3.55 E-12 \\
2.71 E-12\end{array}$ & $\begin{array}{l}-\overline{3.49 E-\infty 6} \\
3.31 E-\infty \\
8.73 E-07 \\
7.08 E-\infty \\
5.15 E-\infty \\
2.64 E-07 \\
2.02 E-07\end{array}$ & $\begin{array}{l}5.29 E-04 \\
1.24 E-04 \\
1.11 E-04 \\
1.28 E-\infty \\
0.29 E-\infty \\
4.76 E-\infty \\
3.65 E-\infty 6\end{array}$ & $\begin{array}{l}-\overline{5.20 E-04} \\
6.53 E-04 \\
7.64 E-04 \\
7.66 E-04 \\
7.75 E-04 \\
8.23 E-04 \\
8.59 E-04\end{array}$ & $\begin{array}{l}2.37 E-11 \\
1.74 E-12 \\
4.18 E-13 \\
0.75 E-17 \\
6.08 E-15 \\
2.25 E-13 \\
1.70 E-13\end{array}$ & $\begin{array}{l}-\overline{1.06 E+01} \\
1.18 E+01 \\
1.24 E+01 \\
1.62 E+01 \\
1.42 E+01 \\
1.26 E+01 \\
1.28 E+01\end{array}$ \\
\hline & tandard D & $\begin{array}{l}\text { Mean: } \\
\text { vation: }\end{array}$ & $\begin{array}{l}1.15 E-\infty \\
2.44 E-\infty\end{array}$ & $\begin{array}{l}7.60 E-11 \\
1.61 E-10\end{array}$ & $\begin{array}{l}5.60 E-\infty \\
1.20 E-\infty\end{array}$ & & & $\begin{array}{l}3.75 E-12 \\
8.16 E-12\end{array}$ & $\begin{array}{l}1.29 E+01 \\
1.66 E+\infty\end{array}$ \\
\hline
\end{tabular}

FILE NAME: CO-60

SAMPLE ID: PEACH BOTTOM $* 4$

\begin{tabular}{|c|c|c|c|c|c|c|c|c|c|}
\hline $\begin{array}{l}\text { LEACH } \\
\text { ID }\end{array}$ & $\begin{array}{l}\text { CUMULATIVE } \\
\text { LEACH TIME } \\
\text { (days) }\end{array}$ & $\begin{array}{l}\text { ACTIVTY } \\
\text { LEACHED } \\
\text { (UCI) }\end{array}$ & $\begin{array}{l}\text { AELEASE } \\
\text { RATE } \\
\text { (uCi.cm-2.s- }\end{array}$ & $\begin{array}{l}\text { RELLEASE } \\
\text { RATE } \\
(\mathrm{cm}-2 \cdot \mathrm{s}-1)\end{array}$ & $\begin{array}{l}\text { RELEASE } \\
\text { RATE } \\
\text { (Ci•yr-1) }\end{array}$ & $\begin{array}{l}\text { INCREMENTA } \\
\text { AELEASE }\end{array}$ & $\begin{array}{l}\text { CUMULATIVE } \\
\text { RELEASE }\end{array}$ & $\begin{array}{l}\text { EFFECTIVE } \\
\text { DIFFUSIVTY } \\
\left.\text { (cm }{ }^{2} \cdot \mathrm{s}^{-1}\right)\end{array}$ & $\begin{array}{l}\text { LEACH } \\
\text { INDEX }\end{array}$ \\
\hline \multirow[t]{2}{*}{$\begin{array}{l}\text { 1. (30s) } \\
\text { 2. (2hr) } \\
\text { 3. (7hy) } \\
\text { 4. (1d) } \\
\text { 5. (2d) } \\
\text { 6. (3d) } \\
\text { 7. (4d) } \\
\text { 8. (5d) }\end{array}$} & $\begin{array}{l}3.47 E-\infty 4 \\
8.44 E-\infty \\
2.03 E-01 \\
1.00 E+\infty \\
2.00 E+\infty \\
3.00 E+\infty \\
4.00 E+\infty \\
5.00 E+\infty\end{array}$ & $\begin{array}{l}1.18 E-\infty \\
1.08 E-01 \\
0.53 E-\infty \\
1.41 E-01 \\
1.13 E-01 \\
8.06 E-\infty \\
6.25 E-\infty \\
4.84 E-\infty\end{array}$ & $\begin{array}{l}--\overline{-}-\overline{-}-\infty \\
3.41 E-\infty 8 \\
1.46 E-\infty 8 \\
8.40 E-\infty \\
6.00 E-\infty \\
4.66 E-\infty \\
3.00 E-\infty\end{array}$ & $\begin{array}{l}--\overline{-}- \\
2.54 E-10 \\
9.09 E-11 \\
3.95 E-11 \\
2.24 E-11 \\
1.60 E-11 \\
1.24 E-11 \\
9.01 E-12\end{array}$ & $\begin{array}{l}----- \\
4.08 E-\infty 4 \\
1.67 E-04 \\
7.28 E-\infty 5 \\
4.13 E-\infty 5 \\
2.95 E-\infty 5 \\
2.29 E-\infty 5 \\
1.77 E-\infty 6\end{array}$ & $\begin{array}{l}--\overline{2.87 E-04} \\
2.54 E-04 \\
3.76 E-04 \\
3.01 E-04 \\
2.15 E-04 \\
1.07 E-04 \\
1.29 E-04\end{array}$ & $\begin{array}{l}-.87 E-04 \\
5.42 E-04 \\
9.17 E-04 \\
1.22 E-\infty \\
1.43 E-\infty \\
1.60 E-\infty \\
1.73 E-\infty\end{array}$ & $\begin{array}{l}----- \\
6.98 E-12 \\
7.33 E-12 \\
4.77 E-12 \\
3.76 E-12 \\
3.27 E-12 \\
2.76 E-12 \\
2.13 E-12\end{array}$ & $\begin{array}{l}-\overline{1.12 E+01} \\
1.11 E+01 \\
1.13 E+01 \\
1.14 E+01 \\
1.15 E+01 \\
1.16 E+01 \\
1.17 E+01\end{array}$ \\
\hline & Standard De & $\begin{array}{l}\text { Mean: } \\
\text { ation: }\end{array}$ & $\begin{array}{l}2.38 E-\infty \\
3.08 E-\infty\end{array}$ & $\begin{array}{l}6.36 E-11 \\
8.21 E-11\end{array}$ & $\begin{array}{l}1.17 E-04 \\
1.51 E-04\end{array}$ & & & $\begin{array}{l}4.43 E-12 \\
1.88 E-12\end{array}$ & $\begin{array}{l}1.14 E+01 \\
1.80 E-01\end{array}$ \\
\hline
\end{tabular}

FILE NAMF: $\mathrm{NI}-63$

SAMPLE ID: PEACH BOTTOM \#4

\begin{tabular}{|c|c|c|c|c|c|c|c|c|c|}
\hline$\underset{\text { ID }}{\text { LEACH }}$ & $\begin{array}{l}\text { CUMULATIVE } \\
\text { LEACH TIME } \\
\text { (daya) }\end{array}$ & $\begin{array}{l}\text { ACTUTY } \\
\text { LEACHED } \\
\text { (UCi) }\end{array}$ & $\begin{array}{l}\text { RELEASE } \\
\text { RATE } \\
\text { (UCl.cm-2.8- }\end{array}$ & $\begin{array}{l}\text { RELEASE } \\
\text { RATE } \\
\left(\mathrm{cm}-2 \cdot \mathrm{s}^{-1}\right)\end{array}$ & $\begin{array}{c}\text { RELEASE } \\
\text { RATE } \\
(C l \cdot y r-1)\end{array}$ & $\begin{array}{l}\text { INCAEMENTAI } \\
\text { RELEASE }\end{array}$ & $\begin{array}{l}\text { CUMULATIVE } \\
\text { AELEASE }\end{array}$ & $\begin{array}{l}\text { EFFECTIVE } \\
\text { DIFFUSIVIY } \\
\left(\mathrm{cm}^{2} \cdot \mathrm{s}^{-1}\right)\end{array}$ & $\begin{array}{l}\text { LEACH } \\
\text { INDEX }\end{array}$ \\
\hline \multirow[t]{2}{*}{$\begin{array}{l}\text { 1. (30s) } \\
\text { 2. (2hr) } \\
\text { 3. (7hr) } \\
\text { 4. (1d) } \\
\text { 5. (2d) } \\
\text { 6. (3d) } \\
\text { 7. (4d) } \\
\text { 8. (5d) }\end{array}$} & $\begin{array}{l}3.47 E-\infty 4 \\
8.44 E-\infty \\
2.03 E-01 \\
1.00 E+\infty \\
2.00 E+\infty \\
3.00 E+\infty \\
4.00 E+\infty \\
5.00 E+\infty\end{array}$ & $\begin{array}{l}6.52 E-\infty 4 \\
6.04 E-\infty \\
6.70 E-\infty \\
8.30 E-\infty \\
5.34 E-\infty \\
3.72 E-\infty \\
2.02 E-\infty \\
4.21 E-\infty\end{array}$ & $\begin{array}{l}5.35 E-\infty \\
2.42 E-\infty \\
6.74 E-10 \\
3.97 E-10 \\
2.77 E-10 \\
1.95 E-10 \\
3.13 E-10\end{array}$ & $\begin{array}{l}--15 E-10 \\
8.15 E-10 \\
3.68 E-10 \\
1.33 E-10 \\
6.06 E-11 \\
4.22 E-11 \\
2.97 E-11 \\
4.78 E-11\end{array}$ & $\begin{array}{l}--E-\infty \\
2.63 E-\infty \\
1.19 E-\infty \\
4.29 E-\infty \\
1.95 E-\infty \\
1.36 E-\infty \\
9.56 E-\infty \\
1.54 E-\infty\end{array}$ & $\begin{array}{l}-\overline{-}-\overline{-} \\
9.20 E-04 \\
1.03 E-\infty \\
1.27 E-\infty 3 \\
8.14 E-04 \\
5.67 E-04 \\
3.90 E-04 \\
0.42 E-04\end{array}$ & $\begin{array}{l}----\overline{-} \\
9.20 E-\infty 4 \\
1.95 E-\infty \\
3.22 E-\infty \\
4.03 E-\infty \\
4.60 E-\infty \\
5.00 E-\infty \\
5.64 E-\infty\end{array}$ & $\begin{array}{l}-\overline{7.17 E-11} \\
1.20 E-10 \\
5.41 E-11 \\
2.75 E-11 \\
2.27 E-11 \\
1.58 E-11 \\
5.26 E-11\end{array}$ & $\begin{array}{l}-\overline{1.01 E+01} \\
9.92 E+\infty \\
1.03 E+01 \\
1.06 E+01 \\
1.06 E+01 \\
1.08 E+01 \\
1.03 E+01\end{array}$ \\
\hline & $\tan c$ & an: & $\begin{array}{l}1.40 E-\infty \\
1.7 \otimes E-\infty\end{array}$ & $\begin{array}{l}2.14 E-10 \\
2.69 E-10\end{array}$ & $\begin{array}{l}0.89 E-\infty \\
0.07 E-\infty\end{array}$ & & & $\begin{array}{l}5.21 E-11 \\
3.34 E-11\end{array}$ & $\begin{array}{l}1.04 E+01 \\
2.65 E-01\end{array}$ \\
\hline
\end{tabular}


Table E-24. (continued).

FILENAME: $8 r-\infty$

BAMPLE ID: PEACH BOTTOM \#4

\begin{tabular}{|c|c|c|c|c|c|c|c|c|c|}
\hline$\underset{I D}{\text { LEACH }}$ & $\begin{array}{l}\text { CUMULATIVE } \\
\text { LEACH TIME } \\
\text { (days) }\end{array}$ & $\begin{array}{l}\text { ACTIVTY } \\
\text { LEACHED } \\
\text { (UCI) }\end{array}$ & $\begin{array}{c}\text { RELEASE } \\
\text { RATE } \\
(\text { UCl-cm-2.03- }\end{array}$ & $\begin{array}{l}\text { RELEASE } \\
\text { RATE } \\
(\mathrm{cm}-2 \cdot 8-1)\end{array}$ & $\begin{array}{l}\text { RELEASE } \\
\text { RATE } \\
(\text { Cl•yr-1) }\end{array}$ & $\begin{array}{l}\text { INCAEMENT } \\
\text { RELEASE }\end{array}$ & $\begin{array}{l}\text { ATIVE } \\
\text { SE }\end{array}$ & $\begin{array}{l}\text { EFFECTIVE } \\
\text { DIFFUSIVITY } \\
\text { (cmens-1) }\end{array}$ & $\begin{array}{l}\text { LEACH } \\
\text { INOEX }\end{array}$ \\
\hline \multirow[t]{2}{*}{$\begin{array}{l}\text { 1. (30s) } \\
\text { 2. (2hr) } \\
\text { 3. (7hr) } \\
\text { 4. (1d) } \\
\text { 5. (2d) } \\
\text { 6. (3d) } \\
\text { 7. (4d) } \\
\text { 8. (5d) }\end{array}$} & $\begin{array}{l}3.47 E-\infty 1 \\
8.44 E-\infty 2 \\
2.03 E-01 \\
1.00 E+\infty \\
2.00 E+\infty \\
3.00 E+\infty \\
4.00 E+\infty \\
5.00 E+\infty\end{array}$ & $\begin{array}{r}3.43 E-\infty \\
1.57 E-\infty \\
N / D \\
N / D \\
3.48 E-\infty \\
N / D \\
3.47 E-\infty \\
N / D\end{array}$ & $\begin{array}{r}-.30 E-11 \\
\text { N/D } \\
\text { N/D } \\
2.50 E-13 \\
\text { N/D } \\
2.58 E-13 \\
\text { N/D }\end{array}$ & $\begin{array}{r}.45 E-\infty \\
\text { N/D } \\
\text { N/D } \\
2.71 E-11 \\
\text { N/D } \\
2.70 E-11 \\
\text { N/D }\end{array}$ & $\begin{array}{r}0.82 E-\infty \\
N / D \\
N / D \\
1.27 E-\infty \\
N / D \\
1.27 E-\infty \\
\text { N/D }\end{array}$ & $\begin{array}{r}1.64 E-\infty \\
\text { N/D } \\
\text { N/D } \\
3.04 E-O 4 \\
\text { N/D } \\
3.63 E-04 \\
\text { N/D }\end{array}$ & $\begin{array}{l}-\overline{1.04 E-\infty} \\
1.64 E-\infty \\
1.64 E-\infty \\
2.00 E-\infty \\
2.00 E-\infty \\
2.37 E-\infty \\
2.37 E-\infty\end{array}$ & $\begin{array}{r}2.28 E-10 \\
N D D \\
N / D \\
5.50 E-12 \\
\text { N/D } \\
1.31 E-11 \\
\text { NDD }\end{array}$ & $\begin{array}{r}0.04 E+\infty \\
N / D \\
N / D \\
1.13 E+01 \\
N / D \\
1.00 E+01 \\
N / D\end{array}$ \\
\hline & & in: & $\begin{array}{l}4.80 E-12 \\
6.42 E-12\end{array}$ & $\begin{array}{l}5.02 E-10 \\
6.72 E-10\end{array}$ & $\begin{array}{l}2.36 E-\infty 8 \\
3.15 E-\infty 8\end{array}$ & & & $\begin{array}{l}8.21 E-11 \\
1.03 E-10\end{array}$ & $\begin{array}{l}1.06 E+01 \\
0.01 E-01\end{array}$ \\
\hline
\end{tabular}

FILE NAME: TC- $\infty$

SAMPLE ID: PEACH BOTTOM *4

\begin{tabular}{|c|c|c|c|c|c|c|c|c|c|}
\hline$\underset{\text { ID }}{\text { LEACH }}$ & $\begin{array}{l}\text { CUMULATIVE } \\
\text { LEACH TIME } \\
\text { (dayo) }\end{array}$ & $\begin{array}{c}\text { ACTIVTY } \\
\text { LEACHED } \\
\text { (UCi) }\end{array}$ & $\begin{array}{c}\text { RELEASE } \\
\text { AATE } \\
\text { (UCl•cm-2.g- }\end{array}$ & $\begin{array}{l}\text { AELEASE } \\
\text { AATE } \\
(\mathrm{cm}-2 \cdot 8-1)\end{array}$ & $\begin{array}{l}\text { RELEASE } \\
\text { RATE } \\
(\mathrm{Ci} \cdot y-1)\end{array}$ & $\begin{array}{l}\text { INCREMENTA } \\
\text { RELEASE }\end{array}$ & $\begin{array}{l}\text { CUMULATIVE } \\
\text { RELEASE }\end{array}$ & $\begin{array}{l}\text { EFFECTIVE } \\
\text { DIFFUSIVTY } \\
\left(\mathrm{cm}^{2} \cdot \mathrm{g}^{-1)}\right.\end{array}$ & $\begin{array}{l}\text { LEACH } \\
\text { INDEX }\end{array}$ \\
\hline \multirow[t]{2}{*}{$\begin{array}{l}\text { 1. (30s) } \\
\text { 2. (2hrr } \\
\text { 3. (7hr) } \\
\text { 4. (1d) } \\
\text { 5. (2d) } \\
\text { 6. (3d) } \\
\text { 7. (4d) } \\
\text { 8. (5d) }\end{array}$} & $\begin{array}{l}3.47 E-04 \\
8.44 E-\infty \\
2.93 E-01 \\
1.00 E+\infty \\
2.00 E+\infty \\
3.00 E+\infty \\
4.00 E+\infty \\
5.00 E+\infty\end{array}$ & $\begin{array}{l}N / D \\
5.05 E-\infty 4 \\
5.41 E-\infty 4 \\
1.24 E-\infty \\
5.22 E-\infty \\
1.01 E-\infty \\
8.31 E-\infty 4 \\
6.28 E-04\end{array}$ & $\begin{array}{l}-\overline{-E-} \\
5.27 E-10 \\
1.03 E-10 \\
1.30 E-10 \\
3.68 E-10 \\
7.53 E-11 \\
6.19 E-11 \\
4.68 E-11\end{array}$ & $\begin{array}{l}-1.2 E-10 \\
4.10 E-11 \\
2.77 E-11 \\
6.24 E-11 \\
1.00 E-11 \\
1.31 E-11 \\
0.92 E-12\end{array}$ & $\begin{array}{l}--\overline{2.50 E-\infty} \\
0.50 E-07 \\
6.40 E-07 \\
1.01 E-\infty \\
3.70 E-07 \\
3.04 E-07 \\
2.30 E-07\end{array}$ & $\begin{array}{l}-\overline{1.20 E-04} \\
1.15 E-04 \\
2.03 E-04 \\
1.11 E-03 \\
2.14 E-04 \\
1.76 E-04 \\
1.33 E-04\end{array}$ & $\begin{array}{l}-\overline{1.26 E-\infty 4} \\
2.41 E-\infty 4 \\
5.04 E-04 \\
1.61 E-\infty 3 \\
1.83 E-\infty \\
2.00 E-\infty \\
2.14 E-\infty\end{array}$ & $\begin{array}{l}-\overline{1.35 E-12} \\
1.40 E-12 \\
2.33 E-12 \\
5.08 E-11 \\
3.24 E-12 \\
3.08 E-12 \\
2.27 E-12\end{array}$ & $\begin{array}{l}-\overline{1.19 E+01} \\
1.18 E+01 \\
1.16 E+01 \\
1.03 E+01 \\
1.15 E+01 \\
1.15 E+01 \\
1.10 E+01\end{array}$ \\
\hline & andard De & ion: & $\begin{array}{l}2.03 E-10 \\
1.71 E-10\end{array}$ & $\begin{array}{l}4.31 E-11 \\
3.04 E-11\end{array}$ & $\begin{array}{l}9.00 E-07 \\
8.42 E-07\end{array}$ & & & $\begin{array}{l}9.23 E-12 \\
1.70 E-11\end{array}$ & $\begin{array}{l}1.15 E+01 \\
4.97 E-01\end{array}$ \\
\hline
\end{tabular}

FILE NAME: $1-120$

SAMPLE ID: PEACHEOTTOM *4

\begin{tabular}{|c|c|c|c|c|c|c|c|c|c|}
\hline$\underset{\text { ID }}{\text { LEACH }}$ & $\begin{array}{l}\text { CUMULATIVE } \\
\text { LEACH TIME } \\
\text { (days) }\end{array}$ & $\begin{array}{l}\text { ACTIVTY } \\
\text { LEACHED } \\
\text { (WCI) }\end{array}$ & $\begin{array}{c}\text { RELEASE } \\
\text { RATE } \\
\left(\text { LCi } \cdot \mathrm{cm}^{2} \cdot \bullet_{\mathrm{s}}-\right.\end{array}$ & $\begin{array}{l}\text { RELEASE } \\
\text { RATE } \\
(\mathrm{cm}-2 \cdot \mathrm{s}-1)\end{array}$ & $\begin{array}{l}\text { RELEASE } \\
\text { AATE } \\
(C i \cdot y r-1)\end{array}$ & $\begin{array}{l}\text { INCREMENTA } \\
\text { RELEASE }\end{array}$ & $\begin{array}{l}\text { CUML } \\
\text { RELE }\end{array}$ & $\begin{array}{l}\text { EFFECTIVE } \\
\text { DIFFUSIVTTY } \\
\left(\mathrm{cm}^{2} \cdot \mathrm{g}^{-1}\right)\end{array}$ & $\begin{array}{l}\text { LEACH } \\
\text { INDEX }\end{array}$ \\
\hline \multirow[t]{2}{*}{$\begin{array}{l}\text { 1. (30a) } \\
\text { 2. (2hrt) } \\
\text { 3. (7hr) } \\
\text { 4. (1d) } \\
\text { 5. (2d) } \\
\text { 6. (3d) } \\
\text { 7. (4d) } \\
\text { 8. (5d) }\end{array}$} & $\begin{array}{l}3.47 E-\infty 4 \\
8.44 E-\infty \\
2.03 E-01 \\
1.00 E+\infty \\
2.00 E+\infty \\
3.00 E+\infty \\
4.00 E+\infty \\
5.00 E+\infty\end{array}$ & $\begin{array}{r}\text { ND } \\
1.07 E-04 \\
N / D \\
3.93 E-06 \\
2.58 E-04 \\
\text { N/D } \\
1.91 E-05 \\
1.01 E-04\end{array}$ & 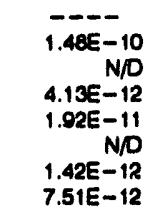 & $\begin{array}{r}-\overline{2.44 E-\infty} \\
N / D \\
6.83 E-10 \\
3.17 E-\infty \\
N / D \\
2.35 E-10 \\
1.24 E-\infty\end{array}$ & $\begin{array}{r}7.27 E-07 \\
N / D \\
2.03 E-\infty 8 \\
9.41 E-\infty \\
N / D \\
6.08 E-\infty \\
3.60 E-\infty\end{array}$ & $\begin{array}{r}2.76 E-\infty \\
N, D \\
0.49 E-\infty \\
4.25 E-\infty \\
N / D \\
3.15 E-\infty \\
1.67 E-\infty\end{array}$ & $\begin{array}{l}-\overline{2 .} \\
2.70 \\
2.76 \\
3.41 \\
7.66 \\
7.60 \\
7.98 \\
9.64\end{array}$ & $\begin{array}{r}-.45 E-\infty \\
N / D \\
1.42 E-\infty \\
7.50 E-08 \\
N / D \\
9.65 E-10 \\
3.55 E-\infty 8\end{array}$ & $\begin{array}{r}7.10 E+\infty \\
N / D \\
6.85 E+\infty \\
7.12 E+\infty \\
N / D \\
0.01 E+\infty \\
7.45 E+\infty\end{array}$ \\
\hline & & $\begin{array}{l}\text { an: } \\
\text { ion: }\end{array}$ & $\begin{array}{l}3.00 E-11 \\
5.03 E-11\end{array}$ & $\begin{array}{l}5.05 E-\infty \\
9.30 E-\infty\end{array}$ & $\begin{array}{l}1.77 E-07 \\
2.77 E-07\end{array}$ & & & $\begin{array}{l}3.55 E-\infty 8 \\
3.08 E-\infty 8\end{array}$ & $\begin{array}{l}7.92 E+\infty \\
8.28 E-01\end{array}$ \\
\hline
\end{tabular}

FILE NANE: $\mathrm{Cr}$

SAMPLE ID: PEACH BOTTOM \#4

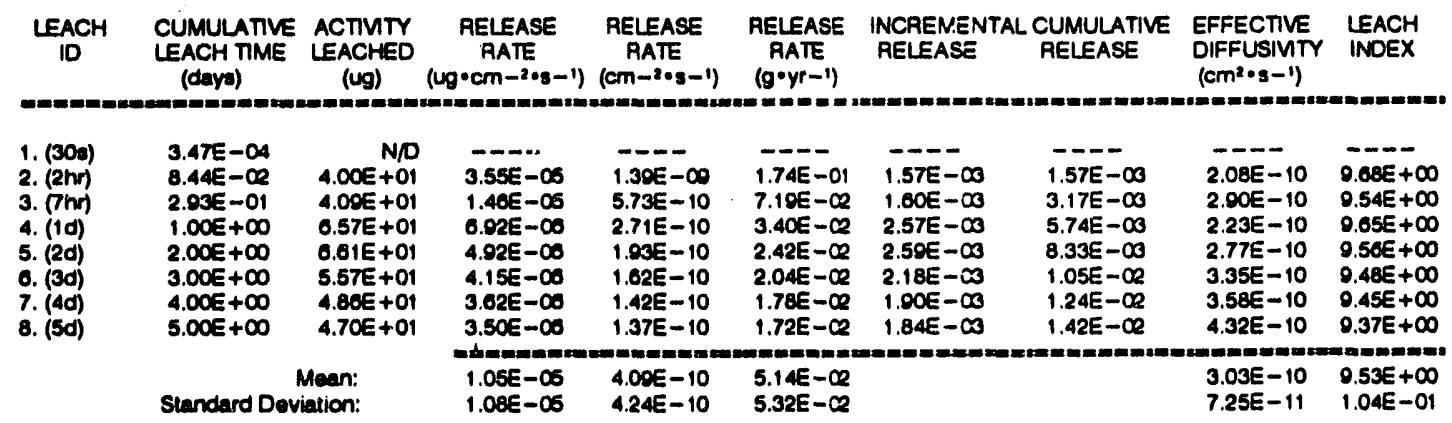


Table E-24. (continued).

FILE NAME: Fo

SAMPLE ID: PEACH BOTTOM \#4

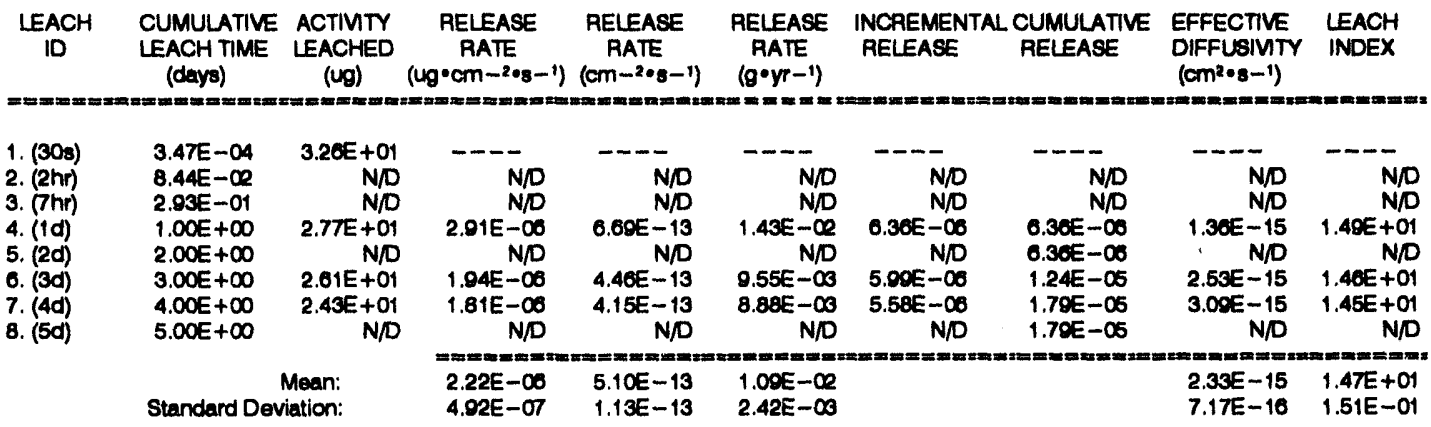

FILE NAME: Co

SAMPLE ID: PEACHBOTTOM \#4

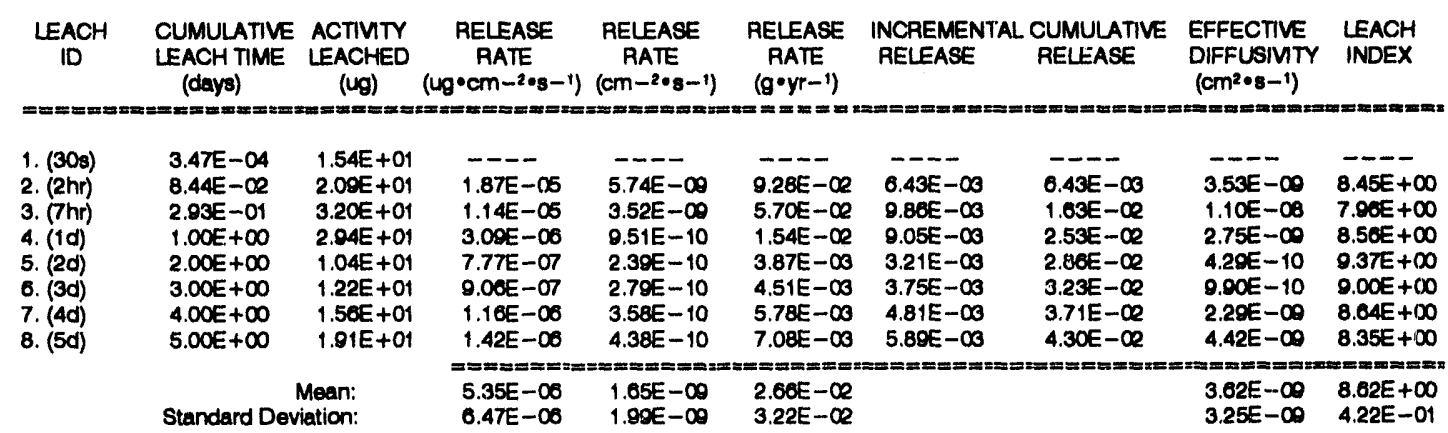

FILE NAME: $\mathrm{Ni}$

SAMPLE ID: PEACHBOTTOM \#4

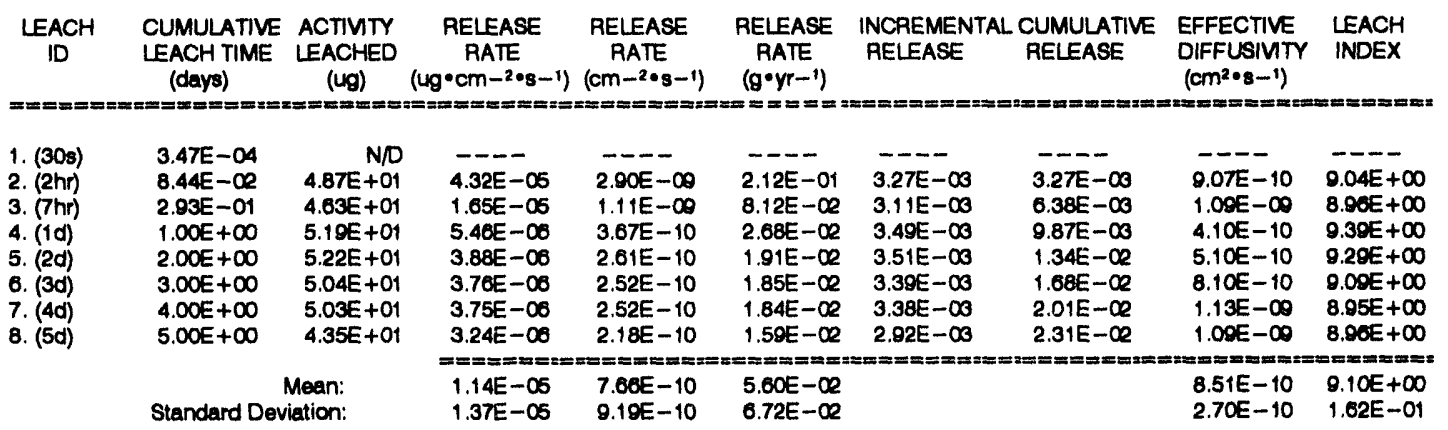

FILE NAME: $\mathbf{Z n}$

SAMPLE ID: PEACH BOTTOM *4

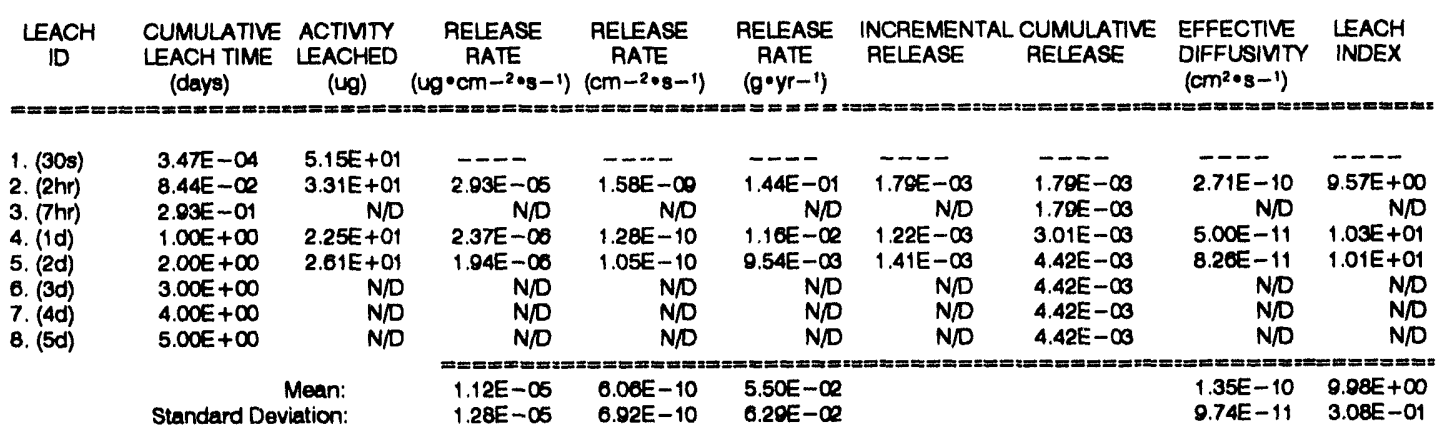


Table E-24. (continued).

FILE NAME: $B$

SAMPLE ID: PEACH BOTTOM \#A

\begin{tabular}{|c|c|c|c|c|c|c|c|c|c|}
\hline$\underset{\text { ID }}{\text { EACH }}$ & $\begin{array}{l}\text { CUMULATIVE } \\
\text { LEACH IIME } \\
\text { (days) }\end{array}$ & $\begin{array}{l}\text { ACTIVTY } \\
\text { LEACHED } \\
\text { (ug) }\end{array}$ & $\begin{array}{c}\text { RELEASE } \\
\text { RATE } \\
(\omega g \cdot \mathrm{cm}-2 \cdot \mathrm{g}-1)\end{array}$ & $\begin{array}{l}\text { RELEASE } \\
\text { RATE } \\
\left(\mathrm{cm}-2 \cdot \mathrm{s}^{-1}-1\right)\end{array}$ & $\begin{array}{l}\text { RELEASE } \\
\text { RATE } \\
(g \cdot y r-1)\end{array}$ & $\begin{array}{l}\text { INCREMENTA } \\
\text { RELEASE }\end{array}$ & $\begin{array}{l}\text { CUMULATIVE } \\
\text { RELEASE }\end{array}$ & $\begin{array}{l}\text { EFFECTIVE } \\
\text { DIFFUSIVIT } \\
\left(\mathrm{cm}^{2} \cdot \mathrm{s}-1\right)\end{array}$ & $\begin{array}{l}\text { LEACH } \\
\text { INDEX }\end{array}$ \\
\hline \multirow[t]{2}{*}{$\begin{array}{l}\text { 1. (30.) } \\
\text { 2. (2hy) } \\
\text { 3. (7hr) } \\
\text { 4. (1d) } \\
\text { 5. (2d) } \\
\text { 6. (3d) } \\
\text { 7. (4d) } \\
\text { 8. (5d) }\end{array}$} & $\begin{array}{l}3.47 E-\infty 4 \\
8.44 E-\infty \\
2.03 E-01 \\
1.00 E+\infty \\
2.00 E+\infty \\
3.00 E+\infty \\
1.00 E+\infty \\
5.00 E+\infty\end{array}$ & $\begin{array}{r}3.43 E+01 \\
3.13 E+01 \\
N D D \\
3.46 E+01 \\
3.46 E+01 \\
3.48 E+01 \\
N D \\
N / D\end{array}$ & $\begin{array}{r}-\pi \overline{2}-\infty \\
N / D \\
3.04 E-\infty \\
2.50 E-\infty \\
2.50 E-\infty \\
N / D \\
N / D\end{array}$ & $\begin{array}{r}0.05 E-\infty \\
\text { ND } \\
7.93 E-10 \\
5.04 E-10 \\
5.64 E-10 \\
\text { N/D } \\
\text { ND }\end{array}$ & $\begin{array}{r}1.36 E-01 \\
\text { N/D } \\
1.79 E-\infty \\
1.27 E-\infty \\
1.27 E-\infty \\
\text { N/D } \\
\text { ND }\end{array}$ & $\begin{array}{r}0.82 E-\infty \\
\text { N/D } \\
7.54 E-\infty \\
7.58 E-\infty \\
7.58 E-\infty \\
\text { N/D } \\
\text { N/D }\end{array}$ & $\begin{array}{l}--\overline{-}-\infty \\
6.82 E-\infty \\
6.82 E-\infty \\
1.44 E-\infty \\
2.10 E-\infty \\
2.95 E-\infty \\
2.95 E-\infty \\
2.95 E-\infty\end{array}$ & $\begin{array}{r}3.94 E-\infty \\
\text { ND } \\
1.92 E-\infty \\
2.38 E-\infty \\
4.05 E-\infty \\
\text { ND } \\
\text { NDO }\end{array}$ & $\begin{array}{r}8.40 E+\infty \\
N / D \\
8.72 E+\infty \\
8.62 E+\infty \\
8.30 E+\infty \\
\text { ND } \\
\text { ND }\end{array}$ \\
\hline & Standard Do & $\begin{array}{l}\text { Aean: } \\
\text { ation: }\end{array}$ & $\begin{array}{l}0.14 E-\infty \\
1.08 E-\infty 6\end{array}$ & $\begin{array}{l}1.90 E-\infty \\
2.34 E-\infty\end{array}$ & $\begin{array}{l}4.4 Q E-\propto \\
5.28 E-\infty\end{array}$ & & & $\begin{array}{l}3.07 E-\infty \\
9.30 E-10\end{array}$ & $\begin{array}{l}8.53 E+\infty \\
1.40 E-01\end{array}$ \\
\hline
\end{tabular}

FILE NAME: Picolinic Acid

SAMPLE ID: PEACH BOTTOM "44

\begin{tabular}{|c|c|c|c|c|c|c|c|}
\hline EACH & $\begin{array}{l}\text { CUMULATIVE } \\
\text { LEACH TMME } \\
\text { (days) }\end{array}$ & $\begin{array}{l}\text { OUANTITY } \\
\text { LEACHEO } \\
\text { (ug) }\end{array}$ & $\begin{array}{c}\text { RELEASE } \\
\text { RATE } \\
\text { ug・cm-2.8-1) }\end{array}$ & $\begin{array}{l}\text { RELEASE } \\
\text { RATE } \\
(\mathrm{cm}-2 \cdot 8-1)\end{array}$ & $\begin{array}{c}\text { RELEASE } \\
\text { RATE } \\
(g \cdot y r-1)\end{array}$ & $\begin{array}{l}\text { NTAAL CUM } \\
=\end{array}$ & $\begin{array}{l}E \\
T Y\end{array}$ \\
\hline
\end{tabular}

\begin{tabular}{|c|c|c|c|c|c|c|c|c|c|}
\hline $\begin{array}{l}\text { 1. (30s) } \\
\text { 2. (2hr) } \\
\text { 3. (7hr) } \\
\text { 4. (1d) } \\
\text { 5. (2d) } \\
\text { 6. (3d) } \\
\text { 7. (4d) } \\
\text { 8. (5d) }\end{array}$ & $\begin{array}{l}3.47 E-\infty 4 \\
8.44 E-\infty \\
2.03 E-01 \\
1.00 E+\infty \\
2.00 E+\infty \\
3.00 E+\infty \\
4.00 E+\infty \\
5.00 E+\infty\end{array}$ & $\begin{array}{r}N / D \\
3.20 E+04 \\
3.26 E+04 \\
6.14 E+04 \\
5.61 E+04 \\
3.64 E+04 \\
2.65 E+04 \\
2.21 E+04\end{array}$ & $\begin{array}{l}--\overline{2.84 E-\infty} \\
1.16 E-\infty \\
6.40 E-\infty \\
4.32 E-\infty \\
2.71 E-\infty \\
2.12 E-\infty \\
1.64 E-\infty\end{array}$ & $\begin{array}{l}---\overline{2}-\infty \\
2.08 E-\infty \\
8.53 E-10 \\
4.74 E-10 \\
3.17 E-10 \\
1.98 E-10 \\
1.55 E-10 \\
1.21 E-10\end{array}$ & $\begin{array}{l}1 .-m- \\
5.72 E+\infty \\
3.18 E+01 \\
2.12 E+01 \\
1.33 E+01 \\
1.04 E+01 \\
8.08 E+\infty\end{array}$ & $\begin{array}{l}----\infty \\
2.35 E-\infty \\
2.39 E-\infty \\
4.50 E-\infty \\
4.26 E-\infty \\
2.66 E-\infty \\
2.00 E-\infty \\
1.62 E-\infty\end{array}$ & $\begin{array}{l}-\overline{-}--\infty \\
2.35 E-\infty \\
4.73 E-\infty \\
9.23 E-\infty \\
1.35 E-\infty \\
1.62 E-\infty \\
1.82 E-\infty \\
1.99 E-\infty\end{array}$ & $\begin{array}{l}-\bar{C}-60 E-10 \\
6.45 E-10 \\
6.84 E-10 \\
7.52 E-10 \\
5.01 E-10 \\
4.31 E-10 \\
3.35 E-10\end{array}$ & $\begin{array}{l}-\overline{-.33 E+\infty} \\
9.19 E+\infty \\
9.17 E+\infty \\
9.12 E+\infty \\
9.30 E+\infty \\
9.37 E+\infty \\
9.48 E+\infty\end{array}$ \\
\hline & Stanctard D & $\begin{array}{l}\text { san: } \\
\text { tion: }\end{array}$ & $\begin{array}{l}8.18 E-\infty \\
8.84 E-\infty\end{array}$ & $\begin{array}{l}0.00 E-10 \\
6.48 E-10\end{array}$ & $\begin{array}{l}4.02 E+01 \\
4.34 E+01\end{array}$ & & & $\begin{array}{l}5.45 E-10 \\
1.40 E-10\end{array}$ & $\begin{array}{l}9.28 E+\infty \\
1.16 E-01\end{array}$ \\
\hline
\end{tabular}


Table E-25. Peach Bottom sample \#8 cumulative fraction releases, release rates, effective diffusivities, and leachability indexes.

FILE NAME: C-14

SAMPLE ID: Paech Bottom "W8

\begin{tabular}{|c|c|c|c|c|c|c|c|c|c|}
\hline $\begin{array}{l}\text { LEACH } \\
\text { ID }\end{array}$ & $\begin{array}{c}\text { TOTAL } \\
\text { TIME } \\
\text { (dayo) }\end{array}$ & $\begin{array}{c}\text { ACTVITY } \\
\text { LEACHED } \\
\text { (UCi) }\end{array}$ & $\begin{array}{l}\text { RELEASE } \\
\text { RATE } \\
\text { (UCl-cm-2 }\end{array}$ & $\begin{array}{l}\text { RELEASE } \\
\text { RATE } \\
\left(\mathrm{cm}^{2} \cdot \mathrm{s}^{-1}\right)\end{array}$ & $\begin{array}{l}\text { RELEASE } \\
\text { RATE } \\
(C i \cdot y-1)\end{array}$ & $\begin{array}{l}\text { INCAEMENT } \\
\text { RELEASE }\end{array}$ & $\begin{array}{l}\text { CUMULATIVE } \\
\text { PELEASE }\end{array}$ & $\begin{array}{l}\text { EFFECTIVE } \\
\text { DIFFUSIVTY } \\
\left(\mathrm{cm}^{2} \cdot \mathrm{s}^{-1}\right)\end{array}$ & $\begin{array}{l}\text { LEACH } \\
\text { INDEX }\end{array}$ \\
\hline \multirow[t]{2}{*}{$\begin{array}{l}\text { 1. (30a) } \\
\text { 2. (2ht) } \\
\text { 3. (7h) } \\
\text { 4. (1d) } \\
\text { 5. (2d) } \\
\text { 6. (3d) } \\
\text { 7. (4d) } \\
\text { 8. (5d) }\end{array}$} & $\begin{array}{l}3.47 E-\infty \\
8.40 E-\infty \\
2.44 E-01 \\
0.30 E-01 \\
1.93 E+\infty \\
2.92 E+\infty \\
3.91 E+\infty \\
4.90 E+\infty\end{array}$ & $\begin{array}{l}1.22 E-\infty \\
1.18 E-01 \\
9.35 E-\infty \\
1.20 E-01 \\
1.18 E-01 \\
8.40 E-\infty \\
7.01 E-\infty \\
1.47 E-01\end{array}$ & $\begin{array}{l}---\overline{-} \\
0.46 E-\infty \\
3.01 E-\infty \\
1.24 E-\infty \\
8.01 E-\infty \\
5.75 E-\infty \\
4.75 E-\infty \\
9.98 E-\infty\end{array}$ & $\begin{array}{l}-\overline{-}-55 E-11 \\
3.53 E-11 \\
1.12 E-11 \\
7.23 E-12 \\
5.10 E-12 \\
4.20 E-12 \\
9.02 E-12\end{array}$ & $\begin{array}{l}5.16 E-\infty 4 \\
2.13 E-04 \\
6.76 E-\infty 5 \\
4.36 E-\infty 5 \\
3.13 E-\infty 5 \\
2.50 E-\infty 6 \\
5.44 E-\infty 6\end{array}$ & 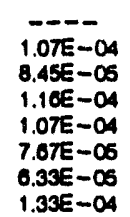 & $\begin{array}{l}-\overline{1.07 E-04} \\
1.92 E-04 \\
3.08 E-04 \\
4.16 E-04 \\
4.01 E-04 \\
5.55 E-04 \\
0.88 E-04\end{array}$ & $\begin{array}{l}--E-- \\
1.00 E-12 \\
1.37 E-12 \\
4.81 E-13 \\
5.10 E-13 \\
4.02 E-13 \\
1.40 E-13 \\
2.55 E-12\end{array}$ & 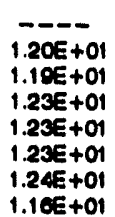 \\
\hline & Standard & an: & $\begin{array}{l}2.50 E-\infty 8 \\
3.05 E-\infty 8\end{array}$ & $\begin{array}{l}2.25 E-11 \\
2.75 E-11\end{array}$ & $\begin{array}{l}1.30 E-04 \\
1.00 E-04\end{array}$ & & & $\begin{array}{l}9.86 E-13 \\
7.20 E-13\end{array}$ & $\begin{array}{l}1.21 E+01 \\
2.75 E-01\end{array}$ \\
\hline
\end{tabular}

FILE NAME: Fe-55

SAMPLE ID: Peach Bottom *B

\begin{tabular}{|c|c|c|c|c|c|c|c|c|c|}
\hline $\begin{array}{l}\text { LEACH } \\
\text { ID }\end{array}$ & $\begin{array}{c}\text { TOTAL } \\
\text { TINE } \\
\text { (days) }\end{array}$ & $\begin{array}{c}\text { ACTVITY } \\
\text { LEACHEO } \\
\text { (UCi) }\end{array}$ & $\begin{array}{l}\text { RELEASE } \\
\text { RATE } \\
\left(\mathrm{LCl} \cdot \mathrm{cm}^{-2} \cdot \mathrm{g}-\right.\end{array}$ & $\begin{array}{c}\text { RELEASE } \\
\text { RATE } \\
\left(\mathrm{cm}-2 \cdot \mathrm{s}^{-1}\right)\end{array}$ & $\begin{array}{c}\text { RELEASE } \\
\text { RATE } \\
(C \mid \cdot y r-1)\end{array}$ & \multicolumn{2}{|c|}{$\begin{array}{l}\text { INCAEMENTAL CUMULATIVE } \\
\text { RELFASE }\end{array}$} & $\begin{array}{l}\text { EFFECTIVE } \\
\text { DIFFUSIVTY } \\
\left(\mathrm{cm}^{2} \cdot \mathrm{g}-1\right)\end{array}$ & $\begin{array}{l}\text { LEACH } \\
\text { INDEX }\end{array}$ \\
\hline $\begin{array}{l}\text { 1. (30a) } \\
\text { 2. (2hr) } \\
\text { 3. (7hr) } \\
\text { 4. (1d) } \\
\text { 5. (2d) } \\
\text { 6. (3d) } \\
\text { 7. (4d) } \\
\text { 8. (5d) }\end{array}$ & $\begin{array}{l}3.47 E-04 \\
8.40 E-\infty \\
2.44 E-01 \\
9.30 E-01 \\
1.93 E+\infty \\
2.92 E+\infty \\
3.91 E+\infty \\
4.00 E+\infty\end{array}$ & $\begin{array}{l}1.01 E-01 \\
1.10 E-01 \\
6.03 E-\infty \\
5.27 E-\infty \\
2.20 E-\infty \\
1.04 E-\infty \\
4.03 E-\infty \\
4.80 E-\infty\end{array}$ & $\begin{array}{l}---\infty \\
0.30 E-\infty \\
2.77 E-\infty \\
5.00 E-\infty \\
1.55 E-\infty \\
7.01 E-10 \\
3.34 E-10 \\
3.26 E-10\end{array}$ & $\begin{array}{l}-\overline{17 E}-\infty \\
1.84 E-\infty \\
3.38 E-10 \\
1.03 E-10 \\
4.65 E-11 \\
2.21 E-11 \\
2.16 E-11\end{array}$ & $\begin{array}{l}--\overline{5}--\infty \\
1.51 E-04 \\
2.78 E-\infty \\
6.43 E-\infty \\
3.82 E-\infty \\
1.82 E-\infty \\
1.77 E-\infty\end{array}$ & $\begin{array}{l}7.72 E-\infty \\
4.40 E-\infty \\
3.50 E-\infty \\
1.52 E-\infty \\
0.87 E-\infty 4 \\
3.27 E-\infty 4 \\
3.18 E-\infty 4\end{array}$ & $\begin{array}{l}7.72 E-\infty \\
1.21 E-\infty \\
1.50 E-\infty \\
1.71 E-\infty \\
1.78 E-\infty \\
1.81 E-\infty \\
1.85 E-\infty\end{array}$ & $\begin{array}{l}-\overline{50 E-\infty} \\
3.71 E-\infty \\
4.35 E-10 \\
1.04 E-10 \\
3.70 E-11 \\
1.10 E-11 \\
1.46 E-11\end{array}$ & $\begin{array}{l}8.24 E+\infty \\
8.43 E+\infty \\
9.30 E+\infty \\
9.08 E+\infty \\
1.04 E+01 \\
1.00 E+01 \\
1.08 E+01\end{array}$ \\
\hline & and & an: & $\begin{array}{l}1.84 E-\infty \\
3.18 E-\infty\end{array}$ & $\begin{array}{l}1.22 E-\infty \\
2.11 E-\infty\end{array}$ & $\begin{array}{l}1.00 E-04 \\
1.73 E-04\end{array}$ & & & $\begin{array}{l}1.43 E-\infty \\
2.14 E-\infty\end{array}$ & $\begin{array}{l}9.74 E+\infty \\
1.02 E+\infty\end{array}$ \\
\hline
\end{tabular}

FILE NAME: CO-60

SAMPLE ID: Peach Bottom *8

\begin{tabular}{|c|c|c|c|c|c|c|c|c|c|}
\hline$\underset{I D}{\text { LEACH }}$ & $\begin{array}{l}\text { TOTAL } \\
\text { TIME } \\
\text { (daye) }\end{array}$ & $\begin{array}{l}\text { ACTIVTY } \\
\text { LEACHED } \\
\text { (UCi) }\end{array}$ & $\begin{array}{c}\text { RELEASE } \\
\text { RATE } \\
\text { Ci.cm-2.8- } \\
\text { com }\end{array}$ & $\begin{array}{l}\text { AELEASE } \\
\text { RATE } \\
(\mathrm{cm}-2 \cdot \mathrm{s}-1)\end{array}$ & $\begin{array}{l}\text { RELEASE } \\
\text { RATE } \\
(C \mid \cdot y(-1)\end{array}$ & $\begin{array}{l}\text { INCREMENY } \\
\text { RELEASE }\end{array}$ & $\begin{array}{l}\text { CUMULATIVE } \\
\text { AELEASE }\end{array}$ & $\begin{array}{l}\text { EFFECTIVE } \\
\text { DIFFUSIVTT } \\
\left(\mathrm{cm}^{2} \cdot \mathrm{s}-1\right)\end{array}$ & $\begin{array}{l}\text { LEACH } \\
\text { INDEX }\end{array}$ \\
\hline \multirow[t]{2}{*}{$\begin{array}{l}\text { 1. (30s) } \\
\text { 2. (2hr) } \\
\text { 3. (7hr) } \\
\text { 4. (1d) } \\
\text { 5. (2d) } \\
\text { 6. (3d) } \\
\text { 7. (4d) } \\
\text { 8. (5d) }\end{array}$} & $\begin{array}{l}3.47 E-\infty 4 \\
8.40 E-\infty \\
2.44 E-01 \\
9.30 E-01 \\
1.93 E+\infty \\
2.92 E+\infty \\
3.91 E+\infty \\
4.00 E+\infty\end{array}$ & $\begin{array}{l}1.21 E-\infty \\
1.04 E-01 \\
9.41 E-\infty \\
2.03 E-01 \\
1.78 E-01 \\
1.18 E-01 \\
1.06 E-01 \\
2.34 E-01\end{array}$ & $\begin{array}{l}-\overline{1.31 E-\infty} \\
3.94 E-\infty \\
1.90 E-\infty \\
1.20 E-\infty \\
8.01 E-\infty \\
7.10 E-\infty \\
1.50 E-\infty\end{array}$ & $\begin{array}{l}---- \\
3.52 E-10 \\
1.00 E-10 \\
5.26 E-11 \\
3.23 E-11 \\
2.15 E-11 \\
1.93 E-11 \\
4.26 E-11 \\
2.0\end{array}$ & $\begin{array}{l}-\overline{7}-13 E-04 \\
2.14 E-04 \\
1.07 E-04 \\
6.55 E-\infty 6 \\
4.37 E-\infty \\
3.02 E-\infty 6 \\
8.64 E-\infty\end{array}$ & 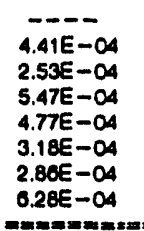 & $\begin{array}{l}-.--- \\
4.41 E-\infty 4 \\
6.93 E-\infty 4 \\
1.24 E-\infty \\
1.72 E-\infty \\
2.04 E-\infty \\
2.32 E-\infty \\
2.95 E-\infty\end{array}$ & $\begin{array}{l}-\overline{-}-\overline{-}-11 \\
1.05 E-11 \\
1.23 E-11 \\
1.06 E-11 \\
1.03 E-11 \\
7.94 E-12 \\
9.00 E-12 \\
5.00 E-11\end{array}$ & $\begin{array}{l}-\overline{-}-\overline{-} \\
1.07 E+01 \\
1.00 E+01 \\
1.10 E+01 \\
1.10 E+01 \\
1.11 E+01 \\
1.10 E+01 \\
1.02 E+01\end{array}$ \\
\hline & Standard De & $\begin{array}{l}\text { san: } \\
\text { tion: }\end{array}$ & $\begin{array}{l}3.33 E-\infty \\
4.11 E-\infty\end{array}$ & $\begin{array}{l}6.95 E-11 \\
1.10 E-10\end{array}$ & $\begin{array}{l}1.81 E-04 \\
2.24 E-04\end{array}$ & & & $\begin{array}{l}1.80 E-11 \\
1.62 E-11\end{array}$ & $\begin{array}{l}1.00 E+01 \\
2.72 E-01\end{array}$ \\
\hline
\end{tabular}

FILE NAME: NI-03

SAMPLE ID: Poech Bottom \#8

\begin{tabular}{|c|c|c|c|c|c|c|c|c|c|}
\hline $\begin{array}{l}\text { LEACH } \\
\text { ID }\end{array}$ & $\begin{array}{l}\text { TOTAL } \\
\text { TME } \\
\text { (days) }\end{array}$ & $\begin{array}{l}\text { ACTIVTY } \\
\text { LEACHED } \\
\text { (UCi) }\end{array}$ & $\begin{array}{l}\text { RELEASE } \\
\text { RATE } \\
\text { (UCi.cm-2.s - }\end{array}$ & $\begin{array}{l}\text { RELEASE } \\
\text { RATE } \\
(\mathrm{cm}-2 \cdot \mathrm{s}-1)\end{array}$ & $\begin{array}{l}\text { RELEASE } \\
\text { RATE } \\
(C i \cdot y P-1)\end{array}$ & $\begin{array}{l}\text { INCREMENT } \\
\text { RELEASE }\end{array}$ & $\begin{array}{l}\text { CUMULATIVE } \\
\text { RELEASE }\end{array}$ & $\begin{array}{l}\text { EFFECTIVE } \\
\text { DIFFUSIVTY } \\
\left(\mathrm{cm}^{2} \cdot \mathrm{s}^{-1)}\right.\end{array}$ & $\begin{array}{l}\text { LEACH } \\
\text { INDEX }\end{array}$ \\
\hline \multirow[t]{2}{*}{$\begin{array}{l}\text { 1. (30s) } \\
\text { 2. (2nr) } \\
\text { 3. (7hr) } \\
\text { 4. (1d) } \\
\text { 5. (2d) } \\
\text { o. (3d) } \\
\text { 7. (4d) } \\
\text { 8. (5d) }\end{array}$} & $\begin{array}{l}3.47 E-04 \\
8.40 E-\infty \\
2.44 E-01 \\
9.39 E-01 \\
1.03 E+\infty \\
2.92 E+\infty \\
3.01 E+\infty \\
4.00 E+\infty\end{array}$ & $\begin{array}{r}2.57 E-\infty 6 \\
1.11 E-\infty 4 \\
7.02 E-\infty 6 \\
0.24 E-\infty 6 \\
3.77 E-\infty 6 \\
1.54 E-\infty 6 \\
N / D \\
N / D\end{array}$ & $\begin{array}{r}-0 .-1 \\
8.69 E-11 \\
2.94 E-11 \\
8.93 E-12 \\
2.55 E-12 \\
1.04 E-12 \\
\text { N/D } \\
\text { N/D }\end{array}$ & $\begin{array}{r}-.30 E-11 \\
4.50 E-12 \\
1.37 E-12 \\
3.91 E-13 \\
1.60 E-13 \\
\text { N/D } \\
\text { N/D }\end{array}$ & $\begin{array}{r}--55 E-07 \\
1.50 E-07 \\
4.57 E-\infty 8 \\
1.31 E-\infty \\
5.34 E-\infty \\
\text { N/D } \\
\text { ND }\end{array}$ & $\begin{array}{r}1.71 E-\infty \\
1.08 E-\infty \\
1.42 E-\infty 5 \\
5.78 E-\infty \\
2.36 E-\infty \\
N D \\
N, D\end{array}$ & $\begin{array}{l}1.71 E-\infty \\
2.78 E-\infty 6 \\
4.20 E-\infty 6 \\
4.78 E-\infty 6 \\
5.02 E-\infty 6 \\
5.02 E-\infty 5 \\
5.02 E-\infty 6\end{array}$ & $\begin{array}{r}2.78 E-14 \\
2.22 E-14 \\
7.17 E-15 \\
1.51 E-15 \\
4.38 E-16 \\
\text { N/D } \\
\text { NDD }\end{array}$ & $\begin{array}{r}1.30 E+01 \\
1.37 E+01 \\
1.41 E+01 \\
1.48 E+01 \\
1.54 E+01 \\
\text { NDD } \\
\text { NDD }\end{array}$ \\
\hline & 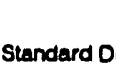 & an: & $\begin{array}{l}2.62 E-11 \\
3.30 E-11\end{array}$ & $\begin{array}{l}4.01 E-12 \\
5.05 E-12\end{array}$ & $\begin{array}{l}1.34 E-07 \\
1.60 E-07\end{array}$ & & & $\begin{array}{l}1.18 E-14 \\
1.12 E=14\end{array}$ & $\begin{array}{l}1.43 E+01 \\
6.01 E-01\end{array}$ \\
\hline
\end{tabular}


Table E-25. (continued).

FILE NNME: $s P-\infty$

SAMPLE ID: Pcach Bction wo

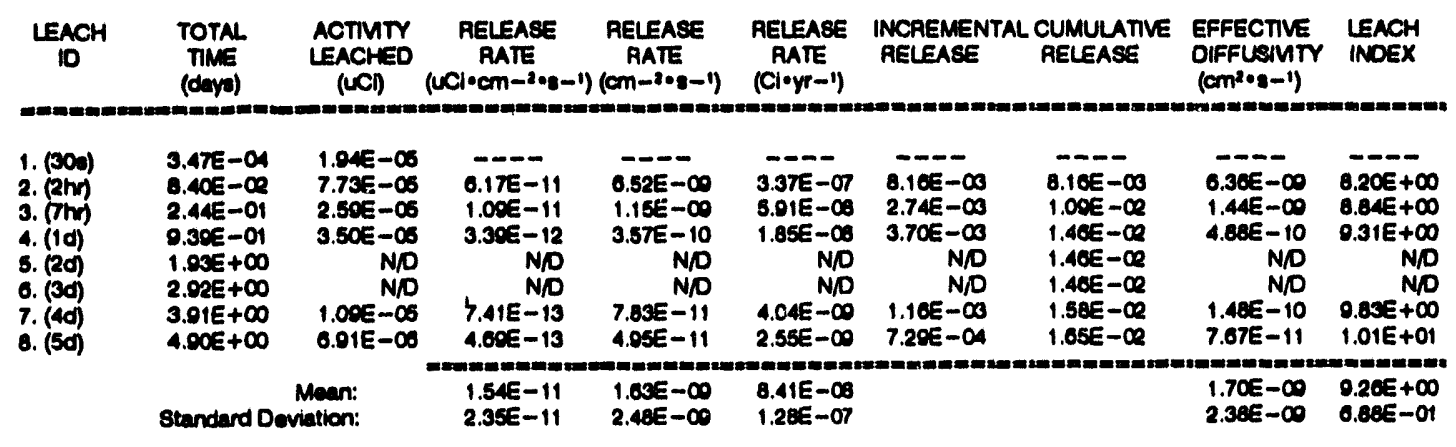

FILE NANE: TC- 9

SAMPLE ID: Peach Bottom \#8

\begin{tabular}{|c|c|c|c|c|c|c|c|c|c|}
\hline $\begin{array}{l}\text { LEACH } \\
\text { ID }\end{array}$ & $\begin{array}{c}\text { TOTAL } \\
\text { TINE } \\
\text { (deys) }\end{array}$ & $\begin{array}{l}\text { ACTIVTY } \\
\text { LEACHED } \\
\text { (UCI) }\end{array}$ & $\begin{array}{l}\text { RELEABE } \\
\text { RATE } \\
\text { (UCi.cm-2.9. }\end{array}$ & $\begin{array}{l}\text { RELEASE } \\
\text { RATE } \\
(\mathrm{cm}-2 \cdot 8-1)\end{array}$ & $\begin{array}{l}\text { RELEASE } \\
\text { RATE } \\
\text { (Cl-yr-1) }\end{array}$ & $\begin{array}{l}\text { INCREMENT } \\
\text { RELEASE }\end{array}$ & $\begin{array}{l}\text { CUMULATIVE } \\
\text { RELEASE }\end{array}$ & $\begin{array}{l}\text { EFFECTIVE } \\
\text { DIFFUSIVTY } \\
\left(\mathrm{cm}^{2} \bullet \mathrm{g}^{-1)}\right.\end{array}$ & $\begin{array}{l}\text { LEACH } \\
\text { INDEX }\end{array}$ \\
\hline \multirow[t]{2}{*}{$\begin{array}{l}\text { 1. (300) } \\
\text { 2. (2hy) } \\
\text { 3. (7hy) } \\
\text { 4. (1d) } \\
\text { 5. (2d) } \\
\text { 6. (3d) } \\
\text { 7. (4d) } \\
\text { 8. (5d) }\end{array}$} & $\begin{array}{l}3.47 E-04 \\
8.40 E-\infty \\
2.44 E-01 \\
9.30 E-01 \\
1.93 E+\infty \\
2.92 E+\infty \\
3.91 E+\infty \\
4.90 E+\infty\end{array}$ & $\begin{array}{l}1.54 E-\infty \\
2.53 E-\infty \\
1.04 E-\infty \\
1.01 E-01 \\
2.05 E-\infty \\
2.74 E-\infty \\
1.20 E-\infty \\
0.46 E-\infty\end{array}$ & $\begin{array}{l}2.02 E-\infty \\
8.15 E-10 \\
9.80 E-\infty \\
1.80 E-10 \\
1.80 E-10 \\
8.53 E-11 \\
4.30 E-10\end{array}$ & 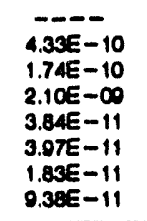 & $\begin{array}{l}--0--\infty \\
1.04 E-\infty \\
4.17 E-\infty \\
5.02 E-\infty \\
0.20 E-07 \\
0.51 E-\infty 7 \\
4.37 E-07 \\
2.25 E-\infty\end{array}$ & $\begin{array}{l}5.42 E-\infty 4 \\
4.17 E-O 4 \\
2.17 E-\infty \\
5.68 E-C 4 \\
5.66 E-O 4 \\
2.70 E-O 4 \\
1.38 E-\infty\end{array}$ & $\begin{array}{l}5.42 E \\
9.50 E \\
2.20 E \\
2.32 E \\
2.38 E \\
2.41 E \\
2.55 E\end{array}$ & $\begin{array}{l}-.-16 \\
3.33 E \\
1.68 E \\
1.46 E \\
2.70 E \\
8.08 E \\
2.76 E\end{array}$ & $\begin{array}{l}1.00 E+01 \\
1.06 E+01 \\
7.78 E+\infty \\
1.08 E+01 \\
1.00 E+01 \\
1.11 E+01 \\
9.56 E+\infty\end{array}$ \\
\hline & & $\begin{array}{l}\text { Ian: } \\
\text { ion: }\end{array}$ & $\begin{array}{l}1.03 E-\infty \\
3.27 E-\infty\end{array}$ & $\begin{array}{l}4.13 E-10 \\
7.00 E-10\end{array}$ & $\begin{array}{l}9.80 E-\infty \\
1.07 E-\infty\end{array}$ & & & $\begin{array}{l}2.45 E-\infty \\
5.84 E-\infty\end{array}$ & $\begin{array}{l}1.01 E+01 \\
1.05 E+\infty\end{array}$ \\
\hline
\end{tabular}

FILE NANE: $80-125$

8AMPLE ID: Peach Bottom

\begin{tabular}{|c|c|c|c|c|c|c|c|c|c|}
\hline $\begin{array}{l}\text { LEACH } \\
\text { ID }\end{array}$ & $\begin{array}{l}\text { TOTAL } \\
\text { Tine } \\
\text { (days) }\end{array}$ & $\begin{array}{c}\text { ACTIVTY } \\
\text { LEACHED } \\
(U C I)\end{array}$ & $\begin{array}{l}\text { RELEASE } \\
\text { AATE } \\
(\text { UCI.cm-2 }\end{array}$ & $\begin{array}{c}\text { RELEASE } \\
\text { RATE } \\
(\mathrm{cm}-2 \cdot 8-1)\end{array}$ & $\begin{array}{l}\text { RELEASE } \\
\text { RATE } \\
(C \cdot \bullet \gamma-1)\end{array}$ & $\begin{array}{l}\text { INCAEMENTA } \\
\text { RELEASE }\end{array}$ & $\begin{array}{l}\text { CUMULATVE } \\
\text { RELEASE }\end{array}$ & $\begin{array}{l}\text { EFFECTIVE } \\
\text { DIFFUSIVTY } \\
\left(\mathrm{cm}^{2} \cdot \mathrm{g}^{-1}\right)\end{array}$ & $\begin{array}{l}\text { LEACH } \\
\text { INDEX }\end{array}$ \\
\hline \multirow[t]{2}{*}{$\begin{array}{l}\text { 1. }(30 \mathrm{~d}) \\
\text { 2. (2hm) } \\
\text { 3. }(\mathrm{mm}) \\
\text { 4. (1d) } \\
\text { 5. (2d) } \\
\text { 6. (3d) } \\
\text { 7. (4d) } \\
\text { 8. (5o) }\end{array}$} & $\begin{array}{l}3.4 \pi E-\infty \\
8.40 E-\infty \\
2.44 E-01 \\
9.30 E-01 \\
1.03 E+\infty \\
2.02 E+\infty \\
3.91 E+\infty \\
1.00 E+\infty\end{array}$ & $\begin{array}{r}2.32 E-04 \\
N / D \\
N D \\
0.72 E-O 4 \\
1.00 E-\infty \\
6.40 E-04 \\
7.22 E-O 4 \\
9.00 E-O 4\end{array}$ & $\begin{array}{r}N / D \\
N D \\
9.39 E-11 \\
7.30 E-11 \\
4.40 E-11 \\
4.80 E-11 \\
6.58 E-11\end{array}$ & $\begin{array}{r}---D \\
N / D \\
N / D \\
7.01 E-11 \\
0.22 E-11 \\
3.70 E-11 \\
4.12 E-11 \\
5.54 E-11\end{array}$ & $\begin{array}{r}N, D \\
N D \\
5.12 E-07 \\
4.02 E-07 \\
2.40 E-07 \\
2.00 E-07 \\
3.58 E-07\end{array}$ & $\begin{array}{r}N D \\
N, D \\
8.10 E-O A \\
9.10 E-O A \\
5.47 E-C A \\
0.00 E-C 4 \\
8.17 E-C 4\end{array}$ & $\begin{array}{r}---\infty D \\
N / D \\
8.10 E-04 \\
1.74 E-\infty \\
2.28 E-\infty \\
1.89 E-\infty \\
3.71 E-\infty\end{array}$ & $\begin{array}{r}N / O \\
N / D \\
2.39 E-11 \\
3.83 E-11 \\
2.35 E-11 \\
4.11 E-11 \\
0.62 E-11\end{array}$ & $\begin{array}{r}N D \\
N D \\
1.00 E+01 \\
1.04 E+01 \\
1.00 E+01 \\
1.04 E+01 \\
1.00 E+01\end{array}$ \\
\hline & & ian: & $\begin{array}{l}6.58 E-11 \\
1.80 E-11\end{array}$ & $\begin{array}{l}5.50 E-11 \\
1.51 E-11\end{array}$ & & & & $\begin{array}{l}-11 \\
-11\end{array}$ & $\begin{array}{l}1.04 E+01 \\
2.23 E-01\end{array}$ \\
\hline
\end{tabular}

FILE NAME: $1-120$

SAMPLE ID: Peach Botton $\%$

\begin{tabular}{|c|c|c|c|c|c|c|c|c|c|}
\hline $\begin{array}{l}\text { LEACH } \\
\text { ID }\end{array}$ & $\underset{\substack{\text { TMNE } \\
\text { (days) }}}{\text { TOTAL }}$ & $\begin{array}{l}\text { ACTIVTY } \\
\text { LEACHED } \\
\text { (UCI) }\end{array}$ & $\begin{array}{l}\text { RELEASE } \\
\text { AATE } \\
\text { (UCl.cm-2.s }\end{array}$ & $\begin{array}{l}\text { RELEAEE } \\
\text { RATE } \\
(\mathrm{cm}-2 \cdot 8-1)\end{array}$ & $\begin{array}{c}\text { RELEASE } \\
\text { RATE } \\
(C i \bullet Y r-1)\end{array}$ & $\begin{array}{l}\text { INCAENENTA } \\
\text { RELEASE }\end{array}$ & $\begin{array}{l}\text { CUMULATIVE } \\
\text { RELEASE }\end{array}$ & $\begin{array}{l}\text { EFFECIVE } \\
\text { DIFFUSIMTY } \\
\left(\mathrm{cm}^{2} \cdot \mathrm{s}^{-1}\right)\end{array}$ & $\begin{array}{l}\text { IEACH } \\
\text { INDEX }\end{array}$ \\
\hline \multirow[t]{2}{*}{$\begin{array}{l}\text { 1. }(30 \mathrm{~d}) \\
\text { 2. (2m) } \\
\text { 3. }(7 \mathrm{~mm}) \\
\text { 4. (1d) } \\
\text { 5. (2d) } \\
\text { 6. (3d) } \\
\text { 7. (4d) } \\
\text { 8. (5d) }\end{array}$} & $\begin{array}{l}3.47 E-\infty 1 \\
8.40 E-\infty \\
2.44 E-01 \\
9.30 E-01 \\
1.93 E+\infty \\
2.92 E+\infty \\
3.01 E+\infty \\
4.00 E+\infty\end{array}$ & $\begin{array}{r}2.74 E-\infty 6 \\
5.80 E-\infty \\
1.47 E-\infty \\
N / D \\
4.16 E-\infty \\
3.67 E-\infty 5 \\
2.00 E-\infty 6 \\
4.10 E-\infty\end{array}$ & $\begin{array}{r}-\overline{4.6 E E-12} \\
6.13 E-12 \\
N / D \\
2.81 E-12 \\
2.42 E-12 \\
1.41 E-12 \\
2.78 E-12\end{array}$ & $\begin{array}{r}7.70 E-10 \\
1.02 E-\infty \\
N D \\
4.00 E-10 \\
4.02 E-10 \\
2.36 E-10 \\
4.03 E-10\end{array}$ & $\begin{array}{r}--5 E-\infty 8 \\
3.34 E-\infty 8 \\
N / D \\
1.53 E-\infty 8 \\
1.32 E-\infty \\
7.70 E-\infty \\
1.52 E-\infty\end{array}$ & $\begin{array}{r}0.75 E-\infty 4 \\
2.44 E-\infty \\
N D \\
6.91 E-\infty \\
5.94 E-\infty \\
3.47 E-\infty \\
0.63 E-\infty\end{array}$ & $\begin{array}{l}-.75 E-\infty \\
3.41 E-\infty \\
3.41 E-\infty \\
1.03 E-\infty \\
1.03 E-\infty \\
1.07 E-\infty \\
2.60 E-\infty\end{array}$ & $\begin{array}{r}-0 .-11 \\
0.00 E-11 \\
1.14 E-\infty \\
N / D \\
2.17 E-\infty \\
2.77 E-\infty \\
1.34 E-\infty \\
0.72 E-\infty\end{array}$ & $\begin{array}{r}1.00 E+\infty \\
8.01 E+\infty \\
N / D \\
8.00 E+\infty \\
8.50 E+\infty \\
8.07 E+\infty \\
8.17 E+\infty\end{array}$ \\
\hline & andard D & tion: & $\begin{array}{l}3.37 E-12 \\
1.57 E-12\end{array}$ & $\begin{array}{l}5.01 E-10 \\
2.01 E-10\end{array}$ & $\begin{array}{l}1.84 E-\infty \\
8.54 E-\infty\end{array}$ & & & $\begin{array}{l}2.37 E-\infty \\
2.12 E-\infty\end{array}$ & $\begin{array}{l}0.885+\infty \\
5.785-01\end{array}$ \\
\hline
\end{tabular}




\section{Appendix E}

Table E-25. (continued).

FILE NAME: Cs-137

SAMFIE ID: Peach Botiom "*B

\begin{tabular}{|c|c|c|c|c|c|c|c|c|c|}
\hline $\begin{array}{l}\text { LEACH } \\
\text { ID }\end{array}$ & $\begin{array}{l}\text { TOTAL } \\
\text { TIME } \\
\text { (daya) }\end{array}$ & $\begin{array}{c}\text { ACTVITY } \\
\text { LEACHED } \\
\text { (UCi) }\end{array}$ & $\begin{array}{l}\text { RELEASE } \\
\text { RATE } \\
(\mathrm{CCl} \cdot \mathrm{cm}-\mathrm{i} \cdot \mathrm{g}-\end{array}$ & $\begin{array}{l}\text { RELEASE } \\
\text { AATE } \\
(\mathrm{cm}-2 \cdot 9-1)\end{array}$ & $\begin{array}{c}\text { RELEASE } \\
\text { RATE } \\
\left(C \mid \cdot \mathrm{y}^{-1}\right)\end{array}$ & $\begin{array}{l}\text { INCREMENT } \\
\text { AELEASE }\end{array}$ & $\begin{array}{l}\text { CUMULATIVE } \\
\text { RELEASE }\end{array}$ & $\begin{array}{l}\text { EFFECTIVE } \\
\text { DIFFUSIVTY } \\
\left(\mathrm{cm}^{2} \cdot \mathrm{s}^{-1}\right)\end{array}$ & $\begin{array}{l}\text { LEACH } \\
\text { INDEX }\end{array}$ \\
\hline \multirow[t]{2}{*}{$\begin{array}{l}\text { 1. (30s) } \\
\text { 2. (2hr) } \\
\text { 3. (7hr) } \\
\text { 4. (1d) } \\
\text { 5. (2d) } \\
\text { 6. (3d) } \\
\text { 7. (4d) } \\
\text { 8. (5d) }\end{array}$} & $\begin{array}{l}3.47 E-\infty 4 \\
8.40 E-\infty \\
2.44 E-01 \\
9.39 E-01 \\
1.93 E+\infty \\
2.92 E+\infty \\
3.91 E+\infty \\
4.90 E+\infty\end{array}$ & $\begin{array}{l}3.25 E-\infty 4 \\
7.70 E-\infty 4 \\
8.11 E-\infty 4 \\
1.46 E-\infty \\
1.12 E-\infty \\
1.11 E-\infty \\
2.38 E-\infty \\
2.38 E-\infty\end{array}$ & $\begin{array}{l}-\overline{-}-1 \\
0.22 E-10 \\
3.39 E-10 \\
1.41 E-10 \\
7.55 E-11 \\
7.51 E-11 \\
1.61 E-10 \\
1.61 E-10\end{array}$ & $\begin{array}{l}--\overline{1.14 E-\infty} \\
0.22 E-10 \\
2.59 E-10 \\
1.39 E-10 \\
1.38 E-10 \\
2.95 E-10 \\
2.96 E-10\end{array}$ & $\begin{array}{l}---- \\
3.39 E-\infty \\
1.85 E-00 \\
7.68 E-07 \\
4.12 E-07 \\
4.09 E-07 \\
8.77 E-07 \\
8.79 E-07\end{array}$ & $\begin{array}{l}---- \\
1.43 E-\infty \\
1.49 E-\infty \\
2.08 E-\infty \\
2.05 E-\infty \\
2.04 E-\infty \\
4.36 E-\infty \\
4.36 E-\infty\end{array}$ & $\begin{array}{l}--\overline{1}-\infty \\
2.43 E-\infty \\
2.92 E-\infty 3 \\
5.59 E-\infty \\
7.64 E-\infty \\
9.67 E-\infty \\
1.40 E-\infty \\
1.84 E-\infty\end{array}$ & $\begin{array}{l}-\overline{1.95 E-10} \\
4.24 E-10 \\
2.55 E-10 \\
1.90 E-10 \\
3.25 E-10 \\
2.11 E-\infty \\
2.74 E-\infty\end{array}$ & $\begin{array}{l}-\overline{0.71 E+\infty} \\
9.37 E+\infty \\
9.50 E+\infty \\
9.72 E+\infty \\
9.40 E+\infty \\
8.68 E+\infty \\
8.50 E+\infty\end{array}$ \\
\hline & anc & $\begin{array}{l}\text { an: } \\
\text { tion: }\end{array}$ & $\begin{array}{l}2.25 E-10 \\
1.82 E-10\end{array}$ & $\begin{array}{l}4.13 E-10 \\
3.33 E-10\end{array}$ & $\begin{array}{l}1.23 E-06 \\
9.90 E-07\end{array}$ & & & $\begin{array}{l}8.92 E-10 \\
9.88 E-10\end{array}$ & $\begin{array}{l}9.30 E+\infty \\
4.48 E-01\end{array}$ \\
\hline
\end{tabular}

FILE NAME: Fe

SAMPLE ID: Peech Bottom \#8

\begin{tabular}{|c|c|c|c|c|c|c|c|c|c|}
\hline$\underset{I D}{\text { LEACH }}$ & $\begin{array}{l}\text { TOTAL } \\
\text { IIME } \\
\text { (days) }\end{array}$ & $\begin{array}{l}\text { QUANTITY } \\
\text { LEACHED } \\
\text { (ug) }\end{array}$ & $\begin{array}{c}\text { RELEASE } \\
\text { RATE } \\
(\mathrm{ug} \cdot \mathrm{cm}-2 \cdot \mathrm{s}-1)\end{array}$ & $\begin{array}{l}\text { AELEASE } \\
\text { RATE } \\
(\mathrm{cm}-2 \cdot s-1)\end{array}$ & $\begin{array}{c}\text { RELEASE } \\
\text { RATE } \\
(g \cdot y r-1)\end{array}$ & $\begin{array}{l}\text { INCREMEN } \\
\text { RELEASE }\end{array}$ & $\begin{array}{l}\text { CUMULATIVE } \\
\text { AELEASE }\end{array}$ & $\begin{array}{l}\text { EFFECTIVE } \\
\text { DIFFUSIVTY } \\
\left(\mathrm{cm}^{2} \bullet \mathrm{s}^{-1)}\right.\end{array}$ & $\begin{array}{l}\text { LEACH } \\
\text { INDEX }\end{array}$ \\
\hline \multirow[t]{2}{*}{$\begin{array}{l}\text { 1. (30s) } \\
\text { 2. (2hr) } \\
\text { 3. (7hr) } \\
\text { 4. (1d) } \\
\text { 5. (2d) } \\
\text { 6. (3d) } \\
\text { 7. (4d) } \\
\text { 8. (5d) }\end{array}$} & $\begin{array}{l}3.47 E-04 \\
8.40 E-\infty \\
2.44 E-01 \\
9.39 E-01 \\
1.93 E+\infty \\
2.92 E+\infty \\
3.91 E+\infty \\
4.90 E+\infty\end{array}$ & $\begin{array}{l}2.03 E+\infty \\
1.10 E+\infty \\
3.28 E+\infty \\
1.03 E+\infty \\
1.38 E+\infty \\
8.62 E+01 \\
5.17 E+01 \\
8.02 E+01\end{array}$ & $\begin{array}{l}----- \\
8.81 E-\infty 4 \\
1.37 E-\infty 4 \\
1.00 E-\infty \\
9.33 E-\infty \\
5.84 E-\infty \\
3.50 E-\infty \\
5.85 E-\infty\end{array}$ & $\begin{array}{l}--\overline{2}-1 \\
2.04 E-10 \\
3.17 E-11 \\
2.31 E-12 \\
2.16 E-12 \\
1.35 E-12 \\
8.09 E-13 \\
1.35 E-12\end{array}$ & $\begin{array}{l}-\overline{-80 E+\infty} \\
7.47 E-01 \\
5.45 E-\infty \\
5.09 E-\infty \\
3.18 E-\infty \\
1.91 E-\infty \\
3.19 E-\infty\end{array}$ & $\begin{array}{l}2.55 E-\infty 4 \\
7.57 E-\infty 6 \\
2.39 E-\infty 6 \\
3.19 E-\infty 6 \\
1.99 E-\infty 6 \\
1.19 E-\infty 6 \\
1.99 E-\infty 5\end{array}$ & $\begin{array}{l}-.55 E-04 \\
2.5 .30 E-04 \\
3.54 E-04 \\
3.86 E-04 \\
4.06 E-04 \\
4.18 E-04 \\
4.38 E-04\end{array}$ & $\begin{array}{l}-\overline{0.20 E-12} \\
1.10 E-12 \\
2.03 E-14 \\
4.01 E-14 \\
3.11 E-14 \\
1.59 E-14 \\
5.72 E-14\end{array}$ & $\begin{array}{l}1.12 E+01 \\
1.20 E+01 \\
1.37 E+01 \\
1.33 E+01 \\
1.35 E+01 \\
1.38 E+01 \\
1.32 E+01\end{array}$ \\
\hline & onten & $\begin{array}{l}\text { ean: } \\
\text { tion: }\end{array}$ & $\begin{array}{l}1.50 E-04 \\
3.02 E-04\end{array}$ & $\begin{array}{l}3.47 E-11 \\
0.07 E-11\end{array}$ & $\begin{array}{l}8.20 E-01 \\
1.64 E+\infty\end{array}$ & & & $\begin{array}{l}1.07 E-12 \\
2.13 E-12\end{array}$ & $\begin{array}{l}1.30 E+01 \\
9.13 E-01\end{array}$ \\
\hline
\end{tabular}


Table E-26. Peach Bottom sample \#12 cumulative fraction releases, release rates, effective diffusivities, and leachability indexes.

FILENAME: $\mathrm{C}-14$

SAMPLE 1D: PEACHBOTTOM \#12

\begin{tabular}{|c|c|c|c|c|c|c|c|c|c|}
\hline$\underset{I D}{\text { IEACH }}$ & $\begin{array}{l}\text { CUMULATIVE } \\
\text { LEACH TIME } \\
\text { (day) }\end{array}$ & $\begin{array}{l}\text { ACTIVTY } \\
\text { LEACHEO } \\
\text { (UCI) }\end{array}$ & 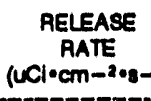 & $\begin{array}{c}\text { RELEASE } \\
\text { RATE } \\
(\mathrm{cm}-2 \cdot 8-1)\end{array}$ & $\begin{array}{l}\text { RELEASE } \\
\text { RATE } \\
\text { (Cl•yr-1) }\end{array}$ & $\begin{array}{l}\text { INCREMENTA } \\
\text { RELEASE }\end{array}$ & $\begin{array}{l}\text { CUMULATIVE } \\
\text { RELEASE }\end{array}$ & $\begin{array}{l}\text { EFFECTIVE } \\
\text { DIFFUSIVTY } \\
\left(\mathrm{cm}^{2} \cdot s-1\right)\end{array}$ & $\begin{array}{l}\text { LEACH } \\
\text { INDEX }\end{array}$ \\
\hline \multirow[t]{2}{*}{$\begin{array}{l}\text { 1. (30s) } \\
\text { 2. (2hr) } \\
\text { 3. (7hr) } \\
\text { 4. (1d) } \\
\text { 5. (2d) } \\
\text { 6. (3d) } \\
\text { 7. (4d) } \\
\text { 8. (5d) }\end{array}$} & $\begin{array}{l}3.47 E-\infty \\
8.37 E-\infty \\
2.02 E-01 \\
1.00 E+\infty \\
2.00 E+\infty \\
3.00 E+\infty \\
4.00 E+\infty \\
5.00 E+\infty\end{array}$ & $\begin{array}{l}7.80 E-\infty \\
1.48 E-\infty \\
9.61 E-\infty \\
7.08 E-\infty \\
9.85 E-\infty \\
1.07 E-\infty \\
4.20 E-\infty \\
3.38 E-\infty\end{array}$ & $\begin{array}{l}-\overline{-}-- \\
1.20 E-\infty \\
3.39 E-\infty \\
7.08 E-10 \\
7.23 E-10 \\
7.84 E-10 \\
3.15 E-10 \\
2.48 E-10\end{array}$ & 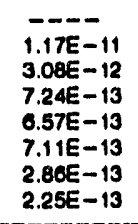 & $\begin{array}{l}--\overline{-}-\infty \\
0.43 E-\infty \\
1.09 E-\infty \\
3.97 E-\infty \\
3.00 E-\infty \\
3.00 E-\infty \\
1.57 E-\infty \\
1.23 E-\infty\end{array}$ & $\begin{array}{l}--\overline{1.34 E-\infty} \\
8.72 E-\infty \\
6.07 E-\infty \\
8.94 E-\infty \\
9.68 E-\infty \\
3.89 E-\infty \\
3.06 E-\infty\end{array}$ & $\begin{array}{l}-\overline{1.34 E-\infty} \\
2.21 E-\infty 6 \\
2.91 E-\infty \\
3.80 E-\infty 6 \\
4.77 E-\infty \\
5.16 E-\infty \\
5.47 E-\infty 5\end{array}$ & 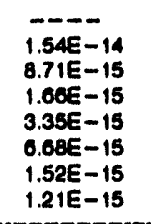 & 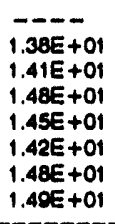 \\
\hline & & $\begin{array}{l}\text { an: } \\
\text { on: }\end{array}$ & $\begin{array}{l}2.74 E-\infty \\
4.27 E-\infty\end{array}$ & $\begin{array}{l}2.49 E-12 \\
3.88 E-12\end{array}$ & $\begin{array}{l}1.36 E-\infty 6 \\
2.13 E-\infty 5\end{array}$ & & & $\begin{array}{l}5.50 E-15 \\
4.83 E-15\end{array}$ & $\begin{array}{l}1.44 E+01 \\
3.05 E-01\end{array}$ \\
\hline
\end{tabular}

FILE NAME: Fo-55

SAMPLE ID: PEACHBOTTOM *12

\begin{tabular}{|c|c|c|c|c|c|c|c|c|c|}
\hline $\begin{array}{l}\text { LEACH } \\
\text { ID }\end{array}$ & $\begin{array}{l}\text { CUMULATIVE } \\
\text { UEACH TIME } \\
\text { (days) }\end{array}$ & $\begin{array}{c}\text { ACTIVTY } \\
\text { LEACHED } \\
\text { (UCi) }\end{array}$ & $\begin{array}{l}\text { RELEASE } \\
\text { RATE } \\
\left(U \mathrm{Cl} \cdot \mathrm{cm}^{2} \cdot \mathrm{s}-1\right.\end{array}$ & $\begin{array}{l}\text { AELEASE } \\
\text { RATE } \\
(\mathrm{cm}-2 \cdot \mathrm{s}-1)\end{array}$ & $\begin{array}{l}\text { RELEASE } \\
\text { RATE } \\
\text { (Ci・yr-1) }\end{array}$ & $\begin{array}{l}\text { INCREMEN } \\
\text { RELEASE }\end{array}$ & $\begin{array}{l}\text { CUMULATIVE } \\
\text { RELEASE }\end{array}$ & $\begin{array}{l}\text { EFFECTIVE } \\
\text { DIFFUSIVTY } \\
\left(\mathrm{cm}^{2} \cdot \mathrm{s}-1\right)\end{array}$ & $\begin{array}{l}\text { LEACH } \\
\text { INDEX }\end{array}$ \\
\hline \multirow[t]{2}{*}{$\begin{array}{l}\text { 1. (30s) } \\
\text { 2. (2hr) } \\
\text { 3. (7hr) } \\
\text { 4. (1d) } \\
\text { 5. (2d) } \\
\text { 6. (3d) } \\
\text { 7. (4d) } \\
\text { 8. (5d) }\end{array}$} & $\begin{array}{l}3.47 E-\infty 4 \\
8.37 E-\infty \\
2.02 E-01 \\
1.00 E+\infty \\
2.00 E+\infty \\
3.00 E+\infty \\
4.00 E+\infty \\
5.00 E+\infty\end{array}$ & $\begin{array}{l}7.86 E-\infty 4 \\
8.63 E-\infty 4 \\
5.81 E-\infty \\
2.44 E-\infty \\
2.88 E-\infty \\
1.26 E-\infty \\
2.62 E-\infty \\
2.58 E-\infty\end{array}$ & $\begin{array}{l}--\overline{-}- \\
7.61 E-10 \\
2.05 E-\infty \\
2.53 E-10 \\
2.11 E-10 \\
9.28 E-10 \\
1.93 E-10 \\
1.90 E-10\end{array}$ & 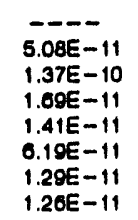 & $\begin{array}{l}-\overline{-19 E-\infty} \\
1.02 E-\infty \\
1.26 E-\infty \\
1.05 E-\infty \\
4.62 E-\infty \\
9.59 E-07 \\
9.43 E-07\end{array}$ & $\begin{array}{l}-.--- \\
5.76 E-\infty \\
3.88 E-C 4 \\
1.63 E-O 4 \\
1.92 E-C 4 \\
8.43 E-C 4 \\
1.75 E-C 4 \\
1.72 E-24\end{array}$ & $\begin{array}{l}5.76 E-\infty \\
4.45 E-04 \\
0.08 E-04 \\
8.00 E-04 \\
1.64 E-\infty \\
1.82 E-\infty \\
1.99 E-\infty\end{array}$ & $\begin{array}{l}2.86 E-13 \\
1.71 E-11 \\
8.08 E-13 \\
1.55 E-12 \\
5.00 E-11 \\
3.07 E-12 \\
3.83 E-12\end{array}$ & $\begin{array}{l}-\overline{1.25 E+01} \\
1.08 E+01 \\
1.20 E+01 \\
1.18 E+01 \\
1.03 E+01 \\
1.15 E+01 \\
1.14 E+01\end{array}$ \\
\hline & & & $\begin{array}{l}6.55 E-10 \\
6.35 E-10\end{array}$ & $\begin{array}{l}4.37 E-11 \\
4.24 E-11\end{array}$ & $\begin{array}{l}3.26 E-\infty \\
3.16 E-\infty\end{array}$ & & & $\begin{array}{l}1.11 E-11 \\
1.70 E-11\end{array}$ & $\begin{array}{l}1.15 E+01 \\
7.05 E-01\end{array}$ \\
\hline
\end{tabular}

FILE NAME: CO-60

SAMPLE ID: PEACH BOTTOM $* 12$

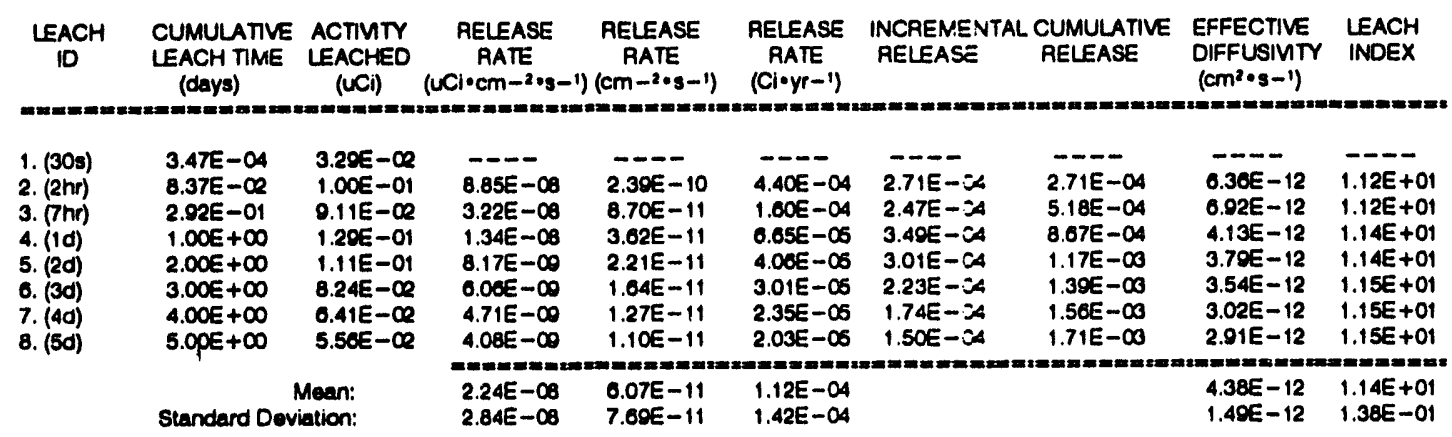

FILE NAME: Ni-63

SAMPLE ID: PEACH BOTTOM *12

\begin{tabular}{|c|c|c|c|c|c|c|c|c|c|}
\hline $\begin{array}{l}\text { LEACH } \\
\text { ID }\end{array}$ & $\begin{array}{l}\text { CUMULATIVE } \\
\text { LEACH TIME } \\
\text { (days) }\end{array}$ & $\begin{array}{l}\text { ACTMTY } \\
\text { LEACHED } \\
\text { (UCi) }\end{array}$ & $\begin{array}{l}\text { RELEASE } \\
\text { RATE } \\
\left(\omega \mathrm{Cl} \cdot \mathrm{cm}^{2} \cdot \mathrm{c}^{-}\right.\end{array}$ & $\begin{array}{l}\text { RELEASE } \\
\text { AATE } \\
(\mathrm{cm}-2 \cdot s-1)\end{array}$ & $\begin{array}{l}\text { RELEASE } \\
\text { RATE } \\
(C i \cdot \gamma r-1)\end{array}$ & \multicolumn{2}{|c|}{$\begin{array}{l}\text { INCREVENTAL CUMULATIVE } \\
\text { RELEASE }\end{array}$} & $\begin{array}{l}\text { EFFECTIVE } \\
\text { DIFFUSIVIT } \\
\left(\mathrm{cm}^{2} \cdot \mathrm{s}^{-1}\right)\end{array}$ & $\begin{array}{l}\text { LEACH } \\
\text { INDEX }\end{array}$ \\
\hline $\begin{array}{l}\text { 1. (30s) } \\
\text { 2. (2hr) } \\
\text { 3. (7hrr) } \\
\text { 4. (1d) } \\
\text { 5. (2d) } \\
\text { o. (3d) } \\
\text { 7. (4d) } \\
\text { 8. (5d) }\end{array}$ & $\begin{array}{l}3.47 E-\infty 4 \\
8.37 E-\infty \\
2.02 E-01 \\
1.00 E+\infty \\
2.00 E+\infty \\
3.00 E+\infty \\
4.00 E+\infty \\
5.00 E+\infty\end{array}$ & $\begin{array}{l}5.50 E-\infty \\
7.13 E-\infty \\
5.07 E-\infty \\
9.00 E-\infty \\
0.70 E-\infty \\
4.42 E-\infty \\
3.70 E-\infty \\
3.06 E-\infty\end{array}$ & $\begin{array}{l}---\overline{-}-\infty \\
2.11 E-\infty \\
9.42 E-10 \\
4.99 E-10 \\
3.25 E-10 \\
2.72 E-10 \\
2.25 E-10\end{array}$ & $\begin{array}{l}--\overline{-}- \\
9.71 E-10 \\
3.25 E-10 \\
1.46 E-10 \\
7.70 E-11 \\
5.01 E-11 \\
4.20 E-11 \\
3.47 E-11\end{array}$ & $\begin{array}{l}-\overline{-}-13 E-\infty \\
1.05 E-\infty \\
4.09 E-\infty \\
2.48 E-\infty \\
1.62 E-\infty \\
1.35 E-\infty \\
1.12 E-\infty\end{array}$ & 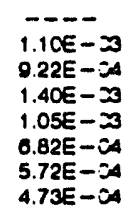 & $\begin{array}{l}-\overline{-10 E-\infty} \\
2.02 E-\infty \\
3.43 E-\infty \\
4.47 E-\infty \\
5.16 E-\infty \\
5.73 E-\infty \\
6.20 E-\infty\end{array}$ & $\begin{array}{l}--\overline{1}-105 E-10 \\
9.07 E-11 \\
6.70 E-11 \\
4.61 E-11 \\
3.32 E-11 \\
3.28 E-11 \\
2.88 E-11\end{array}$ & $\begin{array}{l}--\overline{9}-\overline{-}- \\
1.00 E+01 \\
1.02 E+01 \\
1.03 E+01 \\
1.05 E+01 \\
1.05 E+01 \\
1.05 E+01\end{array}$ \\
\hline & Standard 0 & $\begin{array}{l}\text { an: } \\
\text { on: }\end{array}$ & $\begin{array}{l}1.52 E-\infty \\
2.04 E-\infty\end{array}$ & $\begin{array}{l}2.35 E-10 \\
3.15 E-10\end{array}$ & $\begin{array}{l}7.58 E-\infty \\
1.02 E-\infty\end{array}$ & & & $\begin{array}{l}5.85 E-11 \\
2.93 E-11\end{array}$ & $\begin{array}{l}1.03 E+01 \\
2.15 E-01\end{array}$ \\
\hline
\end{tabular}


Table E-26. (continued).

FILE NAME: $8 ;-\infty$

SAMPLE ID: PEACHBOTTOM 112

\begin{tabular}{|c|c|c|c|c|c|c|c|c|c|}
\hline$\underset{10}{\text { LEACH }}$ & $\begin{array}{l}\text { CUMULATIVE } \\
\text { LEACH TIME } \\
\text { (daY) }\end{array}$ & $\begin{array}{l}\text { ACTMTY } \\
\text { LEACHED } \\
\text { (UCD) }\end{array}$ & $\begin{array}{l}\text { AELEABE } \\
\text { RATE } \\
\text { (UCl.cm-1.8. }\end{array}$ & $\begin{array}{c}\text { AELEASE } \\
\text { AATE } \\
\text { ) (cm-1.9-1) }\end{array}$ & $\begin{array}{l}\text { RELEASE } \\
\text { AATE } \\
\text { (Cley-1) }\end{array}$ & $\begin{array}{l}\text { INCAEMENTA } \\
\text { PELEAEE }\end{array}$ & $\begin{array}{l}\text { CUMU } \\
\text { RELE }\end{array}$ & $\begin{array}{l}\text { EFFECTIE } \\
\text { DIFFUSIVTY } \\
\text { (cmens } 1 \text { ) }\end{array}$ & $\begin{array}{l}\text { IEACH } \\
\text { INDEX }\end{array}$ \\
\hline \multirow[t]{2}{*}{$\begin{array}{l}\text { 1. }(300) \\
\text { 2. (2hy) } \\
\text { 3. (7n) } \\
\text { 4. (1d) } \\
\text { 5. (2d) } \\
\text { 6. (4d) } \\
\text { 7. (4d) } \\
\text { 8. (Bd) }\end{array}$} & $\begin{array}{l}3.47 E-\infty \\
8.37 E-\infty \\
2.02 E-01 \\
1.00 E+\infty \\
2.00 E+\infty \\
3.00 E+\infty \\
4.00 E+\infty \\
5.00 E+\infty\end{array}$ & $\begin{array}{r}\text { No } \\
3.20 E-\infty \\
3.47 E-\infty \\
8.68 E-\infty \\
\text { ND } \\
\text { ND } \\
3.40 E-\infty \\
\text { N/D }\end{array}$ & $\begin{array}{r}-E=- \\
4.60 E-12 \\
1.22 E-12 \\
8.60 E-14 \\
N D \\
N D \\
2.54 E-13 \\
\text { NDD }\end{array}$ & $\begin{array}{r}-\overline{4.80 E-10} \\
1.30 E-10 \\
9.43 E-12 \\
N D \\
N D \\
2.70 E-11 \\
N D\end{array}$ & $\begin{array}{r}2.20 E-\infty \\
6.09 E-\infty \\
4.42 E-10 \\
\text { N/D } \\
\text { N/D } \\
1.27 E-\infty \\
\text { N/D }\end{array}$ & $\begin{array}{r}-\overline{5.34 E-O A} \\
3.00 E-O 4 \\
9.10 E-\infty \\
\text { ND } \\
\text { ND } \\
3.07 E-O 4 \\
\text { ND }\end{array}$ & $\begin{array}{l}5.54 E-\infty \\
0.22 E-\infty \\
1.01 E-\infty \\
1.01 E-\infty \\
1.01 E-\infty \\
1.38 E-\infty \\
1.38 E-\infty\end{array}$ & $\begin{array}{r}2.06 E-11 \\
1.54 E-11 \\
2.81 E-13 \\
N / D \\
N / D \\
1.36 E-11 \\
N D\end{array}$ & $\begin{array}{r}1.00 E+01 \\
1.00 E+01 \\
1.20 E+01 \\
\text { ND } \\
\text { ND } \\
1.00 E+01 \\
\text { NDD }\end{array}$ \\
\hline & & an & $\begin{array}{l}1.54 E-12 \\
1.82 E-12\end{array}$ & $\begin{array}{l}1.04 E-10 \\
1.03 E-10\end{array}$ & $\begin{array}{l}7.085-\infty \\
0.08 E-\infty\end{array}$ & & & $\begin{array}{l}-11 \\
-12\end{array}$ & $\begin{array}{l}1.12 \\
7.80\end{array}$ \\
\hline
\end{tabular}

FILE NAME: TC-⿻

SAMPLE ID: PEACH BOTTOM $\$ 12$

\begin{tabular}{|c|c|c|c|c|c|c|c|c|c|}
\hline $\begin{array}{l}\text { LEACH } \\
\text { ID }\end{array}$ & $\begin{array}{l}\text { CUMULATIVE } \\
\text { LEACH TIME } \\
\text { (doyo) }\end{array}$ & $\begin{array}{l}\text { ACTIVT } \\
\text { LEACHED } \\
\text { (UCI) }\end{array}$ & $\begin{array}{l}\text { RELEASE } \\
\text { RATE } \\
\text { (UCl.cm-2o- }\end{array}$ & $\begin{array}{l}\text { RELEASE } \\
\text { RATE } \\
\left(\mathrm{cm}-2 \cdot \mathrm{c}^{-1}\right)\end{array}$ & $\begin{array}{c}\text { RELEASE } \\
\text { AATE } \\
(C l \bullet Y-1)\end{array}$ & $\begin{array}{l}\text { INCAEMEN } \\
\text { AELEASE }\end{array}$ & $\begin{array}{l}\text { CUMULATIVE } \\
\text { RELEASE }\end{array}$ & $\begin{array}{l}\text { EFFECTIVE } \\
\text { DIFFUSIVIT } \\
\text { (cmes-1) }\end{array}$ & $\begin{array}{l}\text { LEACH } \\
\text { INDEX }\end{array}$ \\
\hline \multirow[t]{2}{*}{$\begin{array}{l}\text { 1. }(30 \mathrm{~s}) \\
\text { 2. }(2 \mathrm{~m}) \\
\text { 3. }(7 \mathrm{hr}) \\
\text { 4. (1d) } \\
\text { 5. (2d) } \\
\text { 6. (3d) } \\
\text { 7. (4d) } \\
\text { 8. (5d) }\end{array}$} & $\begin{array}{l}3.47 E-\infty 4 \\
8.37 E-\infty \\
2.02 E-01 \\
1.00 E+\infty \\
2.00 E+\infty \\
3.00 E+\infty \\
4.00 E+\infty \\
5.00 E+\infty\end{array}$ & $\begin{array}{r}N / 0 \\
0.04 E-\infty \\
7.05 E-04 \\
3.52 E-\infty \\
5.00 E-\infty \\
2.07 E-\infty \\
1.00 E-\infty \\
1.67 E-\infty\end{array}$ & 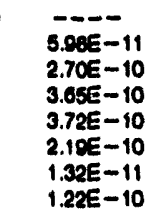 & 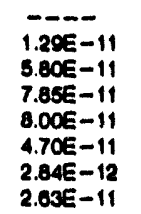 & $\begin{array}{l}-\overline{2.08 E-\infty} \\
1.34 E-\infty \\
1.02 E-\infty \\
1.86 E-\infty \\
1.00 E-\infty \\
0.58 E-\infty \\
0.10 E-07\end{array}$ & $\begin{array}{l}-\overline{1.47 E-\infty} \\
1.64 E-\infty 4 \\
7.56 E-04 \\
1.09 E-\infty \\
0.39 E-\infty 4 \\
3.87 E-\infty \\
3.58 E-04\end{array}$ & $\begin{array}{l}-\overline{-}-\overline{-} \\
1.47 E-\infty \\
1.70 E-\infty 4 \\
9.35 E-\infty 4 \\
2.02 E-\infty \\
2.06 E-\infty \\
2.70 E-\infty \\
3.06 E-\infty\end{array}$ & $\begin{array}{l}-.05 E-14 \\
1.05 E-11 \\
3.00 E-12 \\
1.05 E-11 \\
4.00 E-11 \\
2.01 E-11 \\
1.50 E-13 \\
1.00 E-11\end{array}$ & $\begin{array}{l}-\overline{1.37 E+01} \\
1.15 E+01 \\
1.07 E+01 \\
1.03 E+01 \\
1.05 E+01 \\
1.28 E+01 \\
1.08 E+01\end{array}$ \\
\hline & $\tan$ & $\begin{array}{l}\text { an: } \\
\text { on: }\end{array}$ & $\begin{array}{l}2.03 E-10 \\
1.32 E-10\end{array}$ & $\begin{array}{l}4.30 E-11 \\
2.64 E-11\end{array}$ & $\begin{array}{l}1.01 E-\infty \\
6.59 E-07\end{array}$ & & & $\begin{array}{l}1.00 E-11 \\
1.68 E-11\end{array}$ & $\begin{array}{l}1.15 E+01 \\
1.21 E+\infty\end{array}$ \\
\hline
\end{tabular}

FILE NAME: $1-120$

SAMPLE ID: PEACH BOTTOM 12

\begin{tabular}{|c|c|c|c|c|c|c|c|c|c|}
\hline $\begin{array}{l}\text { LEACH } \\
10\end{array}$ & $\begin{array}{l}\text { CUMULATIVE } \\
\text { LEACH TIME } \\
\text { (days) }\end{array}$ & $\begin{array}{l}\text { ACTMTY } \\
\text { LEACHED } \\
\text { (UCI) }\end{array}$ & $\begin{array}{c}\text { RELEASE } \\
\text { RATE } \\
\text { (LCI.cm-2.s- }\end{array}$ & $\begin{array}{l}\text { RELEASE } \\
\text { AATE } \\
(\mathrm{cm}-2 \cdot 9-1)\end{array}$ & $\begin{array}{l}\text { RELEASE } \\
\text { RATE } \\
(C \mid \cdot Y r-1)\end{array}$ & $\begin{array}{l}\text { INCAEMEN } \\
\text { RELEASE }\end{array}$ & $\begin{array}{l}\text { CUMULATIVE } \\
\text { RELEASE }\end{array}$ & $\begin{array}{l}\text { EFFECTIVE } \\
\text { DIFFUSIVTY } \\
\left(\mathrm{cm}^{2} \cdot \mathrm{s}^{-1)}\right.\end{array}$ & $\begin{array}{l}\text { IEACH } \\
\text { INDEX }\end{array}$ \\
\hline \multirow[t]{2}{*}{$\begin{array}{l}\text { 1. }(300) \\
\text { 2. (2hr) } \\
\text { 3. (7hr) } \\
\text { 4. (1d) } \\
\text { 5. (2d) } \\
\text { 6. (3d) } \\
\text { 7. (4d) } \\
\text { 8. (5d) }\end{array}$} & $\begin{array}{l}3.47 E-\infty \\
0.37 E-\infty \\
2.02 E-01 \\
1.00 E+\infty \\
2.00 E+\infty \\
3.00 E+\infty \\
4.00 E+\infty \\
5.00 E+\infty\end{array}$ & $\begin{array}{r}1.00 E-\infty 6 \\
0.44 E-\infty 6 \\
N / D \\
0.05 E-\infty \\
0.40 E-\infty 6 \\
5.84 E-\infty \\
N D D \\
1.44 E-\infty 4\end{array}$ & $\begin{array}{r}5.63 E-11 \\
N / D \\
6.01 E-12 \\
0.00 E-13 \\
4.30 E-12 \\
N / D \\
1.06 E-11\end{array}$ & $\begin{array}{r}0.42 E-\infty \\
N / D \\
1.10 E-\infty \\
1.10 E-10 \\
7.16 E-10 \\
\text { ND } \\
1.78 E-\infty\end{array}$ & $\begin{array}{r}2.80 E-07 \\
N D \\
3.44 E-\infty \\
3.45 E-\infty \\
2.14 E-\infty 8 \\
N D \\
G .28 E-\infty 8\end{array}$ & $\begin{array}{r}-\overline{1.08 E-\infty} \\
N / D \\
1.11 E-\infty \\
1.57 E-\infty \\
0.78 E-\infty \\
N / D \\
2.42 E-\infty\end{array}$ & $\begin{array}{l}-08 E-\infty \\
1.08 E-\infty \\
1.08 E-\infty \\
2.19 E-\infty \\
2.35 E-\infty \\
3.33 E-\infty \\
3.33 E-\infty \\
5.74 E-\infty\end{array}$ & $\begin{array}{r}9.04 E-\infty \\
N / O \\
4.23 E-\infty \\
1.04 E-10 \\
6.82 E-\infty \\
N / O \\
7.54 E-\infty\end{array}$ & $\begin{array}{r}0.00 E+\infty \\
N / D \\
8.3 \pi E+\infty \\
9.06 E+\infty \\
8.17 E+\infty \\
N / D \\
7.12 E+\infty\end{array}$ \\
\hline & tanda & $\begin{array}{l}\text { can: } \\
\text { ion: }\end{array}$ & $\begin{array}{l}1.58 E-11 \\
2.065-11\end{array}$ & $\begin{array}{l}2.64 E-\infty \\
3.44 E-\infty\end{array}$ & $\begin{array}{l}7.84 E-\infty 8 \\
1.02 E-07\end{array}$ & & & $\begin{array}{l}1.085 \\
2.82 E\end{array}$ & $\begin{array}{l}0.35 E \\
0.316\end{array}$ \\
\hline
\end{tabular}

FILENAME: $\mathrm{Cr}$

8AMPLE ID: PEACHBOTTOM $\$ 12$

\begin{tabular}{|c|c|c|c|c|c|c|c|c|c|}
\hline $\begin{array}{l}\text { LEACH } \\
\text { ID }\end{array}$ & $\begin{array}{l}\text { CUMMUATVE } \\
\text { LEACH TMME } \\
\text { (day) }\end{array}$ & $\begin{array}{l}\text { OUANTIT } \\
\text { LEACHED } \\
\text { (LO) }\end{array}$ & $\begin{array}{l}\text { RELEAES } \\
\text { RATE } \\
\left.g \cdot \mathrm{cm}^{-2} \cdot \mathrm{-}-1\right)\end{array}$ & $\begin{array}{l}\text { RELEASE } \\
\text { AATE } \\
(\mathrm{cm}-2 \cdot 8-1)\end{array}$ & $\begin{array}{c}\text { RELEASE } \\
\text { RATE } \\
\left(g^{\circ} \times-1\right)\end{array}$ & $\begin{array}{l}\text { INCREMENTA } \\
\text { RELEASE }\end{array}$ & $\begin{array}{l}\text { CUMULATIVE } \\
\text { RELEASE }\end{array}$ & $\begin{array}{l}\text { EFFECTIVE } \\
\text { DIFFUSIVIT } \\
\text { (cming-1) }\end{array}$ & $\begin{array}{l}\text { LEACH } \\
\text { INDEXX }\end{array}$ \\
\hline \multirow[t]{2}{*}{$\begin{array}{l}\text { 1. (30d) } \\
\text { 2. (2t) } \\
\text { 3. (7h) } \\
\text { 4. (1d) } \\
\text { 5. (2d) } \\
\text { 6. (3d) } \\
\text { 7. (4d) } \\
\text { 6. (sd) }\end{array}$} & $\begin{array}{l}3.47 E-\infty \\
8.37 E-\infty \\
2.02 E-01 \\
1.00 E+\infty \\
2.00 E+\infty \\
3.00 E+\infty \\
4.00 E+\infty \\
5.00 E+\infty\end{array}$ & $\begin{array}{l}4.50 E+01 \\
0.01 E+01 \\
0.07 E+01 \\
8.00 E+01 \\
7.00 E+01 \\
0.01 E+01 \\
0.23 E+01 \\
5.02 E+01\end{array}$ & $\begin{array}{l}5.03 E-\infty \\
2.14 E-\infty \\
8.30 E-\infty \\
5.63 E-\infty \\
1.80 E-\infty \\
4.58 E=\infty \\
4.34 E-\infty\end{array}$ & $\begin{array}{l}-\overrightarrow{2.31 E}-\infty \\
8.49 E-10 \\
3.31 E-10 \\
2.23 E-10 \\
1.93 E-10 \\
1.81 E-10 \\
1.72 E-1 C\end{array}$ & $\begin{array}{l}-\overline{2.00 E-01} \\
1.07 E-01 \\
4.16 E-\infty \\
2.80 E-\infty \\
2.42 E-\infty \\
2.28 E-\infty \\
2.16 E-\infty\end{array}$ & $\begin{array}{l}--02 E-\infty \\
2.41 E-\infty \\
3.20 E-\infty \\
3.04 E-\infty \\
2.02 E-\infty \\
2.47 E-\infty \\
2.35 E-\infty\end{array}$ & $\begin{array}{l}--\overline{-}-\infty \\
2.02 E-\infty \\
5.03 E-\infty \\
8.23 E-\infty \\
1.13 E-\infty \\
1.30 E-\infty \\
1.04 E-\infty \\
1.87 E-\infty\end{array}$ & $\begin{array}{l}5.03 E-10 \\
6.00 E-10 \\
3.47 E-10 \\
3.87 E-10 \\
4.80 E-10 \\
6.11 E-10 \\
7.09 E-10\end{array}$ & $\begin{array}{l}--25 E+\infty \\
0.16 E+\infty \\
0.40 E+\infty \\
0.41 E+\infty \\
0.31 E+\infty \\
0.21 E+\infty \\
0.16 E+\infty\end{array}$ \\
\hline & $\tan$ & $\begin{array}{l}\text { an: } \\
\text { on: }\end{array}$ & $\begin{array}{l}1.54 \\
1.84\end{array}$ & $\begin{array}{l}6.00 E-10 \\
7.30 E-10\end{array}$ & $\begin{array}{l}7.0 \\
9.16\end{array}$ & & & $\begin{array}{l}-10 \\
-10\end{array}$ & $\begin{array}{l}0.28 \varepsilon+\infty \\
1.10 \varepsilon-01\end{array}$ \\
\hline
\end{tabular}


Table E-26. (continued).

FILE NANE: Fo SAMPLE ID: PEACH BOTTOM

\begin{tabular}{|c|c|c|c|c|c|c|c|c|c|}
\hline $\begin{array}{l}\text { LEACH } \\
\text { ID }\end{array}$ & $\begin{array}{l}\text { CUMULATIVE } \\
\text { LEACH TIME } \\
\text { (days) }\end{array}$ & $\begin{array}{l}\text { QUANTITY } \\
\text { LEACHED } \\
\text { (UD) }\end{array}$ & $\begin{array}{c}\text { RELEASE } \\
\text { RATE } \\
(\text { ug・cm-20g-1) }\end{array}$ & $\begin{array}{l}\text { RELEABE } \\
\text { RATE } \\
(0 m-1 \cdot 8-1)\end{array}$ & $\begin{array}{c}\text { RELEABE } \\
\text { RATE } \\
\left(g^{\circ} y r^{-1}\right)\end{array}$ & $\begin{array}{l}\text { INCAENENT } \\
\text { RELEAEE }\end{array}$ & $\begin{array}{l}\text { CUMULATIVE } \\
\text { RELEABE }\end{array}$ & $\begin{array}{l}\text { EFFECTIVE } \\
\text { DIFFUBIVIT } \\
\left(\mathrm{cm}^{2} \cdot \mathrm{s}^{-1}\right)\end{array}$ & $\begin{array}{l}\text { IEACH } \\
\text { INDEX }\end{array}$ \\
\hline \multirow[t]{2}{*}{$\begin{array}{l}\text { 1. (300) } \\
\text { 2. (2hr) } \\
\text { 3. (7hr) } \\
\text { 4. (1d) } \\
\text { 5. (20) } \\
\text { 6. (3d) } \\
\text { 7. (4d) } \\
\text { 8. (6d) }\end{array}$} & 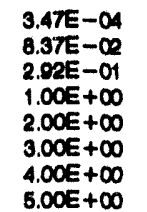 & $\begin{array}{r}N / D \\
5.04 E+01 \\
0.07 E+01 \\
7.20 E+01 \\
5.06 E+01 \\
4.17 E+01 \\
4.36 E+01 \\
N / D\end{array}$ & $\begin{array}{r}---- \\
4.46 E-\infty \\
2.14 E-\infty \\
7.47 E-\infty \\
3.71 E-\infty \\
3.07 E-\infty \\
3.18 E-\infty \\
N / D\end{array}$ & $\begin{array}{r}-.04 E-11 \\
4.08 E-12 \\
1.74 E-12 \\
8.03 E-13 \\
7.14 E-13 \\
7.40 E-13 \\
\text { NDD }\end{array}$ & $\begin{array}{l}-1-\infty \\
2.21 E-01 \\
1.07 E-01 \\
3.72 E-\infty \\
1.86 E-\infty \\
1.68 E-\infty \\
1.58 E-\infty \\
\text { N/D }\end{array}$ & $\begin{array}{l}1.17 E-\infty \\
1.41 E-\infty \\
1.08 E-\infty \\
1.17 E-\infty \\
9.72 E-\infty \\
1.01 E-\infty \\
\text { N/D }\end{array}$ & $\begin{array}{l}-1 . \overline{1}-\infty \\
2.60 E-\infty 6 \\
4.20 E-\infty 6 \\
5.44 E-\infty 6 \\
0.41 E-\infty 6 \\
7.42 E-\infty 6 \\
7.42 E-\infty 6\end{array}$ & 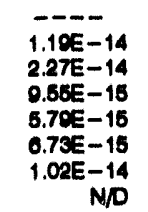 & $\begin{array}{r}-\overline{1.30 E+01} \\
1.30 E+01 \\
1.40 E+01 \\
1.42 E+01 \\
1.42 E+01 \\
1.40 E+01 \\
\text { NDD }\end{array}$ \\
\hline & $\tan$ & $\begin{array}{l}\text { an: } \\
\text { tion: }\end{array}$ & $\begin{array}{l}1.30 E-\infty \\
1.51 E-\infty 6\end{array}$ & $\begin{array}{l}3.23 E-12 \\
3.52 E-12\end{array}$ & $\begin{array}{l}0.01 E-\infty \\
7.52 E-\infty\end{array}$ & & & $\begin{array}{l}1.11 E-14 \\
5.68 E-16\end{array}$ & $\begin{array}{l}1.40 E+01 \\
1.01 E-01\end{array}$ \\
\hline
\end{tabular}

FILE NAME: Co

SAMPLE ID: PEACH BOTTOM *12

\begin{tabular}{|c|c|c|c|c|c|c|c|c|c|}
\hline$\underset{I D}{\text { LEACH }}$ & $\begin{array}{l}\text { CUMULATIVE } \\
\text { LEACH TIME } \\
\text { (days) }\end{array}$ & $\begin{array}{l}\text { QUANTITY } \\
\text { LEACHED } \\
\text { (U⿴囗) }\end{array}$ & $\begin{array}{c}\text { RELEASE } \\
\text { RATE } \\
(\text { ug・cm-208-1) }\end{array}$ & $\begin{array}{l}\text { RELEAEE } \\
\text { RATE } \\
(\mathrm{cm}-2 \cdot 8-1)\end{array}$ & $\begin{array}{c}\text { RELEABE } \\
\text { RATE } \\
\left(g^{\circ} y y^{-1}\right)\end{array}$ & $\begin{array}{l}\text { INCREMENT/ } \\
\text { RELEASE }\end{array}$ & $\begin{array}{l}\text { CUMULATIVE } \\
\text { RELEABE }\end{array}$ & $\begin{array}{l}\text { EFFECTIVE } \\
\text { DIFFUBIVTY } \\
\left(\mathrm{cm}^{2} \cdot \mathrm{s}^{-1}\right)\end{array}$ & $\begin{array}{l}\text { IEACH } \\
\text { INDEX }\end{array}$ \\
\hline \multirow[t]{2}{*}{$\begin{array}{l}\text { 1. (30d) } \\
\text { 2. (2hr) } \\
\text { 3. (7hd) } \\
\text { 4. (1d) } \\
\text { 5. (2d) } \\
\text { 6. (3d) } \\
\text { 7. (4d) } \\
\text { 8. (5d) }\end{array}$} & $\begin{array}{l}3.47 E-04 \\
8.37 E-\infty \\
2.02 E-01 \\
1.00 E+\infty \\
2.00 E+\infty \\
3.00 E+\infty \\
4.00 E+\infty \\
5.00 E+\infty\end{array}$ & $\begin{array}{l}1.00 E+\infty \\
1.30 E+01 \\
1.74 E+01 \\
8.68 E+\infty \\
1.57 E+01 \\
2.78 E+01 \\
2.42 E+01 \\
2.26 E+01\end{array}$ & $\begin{array}{l}---- \\
1.23 E-\infty \\
0.12 E-\infty \\
8.80 E-07 \\
1.16 E-\infty \\
2.05 E-\infty \\
1.78 E-\infty \\
1.60 E-\infty\end{array}$ & $\begin{array}{l}--\overline{-08 E}-\infty \\
1.91 E-\infty \\
2.77 E-10 \\
3.60 E-10 \\
0.38 E-10 \\
5.55 E-10 \\
5.18 E-10\end{array}$ & $\begin{array}{l}---- \\
0.11 E-\infty \\
3.06 E-\infty \\
4.42 E-\infty \\
5.73 E-\infty \\
1.02 E-\infty \\
8.80 E-\infty \\
8.20 E-\infty\end{array}$ & $\begin{array}{l}----- \\
4.34 E-\infty \\
5.41 E-\infty \\
2.07 E-\infty \\
4.88 E-\infty \\
8.68 E-\infty \\
7.56 E-\infty \\
7.06 E-\infty\end{array}$ & $\begin{array}{l}-\overline{4.34 E-\infty} \\
9.75 E-\infty \\
1.24 E-\infty \\
1.73 E-\infty \\
2.00 E-\infty \\
3.35 E-\infty \\
4.06 E-\infty\end{array}$ & $\begin{array}{l}-\overline{1.03 E-\infty} \\
3.33 E-\infty \\
2.43 E-10 \\
1.00 E-\infty \\
5.36 E-\infty \\
5.72 E-\infty \\
6.41 E-\infty\end{array}$ & $\begin{array}{l}-\overline{8.70 E+\infty} \\
8.48 E+\infty \\
9.01 E+\infty \\
9.00 E+\infty \\
8.27 E+\infty \\
8.24 E+\infty \\
8.10 E+\infty\end{array}$ \\
\hline & $d D$ & $\begin{array}{l}\text { san: } \\
\text { tion: }\end{array}$ & $\begin{array}{l}3.70 E-\infty \\
3.60 E-\infty\end{array}$ & $\begin{array}{l}1.15 E-\infty \\
1.20 E-\infty\end{array}$ & $\begin{array}{l}1.84 E-\infty \\
1.02 E-\infty\end{array}$ & & & $\begin{array}{l}3.38 E-\infty \\
2.30 E-\infty\end{array}$ & $\begin{array}{l}8.00 E+\infty \\
4.81 E-01\end{array}$ \\
\hline
\end{tabular}

FILE NAME: N

SAMPLE ID: PEACH BOTTOM *12

\begin{tabular}{|c|c|c|c|c|c|c|c|c|c|}
\hline $\begin{array}{l}\text { LEACH } \\
\text { ID }\end{array}$ & $\begin{array}{l}\text { CUMULATIVE } \\
\text { LEACH TIME } \\
\text { (day) }\end{array}$ & $\begin{array}{l}\text { QUANTITY } \\
\text { LEACHED } \\
\text { (ug) }\end{array}$ & $\begin{array}{c}\text { AELEASE } \\
\text { RATE } \\
(\text { (g・cm-2 }\end{array}$ & $\begin{array}{l}\text { RELEASE } \\
\text { RATE } \\
(\mathrm{cm}-2 \bullet 8-1)\end{array}$ & $\begin{array}{c}\text { RELEASE } \\
\text { RATE } \\
\left(g^{\bullet} y r-1\right)\end{array}$ & $\begin{array}{l}\text { INCPEMEN] } \\
\text { RELEASE }\end{array}$ & $\begin{array}{l}\text { CUMULATIVE } \\
\text { RELEASE }\end{array}$ & $\begin{array}{l}\text { EFFECTIVE } \\
\text { DIFFUSIVTY } \\
\left(\mathrm{cm}^{2} \cdot \mathrm{s}^{-1}\right)\end{array}$ & $\begin{array}{l}\text { IEACH } \\
\text { INC-XX }\end{array}$ \\
\hline \multirow[t]{2}{*}{$\begin{array}{l}\text { 1. }(300) \\
\text { 2. (2hy) } \\
\text { 3. }(7 \mathrm{hy}) \\
\text { 4. (4d) } \\
\text { 5. (2d) } \\
\text { 6. (3d) } \\
\text { 7. (4d) } \\
\text { 8. (5d) }\end{array}$} & $\begin{array}{l}3.47 E-\infty \\
8.37 E-\infty \\
2.02 E-01 \\
1.00 E+\infty \\
2.00 E+\infty \\
3.00 E+\infty \\
4.00 E+\infty \\
5.00 E+\infty\end{array}$ & $\begin{array}{r}\text { ND } \\
7.83 E+01 \\
6.94 E+01 \\
0.20 E+01 \\
6.90 E+01 \\
7.46 E+01 \\
6.40 E+01 \\
6.06 E+01\end{array}$ & $\begin{array}{l}-\overline{-}-\overline{-}-\infty \\
2.45 E-\infty \\
9.00 E-\infty \\
5.11 E-\infty \\
5.50 E-\infty \\
4.70 E-\infty \\
5.11 E-\infty\end{array}$ & $\begin{array}{l}-\overline{-70 E-\infty} \\
1.67 E-\infty \\
6.54 E-10 \\
3.48 E-10 \\
3.74 E-10 \\
3.20 E-10 \\
3.48 E-10\end{array}$ & $\begin{array}{l}--\overline{-}- \\
3.44 E-01 \\
1.22 E-01 \\
4.78 E-\infty \\
2.55 E-\infty \\
2.74 E-\infty \\
2.34 E-\infty \\
2.54 E-\infty\end{array}$ & $\begin{array}{l}--33 E-\infty \\
4.72 E-\infty \\
0.30 E-\infty \\
4.74 E-\infty \\
5.00 E-\infty \\
4.30 E-\infty \\
4.74 E-\infty\end{array}$ & $\begin{array}{l}-\overline{5.33 E-\infty} \\
1.01 E-\infty \\
1.04 E-\infty \\
2.11 E-\infty \\
2.02 E-\infty \\
3.05 E-\infty \\
3.53 E-\infty\end{array}$ & $\begin{array}{l}-\overline{2.45 E-\infty} \\
2.54 E-\infty \\
1.35 E-\infty \\
9.42 E-10 \\
1.85 E-\infty \\
1.00 E-\infty \\
2.80 E-\infty\end{array}$ & $\begin{array}{l}-\overline{8.61 E}+\infty \\
8.50 E+\infty \\
8.87 E+\infty \\
9.03 E+\infty \\
8.73 E+\infty \\
8.72 E+\infty \\
8.64 E+\infty\end{array}$ \\
\hline & & $\begin{array}{l}\text { Mean: } \\
\text { riation: }\end{array}$ & $\begin{array}{l}1.70 E-\infty 5 \\
2.20 E-\infty 5\end{array}$ & $\begin{array}{l}1.20 E-\infty \\
1.50 E-\infty\end{array}$ & $\begin{array}{l}8.78 E-02 \\
1.00 E-01\end{array}$ & & & $\begin{array}{l}1.00 E-\infty \\
0.40 E-10\end{array}$ & $\begin{array}{l}8.73 E+\infty \\
1.50 E-01\end{array}$ \\
\hline
\end{tabular}

FILE NAME: Zn

SAMPLE ID: PEACHBOTTOM *12

\begin{tabular}{|c|c|c|c|c|c|c|c|c|c|}
\hline$\underset{I D}{\text { IEACH }}$ & $\begin{array}{l}\text { CUMULATIVE } \\
\text { LEACH TIME } \\
\text { (days) }\end{array}$ & $\begin{array}{l}\text { QUANTITY } \\
\text { LEACHED } \\
\text { (Ug) }\end{array}$ & $\begin{array}{l}\text { RELEASE } \\
\text { RATE } \\
\left(u g \cdot \mathrm{cm}^{2} \bullet_{8}-1\right)\end{array}$ & $\begin{array}{l}\text { RELEASE } \\
\text { RATE } \\
\left(\mathrm{cm}-2 \cdot 0^{-1}-1\right)\end{array}$ & $\begin{array}{l}\text { RELEASE } \\
\text { RATE } \\
(g \cdot y-1)\end{array}$ & $\begin{array}{l}\text { INCAEMENTA } \\
\text { RELEASE }\end{array}$ & $\begin{array}{l}\text { CUMULATIVE } \\
\text { RELEASE }\end{array}$ & $\begin{array}{l}\text { EFFECTIVE } \\
\text { DIFFUSIVIT } \\
\left(\mathrm{cm}^{2} \cdot \mathrm{s}^{-1}\right)\end{array}$ & $\begin{array}{l}\text { LEACH } \\
\text { INDEX }\end{array}$ \\
\hline $\begin{array}{l}\text { 1. }(30 \mathrm{~s}) \\
\text { 2. (2hr) } \\
\text { 3. (7hr) } \\
\text { 4. (1d) } \\
\text { 5. (2d) } \\
\text { 6. (3d) } \\
\text { 7. (4d) } \\
\text { 8. (5d) }\end{array}$ & $\begin{array}{l}3.47 E-\infty 4 \\
8.37 E-\infty \\
2.02 E-01 \\
1.00 E+\infty \\
2.00 E+\infty \\
3.00 E+\infty \\
4.00 E+\infty \\
5.00 E+\infty\end{array}$ & $\begin{array}{l}2.37 E+01 \\
3.85 E+01 \\
3.00 E+01 \\
4.20 E+01 \\
2.00 E+01 \\
2.20 E+01 \\
2.00 E+01 \\
2.78 E+01\end{array}$ & $\begin{array}{l}--\overline{-}- \\
3.37 E-\infty \\
1.41 E-\infty \\
4.45 E-\infty \\
12.17 E-\infty \\
1.00 E-\infty \\
1.91 E-\infty \\
2.04 E-\infty\end{array}$ & $\begin{array}{l}-\overline{1.85 E-\infty} \\
7.72 E-10 \\
2.44 E-10 \\
1.10 E-10 \\
0.11 E-11 \\
1.05 E-10 \\
1.12 E-10\end{array}$ & $\begin{array}{l}-\overline{1.08 E-01} \\
7.01 E-\infty \\
2.21 E-\infty \\
1.08 E-\infty \\
8.27 E-\infty \\
0.40 E-\infty \\
1.02 E-\infty\end{array}$ & $\begin{array}{l}-\overline{2.10 E-\infty 3} \\
2.10 E-\infty \\
2.36 E-\infty \\
1.02 E-\infty \\
1.24 E-\infty \\
1.42 E-\infty \\
1.53 E-\infty\end{array}$ & $\begin{array}{l}-\overline{2.10 E-\infty} \\
4.20 E-\infty \\
0.04 E-\infty \\
8.26 E-\infty \\
9.50 E-\infty \\
1.00 E-\infty \\
1.24 E-\infty\end{array}$ & $\begin{array}{l}-\overline{-}-- \\
3.80 E-10 \\
5.45 E-10 \\
1.88 E-10 \\
1.10 E-10 \\
1.00 E-10 \\
2.03 E-10 \\
3.00 E-10\end{array}$ & $\begin{array}{l}3.42 E+\infty \\
0.20 E+\infty \\
0.73 E+\infty \\
0.00 E+\infty \\
0.00 E+\infty \\
9.00 E+\infty \\
9.52 E+\infty\end{array}$ \\
\hline & & $\begin{array}{l}\text { san: } \\
\text { tion: }\end{array}$ & $\begin{array}{l}8.58 E-\infty \\
1.11 E-\infty 6\end{array}$ & $\begin{array}{l}\text { 4.70E-10 } \\
6.07 E-10\end{array}$ & $\begin{array}{l}4.27 E-\infty \\
5.51 E-\infty\end{array}$ & & & $\begin{array}{l}2.62 E-10 \\
1.47 E-10\end{array}$ & $\begin{array}{l}0.05 E+\infty \\
2.44 E-01\end{array}$ \\
\hline
\end{tabular}




\section{Appendix E}

Table E-26. (continued).

FILE MANS: B

BANPLE 1D: PEACH BOTTOM \#12

\begin{tabular}{|c|c|c|c|c|c|c|c|c|c|}
\hline $\begin{array}{l}\text { LEACH } \\
\text { ID }\end{array}$ & $\begin{array}{l}\text { CUMULATIVE } \\
\text { LEACH TIME } \\
\text { (dAY) }\end{array}$ & $\begin{array}{l}\text { QUANTITY } \\
\text { LEACHEO } \\
\text { (UD) }\end{array}$ & $\begin{array}{c}\text { AELEABE } \\
\text { AATE } \\
\text { (Ug・cm-2・g-1) }\end{array}$ & $\begin{array}{l}\text { RELEABE } \\
\text { RATE } \\
(\mathrm{cm}-1 \cdot 8-1)\end{array}$ & $\begin{array}{l}\text { RELEABE } \\
\text { RATE } \\
(g \cdot y r-1)\end{array}$ & $\begin{array}{l}\text { INCAEMENTAL } \\
\text { RELEABE }\end{array}$ & $\begin{array}{l}\text { CUMULATIVE } \\
\text { AELEASE }\end{array}$ & $\begin{array}{l}\text { EFFECTIVE } \\
\text { DIFFUSIVTY } \\
\left(\mathrm{cm}^{2} \cdot \mathrm{s}^{-1}\right)\end{array}$ & $\begin{array}{l}\text { LEACH } \\
\text { INOEX }\end{array}$ \\
\hline \multirow[t]{2}{*}{$\begin{array}{l}\text { 1. }(300) \\
\text { 2. }(2 \mathrm{mr}) \\
\text { 3. }(7 \mathrm{hr}) \\
\text { 4. (1d) } \\
\text { 5. (2d) } \\
\text { O. }(3 d) \\
\text { 7. }(4 d) \\
\text { 8. (5d) }\end{array}$} & $\begin{array}{l}3.47 E-\infty \\
0.37 E-\infty \\
2.02 E-01 \\
1.00 E+\infty \\
2.00 E+\infty \\
3.00 E+\infty \\
1.00 E+\infty \\
5.00 E+\infty\end{array}$ & $\begin{array}{r}\text { N/D } \\
\text { N/D } \\
3.47 E+01 \\
3.77 E+01 \\
3.63 E+01 \\
\text { N/D } \\
\text { ND } \\
\text { N/D }\end{array}$ & $\begin{array}{r}--- \\
\text { N/O } \\
1.22 E-\infty \\
3.01 E-\infty \\
2.81 E-\infty \\
\text { N/D } \\
\text { N/D } \\
\text { N/D }\end{array}$ & $\begin{array}{r}\text { ND } \\
2.70 E-\infty \\
8.64 E-10 \\
6.21 E-10 \\
\text { N/D } \\
\text { N/D } \\
\text { N/D }\end{array}$ & $\begin{array}{r}\text { N/O } \\
0.09 E-\infty \\
1.08 E-\infty \\
1.40 E-\infty \\
\text { ND } \\
\text { ND } \\
\text { ND }\end{array}$ & $\begin{array}{r}\text { N/O } \\
7.66 E-\infty \\
8.33 E-\infty \\
8.45 E-\infty \\
\text { N/D } \\
\text { N/D } \\
\text { N/D }\end{array}$ & $\begin{array}{l}--- \\
N D \\
7.06 E-\infty \\
1.60 E-\infty \\
2.44 E-\infty \\
2.44 E-\infty \\
2.44 E-\infty \\
2.44 E-\infty\end{array}$ & $\begin{array}{r}\cdots / D \\
6.08 E-\infty \\
2.36 E-\infty \\
3.00 E-\infty \\
N / D \\
N / D \\
\text { N/D }\end{array}$ & $\begin{array}{r}\text { ND } \\
6.17 E+\infty \\
6.63 E+\infty \\
8.52 E+\infty \\
\text { ND } \\
\text { ND } \\
\text { ND }\end{array}$ \\
\hline & Btandard D & in: & $\begin{array}{l}0.32 E-\infty \\
4.21 E-\infty\end{array}$ & $\begin{array}{l}1.40 E-\infty \\
9.20 E-10\end{array}$ & $\begin{array}{l}3.15 E-\infty \\
2.00 E-\infty\end{array}$ & ate & 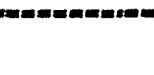 & $\begin{array}{l}1.01 E-\infty \\
1.01 E-\infty\end{array}$ & $\begin{array}{l}0.44 E+\infty \\
1.03 E-01\end{array}$ \\
\hline
\end{tabular}

FILE NAME: Picolinic Acid

SAMPLE ID: PEACHBOTTOM $\# 12$

\begin{tabular}{|c|c|c|c|c|c|c|c|c|c|}
\hline $\begin{array}{c}\text { LEACH } \\
{ }_{10}\end{array}$ & $\begin{array}{l}\text { CUMULATIVE } \\
\text { LEACH TIME } \\
\text { (daya) }\end{array}$ & $\begin{array}{l}\text { QUANTITY } \\
\text { LEACHED } \\
\text { (U) }\end{array}$ & $\begin{array}{l}\text { RELEASE } \\
\text { AATE } \\
\left.g \cdot \mathrm{cm}^{-2} \cdot \mathrm{g}-1\right)\end{array}$ & $\begin{array}{l}\text { RELEASE } \\
\text { RATE } \\
(\mathrm{cm}-2 \cdot 3-1)\end{array}$ & $\begin{array}{c}\text { PELEASE } \\
\text { RATE } \\
(g \cdot y r-1)\end{array}$ & $\begin{array}{l}\text { INCAE } \\
\text { RELE }\end{array}$ & $\begin{array}{l}\text { CUMUL } \\
\text { RELEA }\end{array}$ & $\begin{array}{l}\text { EFFECTIVE } \\
\text { DIFFUBIVTY } \\
\left(\mathrm{cm}^{2} \cdot \mathrm{s}^{-1)}\right.\end{array}$ & $\begin{array}{l}\text { LEACH } \\
\text { INDEX }\end{array}$ \\
\hline \multirow[t]{2}{*}{$\begin{array}{l}\text { 1. (30d) } \\
\text { 2. (2hr) } \\
\text { 3. (7hr) } \\
\text { 4. (1d) } \\
\text { 5. (2d) } \\
\text { 6. (3d) } \\
\text { 7. (4d) } \\
\text { 8. (5d) }\end{array}$} & $\begin{array}{l}3.47 E-\infty 4 \\
8.37 E-\infty \\
2.02 E-01 \\
1.00 E+\infty \\
2.00 E+\infty \\
3.00 E+\infty \\
4.00 E+\infty \\
5.00 E+\infty\end{array}$ & $\begin{array}{r}\text { N/D } \\
2.80 E+04 \\
3.02 E+04 \\
6.04 E+04 \\
5.67 E+04 \\
3.70 E+04 \\
2.84 E+04 \\
2.31 E+04\end{array}$ & $\begin{array}{l}2.55 E-\infty \\
1.00 E-\infty \\
0.26 E-\infty \\
4.17 E-\infty \\
2.79 E-\infty \\
2.08 E-\infty \\
1.70 E-\infty\end{array}$ & $\begin{array}{l}--\overline{1}-\infty \\
7.91 E-\infty \\
4.65 E-10 \\
3.10 E-10 \\
2.07 E-10 \\
1.55 E-10 \\
1.26 E-10\end{array}$ & $\begin{array}{l}1.27 E+\infty \\
5.30 E+01 \\
3.12 E+01 \\
2.07 E+01 \\
1.39 E+01 \\
1.04 E+01 \\
6.45 E+\infty\end{array}$ & $\begin{array}{l}-.14 E-\infty \\
2.24 E-\infty \\
4.48 E-\infty \\
4.21 E-\infty \\
2.82 E-\infty \\
2.11 E-\infty \\
1.72 E-\infty\end{array}$ & $\begin{array}{l}--14 E-\infty \\
4.39 E-\infty \\
8.87 E-\infty \\
1.31 E-\infty \\
1.59 E-\infty \\
1.80 E-\infty \\
1.07 E-\infty\end{array}$ & $\begin{array}{l}-\overline{3.97 E-10} \\
5.72 E-10 \\
6.83 E-10 \\
7.46 E-10 \\
5.65 E-10 \\
4.45 E-10 \\
3.81 E-10\end{array}$ & $\begin{array}{l}-.40 E+\infty \\
9.24 E+\infty \\
9.17 E+\infty \\
9.13 E+\infty \\
0.25 E+\infty \\
9.35 E+\infty \\
0.42 E+\infty\end{array}$ \\
\hline & $\tan$ & $\operatorname{van}$ & $\begin{array}{l}7.59 E-\infty \\
7.84 E-\infty\end{array}$ & $\begin{array}{l}5.63 E-10 \\
5.82 E-10\end{array}$ & $\begin{array}{l}3.78 E+01 \\
3.00 E+01\end{array}$ & & & $\begin{array}{l}5.41 E-10 \\
1.30 E-10\end{array}$ & $\begin{array}{l}9.28 E+\infty \\
1.05 E-01\end{array}$ \\
\hline
\end{tabular}



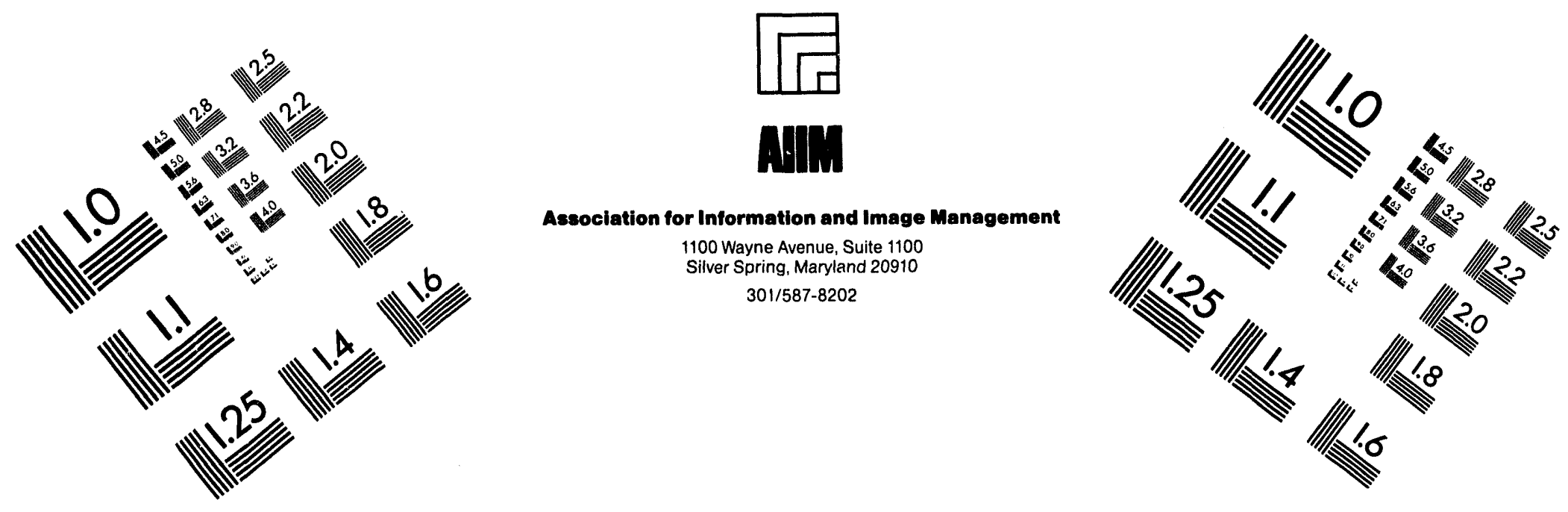

\section{Centimeter}

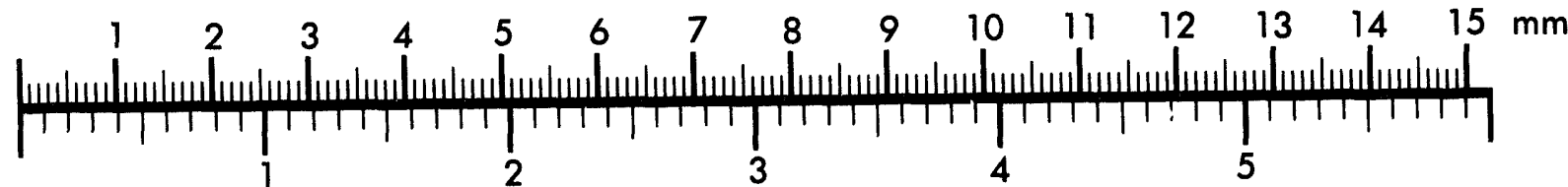
Inches
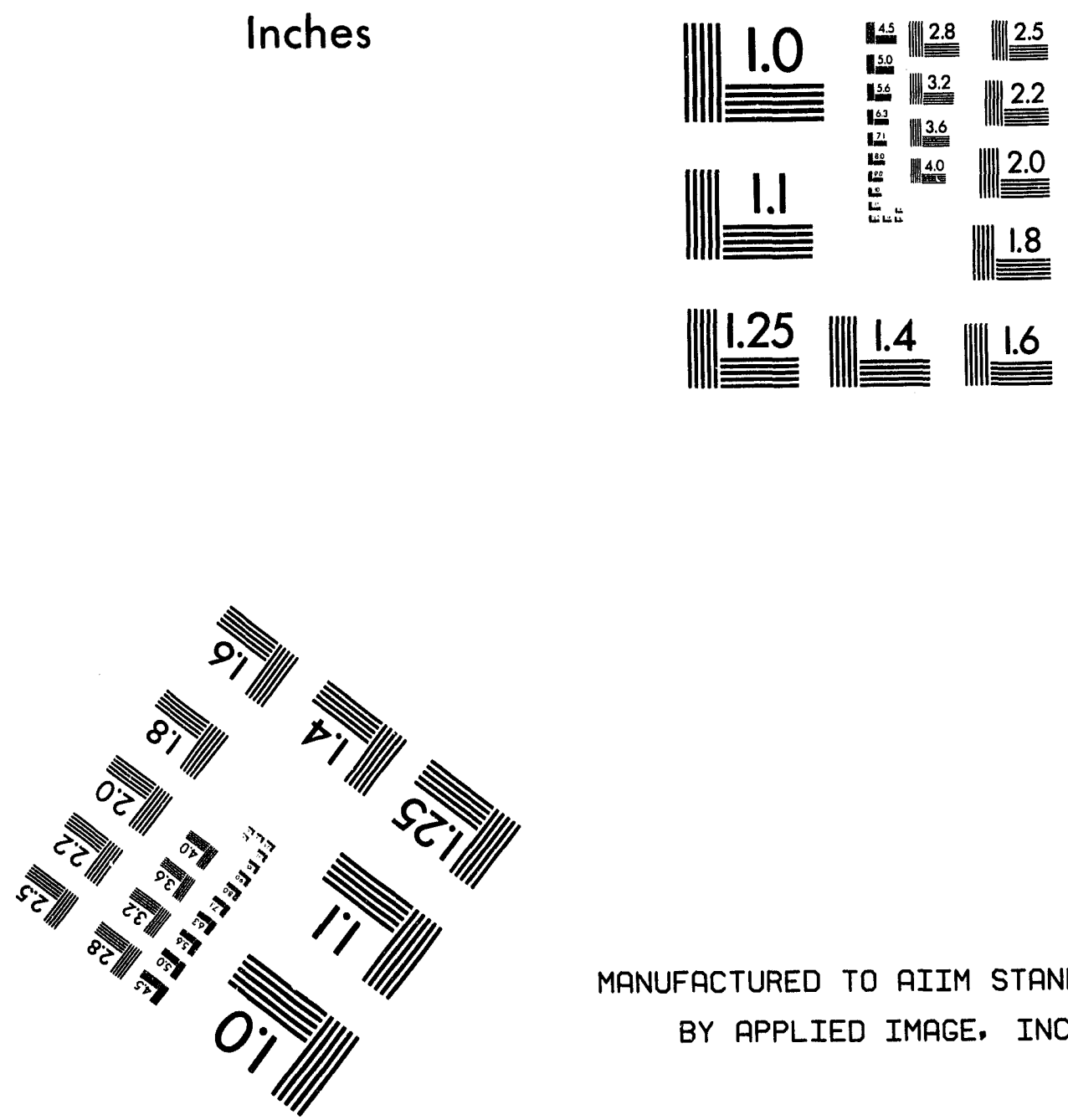

MANUFACTURED TO AIIM STANDARDS

BY APPLIED IMAGE, INC.

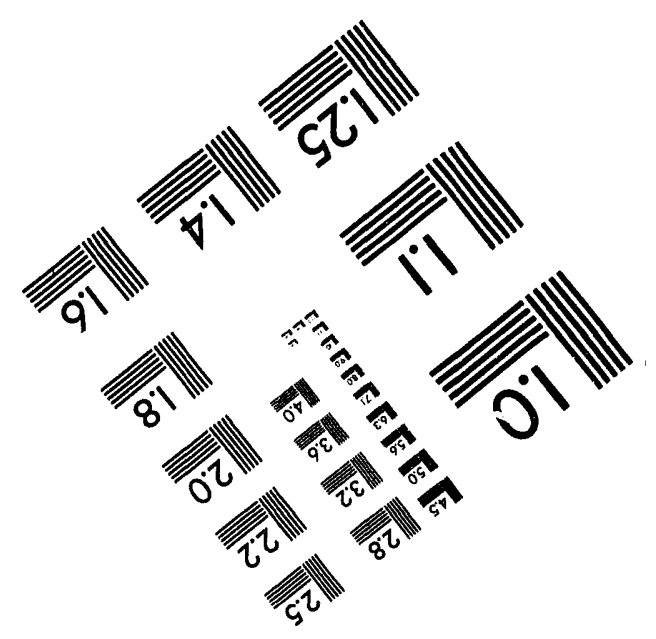



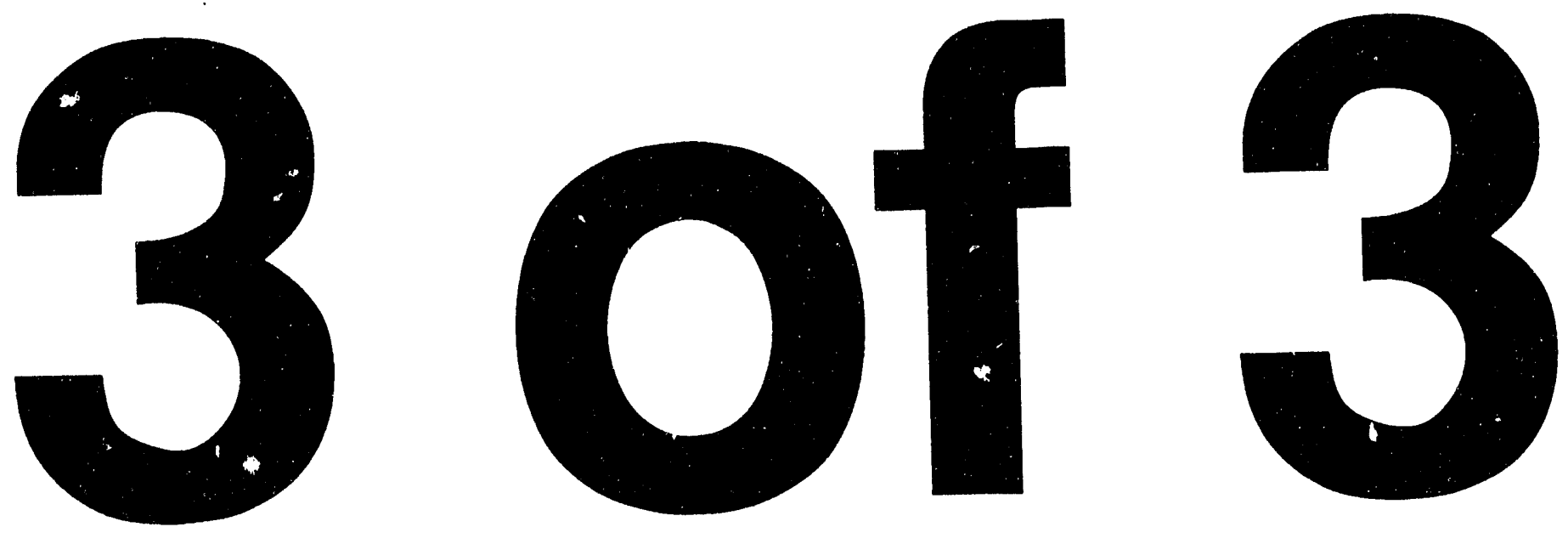


\section{Appendix F \\ Average Release Rates and Effective Diffusivities}




\section{Appendix F}

\section{Average Release Rates and Effective Diffusivities}

Average fractional release rates, average absolute release rates, effective diffusivities, cumulative fractional releases, and leachability indexes were calculated for each leach test. The results of these calculations are shown in the Tables F-1 through F-24. If data were not available or if samples had missing results, calculati onal methods were modified to account for the missing results. When average fractional release rates or effective diffusivities were calculated, two approaches were taken in the earlier reports on which this document is based.

1. When fractional release rate data were available, either data were interpolated between missing points or the average of the numerical values would be taken. The tabies identify which approach was used. Averaging available data will produce an average fractional release rate that is conservatively higher than if detection limit values or are added to the average.

2. When either all or mostly detection limit values were reported, a less-than value would be calculated based on the available data points. This approach would again produce a conservative result assuming that the missing data were at detection limit values.

Summaries of the cumulative fractional releases (CFRs), the average absolute release rates, the average fractional release rates, the effective diffusivities, and the leachability indexes for the samples have been developed. These averages are for nonlinear rate phenomena and, consequently, include high-rate data from early in the leaching process and low-rate data from later in the process. Averages are not typically calculated for phenomena of this type; however, these averages and their associated uncertainties have been calculated as they are the common method used for comparisons with other leach test studies. Consequently, uncertainties associated with the average rates are expected to be large (typically from 50 to $100 \%$ at one standard deviation). Uncertainties listed for the average absolute release rates, the average fractional release rates, and the average effective diffusivities are the internal uncertainties associated with differences in the rate or diffusivity results and do not contain uncertainties associated with counting statistics, waste-form inventories, or other uncertainties associated with the leaching process. These uncertainties have been excluded because they are either small relative to the quoted uncertainty or are not quantifiable based on the tests performed.

In the case of the average leachability index, only real values and detection-limit values would be averaged to determine the leachability index. When detection limit values were used, the leachability index is reported as a greater-than value. However, when data were not available (i.e., no detection-limit values), only real values would be averaged without including all leach periods in the average as defined in ANSI 16.1. This is not in agreement with the ANSI 16.1 standard; however, to use zeros in the leachability index calculation would make the results artificially low.

Comparisons of the averaged effective diffusivity with the average leachability index indicate significant differences due to the calculational method used (i.e., as discussed above, leachability indexes are calculated for leachate and are averaged, whereas the averaged effective diffusivity is based on interpolated results). Consequently, significant differences may result if the "averaged" effective diffusivity is used to calculate a leachability index in contrast to those reported. 
Table F-1. Leach test results for Brunswick-1 cation resin waste-form specimen leached in deionized water. $^{\mathrm{a}}$

\begin{tabular}{|c|c|c|c|c|c|}
\hline \multirow[b]{2}{*}{ Nuclide } & \multirow[b]{2}{*}{ CFR } & \multicolumn{2}{|c|}{ Average release rate } & \multirow{2}{*}{$\begin{array}{c}\text { Effective } \\
\text { diffusivity } \\
\left(\mathrm{cm}^{2} \cdot \mathrm{s}^{-1}\right) \\
\end{array}$} & \multirow{2}{*}{$\begin{array}{c}\text { Leachability } \\
\text { index }\end{array}$} \\
\hline & & $\left(\mu \mathrm{Ci} \cdot \mathrm{cm}^{-2} \cdot \mathrm{s}^{-1}\right)$ & $\left(\mathrm{cm}^{-2} \cdot \mathrm{s}^{-1}\right)^{\mathrm{b}}$ & & \\
\hline${ }^{54} \mathrm{Mn}$ & $1.2 \mathrm{E}-4$ & $6 \pm 2 \mathrm{E}-11$ & $6 \pm 2 E-13$ & $2 \pm 1 \mathrm{E}-14$ & $15.0 \pm 0.5$ \\
\hline${ }^{55} \mathrm{Fe}$ & $2.6 \mathrm{E}-4^{\mathrm{c}}$ & $1 \pm 1 \mathrm{E}-9$ & $3 \pm 3 E-12$ & $1 \pm 1 \mathrm{E}-13$ & $16 \pm 1$ \\
\hline${ }^{58} \mathrm{Co}$ & $<3.0 \mathrm{E}-3$ & $<2.2 \mathrm{E}-10$ & $<2.1 \mathrm{E}-11$ & $<6.5 \mathrm{E}-12$ & $>11.8$ \\
\hline${ }^{60} \mathrm{Co}$ & $8.5 \mathrm{E}-5$ & $1.9 \pm 0.5 \mathrm{E}-10$ & $4 \pm 1 \mathrm{E}-13$ & $1.0 \pm 0.5 \mathrm{E}-14$ & $15.3 \pm 0.5$ \\
\hline${ }^{63} \mathrm{Ni}$ & $3.5 \mathrm{E}-4^{\mathrm{c}}$ & $9 \pm 5 \mathrm{E}-11$ & $9 \pm 5 \mathrm{E}-13$ & $5 \pm 4 E-14$ & $14.5 \pm 0.7$ \\
\hline${ }^{65} \mathrm{Zn}$ & $<4.5 \mathrm{E}-4$ & $<2.1 \mathrm{E}-11$ & $<3.2 \mathrm{E}-12$ & $<1.3 \mathrm{E}-13$ & $>13.4$ \\
\hline${ }^{90} \mathrm{Sr}$ & $6.5 \mathrm{E}-2^{\mathrm{c}}$ & $3 \pm 3 \mathrm{E}-10$ & $1 \pm 1 \mathrm{E}-9$ & $1 \pm 1 \mathrm{E}-8$ & $11 \pm 1$ \\
\hline${ }^{125} \mathrm{Sb}$ & $<5.8 \mathrm{E}-3$ & $<1.2 \mathrm{E}-11$ & $<5.0 \mathrm{E}-11$ & $<1.8 \mathrm{E}-11$ & $>11.2$ \\
\hline${ }^{134} \mathrm{Cs}$ & $<2.1 \mathrm{E}-2$ & $<1.0 \mathrm{E}-11$ & $<1.7 \mathrm{E}-10$ & $<2.8 \mathrm{E}-10$ & $>10.1$ \\
\hline${ }^{137} \mathrm{Cs}$ & $1.2 \mathrm{E}-2$ & $1.8 \pm 0.6 \mathrm{E}-10$ & $7 \pm 2 \mathrm{E}-11$ & $7 \pm 2 \mathrm{E}-11$ & $10.7 \pm 0.3$ \\
\hline${ }^{241} \mathrm{Pu}$ & -d & $<1.3 \mathrm{E}-12$ & $<3.4 \mathrm{E}-12$ & $<1.3 \mathrm{E}-13$ & $>12.9$ \\
\hline Metal & & $\left(\mu \mathrm{g} \cdot \mathrm{cm}^{-2} \cdot \mathrm{s}^{-1}\right)$ & & & \\
\hline Chromium & $<4.1 \mathrm{E}-3^{\mathrm{c}}$ & $<3.3 \mathrm{E}-6$ & $<3.9 \mathrm{E}-11$ & $<6.0 \mathrm{E}-12$ & $>11.7$ \\
\hline Iron & $1.8 \mathrm{E}-3^{\mathrm{c}}$ & $1.0 \pm 0.5 \mathrm{E}-5$ & $9 \pm 4 \mathrm{E}-12$ & $2 \pm 1 E-12$ & $12.7 \pm 0.6$ \\
\hline Cobalt & $<4.3 \mathrm{E}-2^{\mathrm{c}}$ & $<1.6 \mathrm{E}-5$ & $<4.1 \mathrm{E}-10$ & $<5.4 \mathrm{E}-10$ & $>9.6$ \\
\hline Nickel & $<9.8 \mathrm{E}-3^{\mathrm{c}}$ & $<1.3 \mathrm{E}-5$ & $<9.4 \mathrm{E}-11$ & $<2.8 \mathrm{E}-11$ & $>10.9$ \\
\hline \multicolumn{6}{|c|}{ a. Results are for only the first 90 days of leaching. } \\
\hline \multicolumn{6}{|c|}{ b. Fraction of initial inventory released per square centimeter of specimen surface area per second. } \\
\hline \multicolumn{6}{|c|}{$\begin{array}{l}\text { c. Not all leachate samples were analyzed for this radionuclide or metal. CFR value was estimated by interpolating measured } \\
\text { incremental release rates. }\end{array}$} \\
\hline
\end{tabular}


Table F-2. Leach test results for Brunswick-1 mixed-bed resin waste-form specimen leached in deionized water. $^{\mathrm{a}}$

\begin{tabular}{|c|c|c|c|c|c|}
\hline \multirow[b]{2}{*}{ Nuclide } & \multirow[b]{2}{*}{ CFR } & \multicolumn{2}{|c|}{ Average release rate } & \multirow{2}{*}{$\begin{array}{l}\text { Effective } \\
\text { diffusivity } \\
\left(\mathrm{cm}^{2} \cdot \mathrm{s}^{-1}\right)\end{array}$} & \multirow{2}{*}{$\begin{array}{l}\text { Leachability } \\
\text { index }\end{array}$} \\
\hline & & $\left(\mu \mathrm{Ci} \cdot \mathrm{cm}^{-2} \cdot \mathrm{s}^{-1}\right)$ & $\left(\mathrm{cm}^{-2} \cdot \mathrm{s}^{-1}\right)^{\mathrm{b}}$ & & \\
\hline${ }^{54} \mathrm{Mn}$ & $<1.7 \mathrm{E}-3$ & $<8.0 \mathrm{E}-11$ & $<2.6 \mathrm{E}-11$ & $<3.5 \mathrm{E}-12$ & $>12.8$ \\
\hline${ }^{55} \mathrm{Fe}$ & $1.1 \mathrm{E}-2^{c}$ & $1.3 \pm 0.5 \mathrm{E}-9$ & $6 \pm 3 E-11$ & $9 \pm 5 \mathrm{E}-11$ & $11.0 \pm 0.7$ \\
\hline${ }^{58} \mathrm{Co}$ & $<9.9 \mathrm{E}-2$ & $<3.4 \mathrm{E}-10$ & $<8.6 \mathrm{E}-10$ & $<4.8 \mathrm{E}-9$ & $>8.7$ \\
\hline${ }^{60} \mathrm{Co}$ & $1.3 \mathrm{E}-3$ & $4 \pm 2 E-10$ & $2 \pm 1 \mathrm{E}-11$ & $2 \pm 2 \mathrm{E}-12$ & $13.2 \pm 0.5$ \\
\hline${ }^{63} \mathrm{Ni}$ & $3.9 \mathrm{E}-3^{\mathrm{c}}$ & $8 \pm 5 E-11$ & $1.4 \pm 0.8 \mathrm{E}-11$ & $2.6 \pm 0.7 \mathrm{E}-12$ & $12.3 \pm 0.8$ \\
\hline${ }^{65} \mathrm{Zn}$ & $<1.0 \mathrm{E}-2$ & $<2.8 \mathrm{E}-11$ & $<1.0 \mathrm{E}-10$ & $<4.9 \mathrm{E}-11$ & $>10.7$ \\
\hline${ }^{90} \mathrm{Sr}$ & $2.3 \mathrm{E}-1^{\mathrm{c}}$ & $1.6 \pm 0.7 \mathrm{E}-10$ & $1.4 \pm 0.6 \mathrm{E}-9$ & $7 \pm 4 \mathrm{E}-8$ & $9 \pm 1$ \\
\hline${ }^{125} \mathrm{Sb}$ & $5.6 \mathrm{E}-3$ & $4 \pm 2 \mathrm{E}-11$ & $6 \pm 3 \mathrm{E}-11$ & $2.0 \pm 0.5 \mathrm{E}-11$ & $11.2 \pm 0.3$ \\
\hline${ }^{134} \mathrm{Cs}$ & $<1.2 \mathrm{E}-1$ & $<1.5 \mathrm{E}-11$ & $<1.5 \mathrm{E}-9$ & $<8.8 \mathrm{E}-9$ & $>8.6$ \\
\hline${ }^{137} \mathrm{Cs}$ & $2.2 \mathrm{E}-1$ & $1.6 \pm 0.9 \mathrm{E}-10$ & $3 \pm 2 \mathrm{E}-9$ & $3 \pm 1 \mathrm{E}-8$ & $7.9 \pm 0.2$ \\
\hline${ }^{241} \mathrm{Pu}$ & $-d$ & $1.8 \mathrm{E}-12$ & $6.3 \mathrm{E}-12$ & $2.6 \mathrm{E}-13$ & 12.6 \\
\hline \multicolumn{2}{|c|}{ Chelating agent or metal } & \multicolumn{2}{|l|}{$\left(\mu \mathrm{g} \cdot \mathrm{cm}^{-2} \cdot \mathrm{s}^{-1}\right)$} & & \\
\hline Oxalic acid & $6.3 \mathrm{E}-3$ & $1.6 \pm 0.7 \mathrm{E}-4$ & $6 \pm 2 \mathrm{E}-11$ & $2.2 \pm 0.7 \mathrm{E}-11$ & $11.0 \pm 0.2$ \\
\hline Citric acid & $4.0 \mathrm{E}-3$ & $2 \pm 1 \mathrm{E}-4$ & $4 \pm 2 \mathrm{E}-11$ & $1.4 \pm 0.7 \mathrm{E}-11$ & $11.5 \pm 0.3$ \\
\hline Chromium & $<1.9 \mathrm{E}-3^{\mathrm{c}}$ & $<3.5 \mathrm{E}-6$ & $<1.6 \mathrm{E}-11$ & $<1.5 \mathrm{E}-12$ & $>12.3$ \\
\hline Iron & $<2.1 \mathrm{E}-2^{\mathrm{c}}$ & $<1.6 \mathrm{E}-5$ & $<1.7 \mathrm{E}-10$ & $<1.5 \mathrm{E}-10$ & $>10.5$ \\
\hline Cobalt & $<4.3 \mathrm{E}-2^{\mathrm{c}}$ & $<1.3 \mathrm{E}-5$ & $<3.0 \mathrm{E}-10$ & $<4.9 \mathrm{E}-10$ & $>9.6$ \\
\hline Nickel & $<1.6 \mathrm{E}-1^{\mathrm{c}}$ & $<1.0 \mathrm{E}-5$ & $<1.1 \mathrm{E}-9$ & $<6.7 \mathrm{E}-9$ & $>8.5$ \\
\hline \multicolumn{6}{|c|}{ a. Results are for only the first 90 days of leaching. } \\
\hline \multicolumn{6}{|c|}{ b. Fraction of initial inventory released per square centimeter of specimen surface area per second. } \\
\hline \multicolumn{6}{|c|}{$\begin{array}{l}\text { c. Not all leachate samples were analyzed for this radionuclide or metal. CFR value was estimated by interpolating measured } \\
\text { incremental release rates. }\end{array}$} \\
\hline \multicolumn{6}{|c|}{$\begin{array}{l}\text { d. Only the leachate corresponding to leaching interval number three was analyzed for } 241 P u \text {. Leaching results are those deter- } \\
\text { mined for leaching interval number three. }\end{array}$} \\
\hline
\end{tabular}


Table F-4. Leach test results for baked FitzPatrick mixed-bed resin waste-form specimen leached in deionized water. ${ }^{\mathrm{a}}$

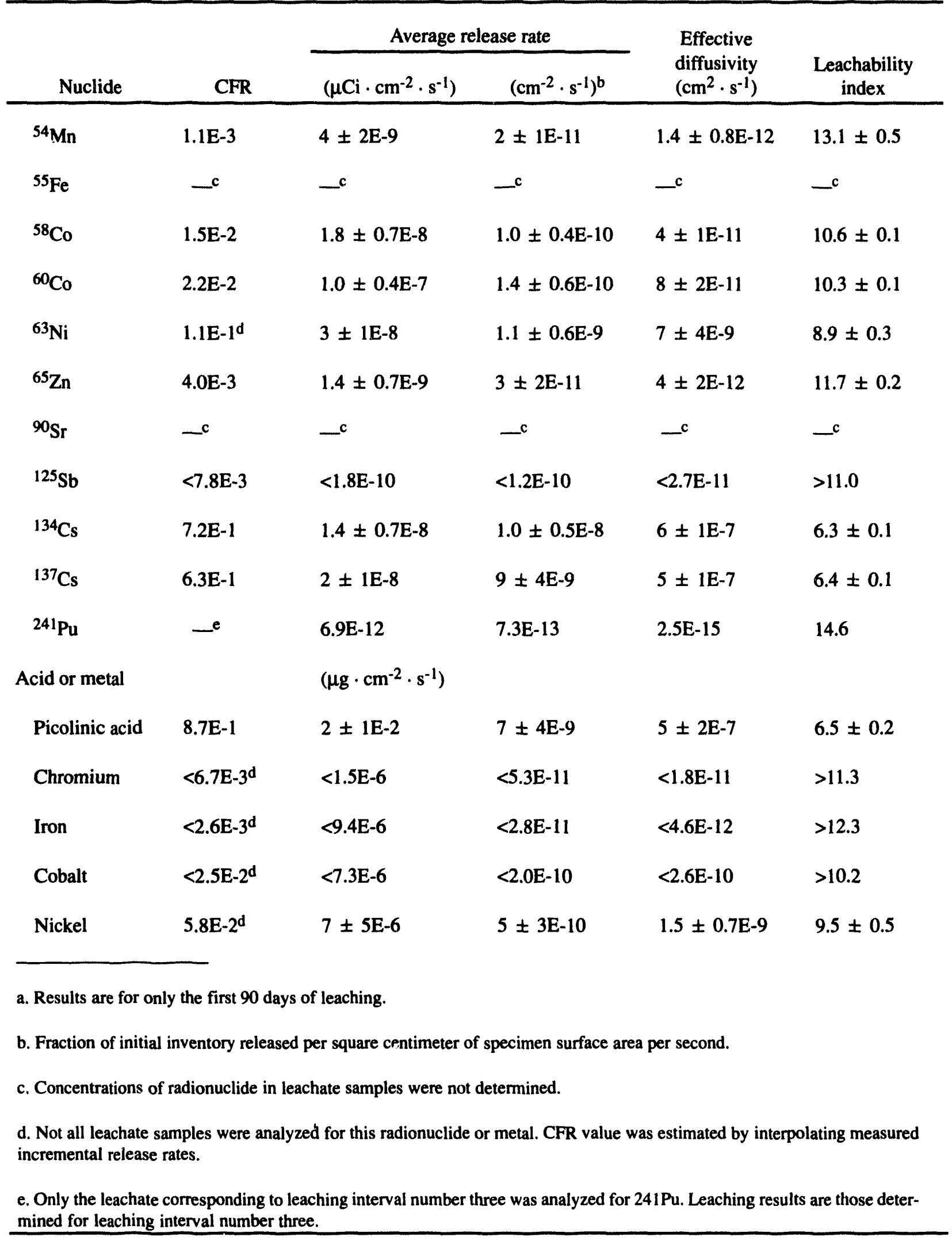


Table F-5. Leach test results for Indian Point mixed-bed resin waste form leached in deionized water.

\begin{tabular}{|c|c|c|c|c|c|}
\hline \multirow[b]{2}{*}{ Nuclide } & \multirow[b]{2}{*}{ CFR } & \multicolumn{2}{|c|}{ Average release rate } & \multirow{2}{*}{$\begin{array}{l}\text { Effective } \\
\text { diffusivity } \\
\left(\mathrm{cm}^{2} \cdot \mathrm{s}^{-1}\right)\end{array}$} & \multirow{2}{*}{$\begin{array}{l}\text { Leachability } \\
\text { index }\end{array}$} \\
\hline & & $\left(\mu \mathrm{Ci} \cdot \mathrm{cm}^{-2} \cdot \mathrm{s}^{-1}\right)$ & $\left(\mathrm{cm}^{-2} \cdot \mathrm{s}^{-1}\right)^{\mathrm{b}}$ & & \\
\hline${ }^{55} \mathrm{Fe}$ & $1.6 \mathrm{E}-4^{\mathrm{a}}$ & $1.4 \pm 2.8 \mathrm{E}-9$ & $7 \pm 15 \mathrm{E}-12$ & $5.0 \pm 9.9 \mathrm{E}-14$ & $14.6 \pm 0.1$ \\
\hline${ }^{60} \mathrm{Co}$ & $1.3 \mathrm{E}-3$ & $2.2 \pm 1.8 \mathrm{E}-9$ & $5.1 \pm 4.1 \mathrm{E}-12$ & $2.0 \pm 1.0 \mathrm{E}-13$ & $12.8 \pm 0.4$ \\
\hline${ }^{63} \mathrm{Ni}$ & $3.1 \mathrm{E}-4$ & $3.3 \pm 5.4 \mathrm{E}-9$ & $6 \pm 10 \mathrm{E}-12$ & $5.3 \pm 3.9 \mathrm{E}-14$ & $13.5 \pm 0.5$ \\
\hline${ }^{137} \mathrm{Cs}$ & 1.0 & $8.4 \pm 8.3 \mathrm{E}-8$ & $5.6 \pm 5.6 \mathrm{E}-9$ & $2.4 \pm 0.9 \mathrm{E}-7^{\mathrm{a}}$ & $6.7 \pm 0.3$ \\
\hline${ }^{241} \mathrm{Pu}$ & - d $^{-1}$ & -d & $-d$ & -d & $>12.3$ \\
\hline $\mathrm{Fe}$ & $4.4 \mathrm{E}-4^{\mathrm{c}}$ & $<4.5 \pm 8.2 \mathrm{E}-6$ & $<6 \pm 11 E-11$ & $<4.3 \pm 5.3 \mathrm{E}-12$ & $>12.1 \pm 1.0$ \\
\hline $\mathrm{Ni}$ & $1.4 \mathrm{E}-2^{\mathrm{c}}$ & $2.0 \pm 2.8 \mathrm{E}-5$ & $2.6 \pm 3.5 \mathrm{E}-10$ & $1.5 \pm 0.9 \mathrm{E}-10$ & $10.1 \pm 0.6$ \\
\hline Formic acid & 0.8 & $3.1 \pm 2.9 \mathrm{E}-3$ & $6.9 \pm 6.6 \mathrm{E}-9$ & $2.3 \pm 0.7 \mathrm{E}-7$ & $6.7 \pm 0.2$ \\
\hline Picolonic acid & 0.6 & $2.2 \pm 1.9 \mathrm{E}-3$ & $4.8 \pm 4.1 \mathrm{E}-9$ & $1.3 \pm 0.5 \mathrm{E}-7$ & $6.9 \pm 0.3$ \\
\hline \multicolumn{6}{|c|}{ a. Based on less than $20 \%$ of incremental release. } \\
\hline \multicolumn{6}{|c|}{ b. Detection limits used for calculation. } \\
\hline \multicolumn{6}{|c|}{ c. Values interpolated based on six limit values. } \\
\hline ir & tern & & & & \\
\hline
\end{tabular}


Table F-6. Leach test results for Cooper cation resin waste-form specimen leached in deionized water.

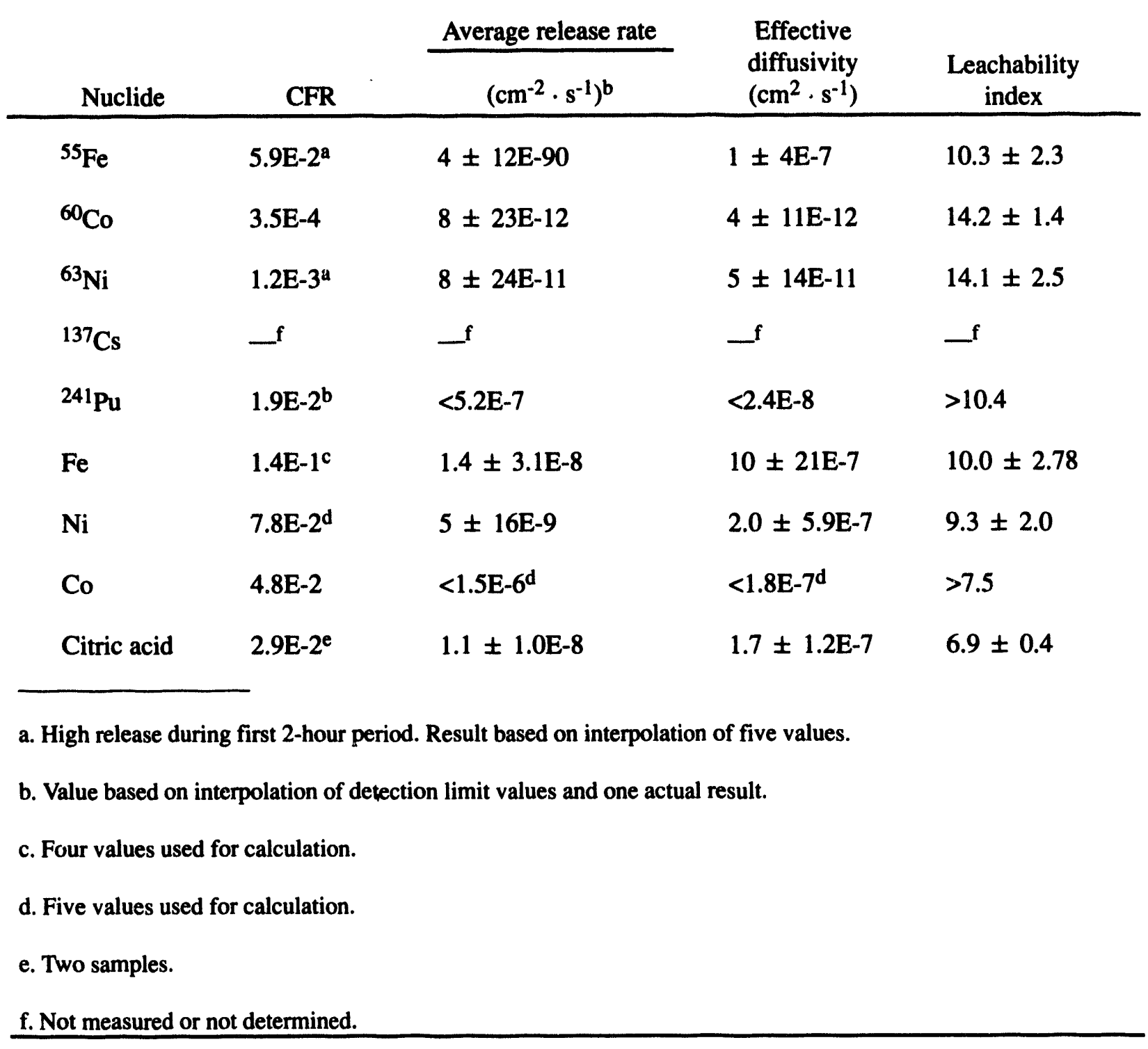


Table F-7. Leach test results for Cooper mixed-bed resin leached in deionized water.

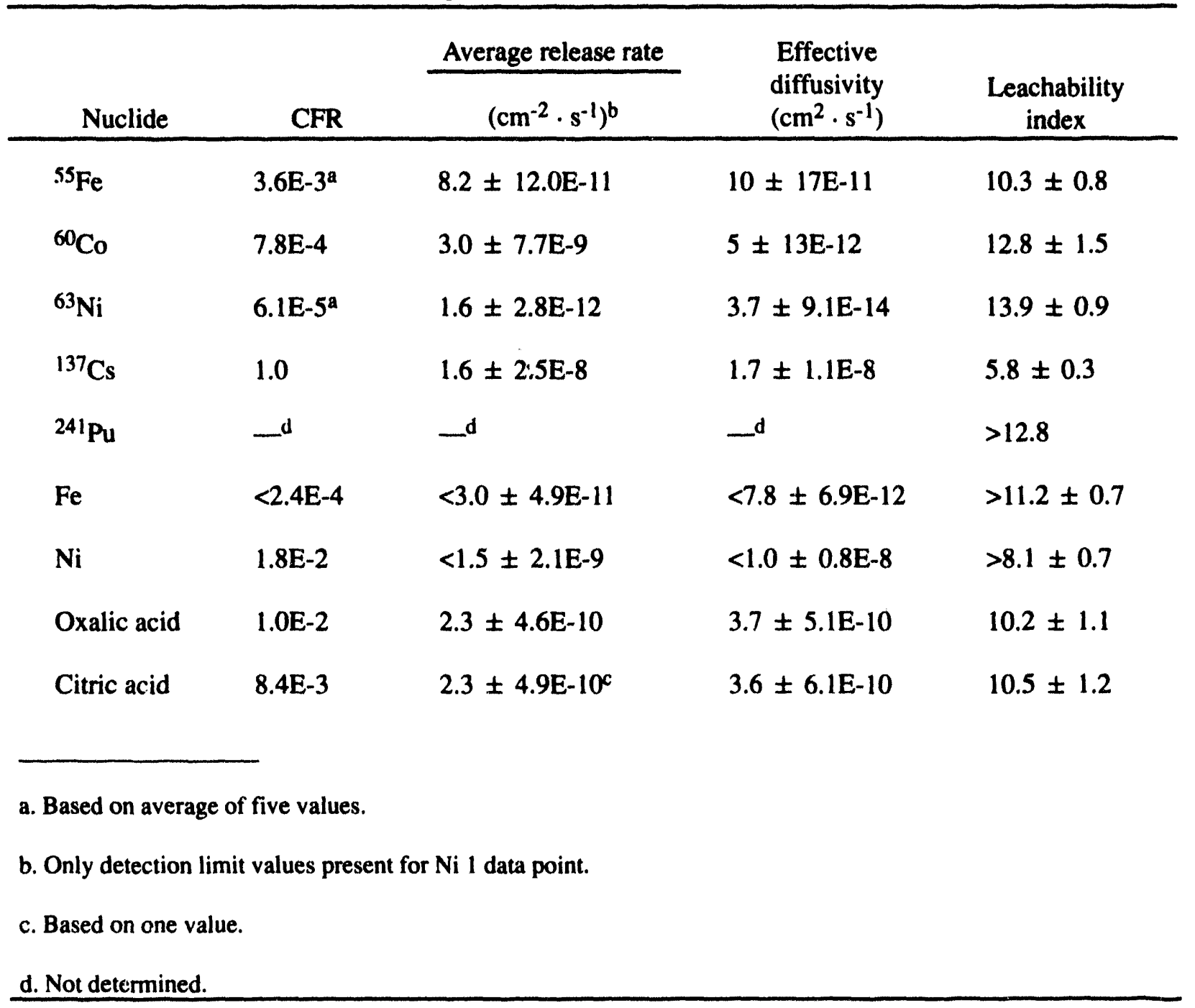


Table F-8. Leach test results for Millstone-1 F-33 sample leached in deionized water.

\begin{tabular}{|c|c|c|c|c|c|}
\hline \multirow[b]{2}{*}{ Nuclide } & \multirow[b]{2}{*}{ CFR } & \multicolumn{2}{|c|}{ Average release rate } & \multirow{2}{*}{$\begin{array}{l}\text { Effective } \\
\text { diffusivity } \\
\left(\mathrm{cm}^{2} \cdot \mathrm{s}^{-1}\right)\end{array}$} & \multirow{2}{*}{$\begin{array}{l}\text { Leachability } \\
\text { index }\end{array}$} \\
\hline & & $\left(\mu \mathrm{Ci} \cdot \mathrm{cm}^{-2} \cdot \mathrm{s}^{-1}\right)$ & $\left(\mathrm{cm}^{-2} \cdot \mathrm{s}^{-1}\right)^{\mathrm{b}}$ & & \\
\hline${ }^{55} \mathrm{Fe}$ & -a & $-a$ & $-\mathbf{a}^{a}$ & $一^{a}$ & $-^{a}$ \\
\hline${ }^{60} \mathrm{Co}$ & $4.4 \mathrm{E}-4$ & $3.3 \pm 3.9 \mathrm{E}-9$ & $6.9 \pm 8.2 \mathrm{E}-12$ & $6.1 \pm 5.8 \mathrm{E}-14$ & $13.6 \pm 0.7$ \\
\hline${ }^{63} \mathrm{Ni}$ & —a & - ${ }^{a}$ & -a & $-^{a}$ & $-^{a}$ \\
\hline${ }^{137} \mathrm{Cs}$ & $9.8 \mathrm{E}-1$ & $3.2 \pm 5.0 \mathrm{E}-9$ & $2.4 \pm 3.5 \mathrm{E}-8$ & $9.7 \pm 4.4 \mathrm{E}-7$ & $6.1 \pm 0.2$ \\
\hline $\mathrm{Fe}$ & $-^{a}$ & $-^{a}$ & $一^{a}$ & $一^{a}$ & - $^{a}$ \\
\hline $\mathbf{N i}$ & $一^{a}$ & $-^{a}$ & - $^{a}$ & $\longrightarrow$ & $-\mathrm{a}$ \\
\hline Oxalic acid & $2.4 \mathrm{E}-2$ & $7 \pm 15 E-3$ & $5.3 \pm 8.3 \mathrm{E}-10$ & $2.4 \pm 1.6 \mathrm{E}-10$ & $10.1 \pm 0.8$ \\
\hline Citric acid & $1.4 \mathrm{E}-2$ & $5.2 \pm 5.5 \mathrm{E}-5$ & $1.3 \pm 3.4 \mathrm{E}-10$ & $8 \pm 19 E-11$ & $10.8 \pm 0.6$ \\
\hline EDTA & $2.3 \mathrm{E}-1$ & $7.7 \pm 7.1 \mathrm{E}-4$ & $2.0 \pm 1.9 \mathrm{E}-9$ & $7.8 \pm 6.6 \mathrm{E}-9$ & $8.3 \pm 0.4$ \\
\hline
\end{tabular}


Table F-9. Leach test results for Millstone-1 F-201 mixed-bed resin leached in deionized water.

\begin{tabular}{|c|c|c|c|c|c|}
\hline \multirow[b]{2}{*}{ Nuclide } & \multirow[b]{2}{*}{ CFR } & \multicolumn{2}{|c|}{ Average release rate } & \multirow{2}{*}{$\begin{array}{c}\text { Effective } \\
\text { diffusivity } \\
\left(\mathrm{cm}^{2} \cdot \mathrm{s}^{-1}\right)\end{array}$} & \multirow{2}{*}{$\begin{array}{c}\text { Leachability } \\
\text { index }\end{array}$} \\
\hline & & $\left(\mu \mathrm{Ci} \cdot \mathrm{cm}^{-2} \cdot \mathrm{s}^{-1}\right)$ & $\left(\mathrm{cm}^{-2} \cdot \mathrm{s}^{-1}\right)^{\mathrm{b}}$ & & \\
\hline${ }^{55} \mathrm{Fe}$ & $6.9 \mathrm{E}-5^{\mathrm{a}}$ & $4.9 \pm 5.8 \mathrm{E}-9$ & $3.1 \pm 4.3 \mathrm{E}-12$ & $9.2 \pm 7.7 \mathrm{E}-15$ & $14.9 \pm 1.4$ \\
\hline${ }^{60} \mathrm{Co}$ & $1.4 \mathrm{E}-3$ & $3.1 \pm 3.6 \mathrm{E}-9$ & $5.9 \pm 6.8 \mathrm{E}-12$ & $1.1 \pm 1.8 \mathrm{E}-13$ & $13.2 \pm 0.4$ \\
\hline${ }^{63} \mathrm{Ni}$ & $5.8 \mathrm{E}-3^{\mathrm{a}}$ & $4.6 \pm 4.2 \mathrm{E}-9$ & $7.9 \pm 7.1 \mathrm{E}-11$ & $1.4 \pm 1.1 \mathrm{E}-11$ & $11.1 \pm 0.5$ \\
\hline${ }^{137} \mathrm{Cs}$ & 0.96 & $3.1 \pm 4.4 \mathrm{E}-9$ & $2.2 \pm 3.0 \mathrm{E}-8$ & $8.7 \pm 3.8 \mathrm{E}-7^{b}$ & $6.1 \pm 0.3$ \\
\hline${ }^{241} \mathrm{Pu}$ & $<2.4 \mathrm{E}-5^{\mathrm{c}}$ & -e & $<6.4 \mathrm{E}-12$ & $<1.1 \mathrm{E}-12^{\mathrm{c}}$ & $>14.3^{b}$ \\
\hline $\mathrm{Fe}$ & $<2.5 \mathrm{E}-5$ & $<2.4 \pm 3.6 \mathrm{E}-6$ & $<6.0 \pm 9.3 \mathrm{E}-12$ & $<2.4 \pm 1.8 \mathrm{E}-14$ & $>14.0 \pm 0.9$ \\
\hline $\mathrm{Ni}$ & $8.1 \mathrm{E}-3^{\mathrm{a}}$ & $2.0 \pm 2.5 \mathrm{E}-5$ & $1.6 \pm 1.9 \mathrm{E}-10$ & $3.2 \pm 2.4 \mathrm{E}-11$ & $10.7 \pm 0.5^{c}$ \\
\hline Co & $<4.6 \mathrm{E}-2^{\mathrm{c}}$ & -e. & $<1.2 \mathrm{E}-8$ & $<8.4 \mathrm{E}-8$ & $>7.5$ \\
\hline $\mathrm{Cr}$ & $<4.2 \mathrm{E}-4^{\mathrm{c}}$ & -ee & $<1.1 \mathrm{E}-10$ & $<7.0 \mathrm{E}-12$ & $>11.5$ \\
\hline Oxalic acidd & $6.8 \mathrm{E}-3$ & $2.0 \pm 1.6 \mathrm{E}-4$ & $9.6 \pm 9.0 \mathrm{E}-10$ & $3.2 \pm 0.6 \mathrm{E}-10$ & $9.5 \pm 0.08$ \\
\hline Citric acidd & $3.1 \mathrm{E}-3$ & $7.1 \pm 2.3 \mathrm{E}-5$ & $1.6 \pm 0.6 \mathrm{E}-10$ & $2.6 \pm 2.3 \mathrm{E}-10$ & $10.4 \pm 0.8$ \\
\hline EDTA $^{d}$ & $3.1 \mathrm{E}-2$ & $5.9 \pm 3.2 \mathrm{E}-4$ & $1.2 \pm 0.9 \mathrm{E}-9$ & $5.8 \pm 3.3 \mathrm{E}-9$ & $8.3 \pm 0.3$ \\
\hline \multicolumn{6}{|c|}{ a. Based on six values. } \\
\hline \multicolumn{6}{|c|}{ b. Effective diffusivity calculated for less than $20 \%$ of total fractional release based on five values. } \\
\hline \multicolumn{6}{|c|}{ c. Based on interpolated detection limit values. } \\
\hline \multicolumn{6}{|c|}{ d. Based on three results. } \\
\hline e. Not determine & & & & & \\
\hline
\end{tabular}


Table F-10. Leach test results for Pilgrim waste form leached in deionized water.

\begin{tabular}{|c|c|c|c|c|c|}
\hline \multirow[b]{2}{*}{ Nuclide } & \multirow[b]{2}{*}{ CFR } & \multicolumn{2}{|c|}{ Average release rate } & \multirow{2}{*}{$\begin{array}{c}\text { Effective } \\
\text { diffusivity } \\
\left(\mathrm{cm}^{2} \cdot \mathrm{s}^{-1}\right)\end{array}$} & \multirow{2}{*}{$\begin{array}{c}\text { Leachability } \\
\text { index }\end{array}$} \\
\hline & & $\left(\mu \mathrm{Ci} \cdot \mathrm{cm}^{-2} \cdot \mathrm{s}^{-1}\right)$ & $\left(\mathrm{cm}^{-2} \cdot \mathrm{s}^{-1}\right)^{\mathrm{b}}$ & & \\
\hline${ }^{55} \mathrm{Fe}$ & $6.4 \mathrm{E}-6^{\mathrm{a}}$ & $2.6 \pm 3.2 \mathrm{E}-10$ & $8 \pm 10 \mathrm{E}-13$ & $3.8 \pm 4.4 \mathrm{E}-16$ & $16.1 \pm 0.9$ \\
\hline${ }^{60} \mathrm{Co}$ & $5.1 \mathrm{E}-?$ & $3.4 \pm 4.0 \mathrm{E}-7$ & $5.6 \pm 6.6 \mathrm{E}-10$ & $9.8 \pm 7.2 \mathrm{E}-10$ & $9.2 \pm 0.4$ \\
\hline${ }^{63} \mathrm{Ni}$ & $3.3 \mathrm{E}-1^{b}$ & $2.1 \pm 2.3 \mathrm{E}-7$ & $6.3 \pm 7.0 \mathrm{E}-9$ & $1.2 \pm 1.1 \mathrm{E}-7$ & $7.1 \pm 0.4$ \\
\hline${ }^{137} \mathrm{Cs}$ & $1.2 \mathrm{E}-3^{\mathrm{b}}$ & $4.2 \pm 2.7 \mathrm{E}-11$ & $1.2 \pm 0.8 \mathrm{E}-11$ & $3.8 \pm 5.0 \mathrm{E}-12$ & $12.1 \pm 0.8$ \\
\hline${ }^{241} \mathrm{Pu}$ & $<1.7 \mathrm{E}-4^{\mathrm{c}}$ & $-e$ & $<3.6 \mathrm{E}-11$ & $<1.8 \mathrm{E}-12$ & $>12$ \\
\hline $\mathrm{Ni}$ & $3.5 \mathrm{E}-1^{\mathrm{d}}$ & $8.1 \pm 6.5 \mathrm{E}-3$ & $4.9 \pm 4.0 \mathrm{E}-9$ & $2.3 \pm 1.8 \mathrm{E}-7$ & $6.9 \pm 0.4$ \\
\hline Oxalic acide & $3.4 \mathrm{E}-1$ & $2.2 \pm 2.7 \mathrm{E}-4$ & $6.3 \pm 7.8 \mathrm{E}-9$ & $8.7 \pm 7.6 \mathrm{E}-8$ & $7.2 \pm 0.4$ \\
\hline Citric acid & $4.0 \mathrm{E}-1$ & $3.8 \pm 5.7 \mathrm{E}-3$ & $1.2 \pm 1.6 \mathrm{E}-8$ & $5.6 \pm 6.9 \mathrm{E}-7$ & $6.5 \pm 0.5$ \\
\hline EDTA & 1.0 & $7.1 \pm 9.7 \mathrm{E}-3$ & $1.7 \pm 2.2 \mathrm{E}-8$ & $2.6 \pm 1.7 \mathrm{E}-6$ & $5.7 \pm 0.5$ \\
\hline DTPA & $3.4 \mathrm{E}-1$ & $1.3 \pm 1.3 \mathrm{E}-4$ & $3.0 \pm 3.1 \mathrm{E}-9$ & $5.7 \pm 5.3 \mathrm{E}-8$ & $7.5 \pm 0.4$ \\
\hline
\end{tabular}
a. Based on three values.
b. Based on five values and interpolated per release rate \& diffusivity.
c. Based on detection limit values.
d. Based on four values.
e. Based on seven values.
f. Not determined. 


\section{Appendix F}

Table F-11. Leach test result for Peach Bottom-2 mixed-bed resin waste form leached in deionized water.

\begin{tabular}{|c|c|c|c|c|c|}
\hline \multirow[b]{2}{*}{ Nuclide } & \multirow[b]{2}{*}{ CFR } & \multicolumn{2}{|c|}{ Average release rate } & \multirow{2}{*}{$\begin{array}{l}\text { Effective } \\
\text { diffusivity } \\
\left(\mathrm{cm}^{2} \cdot \mathrm{s}^{-1}\right)\end{array}$} & \multirow{2}{*}{$\begin{array}{l}\text { Leachability } \\
\text { index }\end{array}$} \\
\hline & & $\left(\mu \mathrm{Ci} \cdot \mathrm{cm}^{-2} \cdot \mathrm{s}^{-1}\right)$ & $\left(\mathrm{cm}^{-2} \cdot \mathrm{s}^{-1}\right)^{\mathrm{b}}$ & & \\
\hline${ }^{60} \mathrm{Co}$ & $1.3 \mathrm{E}-3$ & $5.1 \pm 4.8 \mathrm{E}-9$ & $3.8 \pm 3.5 \mathrm{E}-12$ & $1.6 \pm 0.5 \mathrm{E}-13$ & $12.8 \pm 0.2$ \\
\hline${ }^{137} \mathrm{Cs}$ & $3.6 \mathrm{E}-1$ & $4.7 \pm 5.5 \mathrm{E}-10$ & $1.4 \pm 1.7 \mathrm{E}-9$ & $1.8 \pm 0.5 \mathrm{E}-8$ & $7.8 \pm 0.1$ \\
\hline${ }^{241} \mathrm{Pu}$ & $<1.8 \mathrm{E}-3^{\mathrm{a}}$ & $\sim^{c}$ & $<1.4 \mathrm{E}-10$ & $<1.3 \mathrm{E}-10$ & $>10.1$ \\
\hline Oxalic acid & $1.8 \mathrm{E}-2$ & $1.4 \pm 1.7 \mathrm{E}-10$ & $1.6 \pm 2.5 \mathrm{E}-10$ & $1.5 \pm 1.3 \mathrm{E}-10$ & $10.1 \pm 0.7$ \\
\hline Citric acid ${ }^{b}$ & 2.2E-2 & $1.7 \pm 3.4 \mathrm{E}-4$ & $2.9 \pm 6.0 \mathrm{E}-10$ & $3.7 \pm 6.0 \mathrm{E}-10$ & $10.0 \pm 0.8$ \\
\hline EDTA $^{b}$ & $7.1 \mathrm{E}-2$ & $2.7 \pm 2.6 \mathrm{E}-4$ & $4.8 \pm 4.7 \mathrm{E}-10$ & $2.3 \pm 2.2 \mathrm{E}-9$ & $9.0 \pm 1.0$ \\
\hline \multicolumn{6}{|c|}{ Based on detection limit values. } \\
\hline c. Not determine & S used tor & Mons. & & & \\
\hline
\end{tabular}


Table F-12. Best value leach test results for Peach Bottom-3 solidified resin waste forms leached in deionized water.

\begin{tabular}{|c|c|c|c|c|c|}
\hline \multirow[b]{2}{*}{ Nuclide } & \multirow[b]{2}{*}{$\mathrm{CFR}^{\mathrm{a}}$} & \multicolumn{2}{|c|}{ Average rele $w_{n}$ e rate } & \multirow{2}{*}{$\begin{array}{c}\text { Effective } \\
\text { diffusivity } \\
\left(\mathrm{cm}^{2} \cdot \mathrm{s}^{-1}\right)\end{array}$} & \multirow[b]{2}{*}{$\begin{array}{c}\text { Leachability } \\
\text { index }\end{array}$} \\
\hline & & $\begin{array}{c}\text { Absolute } \\
\left(\mu \mathrm{Ci} \cdot \mathrm{cm}^{-2} \cdot \mathrm{s}^{-1)}\right.\end{array}$ & $\begin{array}{l}\text { Fractional } \\
\left(\mathrm{cm}^{-2} \cdot \mathrm{s}^{-1}\right)\end{array}$ & & \\
\hline${ }^{14} \mathrm{C}^{\mathrm{a}}$ & $8.8 \mathrm{E}-5$ & $3.7 \pm 4.6 \mathrm{E}-9$ & $3.4 \pm 4.1 \mathrm{E}-12$ & $8.8 \pm 6.2 \mathrm{E}-15$ & 14.2 \\
\hline Includes $\# 8^{\mathrm{b}}$ & $2.9 \mathrm{E}-4$ & $5.7 \pm 5.1 \mathrm{E}-9$ & $5.3 \pm 4.6 \mathrm{E}-12$ & $1.5 \pm 0.7 \mathrm{E}-14$ & 13.5 \\
\hline${ }^{55} \mathrm{Fe}^{\mathrm{a}}$ & $1.4 \mathrm{E}-3$ & $7.7 \pm 7.1 \mathrm{E}-10$ & $5.1 \pm 4.7 \mathrm{E}-11$ & $6.1 \pm 7.8 \mathrm{E}-12$ & 12.2 \\
\hline$-^{b}$ & 7.3E-3 & $1.0 \pm 0.9 \mathrm{E}-9$ & $6.8 \pm 5.7 \mathrm{E}-11$ & $9.8 \pm 9.6 \mathrm{E}-12$ & 11.4 \\
\hline${ }^{60} \mathrm{Co}^{\mathrm{a}}$ & $1.7 \mathrm{E}-3$ & $2.3 \pm 2.1 \mathrm{E}-8$ & $6.2 \pm 5.6 \mathrm{E}-11$ & $4.4 \pm 1.2 \mathrm{E}-12$ & 11.4 \\
\hline -b & $2.1 \mathrm{E}-3$ & $2.6 \pm 1.9 \mathrm{E}-8$ & $7.0 \pm 5.0 \mathrm{E}-11$ & $5.2 \pm 1.6 \mathrm{E}-12$ & 11.2 \\
\hline${ }^{63} \mathrm{Ni}^{\mathrm{a}}$ & $5.9 \mathrm{E}-3$ & $1.5 \pm 1.3 \mathrm{E}-9$ & $2.2 \pm 2.1 \mathrm{E}-10$ & $5.5 \pm 2.2 \mathrm{E}-11$ & 10.4 \\
\hline$-^{b}$ & $4.0 \mathrm{E}-3$ & $7.4 \pm 5.5 \mathrm{E}-11$ & $1.5 \pm 1.0 \mathrm{E}-11$ & $5.1 \pm 1.9 \mathrm{E}-14$ & 11.7 \\
\hline${ }^{90} \mathrm{Sr}^{\mathrm{a}}$ & $1.9 \mathrm{E}-3$ & $2.2 \pm 2.0 \mathrm{E}-12$ & $2.4 \pm 2.1 \mathrm{E}-10$ & $2.0 \pm 1.1 \mathrm{E}-11$ & 10.9 \\
\hline$-^{b}$ & $6.9 \mathrm{E}-3$ & $2.9 \pm 2.2 \mathrm{E}-12$ & $3.1 \pm 2.4 \mathrm{E}-10$ & $2.8 \pm 1.4 \mathrm{E}-11$ & 10.4 \\
\hline${ }^{99} \mathrm{Tc}^{\mathrm{a}}$ & $2.6 \mathrm{E}-3$ & $2.0 \pm 1.0 \mathrm{E}-10$ & $4.4 \pm 2.2 \mathrm{E}-11$ & $1.3 \pm 1.2 \mathrm{E}-11$ & 11.5 \\
\hline$-^{b}$ & $1.0 \mathrm{E}-2$ & $2.4 \pm 1.2 \mathrm{E}-10$ & $5.2 \pm 2.7 \mathrm{E}-11$ & $1.6 \pm 1.5 \mathrm{E}-11$ & 11.0 \\
\hline${ }^{129} \mathrm{I}^{\mathrm{a}}$ & $7.7 \mathrm{E}-2$ & $2.1 \pm 2.1 \mathrm{E}-11$ & $3.5 \pm 3.5 \mathrm{E}-9$ & $2.7 \pm 2.1 \mathrm{E}-8$ & 8.1 \\
\hline - $^{b}$ & $6.0 \mathrm{E}-2$ & $5.1 \pm 2.1 \mathrm{E}-12$ & $8.4 \pm 4.1 \mathrm{E}-10$ & $5.5 \pm 3.2 \mathrm{E}-9$ & 8.4 \\
\hline \multicolumn{2}{|c|}{ Chelating agent or metal } & $\left(\mu \mathrm{g} \cdot \mathrm{cm}^{-2} \cdot \mathrm{s}^{-1}\right)$ & & & \\
\hline Chromium & $1.6 \mathrm{E}-2$ & $1.2 \pm 1.0 \mathrm{E}-5$ & $4.8 \pm 3.8 \mathrm{E}-10$ & $3.8 \pm 0.6 \mathrm{E}-10$ & 9.4 \\
\hline Iron & $4.6 \mathrm{E}-5$ & $2.6 \pm 0.7 \mathrm{E}-6$ & $5.9 \pm 1.5 \mathrm{E}-13$ & $3.2 \pm 0.9 \mathrm{E}-15$ & 14.4 \\
\hline - $^{\mathbf{a}}$ & $1.8 \mathrm{E}-4$ & $2.8 \pm 0.8 \mathrm{E}-6$ & $6.4 \pm 1.8 \mathrm{E}-13$ & $3.5 \pm 1.1 \mathrm{E}-15$ & 13.9 \\
\hline Cobalt & $4.2 \mathrm{E}-2$ & $4.3 \pm 3.4 \mathrm{E}-6$ & $1.3 \pm 1.0 \mathrm{E}-9$ & $3.5 \pm 1.9 \mathrm{E}-9$ & 8.6 \\
\hline Nickel & $2.9 \mathrm{E}-2$ & $1.4 \pm 1.2 \mathrm{E}-5$ & $9.3 \pm 8.1 \mathrm{E}-10$ & $1.2 \pm 0.3 \mathrm{E}-9$ & 8.9 \\
\hline Zinc & $8.2 \mathrm{E}-3$ & $9.7 \pm 8.5 \mathrm{E}-6$ & $5.4 \pm 4.6 \mathrm{E}-10$ & $1.9 \pm 0.8 \mathrm{E}-10$ & 9.8 \\
\hline Boron & $2.7 \mathrm{E}-2$ & $7.1 \pm 4.3 \mathrm{E}-6$ & $1.6 \pm 0.9 \mathrm{E}-9$ & $3.3 \pm 0.9 \mathrm{E}-9$ & 8.4 \\
\hline $\begin{array}{l}\text { Picolinic } \\
\text { acid }\end{array}$ & $2.0 \mathrm{E}-2$ & $7.9 \pm 5.8 \mathrm{E}-3$ & $5.8 \pm 4.3 \mathrm{E}-10$ & $5.4 \pm 0.9 \mathrm{E}-10$ & 9.3 \\
\hline
\end{tabular}

a. Results for two samples.

b. Results for three samples, including sample \#8. Distinction is made because a different lab performed the sample \#8 analysis. 
Table F-13. Leach test results for Brunswick-1 cation resin waste-form specimen leached in synthetic Barnwell groundwater with $\mathrm{pH} 10.4 .^{\mathrm{a}}$

\begin{tabular}{|c|c|c|c|c|c|}
\hline \multirow[b]{2}{*}{ Nuclide } & \multirow[b]{2}{*}{ CFR } & \multicolumn{2}{|c|}{ Average release rate } & \multirow{2}{*}{$\begin{array}{l}\text { Effective } \\
\text { diffusivity } \\
\left(\mathrm{cm}^{2} \cdot \mathrm{s}^{-1}\right)\end{array}$} & \multirow{2}{*}{$\begin{array}{l}\text { Leachability } \\
\text { index }\end{array}$} \\
\hline & & $\left(\mu \mathrm{Ci} \cdot \mathrm{cm}^{-2} \cdot \mathrm{s}^{-1}\right)$ & $\left(\mathrm{cm}^{-2} \cdot \mathrm{s}^{-1}\right)^{\mathrm{b}}$ & & \\
\hline${ }^{54} \mathrm{Mn}$ & $<1.3 \mathrm{E}-5$ & $<1.3 \mathrm{E}-11$ & $<1.3 \mathrm{E}-13$ & $<1.8 \mathrm{E}-16$ & $>16.4$ \\
\hline${ }^{55} \mathrm{Fe}$ & $5.1 \mathrm{E}-5^{\mathrm{c}}$ & $9 \pm 7 \mathrm{E}-11$ & $2 \pm 1 \mathrm{E}-13$ & $5 \pm 3 E-16$ & $15.8 \pm 0.4$ \\
\hline${ }^{58} \mathrm{Co}$ & $<2.2 \mathrm{E}-3$ & $<2.3 \mathrm{E}-10$ & $<2.2 \mathrm{E}-11$ & $<7.4 \mathrm{E}-12$ & $>11.9$ \\
\hline${ }^{60} \mathrm{Co}$ & $1.1 \mathrm{E}-5$ & $2.7 \pm 0.9 \mathrm{E}-11$ & $5 \pm 2 E-14$ & $8 \pm 5 \mathrm{E}-17$ & $16.6 \pm 0.2$ \\
\hline${ }^{63} \mathrm{Ni}$ & $5.8 \mathrm{E}-4^{\mathrm{c}}$ & $5 \pm 4 E-10$ & $5 \pm 4 \mathrm{E}-12$ & $3 \pm 3 \mathrm{E}-13$ & $13.6 \pm 0.5$ \\
\hline${ }^{65} \mathrm{Zn}$ & $<2.9 \mathrm{E}-4$ & $<1.7 \mathrm{E}-11$ & $<2.5 \mathrm{E}-12$ & $<9.3 \mathrm{E}-14$ & $>13.6$ \\
\hline${ }^{90} \mathrm{Sr}$ & $4.2 \mathrm{E}-2^{\mathrm{c}}$ & $7 \pm 3 E-12$ & $3 \pm 1 E-11$ & $1.4 \pm 0.9 \mathrm{E}-10$ & $11.2 \pm 0.6$ \\
\hline${ }^{125} \mathrm{Sb}$ & $<5.7 \mathrm{E}-3$ & $<1.7 \mathrm{E}-11$ & $<6.8 \mathrm{E}-11$ & $<3.2 \mathrm{E}-11$ & $>11.0$ \\
\hline${ }^{134} \mathrm{Cs}$ & $<2.1 \mathrm{E}-2$ & $<1.5 \mathrm{E}-11$ & $<2.5 \mathrm{E}-10$ & $<5.3 \mathrm{E}-10$ & $>9.9$ \\
\hline${ }^{137} \mathrm{Cs}$ & $1.1 \mathrm{E}-2$ & $2.3 \pm 0.9 \mathrm{E}-10$ & $9 \pm 3 \mathrm{E}-11$ & $8 \pm 2 \mathrm{E}-11$ & $10.5 \pm 0.3$ \\
\hline${ }^{241} \mathrm{Pu}$ & $\sim^{d}$ & $<1.5 \mathrm{E}-12$ & $<3.9 \mathrm{E}-12$ & $<1.7 \mathrm{E}-13$ & $>12.8$ \\
\hline Metal & & $\left(\mu \mathrm{g} \cdot \mathrm{cm}^{-2} \cdot \mathrm{s}^{-1}\right)$ & & & \\
\hline Chromium & $<1.8 \mathrm{E}-2^{\mathrm{c}}$ & $<1.4 \mathrm{E}-5$ & $<1.6 \mathrm{E}-10$ & $<1.1 \mathrm{E}-10$ & $>10.5$ \\
\hline Iron & $<6.5 \mathrm{E}-3^{\mathrm{c}}$ & $<1.1 \mathrm{E}-4$ & $<9.0 \mathrm{E}-11$ & $<3.6 \mathrm{E}-11$ & $>10.7$ \\
\hline Cobalt & $<2.1 \mathrm{E}-1^{\mathrm{c}}$ & $<7.3 \mathrm{E}-5$ & $<1.8 \mathrm{E}-9$ & $<1.5 \mathrm{E}-8$ & $>8.1$ \\
\hline Nickel & $<4.9 \mathrm{E}-2^{\mathrm{c}}$ & $<5.8 \mathrm{E}-5$ & $<4.2 \mathrm{E}-10$ & $<8.0 \mathrm{E}-10$ & $>9.4$ \\
\hline
\end{tabular}

a. Results are for only the first 90 days of leaching.

b. Fraction of initial inventory released per square centimeter of specimen surface area per second.

c. Not all leachate samples were analyzed for this radionuclide or metal. CFR value was estimated by interpolating measured incremental release rates.

d. Only the leachate corresponding to leaching interval number three was analyzed for ${ }^{241} \mathrm{Pu}$. Leaching results are those determined for leaching interval number three. 
Table F-14. Leach test results for Brunswick-1 cation resin waste-form specimen leached in synthetic Barnwell groundwater with $\mathrm{pH} 4.2$. $^{\mathrm{a}}$

\begin{tabular}{|c|c|c|c|c|c|}
\hline \multirow[b]{2}{*}{ Nuclide } & \multirow[b]{2}{*}{ CFR } & \multicolumn{2}{|c|}{ Average release rate } & \multirow{2}{*}{$\begin{array}{l}\text { Effective } \\
\text { diffusivity } \\
\left(\mathrm{cm}^{2} \cdot \mathrm{s}^{-1}\right) \\
\end{array}$} & \multirow{2}{*}{$\begin{array}{c}\text { Leachability } \\
\text { index }\end{array}$} \\
\hline & & $\left(\mu \mathrm{Ci} \cdot \mathrm{cm}^{-2} \cdot \mathrm{s}^{-1}\right)$ & $\left(\mathrm{cm}^{-2} \cdot \mathrm{s}^{-1}\right)^{\mathrm{b}}$ & & \\
\hline${ }^{54} \mathrm{Mn}$ & $<8.2 \mathrm{E}-6$ & $<6.7 \mathrm{E}-12$ & $<7.4 \mathrm{E}-14$ & $<3.5 \mathrm{E}-17$ & $>16.9$ \\
\hline${ }^{55} \mathrm{Fe}$ & $2.2 \mathrm{E}-5^{\mathrm{c}}$ & $2 \pm 1 \mathrm{E}-11$ & $4 \pm 2 \mathrm{E}-14$ & $9 \pm 6 \mathrm{E}-17$ & $16.6 \pm 0.4$ \\
\hline${ }^{58} \mathrm{Co}$ & $<2.6 \mathrm{E}-3$ & $<2.6 \mathrm{E}-10$ & $<2.8 \mathrm{E}-11$ & $<4.3 \mathrm{E}-12$ & $>11.9$ \\
\hline${ }^{60} \mathrm{Co}$ & $7.6 \mathrm{E}-6$ & $1.9 \pm 0.8 \mathrm{E}-11$ & $4 \pm 2 \mathrm{E}-14$ & $2.0 \pm 0.6 \mathrm{E}-17$ & $17.0 \pm 0.2$ \\
\hline${ }^{63} \mathrm{Ni}$ & $4.6 \mathrm{E}-4^{\mathrm{c}}$ & $1.7 \pm 0.8 \mathrm{E}-10$ & $1.9 \pm 0.9 \mathrm{E}-12$ & $9 \pm 4 \mathrm{E}-14$ & $13.6 \pm 0.5$ \\
\hline${ }^{65} \mathrm{Zn}$ & $<3.5 \mathrm{E}-4$ & $<1.4 \mathrm{E}-11$ & $<2.3 \mathrm{E}-12$ & $<8.4 \mathrm{E}-14$ & $>13.7$ \\
\hline${ }^{90} \mathrm{Sr}$ & $9.9 \mathrm{E}-4^{\mathrm{c}}$ & $3 \pm 2 \mathrm{E}-12$ & $1.0 \pm 0.6 \mathrm{E}-11$ & $5 \pm 2 \mathrm{E}-13$ & $13.0 \pm 0.5$ \\
\hline${ }^{125} \mathrm{Sb}$ & $<5.4 \mathrm{E}-3$ & $<1.1 \mathrm{E}-11$ & $<4.8 \mathrm{E}-11$ & $<1.7 \mathrm{E}-11$ & $>11.3$ \\
\hline${ }^{134} \mathrm{Cs}$ & $<2.3 \mathrm{E}-2$ & $<1.0 \mathrm{E}-11$ & $<1.9 \mathrm{E}-10$ & $<3.1 \mathrm{E}-10$ & $>10.1$ \\
\hline${ }^{137} \mathrm{Cs}$ & $1.1 \mathrm{E}-2$ & $2 \pm 1 \mathrm{E}-10$ & $9 \pm 4 \mathrm{E}-11$ & $8 \pm 2 \mathrm{E}-11$ & $10.7 \pm 0.4$ \\
\hline${ }^{241} \mathrm{Pu}$ & $-d$ & $8.0 \mathrm{E}-13$ & $2.3 \mathrm{E}-12$ & 4.7E-14 & 13.3 \\
\hline Metal & & $\left(\mu \mathrm{g} \cdot \mathrm{cm}^{-2} \cdot \mathrm{s}^{-1}\right)$ & & & \\
\hline Chromium & $<2.3 \mathrm{E}-2^{\mathrm{c}}$ & $<1.5 \mathrm{E}-5$ & $<2.0 \mathrm{E}-10$ & $<1.2 \mathrm{E}-10$ & $>10.3$ \\
\hline Iron & $<7.1 \mathrm{E}-3^{\mathrm{c}}$ & $<1.1 \mathrm{E}-4$ & $<1.0 \mathrm{E}-10$ & $<3.3 \mathrm{E}-11$ & $>10.8$ \\
\hline Cobalt & $<2.5 \mathrm{E}-1^{\mathrm{c}}$ & $<7.6 \mathrm{E}-5$ & $<2.1 \mathrm{E}-9$ & $<1.4 \mathrm{E}-8$ & $>8.2$ \\
\hline Nickel & $<5.7 \mathrm{E}-2^{\mathrm{c}}$ & $<6.0 \mathrm{E}-5$ & $<4.8 \mathrm{E}-10$ & $<7.2 \mathrm{E}-10$ & $>9.5$ \\
\hline
\end{tabular}

a. Results are for only the first $\mathbf{9 0}$ days of leaching.

b. Fraction of initial inventory released per square centimeter of specimen surface area per second.

c. Not all leachate samples were analyzed for this radionuclide or metal. CFR value was estimated by interpolating measured incremental release rates.

d. Only the leachate corresponding to leaching interval number three was analyzed for ${ }^{241} \mathrm{Pu}$. Leaching results are those determined for leaching interval number three. 


\section{Appendix F}

Table F-15. Leach test results for Brunswick-1 cation resin waste-form specimen leached in synthetic Hanford groundwater with $\mathrm{pH} 8.9 .^{\mathrm{a}}$

\begin{tabular}{|c|c|c|c|c|c|}
\hline \multirow[b]{2}{*}{ Nuclide } & \multirow[b]{2}{*}{ CFR } & \multicolumn{2}{|c|}{ Average release rate } & \multirow{2}{*}{$\begin{array}{c}\text { Effective } \\
\text { diffusivity } \\
\left(\mathrm{cm}^{2} \cdot \mathrm{s}^{-1}\right)\end{array}$} & \multirow{2}{*}{$\begin{array}{l}\text { Leachability } \\
\text { index }\end{array}$} \\
\hline & & $\left(\mu \mathrm{Ci} \cdot \mathrm{cm}^{-2} \cdot \mathrm{s}^{-1}\right)$ & $\left(\mathrm{cm}^{-2} \cdot \mathrm{s}^{-1}\right)^{\mathrm{b}}$ & & \\
\hline${ }^{54} \mathrm{Mn}$ & $-1.3 \mathrm{E}-5)$ & $<9.5 \mathrm{E}-12$ & $<1.1 \mathrm{E}-13$ & $<2.0 \mathrm{E}-16$ & $>16.7$ \\
\hline${ }^{55} \mathrm{Fe}$ & $2.3 \mathrm{E}-5^{\mathrm{c}}$ & $3 \pm 2 \mathrm{E}-11$ & $6 \pm 4 \mathrm{E}-14$ & $3 \pm 3 E-16$ & $16.7 \pm 0.6$ \\
\hline${ }^{58} \mathrm{Co}$ & $<2.2 \mathrm{E}-3$ & $<2.3 \mathrm{E}-10$ & $<2.5 \mathrm{E}-11$ & $<2.7 \mathrm{E}-12$ & $>12.1$ \\
\hline${ }^{60} \mathrm{Co}$ & $1.2 \mathrm{E}-5$ & $2.0+0.6 \mathrm{E}-11$ & $4 \pm 1 \mathrm{E}-14$ & $1 \pm 1 \mathrm{E}-16$ & $16.9 \pm 0.3$ \\
\hline${ }^{63} \mathrm{Ni}$ & $1.2 \mathrm{E}-3^{\mathrm{c}}$ & $1.0 \pm 0.8 \mathrm{E}-9$ & $1.1 \pm 0.9 \mathrm{E}-11$ & $8 \pm 6 \mathrm{E}-13$ & $14.0 \pm 1$ \\
\hline${ }^{65} \mathrm{Zn}$ & $<3.3 \mathrm{E}-4$ & $<1.3 \mathrm{E}-11$ & $<2.25-12$ & $<5.0 \mathrm{E}-14$ & $>13.8$ \\
\hline${ }^{90} \mathrm{Sr}$ & $1.4 \mathrm{E}-3^{\mathrm{c}}$ & $2 \pm 1 \mathrm{E}-12$ & $8 \pm 5 E-12$ & $1.0 \pm 0.8 \mathrm{E}-12$ & $12.9 \pm 0.4$ \\
\hline${ }^{125} \mathrm{Sb}$ & $<5.4 \mathrm{E}-3$ & $<1.2 \mathrm{E}-11$ & $<5.3 \mathrm{E}-11$ & $<1.5 \mathrm{E}-11$ & $>11.3$ \\
\hline${ }^{134} \mathrm{Cs}$ & $<1.9 \mathrm{E}-2$ & $<1.0 \mathrm{E}-11$ & $<1.9 \mathrm{E}-10$ & $<2.1 \mathrm{E}-10$ & $>10.3$ \\
\hline${ }^{137} \mathrm{Cs}$ & $1.2 \mathrm{E}-2$ & $3 \pm 1 \mathrm{E}-10$ & $1.1 \pm 0.5 \mathrm{E}-10$ & $9 \pm 2 \mathrm{E}-11$ & $10.8 \pm 0.4$ \\
\hline${ }^{241} \mathrm{Pu}$ & $-d$ & $1.2 \mathrm{E}-12$ & $3.6 \mathrm{E}-12$ & $1.2 \mathrm{E}-13$ & 12.9 \\
\hline Metal & & $\left(\mu \mathrm{g} \cdot \mathrm{cm}^{-2} \cdot \mathrm{s}^{-1}\right)$ & & & \\
\hline Chromium & $<2.2 \mathrm{E}-2^{\mathrm{c}}$ & $<1.5 \mathrm{E}-5$ & $<2.0 \mathrm{E}-10$ & $<1.1 \mathrm{E}-10$ & $>10.3$ \\
\hline Iron & $<1.2 \mathrm{E}-2^{\mathrm{c}}$ & $<1.1 \mathrm{E}-4$ & $<1.0 \mathrm{E}-10$ & $<3.0 \mathrm{E}-11$ & $>10.9$ \\
\hline Cobalt & $<2.4 \mathrm{E}-1^{\mathrm{c}}$ & $<7.4 \mathrm{E}-5$ & $<2.1 \mathrm{E}-9$ & $<1.3 \mathrm{E}-8$ & $>8.2$ \\
\hline Nickel & $<5.6 \mathrm{E}-2^{\mathrm{c}}$ & $<5.9 \mathrm{E}-5$ & $<4.9 \mathrm{E}-10$ & $<6.8 \mathrm{E}-10$ & $>9.5$ \\
\hline
\end{tabular}

a. Results are for only the first 90 days of leaching.

b. Fraction of initial inventory released per square centimeter of specimen surface area per second.

c. Not all leachate samples were analyzed for this radionuclide or metal. CFR value was estimated by interpolating measured incremental release rates.

d. Only the leachate corresponding to leaching intervai number three was analyzed for ${ }^{241} \mathrm{Pu}$. Leaching results are those determined for leaching interval number three. 
Table F-17. Leach test results for Brunswick-1 mixed-bed resin waste-form specimen leached in synthetic Barnwell groundwater with pH 10.4. ${ }^{\mathrm{a}}$

\begin{tabular}{|c|c|c|c|c|c|}
\hline \multirow[b]{2}{*}{ Nuclide } & \multirow[b]{2}{*}{ CFR } & \multicolumn{2}{|c|}{ Average release rate } & \multirow{2}{*}{$\begin{array}{c}\text { Effective } \\
\text { diffusivity } \\
\left(\mathrm{cm}^{2} \cdot \mathrm{s}^{-1}\right)\end{array}$} & \multirow{2}{*}{$\begin{array}{c}\text { Leachability } \\
\text { index }\end{array}$} \\
\hline & & $\left(\mu \mathrm{Ci} \cdot \mathrm{cm}^{-2} \cdot \mathrm{s}^{-1}\right)$ & $\left(\mathrm{cm}^{-2} \cdot \mathrm{s}^{-1}\right)^{\mathrm{b}}$ & & \\
\hline${ }^{54} \mathrm{Mn}$ & $<3.4 \mathrm{E}-4$ & $<9.4 \mathrm{E}-12$ & $<3.5 \mathrm{E}-12$ & $<7.7 \mathrm{E}-14$ & $>13.7$ \\
\hline${ }^{55} \mathrm{Fe}$ & $6.7 \mathrm{E}-4^{\mathrm{c}}$ & $7 \pm 3 \mathrm{E}-11$ & $4 \pm 2 \mathrm{E}-12$ & $2 \pm 1 \mathrm{E}-13$ & $13.4 \pm 0.5$ \\
\hline${ }^{58} \mathrm{Co}$ & $<9.4 \mathrm{E}-2$ & $<3.2 \mathrm{E}-10$ & $<9.1 \mathrm{E}-10$ & $<4.9 \mathrm{E}-9$ & $>8.8$ \\
\hline${ }^{60} \mathrm{Co}$ & $2.2 \mathrm{E}-4$ & $9 \pm 7 \mathrm{E}-11$ & $5 \pm 4 \mathrm{E}-12$ & $4 \pm 3 E-14$ & $14.2 \pm 0.3$ \\
\hline${ }^{63} \mathrm{Ni}$ & $2.1 \mathrm{E}-4^{\mathrm{c}}$ & $6 \pm 3 \mathrm{E}-12$ & $1.2 \pm 0.7 \mathrm{E}-12$ & $1.5 \pm 0.8 \mathrm{E}-14$ & $14.3 \pm 0.4$ \\
\hline${ }^{65} \mathrm{Zn}$ & $<9.2 \mathrm{E}-3$ & $<2.6 \mathrm{E}-11$ & $<1.1 \mathrm{E}-10$ & $<6.7 \mathrm{E}-11$ & $>10.8$ \\
\hline${ }^{90} \mathrm{Sr}$ & $6.9 \mathrm{E}-3^{\mathrm{c}}$ & $7 \pm 4 \mathrm{E}-12$ & $7 \pm 4 \mathrm{E}-11$ & $2 \pm 2 \mathrm{E}-11$ & $11.3 \pm 0.4$ \\
\hline${ }^{125} \mathrm{Sb}$ & $5.8 \mathrm{E}-3$ & $8 \pm 6 \mathrm{E}-11$ & $1.3 \pm 0.9 \mathrm{E}-10$ & $3 \pm 2 \mathrm{E}-11$ & $11.3 \pm 0.4$ \\
\hline${ }^{134} \mathrm{Cs}$ & $<8.9 \mathrm{E}-2$ & $<1.8 \mathrm{E}-11$ & $<2.0 \mathrm{E}-9$ & $<6.8 \mathrm{E}-9$ & $>8.9$ \\
\hline$\therefore{ }^{137} \mathrm{Cs}$ & $1.6 \mathrm{E}-1$ & $2 \pm 2 \mathrm{E}-10$ & $5 \pm 4 \mathrm{E}-9$ & $3 \pm 2 \mathrm{E}-8$ & $8.7 \pm 0.4$ \\
\hline${ }^{241} \mathrm{Pu}$ & $-\mathbf{d}$ & $2.0 \mathrm{E}-12$ & $8.0 \mathrm{E}-12$ & $3.1 \mathrm{E}-13$ & 12.5 \\
\hline \multicolumn{2}{|c|}{ Chelating agent or metal } & $\left(\mu \mathrm{g} \cdot \mathrm{cm}^{-2} \cdot \mathrm{s}^{-1}\right)$ & & & \\
\hline Oxalic acid & $7.4 \mathrm{E}-3$ & $3 \pm 2 \mathrm{E}-4$ & $1.1 \pm 0.7 \mathrm{E}-10$ & $3.0 \pm 0.9 \mathrm{E}-11$ & $11.0 \pm 0.3$ \\
\hline Citric acid & $3.6 \mathrm{E}-3$ & $3 \pm 2 \mathrm{E}-4$ & $6 \pm 4 \mathrm{E}-11$ & $8 \pm 3 E-12$ & $11.6 \pm 0.3$ \\
\hline Chromium & $<9.5 \mathrm{E}-3^{\mathrm{c}}$ & $<2.0 \mathrm{E}-5$ & $<1.0 \mathrm{E}-10$ & $<2.1 \mathrm{E}-11$ & $>11.0$ \\
\hline Iron & $<9.6 \mathrm{E}-2^{\mathrm{c}}$ & $<1.5 \mathrm{E}-4$ & $<1.8 \mathrm{E}-9$ & $<6.3 \mathrm{E}-9$ & $>8.5$ \\
\hline Cobalt & $<2.5 \mathrm{E}-1^{\mathrm{c}}$ & $<9.9 \mathrm{E}-5$ & $<2.8 \mathrm{E}-9$ & $<1.5 \mathrm{E}-8$ & $>8.2$ \\
\hline Nickel & $<8.1 \mathrm{E}-1^{\mathrm{c}}$ & $<7.9 \mathrm{E}-5$ & $<1.0 \mathrm{E}-8$ & $<2.0 \mathrm{E}-7$ & $>7.0$ \\
\hline
\end{tabular}

a. Results are for only the first 90 days of leaching.

b. Fraction of initial inventory released per square centimeter of specimen surface area per second.

c. Not all leachate samples were analyzed for this radionuclide or metal. CFR value was estimated by interpolating measured incremental release rates.

d. Only the leachate corresponding to leaching interval number three was analyzed for ${ }^{241} \mathrm{Pu}$. Leaching results are those determined for leaching interval number three. 
Table F-18. Leach test results for Brunswick-1 mixed-bed resin waste-form specimen leached in synthetic Barnwell groundwater with $\mathrm{pH} 4.2 .^{\mathrm{a}}$

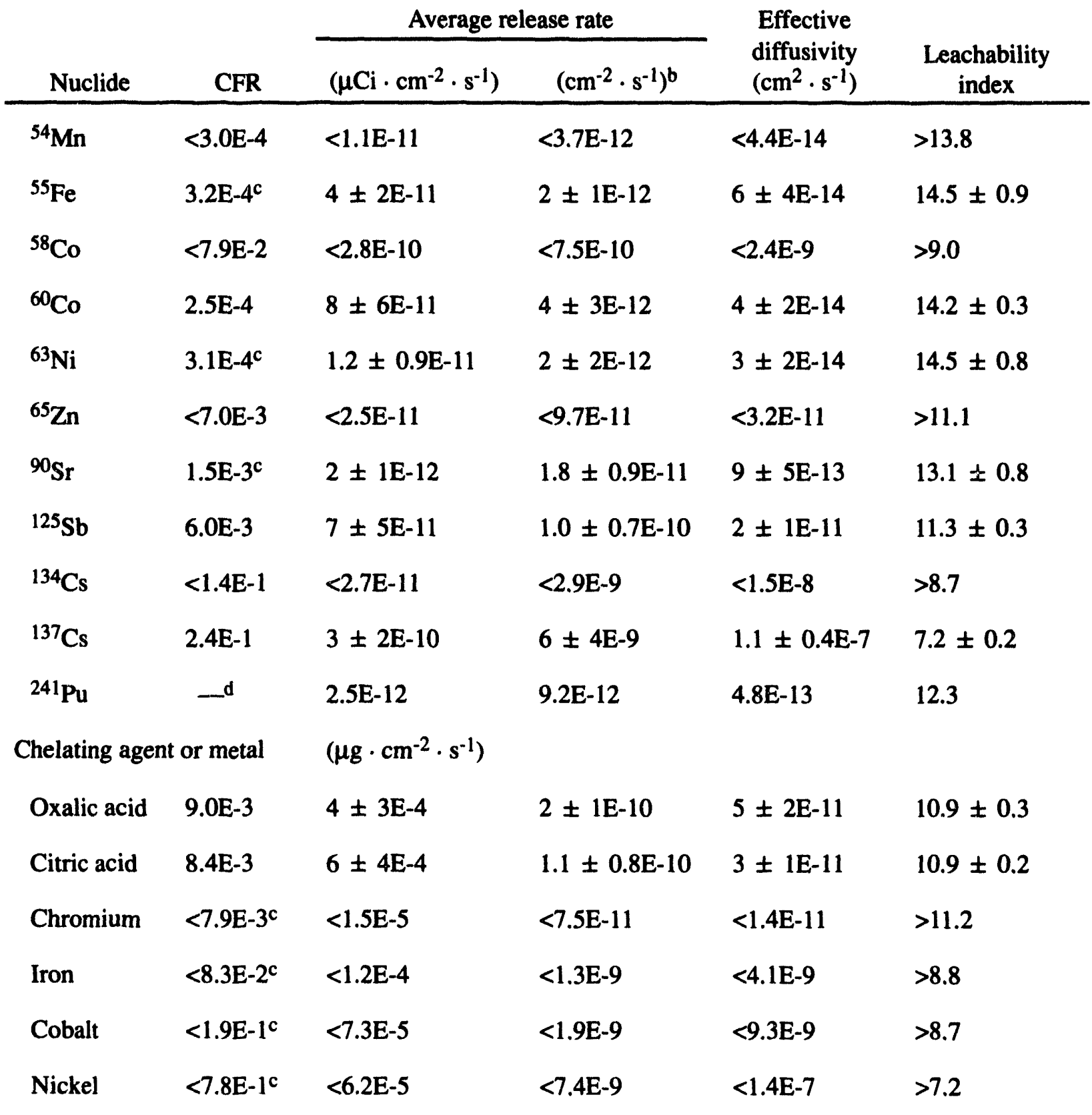

a. Results are for only the first 90 days of leaching.

b. Fraction of initial inventory released per square centimeter of specimen surface area per second.

c. Not all leachate samples were analyzed for this radionuclide or metal. CFR value was estimated by interpolating measured incremental release rates.

d. Only the leachate corresponding to leaching interval number three was analyzed for ${ }^{241} \mathrm{Pu}$. Leaching results are those determined for leaching interval number three. 


\section{Appendix F}

Table F-19. Leach test results for Brunswick-1 mixed-bed resin waste-form specimen leached in synthetic Hanford groundwater with pH 8.9. ${ }^{\mathrm{a}}$

\begin{tabular}{|c|c|c|c|c|c|}
\hline \multirow[b]{2}{*}{ Nuclide } & \multirow[b]{2}{*}{ CFR } & \multicolumn{2}{|c|}{ Average release rate } & \multirow{2}{*}{$\begin{array}{l}\text { Effective } \\
\text { diffusivity } \\
\left(\mathrm{cm}^{2} \cdot \mathrm{s}^{-1}\right)\end{array}$} & \multirow{2}{*}{$\begin{array}{l}\text { Leachability } \\
\text { index }\end{array}$} \\
\hline & & $\left(\mu \mathrm{Ci} \cdot \mathrm{cm}^{-2} \cdot \mathrm{s}^{-1}\right)$ & $\left(\mathrm{cm}^{-2} \cdot \mathrm{s}^{-1}\right)^{\mathrm{b}}$ & & \\
\hline${ }^{54} \mathrm{Mn}$ & $<1.2 \mathrm{E}-3$ & $<4.7 E-11$ & $<2.1 \mathrm{E}-11$ & $<8.0 \mathrm{E}-13$ & $>13.1$ \\
\hline${ }^{55} \mathrm{Fe}$ & $7.6 \mathrm{E}-4^{\mathrm{c}}$ & $7 \pm 5 \mathrm{E}-11$ & $5 \pm 3 \mathrm{E}-12$ & $1 \pm 1 E-12$ & $13.8 \pm 0.8$ \\
\hline${ }^{58} \mathrm{Co}$ & $<1.3 \mathrm{E}-1$ & $<2.4 \mathrm{E}-10$ & $<8.3 \mathrm{E}-10$ & $<8.7$ E-9 & $>8.8$ \\
\hline${ }^{60} \mathrm{Co}$ & $8.4 \mathrm{E}-4$ & $3 \pm 2 \mathrm{E}-10$ & $2 \pm 2 \mathrm{E}-11$ & $6 \pm 4 \mathrm{E}-13$ & $13.9 \pm 0.4$ \\
\hline${ }^{63} \mathrm{Ni}$ & $7.4 \mathrm{E}-4^{\mathrm{c}}$ & $3 \pm 3 E-11$ & $8 \pm 7 \mathrm{E}-12$ & $2 \pm 2 \mathrm{E}-13$ & $14.0 \pm 0.8$ \\
\hline${ }^{65} \mathrm{Zn}$ & $<1.2 \mathrm{E}-2$ & $<2.9 \mathrm{E}-11$ & $<1.5 \mathrm{E}-10$ & $<4.4 \mathrm{E}-11$ & $>10.8$ \\
\hline${ }^{90} \mathrm{Sr}$ & $<9.8 \mathrm{E}-4^{\mathrm{c}}$ & $<1.5 \mathrm{E}-12$ & $<1.8 \mathrm{E}-11$ & $<4.0 \mathrm{E}-13$ & $>13.4$ \\
\hline${ }^{125} \mathrm{Sb}$ & $6.3 \mathrm{E}-3$ & $5 \pm 3 \mathrm{E}-11$ & $9 \pm 6 \mathrm{E}-11$ & $1.1 \pm 0.4 \mathrm{E}-11$ & $11.4 \pm 0.2$ \\
\hline${ }^{134} \mathrm{Cs}$ & $<9.2 \mathrm{E}-2$ & $<7.2 \mathrm{E}-12$ & $<9.9 \mathrm{E}-10$ & $<2.4 \mathrm{E}-9$ & $>9.0$ \\
\hline${ }^{137} \mathrm{Cs}$ & $1.5 \mathrm{E}-1$ & $1.1 \pm 0.8 \mathrm{E}-10$ & $3 \pm 2 \mathrm{E}-9$ & $9 \pm 5 E-9$ & $8.9 \pm 0.4$ \\
\hline${ }^{241} \mathrm{Pu}$ & $-^{d}$ & $<1.4 \mathrm{E}-12$ & $<6.9 \mathrm{E}-12$ & $<1.6 \mathrm{E}-13$ & $>12.8$ \\
\hline \multicolumn{2}{|c|}{ Chelating agent or metal } & \multicolumn{2}{|l|}{$\left(\mu \mathrm{g} \cdot \mathrm{cm}^{-2} \cdot \mathrm{s}^{-1}\right)$} & & \\
\hline Oxalic acid & $1.1 \mathrm{E}-2$ & $2 \pm 1 \mathrm{E}-4$ & $1.1 \pm 0.5 \mathrm{E}-10$ & $3 \pm 1 E-11$ & $10.9 \pm 0.2$ \\
\hline Citric acid & $6.6 \mathrm{E}-3$ & $4 \pm 3 \mathrm{E}-4$ & $9 \pm 7 \mathrm{E}-11$ & $1.1 \pm 0.5 \mathrm{E}-11$ & $11.4 \pm 0.2$ \\
\hline Chromium & $<1.1 \mathrm{E}-2^{\mathrm{c}}$ & $<1.3 \mathrm{E}-5$ & $<8.0 \mathrm{E}-11$ & $<1.9 \mathrm{E}-11$ & $>11.1$ \\
\hline Iron & $<1.6 \mathrm{E}-1^{\mathrm{c}}$ & $<8.2 \mathrm{E}-5$ & $<1.2 \mathrm{E}-9$ & $<3.8 \mathrm{E}-9$ & $>9.2$ \\
\hline Cobalt & $<3.0 \mathrm{E}-1^{\mathrm{c}}$ & $<6.4 \mathrm{E}-5$ & $<2.1 \mathrm{E}-9$ & $<1.3 \mathrm{E}-8$ & $>8.3$ \\
\hline Nickel & $<8.0 \mathrm{E}-1^{\mathrm{c}}$ & $<5.2 \mathrm{E}-5$ & $<7.9 \mathrm{E}-9$ & $<1.8 \mathrm{E}-7$ & $>7.1$ \\
\hline
\end{tabular}

a. Results are for only the first 90 days of leaching.

b. Fraction of initial inventory released per square centimeter of specimen surface area per second.

c. Not all leachate samples were analyzed for this radionuclide or metal. CFR value was estimated by interpolating measured incremental release rates.

d. Only the leachate corresponding to leaching interval number three was analyzed for ${ }^{241}$ Pu. Leaching results are those determined for leaching interval number three. 
Table F-20. Leach test results for Brunswick-1 mixed-bed resin waste-form specimen leached in synthetic seawater with $\mathrm{pH} 6.4 .^{\mathrm{a}}$

\begin{tabular}{|c|c|c|c|c|c|}
\hline \multirow[b]{2}{*}{ Nuclide } & \multirow[b]{2}{*}{ CFR } & \multicolumn{2}{|c|}{ Average release rate } & \multirow{2}{*}{$\begin{array}{c}\text { Effective } \\
\text { diffusivity } \\
\left(\mathrm{cm}^{2} \cdot \mathrm{s}^{-1}\right)\end{array}$} & \multirow{2}{*}{$\begin{array}{c}\text { Leachability } \\
\text { index }\end{array}$} \\
\hline & & $\left(\mu \mathrm{Ci} \cdot \mathrm{cm}^{-2} \cdot \mathrm{s}^{-1}\right)$ & $\left(\mathrm{cm}^{-2} \cdot \mathrm{s}^{-1}\right)^{\mathrm{b}}$ & & \\
\hline${ }^{54} \mathrm{Mn}$ & $<3.2 \mathrm{E}-4$ & $<9.6 \mathrm{E}-12$ & $<2.9 \mathrm{E}-12$ & $<6.1 \mathrm{E}-14$ & $>13.6$ \\
\hline${ }^{55} \mathrm{Fe}$ & -c $_{c}$ & -c $^{c}$ & $-^{c}$ & $-\mathbf{c}$ & _c \\
\hline${ }^{58} \mathrm{Co}$ & $<9.3 \mathrm{E}-2$ & $<3.1 \mathrm{E}-10$ & $<7.0 \mathrm{E}-10$ & $<4.7 \mathrm{E}-9$ & $>8.7$ \\
\hline${ }^{60} \mathrm{Co}$ & $4.5 E-4$ & $2.2 \pm 0.9 \mathrm{E}-11$ & $1.1 \pm 0.4 \mathrm{E}-12$ & $1.7 \pm 0.8 \mathrm{E}-14$ & $14.1 \pm 0.2$ \\
\hline${ }^{63} \mathrm{Ni}$ & $-^{c}$ & $\ldots$ & -c $^{c}$ & $-c$ & $-^{c}$ \\
\hline${ }^{65} \mathrm{Zn}$ & $<8.0 \mathrm{E}-3$ & $<1.8 \mathrm{E}-11$ & $<6.1 \mathrm{E}-11$ & $<5.2 \mathrm{E}-11$ & $>10.9$ \\
\hline${ }^{90} \mathrm{Sr}$ & $\sim_{c}^{c}$ & $-_{c}^{c}$ & -c $^{c}$ & -c & -c $^{c}$ \\
\hline${ }^{125} \mathrm{Sb}$ & $<2.7 \mathrm{E}-3$ & $<1.5 \mathrm{E}-11$ & $<1.9 \mathrm{E}-11$ & $<3.3 \mathrm{E}-12$ & $>11.8$ \\
\hline${ }^{134} \mathrm{Cs}$ & $1.2 \mathrm{E}-1$ & $9 \pm 4 \mathrm{E}-12$ & $8 \pm 4 E-10$ & $5 \pm 1 \mathrm{E}-9$ & $8.5 \pm 0.2$ \\
\hline${ }^{137} \mathrm{Cs}$ & $2.6 \mathrm{E}-1$ & $9 \pm 4 \mathrm{E}-11$ & $1.5 \pm 0.6 \mathrm{E}-9$ & $2.0 \pm 0.3 \mathrm{E}-8$ & $7.74 \pm 0.06$ \\
\hline${ }^{241} \mathrm{Pu}$ & $\perp^{d}$ & $<2.1 \mathrm{E}-12$ & $<6.6 \mathrm{E}-12$ & $<3.4 \mathrm{E}-13$ & $>12.5$ \\
\hline \multicolumn{2}{|c|}{ Chelating agent or metal } & \multicolumn{2}{|l|}{$\left(\mu \mathrm{g} \cdot \mathrm{cm}^{-2} \cdot \mathrm{s}^{-1}\right)$} & & \\
\hline Oxalic acid & - e $^{e}$ & -e & - e & - e & $-e$ \\
\hline Citric acid & $3.2 \mathrm{E}-3$ & $2 \pm 1 \mathrm{E}-4$ & $4 \pm 2 E-11$ & $8 \pm 3 \mathrm{E}-12$ & $11.6 \pm 0.3$ \\
\hline Chromium & $5.1 E-2^{f}$ & $5 \pm 3 E-5$ & $2 \pm 1 \mathrm{E}-10$ & $2.1 \pm 0.6 \mathrm{E}-10$ & $9.7 \pm 0.1$ \\
\hline Iron & $<1.1 \mathrm{E}-1^{\mathrm{f}}$ & $<1.1 \mathrm{E}-4$ & $<1.0 \mathrm{E}-9$ & $<3.0 \mathrm{E}-9$ & $>9.0$ \\
\hline Cobalt & $<1.9 \mathrm{E}-1^{\mathrm{f}}$ & $<7.5 \mathrm{E}-5$ & $<1.6 \mathrm{E}-9$ & $<9.4 \mathrm{E}-9$ & $>8.3$ \\
\hline Nickel & $<7.2 \mathrm{E}-1^{f}$ & $<6.0 \mathrm{E}-5$ & $<6.0 \mathrm{E}-9$ & $<1.3 \mathrm{E}-7$ & $>7.2$ \\
\hline \multicolumn{6}{|c|}{ a. Results are for only the first 90 days of leaching. } \\
\hline \multicolumn{6}{|c|}{ b. Fraction of initial inventory released per square centimeter of specimen surface area per second. } \\
\hline \multicolumn{6}{|c|}{ c. Concentrations of radionuclide in leachate samples were not determined. } \\
\hline \multicolumn{6}{|c|}{$\begin{array}{l}\text { d. Only the leachate corresponding to leaching interval number three was analyzed for }{ }^{24 I} \mathrm{Pu} \text {. Leaching results are } \\
\text { those determined for leaching interval number three. }\end{array}$} \\
\hline \multicolumn{6}{|c|}{ e. Concentrations of acid in leachate samples were below detection limit. } \\
\hline $\begin{array}{l}\text { f. Not all leach } \\
\text { mental release }\end{array}$ & $\begin{array}{l}\text { e samples w } \\
\text { ates. }\end{array}$ & nalyzed for this me & CFR value was e & ted by interpolat & easured incre- \\
\hline
\end{tabular}


Table F-21. Leach test results for FitzPatrick mixed-bed resin waste-form specimen leached in synthetic Barnwell groundwater with $\mathrm{pH} 10.4 .^{\mathrm{a}}$

\begin{tabular}{|c|c|c|c|c|c|}
\hline \multirow[b]{2}{*}{ Nuclide } & \multirow[b]{2}{*}{ CFR } & \multicolumn{2}{|c|}{ Average release rate } & \multirow{2}{*}{$\begin{array}{c}\text { Effective } \\
\text { diffusivity } \\
\left(\mathrm{cm}^{2} \cdot \mathrm{s}^{-1}\right)\end{array}$} & \multirow{2}{*}{$\begin{array}{c}\text { Leachability } \\
\text { index }\end{array}$} \\
\hline & & $\left(\mu \mathrm{Ci} \cdot \mathrm{cm}^{-2} \cdot \mathrm{s}^{-1}\right)$ & $\left(\mathrm{cm}^{-2} \cdot \mathrm{s}^{-1}\right)^{\mathrm{b}}$ & & \\
\hline${ }^{54} \mathrm{Mn}$ & $5.5 \mathrm{E}-4$ & $5 \pm 2 \mathrm{E}-10$ & $3 \pm 1 E-12$ & $5 \pm 1 \mathrm{E}-14$ & $13.6 \pm 0.2$ \\
\hline${ }^{55} \mathrm{Fe}$ & $7.1 \mathrm{E}-3^{\mathrm{c}}$ & $6 \pm 3 \mathrm{E}-10$ & $6 \pm 4 \mathrm{E}-11$ & $2 \pm 1 \mathrm{E}-11$ & $11.6 \pm 0.9$ \\
\hline${ }^{58} \mathrm{Co}$ & $1.2 \mathrm{E}-2$ & $7 \pm 2 \mathrm{E}-9$ & $3.6 \pm 0.9 \mathrm{E}-11$ & $1.6 \pm 0.3 \mathrm{E}-11$ & $11.0 \pm 0.2$ \\
\hline${ }^{60} \mathrm{Co}$ & $1.7 \mathrm{E}-2$ & $3.6 \pm 0.9 \mathrm{E}-8$ & $5 \pm 1 \mathrm{E}-11$ & $3.4 \pm 0.7 \mathrm{E}-11$ & $10.6 \pm 0.2$ \\
\hline${ }^{63} \mathrm{Ni}$ & $1.0 \mathrm{E}-1^{\mathrm{c}}$ & $2 \pm 1 \mathrm{E}-8$ & $8 \pm 5 E-10$ & $5 \pm 3 E-9$ & $9.0 \pm 0.5$ \\
\hline${ }^{65} \mathrm{Zn}$ & $5.9 \mathrm{E}-3$ & $6 \pm 2 \mathrm{~F}-10$ & $1.5 \pm 0.4 \mathrm{E}-11$ & $3.0 \pm 0.8 \mathrm{E}-12$ & $11.7 \pm 0.2$ \\
\hline${ }^{90} \mathrm{Sr}$ & -d & -d $^{d}$ & -d & $-d$ & -d \\
\hline${ }^{125} \mathrm{Sb}$ & $<7.5 \mathrm{E}-3$ & $<7.2 \mathrm{E}-11$ & $<4.8 \mathrm{E}-11$ & $<1.8 \mathrm{E}-11$ & $>11.0$ \\
\hline${ }^{134} \mathrm{Cs}$ & $6.2 \mathrm{E}-1$ & $6 \pm 2 \mathrm{E}-9$ & $4 \pm 1 E-9$ & $1.8 \pm 0.3 \mathrm{E}-7$ & $6.9 \pm 0.2$ \\
\hline${ }^{137} \mathrm{Cs}$ & $5.5 \mathrm{E}-1$ & $1.0 \pm 0.3 \mathrm{E}-8$ & $4 \pm 1 E-9$ & $1.5 \pm 0.3 \mathrm{E}-7$ & $7.0 \pm 0.2$ \\
\hline${ }^{241} \mathrm{Pu}$ & - & $9.3 \mathrm{E}-13$ & $9.8 \mathrm{E}-14$ & $4.4 \mathrm{E}-17$ & 16.4 \\
\hline Acid or metal & & $\left(\mu \mathrm{g} \cdot \mathrm{cm}^{-2} \cdot \mathrm{s}^{-1}\right)$ & & & \\
\hline Picolinic acid & $7.5 \mathrm{E}-1$ & $9 \pm 3 E-3$ & $3 \pm 1 \mathrm{E}-9$ & $1.4 \pm 0.4 \mathrm{E}-7$ & $7.2 \pm 0.3$ \\
\hline Chromium & $<6.7 \mathrm{E}-3^{\mathrm{c}}$ & $<1.6 \mathrm{E}-6$ & $<5.8 \mathrm{E}-11$ & $<2.5 \mathrm{E}-11$ & $>11.2$ \\
\hline Iron & $<3.3 \mathrm{E}-3^{\mathrm{c}}$ & $<1.1 \mathrm{E}-5$ & $<3.2 \mathrm{E}-11$ & $<6.0 \mathrm{E}-12$ & $>11.9$ \\
\hline Cobalt & $<2.6 \mathrm{E}-2^{\mathrm{c}}$ & $<8.0 \mathrm{E}-6$ & $<2.2 \mathrm{E}-10$ & $<3.6 \mathrm{E}-10$ & $>10.0$ \\
\hline Nickel & $5.0 \mathrm{E}-2^{\mathrm{c}}$ & $6 \pm 4 \mathrm{E}-6$ & $4 \pm 2 \mathrm{E}-10$ & $1.0 \pm 0.4 \mathrm{E}-9$ & $9.5 \pm 0.5$ \\
\hline
\end{tabular}

a. Results are for only the first 90 days of leaching.

b. Fraction of initial inventory released per square centimeter of specimen surface area per second.

c. Not all leachate samples were analyzed for this radionuclide or metal. CFR value was estimated by interpolating measured incremental release rates.

d. Concentrations of radionuclide in leachate samples were not determined.

e. Only the leachate corresponding to leaching interval number three was analyzed for $241 \mathrm{Pu}$. Leaching results are those determined for leaching interval number three. 
Table F-22. Leach test results for FitzPatrick mixed-bed resin waste-form specimen leached in synthetic Barnwell groundwater with $\mathrm{pH} 4.2 .^{\mathrm{a}}$

\begin{tabular}{|c|c|c|c|c|c|}
\hline \multirow[b]{2}{*}{ Nuclide } & \multirow[b]{2}{*}{ CFR } & \multicolumn{2}{|c|}{ Average release rate } & \multirow{2}{*}{$\begin{array}{c}\text { Effective } \\
\text { diffusivity } \\
\left(\mathrm{cm}^{2} \cdot \mathrm{s}^{-1}\right)\end{array}$} & \multirow{2}{*}{$\begin{array}{c}\text { Leachability } \\
\text { index }\end{array}$} \\
\hline & & $\left(\mu \mathrm{Ci} \cdot \mathrm{cm}^{-2} \cdot \mathrm{s}^{-1}\right)$ & $\left(\mathrm{cm}^{-2} \cdot \mathrm{s}^{-1}\right)^{\mathrm{b}}$ & & \\
\hline${ }^{54} \mathrm{Mn}$ & $7.2 \mathrm{E}-4$ & $2 \pm 1 \mathrm{E}-9$ & $1.3 \pm 0.8 \mathrm{E}-11$ & $8 \pm 7 \mathrm{E}-13$ & $13.4 \pm 0.3$ \\
\hline${ }^{55} \mathrm{Fe}$ & -c $^{c}$ & $\sim^{c}$ & —c & -c $^{c}$ & _c \\
\hline${ }^{58} \mathrm{Co}$ & $1.2 \mathrm{E}-2$ & $1.0 \pm 0.3 \mathrm{E}-8$ & $5 \pm 2 \mathrm{E}-11$ & $2.2 \pm 0.5 \mathrm{E}-1 \mathrm{i}$ & $10.8 \pm 0.1$ \\
\hline${ }^{60} \mathrm{Co}$ & $1.8 \mathrm{E}-2$ & $5 \pm 2 E-8$ & $8 \pm 3 E-11$ & $4.6 \pm 0.9 \mathrm{E}-11$ & $10.5 \pm 0.1$ \\
\hline${ }^{63} \mathrm{Ni}$ & 8.7E-2 ${ }^{d}$ & $1.3 \pm 0.5 \mathrm{E}-8$ & $5 \pm 2 \mathrm{E}-10$ & $4 \pm 2 \mathrm{E}-9$ & $9.2 \pm 0.6$ \\
\hline${ }^{65} \mathrm{Zn}$ & $5.2 \mathrm{E}-3$ & $1.3 \pm 0.6 \mathrm{E}-9$ & $3 \pm 2 \mathrm{E}-11$ & $4 \pm 2 E-12$ & $11.6 \pm 0.1$ \\
\hline${ }^{90} \mathrm{Sr}$ & -c $^{c}$ & $-c$ & $—^{c}$ & $\longrightarrow^{c}$ & $-^{c}$ \\
\hline${ }^{125} \mathrm{Sb}$ & $<7.5 \mathrm{E}-3$ & $<9.0 \mathrm{E}-11$ & $<5.9 \mathrm{E}-11$ & $<2.3 \mathrm{E}-11$ & $>11.0$ \\
\hline${ }^{134} \mathrm{Cs}$ & $6.9 \mathrm{E}-1$ & $8 \pm 2 \mathrm{E}-9$ & $6 \pm 2 \mathrm{E}-9$ & $2.5 \pm 0.4 \mathrm{E}-7$ & $6.7 \pm 0.1$ \\
\hline${ }^{137} \mathrm{Cs}$ & $6.1 \mathrm{E}-1$ & $1.4 \pm 0.4 \mathrm{E}-8$ & $5 \pm 2 \mathrm{E}-9$ & $1.9 \pm 0.3 \mathrm{E}-7$ & $6.8 \pm 0.1$ \\
\hline${ }^{241} \mathrm{Pu}$ & - e & $3.1 \mathrm{E}-12$ & $3.2 \mathrm{E}-13$ & $5.0 \mathrm{E}-16$ & 15.3 \\
\hline Acid or metal & & $\left(\mu \mathrm{g} \cdot \mathrm{cm}^{-2} \cdot \mathrm{s}^{-1}\right)$ & & & \\
\hline Picolinic acid & $4.2 \mathrm{E}-1$ & $7 \pm 2 \mathrm{E}-3$ & $2.2 \pm 0.7 \mathrm{E}-9$ & $7 \pm 3 E-8$ & $7.5 \pm 0.2$ \\
\hline Chromium & $<6.7 E-3^{d}$ & $<1.6 \mathrm{E}-6$ & $<5.7 \mathrm{E}-11$ & $<2.5 \mathrm{E}-11$ & $>11.2$ \\
\hline Iron & $<5.1 E-3^{d}$ & $<2.0 \mathrm{E}-5$ & $<5.9 \mathrm{E}-11$ & $<2.2 \mathrm{E}-11$ & $>11.6$ \\
\hline Cobalt & $<2.5 \mathrm{E}-2^{\mathrm{d}}$ & $<7.9 \mathrm{E}-6$ & $<2.2 \mathrm{E}-10$ & $<3.6 \mathrm{E}-10$ & $>10.0$ \\
\hline Nickel & $4.8 \mathrm{E}-2^{\mathrm{d}}$ & $4 \pm 2 E-6$ & $2 \pm 1 \mathrm{E}-10$ & $7 \pm 3 E-10$ & $9.5 \pm 0.4$ \\
\hline
\end{tabular}

\footnotetext{
a. Results are for only the first 90 days of leaching.

b. Fraction of initial inventory released per square centimeter of specimen surface area per second.

c. Concentrations of radionuclide in leachate samples were not determined.

d. Not all leachate samples were analyzed for this radionuclide or metal. CFR value was estimated by interpolating measured incremental release rates.
}

e. Only the leachate corresponding to leaching interval number three was analyzed for ${ }^{24} \mathrm{Pu}$. Leaching results are those determined for leaching interval number three. 
Table F-23. Leach test results for FitzPatrick mixed-bed resin waste-form specimen leached in synthetic Hanford groundwater with pH 8.9.a

\begin{tabular}{|c|c|c|c|c|c|}
\hline \multirow[b]{2}{*}{ Nuclide } & \multirow[b]{2}{*}{ CFR } & \multicolumn{2}{|c|}{ Average release rate } & \multirow{2}{*}{$\begin{array}{c}\text { Effective } \\
\text { diffusivity } \\
\left(\mathrm{cm}^{2} \cdot \mathrm{s}^{-1}\right)\end{array}$} & \multirow{2}{*}{$\begin{array}{l}\text { Leachability } \\
\text { index }\end{array}$} \\
\hline & & $\left(\mu \mathrm{Ci} \cdot \mathrm{cm}^{-2} \cdot \mathrm{s}^{-1}\right)$ & $\left(\mathrm{cm}^{-2} \cdot \mathrm{s}^{-1}\right)^{\mathrm{b}}$ & & \\
\hline${ }^{54} \mathrm{Mn}$ & $1.2 \mathrm{E}-4$ & $3 \pm 1 E-10$ & $1.5 \pm 0.8 \mathrm{E}-12$ & $1.0 \pm 0.5 \mathrm{E}-14$ & $14.6 \pm 0.3$ \\
\hline${ }^{55} \mathrm{Fe}$ & $6.3 \mathrm{E}-3^{c}$ & $5 \pm 3 E-10$ & $5 \pm 3 E-11$ & $2 \pm 1 \mathrm{E}-11$ & $11.3 \pm 0.5$ \\
\hline${ }^{58} \mathrm{Co}$ & $8.8 \mathrm{E}-3$ & $6 \pm 1 E-9$ & $3.0 \pm 0.8 \mathrm{E}-11$ & $1.0 \pm 0.2 \mathrm{E}-11$ & $11.1 \pm 0.1$ \\
\hline${ }^{60} \mathrm{Co}$ & $1.3 \mathrm{E}-2$ & $3.0 \pm 0.8 \mathrm{E}-8$ & $4 \pm 1 E-11$ & $2.0 \pm 0.3 E-11$ & $10.8 \pm 0.1$ \\
\hline${ }^{63} \mathrm{Ni}$ & $9.8 \mathrm{E}-2^{\mathrm{c}}$ & $1.5 \pm 0.5 \mathrm{E}-8$ & $6 \pm 2 E-10$ & $4 \pm 1 \mathrm{E}-9$ & $8.9 \pm 0.4$ \\
\hline${ }^{65} \mathrm{Zn}$ & $1.6 \mathrm{E}-3$ & $2.0 \pm 0.9 \mathrm{E}-10$ & $5 \pm 2 E-12$ & $2.3 \pm 0.7 \mathrm{E}-13$ & $12.9 \pm 0.2$ \\
\hline${ }^{90} \mathrm{Sr}$ & $-d$ & $ـ d$ & $-d$ & -d $^{d}$ & $-^{d}$ \\
\hline${ }^{125} \mathrm{Sh}$ & $<5.6 \mathrm{E}-3$ & $<6.9 \mathrm{E}-11$ & $<4.4 \mathrm{E}-11$ & $<1.8 \mathrm{E}-11$ & $>11.2$ \\
\hline${ }^{134} \mathrm{Cs}$ & $6.6 \mathrm{E}-1$ & $6 \pm 2 \mathrm{E}-9$ & $4 \pm 1 \mathrm{E}-9$ & $1.8 \pm 0.3 \mathrm{E}-7$ & $6.9 \pm 0.2$ \\
\hline${ }^{137} \mathrm{Cs}$ & $5.9 \mathrm{E}-1$ & $1.1 \pm 0.3 \mathrm{E}-8$ & $4 \pm 1 E-9$ & $1.5 \pm 0.3 \mathrm{E}-7$ & $7.0 \pm 0.2$ \\
\hline${ }^{241} \mathrm{Pu}$ & -e & $5.4 \mathrm{E}-13$ & $5.6 \mathrm{E}-14$ & $1.5 \mathrm{E}-17$ & 16.8 \\
\hline Acid or metal & & $(\mu \mathrm{g} \cdot \mathrm{cm}-2 \cdot \mathrm{s}-1)$ & & & \\
\hline Picolinic acid & $4.5 \mathrm{E}-1$ & $4 \pm 2 \mathrm{E}-3$ & $1.2 \pm 0.5 \mathrm{E}-9$ & $9 \pm 3 E-9$ & $8.3 \pm 0.2$ \\
\hline Chromium & $<6.5 E-3^{c}$ & $<1.6 \mathrm{E}-6$ & $<5.5 \mathrm{E}-11$ & $<2.4 \mathrm{E}-11$ & $>11.2$ \\
\hline Iron & $<4.3 \mathrm{E}-3^{\mathrm{c}}$ & $<1.2 \mathrm{E}-5$ & $<3.6 \mathrm{E}-11$ & $<1.2 \mathrm{E}-11$ & $>11.5$ \\
\hline Cobalt & $<2.5 \mathrm{E}-2^{\mathrm{c}}$ & $<7.8 \mathrm{E}-6$ & $<2.1 \mathrm{E}-10$ & $<3.5 \mathrm{E}-10$ & $>10.0$ \\
\hline Nickel & $5.1 \mathrm{E}-2^{\mathrm{c}}$ & $6 \pm 5 \mathrm{E}-6$ & $2 \pm 1 \mathrm{E}-10$ & $2 \pm 1 \mathrm{E}-10$ & $10.2 \pm 0.4$ \\
\hline \multicolumn{6}{|c|}{ a. Results are for only the first 90 days of leaching. } \\
\hline \multicolumn{6}{|c|}{ b. Fraction of initial inventory released per square centimeter of specimen surface area per second. } \\
\hline \multicolumn{6}{|c|}{$\begin{array}{l}\text { c. Not all leachate samples were analyzed for this radionuclide or metal. CFR value was estimated by interpolating } \\
\text { measured incremental release rates. }\end{array}$} \\
\hline \multicolumn{6}{|c|}{ d. Concentrations of radionuclide in leachate samples were not determined. } \\
\hline $\begin{array}{l}\text { e. Only the leach } \\
\text { those determined }\end{array}$ & corresponc & $\begin{array}{l}\text { leaching interval } n \\
\text { al number three. }\end{array}$ & ber three was an & d for $241 \mathrm{Pu} . \mathrm{L}$ & ig results are \\
\hline
\end{tabular}


Table F-24. Leach test results for FitzPatrick mixed-bed resin waste-form specimen leached in synthetic seawater with $\mathrm{pH} \mathrm{6.4.^{ \textrm {a } }}$

\begin{tabular}{|c|c|c|c|c|c|}
\hline \multirow[b]{2}{*}{ Nuclide } & \multirow[b]{2}{*}{ CFR } & \multicolumn{2}{|c|}{ Average release rate } & \multirow{2}{*}{$\begin{array}{c}\text { Effective } \\
\text { diffusivity } \\
\left(\mathrm{cm}^{2} \cdot \mathrm{s}^{-1}\right)\end{array}$} & \multirow{2}{*}{$\begin{array}{c}\text { Leachability } \\
\text { index }\end{array}$} \\
\hline & & $\left(\mu \mathrm{Ci} \cdot \mathrm{cm}^{-2} \cdot \mathrm{s}^{-1}\right)$ & $\left(\mathrm{cm}^{-2} \cdot \mathrm{s}^{-1}\right)^{\mathrm{b}}$ & & \\
\hline${ }^{54} \mathrm{Mn}$ & $<4.5 \mathrm{E}-5$ & $<8.8 \mathrm{E}-11$ & $<4.9 \mathrm{E}-13$ & $<1.0 \mathrm{E}-15$ & $>15.4$ \\
\hline${ }^{55} \mathrm{Fe}$ & $-c$ & -c & $-c$ & $ـ^{c}$ & -c $^{c}$ \\
\hline${ }^{58} \mathrm{Co}$ & $1.3 \mathrm{E}-2$ & $9 \pm 3 E-9$ & $5 \pm 2 \mathrm{E}-11$ & $1.9 \pm 0.4 \mathrm{E}-11$ & $10.9 \pm 0.1$ \\
\hline${ }^{60} \mathrm{Co}$ & $2.0 \mathrm{E}-2$ & $5 \pm 2 \mathrm{E}-8$ & $7 \pm 2 \mathrm{E}-11$ & $3.9 \pm 0.7 \mathrm{E}-11$ & $10.5 \pm 0.1$ \\
\hline${ }^{63} \mathrm{Ni}$ & $1.0 \mathrm{E}-1^{\mathrm{d}}$ & $6 \pm 3 E-9$ & $3 \pm 1 \mathrm{E}-10$ & $1.0 \pm 0.4 \mathrm{E}-9$ & $9.4 \pm 0.5$ \\
\hline${ }^{65} \mathrm{Zn}$ & $2.0 \mathrm{E}-3$ & $1.9 \pm 0.6 \mathrm{E}-10$ & $4 \pm 2 \mathrm{E}-12$ & $2.7 \pm 0.9 \mathrm{E}-13$ & $12.9 \pm 0.2$ \\
\hline${ }^{90} \mathrm{Sr}$ & $\sim^{c}$ & $\_^{c}$ & $-^{c}$ & -c $^{c}$ & $-^{c}$ \\
\hline${ }^{125} \mathrm{Sb}$ & $<5.9 \mathrm{E}-3$ & $<7.1 \mathrm{E}-11$ & $<4.6 \mathrm{E}-11$ & $<1.1 \mathrm{E}-11$ & $>11.2$ \\
\hline${ }^{134} \mathrm{Cs}$ & $8.4 \mathrm{E}-1$ & $6 \pm 3 E-9$ & $4 \pm 2 \mathrm{E}-9$ & $2.0 \pm 0.5 \mathrm{E}-7$ & $6.9 \pm 0.1$ \\
\hline${ }^{137} \mathrm{Cs}$ & $7.3 \mathrm{E}-1$ & $1.1 \pm 0.5 \mathrm{E}-8$ & $4 \pm 2 \mathrm{E}-9$ & $1.4 \pm 0.4 \mathrm{E}-7$ & $7.0 \pm 0.1$ \\
\hline${ }^{241} \mathrm{Pu}$ & -e & $6.4 \mathrm{E}-12$ & $6.6 \mathrm{E}-13$ & $2.1 \mathrm{E}-15$ & 14.7 \\
\hline Acid or metal & & $\left(\mu \mathrm{g} \cdot \mathrm{cm}^{-2} \cdot \mathrm{s}^{-1}\right)$ & & & \\
\hline Picolinic acid & $1.1 \mathrm{E}-1$ & $4 \pm 1 \mathrm{E}-3$ & $1.2 \pm 0.4 \mathrm{E}-9$ & $6 \pm 1 \mathrm{E}-9$ & $8.30 \pm 0.08$ \\
\hline Chromium & $<6.6 \mathrm{E}-3^{\mathrm{d}}$ & $<1.6 \mathrm{E}-6$ & $<5.6 \mathrm{E}-11$ & $<2.4 \mathrm{E}-11$ & $>11.2$ \\
\hline Iron & $<4.1 \mathrm{E}-3^{\mathrm{d}}$ & $<1.2 \mathrm{E}-5$ & $<3.4 \mathrm{E}-11$ & $<9.1 \mathrm{E}-12$ & $>11.6$ \\
\hline Cobalt & $<2.5 \mathrm{E}-2^{\mathrm{d}}$ & $<7.9 \mathrm{E}-6$ & $<2.1 \mathrm{E}-10$ & $<3.5 \mathrm{E}-10$ & $>10.0$ \\
\hline Nickel & $<6.4 \mathrm{E}-2^{\mathrm{d}}$ & $<5.0 \mathrm{E}-6$ & $<3.0 \mathrm{E}-10$ & $<8.9 \mathrm{E}-10$ & $>9.2$ \\
\hline
\end{tabular}

a. Results are for only the first 90 days of leaching.

b. Fraction of initial inventory released per square centimeter of specimen surface area per second.

c. Concentrations of radionuclide in leachate samples were not determined.

d. Not all leachate samples were analyzed for this radionuclide or metal. CFR value was estimated by interpolating measured incremental release rates.

e. Only the leachate corresponding to leaching interval number three was analyzed for ${ }^{241} \mathrm{Pu}$. Leaching results are those determined for leaching interval number three. 


\section{Appendix F}

Table F-25. Leach test results for baked FitzPatrick mixed-bed resin waste-form specimen leached in synthetic Barnwell groundwater with $\mathrm{pH} 4.2$. $^{\mathrm{a}}$

\begin{tabular}{|c|c|c|c|c|c|}
\hline \multirow[b]{2}{*}{ Nuclide } & \multirow[b]{2}{*}{ CFR } & \multicolumn{2}{|c|}{ Average release rate } & \multirow{2}{*}{$\begin{array}{c}\text { Effective } \\
\text { diffusivity } \\
\left(\mathrm{cm}^{2} \cdot \mathrm{s}^{-1}\right)\end{array}$} & \multirow{2}{*}{$\begin{array}{c}\text { Leachability } \\
\text { index }\end{array}$} \\
\hline & & $\left(\mu \mathrm{Ci} \cdot \mathrm{cm}^{-2} \cdot \mathrm{s}^{-1}\right)$ & $\left(\mathrm{cm}^{-2} \cdot \mathrm{s}^{-1}\right)^{\mathrm{b}}$ & & \\
\hline${ }^{54} \mathrm{Mn}$ & $1.8 \mathrm{E}-3$ & $5 \pm 3 \mathrm{E}-9$ & $3 \pm 2 \mathrm{E}-11$ & $2 \pm 1 \mathrm{E}-12$ & $13.0 \pm 0.4$ \\
\hline${ }^{55} \mathrm{Fe}$ & $-^{c}$ & $-^{c}$ & $-^{c}$ & $\perp^{c}$ & $\sim^{c}$ \\
\hline${ }^{58} \mathrm{Co}$ & $1.3 \mathrm{E}-2$ & $1.4 \pm 0.6 \mathrm{E}-8$ & $8 \pm 3 \mathrm{E}-11$ & $2.5 \pm 0.8 \mathrm{E}-11$ & $10.8 \pm 0.1$ \\
\hline${ }^{60} \mathrm{Co}$ & $1.9 \mathrm{E}-2$ & $7 \pm 3 E-8$ & $1.1 \pm 0.4 \mathrm{E}-10$ & $5 \pm 2 \mathrm{E}-11$ & $10.5 \pm 0.1$ \\
\hline${ }^{63} \mathrm{Ni}$ & $9.7 E-2^{d}$ & $1.4 \pm 0.6 \mathrm{E}-8$ & $6 \pm 3 E-10$ & $3 \pm 2 \mathrm{E}-9$ & $9.2 \pm 0.4$ \\
\hline${ }^{65} \mathrm{Zn}$ & $1.1 \mathrm{E}-2$ & $2 \pm 1 \mathrm{E}-9$ & $6 \pm 3 \mathrm{E}-11$ & $1.1 \pm 0.6 \mathrm{E}-11$ & $11.3 \pm 0.2$ \\
\hline${ }^{90} \mathrm{Sr}$ & $-^{c}$ & $-^{c}$ & $\sim^{c}$ & $-^{c}$ & $-^{c}$ \\
\hline${ }^{125} \mathrm{Sb}$ & $<9.5 \mathrm{E}-3$ & $<1.4 \mathrm{E}-10$ & $<8.9 \mathrm{E}-11$ & $<2.3 \mathrm{E}-11$ & $>11.0$ \\
\hline${ }^{134} \mathrm{Cs}$ & $6.2 \mathrm{E}-1$ & $8 \pm 3 E-9$ & $6 \pm 2 \mathrm{E}-9$ & $3.1 \pm 0.6 \mathrm{E}-7$ & $6.6 \pm 0.1$ \\
\hline${ }^{137} \mathrm{Cs}$ & $5.9 \mathrm{E}-1$ & $1.5 \pm 0.6 \mathrm{E}-8$ & $5 \pm 2 \mathrm{E}-9$ & $2.3 \pm 0.4 \mathrm{E}-7$ & $6.7 \pm 0.1$ \\
\hline${ }^{241} \mathrm{Pu}$ & -e $^{e}$ & $2.7 \mathrm{E}-12$ & $2.8 \mathrm{E}-13$ & $3.9 \mathrm{E}-16$ & 15.4 \\
\hline Acid or metal & & $\left(\mu \mathrm{g} \cdot \mathrm{cm}^{-2} \cdot \mathrm{s}^{-1}\right)$ & & & \\
\hline Picolinic acid & $4.2 \mathrm{E}-1$ & $4 \pm 2 \mathrm{E}-3$ & $1.3 \pm 0.5 \mathrm{E}-9$ & $1.7 \pm 0.7 \mathrm{E}-8$ & $8.1 \pm 0.2$ \\
\hline Chromiurn & $<6.2 \mathrm{E}-3^{\mathrm{d}}$ & $<1.4 \mathrm{E}-6$ & $<5.1 \mathrm{E}-11$ & $<1.6 \mathrm{E}-11$ & $>11.5$ \\
\hline Iron & $<3.3 \mathrm{E}-3^{\mathrm{d}}$ & $<1.0 \mathrm{E}-5$ & $<3.0 \mathrm{E}-11$ & $<5.7 \mathrm{E}-12$ & $>12.1$ \\
\hline Cobalt & $<2.5 \mathrm{E}-2^{\mathrm{d}}$ & $<7.3 \mathrm{E}-6$ & $<2.0 \mathrm{E}-10$ & $<2.6 \mathrm{E}-10$ & $>10.2$ \\
\hline Nickel & $3.5 \mathrm{E}-2^{\mathrm{d}}$ & $3 \pm 2 \mathrm{E}-6$ & $2 \pm 1 \mathrm{E}-10$ & $5 \pm 4 \mathrm{E}-10$ & $10.1 \pm 0.5$ \\
\hline
\end{tabular}

a. Results are for only the first 90 days of leaching.

b. Fraction of initial inventory released per square centimeter of specimen surface area per second.

c. Concentrations of radionuclide in leachate samples were not determined.

d. Not all leachate samples were analyzed for this radionuclide or metal. CFR value was estimated by interpolating measured incremental release rates.

e. Only the leachate corresponding to leaching interval number three was analyzed for ${ }^{241} \mathrm{Pu}$. Leaching results are those determined for leaching interval number three. 


\section{Appendix G}

Radionuclide, Chelating Agent, and Stable Metal Inventory in Liners Solidified as Part of this Study 


\section{Appendix G}

\section{Radionuclide, Chelating Agent, and Stable Metal Inventory in Liners Solidified as Part of this Study}

Table G-1 summarizes the radionuclide, chelating agent, and stable metal inventories in the liners solidified as part of this study. All inventories are based on the measured radionuclide content in the resins, with the exception of Peach Bottom-3, which is based primarily on the radionuclide content of the cemented waste form.
Resin values were used for two radionuclides $\left({ }^{14} \mathrm{C}\right.$ and $\left.{ }^{99} \mathrm{Tc}\right)$ at Peach Bottom-3. The dates listed in the table indicate when the solidifications took place. Radionuclide inventories were decay corrected to these dates. The sources of this information are References 1 through 3. 


\section{Appendix G}

\section{REFERENCES}

1. C. V. McIsaac and J. W. Mandler, The Leachability of Decontamination Ion-Exchange Resins Solidified in Cement at Operating Nuclear Power Plants, NUREG/CR-5224, March 1989.

2. D. W. Akers et al., Releases of Radionuclides and Chelating Agents from Cement-Solidified Decontamination Low-Level Radioactive Waste Collected from the Peach Bottom Atomic Power Station Unit 3, NUREG/CR-6164, 1994.

3. C. V. McIsaac, D. W. Akers, and J. W. McConnell, Jr., Effect of pH on the Release of Radionuclides and Chelating Agents from Cement-Solidified Decontamination Ion-Exchange Resins Collected from Operating Power Stations, NUREG/CR-5601, June 1991. 
Table G-1. Liner inventories for waste-form samples.

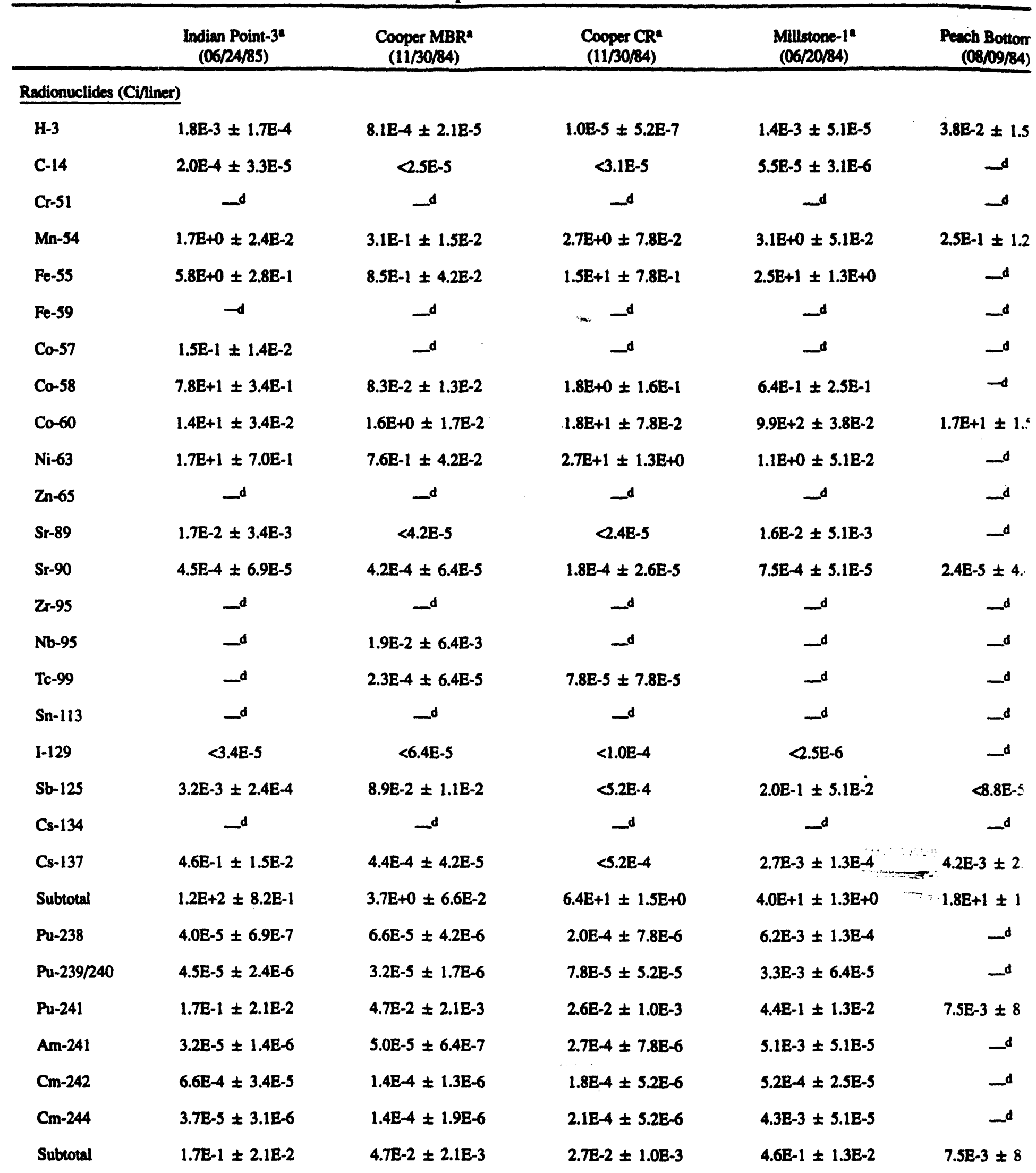




\begin{tabular}{|c|c|c|c|c|c|}
\hline $\begin{array}{l}\text { Peach Bottom-2 } \\
(08 / 09 / 84)\end{array}$ & $\begin{array}{c}\text { Pilgrim } \\
(08 / 17 / 84)\end{array}$ & $\begin{array}{c}\text { Peach Bottom-3b } \\
(10 / 25 / 89)\end{array}$ & $\begin{array}{c}\text { Brunswick-1CRe } \\
(12 / 18 / 87)\end{array}$ & $\begin{array}{c}\text { Brunswick-1 MBR } \\
(12 / 18 / 87)\end{array}$ & $\begin{array}{c}\text { FitaPatricke } \\
(9 / 18 / 88) \\
\end{array}$ \\
\hline $3.8 \mathrm{E}-2 \pm 1.5 \mathrm{E}-3$ & $3.3 \mathrm{E}-5 \pm 1.4 \mathrm{E}-6$ & $-d$ & - d : & $-d$ & $-d$ \\
\hline -d $^{d}$ & $9.4 \mathrm{E}-5 \pm 1.9 \mathrm{E}-5$ & $3.1 \mathrm{E}+1 \pm 3.1 \mathrm{E}-1^{e}$ & - d & $-d$ & $-d$ \\
\hline$-d$ & -d & -d & $-d$ & -d & $1.4 \mathrm{E}+0 \pm 1.7 \mathrm{E}-1$ \\
\hline $2.5 \mathrm{E}-1 \pm 1.2 \mathrm{E}-3$ & $5.9 \mathrm{E}-1 \pm 3.1 \mathrm{E}-2$ & $1.5 \mathrm{E}+0 \pm 0.2 \mathrm{E}-1$ & $2.1 \mathrm{E}+0 \pm 1, \mathrm{BE}-2$ & $7.8 \mathrm{E}-2 \pm 4.6 \mathrm{E}-4$ & $4.2 \mathrm{E}+0 \pm 2.3 \mathrm{E}-2$ \\
\hline -d & $4.2 \mathrm{E}+0 \pm 1.6 \mathrm{E}-1$ & $1.0 \mathrm{E}+0 \pm 3.9 \mathrm{E}-1$ & $1.1 \mathrm{E}+1 \pm 9.3 \mathrm{E}-1$ & $5.2 \mathrm{E}-1 \pm 4.3 \mathrm{E}-2$ & $2.3 \mathrm{E}-1 \pm 3.0 \mathrm{E}-3$ \\
\hline$-d$ & $-d$ & -d & $2.5 \mathrm{E}-1$ & $<4.0 \mathrm{E}-2$ & $1.6 \mathrm{E}+0 \pm 1.0 \mathrm{E}-2$ \\
\hline$-d$ & -d & $-d$ & $-d$ & $-d$ & $1.8 \mathrm{E}-2 \pm 6.9 \mathrm{E}-4$ \\
\hline$-d$ & $1.4 \mathrm{E}-1 \pm 1.4 \mathrm{E}-1$ & -d & $2.2 \mathrm{E}-1 \pm 2.7 \mathrm{E}-2$ & $1.0 \mathrm{E}-2 \pm 1.8 \mathrm{E}-3$ & $4.4 \mathrm{E}+0 \pm 2.3 \mathrm{E}-2$ \\
\hline $1.7 \mathrm{E}+1 \pm 1.5 \mathrm{E}-1$ & $8.1 \mathrm{E}+0 \pm 3.1 \mathrm{E}-2$ & $1.7 \mathrm{E}+1 \pm 8.6 \mathrm{E}-3$ & $1.1 \mathrm{E}+1 \pm 1.4 \mathrm{E}-1$ & $4.8 \mathrm{E}-1 \pm 2.4 \mathrm{E}-3$ & $1.7 \mathrm{E}+1 \pm 1.7 \mathrm{E}-3$ \\
\hline$-d$ & $4.4 \mathrm{E}-1 \pm 1.6 \mathrm{E}-2$ & $1.9 \mathrm{E}-1 \pm 2.2 \mathrm{E}-2$ & $2.0 \mathrm{E}+0 \pm 7.8 \mathrm{E}-2$ & $1.5 \mathrm{E}-1 \pm 8.3 \mathrm{E}-3$ & $5.6 \mathrm{E}-1 \pm 3.0 \mathrm{E}-2$ \\
\hline$\sim^{d}$ & -d & $3.4 \mathrm{E}+0 \pm 1.1 \mathrm{E}+0$ & $1.4 \mathrm{E}-1 \pm 2.45 \mathrm{E}-2$ & $7.0 \mathrm{E}-3 \pm 1.4 \mathrm{E}-3$ & $9.8 \mathrm{E}-1 \pm 2.6 \mathrm{E}-2$ \\
\hline -d & $1.6 \mathrm{E}-3 \pm 9.4 \mathrm{E}-4$ & $-d$ & $-d$ & $-d$ & -d \\
\hline $2.4 \mathrm{E}-5 \pm 4.4 \mathrm{E}-6$ & $2.3 \mathrm{E}-4 \pm 3.1 \mathrm{E}-5$ & $3.0 \mathrm{E}-4 \pm 5.4 \mathrm{E}-5$ & $5.7 \mathrm{E}-3 \pm 3.8 \mathrm{E}-4$ & $2.9 \mathrm{E}-3 \pm 1.6 \mathrm{E}-4$ & $2.5 \mathrm{E}-4 \pm 2.1 \mathrm{E}-5$ \\
\hline$-d$ & $-d$ & $-d$ & $<5.9 \mathrm{E}-2$ & $<1.8 \mathrm{E}-2$ & $2.2 \mathrm{E}-2 \pm 2.0 \mathrm{E}-3$ \\
\hline$-d$ & $\sim^{d}$ & $-d$ & $-d$ & $-d$ & $4.7 \mathrm{E}-2 \pm 3.9 \mathrm{E}-3$ \\
\hline$-d$ & $3.4 \mathrm{E}-5 \pm 9.4 \mathrm{E}-6$ & $1.3 \mathrm{E}-1 \pm 3.0 \mathrm{E}-3^{\mathrm{e}}$ & -d $^{d}$ & $-d$ & $-d$ \\
\hline$-d$ & $-d$ & $-d$ & $-^{d}$ & -d & $2.4 \mathrm{E}-2 \pm 2.3 \mathrm{E}-3$ \\
\hline$-d$ & $<3.1 E-6$ & $1.7 \mathrm{E}-4 \pm 2.5 \mathrm{E}-5$ & $-d$ & $-^{d}$ & $-d$ \\
\hline$<8.8 \mathrm{E}-5$ & $1.3 \mathrm{E}-2 \pm 6.2 \mathrm{E}-4$ & $6.1 \mathrm{E}-2 \pm 3.5 \mathrm{E}-3$ & $5.1 \mathrm{E}-3 \pm 8.2 \mathrm{E}-4$ & $1.9 \mathrm{E}-2 \pm 1.2 \mathrm{E}-4$ & $3.6 \mathrm{E}-2 \pm 2.3 \mathrm{E}-3$ \\
\hline$-d$ & $-d$ & -d & $<1.3 \mathrm{E}-3$ & $<2.6 \mathrm{E}-4$ & $3.2 \mathrm{E}-2 \pm 9.0 \mathrm{E}-4$ \\
\hline $4.2 \mathrm{E}-3 \pm 2.2 \mathrm{E}-5$ & $4.7 \mathrm{E}-2 \pm 1.6 \mathrm{E}-2$ & $1.3 \mathrm{E}-2 \pm 1.8 \mathrm{E}-3$ & $5.6 \mathrm{E}-2 \pm 6.6 \mathrm{E}-4$ & $1.3 \mathrm{E}-3 \pm 4.0 \mathrm{E}-5$ & $6.6 \mathrm{E}-2 \pm 1.8 \mathrm{E}-3$ \\
\hline $1.8 \mathrm{E}+1 \pm 1.5 \mathrm{E}-1$ & $1.4 \mathrm{E}+1 \pm 2.2 \mathrm{E}-1$ & $5.5 \mathrm{E}+1 \pm 1.9 \mathrm{E}+0$ & $2.7 \mathrm{E}+1 \pm 9.4 \mathrm{E}-1$ & $1.3 \mathrm{E}+0 \pm 4.4 \mathrm{E}-2$ & $3.0 \mathrm{E}+1 \pm \mathrm{T} .8 \mathrm{E}-1$ \\
\hline$\sim^{d}$ & $3.4 \mathrm{E}-4 \pm 1.6 \mathrm{E}-5$ & $5.9 \mathrm{E}-4 \pm 3.7 \mathrm{E}-5$ & $1.0 \mathrm{E}-6 \pm 6.4 \mathrm{E}-8^{f}$ & $2.8 \mathrm{E}-7 \pm 2.2 \mathrm{E}-8^{f}$ & $8.4 \mathrm{E}-5 \pm 2.1 \mathrm{E}-6$ \\
\hline$-d$ & $4.8 \mathrm{E}-4 \pm 1.6 \mathrm{E}-5$ & $1.8 \mathrm{E}-4 \pm 1.1 \mathrm{E}-5$ & $8.1 \mathrm{E}-7 \pm 5.2 \mathrm{E}-8$ & $2.5 \mathrm{E}-7 \pm 2.1 \mathrm{E}-8$ & $1.5 \mathrm{E}-4 \pm 2.6 \mathrm{E}-6$ \\
\hline $7.5 \mathrm{E}-3 \pm 8.8 \mathrm{E}-4$ & $5.5 \mathrm{E}-2 \pm 1.6 \mathrm{E}-3$ & $9.9 \mathrm{E}-3 \pm 1.0 \mathrm{E}-3$ & $8.2 \mathrm{E}-3 \pm 6.3 \mathrm{E}-4$ & $7.3 \mathrm{E}-3 \pm 5.8 \mathrm{E}-4$ & $2.3 \mathrm{E}-1 \pm 1.7 \mathrm{E}-2$ \\
\hline -d & $8.3 \mathrm{E}-6 \pm 3.1 \mathrm{E}-7$ & $7.2 \mathrm{E}-4 \pm 5.0 \mathrm{E}-5$ & $-{ }^{d}$ & $-d$ & $1.3 \mathrm{E}-4 \pm 2.2 \mathrm{E}-6$ \\
\hline - $^{d}$ & $2.7 \mathrm{E}-5 \pm 9.4 \mathrm{E}-7$ & $2.9 \mathrm{E}-5 \pm 3.3 \mathrm{E}-6$ & $-4.7 \mathrm{E}-8 \pm 7.8 \mathrm{E}-8$ & $1.2 \mathrm{E}-7 \pm 7.0 \mathrm{E}-8$ & $1.4 \mathrm{E}-4 \pm 2.7 \mathrm{E}-6$ \\
\hline - & $2.2 \mathrm{E}-5 \pm 3.1 \mathrm{E}-7$ & $1.3 \mathrm{E}-4 \pm 1.6 \mathrm{E}-4$ & $1.0 \mathrm{E}-7 \pm 2.0 \mathrm{E}-8$ & $1.9 \mathrm{E}-8 \pm 9.7 \mathrm{E}-9$ & $1.4 \mathrm{E}-5 \pm 4.0 \mathrm{E}-7$ \\
\hline $7.5 \mathrm{E}-3 \pm 8.8 \mathrm{E}-4$ & $5.6 \mathrm{E}-2 \pm 1.6 \mathrm{E}-3$ & $1.0 \mathrm{E}-2 \pm 1.3 \mathrm{E}-3$ & $8.2 \mathrm{E}-3 \pm 6.3 \mathrm{E}-4$ & $7.3 \mathrm{E}-3 \pm 5.8 \mathrm{E}-4$ & $2.3 \mathrm{E}-1 \pm 1.7 \mathrm{E}-2$ \\
\hline
\end{tabular}


Table Q-1. (continued).

\begin{tabular}{|c|c|c|c|c|c|c|c|c|c|}
\hline & \multicolumn{2}{|c|}{$\begin{array}{l}\text { Indian Point-3" } \\
\text { (06/24/85) }\end{array}$} & \multicolumn{2}{|c|}{$\begin{array}{c}\text { Cooper MRR" } \\
\text { (11/30/34) }\end{array}$} & \multicolumn{2}{|c|}{$\begin{array}{l}\text { Cooper CRa } \\
(11 / 30 / 84)\end{array}$} & \multicolumn{2}{|c|}{$\begin{array}{l}\text { Millstone-1" } \\
\text { (06/20/84) }\end{array}$} & $\begin{array}{r}\text { Peanct } \\
(0\end{array}$ \\
\hline \multicolumn{10}{|c|}{ Stable Metals and Chelating Agents (Ke/iner) } \\
\hline $\mathbf{C r}$ & \multicolumn{2}{|c|}{$3.1 \mathrm{E}-1 \pm 1.7 \mathrm{E}-2$} & \multicolumn{2}{|c|}{-} & \multicolumn{2}{|c|}{$7.8 \mathrm{E}-1 \pm 2.6 \mathrm{E}-1$} & \multicolumn{2}{|c|}{$4.4 \mathrm{E}-1 \pm 2.5 \mathrm{E}-2$} & \\
\hline $\mathbf{F e}$ & \multicolumn{2}{|c|}{$2.3 \mathrm{E}+0 \pm 1.0 \mathrm{E}-1$} & \multicolumn{2}{|c|}{$1.1 \mathrm{E}+0=1.3 \mathrm{E}-1$} & \multicolumn{2}{|c|}{$2.9 \mathrm{E}+1 \pm 1.0 \mathrm{E}+1$} & \multicolumn{2}{|c|}{$7.4 \mathrm{E}+0 \pm 3.8 \mathrm{E}-1$} & \\
\hline Co & \multicolumn{2}{|c|}{$<4.0 \mathrm{E}-2$} & \multicolumn{2}{|c|}{$<3.0 \mathrm{E}-2$} & \multicolumn{2}{|c|}{$1.6 \mathrm{E}-1 \pm 5.2 \mathrm{E}-2$} & \multicolumn{2}{|c|}{$2.0 \mathrm{E}-2 \pm 1.0 \mathrm{E}-3$} & \\
\hline $\mathbf{Z n}$ & \multicolumn{2}{|c|}{$-^{d}$} & \multicolumn{2}{|c|}{ - ' } & \multicolumn{2}{|c|}{-d } & \multicolumn{2}{|c|}{$-d$} & \\
\hline $\mathbf{N i}$ & \multicolumn{2}{|c|}{$2.5 \mathrm{E}+0 \pm 1.4 \mathrm{E}-1$} & \multicolumn{2}{|c|}{$1.6 \mathrm{E}-1 \pm 1.3 \mathrm{E}-2$} & \multicolumn{2}{|c|}{$3.1 \mathrm{E}+0 \pm 1.3 \mathrm{E}+0$} & \multicolumn{2}{|c|}{$2.7 \mathrm{E}+0 \pm 1.3 \mathrm{E}-1$} & \\
\hline B & \multicolumn{2}{|c|}{$-d$} & \multicolumn{2}{|c|}{-d } & \multicolumn{2}{|c|}{$-d$} & \multicolumn{2}{|c|}{$-d$} & \\
\hline Subtotal & \multicolumn{2}{|c|}{$3.1 \mathrm{E}+0 \pm 1.7 \mathrm{E}-1$} & \multicolumn{2}{|c|}{$1.3 \mathrm{E}+0 \pm 1.3 \mathrm{E}-1$} & \multicolumn{2}{|c|}{$3.3 \mathrm{E}+1 \pm 1.0 \mathrm{E}+1$} & \multicolumn{2}{|c|}{$1.0 \mathrm{E}+1 \pm 4.0 \mathrm{E}-1$} & \\
\hline Citric acid & \multicolumn{2}{|c|}{-d } & & 2.1E+0 & 2.5E-1 & $2.9 \mathrm{E}-2$ & & $3.8 \mathrm{E}-1$ & $7.5 \mathrm{E}$ \\
\hline Oxalic acid & & & & $=6.4 \mathrm{E}-1$ & $7.0 \mathrm{E}-1$ & $2.6 \mathrm{E}-3$ & & 2.5E-1 & 8.7E \\
\hline EDTA & & & & $d$ & & & 7.8E+ & $5.1 \mathrm{E}-1$ & $7.2 \mathrm{E}$ \\
\hline DPTA & & & & -d & & & & & \\
\hline Picolinic acid & $1.4 \mathrm{E}$ & $6.9 \mathrm{E}-1$ & & -d & & & & & \\
\hline Subtotal & & $6.9 \mathrm{E}-1$ & 8.7E+ & $=2.2 \mathrm{E}+0$ & $9.6 \mathrm{E}-1$ & $2.9 \mathrm{E}-2$ & & 6.8E-1 & 2.3E \\
\hline Liner Characteris & & & & & & & & & \\
\hline & $\mathbf{m}^{3}$ & $\mathrm{ft}^{3}$ & $\mathrm{~m}^{3}$ & $\mathbf{f t}^{\mathbf{3}}$ & $\mathrm{m}^{3}$ & $\mathbf{t}^{3}$ & $\mathrm{~m}^{3}$ & $\mathrm{ft}^{3}$ & $\mathbf{m}^{3}$ \\
\hline $\begin{array}{l}\text { Waste } \\
\text { volume }\end{array}$ & 3.4 & 122 & 2.1 & 75 & 2.6 & 92 & 1.3 & 45 & 1.5 \\
\hline Liner type & NA & NA & L8-120 & L8-120 & L14-170 & L14-170 & L6-80 & L6-80 & L6-81 \\
\hline $\begin{array}{l}\text { Liner } \\
\text { capacity }\end{array}$ & NA & NA & 3.3 & 116 & 4.8 & 169 & 2.2 & 79 & 2.2 \\
\hline
\end{tabular}

a. Information from NUREG/CR-5224 (Reference 1).

b. Information from NUREG/CR-6164 (Reference 2).

c. Information from NUREG/CR-5601 (Reference 3).

d. Nor detected or not measured.

e. Resin inventory value was used due to unreliability of laboratory analysis on cemented waste form.

f. Pu-238 and/or Am-241. Pu-238 and Am-241 in the Brunswick-1 catioa and mixed-bed resins were not separated prior to anslysis by alpha spectrometry. Concentration of acid in resin waste was not determined. Picolinic acid was not expected to be present in the Brunswick-1 resin wastes, and citric and oxali 


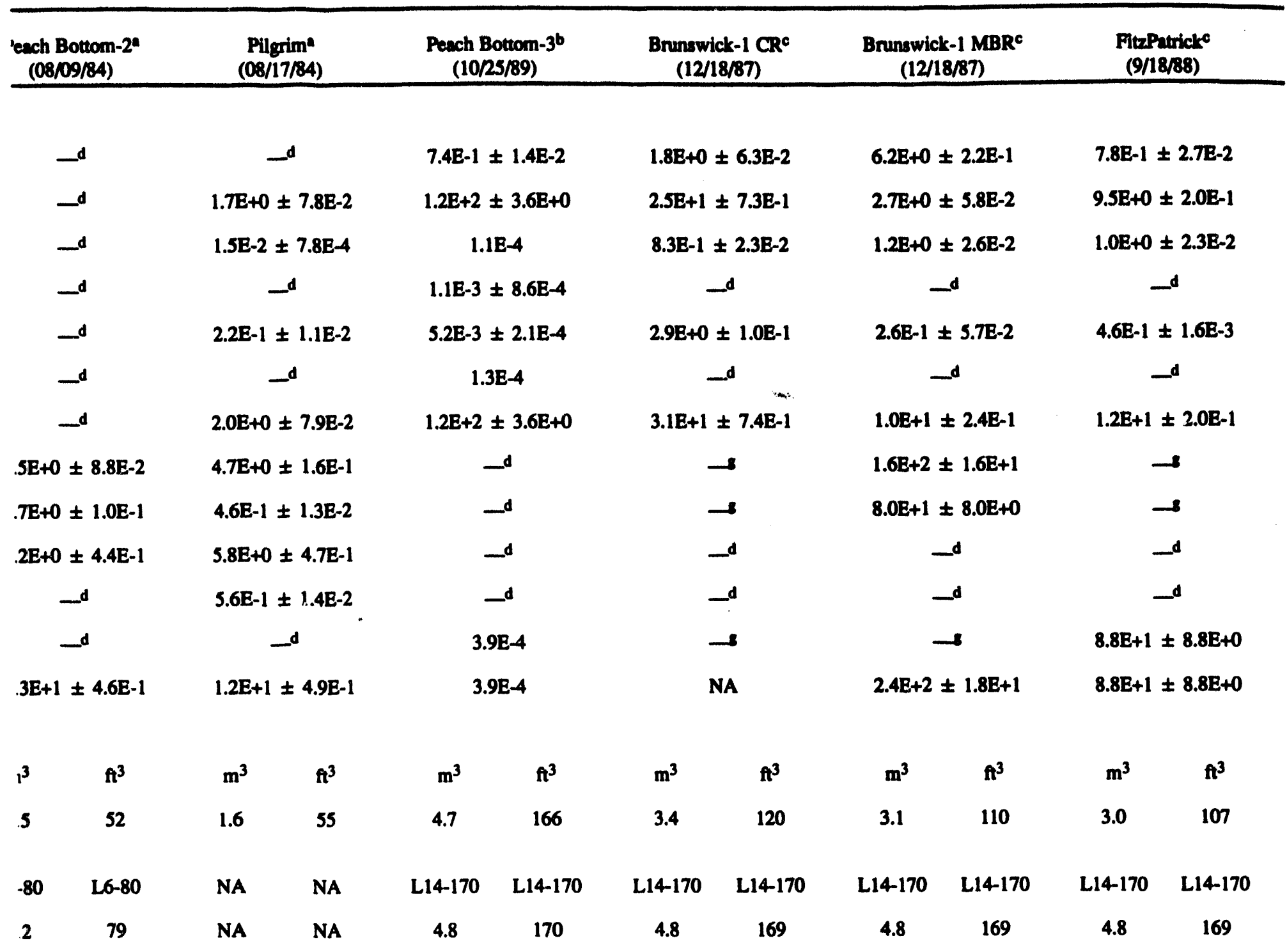



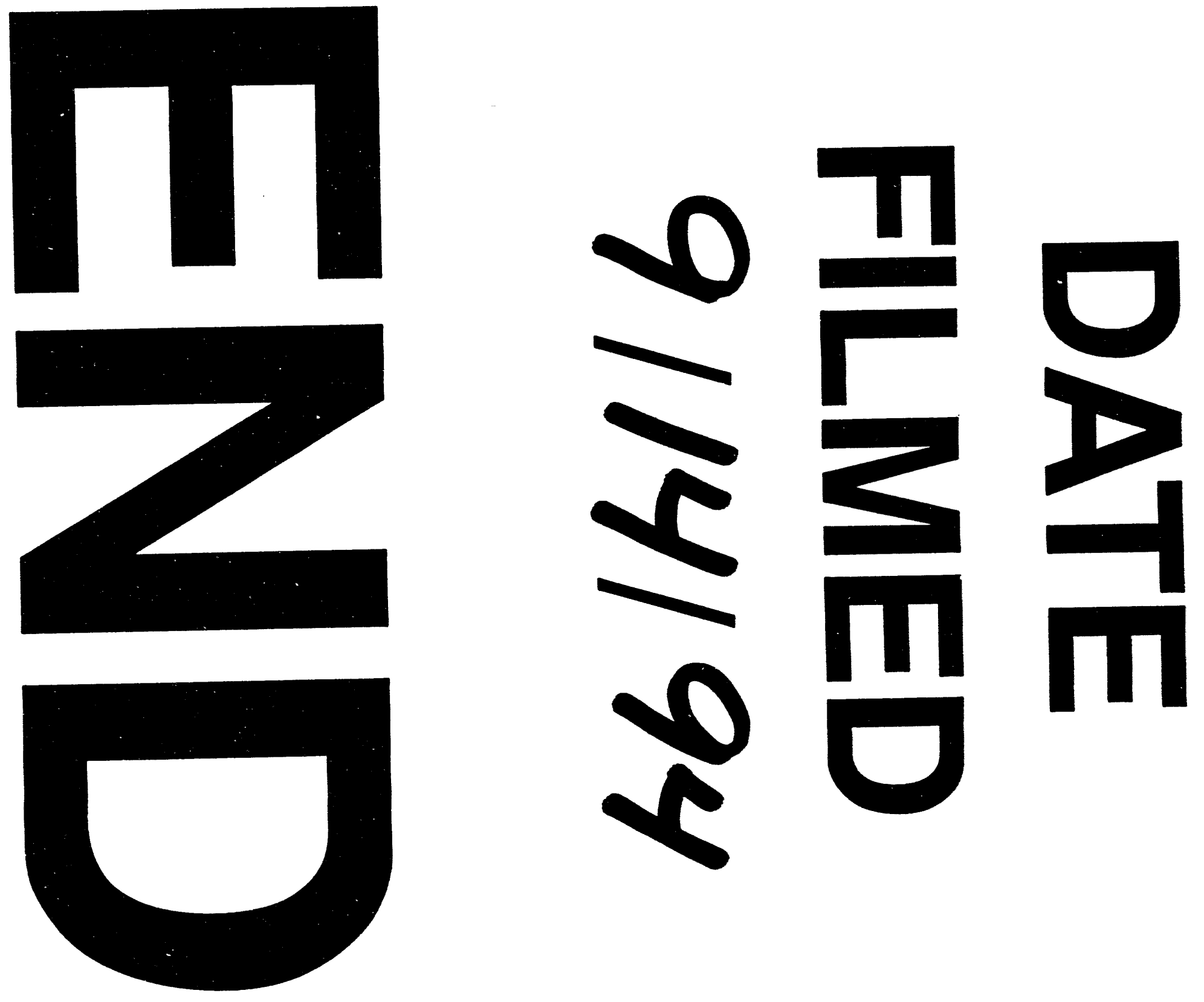
